\title{
UFRRJ
}

INSTITUTO DE TECNOLOGIA

PROGRAMA DE PÓS-GRADUAÇÃo EM CIÊNCIA E TECNOLOGIA DE ALIMENTOS

TESE

EXTRAÇÃO, ISOLAMENTO E CARACTERIZAÇÃO DE ANTOCIANINAS DE FONTES NATURAIS E A SUA APLICAÇÃO NA ANÁLISE DE ALIMENTOS POR CROMATOGRAFIA LÍQUIDA

ANA CRISTINA MIRANDA SENNA GOUVÊA

2015 


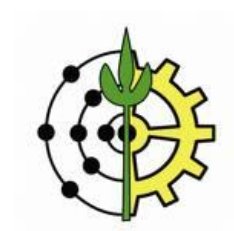

UNIVERSIDADE FEDERAL RURAL DO RIO DE JANEIRO INSTITUTO DE TECNOLOGIA

PROGRAMA DE PÓS-GRADUAÇÃO EM CIÊNCIA E TECNOLGIA DE ALIMENTOS

\section{EXTRAÇÃO, ISOLAMENTO E CARACTERIZAÇÃO DE} ANTOCIANINAS DE FONTES NATURAIS E A SUA APLICAÇÃO NA ANÁLISE DE ALIMENTOS POR CROMATOGRAFIA LÍQUIDA

\section{Ana Cristina Miranda Senna Gouvêa}

Sob a orientação

Prof. Ronoel Luiz de Oliveira Godoy, D.Sc.

\section{E Co-orientação de}

Manuela Cristina Pessanha de Araujo Santiago, D.Sc.

Tese submetida como requisito parcial obtenção do grau de Doutor em Ciências, no Programa de PósGraduação em Ciência e Tecnologia de Alimentos, Área de Concentração em Ciência de Alimentos.

Seropédica, RJ Junho de 2015 
664.07

G719e

T

Gouvêa, Ana Cristina Miranda Senna, 1960-

Extração, isolamento e caracterização de antocianinas de fontes naturais e a sua aplicação na análise de alimentos por cromatografia líquida / Ana Cristina Miranda Senna Gouvêa. - 2015.

198 f.: il.

Orientador: Ronoel Luiz de Oliveira Godoy.

Tese (doutorado) - Universidade Federal Rural do Rio de Janeiro, Curso de Pós-Graduação em Ciência e Tecnologia de Alimentos, 2015.

Bibliografia: f. 156-166.

1. Alimentos - Análise - Teses. 2. Antocianinas - Teses. 3. Análise cromatográfica - Teses. 4. Tecnologia de alimentos - Teses. I. Godoy, Ronoel Luiz de Oliveira, 1951- II. Universidade Federal Rural do Rio de Janeiro. Curso de Pós-Graduação em Ciência e Tecnologia de Alimentos. III. Título. 
UNIVERSIDADE FEDERAL RURAL DO RIO DE JANEIRO

INSTITUTO DE TECNOLOGIA

PROGRAMA DE PÓS-GRADUAÇÃO EM CIÊNCIA E TECNOLOGIA DE ALIMENTOS

\section{ANA CRISTINA MIRANDA SENNA GOUVÊA}

Tese submetida como requisito parcial para obtenção do grau de Doutor em Ciências no Programa de Pós-Graduação em Ciência e Tecnologia de Alimentos, área de Concentração em Ciência de Alimentos.

TESE APROVADA EM 18/06/2015

Ronoel Luiz de Oliveira Godoy, D.Sc.

(Orientador)

Mirian Ribeiro Leite Moura, D.Sc.

(Membro - UFRJ)

\section{Renata Galhardo Borguini, D.Sc}

(Membro - Embrapa-CTAA)

Maria Ivone Martins Jacinto Barbosa, D.Sc.

(Membro - DTA-UFRural-RJ)

Gloria Maria Direito, D.Sc.

(Membro - UFRural-RJ) 


\section{AGRADECIMENTOS}

Primeiro a Deus pelas oportunidades que tem colocado na minha trajetória. Ao meu pai agradeço por ter existido na minha vida e mesmo ausente sinto seu apoio e orgulho por mais essa vitória.

Aos meus orientadores professor (D.Sc) Ronoel L. Oliveira Godoy e (D. Sc) Manuela Cristina P. A. Santiago pelo incentivo, carinho, paciência e pela atenção e suporte de acreditarem no meu trabalho.

Às amigas Renata, Carolina Passos e, especialmente, à Fernanda pelas palavras de incentivo, amizade e troca de experiências.

Com carinho aos colegas do laboratório de Cromatografia: Luzimar, Sídney, Juliana, Allien, Luciana, Elaine, Victor e aos demais que por ventura viemos a trabalhar juntos e cuja convivência foi muito gratificante.

À minha família principalmente mãe e irmãos que compreenderam minha ausência nestes últimos quatro anos.

Ao Dr. Marcelo da Costa Souza, pelas identificações botânicas e orientações para as coletas de plantas.

As minhas amigas Iolanda e Tininha, mais uma vez pela amizade e incentivo e pelo apoio, compreensão e paciência.

À professora (D.Sc) Isabel M.P.L.V.O. Ferreira, pela orientação e carinho, e aos amigos que fiz em Porto, pois devido à recepção calorosa fizeram que eu me sentisse mais perto de casa apesar da grande distância.

Ao CNPq e a Capes pelo apoio financeiro que possibilitou o desenvolvimento desse projeto. 
DEDICATÓRIA

À minha família, pela dedicação e paciência e por compreenderem minha ausência durante essa jornada. Especialmente ao meu marido Ary e minhas filhas Priscila e Gabriela pelo carinho. 
"Não há saber mais ou saber menos: há saberes diferentes"

Paulo Freire 


\section{RESUMO}

GOUVÊA, Ana Cristina Miranda Senna. Extração, isolamento e caracterização de antocianinas de fontes naturais e a sua aplicação na análise de alimentos por cromatografia líquida: Seropédica, RJ. 2015. 198p Tese (Doutor em Ciência, Ciência de Alimentos). Instituto de Tecnologia, Programa de Pós-Graduação em Ciência e Tecnologia de Alimentos, Universidade Federal Rural do Rio de Janeiro, Seropédica, RJ, 2015.

Nos últimos anos, o grande interesse por alimentos naturais, saudáveis e que possam trazer consigo a proposta de atuar como coadjuvantes na redução do risco de doenças crônicas tem impulsionado o meio científico a identificar e quantificar os seus princípios ativos. As antocianinas, pigmentos hidrossolúveis presentes em alimentos de origem vegetal, apresentam efeitos bioativos que estão relacionados ao seu poder antioxidante. Sendo assim, vários trabalhos científicos vêm relatando a importância do seu desempenho na redução do risco de desenvolvimento de doenças como as cardiovasculares, do sistema imunológico, câncer e sua progressão. Para sua análise de identificação e quantificação, há necessidade de se adquirir padrões analíticos. Devido à grande diversidade de substituintes em sua estrutura, o desafio está em encontrar disponíveis comercialmente padrões de referência dessas diversas substâncias. Este trabalho teve como objetivo estudar e selecionar matrizes que possam servir de fontes para obtenção de padrões antociânicos. Neste contexto, a obtenção destes padrões a partir de fontes naturais poderá viabilizar a determinação, de forma mais precisa, das concentrações existentes dessas substâncias em alimentos que estejam na forma natural ou processados. Para condução do trabalho foram realizados estudos para melhoria das etapas cromatográfica, de extração, e de isolamento e purificação das antocianinas. Nas análises cromatográficas foram utilizados os sistemas de Cromatografia Líquida de Alta Eficiência (CLAE/DAD) e Cromatografia de Ultra Eficiência (CLUE) acoplado ao detetor de massas acuradas Q-TOF $\left(\mathrm{ESI}^{+}\right)$. No desenvolvimento do método cromatográfico, reduziu-se o tempo da corrida com uso de coluna com partícula inferior a $3 \mu \mathrm{m}$. Foram testados três procedimentos de extração da substância na matriz, visando proporcionar rapidez à técnica. Para o isolamento e purificação das substâncias, foram utilizados três tipos de técnicas: uso de uma válvula seletora de canais Rheodyne de seis canais; coluna aberta de vidro (fase $\mathrm{C}_{18}$ ) e cartuchos Sep Pak $\mathrm{C}_{18}$ e Oasis ${ }^{\circledR}$ MCX Cation-Exchange SPE (troca iônica). Após as etapas de melhoria e desenvolvimento, foram estudadas ao todo 43 matrizes como potenciais fontes provedoras de padrões de antocianinas. As substâncias foram separadas por CLAE e caracterizadas com auxílio conjunto de quatro parâmetros: tempo de retenção, dados da

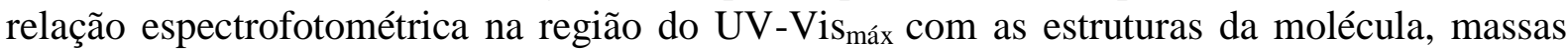
acuradas dos seus íons moleculares e fragmentos e, distinção das rotas de fragmentações. Assim sendo, esses parâmetros permitiram a identificação nas matrizes de substâncias que após isoladas puderam ser utilizadas como padrões, com alto grau de pureza, permitindo assim a identificação e quantificação de antocianinas nas análises cromatográficas. No presente trabalho foi possível ainda realizar a validação do método de análise cromatográfica desenvolvido e implantado, o qual foi aplicado para o estudo e caracterização dos perfis antociânicos até então desconhecidos de dois frutos da família das Myrtaceae.

Palavras Chaves: CLUE-QTOF. CLAE/DAD. Antocianinas. Troca catiônica. Purificação. 


\begin{abstract}
GOUVÊA, Ana Cristina Miranda Senna. Extraction, isolation and characterization of anthocyanins from natural sources and their application in food analysis by liquid chromatography: Seropédica, RJ. 2015. 198p Tese (Doctor of Science, Food Science). Instituto de Tecnologia, Programa de Pós-Graduação em Ciência e Tecnologia de Alimentos, Universidade Federal Rural do Rio de Janeiro, Seropédica, RJ, 2015.
\end{abstract}

In recent years, the great interest for natural, healthy foods and that may bring the proposal to act as an aid in reducing the risk of chronic diseases has driven the scientific community to identify and quantify their active ingredients. Anthocyanins, water-soluble pigments present in plant foods, have bioactive effects that are related to its antioxidant power. Therefore, several scientific papers have reported the importance of their performance in reducing the risk of developing diseases such as cardiovascular, immune system dysfunction, cancer and its progression. For their analysis identification and quantification, it is necessary to purchase analytical standards. Because of the wide variety of substituents in structure, the challenge is to find commercially available reference standards of these various substances. This work aims to study and select matrices that can be used as sources for obtaining anthocyanin standards. In this context, the idolated compound obtained from these natural sources may allow the quantification in more precise manner, of the existing concentration of such substances in food that are in the natural or processed form. Studies were carried out for improvement of chromatographic, extraction, and isolation and purification steps, enabling the work conduction. Chromatographic analysis were performed using High Performance Liquid Chromatography (HPLC / DAD) and Ultra Performance Liquid Chromatography (UPLC) coupled to an accurate mass detector Q-TOF (ESI +). In the development of chromatographic method, the run time was reduced by using column with particles lower than $3 \mu \mathrm{m}$. Three extraction procedures were tested in order to make this step faster. Different methodologies for isolation and purification of substances were evaluated, by using the Rheodyne ${ }^{\circledR}$ channels selector valve, a glass column $\left(\mathrm{C}_{18}\right.$ phase) and Sep-Pak $\mathrm{C}_{18}$ cartridges and Oasis ${ }^{\circledR}$ MCX Cation-Exchange SPE (ion exchange). After the improvement and development steps, 43 matrices were studied as potential sources to be used as anthocyanin standards. The compounds were separated by HPLC and characterized by using four parameters: retention time, relationship between data of the UV-Vis máx $_{\text {spectrophotometric }}$ region and the molecule structures; their molecular ions accurate masses and fragments; and fragmentation routes differences. Thus, these parameters have allowed the identification of substances in the matrices that after isolated could be used as analytical standards, with high purity, thus allowing the identification and quantification of anthocyanins in chromatographic analysis. In the present work, it was possible to validate the developed and implemented chromatographic method, which was applied for the study and characterization of anthocyanin unknown profiles of two fruits of the Myrtaceae family.

Keywords: UHPLC-QTOF. HPLC/DAD. Anthocyanin. Cation-exchange. Purification. 


\section{LISTA DE FIGURAS}

Figura 1: Representa a estrutura das antocianinas e as posições das mais comuns glicosilações e acilações encontradas em vegetais alimentícios.

Figura 2: Estruturas dos açúcares: arabinose; xilose; ramnose; glicose; galactose.

Figura 3: Equilíbrio das antocianinas em solução aquosa. Fonte GIUST e WROLSTAD, 2001).

Figura 4: Exemplo de antocianidina complexada ao alumínio.

Figura 5: Espectro UV-Vis a 520nm - DAD (Detetor de Arranjo de Diodos), característico das antocianinas, mostrando uma absorção máxima na região 490-550nm e uma absorção menos intensa próxima a $275 \mathrm{~nm}$.

Figura 6: Estrutura da antocianina cianidina-3-O-glicosídeo.

Figura 7: Exemplo de copigmentação entre uma antocianina e um copigmento incolor. Fonte: IACOBUCCI e SWEENY, 1983 apud FALCÃO, 2003.

Figura 8: Esquema de uma coluna de adsorção: A-Reservatório; B- Fase Móvel; C-Coluna de vidro recheada com adsorvente; D- Camada de recheio ou areia; E-Amostra; F- Lã de vidro; G- Frasco coletor; H- Analitos isolados coletados.

Figura 9: Esquema básico do sistema cromatográfico.

Figura 10: Esquema de uma fase monolítica (Adaptado da Fonte: SILVA, COLLINS E BOTTOLI, 2011).

Figura 11: Representação dos principais setores de um espectrômetro de massas de alta resolução (QTOF), Fonte: Waters ${ }^{\circledR}, 2008$.

Figura 12: Esquema de uma fonte de ionização por eletrospray (ESI+). Fonte: Waters ${ }^{\circledR}, 2008$.

Figura 13: Organograma com partes de 43matrizes

Figura 14: Processo de retirada das cascas de duas matrizes: A) pitanga de cachorro (Neomitranthes obscura) e B) jamelão (Syzygium cuminii).

Figura 15: Processo de liofilização, produto gerado após serem triturados em moinho de faca, matrizes: A) pitanga de cachorro (Neomitranthes obscura) e B) jamelão (Syzygium cuminii). 
Figura 16: Diagrama esquemático com as etapas da extração II.

Figura 17: Organograma com as operações para as três extrações.

Figura 18: Amostras de arroz: 1) arroz com casca; 2) arroz sem casca; 3) arroz polido.

Figura 19: 1) arroz vermelho; 2) pó do polimento do pericarpo do arroz vermelho (PPAV).

Figura 20: A) Purês obtidos das três amostras trituradas: 1- C (casca); 2- P (entre casca e o caroço); 3- PF (polpa fibrosa próxima ao caroço). B) Apresenta o caroço após a retirada da PF.

Figura 21: Sistema CLUE-QTOF $\left(\mathrm{ESI}^{+}\right)$: UPLC ACQUITY-Synapt, Waters $^{\circledR}$. Fonte: SCHULZ, F. D., 2014.

Figura 22: Foto da Válvula coletora Rheodyne ${ }^{\circledR}$, onde 1, 2, 3, 4, 5 e 6 são canais de saída.

Figura 23: Cromatograma do extrato de arroz preto obtido no CLAE/DAD a $520 \mathrm{~nm}$. Fração 1) tempo de retenção de 1 até 5,5min. Fração 2) tempo de retenção 5,7 até 7,0. Fração 3) tempo de retenção 7,2 até 9,8 min e Fração 4) tempo de retenção 10,0 até $12 \mathrm{~min}$

Figura 24: (A) Perfil cromatográfico do extrato de amora-preta liofilizada extraído usando a condição cromatográfica A da Tabela 14 a $520 \mathrm{~nm}, \mathbf{B}$ ) Expansão do cromatograma entre os tempos de retenção de 15 a 35 minutos.

Figura 25: cromatograma obtido com a condição de análise $\mathbf{B}$, apresenta $\mathbf{o}$ analito 1 eluindo após 30 minutos de corrida.

Figura 26: A) Esquema demonstrativo das alterações nas estruturas, das antocianinas, predominantes quando são submetidas a diferentes níveis de pH. B). Espectro de absorção de uma purificada antocianina (acilada pelargonidina-3-soforosídeo-5-glicosídeo) UV-visível em pH 1,0 e pH 4,5. Fonte: Giusti e Wrolstad (2001).

Figura 27: (A) cromatograma obtido com a condição de análise $\mathbf{C}$, apresenta o 22 minutos de corrida. (B) Expansão do cromatograma entre os tempos de rete minutos.

Figura 28: (A) Cromatograma obtido nas condições de análise D. (B) Expansão do cromatograma entre os tempos de retenção de 5 e 20 minutos $(\lambda$ $520 \mathrm{~nm})$.

Figura 29:(A) Cromatograma do extrato quando se utilizou as condições de análise E. (B) Detalhe da expansão do cromatograma entre 6 e 15 minutos $(\lambda$ $520 \mathrm{~nm})$. 
Figura 30: (A) Cromatograma quando utilizada as condições de análise $F(B)$

Cromatograma quando utilizada as condições de análise $\mathrm{G}(\mathrm{C})$ Cromatograma quando utilizada as condições $\mathrm{H}$, todos os três cromatogramas foram obtidos a $520 \mathrm{~nm}$.

Figura 31: Perfil cromatográfico dos três extratos do arroz vermelho (com casca, sem casca e polido) mantido durante a análise por CLAE a $520 \mathrm{~nm}$.

Figura 32: A) Cromatograma do extrato metanólico PPAV a 520nm. B)

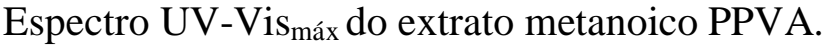

Figura 33: Cromatograma do extrato do fruto açaí liofilizado, extraído utilizando a metodologia I a 520nm.

Figura 34: Cromatograma do extrato metanólico do pó da juçara liofilizada, extraído utilizando a metodologia II a 520nm,

Figura 35: Cromatograma do extrato do pó da casca da berinjela extraído utilizando metodologia II a $520 \mathrm{~nm}$ e espectros de absorção dos quatro picos no UV-Vis máx. $^{2}$

Figura 36: Espectros de massa acurada em modo EM/EM extraídos do CLUE-QTOF/EM (ESI ${ }^{+}$) das substâncias equivalentes aos picos 3 e 4 do extrato da casca da berinjela liofilizada.

Figura 37: Estrutura das antocianinas encontradas na berinjela:

A) delfinidina-3-( $p$-coumarilrutinoside)-5-glicosídeo (nausinin)

B) delfinidina-3-O-rutinose-5-Glicosídeo.

Figura 38: A) Cromatograma do extrato da casca da jabuticaba liofilizada (P. trunciflora) extraído utilizando metodologia II a $520 \mathrm{~nm}$ e, espectros de absorção dos picos 2 e 3 no UV- Vis máx. B) Projeção do cromatograma A no intervalo de 2-14 minutos.

Figura 39: Espectros de massa acurada em modo EM/EM extraídos do CLUE-EM QTOF $\left(\mathrm{ESI}^{+}\right)$das substâncias equivalentes aos picos 2 e 4 do extrato da casca a da jabuticaba liofilizada ( $P$. trunciflora).

Figura 40: A) Cromatograma do extrato casca da maçã liofilizada (variedade Fuji) extraído utilizando metodologia II a $520 \mathrm{~nm}$ e, espectro de absorção do

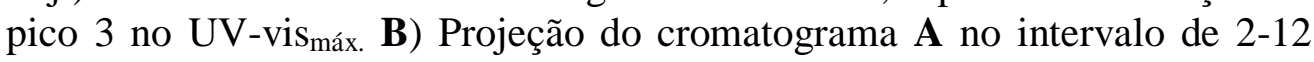
minutos.

Figura 41: Espectros de massa acurada, em modo EM/EM extraídos do CLUE-EM QTOF $\left(\mathrm{ESI}^{+}\right)$, da substância 2 do extrato do pó da casca liofilizada da maçã (Fuji).

Figura 42: Sobreposição e comparação dos cromatogramas do extrato da casca da maçã (preto) e padrão de cianidina-3-O-glicosídeo (vermelho) isolado da matriz Euterpe oleracea Mart. (açaí). 
Figura 43: Cromatogramas obtidos do extrato da casca de quatro cultivares de maçã, onde o pico 1, majoritário, e a cianidina-3-O-galactosídeo.

Figura 44: Sobreposição dos cromatogramas do extrato de quatro cultivares de maçã (Red Delicius, Argentina, Gala e Fuji).

Figura 45: Cromatograma gerado da análise realizada por CLAE/DAD no extı do jamelão (Syzygium cuminii), apresentou seis picos com duas bandas de abso1 Vis máx $_{\text {a }} 520 \mathrm{~nm}$.

Figura 46: Espectros de absorção UV-Vis máx $_{0}$ obtidos no DAD $(520 \mathrm{~nm})$, das seis substâncias da casca liofilizada do fruto do jamelão (Syzygium cuminii L.).

Figura 47: Espectros de massa acurada, em modo EM/EM extraídos do CLUE-EM QTOF (ESI ${ }^{+}$), das substâncias equivalentes aos picos 1 ao 6 do extrato da casca liofilizada do fruto do jamelão (Syzygium cuminii L.).

Figura 48: Esquema com as estruturas das antocianinas: diglicosiladas no $\mathrm{C}_{3}$ e $\mathrm{C}_{5}$; monoglicosilada no $\mathrm{C}_{3}$ ou $\mathrm{C}_{5} \mathrm{e}$, da antocianidina livre indicando as perdas dos glicosídeos.

Figura 49: Cromatograma gerado da análise realizada por CLAE/DAD do extrato do morango liofilizado a $520 \mathrm{~nm}$ e espectros de absorção das 4 substâncias no UV-Vis máx.

Figura 50: Espectro de massa acurada em modo EM/EM extraídos do CLUE-EM QTOF $\left(\mathrm{ESI}^{+}\right)$dos picos 1 e 2 do extrato do morango liofilizado.

Figura 51: Espectro de massa acurada em modo EM/EM extraídos do CLUEEM QTOF $\left(\mathrm{ESI}^{+}\right)$das substâncias 3 e 4 do extrato do morango liofilizado.

Figura 52: A) Cromatograma do extrato do pericarpo do mangostin liofilizado (Garcinia mangostana L.) extraído utilizando metodologia II a 520 nm e, espectros de absorção dos picos 3 e 5 no UV-Vis máx. B) Expansão do cromatograma A no intervalo de 1,0-7,5 minutos.

Figura 53: A) Cromatograma em modo EM/EM extraídos do CLUE-EM QTOF $\left(\mathrm{ESI}^{+}\right)$das substâncias 3 e 5, isoladas do extrato do pericarpo liofilizado do mangostin (Garcinia mangostana L.), filtrando os íons a $\mathrm{m} / z$ 611 (pico 3) e 449 (pico5), B e C) Espectros em modo EM/EM extraídos no CLUE-EM QTOF $\left(\mathrm{ESI}^{+}\right)$onde (B) substância do pico 3 e (C) substância do pico 5 .

Figura 54: Espectro de massa da substância isolada 3 (mangostin) gerado no modo EM/EM, em condições de seis diferentes valores de energias de impacto $(4,6,8,10,12$ e $16 \mathrm{eV})$. 
Figura 55: Apresenta sobreposição dos cromatogramas no CLAE/DAD (520 $\mathrm{nm}$ ), do extrato do pericarpo liofilizado do mangostin (preto) e do padrão cianidina-3-O-glicosídeo (vermelho), isolado da matriz Euterpe oleracea Mart. (açaí).

Figura 56: A) Cromatograma do extrato do mirtilo (Vaccinium spp) extraído utilizando metodologia II a $520 \mathrm{~nm}$, B) Expansão do cromatograma A no intervalo de 13,7-18,0 minutos.

Figura 57: A) Cromatograma do extrato do mirtilo (Vaccinium spp) extraído utilizando metodologia II a $520 \mathrm{~nm}$, B) Expansão do cromatograma A no intervalo de 3,5-19,0 minutos e C) Expansão do cromatograma B no intervalo de 13,7-18,5 minutos.

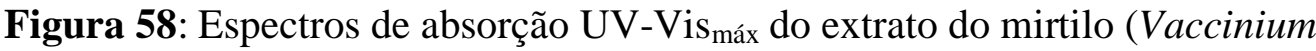
spp) obtidos no DAD (520 nm) enumerados conforme cromatograma da Figura 57.

Figura 59: Espectros de absorção UV-Vis máx $_{\text {do }}$ extrato do mirtilo (Vaccinium spp) obtidos no DAD $(520 \mathrm{~nm})$ enumerados conforme cromatograma da Figura 57.

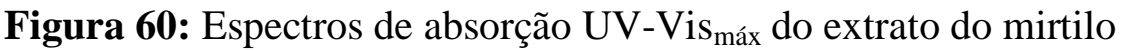

(Vaccinium spp) obtidos no DAD (520 nm) enumerados conforme cromatograma da Figura 57.

Figura 61: Cromatograma extraído no CLUE TOF-ESI ${ }^{+}$das substâncias 1 e 2, isoladas do extrato do mirtilo (Vaccinium spp), filtrando o íon a $m / z 465$.

Figura 62: Espectros de massa acurada em modo EM/EM no CLUE-EMQTOF $\left(\mathrm{ESI}^{+}\right)$: (A) substância equivalente ao pico 1 e (B) substância equivalente ao pico 2 .

Figura 63: Cromatograma extraído do CLUE-EM-QTOF $\left(\mathrm{ESI}^{+}\right)$das substâncias equivalente ao pico 3a, isoladas do extrato do mirtilo (Vaccinium spp), filtrando os íons a $m / z$ 449,1050 (B) e 435,0936 (C) e (A) Sobreposição dos cromatogramas $(\mathbf{B})$ e $(\mathbf{C})$.

Figura 64: Espectros de massa acurada em modo EM/EM no CLUE-EMQTOF $\left(\mathrm{ESI}^{+}\right.$) da substância 3 (Figura 45): (A) delfinidina-3-O-arabinosídeo e (B) cianidina-3-O-galactosídeo.

Figura 65: Figura 65: Espectros de massa acurada em modo EM/EM (ESI $\left.{ }^{+}\right)$ da substância 5: (A) cianidina-3-O-glicosídeo; (B) petunidina-3-Ogalactosídeo; (C) cianidina-3-O-arabinosídeo e; (D) petunidina-3-Oglicosídeo.

Figura 66: Cromatogramas extraídos no CLUE-EM-QTOF $\left(\mathrm{ESI}^{+}\right)$das substâncias equivalentes aos picos: $3 \mathrm{a}(\mathbf{A})$ e $5(\mathbf{B})$, isoladas do extrato do 
mirtilo (Vaccinium spp), filtrando o íon a $\mathrm{m} / \mathrm{z}$ 449. (C) Sobreposição dos cromatogramas (A) e (B).

Figura 67: Espectros de massa acurada em modo EM/EM no CLUE-EM-

QTOF $\left(\mathrm{ESI}^{+}\right)$: (A) substância equivalente ao pico 9 e (B) substância equivalente ao pico 10 do cromatograma da Figura 57.

Figura 68: Cromatograma extraído do CLUE-EM-QTOF $\left(\mathrm{ESI}^{+}\right)$das substâncias equivalentes ao pico: 9, isoladas do extrato do mirtilo (Vaccinium spp), filtrando os íons a $m / z$ 449,1050 (A) e 463,1252 (B) e (C) Sobreposição dos cromatogramas $(\mathbf{B})$ e $(\mathbf{C})$.

Figura 69: Espectros de massa acurada em modo EM/EM (ESI $\left.{ }^{+}\right)$: (A) substância equivalente ao pico 11 ; (B) substância equivalente ao pico 12 ; (C) substância equivalente ao pico 13; (D) substância equivalente ao pico 15.

Figura 70: Espectros de massa acurada em modo EM/EM $\left(\mathrm{ESI}^{+}\right):(\mathbf{A})$ substância equivalente ao pico 16; (B) substância equivalente ao pico $19 \mathrm{E}$; (C) substância equivalente ao pico 20.

Figura 71: Cromatograma no CLAE/DAD a $520 \mathrm{~nm}$ do extrato do epicarpo da uva-preta do Chile (Vitis vinifera spp) utilizando metodologia II.

Figura 72: Espectros de absorção na região $U V-V i s_{\text {máx }}$ do extrato do epicarpo da uva-preta do Chile (Vitis vinifera spp) obtidos no DAD (520 nm) enumerados conforme cromatograma da Figura 71.

Figura 73: Espectros de massa acurada em modo EM/EM no CLUE-EMQTOF $\left(\mathrm{ESI}^{+}\right)$: (A) substância equivalente ao pico 1; (B) substância equivalente ao pico 2; (C) substância equivalente ao pico 3; (D) substância equivalente ao pico 4 e; (E) substância equivalente ao pico 5.

Figura 74: Sobreposição dos cromatogramas obtidos no CLAE/DAD a 520 nm. (A) Cromatograma em preto obtido do extrato do epicarpo da uva-preta, (B) cromatograma em vermelho do extrato da Juçara, onde pico 2: cianidina3-O-glicosídeo e 3 cianidina-3-O-rutenosídeo.

Figura 75: Cultivares (cv) de uvas finas tintas de mesa: Uva-preta do Chile; Red-Globe (RG); Niagara Rosada (NR); Kyoho (K), Fonte: (Embrapa, 2005; DETONI et al., 2005).

Figura 76: Cromatogramas (perfis das antocianinas) extraídos do CLAE/DAD a $520 \mathrm{~nm}$ dos extratos do epicarpo das uvas: Uva-Preta do Chile; Red Globe; Niagara Rosada; e Kyoho. Identificação dos picos Tabela 19. 
Figura 77: Cromatograma no CLAE/DAD a $520 \mathrm{~nm}$ do extrato da acerola utilizando metodologia II.

Figura 78: Espectros de absorção na região UV-Vis ${ }_{\text {máx }}$ do extrato da acerola 105 obtidos no DAD $(520 \mathrm{~nm})$ enumerados conforme cromatograma da Figura 77.

Figura 79: Espectros de massa acurada em modo EM/EM no EM-QTOF $\left(\mathrm{ESI}^{+}\right)$das substâncias equivalentes aos picos 1e 2 (Figura 77): (A) cianidina3-O-ramnosídeo e (B) pelargonidina-3-O- ramnosídeo.

Figura 80: Cromatograma do extrato metanólico da cebola roxa (A) e framboesa vermelha (B), extraído utilizando a metodologia II de análise no CLAE/DAD a 520nm. Identificação dos picos 1 e 2, nos dois cromatogramas, na Tabela 21.

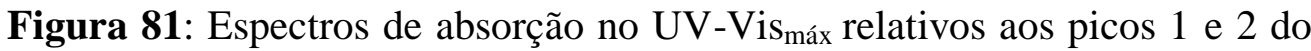
extrato da: (A) cebola roxa e (B) framboesa, obtidos no DAD $(520 \mathrm{~nm})$ enumerados conforme cromatograma da Figura 80.

Figura 82: Estruturas das antocianinas: A) cianidina-3-O-soforosídeo e B) cianidina-3-O-laminaribiosídeo.

Figura 83: Cromatograma do extrato metanólico do repolho roxa extraído utilizando a metodologia II de análise no CLAE/DAD a 520nm. Espectro de absorção no UV-Vis máx $_{\text {da substância equivalente ao pico } 1 .}$

Figura 84: Espectro de massa acurada em modo EM/EM no EM-QTOF $\left(\mathrm{ESI}^{+}\right)$, após energia de colisão de $8 \mathrm{eV}$, da substância equivalente ao pico 1 da Figura 83 e, rota de fragmentação proposta.

Figura 85: Cromatograma do extrato metanólico da alface roxa extraído no CLAE/DAD a 520nm, utilizando a metodologia II de análise. Espectros de absorção no UV-Vis máx relativo as substâncias equivalentes aos picos de 1 a 4.

Figura 86: Estrutura da antocianidina cianidina-3-O- (6"malonilglicosídeo), indicando a massa acurada de seus fragmentos, após perda de massa neutra 86 Da e 162 Da.

Figura 87: Cromatograma do extrato do fruto da amêndeira, CLAE/DAD $(520 \mathrm{~nm})$,e os espectros de absorção na região do UV-Vis máx.

Figura 88: Espectros de massa em modo EM/EM, obtidos no EM QTOF $\left(\mathrm{ESI}^{+}\right)$, das substâncias: picos (1); (2); (3), respectivamente.

Figura 89: Fruto da amendoeira (Terminalia catappa L.) - C (casca); P (Polpa); PF (Parte Fibrosa).

Figura 90: Apresenta os três cromatogramas, representando o perfil, dos extratos metanólicos obtidos da Casca, Polpa e Polpa Fibrosa do fruto da 
amendoeira (Terminalia catappa L.).

Figura 91: Cromatogramas extraído no CLAE/DAD a $520 \mathrm{~nm}$ das matrizes: A) ameixa vermelha; B) jambo vermelho; C) Amora silvestre; D) Jabuticaba (cv. Plinia grandifolia). Identificação das substâncias numeradas, Quadro 1.

Figura 92: Cromatogramas extraído no CLAE/DAD A $520 \mathrm{~nm}$ das matrizes: E) Pera casca vermelha; F) Manga cv. Tommy G) Soja casca preta; H) Frutoda romãzeira; I) Flor do jambeiro. Identificação das substâncias numeradas, Quadro 1.

Figura 93: Cromatogramas extraído no CLAE/DAD A $520 \mathrm{~nm}$ das matrizes: J) Brácteas vermelha da planta Bico de Papagaio; L) Flor da Erythrina; M) Flor do Ipê roxo; N) Flor do Hibiscos. Identificação das substâncias numeradas na Quadro 1.

Figura 94: Cromatogramas extraído no CLAE/DAD A $520 \mathrm{~nm}$ das matrizes: O) Flor da romãzeira; P) Esparta da Flor Ave do Paraiso. Identificação das substâncias numeradas na Quadro 1.

Figura 95: Cromatograma do perfil da matriz da flor do Jambeiro, mostrando um limite usado para recolhimento nas amostras que proporcione pureza adequada nas substâncias isoladas.

Figura 96: Cromatograma do perfil de antocianinas do extrato metanólico do arroz preto extraído no CLAE/DAD a $520 \mathrm{~nm}$.

Figura 97: Cromatogramas extraídos no CLAE/DAD (520 nm). A) Extrato do arroz preto; B) Extrato da Fração 1 isolada C) Extrato da Fração 2 isolada; D) Extrato da Fração 3 isolada e; E) Extrato da Fração 4 isolada.

Figura 98: Espectros de absorção UV-Vis ${ }_{\max }$ do extrato do arroz preto (IAC $600)$ obtidos no DAD $(520 \mathrm{~nm})$, substancias relacionadas aos cromatogramas das Figuras 96 e 97.

Figura 99: Figura 99: Cromatograma do perfil das antocianinas do arroz preto analisado e identificação das antocianinas por padrões e confirmação pela técnica de CL/EM (ES ${ }^{+}$). Fonte: Hou et al., 2011.

Figura 100: Sobreposições dos cromatogramas: Em preto o cromatograma com perfil de antocianinas do arroz preto, (A) em roxo o cromatograma com o perfil da casca de uva preta sem semente do Chile, (B) em azul o cromatograma com o perfil da casca do jamelão e (C) em vermelho o cromatograma com o perfil da juçara.

Figura 101: Cromatograma do perfil de antocianinas do extrato metanólico da Fração 2, extraído no CLAE/DAD a $520 \mathrm{~nm}$.

Figura 102: Cromatogramas do extrato do fruto da amendoeira extraídos no CLAE/DAD a 280, 360 e $520 \mathrm{~nm}$. 
Figura 103: Cromatograma extraído do CLAE/DAD (520nm) do extrato concentrado da Uva-Preta do Chile.

Figura 104: Esquema de funcionamento da válvula seletora com seis canais.

Figura 105: Exemplo do procedimento de monitoramento pelo software Empower $^{\circledR}$ : cromatogramas da substância isolada e purificada, cianidina-3- $O$ glicosídeo em três comprimentos de onda 520, 360 e $280 \mathrm{~nm}$.

Figura 106: Cromatograma com a ordem de eluição das seis antocianinas (delfinidina, cianidina, petunidina, pelargonidina, peonidina e malvidina) monoglicosiladas isoladas, CLAE/DAD a 520nm.

Figura 107: Cromatograma com seis antocianinas monoglicosiladas (1 delfinidina 3-glicosídeo; cianidina 3-glicosídeo, 3- petunidina 3-glicosídeo, 4- pelargonidina 3-glicosídeo, 5-peonidina 3-glicosídeo, 6- malvidina 3glicosídeo) e seus respectivos espectros UV-Vis máx a 520nm.

Figura 108: Extratos puros das seis antocianinas monoglicosiladas: Pelargonidina 3-glicosídeo; cianidina 3-glicosídeo; peonidina 3-glicosídeo; petunidina 3-glicosídeo e; malvidina 3-glicosídeo diluídos na solução 1 (item 3.3, página 28 ).

Figura 109: Estrutura da molécula da antocianina. Em destaque o $\mathrm{C}_{3}$ do anel pirano e $\mathrm{C}_{5}$ do anel $\mathrm{A}$.

Figura 110: Cromatogramas das seis antocianinas isoladas no CLUE/EM QTOF $\left(\mathrm{ESI}^{+}\right)$.

Figura 111: Estrutura química do sorbente MCX e molécula da antocianina em condições de pH diferentes, Fonte: He e Giust, 2011.

Figura 112: Cromatograma do extrato de cianidina-3-O-glicosídica purificada no $\lambda$ de 250-700nm (Max Plot), obtido do CLAE/DAD. Percentagens das substâncias na Tabela 28.

Figura 113: A) Árvore frutífera Eugenia sulcata Spring ex Mart. B), fruto da Eugenia sulcata (Pitanga-Negra Selvagem).

Figura 114: Perfil cromatográfico, no CLAE/DAD (520 nm), do extrato do fruto liofilizado da Pitanga-Negra Selvagem. Em destaque a expansão do cromatograma entre 1,5 e 11,0 minutos.

Figura 115: Neomitranthes obscura em quatro estágios de maturação. 


\section{LISTA DE TABELAS}

Tabela 1: Exemplos de antocianinas identificadas em matrizes de origem vegetal.

Tabela 2: Diferentes valores de absortividade molar relatadas na literatura.

Tabela 2: Diferentes valores de absortividade molar relatadas na literatura (continuação).

Tabela 2: Diferentes valores de absortividade molar relatadas na literatura (continuação).

Tabela 2: Diferentes valores de absortividade molar relatadas na literatura (continuação).

Tabela 3: Coeficiente de absortividade molar em sistemas de solventes diferentes.

Tabela 4: Teste para extração do arroz vermelho.

Tabela 5: Valores das massas pesadas.

Tabela 6: Gradiente de eluição para o método cromatográfico I.

Tabela 7: Gradiente de eluição para o método cromatográfico II.

Tabela 8: pH das soluções de ácido fórmico aquoso.

Tabela 9: Gradiente de eluição para análise no CLUE.

Tabela 10: Condições de análise por massas.

Tabela 11: Massa Nominal e Massa Exata (monoisotópica) dos elementos.

Tabela 12: Condições de análise cromatográfica testadas para a separação de antocianinas.

Tabela 13: Massa molecular (MM), massa exata e fórmula molecular das antocianinas e antocianidinas.

Tabela 14: Antocianinas identificadas na literatura nas matrizes açaí (Euterpe oleracea Mart.) e juçara (Euterpe edulis).

Tabela 15: Antocianinas observadas no cromatograma do pó da casca da berinjela (Figura 35).

Tabela 16: Apresenta as massas encontradas nas condições de seis diferentes valores de energias de impacto.

Tabela 17: Apresenta metodologias de separação cromatográfica de 
antocianinas em algumas variedades de mirtilo.

Tabela 18: Tempo de retenção das substâncias no cromatograma da Figura 71 e, valores da razão $E_{440} / \mathrm{E} \lambda$ vis-máx revelando as características espectroscópicas dos picos correspondentes as suas glicosilações.

Tabela 19: Tabela com identificações das antocianinas da Figura 76.

Tabela 20: Identificação das substâncias relativas aos picos 1 e 2 dos cromatogramas na Figura 80.

Tabela 21: Intensidade dos íons no EM-QTOF (ESI+), quando o íon molecular 773 filtrado é submetido à energia de colisão de 4, 8 e 16 eV.

Tabela 22: Tempo de retenção no CLAE/DAD, no gradiente da metodologia II, de derivados de cianidinas do extrato do repolho roxo.

Tabela 23: Massas e áreas observadas nos estratos analisados por CLAE/DAD.

Tabela 24: Apresenta as antocianinas identificadas no perfil cromatográfico e suas concentrações na amostra.

Tabela 25: Identificação das antocianinas referentes aos picos do cromatograma da Figura 100 por comparação dos $t_{R}$ das substâncias com o $t_{R}$ das substâncias já identificadas na uva, juçara e jamelão.

Tabela 26: Percentagem de pureza dos analitos coletados em três comprimentos de onda.

Tabela 27: Dados cromatográficos, espectroscópicos e espectrométricos das seis antocianinas purificadas.

Tabela 28: Percentagem da cianidina-3-O-glicosídeo purificada extraída no CLAE/DAD.

Tabela 29: Antocianinas com percentagem de pureza acima de $80 \%$ a 520 nm.

Tabela 30: Antocianinas isoladas de fontes naturais para uso como padrões.

Tabela 31: Antocianinas derivadas de Pelargonidina presentes em fontes naturais para uso como padrões.

Tabela 32: Antocianinas derivadas de Cianidina presentes em fontes naturais para uso como padrões.

Tabela 33: Antocianinas derivadas de Delfinidina presentes em fontes naturais para uso como padrões analíticos. 
Tabela 34: Antocianinas derivadas de Petunidina presentes em fontes naturais para uso como padrões, identificadas neste trabalho.

Tabela 35: Antocianinas derivadas de Peonidina presentes em fontes naturais para uso como padrões.

Tabela 36: Antocianinas derivadas de Malvidina presentes em fontes naturais 150 para uso como padrões, identificadas neste trabalho. 


\section{LISTA DE EQUAÇÕES}

Equação I: Cálculo da pureza da pureza dos padrões de antocianinas. $\quad \mathbf{4 0}$

Equação II: Cálculo da massa exata das antocianinas.

Equação III: Cálculo do erro em ppm.

\section{LISTA DE QUADROS}

Quadro 1: Dados obtidos nas análises: CLAE/DAD e EM-QTOF $\left(\mathrm{ESI}^{+}\right.$),

EM/EM. Picos numerados conforme cromatogramas das Figuras 91 até 94.

Quadro 1: Dados obtidos nas análises: CLAE/DAD e EM-QTOF $\left(\mathrm{ESI}^{+}\right)$,

EM/EM. Picos numerados conforme cromatogramas das Figuras 91 até 94 (continuação).

Quadro 2: Dados obtidos da análise no CLAE/DAD e no EM-QTOF (ESI ${ }^{+}$) do extrato do arroz preto (IAC 600). Picos numerados conforme cromatograma da Figura 96.

Quadro 3: Dados das análises do extrato do fruto da Eugenia sulcata no CLAE/DAD e EM/QTOF (ESI+) em modo EM/EM. 


\section{LISTA DE ABREVIAÇÕES E SIGLAS}

ABTS -[2,2'-azino-bis (3-etilbenzotiazolin) 6-ácido sulfônico]

$\lambda_{\text {máx }}$ - comprimento de onda de absorção máxima

$\varepsilon-$ Absortividade Molar

ACN - Acetonitrila

ACY - ou acy, antocianina

$\mathrm{Al}$ - Alumínio

ANVISA - Agência Nacional de Vigilância Sanitária

APCI- Atmospheric Pressure Chemical Ionization - Ionização Química à Pressão Atmosfera

API - Atmospheric Pressure Ionization - Ionização à Pressão Atmosfera

APPI - Atmospheric Pressure Photoionization - Fotonização à Pressão Atmosfera

$\mathrm{C}-$ Casca

$\mathrm{CO}_{2}$ - Dióxido de carbono

CBD - Secretariat of the Convention on Biological Diversity

CL - Cromatografia Líquida

CLAE - Cromatografia Líquida de Alta Eficiência

CLC - Cromatografia Líquida Clássica

ClK - Cloreto de potássio

CLUE - Cromatografia Líquida de Ultra Eficiência

CPU- Central Processing Unit

$\mathrm{C}_{\mathrm{n}}$ - Carbono de número $\left(\mathrm{n}=3,5,7,3^{\prime}, 4^{\prime}\right.$ 'e 5')

$\mathrm{C}_{18}$ - Fase estacionária reversa octadecilisilano

cv. - Cultivar

Cy - Cianidina

Da - Daltons

DAD - Detetor de arranjo de diodos

Dp - Delfinidina

EFS - Extração em fase sólida

EM - Espectrômetro de massas

ESI - Eletronspray

$\mathrm{ESI}^{+}-$Eletronspray positivo

$\mathrm{EtOH}-$ Etanol

FE - Ferro

$\mathrm{HCl}$ - Ácido clorídrico

HPLC - High Pressure Liquid Chromatography

M - Molar

MeTOH - Metanol

MM - Massa Molar

$\mathrm{mDa}$ - mili Daltons

mL- Unidade de volume: mililitro $\left(10^{-3} \mathrm{~L}\right)$

Mv - Malvidina 
$m / z$ - Relação massa carga

$\mathrm{N}_{2}-$ Gás nitrogênio

$\mathrm{NH}_{4} \mathrm{OH}$ - Hidróxido de amônio

nm - nanômetro

OMS - Organização Mundial da Saúde

PEF - Pulsed Electric Field (Campo Elétrico Pulsado)

$\mathrm{PF}$ - Polpa

Pg - Pelargonidina

$\mathrm{pH}$ - potencial hidrogeniônico ou potencial hdirogênio iônico

PLE - Pressurized Liquid Extraction (Extração com Líquido Pressurizado)

$\mathrm{Pn}$ - Peonidina Pt - Petunidina

PPAV - Pó do polimento do arroz vermelho

ppm - Parte por milhão

PTFE - Politetrafluoretilen

QTOF - Detetores: Quadrupolo + Tempo de Voo

$\mathrm{RF}-$ Fator de retardamento

RMN -Ressonância Magnética Nuclear

rpm - Rotação por minuto

SFE - Supercritical Fluid Extraction (Extração com Fluído Supercrítico)

$\mathrm{Sn}-$ Estanho

sp - Espécie ( uma espécie no gênero)

SPE - Solid phase extraction (EFS- Extração em Fase Sólida)

spp - Espécies (mais de uma espécie no gênero)

TOF - Detetor de massas de tempo de voo

$t_{R}$ - Tempo de retenção

$\mu \mathrm{L}$ - Unidade de volume: microlitros $\left(10^{-6} \mathrm{~L}\right)$

$\mu \mathrm{m}$ Unidade de medida: micrometros, 1 milionésimo de metro $\left(10^{-6} \mathrm{~m}\right)$

UV - Espectro de absorção na região ultra violeta

$\mathrm{v}-$ Volume

Vis $_{\text {máx }}$-Espectro de absorção na região do visível com comprimento de onda máximo 


\section{SUMÁRIO}

1 INTRODUÇÃO.

1.1 Justificativa

1.2 Objetivo

2 REVISÃO BIBLIOGRÁFICA...................................................................

2.1 Pigmentos Naturais............................................................................

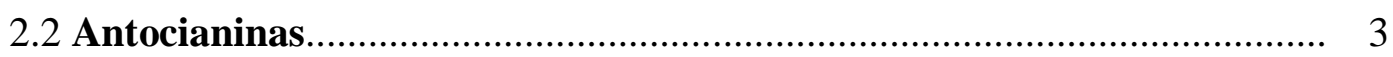

2.3 Antocianinas em Alimentos................................................................... 7

2.4 Métodos de Análise ........................................................................... 10

2.4.1 Extração.................................................................................. 10

2.4.2 Purificação do extrato.......................................................................... 11

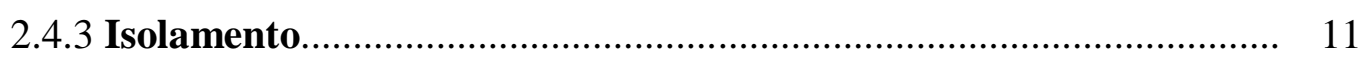

2.5 Identificação e Quantificação de Antocianinas........................................... 11

2.5.1 Cromatografia líquida ................................................................... 18

2.5.1.1 Cromatografia Líquida Clássica (CLC) ……………………….... 19

2.5.1.2 Cromatografia Líquida de Alta Eficiência........................................ 19

2.5.2 Utilização da técnica Cromatografia Líquida de Ultra

Performance acoplada à espectrometria de massas em Tandem (CLUE-EM/EM) ........................................................................ 22

3 MATERIAL E MÉTODOS .......................................................................... 26

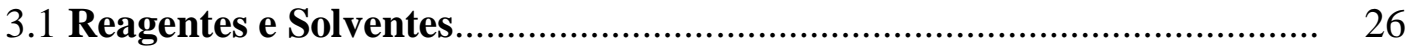

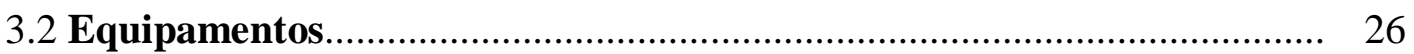

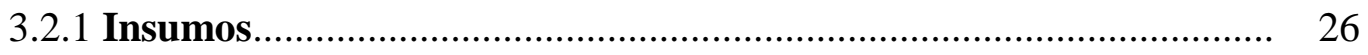

3.3 Preparo de Soluções.............................................................................. 26

3.4 Matrizes Estudadas................................................................................ 28 
3.4.1 Origem das matrizes

3.4.1.1 Pré-tratamento das matrizes......................................................... 30

3.4.2 Métodos de extração..................................................................... 31

3.4.2.1 Extração para verificar a presença de antocianinas nas matrizes de arroz (Oryza sativa L.) ............................................................ 33

3.5 Análises Cromatográficas............................................................. 36

3.5.1 Métodos cromatográficos utilizando o sistema CLAE/DAD...... 36

3.5.2 Procedimento para desenvolver a metodologia de separação cromatográfica (CLAE) de antocianinas............................. 36

3.5.3 Método cromatográfico utilizando o sistema CLUE acoplado ao espectrômetro de massa híbrido QTOF-Synapt........................ 37

3.5.3.1 Preparo da Amostra e condição de análise no sistema CLUE-TOF 37

3.6 Separação de Antocianinas nas Matrizes Estudadas por CLAE ... 39

3.7 Coletas dos Pigmentos Antociânicos............................................. 39

3.7.1 Purificação e Concentração dos Extratos Antociânicos Isolados...... 40

3.7.2 Extração e análises de antocianinas por CLAE ................................ 40

3.7.3 Análise cromatográfica por CLUE/EM-QTOF (ESI ${ }^{+}$), modo 40 EM/EM para identificação das antocianinas.

3.7.3.1 Cálculo para exatidão de Massas..................................................... 40

3.7.4 Procedimento para avaliar as antocianinas de baixa concentração da matriz do arroz preto (IAC 600)

3.7.4. 1 Coleta das substâncias no arroz preto.............................................. 42

3.7.5 Técnicas combinadas para purificação de antocianinas.................. 43

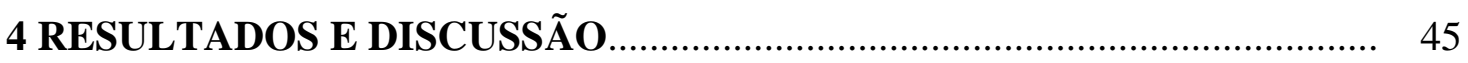

4.1Pré-tratamento das Matrizes...................................................... 45

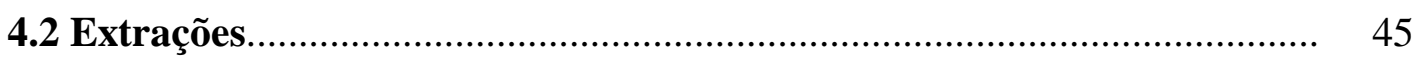

4.2.1 Extração I - Análise Qualitativa.................................................. 45

4.2.2 Extração II - Análise Quantitativa................................................ 45 
4.3 Otimização da separação cromatográfica de antocianinas (CLAE/DAD)

4.3.1 Avaliações de procedimentos de extração para verificar a presença de antocianinas na matriz de arroz (Oryza sativa L.) ...

4.4 Separação e Identificação das Antocianinas Presentes nas 41 matrizes.

4.4 Separação e Identificação das Antocianinas Presentes nas 41 matrizes.

4.4.1 Cálculo das massas exatas das antocianidinas e antocianinas com diferentes substituintes

4.4.2 Análises realizadas no Grupo 1 e Grupo 2................................. $\quad 56$

4.5 Isolamentos dos Pigmentos Antociânicos.............................................. 134

4.5.1 Purificação e concentração das soluções com os pigmentos isolados 136

4.5.2 Análise cromatográfica das antocianinas isoladas (CLAE/DAD) .... 136

4.5.3 Análise no CLUE/QTOF (ESI ${ }^{+}$, em modo EM/EM das substâncias isoladas.

4.5.4 Técnicas combinadas para purificação de antocianinas.................... 144

4.6 Aplicação dos Padrões Obtidos de Fontes Naturais................................. 150

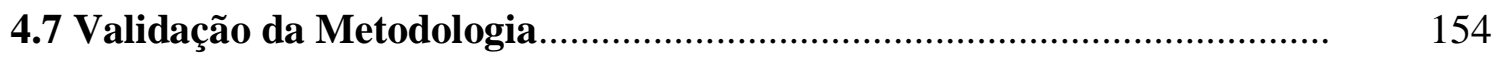

5 CONCLUSÃO

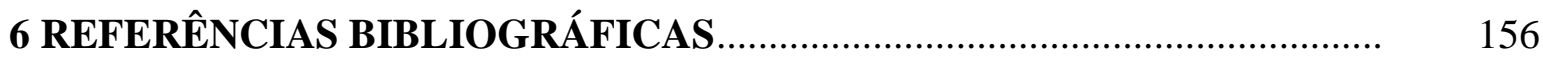

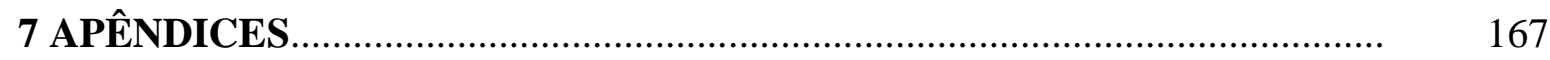

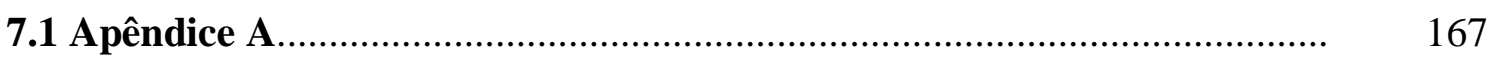

Evaluation of anthocyanin profile in apple peel of three cultivars produced in Brazil

7.2 Apêndice B

Identification of jambo (Syzygium malaccense L.) major anthocyanin by LC-MS-MS

7.3 Apêndice C

Identificação das antocianinas majoritárias na casca de uva tinta sem semente utilizando CLUE-ESI-EM/EM 
7.4 Apêndice D

Caracterização de antocianinas por CLAE e identificação por espectrometria de massa de alta resolução (Q-TOF) em seis frutos de fácil acesso para uso como fonte de padrões analíticos

7.5 Apêndice E

Avaliação de fontes naturais de antocianinas para uso como padrões para análise em frutos vermelhos e seus produtos

7.6 Apêndice F

Isolamento de antocianinas do epicarpo de uvas pretas (Vitis spp) por CLAE/DAD e sua identificação através do sistema CLUE-QTOF-ESI$\mathrm{EM} / \mathrm{EM}$

7.7 Apêndice G

Identification and quantification of anthocyanins in fruits from Neomitranthes obscura (DC) N.Silveira na endemic specie from Brazil by comparison of chromatographic methodologies

7.8 Apêndice $H$.

Analytical standards production for the analysis of pomegranate anthocyanins by HPLC 


\section{INTRODUÇÃO}

O grande interesse por alimentos naturais, saudáveis e que possam trazer consigo a proposta de atuar como coadjuvantes na redução do risco de doenças crônicas, tem impulsionado o meio científico a identificar e quantificar os seus princípios ativos.

As antocianinas têm tido grande destaque nos últimos anos principalmente devido as suas propriedades benéficas à saúde. Atualmente observa-se um crescente interesse no uso de antocianinas em diversos segmentos, havendo um grande destaque para as indústrias alimentícias e de cosméticos. A demanda por frutas tem aumentado sistematicamente nos últimos anos devido à associação entre consumo de frutas e benefícios à saúde, sendo as mais procuradas as com elevado teor de compostos bioativos, como antocianinas, carotenoides e compostos fenólicos.

Devido à grande diversidade de frutos tropicais, neste cenário o Brasil foi favorecido como provedor de matrizes nativas e exóticas. Além dos frutos tropicais já tão divulgados e estudados, o Brasil também apresenta inúmeros outros frutos que podem ser considerados fontes alternativas desses compostos bioativos. $\mathrm{O}$ uso destes frutos como matéria-prima para a obtenção de antocianinas possibilita uma grande diversidade de fontes. Dentre os frutos, podem ser citados como exemplo a jabuticaba (Mircyaria cauriflora), o jambo (Syzygium malaccense), o jamelão (Syzygium cumini), a grumixama (Eugenia brasiliense), a pitanga negra selvagem (Eugenia sulcata spring ex Mart.), o mangostin (Garcinia mangostana L.), o fruto da amendoeira (Terminalia catappa) entre outros, estando todos os citados acima incluídos neste estudo.

Assim como nas cascas de alguns frutos, as antocianinas na maioria das vezes também estão presentes nas flores, principalmente quando estas apresentam coloração do vermelho ao púrpuro e/ou azul. As condições edafoclimáticas deste país tornam possíveis, além de uma grande diversidade de frutos, a presença de flores durante o ano todo.

\subsection{Justificativa}

Para as análises de identificação e quantificação de antocianinas por Cromatografia Líquida de Alta Eficiência (CLAE), há necessidade de uso de padrões analíticos, mas, devido à grande diversidade de substituintes em sua estrutura, o desafio está em encontrar disponíveis comercialmente padrões de referência desses diversos compostos. Além disso, os padrões comerciais existentes são muito onerosos e por serem importados há demora em sua aquisição. Neste contexto, a obtenção destes padrões a partir de fontes naturais, poderá viabilizar a determinação, de forma mais acessível e precisa, as concentrações existentes dessas substâncias em alimentos que estejam na forma natural ou processados.

\subsection{Objetivo}

Isolar antocianinas, a partir de matrizes naturais, de fácil acesso, que possibilitem a identificação e quantificação por CLAE-DAD e CLUE-EM/QTOF (ESI ${ }^{+}$) dessas substâncias em alimentos. 
Objetivos específicos

- Desenvolver a metodologia de análise cromatográfica de antocianinas em matrizes vegetais

- Avaliar as matrizes que possuam potencial para isolamento de antocianinas

- Identificação das antocianinas utilizando espectrometria de massas (CLUEEM/EM-Q-TOF-ESI ${ }^{+}$).

- Isolamento das antocianinas utilizando Cromatografia Líquida de Alta Eficiência (CLAE/DAD).

- Validar a eficiência da metodologia cromatográfica desenvolvida

O estudo foi conduzido no laboratório de Cromatografia Líquida da Embrapa Agroindústria de Alimentos-RJ, onde se encontravam os equipamentos: Cromatógrafo Líquido de Ultra Eficiência -Waters ${ }^{\circledR}$ e Espectrômetro de Massas Synapt, Waters ${ }^{\circledR}$, QTOF $\left(\mathrm{ESI}^{+}\right)$com alta resolução (CLUE-QTOF/EM-EM). 


\section{REVISÃO BIBLIOGRÁFICA}

\section{1-Pigmentos Naturais}

O uso de corantes naturais tem sido uma proposta alternativa para manter ou conferir coloração aos alimentos de um modo geral, principalmente, quando estes são submetidos a processamentos industriais. A aparência de um alimento concorre de forma incondicional para a sua aceitabilidade. De certo, esta é uma das razões pela qual a cor seja uma das propriedades mais importantes dos alimentos, estando ele na sua forma natural ou que tenha sofrido algum tipo de processo (BOBBIO e BOBBIO, 1995).

Frequentemente se pode observar a perda da coloração durante o processamento. Sendo assim, a restituição da cor perdida é uma maneira de manter o aspecto de frescor nos alimentos. Dentre os pigmentos de origem vegetal, visíveis a olho nu, podemos citar a clorofila, carotenoides e antocianinas, sendo deste modo considerado as principais classes de pigmentos responsáveis pela coloração das partes dos vegetais como: flores, folhas, caule, raízes e frutos. Outros dois grupos de pigmentos que também podem ser encontrados, são as betalaínas (compostos nitrogenados) e taninos (condensados e hidrolisáveis) (BOBBIO e BOBBIO, 1995).

\section{2-Antocianinas}

As antocianinas, flavonoides com intensa atividade antioxidante, são os mais importantes pigmentos hidrossolúveis de origem exclusivamente vegetal (BRAVO, 1998), responsáveis pela maioria da coloração violeta e vários tons de vermelho ao alaranjado que compõem flores, frutos e alguns caules e raízes (BROUILLARD, 1982). Esses pigmentos se encontram dispersos nos vacúolos celulares (DEGÁSPARI, 2004). Nos alimentos de origem vegetal, pode ser encontrada em ao menos 27 famílias, 73 gêneros e numa grande variedade de espécies (BRIDLE e TIMBERLAKE, 1997). As principais antocianidinas encontradas em alimentos são: delfinidina; cianidina; pelargonidina; peonidina; petunidina e malvidina (Figura 1).

Como ocorre com os outros flavonoides, a grande diversidade das antocianinas está relacionada com a possibilidade de várias combinações de grupos substituintes em sua molécula, da natureza e do número de açúcares e de ácidos alifáticos e/ ou aromáticos (Figura 1), bem como da localização desses compostos presentes na sua aglicona, o que irá conferir à sua molécula uma maior estabilidade (STRACK et al., 1994). Portanto, é raro no reino vegetal a molécula na forma livre, aglicona. Podem estar glicosiladas em várias posições, mas ocorre naturalmente com maior frequência na posição $\mathrm{C}_{3}$. $\mathrm{O}$ segundo açúcar quando presente na molécula, encontra-se na posição $\mathrm{C}_{5}$. Porém podem ocorrer glicosilações nas posições $\mathrm{C}_{7}$, $\mathrm{C}_{3}, \mathrm{C}_{4}$, e $\mathrm{C}_{5}$, (BROUILLARD,1982).

Glicose, arabinose, galactose, xilose e ramnose são os açúcares (Figura 2) mais comuns ligados às agliconas. Dissacarídeos e trissacarídeos, oligossacarídios, formados pela combinação destes cinco monossacarídeos podem também glicosilar algumas antocianinas (WU e PRIOR, 2005; HARBONE, 1986). Em muitos casos, os açúcares podem ser acilados 
por ácidos fenólicos como p-cumárico, caféico, ferúlico e sinápico (MAZZA e BROUILLARD, 1987).<smiles>[R2]c1cc(-c2[o+]c3cc(O)cc(O)c3cc2O)cc([R2])c1O</smiles>

$\begin{gathered}\text { Aglicona } \\ (\text { Anel B })\end{gathered}$
$\mathrm{R}_{1}=\mathrm{R}_{2}=\mathrm{H}$ Pelagornidina
$\mathrm{R}_{1}=\mathrm{OH}, \mathrm{R}_{2}=\mathrm{H}$ Cianidina
$\mathrm{R}_{1}=\mathrm{R}_{2}=\mathrm{OH}$ Delfinidina
$\mathrm{R}_{1}=\mathrm{OCH}_{3}, \mathrm{R}_{2}=\mathrm{H}$ Peonidina
$\mathrm{R}_{1}=\mathrm{OCH}_{3}, \mathrm{R}_{2}=\mathrm{OH}$ Petunidina
$\mathrm{R}_{1}=\mathrm{R}_{2}=\mathrm{OCH}_{3}$ Malvidina

Aglicona

(Anel B)
$\mathrm{R}_{1}=\mathrm{R}_{2}=\mathrm{H}$ Pelagornidina
$\mathrm{R}_{1}=\mathrm{R}_{2}=\mathrm{OCH}_{3}$ Malvidina

\begin{tabular}{cc}
\multicolumn{2}{c}{$\begin{array}{c}\text { Glicosilação } \\
\text { (Posição 3 e 5) }\end{array}$} \\
Glicose & Sambubiose \\
Arabinose & Lathirose \\
Xilose & Soforose \\
Galactose & Laminaribiose \\
Ramnose & Gentiobiose \\
Rutinose & \\
\hline
\end{tabular}

\begin{tabular}{cc}
\multicolumn{2}{c}{ Acilação } \\
Ác. Alifáticos & Ác. Aromáticos \\
Ácido malônico & Ácido cafêico \\
Ácido succínico & Ácido ferúlico \\
Ácido málico & Ácido $p$-hidroxibenzoico \\
Ácido acético & Ácido sinápico \\
Ácido propiônico & Ácido $p$-cumárico
\end{tabular}

Ác. Alifáticos

Acido propionnico

Figura 1: Representa a estrutura das antocianinas e as posições das mais comuns glicosilações e acilações encontradas em alimentos de origem vegetal.

A variedade de substituintes no anel B da sua estrutura básica (Figura 1) é que confere a este pigmento diversidade na tonalidade da coloração nos vegetais. Além disso, à medida que o vegetal apresenta uma composição de diferentes antocianinas na sua matriz, as quais podem ou não ser composta por diferentes agliconas. A diferença de concentração entre elas, também irá influenciar tanto na tonalidade quanto na diferença da coloração do vegetal. Pomar, Novo e Masa (2005) que a concentração e a variedade dos tipos de antocianinas é que irão determinar a intensidade da coloração dos vários cultivares de uvas.

Estes pigmentos sofrem transformações estruturais reversíveis com mudança de $\mathrm{pH}$ em solução aquosa (Figura 3) manifestada por espectros de absorvância muito diferentes (GUIST e WROLSTAD, 2001). A mudança da coloração de uma mesma antocianina, também está relacionada à mudança do $\mathrm{pH}$, associação com cátions ou com outros flavonoides presentes na planta (BOBBIO e BOBBIO, 1995).

Em soluções aquosas, as antocianinas apresentam diferentes estruturas químicas em equilíbrio. Quando o $\mathrm{pH}$ se encontra abaixo de 2,0, as antocianinas apresentam coloração intensamente avermelhada devido ao predomínio da forma cátion flavílico $\left(\mathrm{AH}^{+}\right)$. Com o $\mathrm{pH}$ em torno de 4,5 é observado um equilíbrio entre a pseudo base carbinol ou forma hemicetal, incolor e chalconas. Com o aumento do $\mathrm{pH}$ ocorre uma rápida desprotonação resultando na formação predominante da base quinoidal (A) que tem coloração azul (BOBBIO e BOBBIO, 1995; GIUST e WROLSTAD, 2001). 
A pressão dos consumidores por alimentos de qualidade tem pressionado indústrias alimentícias a procurar alternativas para substituição de corantes artificiais, somando-se a esse fato, limitações de seu uso amparadas por legislações e pelos resultados cada vez mais preocupantes das pesquisas envolvendo prejuízos à saúde em longo prazo. Desse modo, impulsiona-se cada vez mais pesquisas na direção da sua substituição por corantes a partir de fontes naturais.

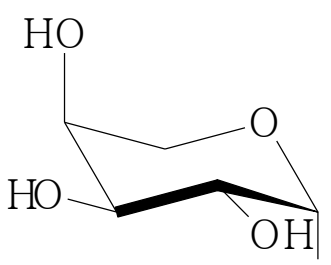

Arabinose

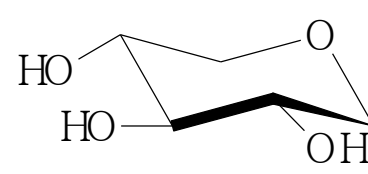

$\mathrm{OH}$

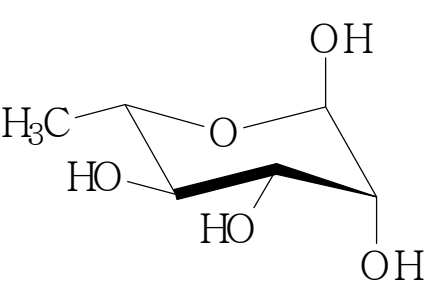

Ramnose

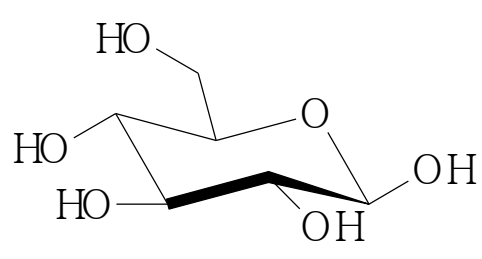

Glicose

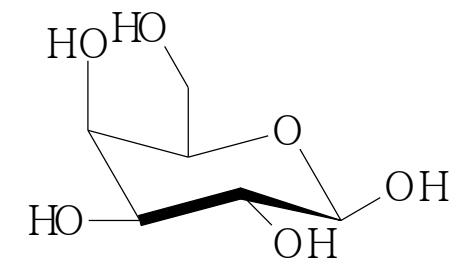

Galactose

Figura 2: Estruturas dos açúcares: arabinose; xilose; ramnose; glicose; galactose.

Há publicações de estudos do Codex Alimentarius, órgão ligado à Organização Mundial da Saúde (OMS), que já fundamentaram a banição de alguns corantes sintéticos em todos os países. Em 1987, a portaria $n^{\circ} 02$ da Agência Nacional de Vigilância Sanitária (ANVISA) relatou a proibição de alguns corantes sintéticos como: o vermelho sólido, que era usado para recheios e revestimentos de biscoitos; o escarlate GN, aplicado em recheios de confeitarias, além do azul de alizarina, corante que era usado em óleos emulsionados e gelatina, dentre outros (FAVARO, 2008). Desta forma, devido à toxicidade de alguns corantes sintéticos e à proibição do uso de alguns deles, nota-se um crescente interesse por corantes obtidos a partir de fontes naturais (MACZ-POP et al., 2006; TÜRKER e ERDOGDU, 2006; GIUSTI et al., 2003).

Várias pesquisas são realizadas com o intuito de se eliminar ou pelo menos reduzir o uso de corantes alimentícios sintéticos, dando lugar ao uso nos alimentos de corantes de fontes naturais. As antocianinas são corantes permitidos em alimentos, mas elas ainda não têm muitas aplicações. Seu uso como aditivo ainda é bastante restrito em função de limitações como a disponibilidade de matéria-prima produtora de pigmentos na quantidade e qualidade requerida (STRINGHETA, 2000). Além disso, tem-se visto que elas são corantes fortes apenas em valores baixos de $\mathrm{pH}$, o que limita ainda mais seu uso (COULTATE, 2004). Durante o armazenamento, as antocianinas podem sofrer modificações devido à sensibilidade ao efeito da temperatura, oxigênio, luz e ação enzimática (SKREDE, 2000; SHENOY, 1993; FRANCIS, 1989; JACKMAN et al.; 1987). 
Antocianinas com hidroxilas em posição orto em presença de cátions de alumínio (Al), ferro $(\mathrm{Fe})$, estanho $(\mathrm{Sn})$ e outros metais, formam produtos insolúveis que no caso do alumínio encontram aplicações como corantes que apresentam estabilidade ao calor, $\mathrm{pH}$ e oxigênio superior à das antocianinas livres (MARÇO e POPPI, 2008). Como exemplos, têm a cianidina, delfinidina e petunidina (Figura 4).<smiles>[R]C1=CC(=C2Oc3cc(O)cc(O[Ga])c3C=C2O[Na])C=C([R2])C1=O</smiles>

Base quinoidal: azul $\mathrm{pH}=7$<smiles>[R2]c1cc(C(=O)/C(O)=C/c2c(O)cc(O)cc2O)cc([R2])c1O</smiles>

Chalcona: incolor $\mathrm{pH}=9,5$

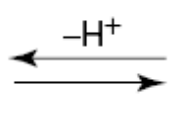<smiles></smiles>

Cátion Flavílio: laranja a púrpura $\mathrm{pH}=1$

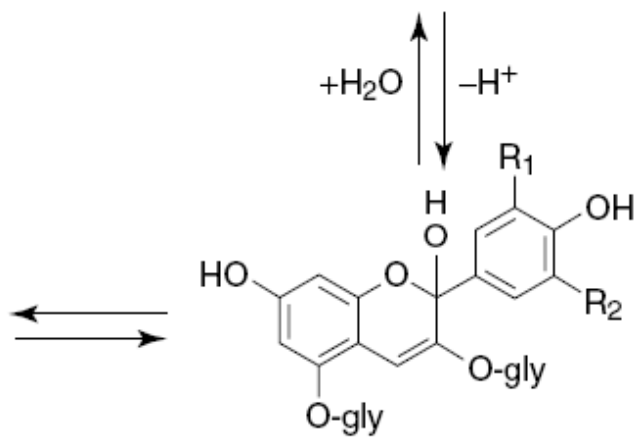

Pseudobase Carbinol (Hemicetal): incolor $\mathrm{pH}=4,5$

Figura 3: Equilíbrio das antocianinas em solução aquosa. Fonte: GIUST e WROLSTAD, 2001.<smiles></smiles>

\begin{tabular}{c|l}
$\mathbf{R}$ & Antocianidina \\
\hline $\mathrm{H}$ & Cianidina \\
$\mathrm{OH}$ & Delfinidina \\
$\mathrm{OCH}_{3}$ & Petunidina
\end{tabular}

Figura 4: Exemplo de antocianidina complexada ao alumínio. 
A luz é outro fator de grande importância na alteração da cor das antocianinas e, a transformação é mais intensa quando esse fator está associado com o efeito do oxigênio (MARÇO e POPPI, 2008).

A síntese artificial de antocianinas ainda não é um processo simples nem barato. Por isso aplicações desses compostos envolvem sua extração a partir de espécies vegetais, principalmente frutas, nas quais o teor de antocianinas é mais alto. $O$ custo de comercialização de antocianinas isoladas e quimicamente puras é muito alto e, dependendo do tipo de antocianina um miligrama pode custar mais de 1.000 dólares.

Portanto, é necessário expandir as possibilidades de sua obtenção em larga escala, a partir de fontes naturais de forma sustentável, para viabilizar o desenvolvimento de suas aplicações, com grandes benefícios para a sociedade (CANAL CIÊNCIA, 2011).

\section{3- Antocianinas em Alimentos}

O consumo de alimentos in natura, como hortaliças frescas e frutas tropicais, vêm aumentando tanto nacional quanto internacionalmente, devido ao crescente reconhecimento sobre os seus valores nutricionais e terapêuticos (RUFINO et al., 2010). O aumento no consumo desses alimentos não é mais somente resultado do sabor e da preferência individual, mas se tornou resultado também da preocupação com a saúde devido aos nutrientes presentes em sua composição. Além dos nutrientes essenciais, a maioria dos vegetais apresentam concentrações consideráveis de micronutrientes como minerais e vitaminas. Evidências crescentes demonstram a importância desses micronutrientes para a saúde humana (VASCO, RUALES, e KAMAL-ELDIN, 2008; VEER, JANSEN, KLERK, e KOK, 2000).

Uma ampla variedade de frutas nativas e/ou exóticas é consumida no Brasil, mas existem poucos estudos sobre a viabilidade da introdução das mesmas nos mercados domésticos. Estas frutas, como amora-preta, jabuticaba, jambo e pitanga entre outras, são consumidas no Brasil há muitos anos, sendo bem adaptadas às diversas condições climáticas brasileiras, e são fontes potenciais de antioxidantes na dieta (CLERICI e CARVALHOSILVA, 2011). Existe uma iniciativa internacional multidisciplinar que reconhece o papel essencial da biodiversidade e promove o seu uso sustentável, como meio de alcançar a segurança alimentar e nutricional das populações, contribuindo para o cumprimento do Millenium Development Goals (CBD 2005, deliberação VII/32). Esta iniciativa contraria a simplificação de dietas, sistemas agroalimentares e ecossistemas, além de evitar a erosão das culturas alimentares.

Um bom exemplo desse tipo de consumo alternativo é o fruto da palmeira Euterpe oleracea Mart., palmeira tropical nativa da região amazônica, cujo fruto o açaí ganhou mercado nacional e internacional divulgado por consumidores que buscaram mudanças em seus hábitos alimentares, a chamada "geração saúde" aprovou o produto incluindo-o na sua dieta alimentar, o aumento da demanda, proporcionou o grande crescimento das regiões produtoras trazendo consigo o desenvolvimento socioeconômico da região. Além disso, o crescimento do seu consumo despertou também o interesse da comunidade científica. Esse fato pode ser explicado devido às propriedades nutricionais e valor energético, pois é um alimento rico em lipídeos, fibras, vitaminas $\mathrm{E}, \mathrm{B}_{1}$, alguns micronutrientes minerais, compostos fenólicos como flavonoides, principalmente antocianinas, as quais estão relacionadas diretamente à sua coloração.

Para que ocorra promoção à utilização dos produtos alimentos não convencionais, é necessário que a sua composição seja conhecida, especialmente em termos de nutrientes e 
substâncias bioativas com propriedades promotoras da saúde. Dentre os nutrientes capazes de contribuírem para redução do risco do aparecimento de várias doenças, as antocianinas recebem grande destaque devido as suas propriedades antioxidantes (KUSKOSKI et al., 2004; MARTÍNEZ-FLORES, 2002; DOWNHAM e COLLINS, 2000).

Fatehi e colaboradores (2005) reportaram efeitos benéficos da Berberis vulgaris (Barberry), fruta de origem Iraniana, tanto em sistema cardiovascular como neurológico e sugeriram sua utilização no tratamento de hipertensão, taquicardia e algumas desordens neuronais, tais como epilepsia e convulsões.

A elevada capacidade antioxidante das antocianinas está diretamente relacionada à deficiência de elétrons do núcleo flávílio e presença de grupos hidroxilas livres, como por exemplo, das delfinidinas e cianidinas (KUSKOSKI et al., 2004). O alto poder de reação do grupo hidroxil com o radical faz com que o mesmo fique inativo (NIJVELDT et al., 2001). Com a reação ocorrendo da seguinte forma:

\section{$\mathrm{ACY}-\mathrm{OH}+\mathrm{R} *>\mathrm{ACY}-\mathrm{O} *+\mathrm{RH}$}

Onde: $\mathrm{ACY}=$ antocianina, $\mathrm{R}^{*}=$ radical livre e $\mathrm{O}^{*}=$ radical livre de oxigênio

$\mathrm{Na}$ última década, muitos estudos sobre as antocianinas têm se concentrado no potencial biológico e seus efeitos na saúde humana. Embora exista grande quantidade de evidências indicando sua bioatividade, pouco progresso foi feito para estabelecer a farmacocinética destes compostos em relação a sua absorção e metabolismo (KAY et al., 2005).

Nos Estados Unidos, por exemplo, as antocianinas são de interesse nutricional uma vez que a dose diária de ingestão recomendada para as mesmas é de 180 a $215 \mathrm{mg} / \mathrm{dia}$, o que é muito maior do que a recomendada (23 mg/dia) para outros flavonoides, incluindo a quercetina, kaempferol, miricetina, entre outros (GALVANO et al., 2004).

Uma boa fonte de pigmentos antociânicos é o fruto da jabuticabeira. A jabuticaba (Plinia spp.) é uma planta nativa brasileira, cultivada principalmente em alguns estados da região sudeste do país (MELLETI, 2000). Segundo Silva et al. (2010), as cascas de jabuticaba mostraram-se boas fontes de pigmentos antociânicos por apresentar elevados teores desse composto bioativo, apresentando-se como alternativas viáveis na obtenção de corantes naturais.

Segundo Augusta et al. (2010), a casca do jambo vermelho (Syzygium malaccensis) apresentou composição química adequada para enriquecer alimentos ou como fonte para extração de corante e antioxidantes, usados na indústria de alimentos, devido ao alto teor de carboidratos, o baixo valor energético, a elevada acidez e as altas concentrações de ácido ascórbico, antocianinas e fibra alimentar.

Quando submetidas à hidrólise ácida, as antocianinas liberam suas agliconas denominadas de antocianidinas e, dentre as encontradas na natureza, apenas seis são as mais comuns em alimentos: cianidina, pelargonidina, peonidina, delfinidina, petunidina e malvidina que diferem entre si pelo número de hidroxilas presentes no anel $\mathrm{B}$ e o grau de metilação desses grupos (BOBBIO \& BOBBIO, 1995; GALVANO et al., 2004; LIMA et al., 2006). A presença de grupos -OCH3 (metoxila) confere, em geral, cor mais avermelhada e maior estabilidade à oxidação e ao calor do que o aumento das hidroxilações, que por sua vez proporcionam predomínio das cores rosa e azul (BELITZ et al., 2009). Alguns alimentos já possuem suas antocianinas identificadas na literatura (Tabela1). 
Tabela 2: Exemplos de antocianinas identificadas em matrizes de origem vegetal.

\begin{tabular}{|c|c|}
\hline Antocianinas & Alimentos \\
\hline Cianidina-3-glicosídeo & $\begin{array}{l}\text { Cerejas*, jambolão*, uvas*, morangos*, } \\
\text { amoras vermelhas*, açaí }(\text { E. oleracea }) * * * \\
\text { juçara }(\text { E.edulis })^{* *} \text { cranwberry***** }\end{array}$ \\
\hline Cianidina-3-ramnosídeo & Acerola $* *$, juçara $(\text { E.edulis })^{* *}$ \\
\hline Cianidina-3-rutenosídeo & $\begin{array}{l}\text { Açaí }(\text { E. oleracea }) * * *, \text { juçara }(\text { E.edulis }) * *, \\
* * * * \text { amoras preta }(\text { R.ssp. }) \text { e ameixa }(P . \\
\text { domestica }) .\end{array}$ \\
\hline Cianidina-3,5- diglicosídeo & Jambolão ** \\
\hline Cianidina-3-arabinosídeo & Mirtilo, cranwberrry \\
\hline Cianidina-3-galactosídeo & Maçã (Fuji, Red, Gala), cranwberrry****** \\
\hline Peonidina-3-glicosídeo & $\begin{array}{l}\text { Cerejas*, jabuticaba*, uvas*, } \\
\text { cranwberry***** }\end{array}$ \\
\hline Peonidina-3,5- diglicosídeo & Jambolão** \\
\hline Peonidina-3-galactosídeo & Cranwberry***** \\
\hline Peonidina-3-arabinosídeo & Cranwberry***** \\
\hline Malvidina-3-glicosídeo & Uvas* \\
\hline Malvidina-3,5- diglicosídeo & Jambolão** \\
\hline Pelargonidina-3-glicosídeo & Morangos*, juçara (E.edulis)** \\
\hline Pelargonidina-3-ramnosídeo & Acerola $* *$ \\
\hline Pelargonidina-3-rutenosídeo & Juçara $($ E.edulis $) * *$ \\
\hline Delfinidina-3,5-diglicosídeo & Berinjelas*, jambolão** \\
\hline Delfinidina-3-galactosídeo ou glicosídeo & Guajiru ** \\
\hline Petunidina-3-glicosídeo & Uvas* \\
\hline Petunidina-3-glicosídeo ou galactosídeo & Guajiru** \\
\hline Petunidina-3,5- diglicosídeo & Jambolão** \\
\hline
\end{tabular}




\section{4- Métodos de Análise}

Os métodos que são utilizados para análise de compostos antociânicos relatados literariamente incluem desde cromatografia de papel até o mais sofisticado equipamento de espectrometria (espectrometria de massas - EM e espectrometria de ressonância magnéticaRMN). Devido ao grande avanço tecnológico da instrumentação alcançado nas últimas décadas, RMN e EM tornaram-se sem dúvida as ferramentas mais sofisticadas de análise que se encontram à disposição do químico orgânico (SILVERTEIN e WEBSTER, 2000). Mas, o alto custo de aquisição desses equipamentos, assim como sua manutenção e disponibilidade de pessoas qualificadas para operá-los, ainda é um grande desafio para sua adequação em laboratório analítico. Portanto, análises que utilizam materiais ou equipamentos mais simples, ainda são utilizados por grande parte da área analítica.

\subsubsection{Extração}

As antocianinas são substâncias hidrossolúveis, e seu grau de hidrossolubilidade aumenta à medida que sua estrutura básica apresenta grupamentos hidroxílicos livres e grupamentos glicosídeos associados às suas agliconas. Muitas metodologias de extração de antocianinas foram testadas e propostas na literatura. Dependendo do que se objetiva com a extração, poderá ser efetuada desde uma simples extração, realizada através da utilização de solventes polares orgânicos com ou sem água e utilizando diferentes valores de $\mathrm{pH}$ (Revilla, Ryan, e Martin-Ortega, 1998), até uma extração utilizando técnicas mais elaboradas como: Fluido Supercrítico (SFE - Supercritical Fluid Extraction); Extração com Líquido Pressurizado (PLE ${ }^{\circledR}$ Pressurized Liquid Extraction); Campo Elétrico Pulsado (PEF- Pulsed Electric Field) (GASCHOVSKA et al., 2010; PUERTOLA et al., 2013) entre outras.

A técnica com fluido supercrítico consiste na utilização do dióxido de carbono $\left(\mathrm{CO}_{2}\right)$ que em alta pressão se transforma em solvente, facilitando a extração dos compostos bioativos da matriz vegetal. Os pesquisadores que utilizam a metodologia SFE defendem que ela apresenta como vantagem sobre os métodos convencionais a utilização de pouco ou nenhum solvente orgânico, e quando necessário o solvente orgânico utilizado pode ser facilmente removido do soluto. O mesmo se pode dizer da PEF, tecnologia emergente, que tem ganhado crescente interesse na indústria de alimentos nos últimos anos para proporcionar melhorias nas operações de transferência de massas. Esta tecnologia vem sendo reportada na literatura como promissora na extração de corantes tais como antocianinas a partir de uvas ou repolho roxo através de extração aquosa (GASCHOVSKA et al., 2010; PUERTOLA et al., 2013).

Quando o objetivo é a extração analítica com finalidade de determinação da concentração de antocianina nas amostras analisadas, há necessidade do uso de metodologia que utiliza solvente orgânico polar mais eficaz, como o metanol que apesar da sua toxicidade é o mais utilizado e segundo Terci (2004) apresenta eficiência de extração $20 \%$ a mais do que o etanol e $73 \%$ do que a água. Há também a influência do $\mathrm{pH}$ que está diretamente relacionado com o equilíbrio ácido/ base destes compostos, afetando sua estrutura, refletindo, portanto, diretamente na sua extração. No entanto, não podemos deixar de citar outros fatores que também exerce grande influência no rendimento de extração como: concentração, tempo e temperatura utilizada na extração.

Muitos pesquisadores acidificam os solventes de extração com intenção de prevenir a oxidação das antocianinas extraídas e, dentre os ácidos utilizados encontram-se o ácido clorídrico, ácido acético e ácido fórmico. Porém, segundo Jackman et al. (1987) e Revilla et al. (1989), a concentração do ácido clorídrico não deve ser superior a 1\%, pois na tentativa de 
estabilizar a antocianina, o ácido pode proporcionar hidrólise parcial das antocianinas aciladas, e consequentemente, na estimação incorreta do teor de antocianinas quando quantificadas de forma individual ou totais. $\mathrm{O}$ excesso de acidez também pode proporcionar a liberação dos açúcares, que se encontram esterificados à sua aglicona, através de uma hidrólise parcial ou total. Campos (2006) relatou a importância do controle da temperatura, quando os extratos alcoólicos acidificados com $1 \%$ de $\mathrm{HCl}$ são submetidos à temperatura de $60^{\circ} \mathrm{C}$ durante 1 hora ou à evaporação sob aquecimento para eliminação do solvente. Com isso poderá ocorrer a hidrólise dos açúcares ligados a antocianinas liberando suas agliconas, proporcionando dessa forma quantificação incorreta da substância original e podendo ainda ocorrer a degradação da amostra, visto que, as agliconas (antocianidina) são muito mais instáveis e reativas do que sua forma glicosilada (antocianinas).

Segundo Xavier (2004), com metanol o ácido cítrico é o ácido orgânico mais efetivo, seguido pelos ácidos tartárico, fórmico, acético, propriônico, nesta ordem; com água, os melhores ácidos são ácidos acético, cítrico, tartárico e hidroclorídrico.

\subsubsection{Purificação do extrato}

Quando necessário, deve-se fazer a purificação do extrato. Pois após a extração, o extrato antociânico contém além de antocianinas, outros compostos fenólicos, açúcares, polissacarídeos solúveis, proteínas, cátions e ácidos orgânicos (CAMPOS, 2006).

Giusti e Wrolstad (1998) relataram o método de extração em fase sólida (SPE - Solid Phase Extraction) para purificação prévia de extrato antociânico. Os cartuchos $\mathrm{C}_{18}$ ou Sephadex são habitualmente os mais usados. Consiste na aplicação de extrato das antocianinas bruto no cartucho contendo material sorbente. As antocianinas são sorvidas fortemente neste material (fase estacionária) por suas hidroxilas livres. Desta forma, as substâncias mais polares que as antocianinas, como açúcares e ácidos orgânicos são, primeiramente, eluídas quando o cartucho é submetido à lavagem com água. Em seguida, as antocianinas são eluídas com solvente alcoólico acidificado (TERCI, 2004; KONG, 2003; KONG et al., 2008).

\subsubsection{Isolamento}

Segundo Pacheco (2009), o uso da cromatografia em coluna aberta pode ser uma técnica alternativa para isolamento de substâncias em quantidade relativamente significante e com alta pureza, as quais podem ser usadas posteriormente como padrões analíticos.

Por oferecer ótimas separações, alta sensibilidade, tempo de análise relativamente curto e não necessitar de extratos com elevada pureza, a cromatografia líquida de alta eficiência (CLAE) tem sido a técnica cromatográfica de escolha para a separação e isolamento de antocianinas. Campos (2006) relatou o isolamento de antocianinas presentes em extrato previamente purificado por CLAE. As coletas das frações foram realizadas individualmente, diretamente do cromatógrafo para tubos de ensaio, sendo em seguida realizadas leituras de absorvância em espectrofotômetro em $517 \mathrm{~nm}$. Para eliminar o solvente ela submeteu as frações por aproximadamente quatro horas em evaporador a vácuo.

\subsection{Identificação e Quantificação de Antocianinas}

A identificação das antocianinas pode ser realizada através de várias técnicas, dentre elas a espectrofotometria na região do ultravioleta e do visível (UV-Vis) é ainda a mais 
utilizada, visto que apresenta baixo custo. Ultimamente, tem sido muito mais eficiente quando associada a outras técnicas como a Cromatografia de Alta Eficiência (CLAE). Nos últimos anos, a CLAE vem sendo a técnica mais indicada para a separação dos analitos, e quando associada ao detetor de arranjo de fotodiodo (DAD) poderá fornecer informações que permitam identificar através do $\lambda_{\text {máx }}$ na região do visível, dados importantes sobre as propriedades estrutural das antocianinas (JORDHEIM et al.,2007; GIUSTI e WROSLTAD, 2001; GIUSTI, SAONA e WROLSTAD, 1999; HARBONE, 1967).

É importante distinguir procedimentos que identificam a classe das antocianinas e os procedimentos que identificam cada antocianina presente. $\mathrm{O}$ espectro eletrônico de absorção das antocianinas e suas agliconas têm sido muito úteis para a identificação desta classe de pigmentos de forma isolada e comparadas a padrões de referência (HARBORNE, 1967). Em meio ácido, estes compostos apresentam uma absorção máxima característica entre 490 e 550 nm e uma absorção menos intensa próxima a 275 nm (GIUSTI e WROLSTAD, 2001) (Figura $5)$.

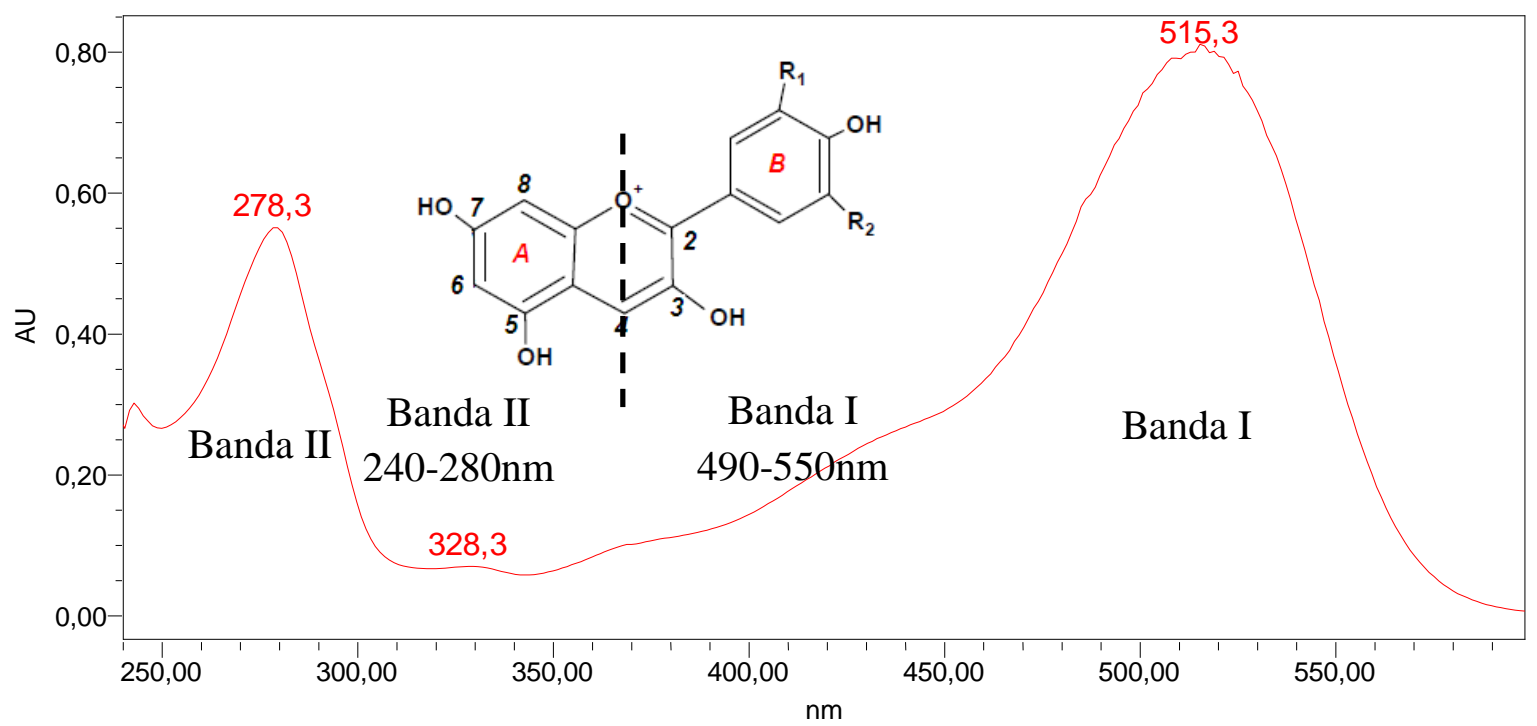

Figura 5: Espectro UV-Vis ${ }_{\text {máx a }} 520 \mathrm{~nm}$ - DAD (Detetor de Arranjo de Diodos), característico das antocianinas, mostrando uma absorção máxima na região 490-550 nm e uma absorção menos intensa próxima a $275 \mathrm{~nm}$.

O perfil cromatográfico das antocianinas é como se fosse sua impressão digital. Apresentam-se diferente entre si, em se tratando de frutos, flores, ou seja, matrizes vegetais diferentes, e dependendo do seu cultivar pode ainda apresentar antocianinas distintas ou em concentrações diferentes.

Hong e Wrolstad (1990) relataram que durante as análises do extrato de Cranberry e Roselle por CLAE/DAD (520nm), puderam observar a presença de duas antocianidinas cianidina e peonidina associadas a três diferentes tipos de açúcar (galactose, glicose e arabinose) na matriz do cranberry, e a delfinidina e cianidina associadas a dois tipos diferentes de açúcar (sambubiosídeo e glicose), na matriz de Roselle. Neste mesmo trabalho eles ainda relataram que os espectros também podem fornecer informações sobre onde ocorre a glicosilação. A 3-glicosilação e a 3,5-diglicosilação possuem um espectro no $\lambda_{\text {máx }}$ similares, mas, mostram valores diferentes na região de $400-440 \mathrm{~nm}$, portanto, podem ser diferenciados 
quando se faz a razão entre $E_{440} / \mathrm{E} \lambda_{\text {máx }}$, o valor obtido caracteriza a presença de um ou dois açúcares glicosilando a molécula em carbonos distintos.

Através do uso de técnicas cromatográficas, onde o fator de retardamento $(\mathrm{RF})-$ observados nas cromatografias em placa ou papel, ou tempo de retenção $\left(t_{R}\right)$, quando se utiliza cromatografia em coluna, torna-se possível identificar as antocianinas por comparação direta quando há padrões disponíveis e indireta quando os dados são comparados com os reportados na literatura, guardadas as devidas limitações deste procedimento, visto que, este procedimento pode ocasionar erros, mas seu uso vem sendo justificado justamente pela falta de padrões e pelo trabalhoso procedimento para identificá-las (HARBONE, 1984). O t $t_{R}$ está diretamente relacionado com o grau de polaridade da molécula antociânica na cromatografia de fase reversa. Este fator é influenciado diretamente pela quantidade de grupos hidroxilas, o grau de metilação, acilação, o tipo de açúcar, assim como, a quantidade deles ligada à sua estrutura básica (JACKMAN et al., 1987).

Alguns autores utilizam a cianidina-3-glicosídeo (Figura 6), como padrão de referência para quantificação de antocianinas em alimentos, visto que este pigmento é, dentre os outros pigmentos antociânicos, considerado o mais abundante na natureza. Assim, os autores reportam a quantificação individual por cromatografia líquida das antocianinas presentes na amostra, por equivalência à cianidina-3-glicosídeo (Brito, et al., 2007). Este procedimento vem sendo aceito, justamente pela dificuldade em se obter vários tipos de padrão, o que tornaria as análises muito onerosas. No entanto, as concentrações relatadas podem ser inferiores aos reais, pois, os valores de absortividade molar e massa molar da cianidina-3glicosídeo são diferentes das outras antocianinas (HONG e WROLSTAD, 1990; FRANCIS, 1982) e dependendo do sistema de solvente utilizado, a mesma antocianina pode apresentar valores muito diferentes de coeficiente de absortividade (Tabela 2).<smiles>Oc1cc(O)c2cc(O[C@@H]3O[C@H](O)[C@H](O)[C@H](O)[C@H]3O)c(-c3ccc(O)c(O)c3)[o+]c2c1</smiles>

Figura 6: Estrutura da antocianina cianidina-3-O-glicosídeo. 
Tabela 2: Diferentes valores de absortividade molar relatadas na literatura.

\begin{tabular}{|c|c|c|c|c|}
\hline Antocianinas & Solvente & $\begin{array}{l}\lambda \text { vis- } \\
\text { máx }\end{array}$ & $\begin{array}{l}\text { Absortividade } \\
\text { Molar }(\varepsilon)\end{array}$ & Referência \\
\hline \multicolumn{5}{|c|}{ Cianidina (Cy) } \\
\hline $\begin{array}{l}\text { Cy-3-sam-5- } \\
\text { gli+sinápico+ferúlico }\end{array}$ & Tampão aquoso (pH0,9) & 528 & 15100 & Figueiredo et al., 1996* \\
\hline $\begin{array}{l}\text { Cy-3-sam-5- } \\
\text { gli+sinápico+ferúlico+ } \\
\text { malônico }\end{array}$ & Tampão aquoso (pH0,9) & 538 & 21200 & Figueiredo et al., 1996* \\
\hline \multirow{2}{*}{$\begin{array}{l}\text { Cy-3-sam-5-gli+sinápico+ } \\
\text { p-coumárico }\end{array}$} & Tampão aquoso (pH0,9) & 528 & 15100 & Figueiredo et al., 1996* \\
\hline & Tampão aquoso (pH0,9) & 536 & 19000 & Figueiredo et al., 1996* \\
\hline Cy-3-sof-5-glic & MetOH acid com $\mathrm{HCl}$ & 524 & 37150 & Hrazdina et al.,1977* \\
\hline Cy-3-sof-5-glic+malônico & MetOH acid com $\mathrm{HCl}$ & 528 & 32360 & Hrazdina et al., $1977^{*}$ \\
\hline Cy-3-sof-5-glic+sinápico & MetOH acid com $\mathrm{HCl}$ & 528 & 37150 & Hrazdina et al.,1977* \\
\hline Cy-3-sof-5-glic+di-sinápico & MetOH acid com $\mathrm{HCl}$ & 530 & 38020 & Hrazdina et al.,1977* \\
\hline Cy-3-sof-5-glic+ferúlico & MetOH acid com $\mathrm{HCl}$ & 528 & 32360 & Hrazdina et al.,1977* \\
\hline Cy-3-sof-5-glic+di-ferúlico & MetOH acid com $\mathrm{HCl}$ & 530 & 34670 & Hrazdina et al.,1977* \\
\hline $\begin{array}{l}\text { Cy-3-sof-5-glic+ } p \text { - } \\
\text { coumárico }\end{array}$ & MetOH acid com $\mathrm{HCl}$ & 526 & 38020 & Hrazdina et al.,1977* \\
\hline $\begin{array}{l}\text { Cy-3-sof-5-glic+ di- } p \text { - } \\
\text { coumárico }\end{array}$ & MetOH acid com $\mathrm{HCl}$ & 528 & 32600 & Hrazdina et al., $1977^{*}$ \\
\hline \multicolumn{5}{|c|}{ Delfinidina (Dp) } \\
\hline Dp (aglicona) & $0,1 \% \mathrm{HC} / \mathrm{EtOH}$ & 522,5 & 34700 & Schou, 1927* \\
\hline \multirow[t]{2}{*}{ Dp-3-gli } & $1 \% \mathrm{HCl} / \mathrm{MetOH}$ & 543 & 29000 & Asen et al, 1959* \\
\hline & $10 \% \mathrm{EtOH}(\mathrm{pH} 1,5)$ & 520 & 23700 & Heredia et al., 1998* \\
\hline \multicolumn{5}{|c|}{ Malvidina (Mv) } \\
\hline Mv (aglicona) & $0,1 \% \mathrm{HCl} / \mathrm{EtOH}$ & 520 & 37200 & Schou, 1927* \\
\hline & $0,1 \% \mathrm{HCl} / \mathrm{EtOH}$ & 557 & 36200 & Ribereau-Gayon, 1959* \\
\hline Mv-3,5-diglic & $0,1 \% \mathrm{HCl} / \mathrm{EtOH}$ & 519 & 10700 & Schou, 1927* \\
\hline
\end{tabular}

Fonte: Jordheim et al.,2007; *Giusti e Wrolstad (2001); Giuist, Rodríguez-Saona, Wrolstad (1999).

Abreviações: ara: arabinose; gal: galactosídeo; glic: glicosídeo; rut: rutinosídeo; sam: sambibiosídeo; sof: soforosídeo 
Tabela 2: Diferentes valores de absortividade molar relatadas na literatura (continuação)

\begin{tabular}{|c|c|c|c|c|}
\hline Antocianinas & Solvente & $\begin{array}{l}\lambda \text { vis- } \\
\text { máx }\end{array}$ & $\begin{array}{c}\text { Absortividade } \\
\text { Molar ( } \varepsilon)\end{array}$ & Referência \\
\hline \multicolumn{5}{|c|}{ Malvidina (Mv) } \\
\hline \multirow[t]{2}{*}{ Mv-3,5-diglic } & $0,1 \% \mathrm{HCl} / \mathrm{EtOH}$ & 545 & 10300 & Ribereau-Gayon, 1959* \\
\hline & $0,1 \mathrm{~N} \mathrm{HCl}$ & 520 & 37700 & Niketic-Aleksi e Harazdina, 1972* \\
\hline \multirow[t]{2}{*}{ Mv-3-glic } & $0,1 \% \mathrm{HCl} / \mathrm{MetOH}$ & 546 & 13900 & Somers, $1996^{*}$ \\
\hline & $0,1 \% \mathrm{HCl} / \mathrm{MetOH}$ & 538 & 29500 & Koeppen e Basson, 1966* \\
\hline \multirow[t]{5}{*}{ Mv-3-glic } & $0,1 \% \mathrm{HCl}$ & 520 & 28000 & Niketic-Aleksi e Harazdina, 1972* \\
\hline & MetOH (pH1,0) & 535 & 36400 & Metivier et al,1980* \\
\hline & $10 \% \mathrm{EtOH}(\mathrm{pH} 1,5)$ & 520 & 20200 & Heredia et al., 1998* \\
\hline & Tampão aquoso (pH 1) & 517 & 23000 & Jordheim et al.,2007* \\
\hline & MetOH acid com $\mathrm{HCl}$ & 529 & 25000 & Jordheim et al.,2007* \\
\hline \multirow[t]{2}{*}{ Mv-3-glic +p-coumárico } & $0,1 \% \mathrm{HCl} / \mathrm{MetOH}$ & 536 & 30200 & Koeppen e Basson, 1966* \\
\hline & \multicolumn{3}{|c|}{ Pelargonidina (Pg) } & \\
\hline \multirow[t]{3}{*}{ Pg (aglicona) } & $0,1 \% \mathrm{HCl} / \mathrm{EtOH}$ & 504,5 & 17800 & Schou, 1927* \\
\hline & 0,025M Tampão ClK (pH 1) & 505 & 18420 & Giusti et al., 1999 \\
\hline & $0,1 \% \mathrm{HCl} / \mathrm{MetOH}$ & 524 & 19780 & Giusti et al., 1999 \\
\hline Pg-3,5-diglic & $\mathrm{HCl} / \mathrm{MetOH}$ & 510 & 32360 & Swain, $1965^{*}$ \\
\hline \multirow[t]{2}{*}{$\begin{array}{l}\text { Pg-3,5-(dicafeilglic sof-5- } \\
\text { glic }\end{array}$} & Tampão aquoso, pH(0,8) & 512 & 28000 & Dangles et al.,1993* \\
\hline & & 528 & 32600 & Hrazdina et al.,1977* \\
\hline \multirow[t]{4}{*}{ Pg-3-glic } & $1 \% \mathrm{HCl} /$ água & 496 & 27300 & Joergensen e Geissman, 1955* \\
\hline & Tampão aquoso (pH1) & 497 & 21000 & Jordheim et al..,2007 \\
\hline & $\mathrm{HCl} / \mathrm{MetOH}$ & 502 & 24000 & Jordheim et al..,2007 \\
\hline & $1 \% \mathrm{HCl}$ & 513 & 22390 & Swain, $1965^{*}$ \\
\hline
\end{tabular}

Fonte: Jordheim et al.,2007; *Giusti e Wrolstad (2001); Giuist, Rodríguez-Saona, Wrolstad (1999).

Abreviações: ara: arabinose; gal: galactosídeo; glic: glicosídeo; rut: rutinosídeo; sam: sambibiosídeo; sof: soforosídeo 
Tabela 2: Diferentes valores de absortividade molar relatadas na literatura (continuação).

\begin{tabular}{|c|c|c|c|c|}
\hline Antocianinas & Solvente & $\lambda$ vis-máx & $\begin{array}{c}\text { Absortividade } \\
\text { Molar }(\varepsilon)\end{array}$ & Referências \\
\hline \multicolumn{5}{|c|}{ Pelargonidina (Pg) } \\
\hline \multirow[t]{3}{*}{ Pg-3-glic } & $1 \% \mathrm{HCl} / \mathrm{EtOH}$ & 516 & 31620 & Swain, $1965^{*}$ \\
\hline & 0,025M Tampão ClK (pH 1) & 496 & 15600 & Giusti et al., 1999 \\
\hline & $0,1 \% \mathrm{HCl} / \mathrm{MetOH}$ & 508 & 17330 & Giusti et al., 1999 \\
\hline $\begin{array}{l}\text { Pg-3-rut-5-glic+ } p \text { - } \\
\text { coumárico }\end{array}$ & 0,025M Tampão ClK (pH 1) & 504 & 32080 & Giusti et al., 1999 \\
\hline \multirow[t]{2}{*}{ Pg-3-sof-5-glic } & $0,1 \% \mathrm{HCl} / \mathrm{MetOH}$ & 511 & 39591 & Giusti et al., 1999 \\
\hline & Tampão aquoso (pH 0,8) & 498 & $18000-20000$ & Dangles et al.,1993* \\
\hline \multirow[t]{3}{*}{ Pg-3-sof-5-glic } & 0,025M Tampão ClK (pH 1) & 497 & 25370 & Giusti et al., 1999 \\
\hline & $0,1 \% \mathrm{HCl} / \mathrm{MetOH}$ & 506 & 30690 & Heredia et al., 1998* \\
\hline & Tampão aquoso (pH 0,8) & 498 & $18000-20000$ & Dangles et al.,1993* \\
\hline \multirow[t]{2}{*}{ Pg-3-sof-5-glic+ferúlico } & 0,025M Tampão ClK (pH 1) & 506 & 24140 & Giusti et al., 1999 \\
\hline & $0,1 \% \mathrm{HCl} / \mathrm{MetOH}$ & 507 & 29636 & Giusti et al., 1999 \\
\hline $\begin{array}{l}\text { Pg-3-sof-5-glic cafeoil } \\
\text { derivados }\end{array}$ & Tampão aquoso, pH(0,8) & 498 & $18000-20000$ & Dangles et al., 1993* \\
\hline \multirow{2}{*}{$\begin{array}{l}\text { Pg-3-sof-5-glic+ } p \text { - } \\
\text { coumárico }\end{array}$} & 0,025M Tampão ClK (pH 1) & 506 & 28720 & Giusti et al., 1999 \\
\hline & $0,1 \% \mathrm{HCl} / \mathrm{MetOH}$ & 508 & 34889 & Giusti et al., 1999 \\
\hline $\begin{array}{l}\text { Pg-3-sof-5-glic+ } p \text { - } \\
\text { coumárico+malônico }\end{array}$ & 0,025M Tampão ClK (pH 1) & 508 & 33010 & Giusti et al., 1999 \\
\hline \multirow{2}{*}{$\begin{array}{l}\text { Pg-3-sof-5- } \\
\text { glic+ferúlico+malônico }\end{array}$} & 0,025M Tampão ClK (pH 1) & 508 & 31090 & Giusti et al., 1999 \\
\hline & $0,1 \% \mathrm{HCl} / \mathrm{MetOH}$ & 508 & 39384 & Giusti et al., 1999 \\
\hline \multirow{3}{*}{ Pn (aglicona) } & Pec & onidina (P & & \\
\hline & $0,1 \% \mathrm{HCl} / \mathrm{EtOH}$ & 511 & 37200 & Schou, 1927* \\
\hline & $15: 85,0,1 \mathrm{~N} \mathrm{HCl} /$ Etanol & 532 & 40800 & Sakamura e Francis, 1961* \\
\hline \multirow[t]{2}{*}{ Pn-3-ara } & $15: 85,0,1 \mathrm{~N} \mathrm{HCl} /$ Etanol & 532 & 46100 & Zapsalis e Francis, 1965* \\
\hline & $15: 85,0,1 \mathrm{~N} \mathrm{HCl} /$ Etanol & 532 & 46070 & Fuleki e Francis, 1968a * \\
\hline Pn-3,5-diglic & $0,1 \% \mathrm{~N} \mathrm{HCl}$ & 520 & 36654 & Niketic-Aleksic e Harazdina,1972* \\
\hline
\end{tabular}

Fonte: Jordheim et al.,2007; *Giusti e Wrolstad (2001); Giuist, Rodríguez-Saona, Wrolstad (1999).

Abreviações: ara: arabinose; gal: galactosídeo; glic: glicosídeo; rut: rutinosídeo; sam: sambibiosídeo; sof: soforosídeo 
Tabela 2: Diferentes valores de absortividade molar relatadas na literatura (continuação)

\begin{tabular}{|c|c|c|c|c|}
\hline Antocianinas & Solvente & $\lambda$ vis-máx & $\begin{array}{c}\text { Absortividade } \\
\text { Molar }(\varepsilon)\end{array}$ & Referência \\
\hline \multicolumn{5}{|c|}{ Peonidina (Pn) } \\
\hline \multirow[t]{3}{*}{ Pn-3-gal } & $15: 85,0,1 \mathrm{~N} \mathrm{HCl} /$ Etanol & 532 & 48400 & Sakamura e Francis, 1961* \\
\hline & $15: 85,0,1 \mathrm{~N} \mathrm{HCl} /$ Etanol & 532 & 48400 & Zapsalis e Francis, 1965 \\
\hline & $15: 85,0,1 \mathrm{~N} \mathrm{HCl} /$ Etanol & 531 & 48340 & Fuleki e Francis, 1968a * \\
\hline \multirow[t]{2}{*}{ Pn-3-gli } & $0,1 \% \mathrm{HCl} / \mathrm{MetOH}$ & 536 & 11300 & Somers, $1966^{*}$ \\
\hline & $10 \% \mathrm{EtOH}(\mathrm{pH} 1,5)$ & 512 & 14100 & Heredia et al., 1998* \\
\hline \multicolumn{5}{|c|}{ Petunidina (Pt) } \\
\hline Pt-3,5-diglic & $\mathrm{HCl} / \mathrm{MetOH}$ & 535 & 23440 & Swain, $1965^{*}$ \\
\hline Pt-3,5-diglic & $0,1 \mathrm{~N} \mathrm{HCl}$ & 520 & 33040 & $\begin{array}{l}\text { Niketic-Aleksic e } \\
\text { Harazdina,1972* }\end{array}$ \\
\hline \multirow[t]{2}{*}{ Pt-3,5-diglic } & $0,1 \mathrm{~N} \mathrm{HCl}$ & 520 & 33040 & $\begin{array}{l}\text { Niketic-Aleksic e } \\
\text { Harazdina,1972* }\end{array}$ \\
\hline & $\mathrm{HCl} / \mathrm{MetOH}$ & 535 & 23440 & Swain, $1965^{*}$ \\
\hline \multirow[t]{4}{*}{ Pt-3-glic } & $0,1 \% \mathrm{HCl} / \mathrm{MetOH}$ & 546 & 12900 & Somers, $1966^{*}$ \\
\hline & $10 \% \mathrm{EtOH}(\mathrm{pH} 1,5)$ & 520 & 18900 & Heredia et al., 1998* \\
\hline & Tampão aquoso (pH 1) & 511 & 21000 & Jordheim et al..,2007 \\
\hline & $\mathrm{HCl} / \mathrm{Metanol}$ & 527 & 23000 & Jordheim et al.,2007 \\
\hline
\end{tabular}

Fonte: Jordheim et al.,2007; *Giusti e Wrolstad (2001); Giuist, Rodríguez-Saona, Wrolstad (1999).

Abreviações: ara: arabinose; gal: galactosídeo; glic: glicosídeo; rut: rutinosídeo; sam: sambibiosídeo; sof: soforosídeo

A maioria dos valores reportados na literatura é de 1970 ou inferior a essa data. É necessário considerar que não existiam técnicas tão avançadas como nos dias de hoje. Sendo assim, a grande variação nos valores relatados também pode ser atribuída às dificuldades na preparação de uma solução cristalina de antocianina, livre de impurezas e em quantidade suficiente que permitisse uma pesagem confiável (FULEKI e FRANCIS, 1968: FRANCIS, 1982), pois, a presença de impurezas na amostra poderá levar a uma baixa estimação no cálculo do coeficiente de absortividade, erro que pode ser atribuído à presença de compostos que contribuam para o peso, mas, que não interferem na cor. Outro efeito que poderá ocorrer com presença de outros compostos fenólicos na matriz, seria o efeito hipercrômico que se explica através da copigmentação entre a antocianina e outro composto fenólico incolor (Figura 7), causando assim uma superestimação no valor do coeficiente de absortividade (IACOBUCCI e SWEENY,1983; MAZZA e BROUILLARD, 1990; GIUST, RODRÍGUEZSAONA, WROLSTAD, 1999; FALCÃO, 2003).

A Tabela 2 permite observarmos que a maioria dos valores de absortividades calculados nos períodos de 1980 até 2007, apresentam-se mais baixos do que os observados anteriormente a esse período. O coeficiente de absortividade observado para a cianidina-3glicosídeo pode ser um exemplo desta observação. Pode-se observar que foi utilizado pelos dois autores de décadas diferentes (1966 e 2007) o mesmo sistema de solvente. No caso, foi utilizado o tampão aquoso $(\mathrm{pH} \mathrm{1,0).} \mathrm{Os} \mathrm{dois} \mathrm{trabalhos} \mathrm{relatam} \mathrm{que} \mathrm{observaram} \mathrm{o} \mathrm{mesmo}$ comprimento de onda, $510 \mathrm{~nm}$, para a cianidina-3-O-glicosídeo, mas o coeficiente de absortividade apresenta uma variação entre a observação dos autores Jordheim et al. (2007) de 
um percentual de 34,5\% para menos do que o observado pelos autores Jurd e Arsen em 1966. Giust e colaboradores, em 1999 relatam a similaridade do valor do coeficiente de absortividade da aglicona pelargonidina ao compararem seu dado obtido no trabalho com o relatado pelo Schou em 1927 (Tabela 2). No entanto, eles também observaram neste mesmo trabalho que o coeficiente de absortividade obtido para a pelargonidina-3- glicosídeo por eles apresentou um valor inferior ao reportado anteriormente por Jorgensen e Geissman. (1955) (Tabela 3). Vale neste caso fazer uma observação que nos dois experimentos não foi utilizado o mesmo sistema de solvente. Isso poderá de certa forma vir a justificar a diferença de valores encontrados entre eles, visto que, em 2007 o trabalho de Jordheim et al. (2007) também observou valor superior ao observado por Giust et al. (1999) e nesse caso só houve uma variação na concentração do ácido (HCl) utilizado no sistema, Tabela 3.

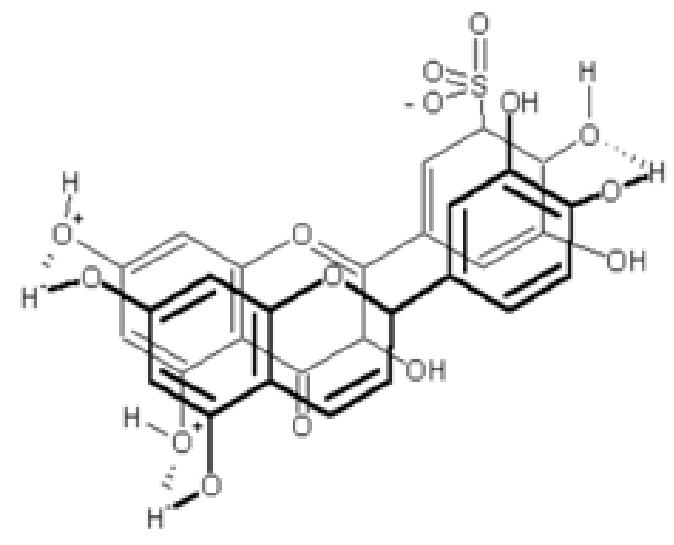

Figura 7: Exemplo de copigmentação entre uma antocianina e um copigmento incolor. Fonte: IACOBUCCI e SWEENY, 1983 apud FALCÃO, 2003.

Tabela 3: Coeficiente de absortividade molar em sistemas de solventes diferentes

\begin{tabular}{lcccc}
\hline Antocianina & Solvente & $\begin{array}{c}\lambda \text { vis- } \\
\text { máx }\end{array}$ & $\begin{array}{c}\text { Absortividade } \\
\text { Molar }(\varepsilon)\end{array}$ & Referências \\
\hline & $1 \% \mathrm{HCl} /$ água & 496 & 27300 & Joergensen e Geissman, 1955* \\
& $0,1 \% \mathrm{HCl} / \mathrm{MetOH}$ & 508 & 17330 & Giusti et al., 1999 \\
Pelargonidina-3-glicosídeo & $0,01 \% \mathrm{HCl} / \mathrm{MetOH}$ & 502 & 24000 & Jordheim et al.,2007 \\
& & & &
\end{tabular}

Fonte: *Giusti et al. (1999); Jordheim et al.,(2007).

\subsubsection{Cromatografia Líquida}

Esta metodologia ficou definida no início da primeira década do século XX, devido aos experimentos realizados pelo botânico russo Mikhail Semenovich Tswett, considerado por muitos como o pai da cromatografia moderna. A partir de seus experimentos, onde efetuou a 
separação de extratos de plantas por adsorção diferencial em colunas de vidro, ficou visível o potencial da metodologia em separar os componentes de uma mesma matriz. Desde então, grandes avanços nesta área vêm sendo relatados na literatura. Sendo assim, devido a esses "grandes avanços", hoje em dia pode-se dizer que a cromatografia líquida está dividida em dois grupos: Cromatografia Líquida "Clássica" (CLC) e a Cromatografia Líquida de Alta Eficiência (CLAE).

\subsubsection{Cromatografia Líquida Clássica (CLC)}

O termo Cromatografia Líquida Clássica é utilizado hoje em dia para designar a técnica em que se usam colunas de vidro para a realização de experimentos. A CLC utiliza coluna de vidro de diâmetro interno variado. De uma maneira geral, a coluna de vidro é um tubo de vidro, com a extremidade inferior afilada, podendo ou não terminar em uma torneira, que permitirá o controle da vazão da fase móvel. A parte superior da coluna é aberta, para permitir a entrada da amostra e fase móvel. A fase estacionária poderá rechear a coluna com partículas de tamanho que pode variar de 60 à $200 \mu \mathrm{m}$. Esta fase é suportada próximo à parte afilada, com chumaço de lã de vidro ou por uma placa porosa de politetrafluoretileno (PTFE), conforme demonstra a Figura 8.

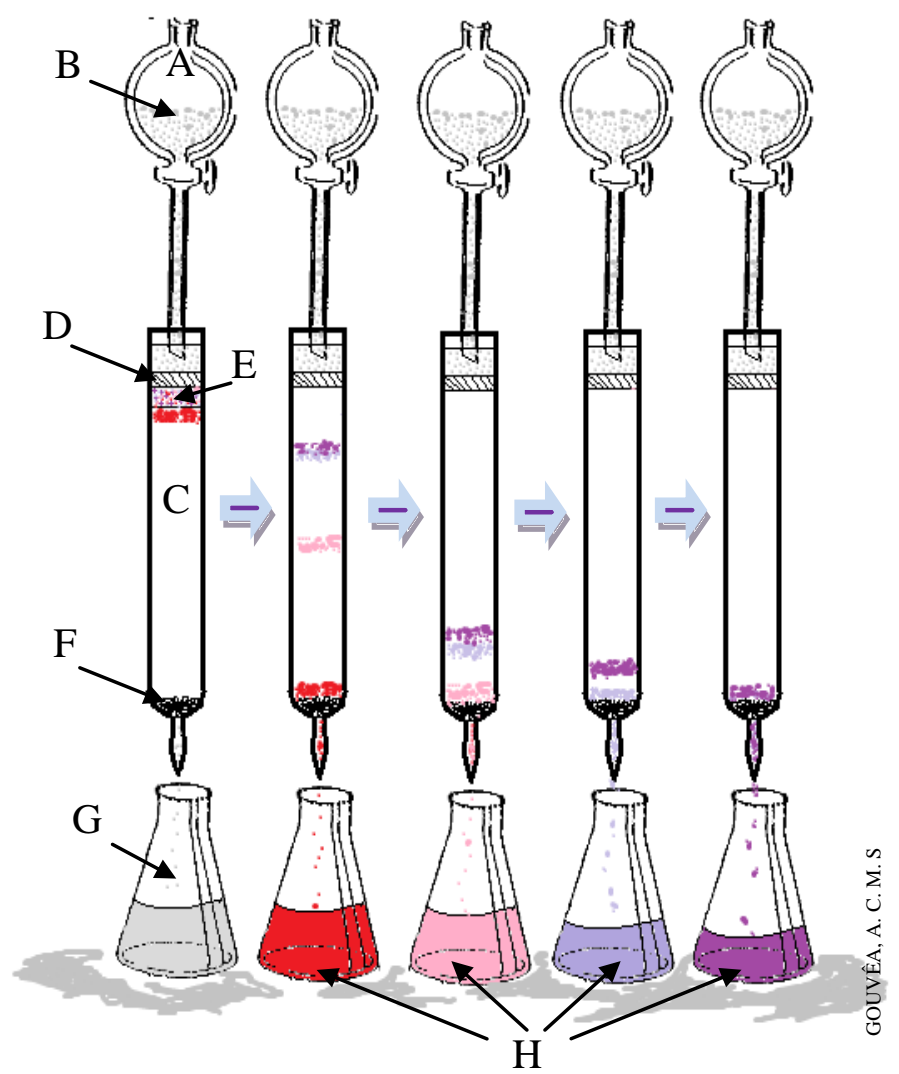

Figura 8: Esquema de uma coluna de adsorção: A-Reservatório; B- Fase Móvel; C- Coluna de vidro recheada com adsorvente; D- Camada de recheio ou areia; E-Amostra; F- Lã de vidro; G- Frasco coletor; H- Analitos isolados coletados. 
A fase móvel percola a coluna devido à força gravitacional ou com a aplicação de uma pressão reduzida (vácuo). Dependendo do adsorvente e do que compõe a amostra, o recheio da coluna só poderá ser utilizado uma só vez. Dessa maneira, essa metodologia pode apresentar desperdiço de material além de se tornar muito trabalhosa para o operador. Outra desvantagem está relacionada ao analito. A observação da separação só é eficiente se este apresentar coloração no comprimento de onda visível. Após a coleta do material, será necessário utilizar uma técnica auxiliar, tal como espectrofotometria, ou simplesmente um registro gravimétrico, para dosar cada um dos componentes da amostra nas frações coletadas. Finalmente registra o resultado sob a forma de um cromatograma: gráfico de concentração da amostra versus o número da fração (COLLINS, BRAGA e BONATO, 2008).

\subsubsection{Cromatografia Líquida de Alta Eficiência}

Nos últimos anos, a cromatografia líquida vem sendo uma das técnicas mais empregadas pela ciência nas mais diversas áreas. A cromatografia líquida permite a separação, e com ajuda de padrões de referência para montar uma curva analítica, a quantificação de analitos em amostras complexas, à medida que seus equipamentos foram ficando mais modernos e sofisticados. A partir da década de 70, vários nomes têm sido utilizados para denominar essa técnica. A sigla HPLC inicialmente significando "High Pressure Liquid Chromatography" e posteriormente com a evolução da técnica, passou a ser conhecida como "High Performance Liquid Chromatography" (LANÇAS, 2009), e em portugues CLAE "Cromatografia Líquida de Alta Eficiência" são as mais utilizadas (COLLINS, BRAGA e BONATO, 2008). Em termo de praticidade, alguns fabricantes desenvolveram equipamentos modulares. Isso não somente permitiu ao usuário configurar o cromatógrafo líquido de acordo com sua necessidade analítica, como também tornou possível intercambiar com módulos de diferentes fabricantes. Com o auxílio de novos detetores como: espectrofotométricos que podem operar em comprimento de onda variável; fluorescência induzida por laser; espectrômetro de massas, tornou-se possível a deteção de uma faixa mais ampla de substâncias e de compostos que se encontram em baixa concentração na amostra analisada.

No mercado podem ser encontrados vários tipos de equipamentos cromatográficos, mas basicamente seguem uma linha de funcionamento como é descrito a seguir: a técnica consiste na introdução da amostra no equipamento através de um injetor (manual ou automático), onde encontra o solvente apropriado para a análise (fase móvel ou eluente) que é impulsionado por uma bomba de alta pressão em direção à coluna onde ocorre a separação dos analitos. O efluente que sai da coluna passa pelo detetor, que acusa o (s) analito (s) eluído (s) gerando um sinal que é captado por um software adequado, desenvolvido especificamente para sistemas de CLAE, instalado numa CPU que se encontra interligado ao equipamento, permitindo assim a aquisição de dados (Figura 9). O resultado é obtido em tempo real ao da análise através de um cromatograma, gerado na tela do computador, em função do sinal interpretado e o tempo de corrida, (LANÇAS, 2009 apud DONG, 2006; McMASTER, 2007; MEYER, 2004; SNYDER, 2009). Esses softwares também permitem ajustes de picos, cálculo automático de concentração, correção da linha de base, etc.

Nessas últimas décadas, além de ter ocorrido avanço na instrumentação houve também um grande salto no desenvolvimento tecnológico para confecção de colunas cromatográficas, possibilitando o preparo de partículas com diâmetros menores da fase estacionária. Isso tem permitido corridas mais rápidas sem, contudo, comprometer o desempenho cromatográfico (MALDENER e JARDIM, 2009; LANÇAS, 2010), proporcionando separações mais 
eficientes, corroborando com a necessidade atual de aumento no número de análises com a intenção de melhoria na produção e redução de custos.

De uma forma geral, a redução no tempo de análise vai impactar na questão ambiental, pois, análises por CLAE geram uma grande quantidade de resíduos, e dependendo dos tipos de solventes empregados nas análises podem apresentar grande grau de toxicidade. Dessa forma, justificam-se com isso modificações nos métodos para minimizar o consumo dos mesmos. Pois, o ajuste do método só se justifica quando não há comprometimento na eficiência da análise, mantendo assim uma boa resolução entre os componentes da amostra.

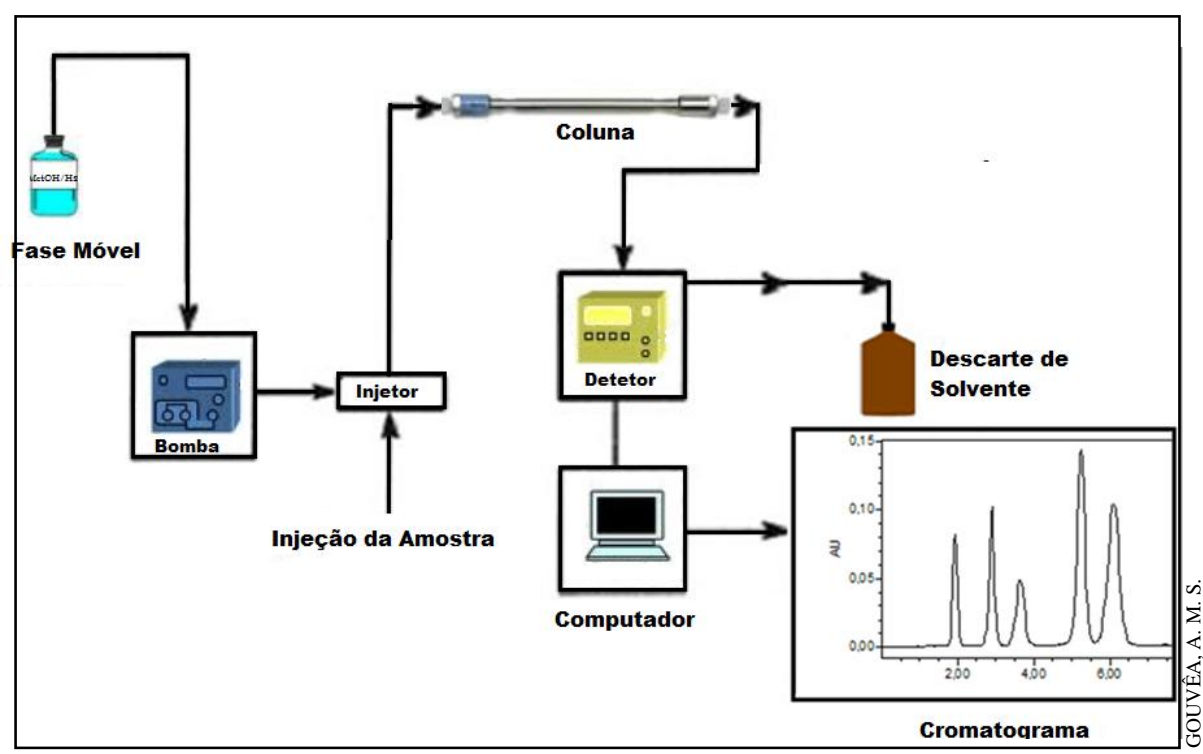

Figura 9: Esquema básico do sistema cromatográfico.

Também nessa área, podemos destacar o desenvolvimento de colunas com suportes monolíticos (Figura 10), que consistem em um único bloco cilíndrico poroso, inserido no tubo da coluna cromatográfica.

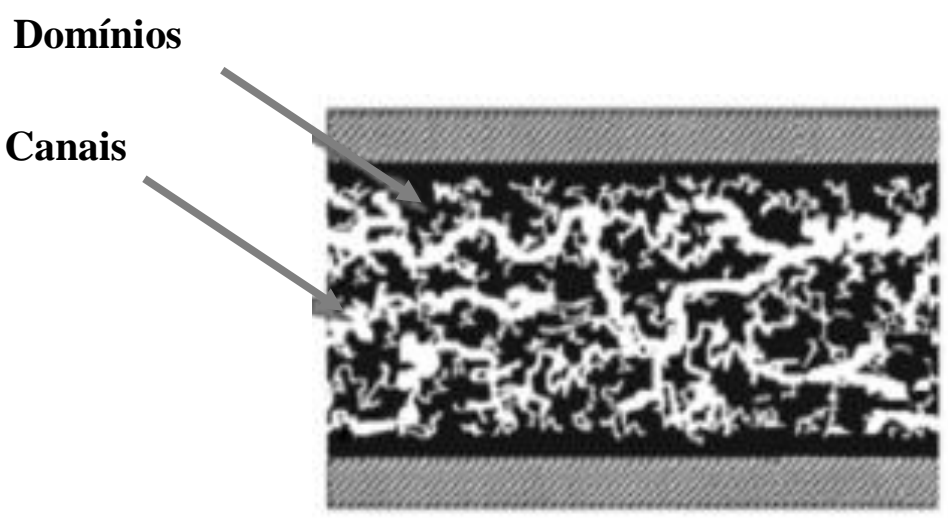

Figura 10: Esquema de uma fase monolítica (Adaptado da fonte: SILVA, COLLINS E BOTTOLI, 2011). 
O material monolítico pode ser orgânico ou inorgânico, polimetacritato e poli (estireno-divinilbenzeno). Os mais usados em CLAE são os monolíticos a base de sílica. As vantagens deste tipo de colunas é que a sua estrutura e geometria oferecem menor resistência à vazão da fase móvel comparada aos materiais particulados. Portanto, análises com fluxos maiores que $5 \mathrm{~mL} / \mathrm{min}$ podem ocorrer sem perdas significativas da eficiência de separação (FARIA et al., 2006; LANÇAS, 2011)

\section{Colunas (Core Shell)}

Mais recentemente a utilização de partículas sólidas não porosas, recobertas com filmes (camadas) de material poroso, vem ganhando grande destaque na comunidade científica. Esse conceito de fase estacionária surgiu nos anos $60 \mathrm{com}$ partículas solidas em torno de 60 micrometros. O uso dessas partículas teve muita aplicação para separação de proteínas. Nos anos seguintes, mais recentes, houve uma grande evolução no tamanho do diâmetro das partículas, diminuição. Atualmente, muitos estudos mostram uma enorme vantagem no emprego dessa partícula porosa recobrindo um material não poroso sobre as colunas utilizando partícula totalmente porosa. Essas colunas, hoje em dia, usam partículas com diâmetro reduzido, menor que 3 micrometros, com menor pressão e maior eficiência, podendo ser utilizadas em aparelhos que não são de ultra pressão.

\subsection{2- Utilização da técnica Cromatografia Líquida de Ultra Performance acoplada à espectrometria de massas em Tandem (CLUE-EM/EM)}

A Cromatografia líquida é uma técnica de separação fundamental e capaz de analisar substâncias não voláteis ou termicamente frágeis. A Cromatografia Líquida de Ultra Performance, é uma técnica recente que utiliza pressões altíssimas (até 15000 psi), vazões na ordem de nanolitros e colunas com partículas de até $1,7 \mu \mathrm{m}$ de diâmetro $(2,1 \mathrm{mn}$ DI de comprimento), produzindo separações extremamente rápidas e bem resolvidas.

Os avanços na instrumentação e nas técnicas de ionização tem permitido nos últimos anos o uso da Espectrometria de Massas (EM) como uma grande e sofisticada ferramenta de identificação de compostos orgânicos desconhecidos. O processo é mais uma confirmação do que identificação da estrutura, pois, o uso desta técnica requer prévias informações para que se possa escolher adequadamente qual seria o melhor processo de ionização a ser utilizado na análise.

Outras informações como: origem da amostra; como foi obtida; processo de extração; solventes utilizados; e informações sobre substâncias semelhantes, serão também essências para solucionar muitos problemas na identificação. Na prática, muitas dificuldades são causadas, justamente, porque para essa análise são utilizadas pequenas quantidades, sendo, portanto necessário considerar: o isolamento, purificação; remoção de solventes; prevenção de contaminação; e decomposição de compostos instáveis (SILVERSTEIN e WEBSTER, 2000).

Sendo assim, o desenvolvimento da EM até seu estágio atual permitiu que essa técnica se tornasse uma das mais importantes ferramentas analíticas disponíveis. Hoje, é capaz de gerar um sinal tridimensional (intensidade $\mathrm{x}$ tempo x dados espectrais) e fornecer informações de peso molecular, de características estruturais, de quantidade, identidade e pureza de uma 
amostra. Segundo o Prof. John Bennett Fenn (Nobel em Química em 2002), “A Espectrometria de Massas é uma arte de medir átomos e moléculas para determinar suas massas moleculares". Considerando que as informações sobre a massa molecular sejam exatas (soma das massas monoisotópicas dos átomos), seria, portanto, frequentemente útil para a determinação da identidade de um composto ou substância, pois é única para cada fórmula molecular. A Figura 11 mostra um esquema de um espectrômetro de massas de alta resolução (massas acuradas).

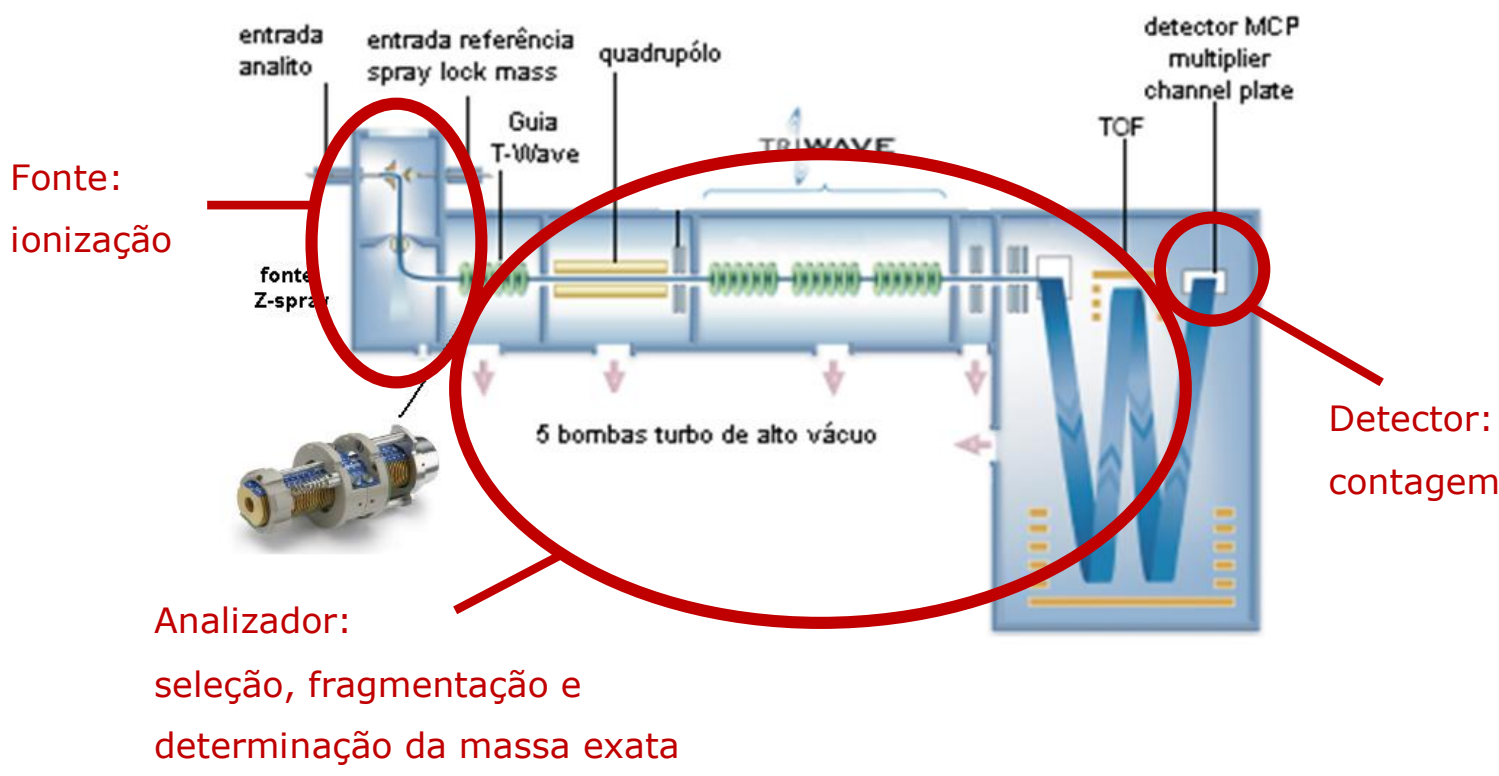

Figura 11: Representação dos principais setores de um espectrômetro de massas de alta resolução (QTOF), Fonte: Waters ${ }^{\circledR}, 2008$.

De uma forma geral, a EM baseia-se na medida da relação massa/carga $(\mathrm{m} / \mathrm{z})$ de fragmentos iônicos gerados a partir de um processo de ionização da amostra. O uso dessa técnica requer certo conhecimento de química orgânica para que se possa interpretar as massas dos íons moleculares $(\mathrm{m} / \mathrm{z})$, assim como os fragmentos gerados durante as análises dos compostos orgânicos. Por isso, a EM além de ser uma técnica que demanda uso de instrumentação onerosa, necessita também de operadores e/ou analistas qualificados no manuseio e interpretação dos espectros gerados, permitindo assim, que se monte uma espécie de "quebra-cabeças" da estrutura química da substância de interesse.

A amostra a ser analisada pode ser introduzida de forma direta ou indireta. A introdução direta da amostra é realizada através de um dispositivo (uma seringa) ligada a fonte de ionização, onde ocorre a vaporização, por um capilar. Com o desenvolvimento das técnicas cromatográficas criou-se a possibilidade do uso de um Cromatógrafo como fonte de introdução de amostras de forma indireta e automatizada no EM. 
Os dois componentes principais deste processo são a fonte de íons que ioniza a amostra e o analisador de massas que separa os íons de interesse. A combinação dos vários tipos de ionização com os analisadores de massas existentes dependerá do tipo de informação necessária e da química de amostra.

A técnica de ionização mais eficiente nem sempre é fácil de ser prevista. A natureza química do analito e as condições de separação têm grande influência sobre a escolha. Atualmente, para separações por Cromatografia Líquida (CL), as principais fontes de íons são baseadas no princípio da desorção. A técnica chamada de API (Atmospheric Pressure Ionization) tem a vantagem de ser aplicável a substâncias não voláteis e termicamente instáveis. A molécula no estado líquido é convertida diretamente a íons gasosos, ou seja, a amostra das moléculas é vaporizada e depois sofre ionização. Os íons do analito são separados das moléculas neutras mecânica e eletrostaticamente (SKOOG, 1997). Algumas variações da técnica de ionização à pressão atmosférica são:

- ESI (Eletronspray) -O eluente cromatográfico é nebulizado em uma câmara na presença de um campo eletrostático e um gás aquecido. É uma fonte onde a ionização ocorre à pressão atmosférica (API- Atmospheric Pressure Ionization). O campo eletrostático causa dissociação das moléculas do analito e o gás produz a evaporação do solvente. É especialmente útil para análise de biomoléculas grandes como proteínas e peptídeos, mas também pode analisar moléculas menores. Moléculas grandes frequentemente adquirem mais de uma carga e torna-se necessário utilizar um processamento matemático chamado deconvolução (Figura 12).

- APCI (Atmospheric Pressure Chemical Ionization) - O eluente cromatográfico é vaporizado. O solvente gasoso resultante é ionizado por uma descarga de elétrons. Os íons do solvente transferem carga para as moléculas do analito através de reações químicas. É aplicável para uma vasta faixa de moléculas polares e não polares. Como necessita de aquecimento normalmente não é compatível para grandes biomoléculas.

- APPI (Atmospheric Pressure Photoionization) - O eluente cromatográfico é vaporizado. Uma lâmpada de descarga gera fótons em uma faixa estreita de energia de ionização. Esta faixa é cuidadosamente selecionada para maior parte das moléculas do analito com o mínimo possível de ionização das moléculas do solvente. É aplicável para as mesmas espécies químicas da técnica APCI, especialmente compostos não polares e baixos fluxos. 


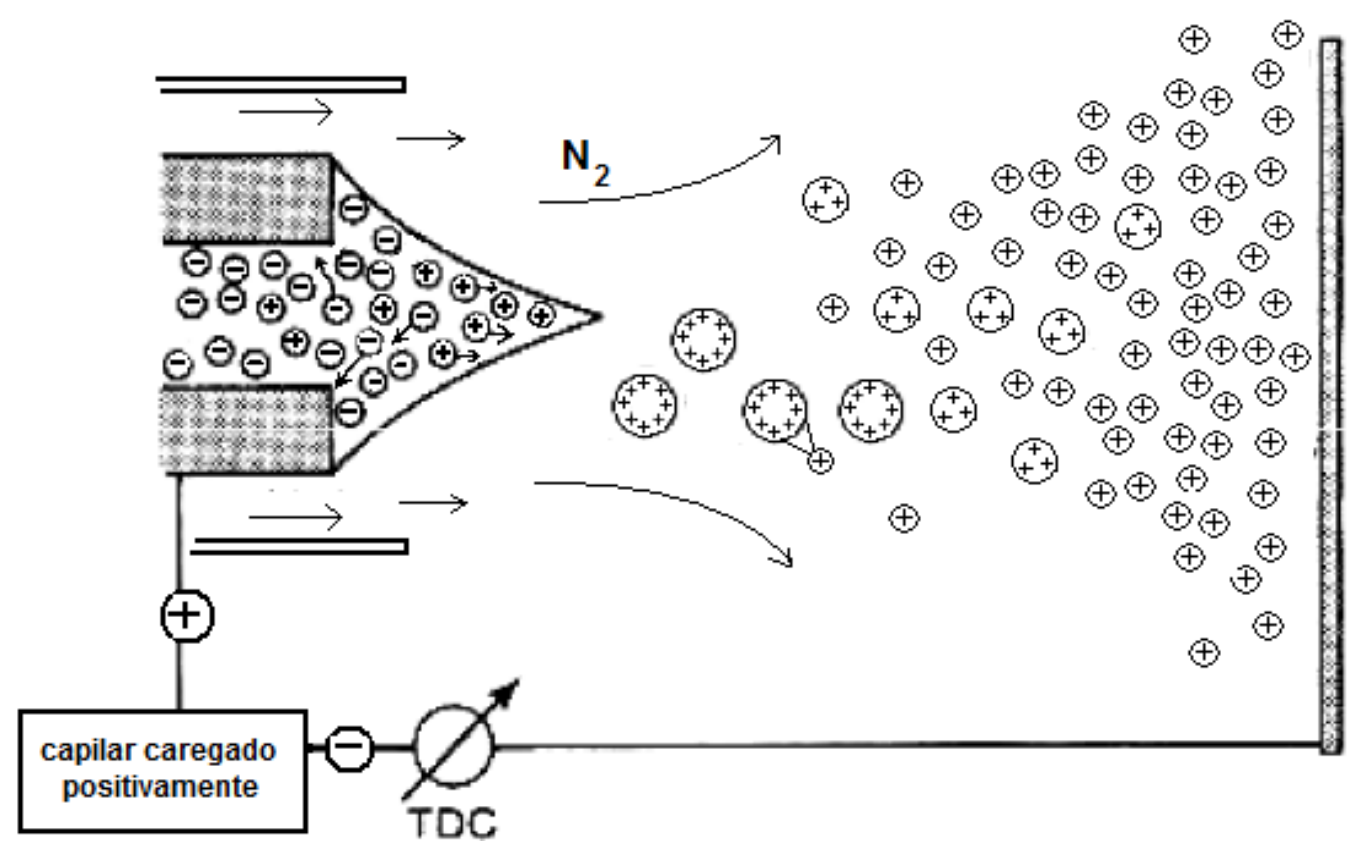

Figura 12: Esquema de uma fonte de ionização por eletrospray $\left(\mathrm{ESI}^{+}\right)$, Fonte: Waters ${ }^{\circledR}, 2008$. 


\section{MATERIAL E MÉTODOS}

\subsection{Reagentes e Solventes}

Os solventes e reagentes empregados nos experimentos foram: ácido clorídrico P.A $\left(\right.$ Tedia $\left.^{\circledR}\right)$; acetonitrila $\left(\right.$ Tedia $\left.^{\circledR}\right)$, metanol $\left(\right.$ Tedia $^{\circledR}$ e Merck $^{\circledR}$ ) e ácido fórmico: 96\% (Tedia $\left.^{\circledR}\right)$; e 98\% (Merck), todos grau HPLC (CLAE), metanol (Tédia ${ }^{\circledR}$ ) grau para as análises no espectrômetro de massa. Utilizou-se também água ultrapura grau Milli-Q ${ }^{\circledR}$ Gradient 10A.

\subsection{Equipamentos}

Para o desenvolvimento dos experimentos foram utilizados os equipamentos: balança analítica com 4 casas decimais (BEL-Engineering); centrífuga THERMO $^{\circledR}$ (Electron Corporation Sorvall Biofuge Stratos), microcentrífuga modelo Bransonic ${ }^{\circledR}$; Liofilizador modelo L101, marca - Líotop; Cromatógrafo Líquido de Alta Eficiencia (Alliance ${ }^{\circledR} 2695$ Waters) com forno para colunas, injetor automático e equipado com válvula de 6 canais (Rheodyne ${ }^{\circledR}$ ); detetor de arranjo de fotodiodos UV-Vis (2996 Waters); sistema de aquisição de dados software Empower; sistema de purificação de água Milli-Q A 10; vórtex; rotaevaporador (Büchi); ultrasson Cleaners; Cromatógrafo Líquido de Ultra Eficiência com forno e injetor automático (ACQUITYTM Ultraperformace LC - Waters) acoplado ao espectrômetro de massas QTOF (SYNAPT mass espectrometry, Waters); espectrofotômetro Shimadzu ${ }^{\circledR}$ UV-Vis 1800; medidor de pH PHmetro Microprocessado de bancada, modelo W3B (BEL-Engineering); moinho de facas ( IKA) modelo A11 e Blender.

\subsubsection{Insumos}

Colunas cromatográficas: $\mathrm{C}_{18}$ : Symmetry $(150$ x 4,6mm) tamanho de partícula 3,5 $\mu \mathrm{m}$, Thermo Scientific $\mathrm{C}_{18}$ BDS $^{\circledR}(100 \mathrm{x} 4,6 \mathrm{~mm})$, tamanho de partícula $2,4 \mu \mathrm{m}$; ACQUITY UPLC ${ }^{\circledR}$ BEH 2,1 x $150 \mathrm{~mm}$ ) tamanho de partícula $1,7 \mu \mathrm{m}$. Coluna de vidro (30 $\mathrm{cm}$ de comprimento por $2 \mathrm{~cm}$ de diâmetro interno), recheio de fase $\mathrm{C}_{18}$, carbon 17\%, 60 A Silicycle (ultra pure sílica gels). Cartuchos: Sep-Pak ${ }^{\circledR} \mathrm{C}_{18}$ (20cc) 5,0g e 1,0g (Waters), e Oasis ${ }^{\circledR}$ MCX (20cc) 1 g Cationexchange SPE. Filtros millipore 0,45 e 0,22 $\mu \mathrm{m}$ (membrana hidrofílica),

\subsection{Preparo de Soluções}

Solução 1- Solução de extração: ácido fórmico/metanol (10:90- v/v)

Para o preparo de 1 litro de solução de extração, mediu-se $100 \mathrm{~mL}$ de ácido fórmico (98\%), em uma proveta com tampa, completou-se o volume com metanol até completar 1 litro. A solução foi homogeneizada e transferida para um frasco com tampa.

Para o preparo da solução utilizando ácido fórmico (96\%), foram adicionados 104,15 $\mathrm{mL}$ do ácido fórmico $(100 \mathrm{~mL}$ foi medido em uma proveta e $4,15 \mathrm{~mL}$ em uma pipeta automática de $5 \mathrm{~mL}$ ), em uma proveta com tampa, e adicionou-se metanol até completar 1 litro. A solução foi homogeneizada e transferida para um frasco com tampa. 
Solução 2- Solução: ácido fórmico/ metanol/ água Milli-Q (10:10:80- v/v/v)

Para o preparo de $500 \mathrm{~mL}$ de água de Milli-Q foram transferidos para um balão de 1 litro, em seguida acrescentou-se $10 \mathrm{~mL}$ de ácido fórmico $(98 \%)$ ou $10,42 \mathrm{~mL}(10,0 \mathrm{~mL}$ foi medido em uma proveta e $0,42 \mathrm{~mL}$ em uma pipeta automática de $1 \mathrm{~mL}$ ) de ácido fórmico (96\%), $10 \mathrm{~mL}$ de metanol e completou-se o volume até 1 litro com a água de Milli-Q. Homogeneizouse a mistura e transferiu-se para um frasco com tampa.

Solução 3- Solução: ácido fórmico/ água Milli-Q (10:90- v/v)

Para o preparo de 1 litro da solução de ácido fórmico 10\%: $500 \mathrm{~mL}$ de água de Milli-Q foram transferidos para um balão de 1 litro, em seguida acrescentou-se $100 \mathrm{~mL}$ de ácido fórmico (98\%) ou 104,15 mL (100 mL foi medido em uma proveta e 4,15 mL em uma pipeta automática de $5 \mathrm{~mL}$ ) de ácido fórmico (96\%), completou-se o volume até 1 litro com a água de Milli-Q. Homogeneizou-se a mistura e transferiu-se para um frasco com tampa.

Solução 4-Solução: ácido fórmico/água Milli-Q (5:95- v/v)

Para o preparo de 1 litro de solução de ácido fórmico 5\%: $500 \mathrm{~mL}$ de água de Milli-Q foi tranam transferidos para um balão de 1 litro, em seguida acrescentou-se $50 \mathrm{~mL}$ de ácido fórmico $(98 \%)$ ou $52,1 \mathrm{~mL}(50 \mathrm{~mL}$ foi medido em uma proveta e $2,1 \mathrm{~mL}$ em uma pipeta automática de $5 \mathrm{~mL}$ ) de ácido fórmico (96\%), e completou-se o volume com a água Milli-Q. Homogeneizou-se a solução e transferiu-se para um frasco com tampa.

Solução 5-Solução: ácido fórmico/ água Milli-Q (1:99- v/v)

Para o preparo de 1 litro de solução ácido fórmico 1\%: $500 \mathrm{~mL}$ de água de Milli-Q foram transferidos para um balão de 1 litro, em seguida foram adicionados $10 \mathrm{~mL}$ de ácido fórmico ( $98 \%$ ) e completou-se o volume com a água Milli-Q. Homogeneizou-se a solução e transferiuse para um frasco com tampa.

Solução 6-Solução: ácido fórmico/água Milli-Q (0,1:99,9- v/v)

Para o preparo de 1 litro da solução ácido fórmico $0,1 \%, 500 \mathrm{~mL}$ de água de Milli-Q foram transferidos para um balão de 1 litro, adicionou-se $1 \mathrm{~mL}$ de ácido fórmico (98\%) e completou-se o volume com a água Milli-Q. Homogeneizou-se a solução e transferiu-se para um frasco com tampa.

Solução 7-Solução: ácido clorídrico/metanol (1:99- v/v)

Para o preparo de $100 \mathrm{~mL}$ da solução ácido clorídrico $1 \% /, 50 \mathrm{~mL}$ de metanol foram transferidos para um balão de $100 \mathrm{~mL}$, em seguida $3,3 \mathrm{~mL}$ (medido em uma pipeta automática de $5 \mathrm{~mL}$ ) de ácido clorídrico (36\%) foram adicionados e completou-se o volume com o metanol. Homogeneizou-se a solução e transferiu-se para um frasco com tampa.

Solução 8- Solução: ácido fórmico/ metanol (1:99-v/v)

Para o preparo de $100 \mathrm{~mL}$ da solução ácido fórmico 1\%: $50 \mathrm{~mL}$ de metanol foram transferidos para um balão de $100 \mathrm{~mL}$, em seguida acrescentou-se $1 \mathrm{~mL}$ de ácido fórmico (98\%), completou-se o volume até $100 \mathrm{~mL}$ com o metanol. Homogeneizou-se a mistura e transferiu-se para um frasco com tampa. 
Solução 9- Solução: ácido fórmico/ água Milli Q/metanol (0,6: 59,4:40,0- v/v/v)

Para o preparo de $100 \mathrm{~mL}$ da solução de ácido fórmico $1 \%$ em metanol, 59,4 mL de água Milli-Q foram transferidos para um balão de $100 \mathrm{~mL}$, em seguida acrescentou-0,6 $\mathrm{mL}$ de ácido fórmico (98\%), completou-se o volume até $100 \mathrm{~mL}$ com metanol. Homogeneizou-se a mistura e transferiu-se para um frasco com tampa.

Solução 10- Solução metanol / ácido fórmico /água MilliQ (10,0:0,9:89,1- v/v/v)

Para o preparo de $100 \mathrm{~mL}$ da solução, $84,5 \mathrm{~mL}$ de água Milli-Q foram transferidos para um balão de $100 \mathrm{~mL}$, em seguida acrescentou-5,5 mL de ácido fórmico (98\%), completou-se o volume até $100 \mathrm{~mL}$ com metanol. Homogeneizou-se a mistura e transferiu-se para um frasco com tampa.

\subsection{Matrizes Estudadas}

As espécies vegetais utilizadas para a execução deste trabalho foram: flor do jambeiro (Syzygium malaccense L.); flor de Ipê roxo (Tabebuia avellanedae), flor da Romãzeira (Punica granatum L); flor de Erythrina (Erythrina speciosa); brácteas vermelha da planta Bico de Papagaio (Euphorbia pulcherrina); espata da flor de estrelítzia ou ave-do-paraíso (Strelitzia reginae); Flor do Hibisco dobrado cor de salmão (Hibiscos sinensis); açaí (Euterpe oleracea Mart.); acerola (Malpighia punicifolia L); ameixa vermelha (Prumus sp.); amora preta (cv.Tupy); fruto da amendoeira (Terminalia catappa); jabuticaba (Plinia trunciflora ou sinomia Myrciaria trunciflora O. Berg e Plinia grandifolia Mattos ou sinomia Myrciaria grandifolia Mattos); jambo (Syzygium malaccense L); jamelão (Syzygium cumini L, ex-Eugenia jambolana Lam. ou Syzygium jambolanum DC); framboesa (Rubus sp.); juçara (Euterpe edulis); amorapreta silvestre (Morus nigra); maçã ( Malus domésticas, cultivares: Fuji; Argentina, Gala, Red Delicius); manga casca vermelha (Mangifera indica L, cultivar Tommy); morango (Fragaria spp.); mirtilo (Vaccinium spp.); mangostin (Garcinia mangostana L.); pêra de casca vermelha (Pyrus comunis, cultivar red Bartlett); pitanga negra selvagem (E. sulcata); Neomitranthes obscura (DC.) N. Silveira variedade de casca preta, conhecida popularmente como pitanga de cachorro, camboim de cachorro ou pitanga da restinga; romã (Punica granatum L.); uva (Vitis vinífera spp.) denominada uva-preta sem semente do Chile; Kyoho, Red Globe, Niagara Rosada; arroz-vermelho (Oryzza sativa); arroz-preto (Oryzza sativa); soja-preta (Glycine L.); berinjela (Solanum melongena); cebola roxa (Allium cepa); repolho roxo (Brassica oleracea L., cultivar capitata.), alface roxa (Lactuca sativa L.). As partes utilizadas de cada espécie podem ser observadas no organograma da Figura 13.

\subsubsection{Origem das matrizes}

Foram avaliadas as antocianinas contidas em 43 amostras de vegetais, onde 36 dessas matérias-primas eram provenientes de matrizes alimentícias (frutas e hortaliças) e 7 oriundas de flores. Onde $57 \%$ dessas matérias-primas foram adquiridas em mercado local no Rio de Janeiro [ameixa, framboesa, manga Tommy, morango, mirtilo, mangostin, pera de casca vermelha, maçã (cultivares: fuji; argentina; gala e red), uva (cultivares: Kyoho; NiagaraRosada; Red Globe) e uva sem semente de casca preta vendida no mercado como "uva preta do Chile”, soja preta, berinjela, cebola roxa, repolho roxo, alface roxo, arroz-preto da marca Tio João]. Amora-preta (cv. Tupy) foi adquirido no comércio varejista do Rio de Janeiro da empresa "Mais Fruta Indústria e Comércio Ltda". 


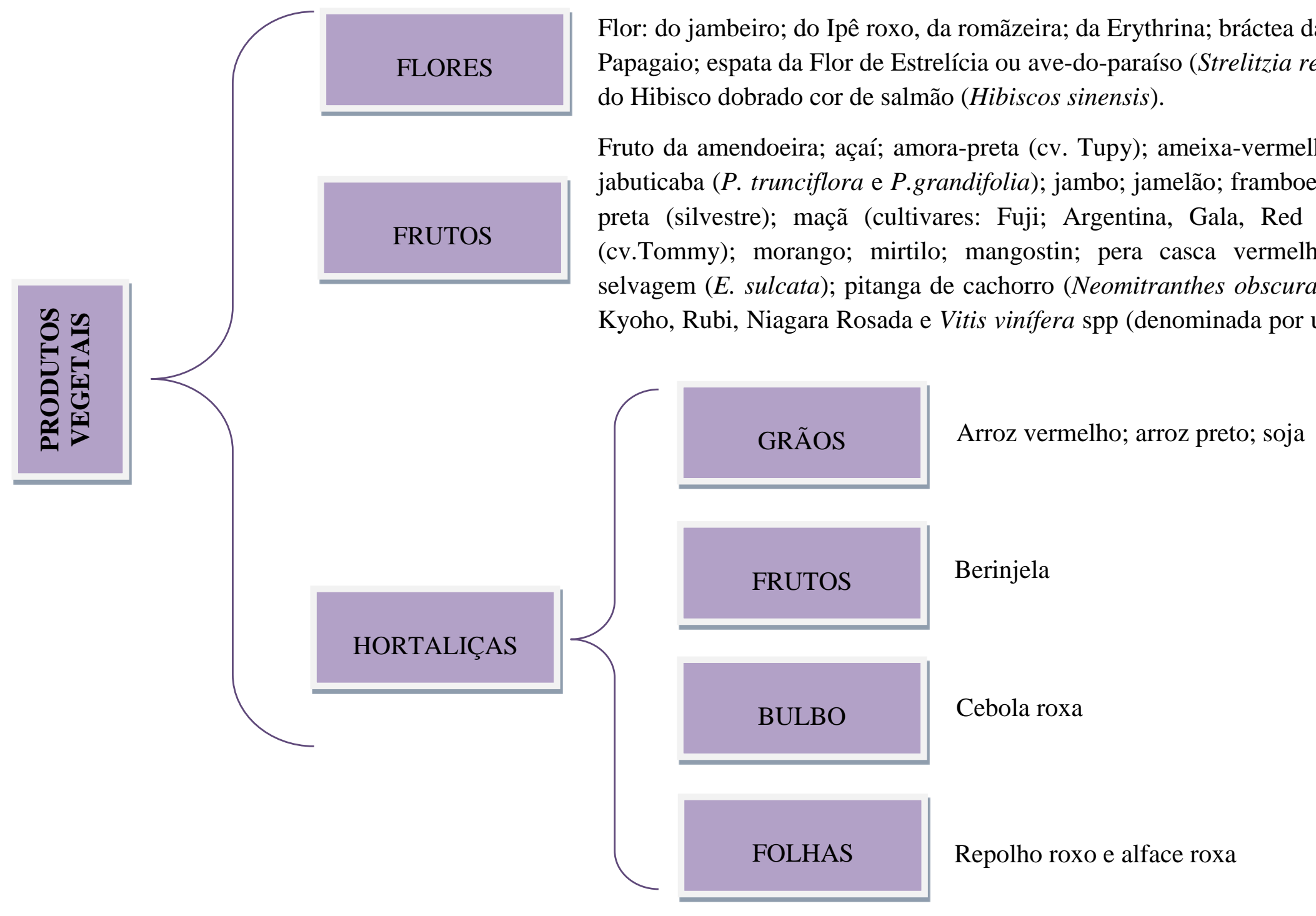

Figura 13: Organograma com as partes de 43 matrizes. 
A polpa de açaí pasteurizada foi proveniente de uma indústria processadora de açaí, localizada em Tomé-Açu/Pará. Arroz vermelho e juçara foram matérias-primas provenientes de estudos realizados na Embrapa CTAA. As matérias-primas restantes como fruto da amendoeira; jambo, jamelão (Syzygium cuminii), foram coletadas na Região de Guaratiba.

A jabuticaba (P. trunciflora e P.grandifolia), Eugenia sulcata spring ex Mart. (pitanguinha roxa selvagem) e Neomitranthes obscura (DC.) N. Silveira (pitanga de cachorro), foram adquiridas a partir de coletas realizadas no estado do Rio de Janeiro, sob a supervisão do Botânico, D.Sc. Marcelo da Costa Souza, na época trabalhando no Museu Nacional do Rio de Janeiro.

Os frutos Eugenia sulcata spring ex Mart. e Neomitranthes obscura (DC.) N. Silveira tiveram suas exsicatas depositadas no herbarium da Universidade Federal Rural do Rio de Janeiro sob o número RBR35798 e RBR35925, respectivamente.

\subsubsection{Pré- tratamento das matrizes}

As matrizes jabuticaba (P.trunciflora e P. grandifolia), ameixa-vermelha; jambo, jamelão; maçã (Fuji; Argentina, Gala, Red Delicius), manga (Tommy), mangostin, morango, pera vermelha, uva (Uva-preta do Chile sem semente; Kyoho, Red Globe, Niagara Rosada) pitanga da restinga ( $N$. obscura), pitanga negra selvagem (E. sulcata) e berinjela foram lavadas com água filtrada e descascadas manualmente com auxílio de faca inox quando necessário (Figura 14).

As matrizes açaí, juçara, amora-preta e romã foram diluidas com volume suficiente de água para que pudessem ser processadas em blender até formar uma solução homogênia. As matrizes de fruto de amendoeira, cebola roxa (Alliun cepa L.), repolho roxo (Brassica oleracea L.), alface roxa (Lactuca sativa) e flor do jambeiro, foram cortadas em pequenos pedaços.

Posteriormente a cada procedimento, o material obtido foi congelado em freezer ($18^{\circ} \mathrm{C}$ ) e submetido ao processo de liofilização.

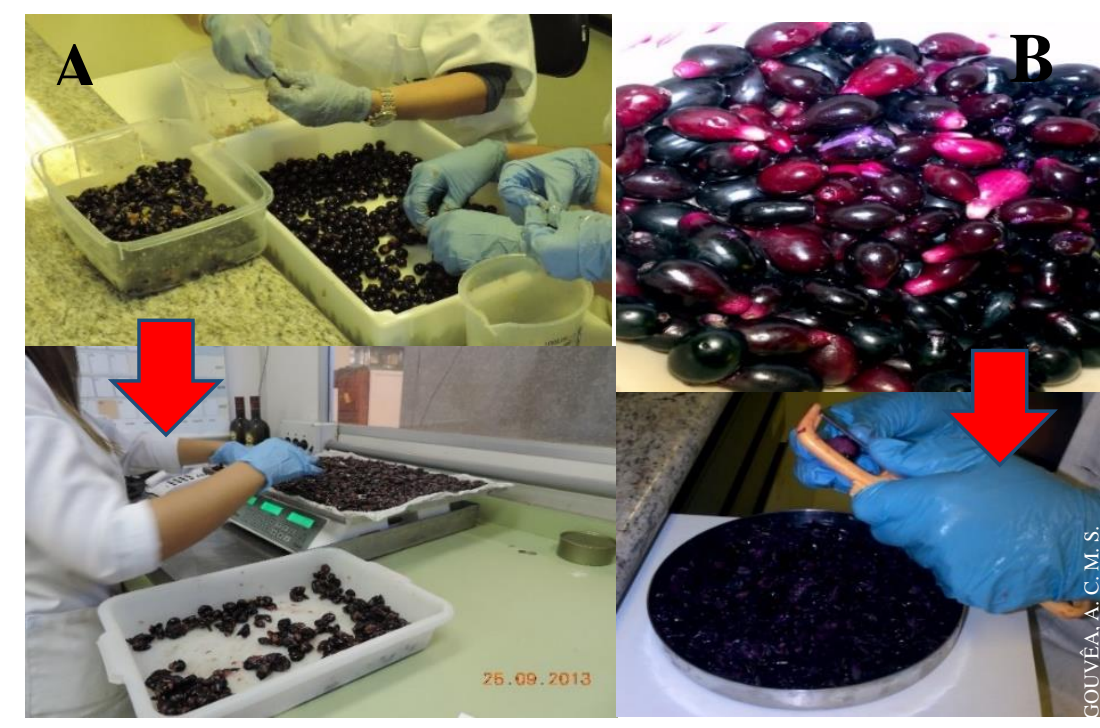

Figura 14: Processo de retirada das cascas de duas matrizes: A) pitanga de cachorro (Neomitranthes obscura) e B) jamelão (Syzygium cuminii). 
$\mathrm{O}$ processo foi realizado em Liofilizador Líotop (Figura 15) à temperatura de $-40^{\circ} \mathrm{C}$ durante 24 a 48 horas. Após a liofilização o material obtido foi triturado em moinho de facas até serem transformados em um pó, em seguida foram acondicionados em sacos de alumínio hermeticamente fechados.

As matrizes acerola (M.emarginata), framboesa (Rubus idaeus L.) e mirtilo (Vaccinium spp.), foram apenas maceradas e uma parte, \pm 1 grama, foi separada para análise qualitativa sendo o restante guardado congelado no freezer $\left(-18^{\circ} \mathrm{C}\right)$. As pétalas das flores do Ipê roxo, da romãzeira, da Eryithrina, do hibisco salmão e a espata da flor estrelítzia ou ave-do-paraíso e as brácteas da planta Bico de Papagaio foram apenas cortadas em pequenos pedaços e postas em imersão na solução 1 (ácido fórmico/metanol; 10:90, v/v).

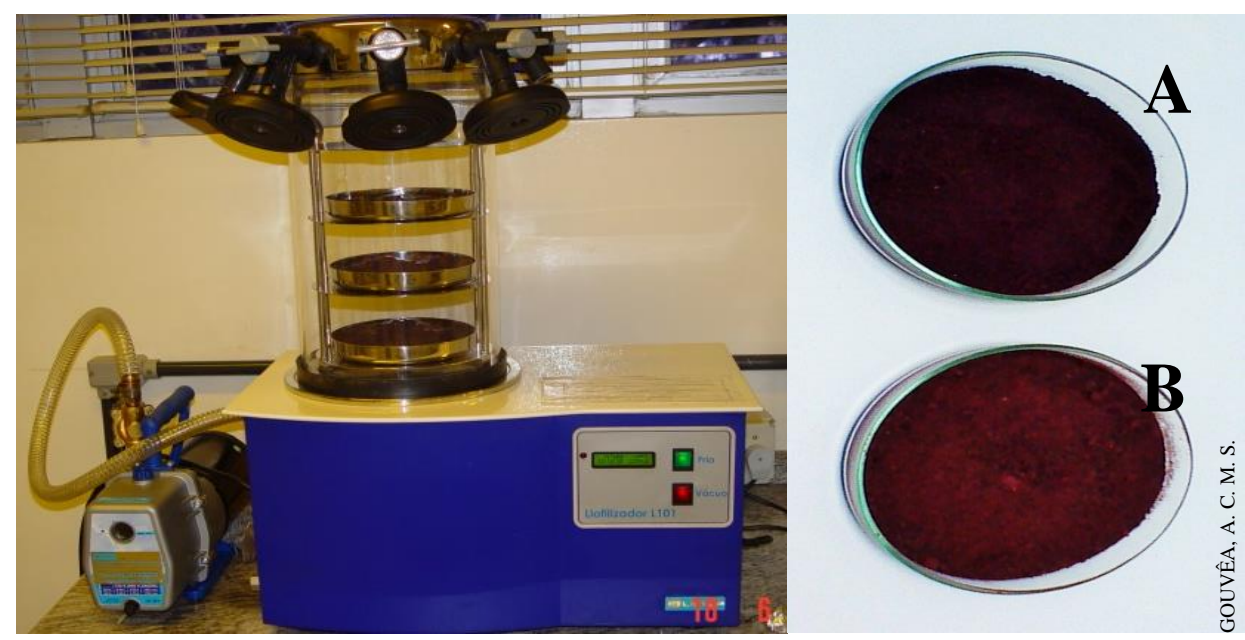

Figura 15: Processo de liofilização, produto gerado após serem triturados em moinho de faca, matrizes: A) pitanga de cachorro (Neomitranthes obscura) e B) jamelão (Syzygium cuminii).

\subsubsection{Métodos de extração}

- Extração I- Para análise qualitativa

Foi pesado de 0,1 a $0,5 \mathrm{~g}$ da amostra em tubo de microcentrífuga (volume de $2 \mathrm{~mL}$ ) e, logo em seguida, completado com a solução 2 (ácido fórmico/ metanol/água Milli Q; 10:10:80, $\mathrm{v} / \mathrm{v} / \mathrm{v}$ ), quando necessário triturou-se com bastão de vidro, após levou-se ao vortex por 1 minuto e, por fim, foi centrifugado na microcentrífuga na velocidade de $14.000 \mathrm{rpm}$ por 5 minutos. Retirou-se o sobrenadante transferindo-o para um vial que foi imediatamente levado ao injetor para análise cromatográfica.

\section{- Extração II-Para análise quantitativa}

Pesou-se de 0,05 a $1 \mathrm{~g}$ do pó liofilizado em tubo $(50 \mathrm{~mL})$ de tampa com rosca apropiada para ser utilizado em centrífuga. Em seguida, adicionou-se ao tubo 2,0 $\mathrm{mL}$ de solução 1 (ácido fórmico/metanol; 10:90, v/v), levou-se ao vortex para ser agitado durante 1 minuto, ao ultrassom por 10 minutos e posteriormente centrifugou-se a $6.000 \mathrm{rpm}$ por 10 minutos. $\mathrm{O}$ sobrenadante foi então transferido para um balão volumétrico de $10,0 \mathrm{~mL}$. Repetiu-se o processo de lavagem descrito acima com o resíduo que ficou no tubo, até que o sobrenadante obtido não apresentasse mais coloração. Por fim, completou-se o volume do balão com a solução 1. Uma alíquota de $1,2 \mathrm{~mL}$, desta solução, foi microcentrifugada na velocidade de 
$14.000 \mathrm{rpm}$ por 5 minutos. Por fim, retirou-se uma alíquota de $200 \mu \mathrm{L}$, do material microcentrifugado, que foi submetida à evaporação utilizando fluxo de ar comprimido, filtrado, até a secura. Em seguida, a amostra foi solubilizada no mesmo volume $(200 \mu \mathrm{L})$, com a solução 2 (ácido fórmico/metanol/água Milli Q; 10/10/80, v/v/v). O extrato obtido foi transferido para um vial, com um redutor de volume e, levado ao injetor do cromatógrafo. Todos os procedimentos (Figura 16) foram realizados em triplicata.

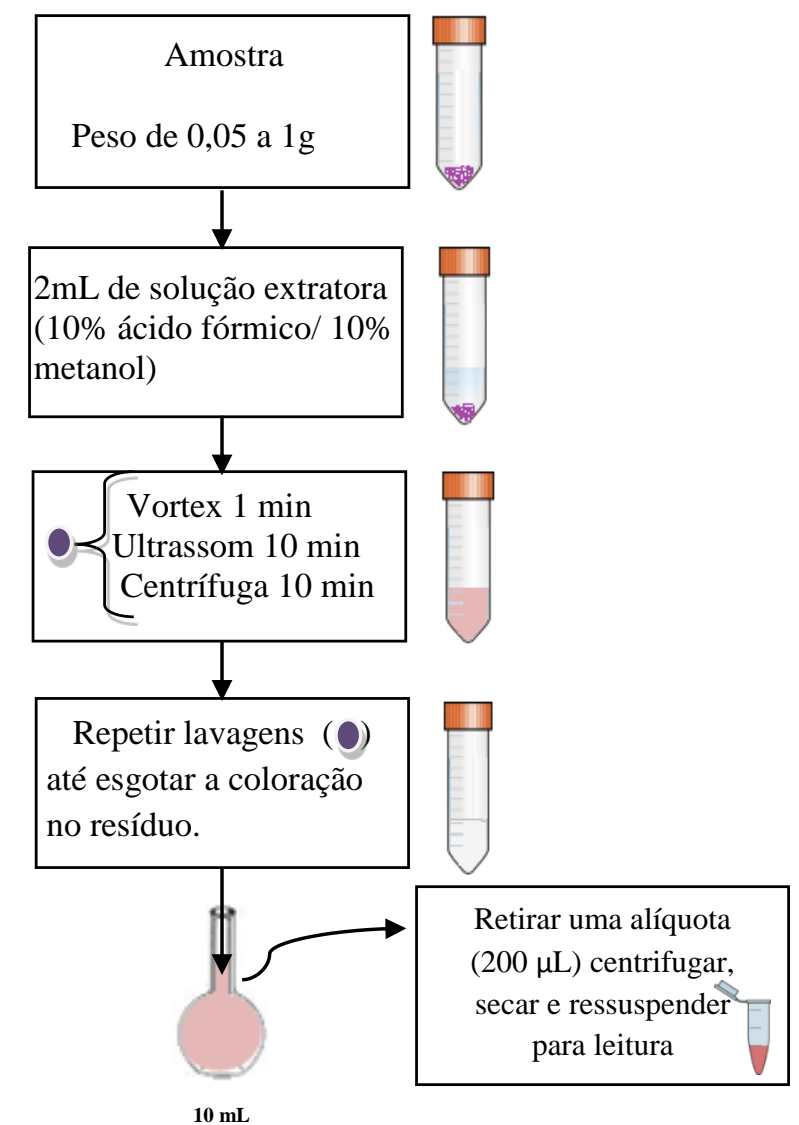

Figura 16: Diagrama esquemático com as etapas da extração II

- Extração III-Para isolamento de antocianinas

Foram pesados e divididos em quatros tubos de $50 \mathrm{~mL}$ de volume a massa de 4,0 a 8,0 $\mathrm{g}$ de pó liofilizado, com tampa, específicos para centrífuga. Adicionou-se 4,0 $\mathrm{mL}$ da solução 1 (ácido fórmico/metanol; 10:90, v/v) em cada tubo e, levou-se ao vortex para ser agitado durante 1 minuto, em seguida ao ultrassom por 10 minutos e posteriormente centrifugou-se a $6000 \mathrm{rpm}$ por 10 minutos. Todo o sobrenadante dos quatro tubos foi coletado e levado ao rotavapor Büchi à temperatura de $38 \pm 2^{\circ} \mathrm{C}$ até a retirada total do solvente extrator.

Ao extrato seco foram adicionados $8,0 \mathrm{~mL}$ de solução 2 utilizada para análise no cromatógrafo (ácido fórmico/metanol/água Milli Q; 10/10/80, v/v/v). O material agora diluido foi filtrado utilizando filtros de membrana hidrofílica Millex $(0,45 \mu \mathrm{m})$ e acondicionado em vials que foram, em seguida, levados ao injetor do cromatógrafo. 
A Figura 17 apresenta o organograma compondo as operações das três extrações nas matrizes de vegetais.

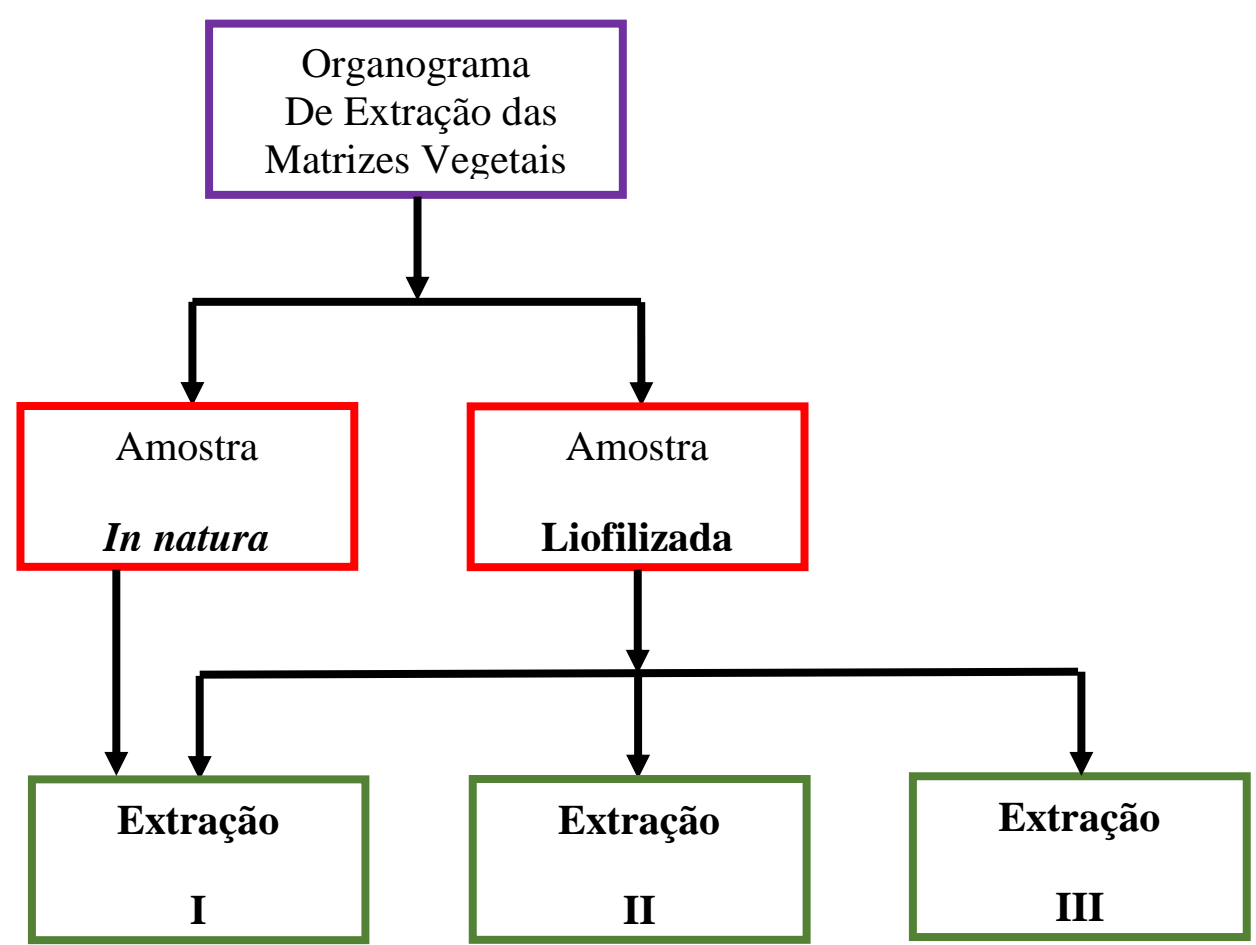

Figura 17: Organograma com as operações para as três extrações

3.4.2.1 Extração para verificar a presença de antocianinas nas matrizes de arroz (Oryza sativa L.).

1) Arroz vermelho

- Teste 1: extração do arroz vermelho: com casca, sem casca e arroz polido (Figura 18)

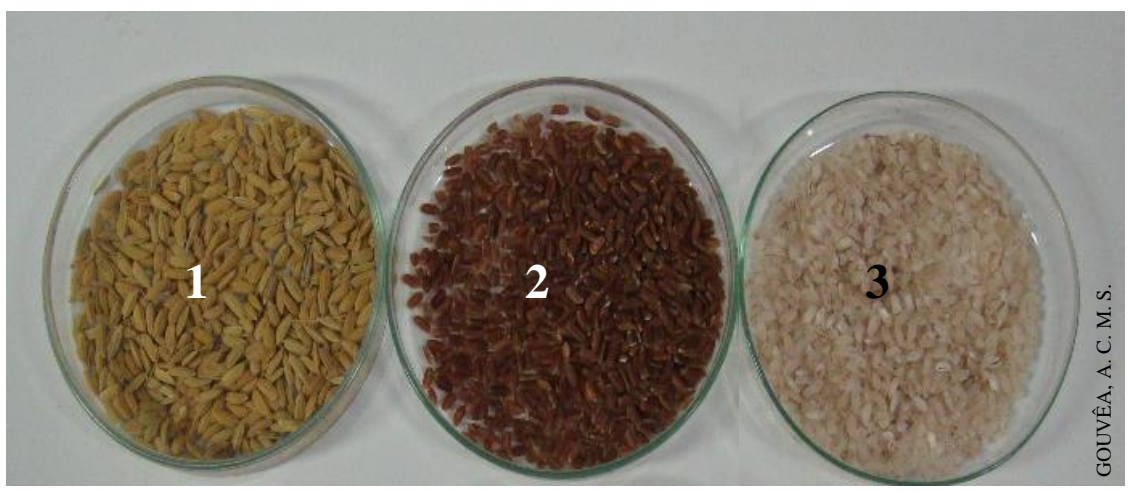

Figura 18: Amostras de arroz: 1) arroz com casca; 2) arroz sem casca; 3) arroz polido. 
As amostras foram pesadas e submetidas à extração seguindo a metodologia descrita na Extração II. Foram feitas extrações em duplicata nas três amostras (Tabela 4).

Tabela 4: Teste para extração do arroz vermelho.

\begin{tabular}{cccc}
\hline Amostra & Massa & Alíquota & Ressuspender \\
\hline Arroz c/casca 1 & $0,9843 \mathrm{~g}$ & $1,0 \mathrm{ml}$ & $200,0 \mu \mathrm{l}$ \\
Arroz c/casca 2 & $1,0091 \mathrm{~g}$ & $1,0 \mathrm{ml}$ & $200,0 \mu \mathrm{l}$ \\
Arroz polido 1 & $1,0099 \mathrm{~g}$ & $1,0 \mathrm{ml}$ & $200,0 \mu \mathrm{l} *$ \\
Arroz polido 2 & $1,0261 \mathrm{~g}$ & $1,0 \mathrm{ml}$ & $200,0 \mu \mathrm{l}$ \\
Arroz s/casca 1 & $0,9978 \mathrm{~g}$ & $1,0 \mathrm{ml}$ & $200,0 \mu \mathrm{l}$ \\
Arroz s/casca 2 & $0,9918 \mathrm{~g}$ & $1,0 \mathrm{ml}$ & $200,0 \mu \mathrm{l}$ \\
\hline
\end{tabular}

* Essa amostra foi perdida. PPAV.

A extração foi realizada utilizando somente o pó proveniente do polimentodo pericarpo do arroz vermelho (PPAV) (Figura 19). Foi pesada em duplicata 200,0 mg de PPAV, a extração foi realizada conforme procedimento Extração II.

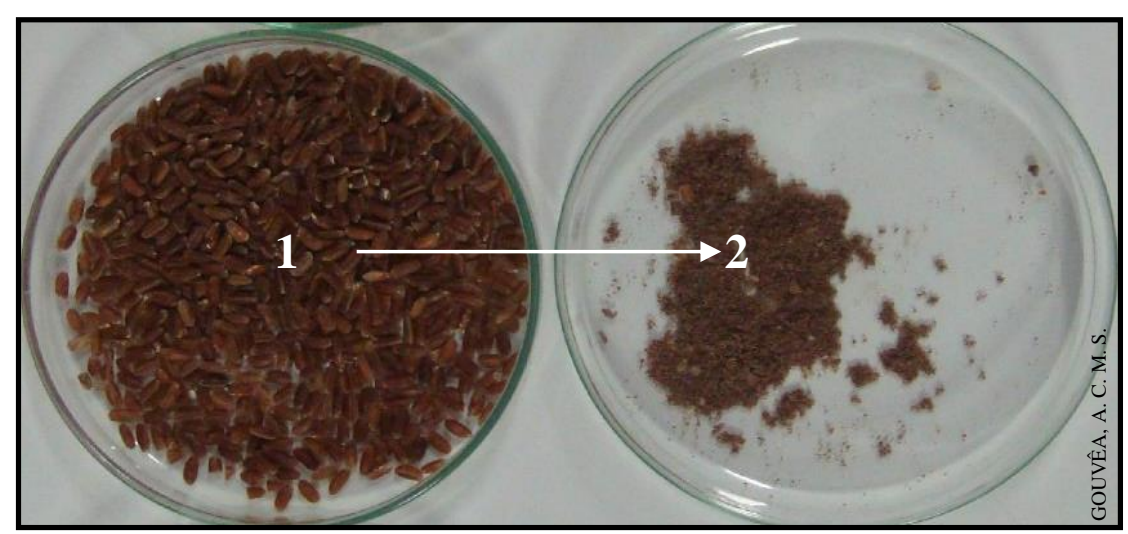

Figura 19: 1) arroz vermelho; 2) pó do polimento do pericarpo do arroz vermelho (PPAV).

\section{2) Arroz preto}

Para o procedimento de extração das antocianinas vinte grãos foram submersos em água filtrada por no mínimo 2 horas. O extrato aquoso obtido foi eluído em cartucho Sep-Pak $\mathrm{C}_{18}$ Waters ${ }^{\circledR}$ previamente acondicionado com solução 8 (1\% de ácido fórmico/metanol). Após saturação o mesmo foi lavado com $5 \mathrm{~mL}$ de solução 6 (0,1\% de ácido fórmico/ água de MilliQ). Em seguida foi eluído com solução 8, o extrato obtido foi concentrado no rotaevaporador, uma alíquota de $200,0 \mu \mathrm{L}$ foi retirada e submetida à secura usando fluxo de $\mathrm{N}_{2}$. O material seco 
foi dissolvido em 1,0 mL da solução 2 de análise (ácido fórmico/metanol/água Milli-Q; $10: 10: 80-\mathrm{v} / \mathrm{v} / \mathrm{v})$.

\subsubsection{Extração de antocianinas no fruto da amendoeira (Terminalia catappa.)}

O fruto da amendoeira foi lavado e seco com papel toalha, logo em seguida, foi descascado, e as partes foram separadas em três grupos: casca (C); polpa entre a casca e o caroço $(\mathrm{P})$ e; polpa fibrosa próxima ao caroço (PF) (Figura 20). Cada grupo foi triturado em Blender até formação de um purê homogêneo.

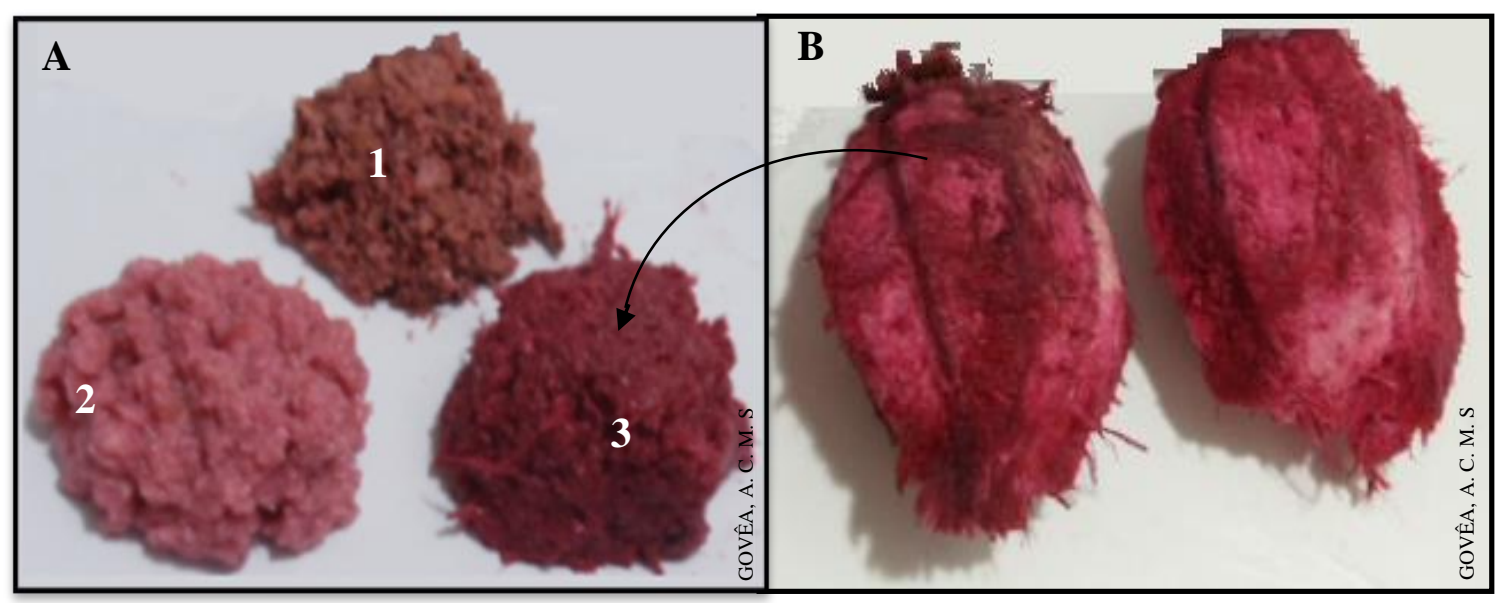

Figura 20: A) Purês obtidos das três amostras trituradas: 1- C (casca); 2- P (entre casca e o caroço); 3- PF (polpa fibrosa próxima ao caroço). B) Caroço do fruto da amendoeira após a retirada da PF.

Foi pesada uma massa de aproximadamente $0,200 \mathrm{~g}$ em duplicata para cada amostra conforme a Tabela 5. A extração foi realizada conforme o procedimento descrito no item Extração II.

Tabela 5: Valores das massas pesadas.

\begin{tabular}{cc}
\hline Amostra & Massa (gramas) \\
\hline C1 & 0,2505 \\
C2 & 0,2514 \\
P1 & 0,2145 \\
P2 & 0,2065 \\
PF1 & 0,2266 \\
PF2 & 0,2441 \\
\hline
\end{tabular}




\subsection{Análises Cromatográficas}

\subsubsection{Métodos Cromatográficos utilizando o sistema CLAE/DAD}

As análises cromatográficas foram realizadas em sistema cromatográfico com detetor de arranjo de fotodiodos a 520nm descrito no item 3.1.

- Método cromatográfico I

A etapa cromatográfica foi adaptada da metodologia descrita para amostras liofilizadas proposta por Brito et al. (2007). A separação cromatográfica foi realizada utilizando coluna $\mathrm{C}_{18}$ Symmetry, fluxo de $1,0 \mathrm{~mL} / \mathrm{min}$, temperatura da coluna $30^{\circ} \mathrm{C}$ e modo gradiente descrito na Tabela 6, onde o solvente A é a solução 3 descrita no item 3.2 e solvente B metanol.

Tabela 6: Gradiente de eluição para o método cromatográfico I.

\begin{tabular}{cccc}
\hline Tempo (min) & $\begin{array}{c}\text { Solvente A }\left(\mathbf{1 0 \%} \text { Ác. Fórm. }{ }^{*}\right) \\
\text { \% }\end{array}$ & $\begin{array}{c}\text { Solvente B (Metanol *) } \\
\text { \% }\end{array}$ & $\begin{array}{c}\text { Fluxo } \\
(\mathbf{m L} / \\
\text { min })\end{array}$ \\
\hline $\mathbf{0 - 2 0}$ & $95-85$ & $5-15$ & 1 \\
$\mathbf{2 0 - 3 5}$ & $85-75$ & $15-25$ & 1 \\
$\mathbf{3 5 - 4 0}$ & $75-95$ & $25-5$ & 1 \\
$\mathbf{4 0 - 4 5}$ & 95 & 5 & 1 \\
\hline
\end{tabular}

* Todos solventes utilizados foram grau HPLC.

\subsubsection{Procedimento para desenvolver a metodologia de separação cromatográfica (CLAE) de antocianinas}

Para esta etapa foi utilizado como matéria-prima o extrato metanólico obtido de amorapreta (cultivar Tupy). Os frutos foram tratados e processados segundo descrito no item 3.4.1. Em seguida foi realizada a extração seguindo a metodologia para amostras liofilizadas, extração II.

Uma alíquota de 2,0 mL do sobrenadante foi evaporada sobre fluxo de ar comprimido filtrado realizando em seguida diluição com o mesmo volume de solução 2 (ácido fórmico/metanol/água, 10:10:80, v/v/v). O extrato diluído foi transferido para um vial e injetado para análise no cromatógrafo líquido (CLAE/DAD).

- Método cromatográfico I I

A separação cromatográfica foi realizada utilizando coluna cromatográfica $\mathrm{C}_{18}$ Thermo Scientific $\mathrm{C}_{18} \mathrm{BDS}^{\circledR}$, fluxo $1 \mathrm{~mL} / \mathrm{min}$, temperatura de coluna $40^{\circ} \mathrm{C}$ e modo gradiente descrito na Tabela 7. Onde o solvente A é a solução 4 descrita no item 3.2 e solvente B acetonitrila. 
Tabela 7: Gradiente de eluição para o método cromatográfico II

\begin{tabular}{cccc}
\hline Tempo (min) & $\begin{array}{c}\text { Solvente A (5\% Ác. Fórm. *) } \\
\text { \% }\end{array}$ & $\begin{array}{c}\text { Solvente B (ACN *) } \\
\text { \% }\end{array}$ & $\begin{array}{c}\text { Fluxo } \\
(\mathbf{m L} / \mathbf{M i n})\end{array}$ \\
\hline- & 95 & 5 & 1 \\
$\mathbf{1 0}$ & 87 & 13 & 1 \\
$\mathbf{1 4}$ & 86 & 14 & 1 \\
$\mathbf{1 6 , 5}$ & 95 & 5 & 1 \\
$\mathbf{2 0}$ & 95 & 5 & 1 \\
\hline
\end{tabular}

* Todos solventes utilizados foram grau HPLC.

As análises cromatográficas seguiram as condições cromatográficas do item 3.5.1 e 3.5.2 utilizando as metodologias I e II. Trabalhou-se com três concentrações de ácido fórmico para a fase móvel A, soluções $3(10 \%), 4(5 \%)$ e 5 (1\%), para cada concentração foram medidos os seus respectivos valores de $\mathrm{pH}$, Tabela 8 .

Tabela 8: pH das soluções de ácido fórmico aquoso.

\begin{tabular}{cc}
\hline $\begin{array}{c}\text { Fase Móvel } \\
\text { (Ácido Fórmico/ água grau Milli-Q®) }\end{array}$ & $\mathbf{p H}$ \\
\hline $10 \%$ & 1,87 \\
$5 \%$ & 1,97 \\
$1 \%$ & 2,36 \\
\hline
\end{tabular}

\subsubsection{Método Cromatográfico utilizando o sistema CLUE acoplado ao espectrômetro de massa híbrido QTOF-Synapt}

As análises cromatográficas foram realizadas em sistema cromatográfico líquido de ultra eficiência acoplado ao detetor de espectrometria de massas, fonte $\left(\mathrm{ESI}^{+}\right)$, com analisadores Quadrupolo em série com TOF para realizar as análises EM/EM, analisador TOF em modo V. Os equipamentos estão descritos no item 3.1 e ilustrado na Figura 21.

\subsubsection{Preparo da Amostra e condição de análise no sistema CLUE-TOF}

Foi retirada uma alíquota de $100,0 \mu \mathrm{L}$ de cada extrato obtido de todas as matrizes analisadas, utilizando a metodologia de extração I. Essa alíquota foi diluída em $1,5 \mathrm{~mL}$ de solução 9 (ácido fórmico /água Milli Q/ metanol- 0,6: 59,4: 40- v/v/v), filtrada em membrana filtrante Millex da Millipore $(0,22 \mu \mathrm{m})$, transferida para vial e injetada no volume de $1 \mu \mathrm{L}$ sob fluxo de $0,35 \mu \mathrm{L} / \mathrm{min}$, temperatura da coluna de $45^{\circ} \mathrm{C}$, energia de colisão de $4,0 \mathrm{~V}$ para análises EM e variando na faixa de 4,0 a 20,0V para análises EM/EM. As condições de análise foram conforme gradiente descrito na Tabela 9 e parâmetros utilizados no espectrômetro de massas descritos na Tabela 10 para inserção no EM através do sistema cromatográfico. 


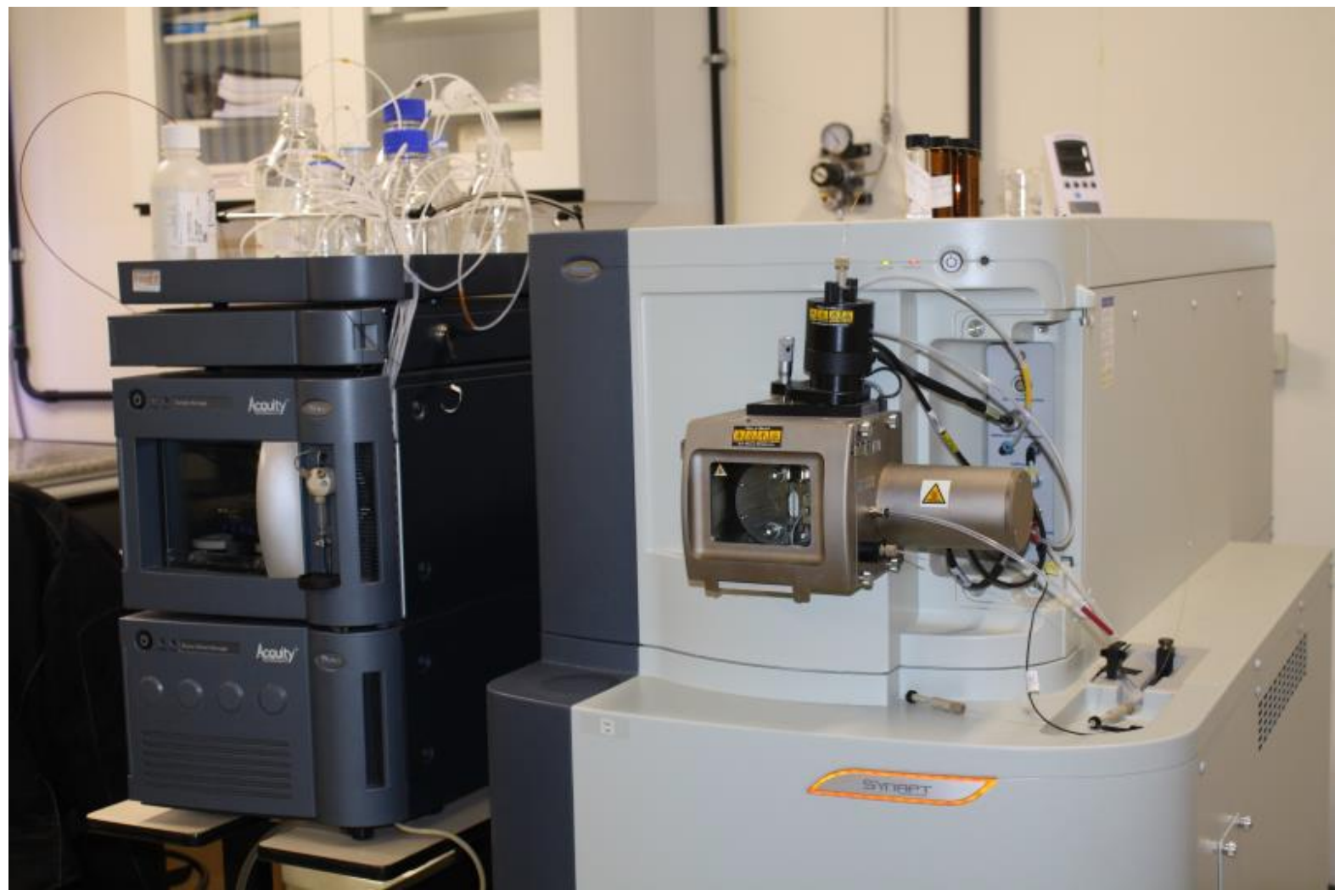

Figura 21: Sistema CLUE-QTOF (ESI $\left.{ }^{+}\right)$: UPLC ACQUITY-Synapt, Waters ${ }^{\circledR}$. Fonte: SCHULZ, F. D., 2014.

Tabela 9: Gradiente de eluição para análise no CLUE.

\begin{tabular}{cccc}
\hline Tempo (min) & $\begin{array}{c}\text { Solvente A } \\
(\mathbf{0 , 1 \%} \text { Ác. Fórmico } \\
\text { \% }\end{array}$ & $\begin{array}{c}\text { Solvente B } \\
(\text { Metanol }\end{array}$ & $\begin{array}{c}\text { Fluxo } \\
\text { \% }\end{array}$ \\
\hline- & 95 & 5 & 0,35 \\
$\mathbf{1 . 0 0}$ & 90 & 10 & 0,35 \\
$\mathbf{2 . 0 0}$ & 88 & 12 & 0,35 \\
$\mathbf{3 . 5 0}$ & 85 & 15 & 0,35 \\
$\mathbf{4 . 5 0}$ & 85 & 15 & 0,35 \\
$\mathbf{6 . 5 0}$ & 80 & 20 & 0,35 \\
$\mathbf{8 . 5 0}$ & 70 & 30 & 0,35 \\
$\mathbf{8 . 5 1}$ & 90 & 10 & 0,35 \\
$\mathbf{9 . 0 0}$ & 95 & 5 & 0,35 \\
$\mathbf{1 2 . 0 0}$ & 95 & 5 & 0,35 \\
\hline
\end{tabular}

* Todos solventes utilizados foram grau massa (EM). 
Tabela 10: Condições de análise por massas.

\begin{tabular}{cc}
\hline Capilar $(\mathrm{Kv})$ & 3,0 \\
Cone $(\mathrm{Kv})$ & 25.0 \\
Temperatura de dissolvatação $\left({ }^{\circ} \mathrm{C}\right)$ & 350,0 \\
Temperatura da Fonte $\left({ }^{\circ} \mathrm{C}\right)$ & 80,0 \\
Fluxo Gás de dissolvatação $(\mathrm{L} / \mathrm{Hr})$ & 750,0 \\
Fluxo do Gás do Cone $(\mathrm{L} / \mathrm{Hr})$ & 25,0 \\
Escaneamento da Massa & $100,0-1000,0$ \\
\hline
\end{tabular}

\subsection{Separação de Antocianinas nas Matrizes Estudadas por CLAE}

As separações cromatográficas nos extratos obtidos da matriz de arroz vermelho seguiram a metodologia I, para as demais matrizes foi utilizada a metodologia II (item 3.5.1 e 3.5.2).

\subsection{Coletas dos Pigmentos Antociânicos}

As coletas das antocianinas foram realizadas, automaticamente, com o auxílio de uma válvula Rheodyne ${ }^{\circledR}$, com 6 canais (Figura 22) conectada a saída do detetor (DAD). A válvula foi programada, através do software Empower ${ }^{\circledR}$, direcionando a saída do detetor para o canal desejado $(2,3,4,5$ e 6), logo após o início da eluição da antocianina de interesse, voltando à programação para o canal referente ao descarte (lixo), canal 1, quando quase todo o analito estivesse eluído.

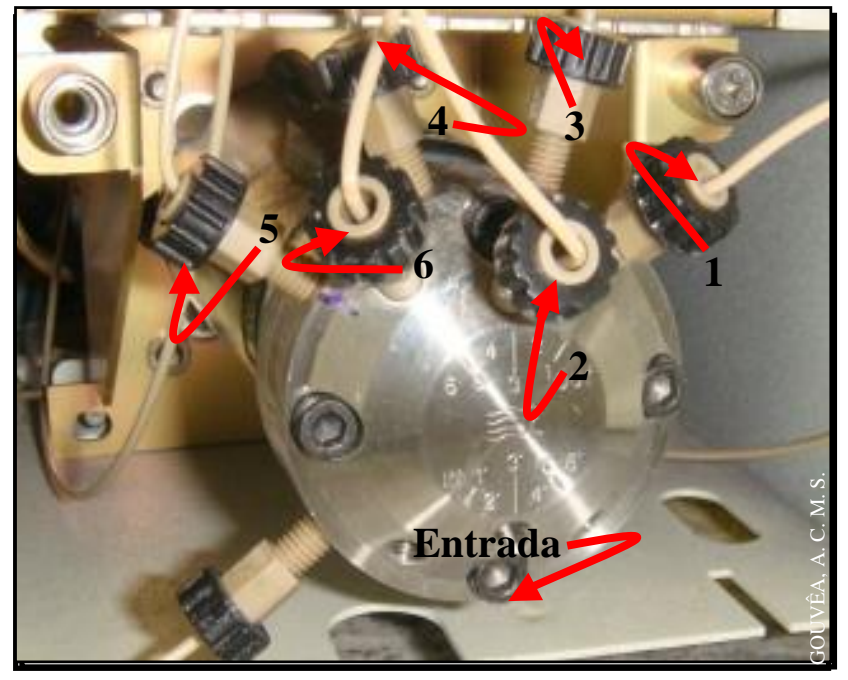

Figura 22: Foto da Válvula coletora Rheodyne ${ }^{\circledR}$, onde 1, 2, 3, 4, 5 e 6 são canais de saída. 
Para obtenção dos padrões das antocianinas delfinidina-3-glicosídeo, cianidina-3glicosídeo, petunidina 3- glicosídeo, pelargonidina 3- glicosídeo, peonidina3- glicosídeo e malvidina 3- glicosídeo foram utilizadas três fontes provedoras de extratos: do fruto da amendoeira; do epicarpo da Uva- Preta sem semente do Chile (Vitis vinífera) e do morango.

\subsubsection{Purificação e Concentração dos Extratos Antociânicos Isolados}

A purificação do extrato antociânico foi realizada utilizando-se cartuchos Sep-Pak ${ }^{\circledR} \mathrm{C}_{18}$ $1,0 \mathrm{~g}$ da Waters, previamente acondicionado com 5,0 mL da solução 1 (ácido fórmico/metanol; 10:90- v/v). Após a percolação e saturação do cartucho usando extrato de antocianina isolada, este foi lavado com 10,0 mL de água acidificada, solução 6 (água Milli-Q/ácido fórmico; 99,9/0,1- v/v). Após a lavagem do cartucho, as antocianinas foram eluidas com $5 \mathrm{~mL}$ da solução 1. Para cada antocianina isolada foi utilizado um cartucho novo.

\subsubsection{Análise cromatográfica das antocianinas isoladas (CLAE/DAD)}

Uma alíquota de 100,0 $\mu \mathrm{L}$ do extrato antociânico isolado obtido foi seco e, logo em seguida, diluído ao mesmo volume em solução 2 (ácido fórmico/metanol/água Milli-Q; 10:10:80- v/v/v) foi injetado cromatógrafo e analisado para conferir o percentual de pureza. A condição de corrida está descrita no item 3.5.2 e gradiente de corrida descrito na Tabela 5. A pureza obtida foi calculada através da equação I.

Equação I: Cálculo da pureza da pureza dos padrões de antocianinas

$$
\text { Pureza \% }(\mathrm{P})=\frac{\text { Área do pico de interesse }}{\text { Área de todos os picos }} \times 100 \quad \text { Eq.I }
$$

\subsubsection{Análise cromatográfica por CLUE/EM-QTOF (ESI $\left.{ }^{+}\right)$, modo EM/EM para identificação das antocianinas}

Os espectros de massa foram obtidos por injeção no sistema CLUE-QTOF, análises foram monitoradas em modo EM e EM/EM. O preparo da amostra está descrito no item 3.5.3.1, assim como as condições e parâmetros de análise.

As análises também foram realizadas através da inserção direta no EM-QTOF $\left(\mathrm{ESI}^{+}\right)$, no modo EM/EM.

\subsubsection{Cálculo para exatidão de Massa}

Para o cálculo da massa exata das antocianinas e antocianidinas foram utilizadas as massas monoisotópicas (massa do isótopo mais abundante) de cada elemento componente da molécula (Tabela 11).

A exatidão da medida da massa das substâncias obtidas nos espectros em modo EM ou EM/EM foram calculadas com a diferença (erro) entre a massa medida (experimental) e a massa 
teórica (Equação II). A exatidão de massas foi medida em miliDaltons ( $1 \mathrm{mDa}=0,01$ unidades de massa) ou ppm (partes por milhão) (Equação III).

Tabela 11: Massa Nominal e Massa Exata (monoisotópica) dos elementos.

\begin{tabular}{ccc}
\hline Elementos & $\begin{array}{c}\text { Massa } \\
\text { Nominal }\end{array}$ & $\begin{array}{c}\text { Massa Exata } \\
\text { (Massa Monoisotópica) }\end{array}$ \\
\hline \hline $\mathrm{H}$ & 1 & 1,0078 \\
$\mathrm{C}$ & 12 & 12,0000 \\
$\mathrm{O}$ & 16 & 15,9949 \\
$\mathrm{Na}$ & 14 & 22,9898 \\
\hline $\mathrm{H}=$ hidrogênio, $\mathrm{C}=$ carbono, $\mathrm{O}=$ oxigênio e $\mathrm{Na}=$ sódio
\end{tabular}

O cáculo das massas exatas das seis principais antocianidinas em alimentos (cianidina, delfinidina, pelargonidina, peonidina, petunidina e malvidina) e das suas respectivas antocianinas com diferentes substituintes foi realizado através do software de espectrometria de massa MassLynx (Waters).

Equação II: Cálculo da massa exata das antocianinas.

$$
\mathrm{Da}=\boldsymbol{M}_{\text {experimental }}-\boldsymbol{M}_{\text {teórica }}=\mathbf{X} \mathbf{m D a} \quad \text { Eq.II }
$$

Equação III: Cálculo do erro em ppm

$$
\text { Erro ppm }=\frac{\boldsymbol{M}_{\text {experimetal }}-\boldsymbol{M}_{\text {teórica }}}{\boldsymbol{M}_{\text {teórica }}} \times \mathbf{1 0}^{\mathbf{6}}=\mathbf{X} \mathbf{p p m} \quad \text { Eq III }
$$

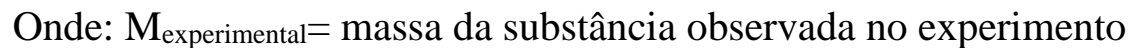

$\mathbf{M}_{\text {teórica }}=$ massa teórica da substância

$\mathrm{mDa}=$ mili Daltons

$\mathrm{Ppm}=$ parte por milhão 


\subsubsection{Procedimento para avaliar as antocianinas de baixa concentração da matriz do arroz preto (IAC 600)}

O arroz preto (IAC 600) foi adquirido no supermercado do Rio de Janeiro. Em torno de $20 \mathrm{~g}$ de arroz preto foi moído no moinho de facas IKA) modelo A11. Em seguida $1 \mathrm{~g}$ do pó foi submetido a extração. A massa foi dividida em dois tubos ( $0,5 \mathrm{~g}$ cada). Após, seguiu-se com a metodologia de extração descrita no item 3.4.2 (Extração I para análise qualitativa)

\subsection{1 Coleta das substâncias no arroz preto}

Esse procedimento foi realizado em duas etapas:

1) Uso da válvula Rheodyne ${ }^{\circledR}$, seletora de canais (item 3.7), para a coleta no extrato do arroz preto, após a separação cromatográfica dividida em quatro tempos, chamadas de Frações (Figura 23).

A válvula seletora foi programada para direcionar a saída do detetor para o canal 2 logo após do início da corrida no $t_{R} 1$ minuto e, após a eluição da Fração 1 voltando à programação de descarte para o lixo (canal 1), $t_{R} 5,5$ min. Repetiu-se o mesmo procedimento para a coleta das restantes frações: fração 2, abertura do canal 3 no $t_{R} 5,7$ min e fechamento no $t_{R} 7,0$ min; fração 3 , abertura do canal 4 no $t_{R} 7,2$ min e fechamento no $t_{R} 9,8$ min e; fração 4 , abertura do canal 5 no $t_{R} 10,0$ min e fechamento no $t_{R} 12,0$ min. Voltando para o canal 1 , de descarte lixo, até o final da corrida (20 min).

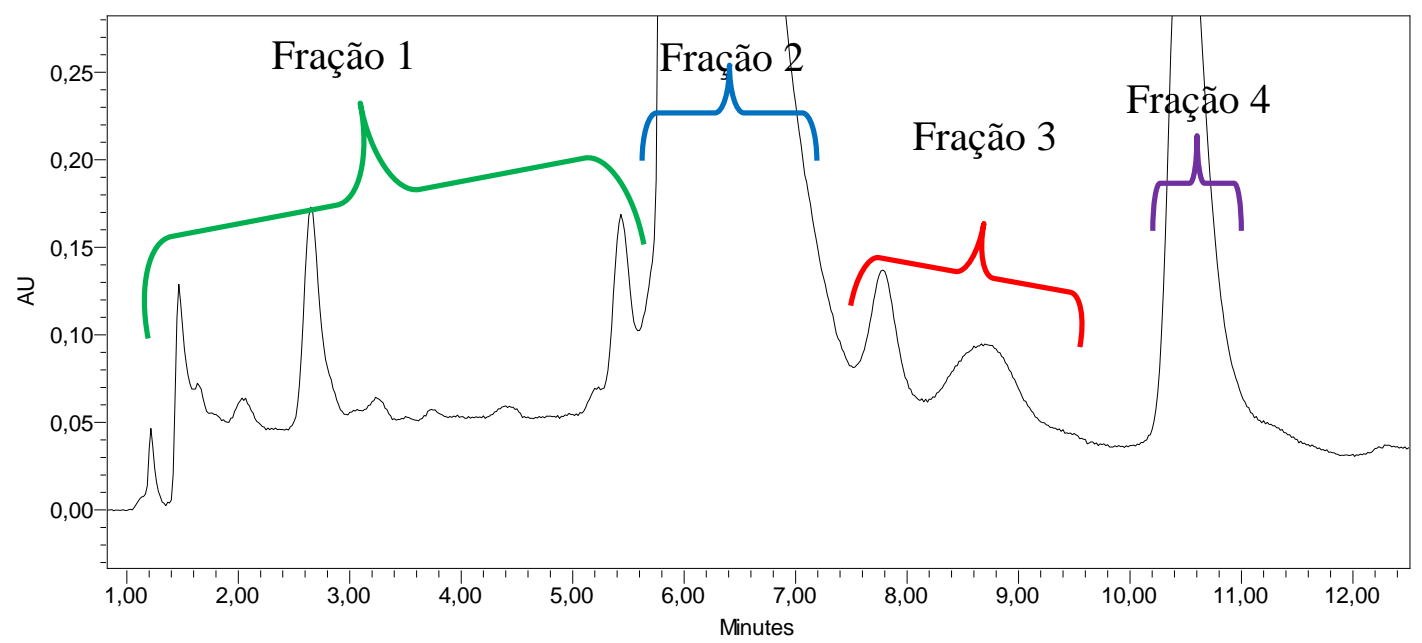

Figura 23: Cromatograma do extrato de arroz preto obtido no CLAE/DAD a $520 \mathrm{~nm}$. Fração 1) tempo de retenção de 1 até 5,5min. Fração 2) tempo de retenção 5,7 até 7,0. Fração 3) tempo de retenção 7,2 até 9,8 min e Fração 4) tempo de retenção 10,0 até 12 min.

2) Utilização de coluna de vidro recheada com fase $\mathrm{C}_{18}$, descrita no item 3.2.1. Para as concentrações das amostras coletas pela válvula seletora de canais, realizou-se o procedimento:

a. Lavagem da coluna com $20 \mathrm{~mL}$ utilizando solução 1 (item 3.3);

b. Lavagem da coluna com $10 \mathrm{~mL}$ utilizando solução 5 (item 3.3); 
c. Aplicação de $5 \mathrm{~mL}$ do extrato de arroz-preto (obtido no item 3.7 5);

d. Lavagem da coluna com os pigmentos adsorvidos utilizando $20 \mathrm{~mL}$ da solução 5 (item 3.3).

e. Eluição dos pigmentos com a solução $1(5 \mathrm{~mL})$.

\subsubsection{Técnicas combinadas para purificação de antocianinas}

Purificação das antocianinas utilizando coluna de vidro fase $\mathrm{C}_{18} /$ Cartucho Oasis ${ }^{\circledR}$ (troca catiônica) / Cartucho Sep Pak $\mathrm{C}_{18}$. Como matriz foi utilizado o pó liofilizado do fruto da amendoeira, o extrato foi preparado conforme o item 3.4.2, utilizando a metodologia de extração I.

O procedimento de purificação foi realizado em três etapas:

A) Utilização de coluna de vidro recheada com fase $\mathrm{C}_{18}$, descrita no item 3.2.1

Pré-tratamento para retirada de contaminantes

- Lavagem da coluna com 20 mL utilizando solução 1 (item 3.3);

- Lavagem da coluna com 10 mL utilizando solução 5 (item 3.3);

- Aplicação de $5 \mathrm{~mL}$ do extrato do fruto da amendoeira (obtido no item 3.7. $5)$;

- Lavagem da coluna com os pigmentos adsorvidos utilizando $20 \mathrm{~mL}$ da solução 5 (item 3.3);

- Eluição dos pigmentos com a solução 10

A cada $1 \mathrm{~mL}$ de solução obtida deverá ser diluída 10 vezes em água ultrapura.

B) Purificação no Cartucho Oasis ${ }^{\circledR}$ (troca catiônica)

- Verter $12 \mathrm{~mL}$ da solução aquosa da amostra no cartucho

- Lavar com 12 mL solução de $0,1 \%$ TFA

- Lavar com 12 mL de solução MetOH/0,1\% TFA

- Lavar com $6 \mathrm{~mL} \mathrm{MetOH/0,1 \%} \mathrm{NH}_{4} \mathrm{OH}$

- Lavar com 6 mL (água: metanol, 40:60, v/v) /0,1\% $\mathrm{NH}_{4} \mathrm{OH}$ 
Após a eluição do pigmento, acidificá-lo com $250 \mu \mathrm{L}$ de ácido fórmico (99\%). Diluir novamente com $20 \mathrm{~mL}$ da solução 5 .

C) Uso do cartucho Sep Pak $\mathrm{C}_{18}$

- $\quad$ Lavagem do cartucho com 5 mL utilizando solução 1 (item 3.3);

- $\quad$ Lavagem do cartucho com 10 mL utilizando solução 5 (item 3.3);

- Aplicação dos $20 \mathrm{~mL}$ do extrato aquoso obtido do cartucho de troca catiônica

- Lavagem do cartucho com os pigmentos adsorvidos utilizando $20 \mathrm{~mL}$ da solução 5 (item 3.3).

- Eluição dos pigmentos com a solução $1(5 \mathrm{~mL})$ 


\section{RESULTADOS E DISCUSSÃo}

Foram estudas 43 matrizes de frutos folhas e flor, com caracteristicas de conter pigmentos antocianicos. O objetivo foi de encontrar fontes que apresentassem concentrações de antocianinas que permitissem isola-las e purifica-las de maneira que possam ser usadas como padrões analíticos.

\subsection{Pré-tratamento das Matrizes}

As amostras foram liofilizadas e em seguida trituradas até a formação de um pó, o que além de possibilitar a sua conservação para trabalhos futuros, garantiu homogeneidade às mesmas. Esse procedimento pode ser sempre realizado, desde que, as matrizes não apresentem altas concentrações de açúcar, pois tornam o produto liofilizado vítreo e gomoso ao absorver umidade do ar. A polpa e o suco das matrizes testadas também foram liofilizados, visando sua conservação e uso futuro. As flores e folhas quando em grandes quantidades seguiram o mesmo procedimento dos sucos e polpas, pois como os sucos, a liofilização serviu mais para garantir sua utilização futura do que para facilitar a extração, visto que sua superfície de contato, assim como o tipo de tecido vegetal, facilitaram a extração do analito quando submersas no solvente de extração, garantindo, portanto, a extração total do pigmento.

\subsection{Extrações}

\subsubsection{Extração I - Análise Qualitativa}

Para análise qualitativa (Extração I, pag.31) não foi necessário partir de uma alíquota com massa conhecida. Quanto maior a pigmentação menor a massa requerida para extração. Para algumas matrizes, como por exemplo, a matriz alface roxo, devido a presença de outros pigmentos, como carotenoides, ocorreu a necessidade de fazer extração líquido/líquido ou utilizar a técnica extração em fase sólida (EFS = SPE - Solid Phase Extraction), pois, após a extração com o solvente polar, algumas substâncias menos polares, mas com polaridade suficiente para serem carreadas pelo solvente extrator, ainda mascaravam sua coloração.

\subsubsection{Extração II - Análise Quantitativa}

Para análise quantitativa (Extração II, pág. 32), as extrações das antocianinas foram realizadas de acordo com o tipo de matriz utilizada. Mas, para matrizes provenientes de suco, polpa ou pó do liofilizado, o procedimento foi o mesmo. Três lavagens foram suficientes para a maioria das amostras. Para as matrizes que a torta ainda apresentava coloração foi realizada uma quarta lavagem.

Os resultados obtidos nas análises indicaram grande eficiência da Extração II. Análise realizada no resíduo, após o término das extrações, indicou que o analito foi totalmente extraído durante o procedimento. Além disso, os cromatogramas obtidos com os extratos das matrizes 
apresentaram uma ótima separação das antocianinas, com picos de magnitude que viabilizam uma futura quantificação da substância.

\subsubsection{Extração III}

A matéria-prima liofilizada associada a metodologia de Extração III, tornou possível obter extratos com altas concentrações do analito. Desse modo, não houve necessidade de muitas corridas para se obter um extrato, da substância pura, com concentração que permitisse a confecção de uma curva de calibração.

\subsection{Otimização da separação cromatográfica de antocianinas (CLAE/DAD)}

Atualmente o que se espera em análise cromatográfica é uma redução no tempo e uma melhor resolução dos analitos. Desta forma, desenvolveu-se uma metodologia utilizando coluna com tamanho de partículas $2,4 \mu \mathrm{m}$ e mudanças na fase móvel para análise de antocianinas por CLAE/DAD, de forma rápida e eficiente para estudo de matrizes com potencial para serem isoladas. As condições de trabalho foram desenvolvidas com o extrato de amora preta (cultivar Tupy) liofilizada como descrito na parte experimental (item 3.4.1, pag.28).

Durante o desenvolvimento foram testadas várias condições cromatográficas e os parâmetros estudados para a otimização do método foram: composição da fase móvel; tipo de coluna; temperatura da coluna e fluxo conforme informado na Tabela 14. Os gradientes utilizados encontram-se descritos nas Tabelas 6 e 7 (pág. 36 e 37).

A Tabela 14 mostra oito diferentes (A até $\mathbf{H}$ ) condições cromatográficas utilizadas para desenvolvimento do método. A condição A mostra a metodologia utilizada como ponto de partida. Um cromatograma, utilizando a condição A, está demonstrado na Figura 24. Onde foi observado que nestas condições a antocianina cianidina-3-O-glicosídeo apresenta um tempo de retenção acima de 15 minutos.

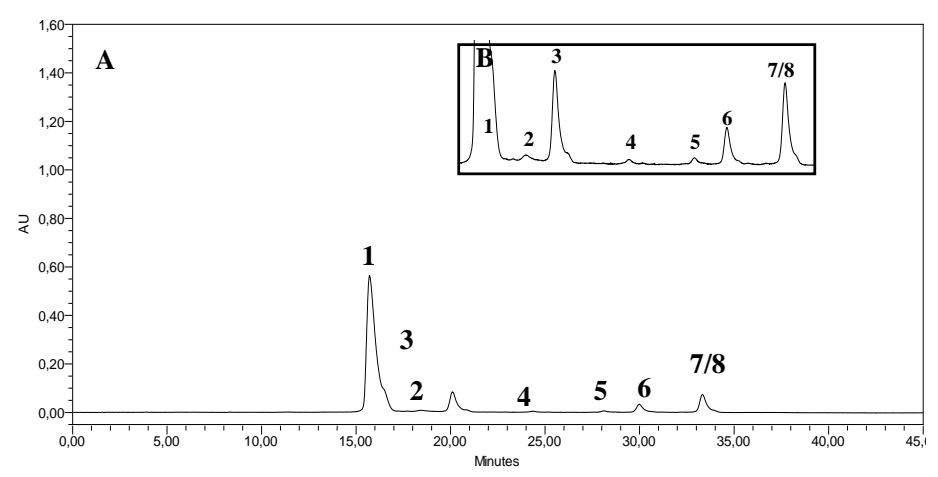

\begin{tabular}{cl}
\hline Pico & ACN \\
\hline 1 & Cy-3-Glicosídeo \\
2 & NI \\
3 & Cy-3-Rutenosídeo \\
4 & NI \\
5 & Cy-3- Arabinose \\
6 & Cy-3-6"malonil glicosídeo \\
7 & NI \\
8 & Cy-3-dioxalil glicosídeo \\
ACN: Antocianina; NI: Não Identificadas; Cy: Cianidina
\end{tabular}

Figura 24: (A) Perfil cromatográfico do extrato de amora-preta liofilizada extraído usando a condição cromatográfica A da Tabela 14 a 520 nm, B) Expansão do cromatograma entre os tempos de retenção de 15 a 35 minutos. 
O primeiro parâmetro testado foi a mudança da concentração do ácido fórmico, com consequente mudança do $\mathrm{pH}$ da fase móvel, condição B. A redução na concentração do ácido fórmico de $10 \%$ para $1 \%$ mostrou um grande deslocamento do tempo de retenção das antocianinas. Observou-se que os analitos não eluiram até 30 minutos (Figura 25), aumentando em 15 minutos o tempo de retenção em relação à condição A. Além disso os picos também apresentaram alargamento na base. Isso ocorreu devido ao aumento da interação do analito com a fase estacionária, o que caracteriza redução na força do solvente da fase móvel. Foi observada também uma redução na área do pico, caracterizando perda na sensibilidade, estando isso relacionado ao deslocamento do equilíbrio para o sentido de formação da sua forma incolor Carbinol (Figura 26), influenciando assim no sinal registrado pelo detetor (DAD) utilizado na análise. Esta condição de análise se mostrou inviável em relação à proposta deste trabalho, pois necessitaria de um aumento do tempo da corrida para possibilitar a eluição de todas as substâncias

Tabela 12: Condições de análise cromatográfica testadas para a separação de antocianinas.

\begin{tabular}{|c|c|c|c|c|c|}
\hline Condição & Coluna & $\begin{array}{r}\text { Temperatura } \\
\text { da coluna }\left({ }^{\circ} \mathrm{C}\right)\end{array}$ & Fase Móvel & $\begin{array}{c}\text { Fluxo } \\
\text { mL/min }\end{array}$ & $\begin{array}{c}\text { Tempo de corrida } \\
\text { (min) }\end{array}$ \\
\hline $\mathbf{A}$ & $\begin{array}{c}\text { Symmetry }{ }^{\circledR} \\
\left(\mathrm{C}_{18}\right)\end{array}$ & 30 & $\begin{array}{c}\text { Metanol }^{1} \\
\text { Ácido Fórmico } 10 \%{ }^{2}\end{array}$ & 1,0 & 45 \\
\hline B & $\begin{array}{l}\text { Symmetry }{ }^{\circledR} \\
\left(C_{18}\right)\end{array}$ & 30 & $\begin{array}{c}\text { Metanol }^{1} \\
\text { Ácido Fórmico 1\%² }\end{array}$ & 1,0 & 45 \\
\hline $\mathrm{C}$ & $\begin{array}{c}\text { Symmetry }{ }^{\circledR} \\
\left(\mathrm{C}_{18}\right)\end{array}$ & 30 & $\begin{array}{c}\text { Metanol }^{1} \\
\text { Ácido Fórmico 5\% }\end{array}$ & 1,0 & 45 \\
\hline D & $\begin{array}{c}\text { Symmetry }{ }^{\circledR} \\
\left(\mathrm{C}_{18}\right)\end{array}$ & 30 & $\begin{array}{l}\text { Acetonitrila }^{1} \\
\text { Ácido Fórmico } 5 \%{ }^{2}\end{array}$ & 1,0 & 45 \\
\hline $\mathbf{E}$ & $\begin{array}{c}\text { Thermo } \\
\text { Scientific } \\
\quad\left(\mathrm{C}_{18}\right)\end{array}$ & 30 & $\begin{array}{c}\text { Acetonitrila }^{1} \\
\text { Ácido Fórmico } 5 \%{ }^{2}\end{array}$ & 1,0 & 20 \\
\hline $\mathbf{F}$ & $\begin{array}{c}\text { Thermo } \\
\text { Scientific } \\
\left(C_{18}\right)\end{array}$ & 30 & $\begin{array}{c}\text { Acetonitrila }^{1} \\
\text { Ácido Fórmico } 5 \%{ }^{2}\end{array}$ & 1,5 & 20 \\
\hline G & $\begin{array}{c}\text { Thermo } \\
\text { Scientific } \\
\left(\mathrm{C}_{18}\right)\end{array}$ & 35 & $\begin{array}{c}\text { Acetonitrila }^{1} \\
\text { Ácido Fórmico 5\% }\end{array}$ & 1,5 & 20 \\
\hline H & $\begin{array}{c}\text { Thermo } \\
\text { Scientific } \\
\left(C_{18}\right)\end{array}$ & 40 & $\begin{array}{c}\text { Acetonitrila }^{1} \\
\text { Ácido Fórmico 5\% }\end{array}$ & 1,0 & 20 \\
\hline
\end{tabular}

Constituintes do gradiente: (1) Solvente $\mathrm{A} \mathrm{e}^{(2)}$ Solvente $\mathrm{B}$ 

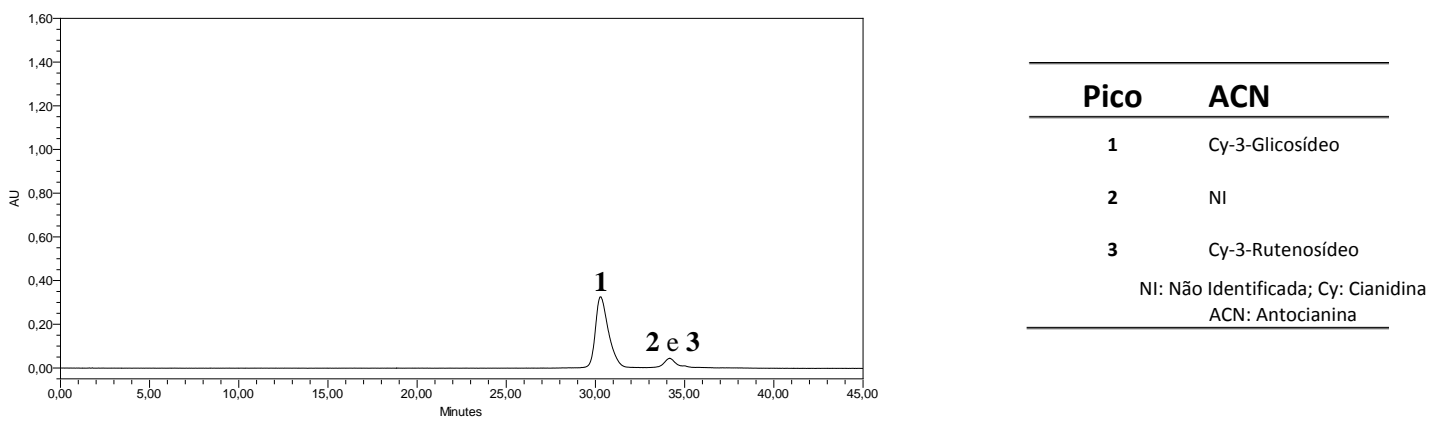

Figura 25: cromatograma obtido com a condição de análise $\mathbf{B}$, apresenta o analito $\mathbf{1}$ eluindo após 30 minutos de corrida $(\lambda$ de $520 \mathrm{~nm})$.

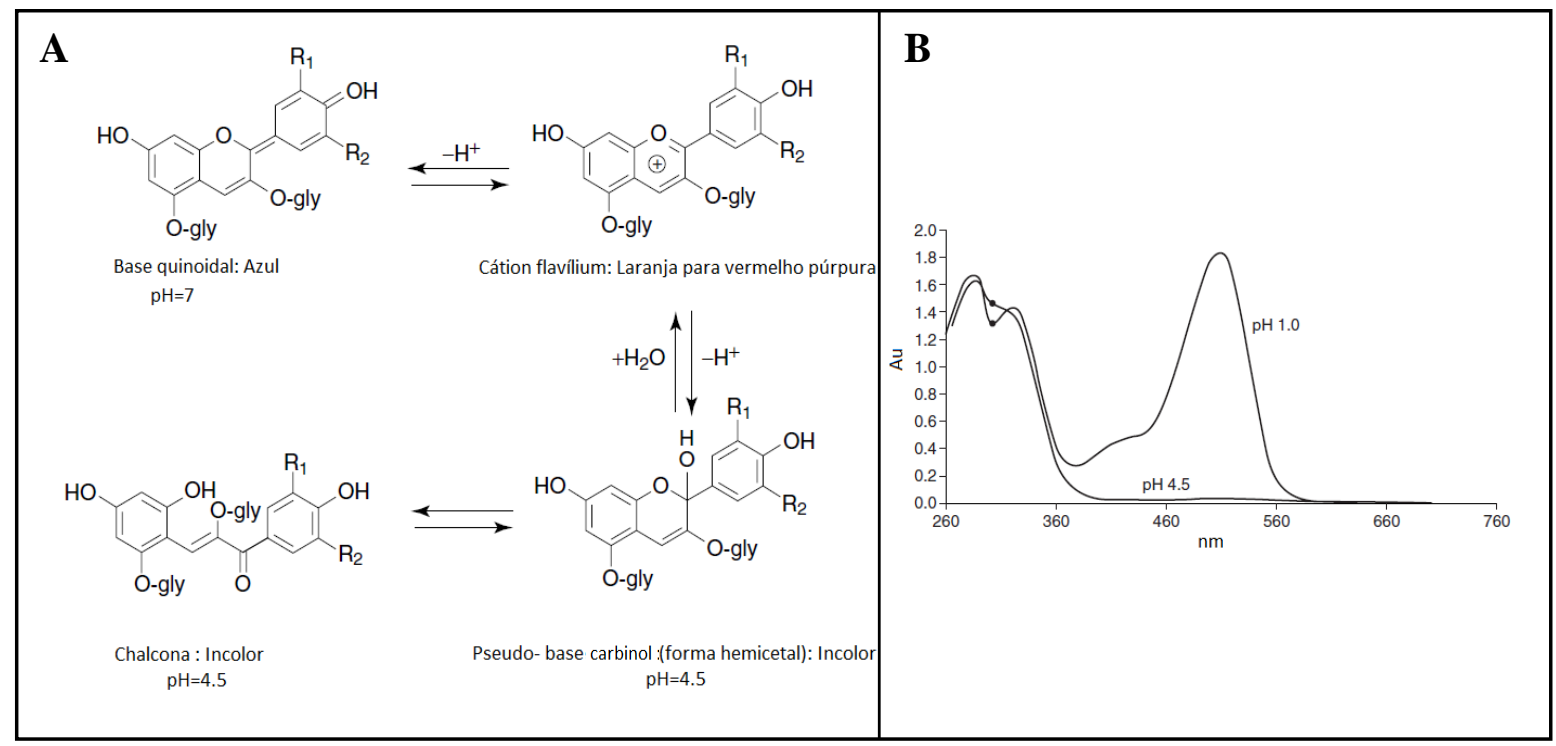

Figura 26: A) Esquema demonstrativo das alterações nas estruturas, das antocianinas, predominantes quando são submetidas a diferentes níveis de $\mathrm{pH}$. B). Espectro de absorção de uma purificada antocianina (acilada pelargonidina-3-soforosídeo-5-glicosídeo) UV-visível em pH 1,0 e pH 4,5. Fonte: Giusti e Wrolstad, 2001.

A mudança do percentual para 5\% de ácido fórmico, condição de análise $\mathbf{C}$, representada pelo cromatograma da Figura 27, também foi observado um aumento no tempo de retenção e um alargamento da base dos picos. Entretanto, em menor proporção quando comparado com a condição A. Foi observado que além dos picos 7 e 8 os picos 4 e 5 também co-eluiram, caracterizando perda de resolução. O deslocamento para tempo de retenção maior mostrou que essa condição não era melhor que a original $\mathbf{A}$. 

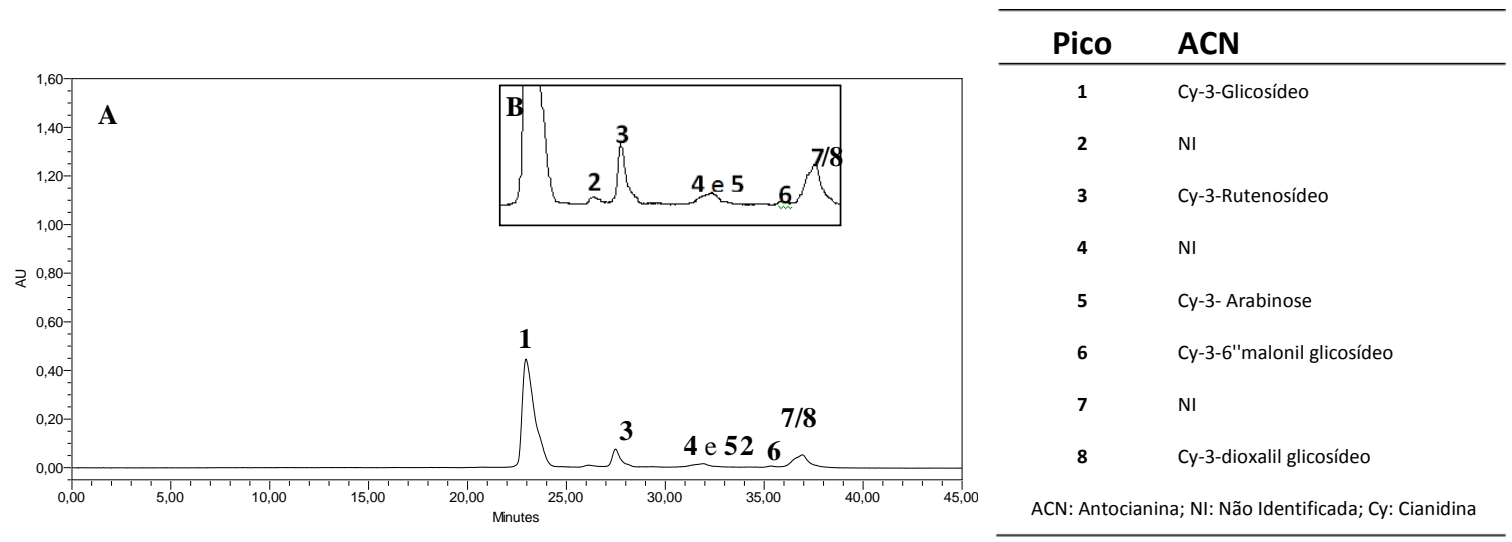

Figura 27: (A) cromatograma obtido com a condição de análise C, apresenta o analito 1 eluindo após 22 minutos de corrida. (B) Expansão do cromatograma entre os tempos de retenção de 22 e 38 minutos.

O próximo passo foi alteração na força do solvente da fase móvel, condição D, substituindo o metanol por acetonitrila. A troca de solvente proporcionou uma redução no tempo de retenção e um aumento na sensibilidade. Também mostrou a separação das substâncias 4 e 5, mas os picos 7 e 8 ainda co-eluem. Um cromatograma obtido nas condições acima está representado na Figura 28 , mostrando uma melhoria no método em relação as condições de $\mathbf{A}$.

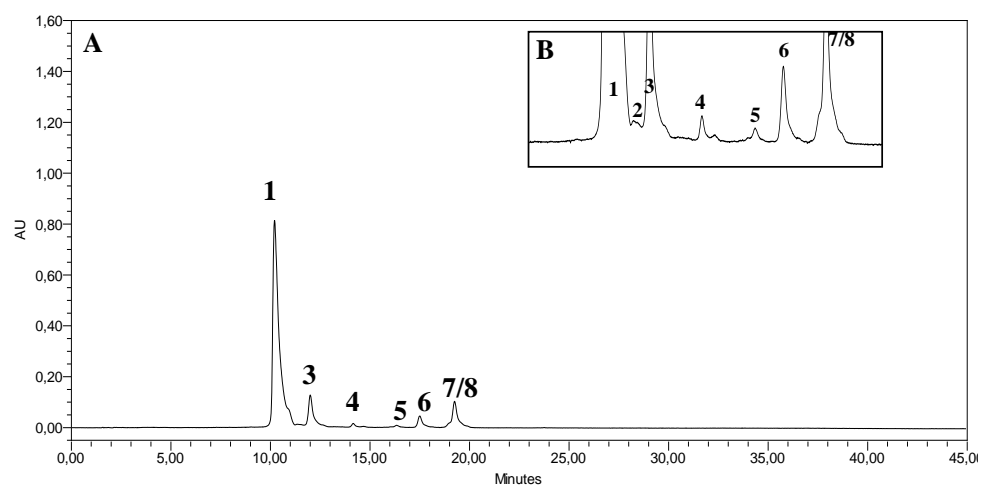

\begin{tabular}{cl}
\hline Pico & ACN \\
\hline $\mathbf{1}$ & Cy-3-Glicosídeo \\
$\mathbf{2}$ & NI \\
$\mathbf{3}$ & Cy-3-Rutenosídeo \\
$\mathbf{4}$ & NI \\
$\mathbf{5}$ & Cy-3- Arabinose \\
$\mathbf{6}$ & Cy-3-6"malonil glicosídeo \\
$\mathbf{7}$ & NI \\
$\mathbf{8}$ & Cy-3-dioxalil glicosídeo \\
ACN: Antocianina; NI: Não Identificadas; Cy: Cianidina
\end{tabular}

Figura 28: (A) Cromatograma obtido nas condições de análise D. (B) Expansão do cromatograma entre os tempos de retenção de 5 e 20 minutos $(\lambda 520 \mathrm{~nm})$.

$\mathrm{Na}$ condição $\mathbf{E}$ houve a troca para uma coluna com fase estacionária com partículas de $2,4 \mu \mathrm{m}$ de tamanho. Nesta condição o cromatograma, representado na Figura 29, mostrou que ocorreu um grande aumento na sensibilidade, diminuição do tempo de retenção e maior eficiência de separação com aumento na resolução das substâncias, caracterizados pelos picos 7 e 8 . A melhora nas condições cromatográficas indica agora a presença de oito substâncias, o que não era possível de se observar com a coluna usada anteriormente. 

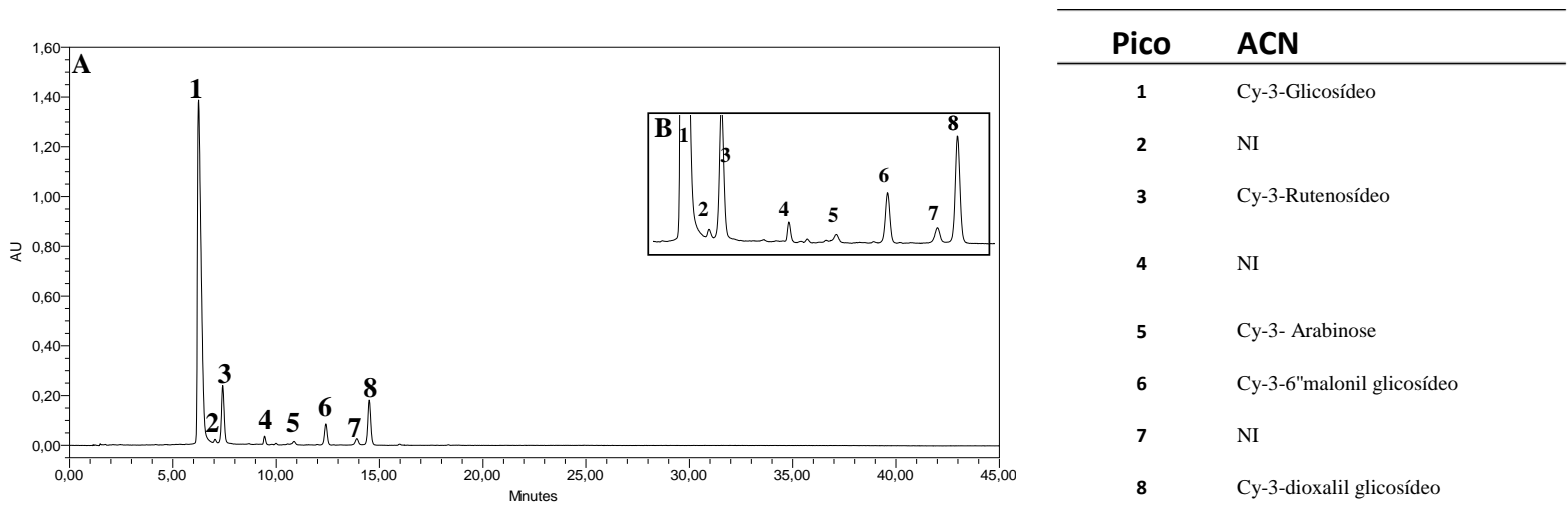

ACN: Antocianina; NI: Não Identificadas; Cy: Cianidina

Figura 29:(A) Cromatograma do extrato quando se utilizou as condições de análise E. (B) Detalhe da expansão do cromatograma entre 6 e 15 minutos $(\lambda 520 \mathrm{~nm})$.

Após a mudança fase móvel e principalmente da coluna, optou-se por trabalhar com alteração no fluxo da fase móvel e, consequentemente, variação da temperatura. $\mathrm{O}$ aumento do fluxo leva a uma melhor resolução para esse tipo de coluna, com consequente aumento a pressão, o que foi corrigido com o aumento da temperatura. $\mathrm{O}$ aumento do fluxo de 1,0 para 1,5 $\mathrm{mL} / \mathrm{mim}$, possibilitou uma redução ainda maior no tempo de retenção, mas com perda de resolução. Trabalhou-se então com fluxo de $1,0 \mathrm{~mL} / \mathrm{mim}$ e aumentou-se a temperatura de 30 para $40^{\circ} \mathrm{C}$. Essas condições possibilitaram a eluição de todos os picos, em um tempo de 10 mim, inferior as demais condições e com a melhor resolução até o momento. O que levou à escolha do método $\mathrm{H}$. Os cromatogramas relacionados às condições testadas estão representados na Figura 30.

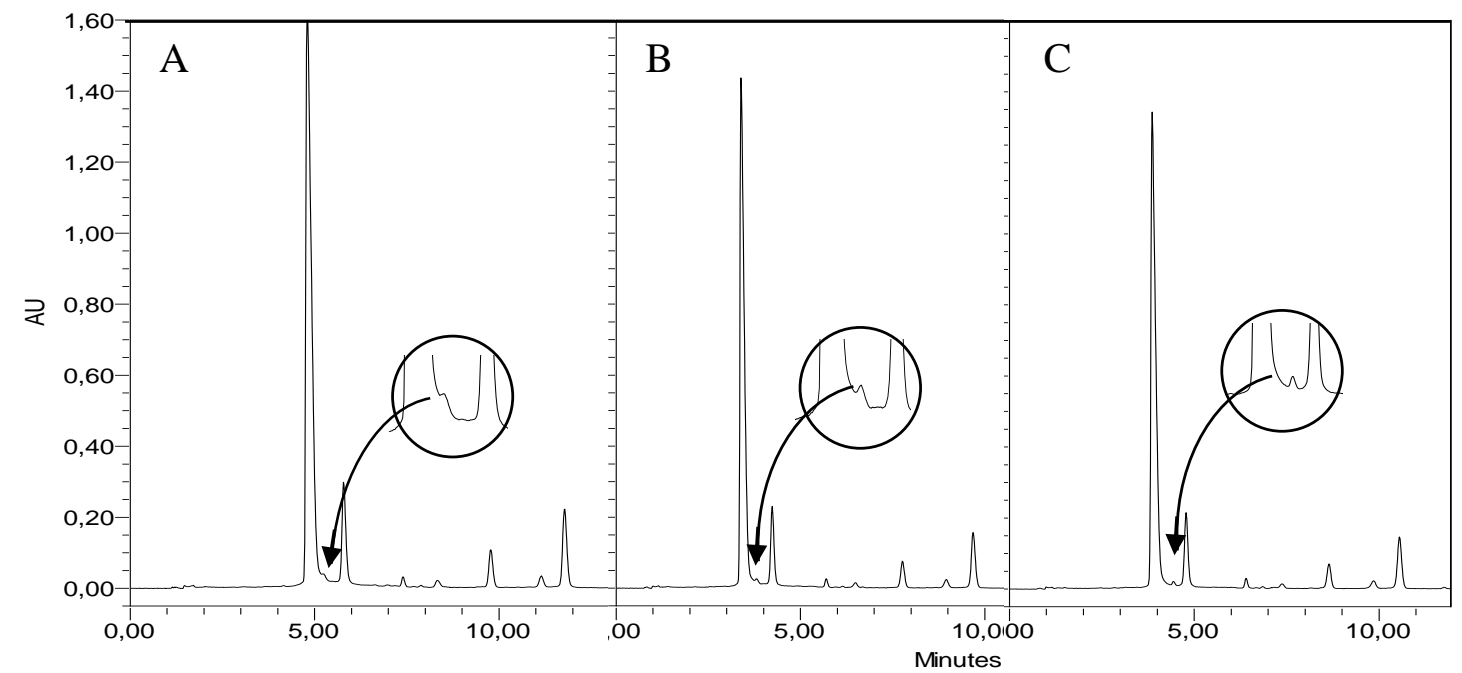

Figura 30: (A) Cromatograma quando utilizada as condições de análise F (B) Cromatograma quando utilizada as condições de análise $\mathrm{G}(\mathrm{C})$ Cromatograma quando utilizada as condições $\mathrm{H}$, todos os três cromatogramas foram obtidos a $520 \mathrm{~nm}$.

Em suma, dentre as alternativas testadas nestes experimentos, os melhores desempenhos foram apresentados quando houve emprego da coluna Thermo Scientific $\mathrm{C}_{\mathbf{1 8}}$ BDS $^{\circledR}$ (100x 4,6 $\mathrm{mm} ; 2,4 \mu \mathrm{m}$ ) associada à fase móvel constituída de acetonitrila (solvente A) e solução aquosa 
de ácido fórmico 5\% (solvente B). De uma maneira geral, as condições de análise que mantiveram estes dois parâmetros apresentaram cromatogramas com picos finos (melhor fator resposta) e redução no tempo de corrida. Como após 15 minutos não houve eluição de outros analitos neste comprimento $(520 \mathrm{~nm})$, optou-se pela redução do tempo de análise para 20 minutos onde, após alguns experimentos e ajustes nas condições de percentagem dos solventes descritos na Tabela 7 (pág.37) mostrou ser o gradiente, com o menor tempo de eluição, onde seria possível estabilizar a coluna sem comprometer a próxima análise. Obteve-se assim, um método com melhor resolução, menor tempo de análise, menor gasto de solvente e com uma fase menos agressiva à coluna e ao equipamento (5\% de ácido em vez de $10 \%$ ).

\subsubsection{Avaliações de procedimentos de extração para verificar a presença de antocianinas na matriz de arroz (Oryza sativa L.)}

\section{1) Arroz Vermelho}

Teste 1- No cromatogramas do extrato do arroz vermelho com casca [Figura 18 (1), pág. 33] e do arroz polido [Figura 18 (3), pág. 33], nada foi observado. No entanto, no extrato do arroz sem casca de pericarpo vermelho [Figura 18 (2), pág.33], apesar de apresentar uma forte coloração não foi observado sinal significativo da presença de antocianinas a $520 \mathrm{~nm}$. Os cromatogramas dos extratos do arroz vermelho com casca, sem casca e polido não apresentaram nenhuma diferença entre eles a $520 \mathrm{~nm}$, indicando que não foi possível observar o pigmento nas amostras. (Figura 31).

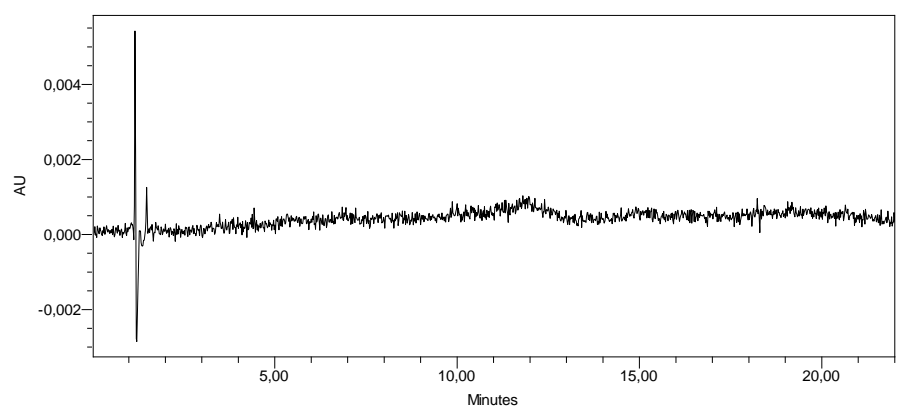

Figura 31: Perfil cromatográfico dos três extratos do arroz vermelho (com casca, sem casca e polido) mantido durante a análise por CLAE a $520 \mathrm{~nm}$.

Teste 2- Como o pigmento vermelho se encontra numa fina camada do pericarpo do arroz, ao ser triturado o pigmento extraído ficou muito diluído. Foi inserida, portanto, uma etapa, onde o arroz foi polido e o pó resultante, com uma coloração bem acentuada do pigmento, foi recolhido e submetido à extração.

O extrato do pó do polimento do arroz vermelho (PPAV), apresentou um único sinal significante no cromatograma (Figura 32, A). Mas, o espectro de absorção observado no visível, (Figura 32, B) com absorção à 450,8 nm, não é característico de antocianinas monoméricas. O comprimento de onda observado encontra-se fora da faixa esperada para antocianinas, entre 490-550nm (GIUSTI e WROLSTAD, 2001). Portanto, a cor vermelha do arroz estudado não era proveniente das antocianinas, mas sim de outro pigmento que não será avaliado por este estudo. 


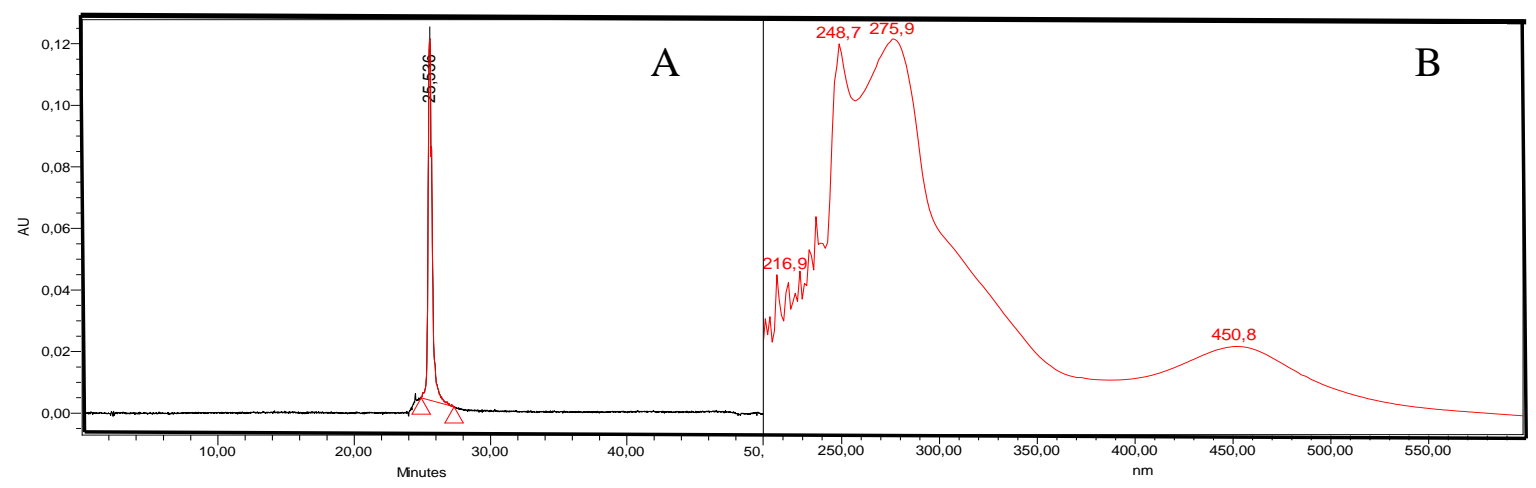

Figura 32: A) Cromatograma do extrato metanólico PPAV a 520nm. B) Espectro UV-Vis ${ }_{\text {máx }}$ do extrato metanoico PPVA.

\subsection{Separação e Identificação das Antocianinas Presentes nas 41 matrizes}

Todas as matrizes analisadas foram divididas em 2 grupos:

Grupo1: As matrizes: acerola (M.emarginata); açaí (Euterpe oleracea Mart.); alfaceroxa; amora-preta (silvestre); ameixa-vermelha; arroz-preto ; berinjela; framboesa (Rubus idaeus L.); flor e fruto da romãzeira (Punica granatum); jabuticaba (P.trunciflora ); jamelão (Syzygium cumini); juçara (Euterpe edulis); maçã (cv.: Fuji; Argentina, Gala, Red); mangostin (Garcinia mangostana L.); mirtilo (Vaccinium spp.); morango (Fragaria ssp); uva (cv.: Red Globe, Niagara Rosada e Kyoho); repolho-roxo; cebola roxa (Alliun cepa L.); soja- preta foram escolhidas baseadas em trabalhos na literatura que apresentavam as antocianinas já caracterizadas e identificadas (HONG e WROLSTAD, 1990; GIUSTI, RODRÍGUES-SAONA, WROLSTAD, 1999; WU e PRIOR, 2005a; WU e PRIOR, 2005b; BRITO et al.,2007; GOUVÊA et al., 2012).

Grupo2: as matrizes: fruto da amendoeira (Terminalia catappa); jabuticaba (P.grandifolia); Flor e fruto do Jambeiro vermelho (Syzygium malaccanse (L.) Merryl et Ferry); Eugênia sulcata spring ex Mart. (pitanga roxa selvagem); Neomitranthes obscura (pitanga de cachorro); Flor do Jambeiro (Syzygium malaccanse (L.) Merryl et Ferry); Flor do Ipê roxo (Tabebuia impetiginosa); casca de pera vermelha ( ); Uva-preta do Chile, sem semente (Vitis vinífera spp) e manga (cv. Tommy); bráctea da Planta Bico de Papagaio; Flor do Hibiscos (salmão); espata da Flor Ave do Paraíso ou estrelitzia e Flor da Erythrina. Todas as matrizes até o momento do início do estudo não possuíam relatos literários sobre os seus perfis de antocianinas.

Para o extrato obtido da matriz de açaí do grupo 1, foi realizada a separação por CLAE utilizando metodologia I e, as matrizes restantes tiveram seus extratos analisados utilizando metodologia II. A ordem de eluição, $t_{R}$, das antocianinas presentes somado aos dados obtidos por EM e/ou EM/EM foram comparados com os relatados na literatura. Além disso, os seus respectivos espectros de absorção na região do UV-Vis máx, somados aos outros resultados, também serviram como ferramenta para identificação das matrizes. Os picos foram numerados de acordo com seus tempos de retenção $\left(t_{R}\right)$. A hidrofobicidade das moléculas associadas ao 
grau de glicosilação e a natureza de seus substituintes, são parâmetros que influenciam nos $t_{R}$ das substâncias que eluem em condições de fase-reversa.

\subsubsection{Cálculo das massas exatas das antocianidinas e antocianinas com diferentes substituintes.}

Para esse cálculo foi utilizado a Equação II e os valores da massa do isótopo mais abundante de cada átomo constituinte da molécula (Tabela 11), os valores foram inseridos e calculados através do software MassLynx (Wathers) e encontram-se na Tabela 13.

Tabela 13: Massa molecular (MM), massa exata e fórmula molecular das antocianinas e antocianidinas.

\begin{tabular}{|c|c|c|c|}
\hline Antocianina & $\begin{array}{c}\text { Fórmula } \\
\text { Molecular }\end{array}$ & Massa & $\begin{array}{c}\text { Massa Exata } \\
(\text { ESI })^{+} \\
\end{array}$ \\
\hline Pelargonidina & $\mathrm{C}_{15} \mathrm{H}_{11} \mathrm{O}_{5}$ & 271 & 271,0303 \\
\hline Cianidina & $\mathrm{C}_{15} \mathrm{H}_{11} \mathrm{O}_{6}$ & 287 & 287,0556 \\
\hline Delfinidina & $\mathrm{C}_{15} \mathrm{H}_{11} \mathrm{O}_{7}$ & 303 & 303,0505 \\
\hline Peonidina & $\mathrm{C}_{16} \mathrm{H}_{13} \mathrm{O}_{6}$ & 301 & 301,0712 \\
\hline Petunidina & $\mathrm{C}_{16} \mathrm{H}_{13} \mathrm{O}_{7}$ & 317 & 317,0661 \\
\hline Malvidina & $\mathrm{C}_{17} \mathrm{H}_{15} \mathrm{O}_{7}$ & 331 & 331,0818 \\
\hline Pelargonidina-3-O--galactosídeo & $\mathrm{C}_{21} \mathrm{H}_{21} \mathrm{O}_{10}$ & 433 & 433,1134 \\
\hline Pelargonidina-3- $O$-glicosìdeo & $\mathrm{C}_{21} \mathrm{H}_{21} \mathrm{O}_{10}$ & 433 & 433,1134 \\
\hline Cianidina-3-O--galactosídeo & $\mathrm{C}_{21} \mathrm{H}_{21} \mathrm{O}_{11}$ & 449 & 449,1084 \\
\hline Cianidina-3- $O$ - glicosídeo & $\mathrm{C}_{21} \mathrm{H}_{21} \mathrm{O}_{11}$ & 449 & 449,1084 \\
\hline Delfinidina-3-O--galactosídeo & $\mathrm{C}_{21} \mathrm{H}_{21} \mathrm{O}_{12}$ & 465 & 465,1033 \\
\hline Delfinidina-3-O-glicosídeo & $\mathrm{C}_{21} \mathrm{H}_{21} \mathrm{O}_{12}$ & 465 & 465,1033 \\
\hline Peonidina-3-O-galactosídeo & $\mathrm{C}_{22} \mathrm{H}_{23} \mathrm{O}_{11}$ & 463 & 463,1240 \\
\hline Peonidina-3-O-glicosídeo & $\mathrm{C}_{22} \mathrm{H}_{23} \mathrm{O}_{11}$ & 463 & 463,1240 \\
\hline Petunidina-3-O-galactosídeo & $\mathrm{C}_{22} \mathrm{H}_{23} \mathrm{O}_{12}$ & 479 & 479,1189 \\
\hline Petunidina-3-O-glicosídeo & $\mathrm{C}_{22} \mathrm{H}_{23} \mathrm{O}_{12}$ & 479 & 479,1189 \\
\hline Malvidina-3- $O$-galactosídeo & $\mathrm{C}_{23} \mathrm{H}_{25} \mathrm{O}_{12}$ & 493 & 493,1346 \\
\hline
\end{tabular}


Tabela 13: Massa molecular (MM), massa exata e fórmula molecular das antocianinas e antocianidinas (continuação).

\begin{tabular}{|c|c|c|c|}
\hline Antocianina & $\begin{array}{c}\text { Fórmula } \\
\text { Molecular }\end{array}$ & Massa & $\begin{array}{c}\text { Massa Exata } \\
(\text { ESI })^{+} \\
\end{array}$ \\
\hline Malvidina-3-O-glicosídeo & $\mathrm{C}_{23} \mathrm{H}_{25} \mathrm{O}_{12}$ & 493 & 493,1346 \\
\hline Pelargonidina-3- $O$ - arabinosídeo & $\mathrm{C}_{20} \mathrm{H}_{19} \mathrm{O}_{9}$ & 403 & 403,1029 \\
\hline Pelargonidina-3- $O$-xilosídeo & $\mathrm{C}_{20} \mathrm{H}_{19} \mathrm{O}_{9}$ & 403 & 403,1029 \\
\hline Cianidina-3- $O$ - arabinosídeo & $\mathrm{C}_{20} \mathrm{H}_{19} \mathrm{O}_{10}$ & 419 & 419,0978 \\
\hline Cianidina-3- $O$-xilosídeo & $\mathrm{C}_{20} \mathrm{H}_{19} \mathrm{O}_{10}$ & 419 & 419,0978 \\
\hline Delfinidina-3-O- arabinosídeo & $\mathrm{C}_{20} \mathrm{H}_{19} \mathrm{O}_{11}$ & 435 & 435,0927 \\
\hline Delfinidina-3- $O$-xilosídeo & $\mathrm{C}_{20} \mathrm{H}_{19} \mathrm{O}_{11}$ & 435 & 435,0927 \\
\hline Peonidina-3- $O$ - arabinosídeo & $\mathrm{C}_{21} \mathrm{H}_{21} \mathrm{O}_{10}$ & 433 & 433,1135 \\
\hline Peonidina-3- $O$-xilosídeo & $\mathrm{C}_{21} \mathrm{H}_{21} \mathrm{O}_{10}$ & 433 & 433,1135 \\
\hline Petunidina-3- $O$-arabinosídeo & $\mathrm{C}_{21} \mathrm{H}_{21} \mathrm{O}_{11}$ & 449 & 449,1084 \\
\hline Petunidina-3-O-xilosídeo & $\mathrm{C}_{21} \mathrm{H}_{21} \mathrm{O}_{11}$ & 449 & 449,1084 \\
\hline Malvidina-3-O- arabinosídeo & $\mathrm{C}_{22} \mathrm{H}_{23} \mathrm{O}_{11}$ & 463 & 463,1240 \\
\hline Malvidina-3- $O$-xilosídeo & $\mathrm{C}_{22} \mathrm{H}_{23} \mathrm{O}_{11}$ & 463 & 463,1240 \\
\hline Pelargonidina-3- $O$-ramnosídeo & $\mathrm{C}_{21} \mathrm{H}_{21} \mathrm{O}_{9}$ & 417 & 417,1186 \\
\hline Cianidina-3-O-ramnosídeo & $\mathrm{C}_{21} \mathrm{H}_{21} \mathrm{O}_{10}$ & 433 & 433,1135 \\
\hline Delfinidina-3- $O$ - ramnosídeo & $\mathrm{C}_{21} \mathrm{H}_{21} \mathrm{O}_{11}$ & 449 & 449,1084 \\
\hline Peonidina-3- $O$-ramnosídeo & $\mathrm{C}_{22} \mathrm{H}_{23} \mathrm{O}_{10}$ & 447 & 447,1291 \\
\hline Petunidina-3- $O$ - ramnosídeo & $\mathrm{C}_{22} \mathrm{H}_{23} \mathrm{O}_{11}$ & 463 & 463,1240 \\
\hline Malvidina-3-O- ramnosídeo & $\mathrm{C}_{23} \mathrm{H}_{25} \mathrm{O}_{11}$ & 477 & 477,1397 \\
\hline Pelargonidina-3,5-di- $O$-glicosídeo & $\mathrm{C}_{27} \mathrm{H}_{31} \mathrm{O}_{15}$ & 595 & 595,1663 \\
\hline Cianidina-3,5-di-O-glicose / -3-O-diglicosídeo & $\mathrm{C}_{27} \mathrm{H}_{31} \mathrm{O}_{16}$ & 611 & 611,1612 \\
\hline Delfinidina-3,5-di- $O$-glicose / -3-O-diglicosídeo & $\mathrm{C}_{27} \mathrm{H}_{31} \mathrm{O}_{17}$ & 627 & 627,1561 \\
\hline Peonidina-3,5-di- $O$-glicose / -3-O-diglicosídeo & $\mathrm{C}_{28} \mathrm{H}_{33} \mathrm{O}_{16}$ & 625 & 625,1769 \\
\hline
\end{tabular}


Tabela 13: Massa molecular (MM), massa exata e fórmula molecular das antocianinas e antocianidinas (continuação).

\begin{tabular}{|c|c|c|c|}
\hline Antocianina & $\begin{array}{l}\text { Fórmula } \\
\text { Molecular }\end{array}$ & Massa & $\begin{array}{c}\text { Massa Exata } \\
(\text { ESI })^{+}\end{array}$ \\
\hline Petunidina-3,5-di- $O$-glicose / -3-O-diglicosídeo & $\mathrm{C}_{28} \mathrm{H}_{33} \mathrm{O}_{17}$ & 641 & 641,1718 \\
\hline Malvidina-3,5-di- $O$-glicose / -3-O-diglicosídeo & $\mathrm{C}_{29} \mathrm{H}_{35} \mathrm{O}_{17}$ & 655 & 655,1874 \\
\hline Pelargonidina-3- $O$-rutenosídeo & $\mathrm{C}_{27} \mathrm{H}_{31} \mathrm{O}_{14}$ & 579 & 579,1714 \\
\hline Cianidina-3-O-rutenosídeo & $\mathrm{C}_{27} \mathrm{H}_{31} \mathrm{O}_{16}$ & 639 & 639,1925 \\
\hline Delfinidina-3-O-rutenosídeo & $\mathrm{C}_{27} \mathrm{H}_{31} \mathrm{O}_{15}$ & 595 & 595,1663 \\
\hline Peonidina-3- $O$-rutenosídeo & $\mathrm{C}_{28} \mathrm{H}_{33} \mathrm{O}_{15}$ & 609 & 609,1819 \\
\hline Petunidina-3-O-rutenosídeo & $\mathrm{C}_{28} \mathrm{H}_{33} \mathrm{O}_{16}$ & 625 & 625,1769 \\
\hline Malvidina-3-O-rutenosídeo & $\mathrm{C}_{29} \mathrm{H}_{35} \mathrm{O}_{16}$ & 639 & 639,1925 \\
\hline Pelargonidina-3-O-(6"acetoila) galactosídeo & $\mathrm{C}_{23} \mathrm{H}_{23} \mathrm{O}_{11}$ & 475 & 475,1240 \\
\hline Pelargonidina-3-O-(6"acetoila) glicosídeo & $\mathrm{C}_{23} \mathrm{H}_{23} \mathrm{O}_{11}$ & 475 & 475,1240 \\
\hline Cianidina-3-O-(6"acetoila) galactosídeo & $\mathrm{C}_{23} \mathrm{H}_{23} \mathrm{O}_{12}$ & 491 & 491,1190 \\
\hline Cianidina-3-O-(6"acetoila) glicosídeo & $\mathrm{C}_{23} \mathrm{H}_{23} \mathrm{O}_{12}$ & 491 & 491,1190 \\
\hline Delfinidina-3-O-(6"acetoila) galactosídeo & $\mathrm{C}_{23} \mathrm{H}_{23} \mathrm{O}_{13}$ & 507 & 507,1139 \\
\hline Delfinidina-3-O-(6"acetoila) glicosídeo & $\mathrm{C}_{23} \mathrm{H}_{23} \mathrm{O}_{13}$ & 507 & 507,1139 \\
\hline Peonidina-3-O-(6"acetoila) galactosídeo & $\mathrm{C}_{24} \mathrm{H}_{25} \mathrm{O}_{12}$ & 505 & 505,1346 \\
\hline Peonidina-3-O-(6"acetoila) glicosídeo & $\mathrm{C}_{24} \mathrm{H}_{25} \mathrm{O}_{12}$ & 505 & 505,1346 \\
\hline Petunidina-3-O-(6"acetoila) galactosídeo & $\mathrm{C}_{24} \mathrm{H}_{25} \mathrm{O}_{13}$ & 521 & 521,1295 \\
\hline Petunidina-3-O-(6"acetoila) glicosídeo & $\mathrm{C}_{24} \mathrm{H}_{25} \mathrm{O}_{13}$ & 521 & 521,1295 \\
\hline Malvidina-3-O-(6"acetoila) galactosídeo & $\mathrm{C}_{25} \mathrm{H}_{27} \mathrm{O}_{13}$ & 535 & 535,1452 \\
\hline Malvidina-3-O-(6"acetoila) glicosídeo & $\mathrm{C}_{25} \mathrm{H}_{27} \mathrm{O}_{13}$ & 535 & 535,1432 \\
\hline
\end{tabular}




\subsubsection{Análises realizadas no Grupo 1 e Grupo 2}

\section{Açaí (Euterpe oleracea Mart.)}

O cromatograma gerado da análise realizada por CLAE/DAD do extrato de frutos do açaí liofilizado, apresentou sete picos que absorvem em 520nm (Figura 33). Para esse estudo apenas as duas substâncias dos picos majoritários, picos 2 e 4 , foram isoladas (segundo o item 3.7, pág.39) e seus espectros de absorção UV-Vis máx e de massa acurada em modo EM/EM foram avaliados.

$\mathrm{Na}$ análise da substância equivalente ao pico 2 o espectro de UV-Vis máx mostrou duas bandas de absorção com $\lambda_{\text {máx }} 279,5$ e $516,4 \mathrm{~nm}$. Os dados obtidos em EM/EM mostrou a presença do íon molecular a $\mathrm{m} / \mathrm{z}$ a 449,3719 e fragmento $\mathrm{m} / \mathrm{z}$ 287,2214 após a perda de uma hexose $\left([\mathrm{M}-162 \mathrm{Da}]^{+}\right)$. Para a substância do pico 4, no espectro de UV-Vis máx foram observadas as bandas $\lambda_{\text {máx }} 279,5$ e $517,6 \mathrm{~nm}$ e nos dados gerados por EM/EM o íon molecular a $\mathrm{m} / \mathrm{z}$ a 595,4195 e dois fragmentos, um a $\mathrm{m} / \mathrm{z}$ 449,2983 após a perda de uma desóxi-hexose ([M$146 \mathrm{Da}]^{+}$) e outro a $\mathrm{m} / z$ 287,1731 relativo à perda de hexose+desóxi-hexose $\left([\mathrm{M}-308 \mathrm{Da}]^{+}\right)$.

As bandas de absorção observadas ( $\lambda_{\operatorname{máx}} 279,5$ e $516,4 \mathrm{~nm}$ e $\lambda_{\operatorname{máx}} 279,5$ e $517,6 \mathrm{~nm}$ ) e a presença do íon a $m / z 287$ indicam que o pico 2 e 4 são antocianinas cuja aglicona é a cianidina. A substância 2 apresentou apenas um fragmento após a perda de $162 \mathrm{Da}$, indicando que essa antocianina possuía uma hexose como substituinte. A substância 4 apresentou o perfil no $\mathrm{EM} / \mathrm{EM}$ um íon molecular a $\mathrm{m} / \mathrm{z} 595$ e dois fragmentos a $\mathrm{m} / \mathrm{z} 449$ e 287 . O primeiro fragmento a $\mathrm{m} / z 449$ corresponde a antocianindina ligada a uma molécula de hexose após a perda de uma desóxi-hexose (146 Da) e, o fragmento a $\mathrm{m} / \mathrm{z} 287$ que corresponde a aglicona cianidina, quando há perda total da rutinose $(308 \mathrm{Da})$.

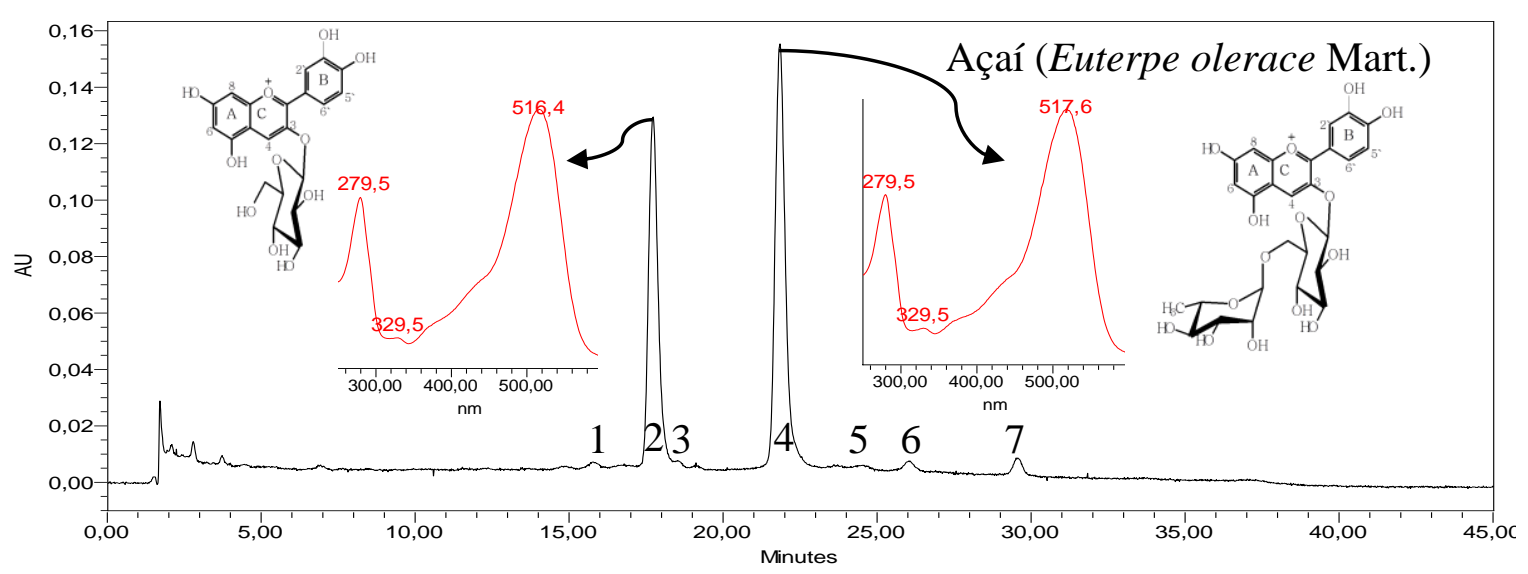

Figura 33: Cromatograma do extrato do fruto açaí liofilizado, extraído utilizando a metodologia I a 520nm.

As antocianinas foram identificadas como cianidina-3- $O$-glicosídeo e cianidina-3- $O$ rutenosídeo e ambos os glicosídeos estão coerentes com aqueles que já foram observados nos frutos de açaí em dados da literatura (GALLORI et al., 2004; ROSSO et al.; 2008; GOUVÊA et al., 2012). 


\section{Juçara (Euterpe edulis)}

Seis picos compõem o cromatograma gerado na análise realizada por CLAE/DAD no extrato do pó liofilizado da matriz juçara (Figura 34), previamente identificada na literatura (BRITO et al., 2007). As substâncias dos dois picos majoritários foram isoladas e analisadas por espectrometria de massas acuradas em modo EM/EM. A análise por EM/EM, apresentou o mesmo resultado observado na análise realizada no fruto do açaí. As substâncias majoritárias apresentaram o íon molecular a $\mathrm{m} / \mathrm{z} 449,1089$ e fragmento a $\mathrm{m} / \mathrm{z} 287,0675$ após a perda de uma hexose $\left([\mathrm{M}-162 \mathrm{Da}]^{+}\right)$para a substância 2, e um íon molecular a $\mathrm{m} / \mathrm{z}$ a 595,1681 e dois fragmentos, um a $m / \mathrm{z} 449,1098$ após a perda de uma desóxi-hexose $\left([\mathrm{M}-146 \mathrm{Da}]^{+}\right)$e o outro a $m / z, 287,0561$ relativos a perda de hexose+ desóxi-hexose $\left([\mathrm{M}-308 \mathrm{Da}]^{+}\right)$referente a substância 3. Ambos os glicosídeos foram definitivamente identificados como cianidina-3-O-glicosídeo e cianidina-3-O-rutenosídeo por coeluição com os padrões isolados (segundo o item 3.7, pág.39) do extrato do fruto de açaí segundo Gouvêa e colaboradores (2012).

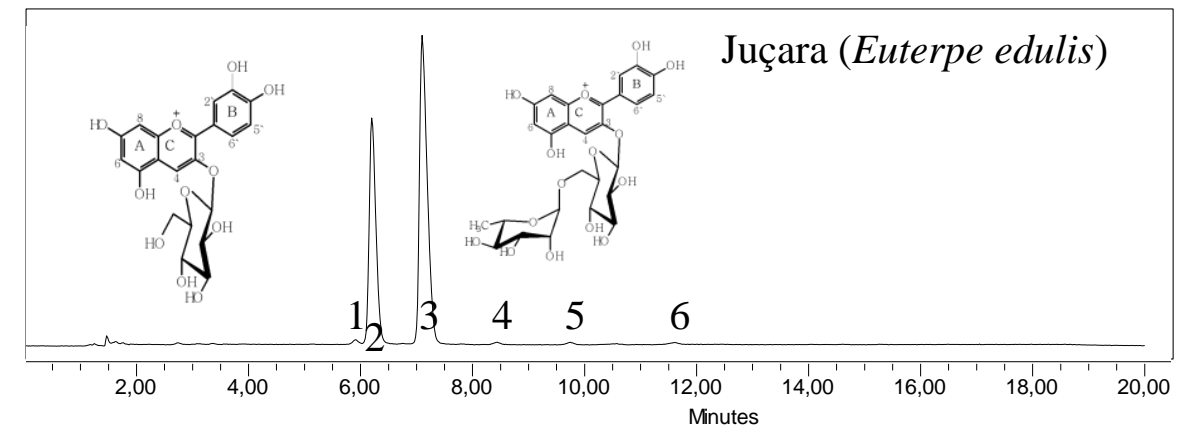

Figura 34: Cromatograma do extrato metanólico do pó da juçara liofilizada, extraído utilizando a metodologia II a $520 \mathrm{~nm}$.

Os frutos Euterpe oleracea Mart. (açaî) e Euterpe edulis (juçara) são espécies pertencentes ao mesmo gênero Euterpe e, apresentam similaridade quanto a composição química com qualidades nutricionais compatíveis (SILVA, BARRETO \& SÊRODIO, 2004). Apesar de apresentarem os cromatogramas semelhantes (Figura 33 e 34), apenas três do total das antocianinas presentes em seus perfis são relatadas, comumente, na literatura nas duas espécies (BRITO et al., 2007; DIAS et al.,2012). Dentre elas, cianidina-3-O-glicosídeo e cianidina-3-O-rutenosídeo são as antocianinas que foram encontradas em comum nas duas espécies como majoritárias (Tabela 14), divergindo apenas nas concentrações entre elas. 
Tabela 14: Antocianinas identificadas na literatura nas matrizes açaí (Euterpe oleracea Mart.) e juçara (Euterpe edulis).

\begin{tabular}{|c|c|c|}
\hline Matriz & ANTOCIANINAS & Referência \\
\hline Açaí & $\begin{array}{l}\text { Derivado de Cy (1); Cy-3-O-glicosídeo (2); } \underline{\mathrm{Cy}-3-O-} \\
\text { rutenosídeo (3) }\end{array}$ & GALLORI et al., 2004 \\
\hline Açaí & $\begin{array}{l}\text { Cy-3-O-glicosideo (1); Cy-3-O-rutenosídeo (2); } \\
\text { Pg-3-O-glicosídeo (3); Pn-3-O-glicosídeo (4) }\end{array}$ & $\begin{array}{l}\text { PACHECO-PALENCIA, } \\
\text { TALCOTT e TALCOTT, } 2010\end{array}$ \\
\hline Açaí & $\begin{array}{l}\underline{\text { Cy-3-O-glicosideo }}(1) ; \mathrm{Cy}-3-O \text {-sambubiosideo }(2) ; \underline{\text { Cy-3- }} \\
\underline{O \text {-rutenosídeo (3); Pn-3-O-rutenosídeo (4) }}\end{array}$ & $\begin{array}{l}\text { MULABAGAL e CALDERÓN, } \\
2012\end{array}$ \\
\hline Açaí & $\begin{array}{l}\text { Cy -3-di- } O \text {-glicosideo (1); Cy-di-3-O-glicosideo } \\
\text { (Isômero do primeiro) (2); Cy-3-O-glicosídeo (3); Cy-3- } \\
O \text {-rutenosídeo (4); Pg-3-O-glicosídeo (5); Pn-3-O- } \\
\text { glicosídeo (6); Pn-3-O-rutinosídeo (7) }\end{array}$ & DIAS et al., 2012 \\
\hline Juçara & $\begin{array}{l}\text { Cy-di-O-sambubiosideo (1); Cy-3-O-glicosídeo (2); } \\
\text {; Cy-3-O-rutenosídeo (3); Pg-3-O-glicosídeo (4); Pg-3-O- } \\
\text { rutinosídeo (5); Cy-3-O-ramnosideo (6) }\end{array}$ & BRITO et al., 2007 \\
\hline Juçara & $\begin{array}{l}\text { Cy-3,5-di-O-glicosídeo (1); Cy-3-O-glicosídeo (2); Cy-3- } \\
O \text {-rutenosídeo (3); Pg-3-O-rutenosídeo (4); Pn-3-O- } \\
\text { glicosídeo (5); Pn-3-O-rutenosídeo }\end{array}$ & BICUDO, RIBANI e BETA, 2014 \\
\hline
\end{tabular}

Cy- cianidina; Pg - pelargonidina; Pn- peonidina

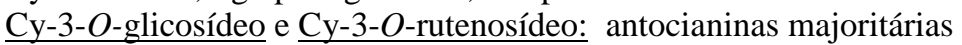

Berinjela cultivar de casca roxo-escuro (Solanum melongena L.)

O cromatograma gerado na análise por CLAE/DAD do extrato da casca da berinjela liofilizada, apresentou 4 picos que absorvem na região de $520 \mathrm{~nm}$ (Figura 35). Para este estudo foram analisados os espectros de absorção UV-Vis máx das 4 substâncias, mas, apenas as substâncias equivalentes aos picos 3 e 4 foram isoladas e analisadas por espectrometria de massas acuradas em modo EM/EM no CLUE-EM-QTOF $\left(\mathrm{ESI}^{+}\right)$.

A análise das substâncias no DAD (UV-Vis máx) mostrou duas bandas de absorção na região UV-Vismáx (em torno 280 e $520 \mathrm{~nm}$ ) típico de antocianinas (Figura 35). Os dados do DAD (UV-Vis máx) mostraram absorção no visível com $\lambda_{\text {máx }}$ compatíveis de derivados de delfinidina, petunidina ou malvidina em solução de metanol acidificado (HONG e WROLSTAD, 1990). 

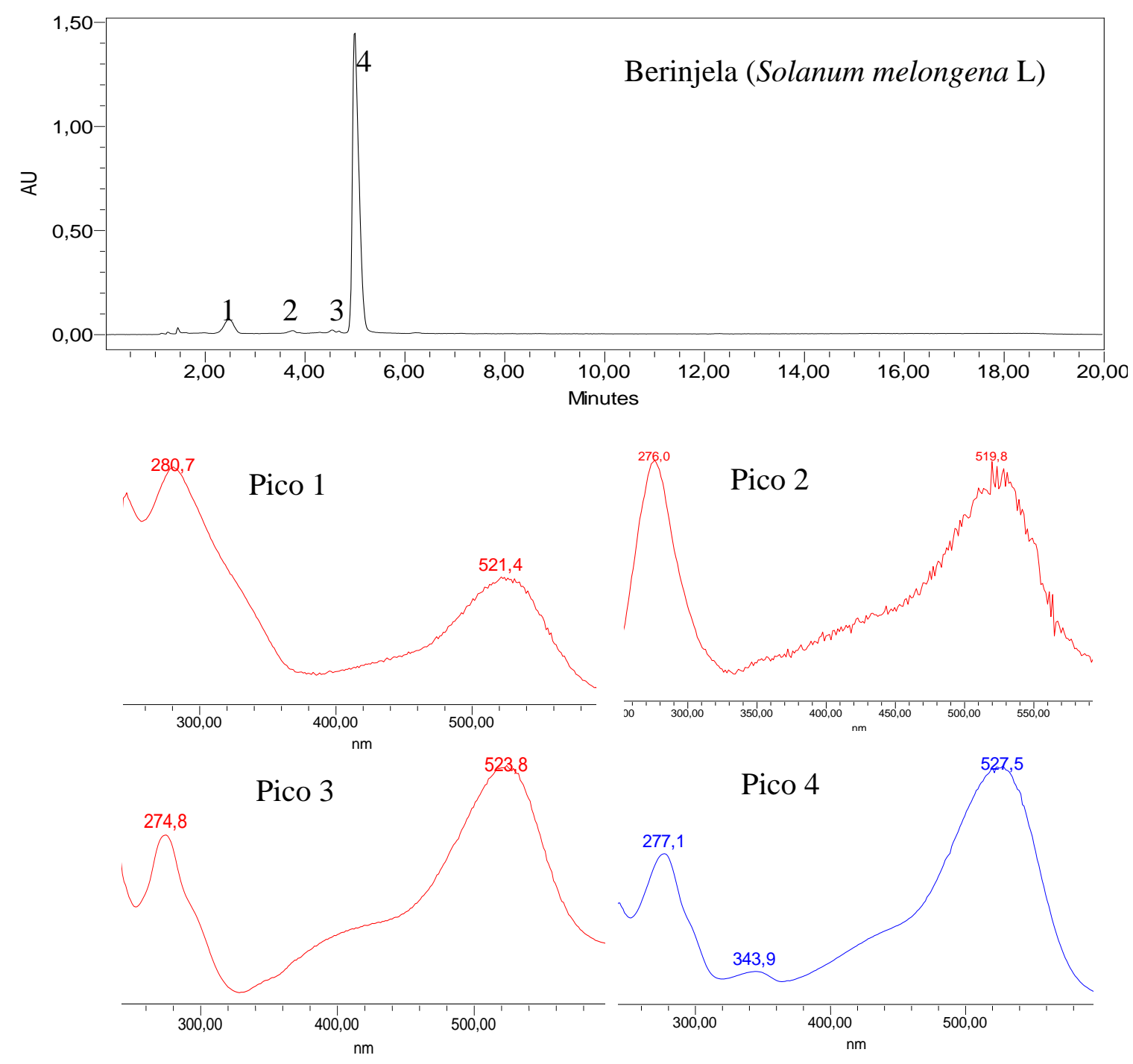

Figura 35: Cromatograma do extrato do pó da casca da berinjela extraído utilizando metodologia II a $520 \mathrm{~nm}$ e espectros de absorção dos quatro picos no UV-Vis máx.

$\mathrm{Na}$ análise da substância do pico 3 os espectros de absorção UV- Vis máx mostraram duas bandas de absorção na região com $\lambda_{\text {máx }} 274,8$ e $522,8 \mathrm{~nm}$. Os dados obtidos no modo $\mathrm{EM} / \mathrm{EM}$, extraído no CLUE-EM-QTOF (ESI ${ }^{+}$, mostrou a presença para a substância 3 do íon molecular a $m / z$ 465,1116 e fragmento a $m / z, 303,0526$ após a perda de uma hexose ([M-162 Da $]^{+}$). Para a substância 4, no espectro de UV-Vis máx foram observadas as bandas $\lambda_{\text {máx }} 277,1$ e $527,5 \mathrm{~nm}$ e nos dados gerados por EM/EM o íon molecular a $\mathrm{m} / \mathrm{z}$ a 611,1583 e dois fragmentos, um a $\mathrm{m} / \mathrm{z}$ 465,1192 após a perda de uma desóxi-hexose $\left([\mathrm{M}-146 \mathrm{Da}]^{+}\right)$e outro a $m / z, 303,0522$ relativos a perda de hexose+desóxi-hexose $\left([\mathrm{M}-308 \mathrm{Da}]^{+}\right)$. 
As bandas de absorção observadas no DAD ( $\lambda_{\text {máx }} 274,8$ e 522,8 nm e $\lambda_{\text {máx }} 277,1$ e 527,5 $\mathrm{nm}$ ) e a presença do íon a $\mathrm{m} / \mathrm{z} 303$ indica que as substâncias 3 e 4 são antocianinas cuja aglicona é a delfinidina. A substância 3 apresentou apenas um fragmento após a perda de 162 Da, indicando que essa antocianina possuía uma hexose como substituinte. A substância 4 apresentou o perfil no espectro de massa acurada em modo EM/EM o íon molecular a $\mathrm{m} / \mathrm{z}$ 611,1583 e dois fragmentos a $\mathrm{m} / \mathrm{z}, 465,1192$ e 303,0522 . O primeiro fragmento $(\mathrm{m} / \mathrm{z}, 465,1192)$ corresponde a aglicona ligada a uma molécula de hexose após a perda de uma desóxi-hexose (146 Da) e, o fragmento a $\mathrm{m} / z$ 303,0522 que corresponde a aglicona delfinidina, quando há perda total da rutinose (308 Da) (Figura 36).

MSMS

Espectro Pico 3 100

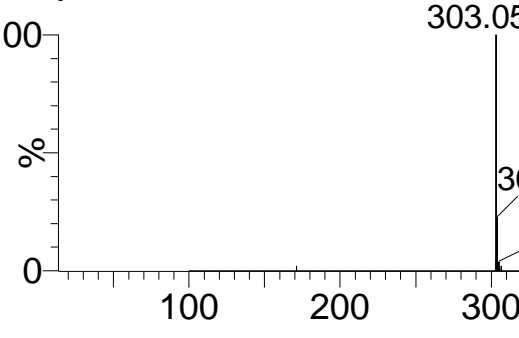

$162 \mathrm{Da}$

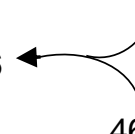

465.1116

304.0639

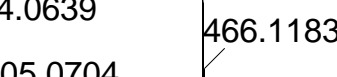

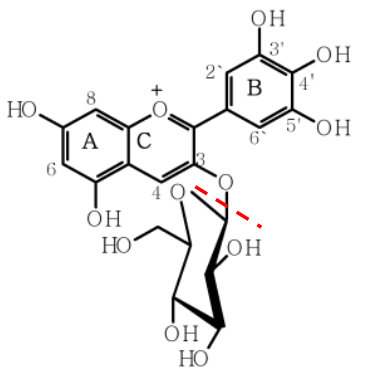

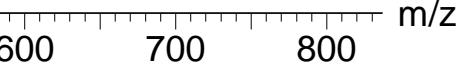

Espectro Pico 4

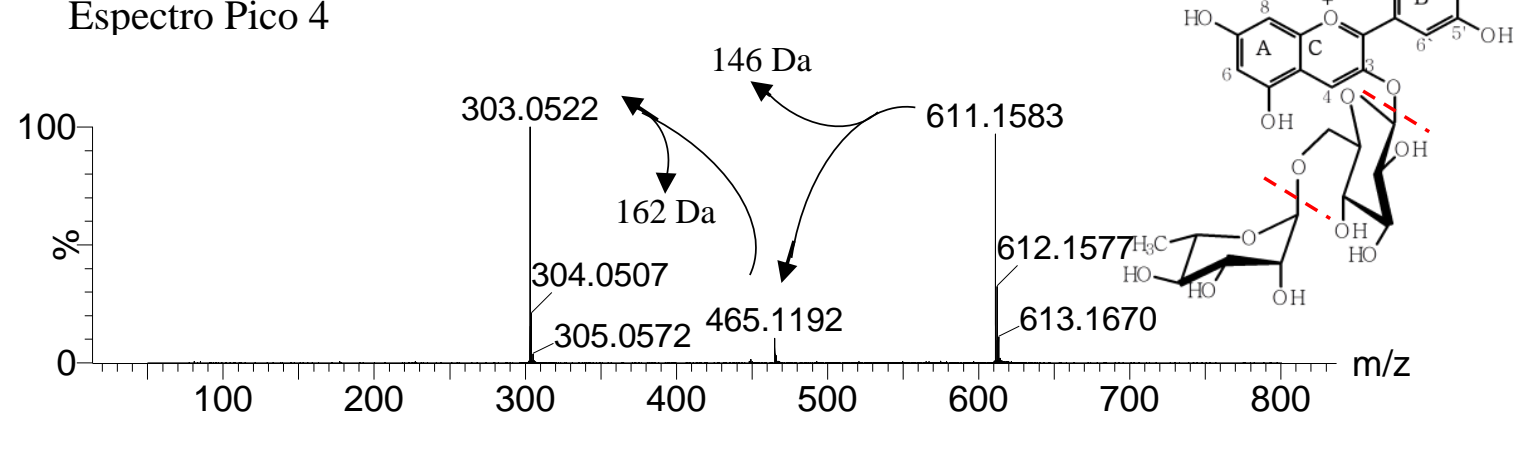

Figura 36: Espectros de massa acurada em modo EM/EM extraídos do CLUE-QTOF/EM (ESI ${ }^{+}$) das substâncias equivalentes aos picos 3 e 4 do extrato da casca da berinjela liofilizada.

O pigmento antociânico da berinjela tem sido identificado como derivado de delfinidinas (Sakamura, Watanabe, e Obata, 1963; Wu e Prior, 2005a). Existem muitas variedades de berinjela, a fonte e variedade exerce grande influência sobre a glicosilação e acilação das antocianinas. As berinjelas procedentes dos EUA foram investigadas por $\mathrm{Wu}$ e Prior (2005) e identificadas como: delfinidina-3- $O$-rutinose-5- $O$-galactosídeo; delfinidina-3- $O$ rutinose-5-O-glicosídeo (Figura 37-B); delfinidina-3-O-glicosideo e a majoritária dentre elas como delfinidina-3- $O$ - rutinosideo. No entanto, em estudo da berinjela encontrada no Japão foi identificada como majoritária a antocianina delfinidina-3-( $p$-coumarilrutinoside)-5- $O$ glicosídeo, nasunin (Figura 37-A) (Sakamura, Watanabe, e Obata, 1963,). Variedades chinesas, também conhecidas por berinjelas japonesas, geralmente em forma de um pepino estreito, apresentam como antocianina majoritária a delfinidina-3-[(4"-p-coumaroil)ramnosil $(1 \rightarrow 6)$ glicosídeo]-5-O-glicosídeo (nasunin) (Figura 37- A) (JING et al.,2015). 

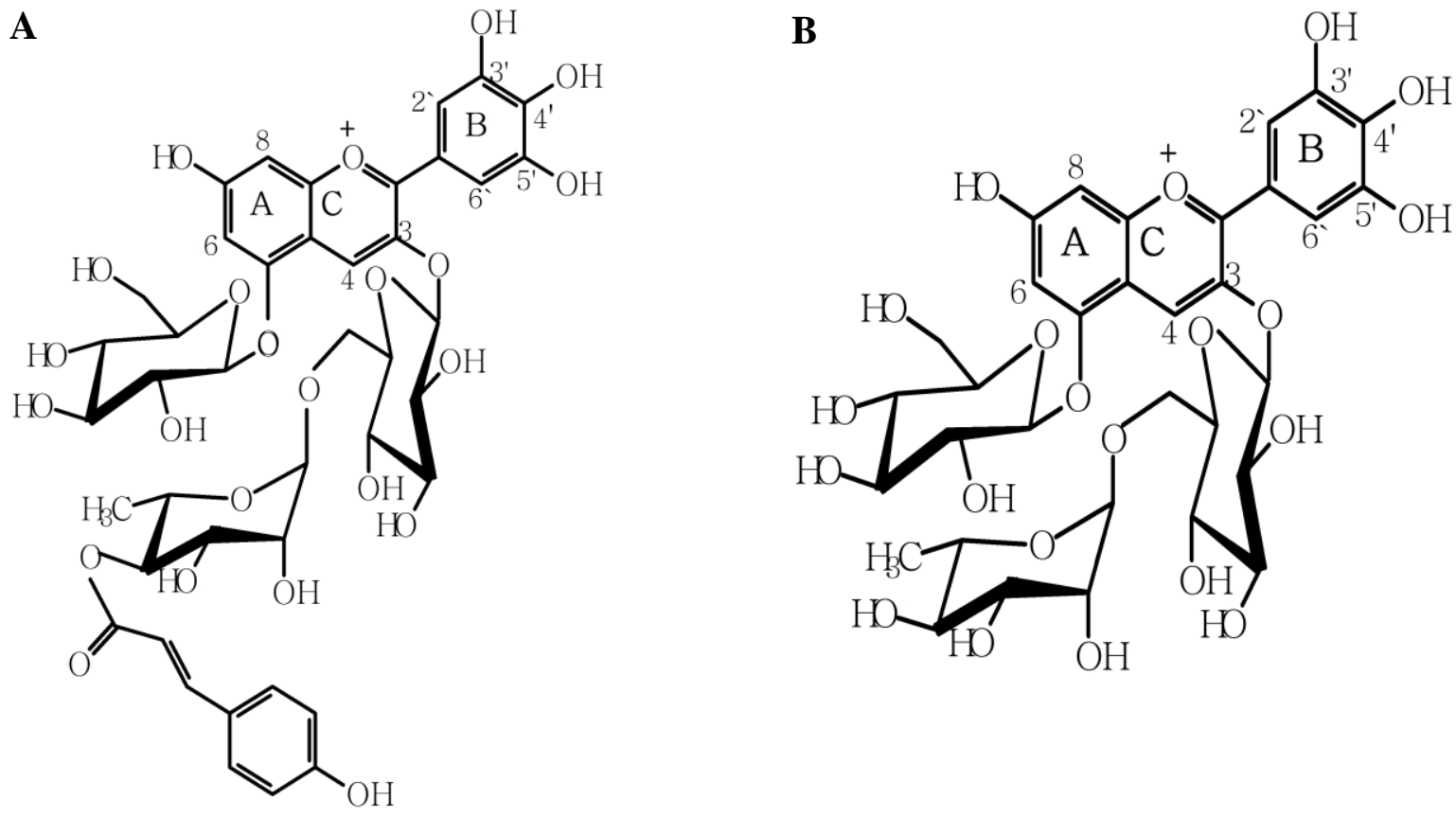

Figura 37: Estrutura das antocianinas encontradas na berinjela: A) delfinidina-3-( $p$-coumarilrutinoside)-5glicosídeo (nausinin) B) delfinidina-3-O-rutinose-5-Glicosídeo.

Dados da literatura relataram, somente, a existência de derivados de delfinidinas identificadas nas variedades de berinjela analisadas (JING et al., 2014). Somando-se esse fato aos dados observados no DAD por esse estudo, sugere-se que todas as antocianinas observadas por este estudo sejam derivados de delfinidina.

Foi observado grande similaridade entre o perfil cromatográfico obtido neste estudo com o perfil cromatográfico do extrato da casca da berinjela apresentado por WU e PRIOR (2005b). Essa comparação possibilitou identificar o pico 3 como a antocianina delfinidina-3$O$-glicosídeo, e o pico 4 como delfinidina-3-O-rutenosídeo. Para a identificação do pico 1 e 2 serão necessárias investigações futuras, sugere-se no momento apenas relatar como derivados de delfinidina. Vale a pena salientar que a antocianina majoritária presente na matriz de berinjela estudada (delfinidina-3-O-rutenosídeo) apresentou pureza superior a $93 \%$ a $520 \mathrm{~nm}$ (Tabela 16).

Tabela 15: Antocianinas observadas no cromatograma do pó da casca da berinjela (Figura 35).

\begin{tabular}{ccccc}
\hline Pico & Nome & $\mathbf{t}_{\boldsymbol{R}}$ & Área & \% Área \\
\hline 1 & Derivado de Delfinidina & 2,473 & 753048 & 5,44 \\
2 & Derivado de Delfinidina & 3,749 & 75089 & 0,54 \\
3 & Delfinidina-3- $O$-glicosídeo & 4,542 & 62405 & 0,45 \\
4 & Delfinidina-3- $O$-rutenosídeo & 4,996 & 12946599 & 93,57 \\
\hline
\end{tabular}




\section{Jabuticaba (Plinia trunciflora ou Myciaria trunciflora)}

O cromatograma gerado da análise por CLAE/DAD do extrato da casca da jabuticaba liofilizada ( $P$. trunciflora) apresentou 11 picos no seu perfil cromatográfico a $520 \mathrm{~nm}$ (Figura 38). Mas somente os mais concentrados, as substâncias dos picos 2 e 4, foram extraídas e analisadas por este estudo através dos seus espectros de absorção observados no DAD (UVVis max $_{\text {) }}$ e, espectros obtidos no espectrômetro de massa acurada, em modo, EM/EM.

$\mathrm{Na}$ análise da substância 2 o espectro de absorção UV- Vis máx mostrou duas bandas de absorção na região com $\lambda_{\text {máx }} 275,6$ e 526,2 nm. Os dados obtidos no espectrômetro de massas acuradas, CLUE-EM QTOF (ESI $\left.{ }^{+}\right)$, em modo EM/EM, mostrou a presença do íon molecular a $\mathrm{m} / \mathrm{z}$ a 465,1116 e fragmento a $\mathrm{m} / \mathrm{z}$ 303,0590 após a perda de uma hexose ([M-162 Da $\left.]^{+}\right)$. Para a substância 4, no espectro de absorção UV- Vis máx foi observado as bandas $\lambda_{\text {máx }} 279,5$ e 516,5 nm e, nos dados gerados no espectrômetro de massa acurada em modo EM/EM, o íon molecular a $\mathrm{m} / \mathrm{z}$ a 449,1083 e fragmento a $\mathrm{m} / \mathrm{z} 287,0556$ após a perda de uma hexose $\left([\mathrm{M}-162 \mathrm{Da}]^{+}\right)$ (Figura 39).

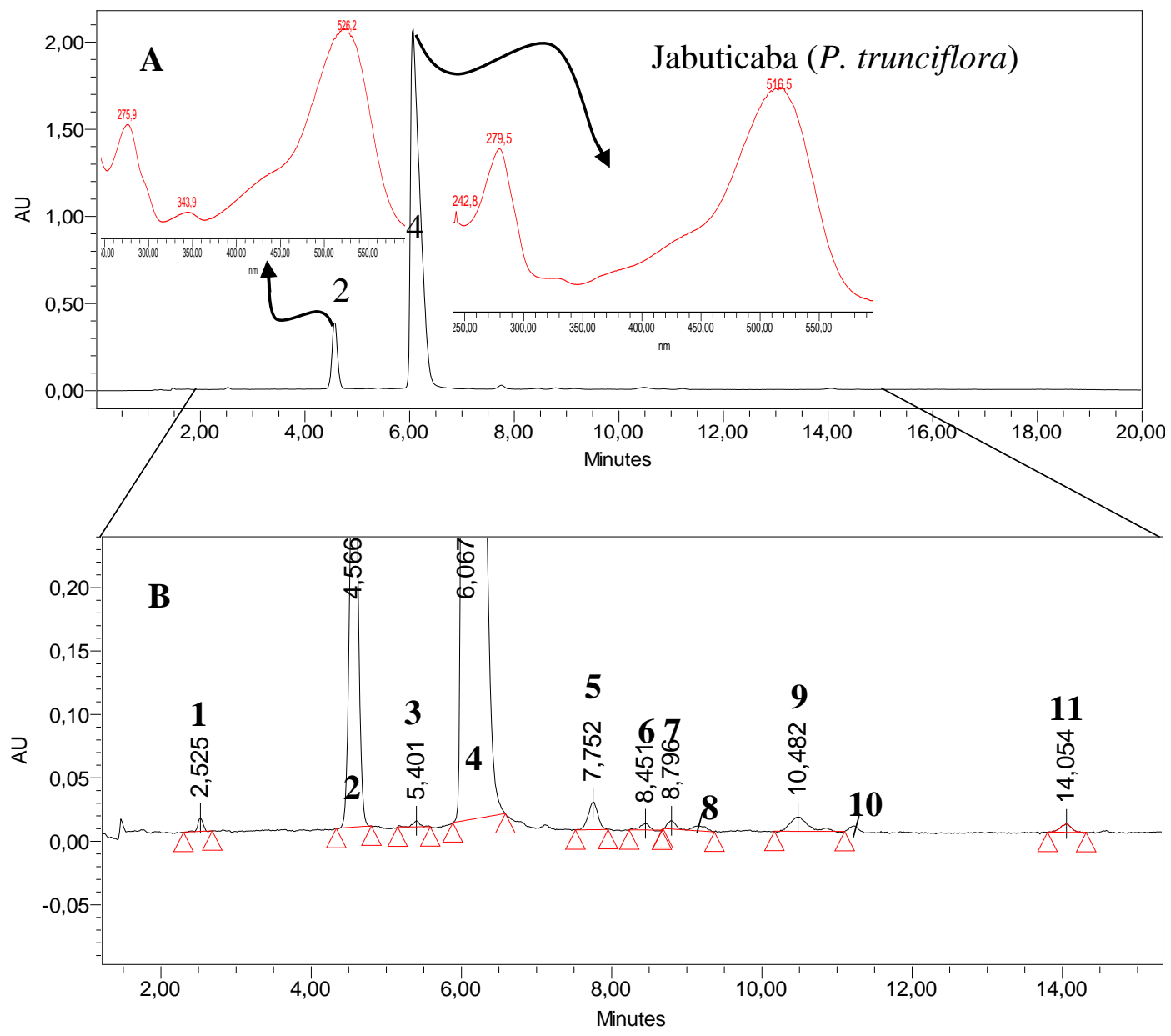

Figura 38: A) Cromatograma do extrato da casca da jabuticaba liofilizada ( $P$. trunciflora) extraído utilizando metodologia II a $520 \mathrm{~nm}$ e, espectros de absorção dos picos 2 e 3 no UV- Vis máx. B) Projeção do cromatograma A no intervalo de 2-14 minutos. 


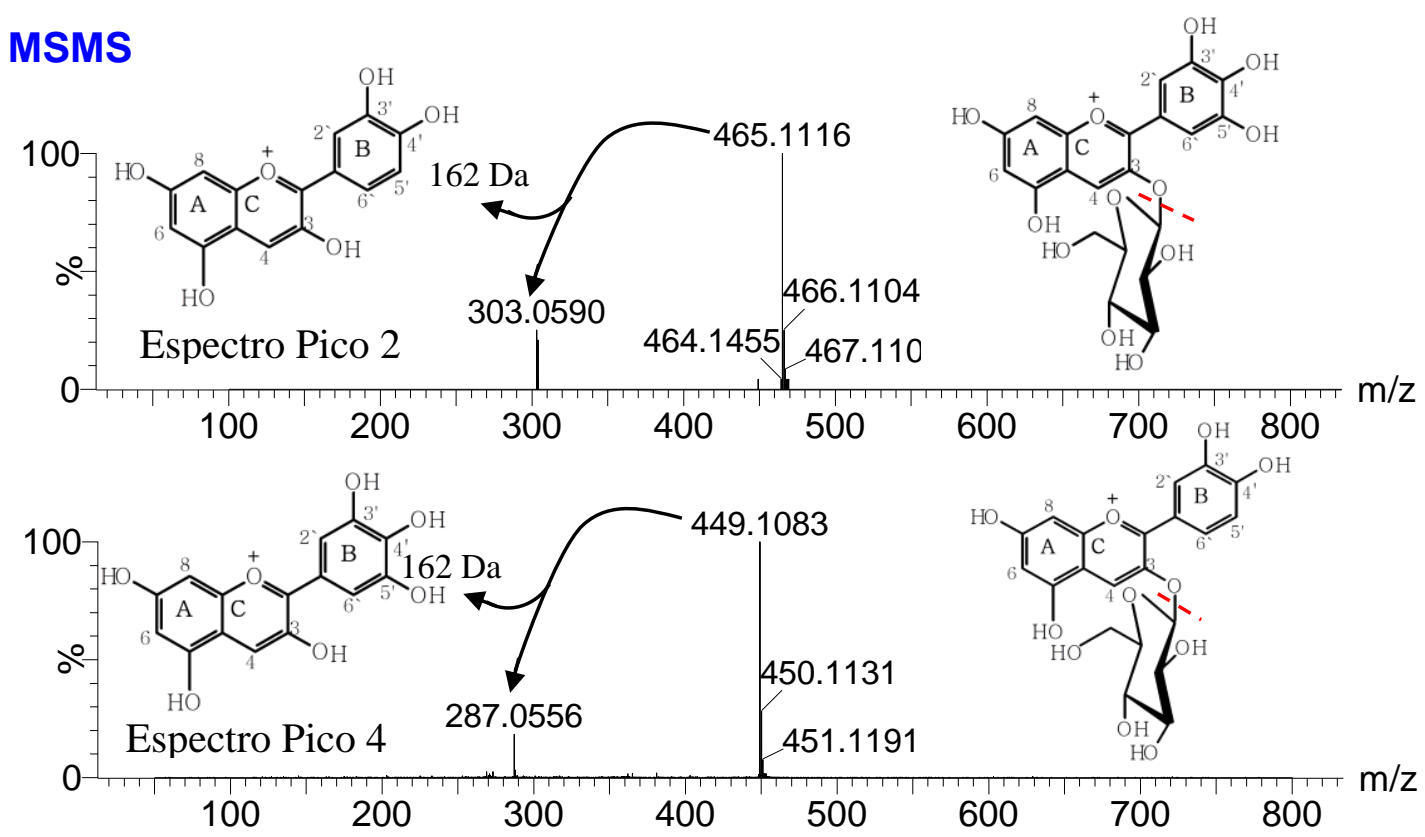

Figura 39: Espectros de massa acurada em modo EM/EM extraídos do CLUE-EM QTOF (ESI ${ }^{+}$) das substâncias equivalentes aos picos 2 e 4 do extrato da casca a da jabuticaba liofilizada (P. trunciflora).

As bandas de absorção observadas no DAD ( $\lambda_{\text {máx }} 275,6$ e 526,2 nm) e a presença do íon a $\mathrm{m} / z$ 303,0590 indica que a substância 2 é uma antocianina cuja aglicona é a delfinidina. A substância 2 apresentou apenas um fragmento após a perda de $162 \mathrm{Da}$, indicando que essa antocianina possuía uma hexose como substituinte. A substância 4 apresentou bandas $\left(\lambda_{\text {máx }}\right.$ 279,5 e 516,5 nm) e a presença do íon a $\mathrm{m} / z$ 287,0556 indica que essa substância é uma antocianina cuja aglicona é a cianidina. A observação de apenas um fragmento após a perda de $162 \mathrm{Da}$, indica que essa antocianina possuía uma hexose como substituinte. Sendo assim, os valores encontrados correspondem à delfinidina-3- $O$-glicosídeo e cianidina-3- $O$-glicosídeo, respectivamente. As antocianinas delfinidina-3- $O$-glicosídeo e cianidina-3-O-glicosídeo foram definitivamente identificadas quando foi realizada a comparação dos $t_{R}$ das substâncias na matriz estudada (jabuticaba) com os $t_{R}$ dos padrões de delfinidina-3- $O$-glicosídeo e cianidina3-O-glicosídeo, isolados (segundo item 3.7, pág.39) do extrato da casca de berinjela (pico 3) e do extrato do fruto do açaí (pico 2), respectivamente.

Maçã (Fuji)

A casca de maçã, variedade Fuji, foi escolhida com o propósito de se obter uma matriz que fornecesse a antocianina cianidina-3- $O$-galactosídeo. Wu e Prior (2005a) relataram a presença de apenas duas antocianinas nessa variedade, a cianidina 3-galactosídeo e cianidina3-O-arabinosídeo, sendo majoritária a cianidina-3- $O$-galactosídeo. No entanto, a análise realizada pelo presente estudo no extrato da casca da maçã por CLAE/DAD, revelou a presença de mais 7 picos absorvendo na região de $520 \mathrm{~nm}$ (Figura 40). 
Para esse estudo, apenas a substância relativa ao pico 3 (majoritário) foi extraída e seus espectros de absorção UV-Vis máx e de massa acurada em modo EM/EM avaliados. As outras substâncias serão futuramente investigadas.

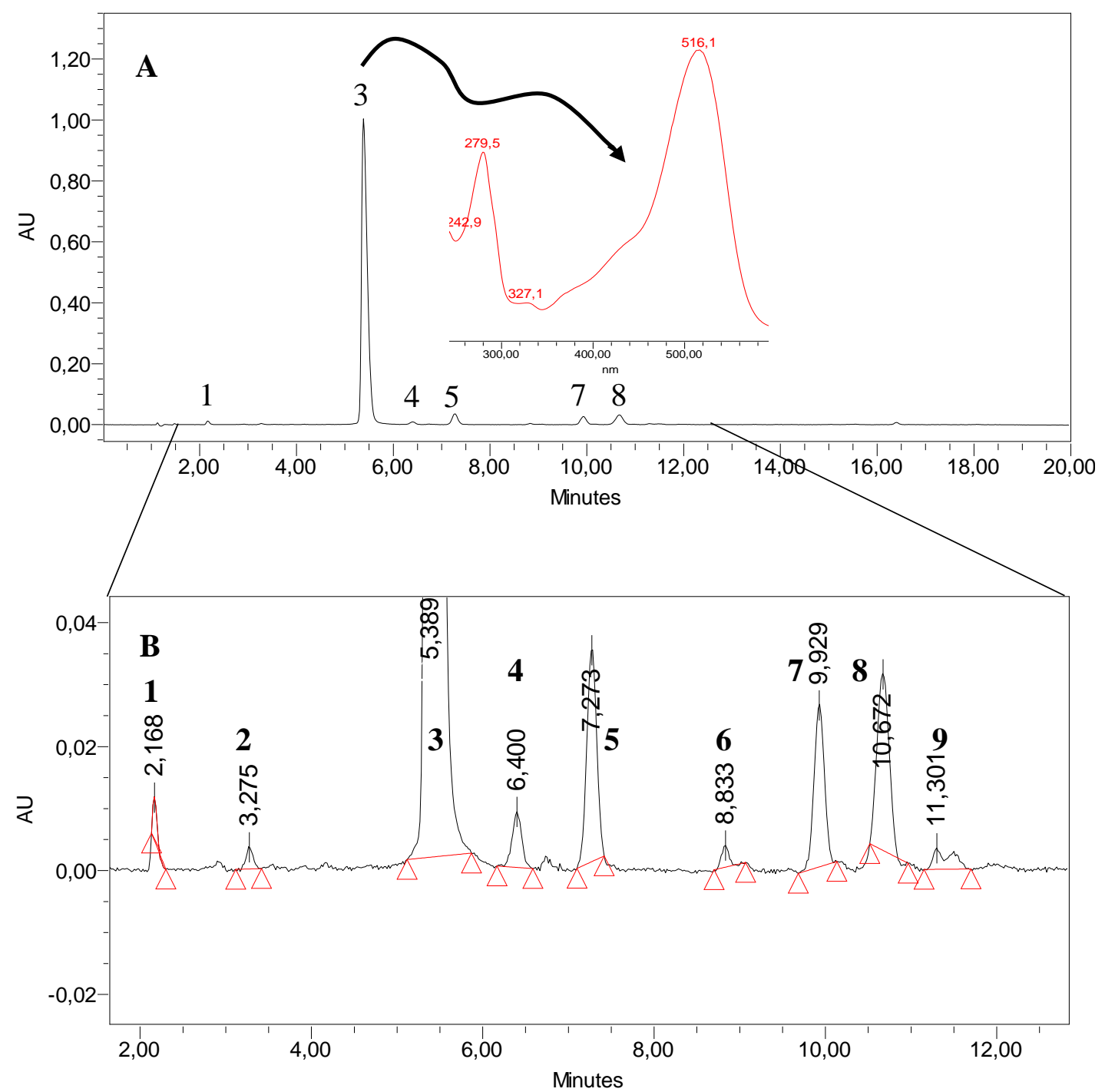

Figura 40: A) Cromatograma do extrato casca da maçã liofilizada (variedade Fuji) extraído utilizando

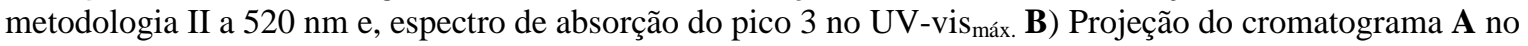
intervalo de 2-12 minutos.

$\mathrm{Na}$ análise da substância 3 o espectro de UV-Vismáx mostrou duas bandas de absorção na região com $\lambda_{\text {máx }} 279,5$ e $516,1 \mathrm{~nm}$. Os dados obtidos em EM/EM mostrou a presença do íon molecular a $\mathrm{m} / \mathrm{z}$ a 449,1595 e fragmento $\mathrm{m} / \mathrm{z}$ 287,0885 após a perda de uma hexose ([M-162 $\mathrm{Da}]^{+}$) (Figura 41).

As bandas de absorção com $\lambda_{\text {máx }} 279,5$ e $516,1 \mathrm{~nm}$ e a presença do íon a $\mathrm{m} / z 287$ indicam que a substância 3 é uma antocianina cuja aglicona é a cianidina. A perda de $162 \mathrm{Da}$, indica que essa antocianina perdeu apenas uma hexose. 


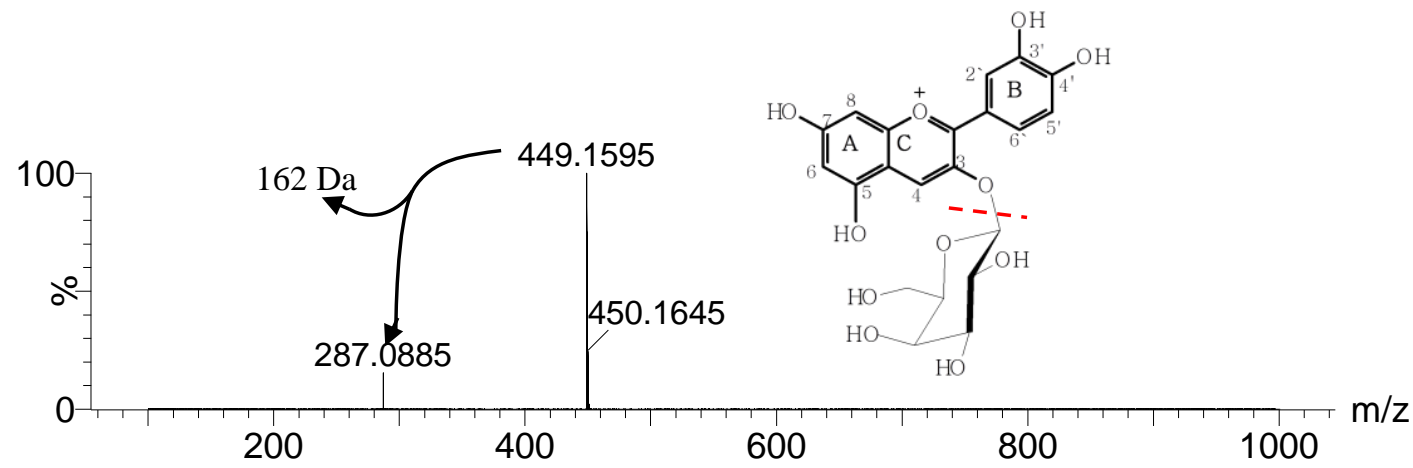

Figura 41: Espectros de massa acurada, em modo EM/EM extraídos do CLUE-EM QTOF (ESI ${ }^{+}$), da substância 2 do extrato do pó da casca liofilizada da maçã (Fuji).

Como a cianidina glicosilada e galactosilada possuem o mesmo íon molecular (449), fragmento (287) e bandas dos espectros de absorção na região do UV-Vis máx similares. Não é possível com apenas esses dados diferenciar a natureza do açúcar que estará ligado à molécula de antocianindina.

A diferença no $t_{R}$ está diretamente relacionada a hidrofobicidade conferida à molécula, influenciada pela natureza do açúcar. Portanto, $\mathrm{o} t_{\mathrm{R}}$ foi uma das ferramentas utilizadas para complementar a identificação da presença da cianidina ligada ao açúcar "galactose". De acordo com dados literários, a antocianina que possui como substituinte a galactose possui $t_{R}$ inferior à que possui como substituinte a glicose. Foi utilizada para a identificação do açúcar como galactose, a comparação do seu tempo de retenção ( $t_{R}$ maçã) com o tempo de retenção ( $t_{R}$ padrão do padrão cianidina-3-O-glicosídeo (Figura 42) isolado (segundo o item 3.7), da matriz do açaí, Euterpe oleracea Mart. (GOUVÊA et al., 2012).

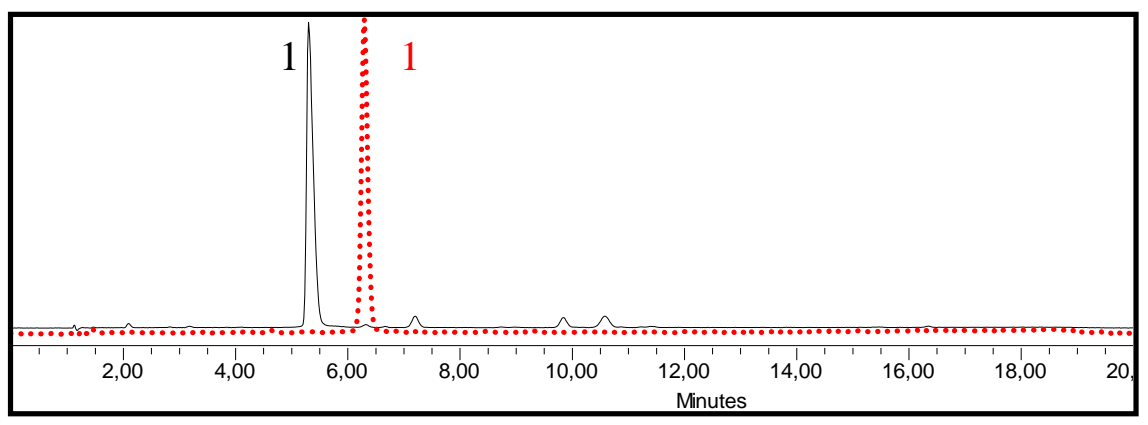

Figura 42: Sobreposição e comparação dos cromatogramas do extrato da casca da maçã (preto) e padrão de cianidina-3-O-glicosídeo (vermelho) isolado da matriz Euterpe oleracea Mart. (açaí).

Sendo assim, como a cianidina-3-O-glicosídeo eluí em t $t_{\mathrm{R}}$ superior ao da cianidina-3-Ogalactosídeo foi possível por exclusão identificar a presença da cianidina-3- $O$-galactosídeo no pico 3 do extrato de casca de maçã. Este fato pode ser observado em relatos literários em frutos como: cranberry, blueberry (mirtilo), ameixa-preta (Black Plum) e ameixa vermelha (Plum), matrizes que apresentam as duas antocianinas (cianidina-3- $O$-galactosídeo e cianidina-3-O glicosídeo) no seu perfil antociânico (WU e PRIOR, 2005a). Em relação a percentagem desta antocianina na matriz, observou-se $89,6 \%$ de teor a $520 \mathrm{~nm}$ (DAD). 


\section{Maçã (Gala, Argentina e Red Delicius)}

Outras três variedades de maçã foram estudadas (Figura 43), além do cultivar Fuji. Os cromatogramas gerados por CLAE/DAD, apresentaram: cinco picos para a variedade Gala e seis picos para as variedades Red Delicius e Argentina.

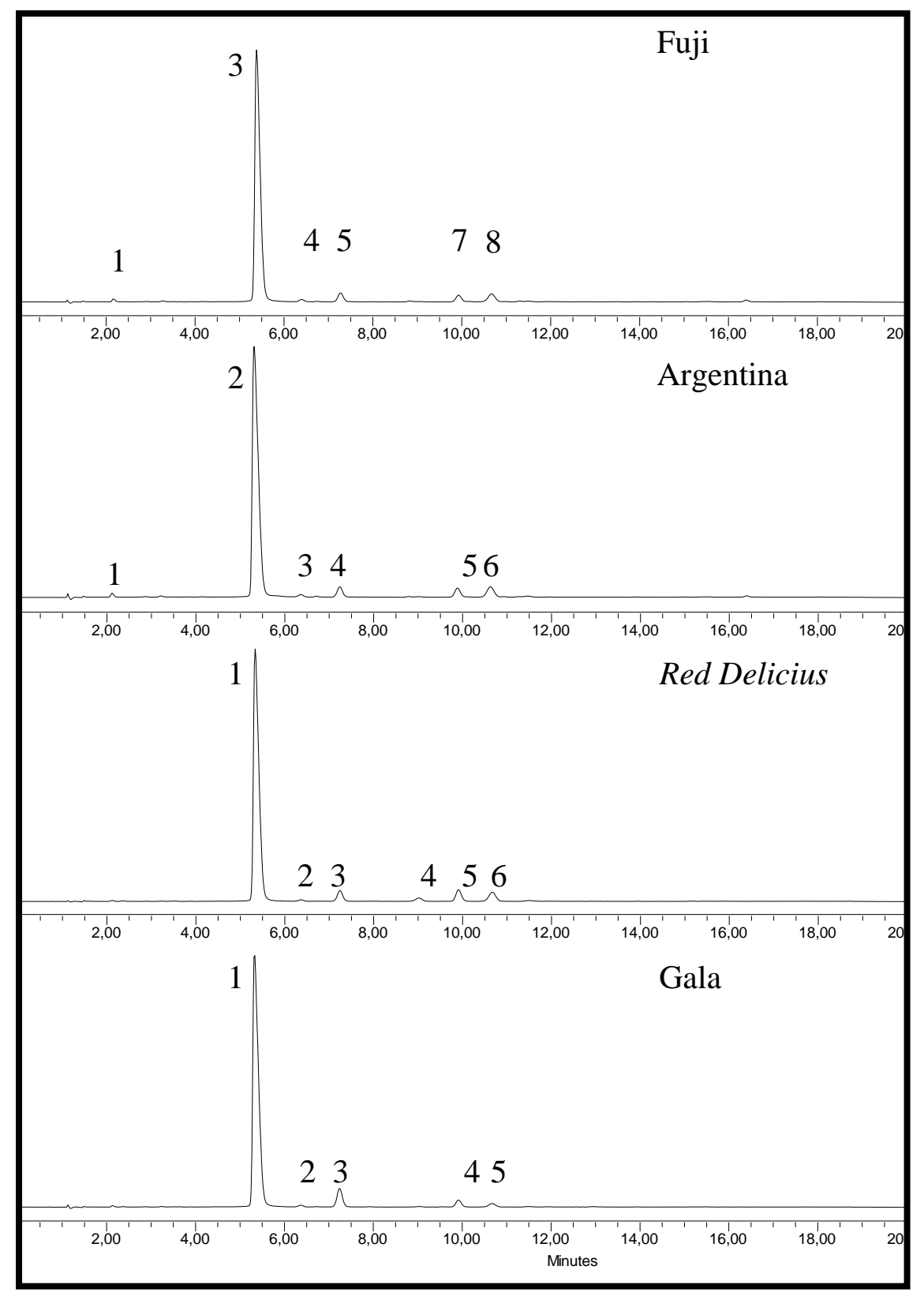

Figura 43: Cromatogramas obtidos do extrato da casca de quatro cultivares de maçã, onde o pico 1, majoritário, e a cianidina-3-O-galactosídeo. 
A confirmação da presença da cianidina-3-O-galactosídeo nestas matrizes, foi realizada através da sobreposição dos cromatogramas gerados nas mesmas condições de análise (Figura 44). A título de exemplificação pode-se observar o APÊNDICE A.

Cinco antocianinas presentes, nos quatros cultivares de maçãs, eluiram apresentando o mesmo $t_{R}$. Estes resultados estão coerentes com os dados apresentados por Wu e Prior (2005a). Houve apenas divergência em relação à quantidade de picos por eles observados nas cultivares Fuji e Gala. Outros parâmetros também podem influenciar na produção de antocianinas na epiderme do fruto. Brackmann, Steffens e Giehl (2004) citam o trabalho de Wang e Dilley (2001), onde os autores relacionam uma diminuição significativa da produção de antocianinas, com consequente redução da coloração vermelha do fruto à aplicação de aminoetoxiviniliglina (promotor inibidor de etileno). Estes autores ainda sugeriram que o aminoetoxivinilglicina, pela inibição da síntese de etileno, pode suprimir a expressão dos genes relacionados à biossíntese de antocianinas.

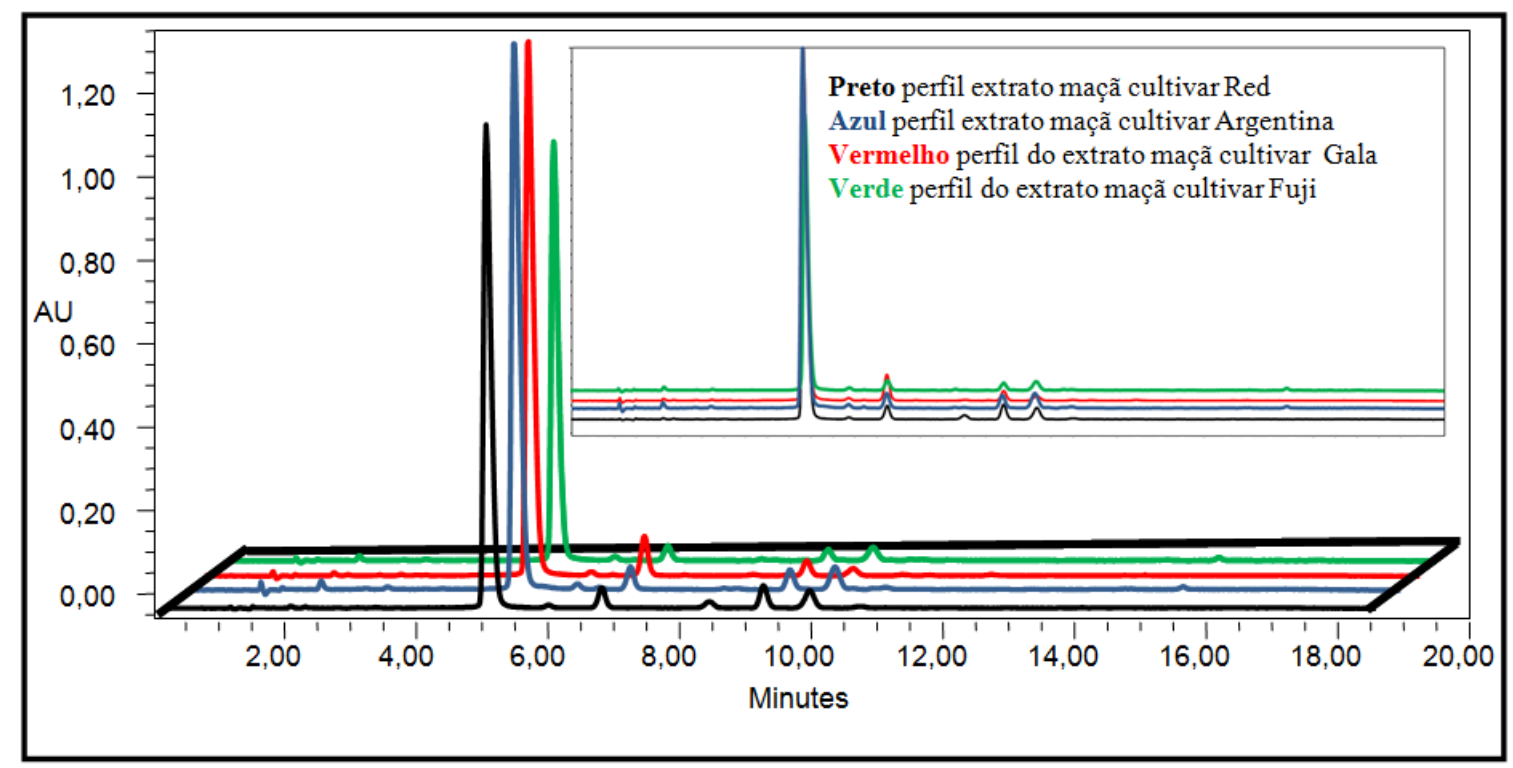

Figura 44: Sobreposição dos cromatogramas do extrato de quatro cv. de maçã (Red Delicius, Argentina, Gala e Fuji).

\section{Jamelão (Syzygium cuminii)}

O cromatograma gerado da análise realizada por CLAE/DAD no extrato do pó liofilizado da casca dos frutos do jamelão, apresentou seis picos com duas bandas de absorção na região do UV-Vis máx a 520nm (Figura 45). Os seis picos foram isolados (segundo o item 3.7, pág.39), e seus espectros de absorção UV-Vis máx e de massa acurada em modo EM/EM no CLUE-EM-QTOF $\left(\mathrm{ESI}^{+}\right)$foram avaliados.

A análise das substâncias equivalentes aos 6 picos mostrou no espectro de UV-Vis máx duas bandas de absorção a $520 \mathrm{~nm}$ (Figura 46). Os dados obtidos em EM/EM mostraram que nas substâncias 1, 2, 4, 5 e 6 apresentam íon molecular a $\mathrm{m} / \mathrm{z}$ a 627,2425, 611,1835, 641,3052, 625,1740 e 655,3374, respectivamente. Estas substâncias também apresentaram dois fragmentos, derivados de duas perdas consecutivas de $162 \mathrm{Da}$, em vez de apenas um fragmento decorrente da perda de 324 Da. Esse padrão de comportamento indica que há nessas 
antocianinas a presença de duas hexoses ligadas em posições diferentes $\left(\mathrm{C}_{3}\right.$ e $\mathrm{C}_{5}$, provavelmente), possibilitando assim o acesso para que ocorresse a quebra da ligação e a liberação do açúcar, quando aplicado a energia de colisão. Para a substância 3 a análise em EM/EM (CLUE-EM QTOF (ESI ${ }^{+}$) apresentou a presença do íon a $\mathrm{m} / \mathrm{z}$ 465,2780 e um fragmento a $m / z$ 303,1943 após a perda de uma hexose $\left([\mathrm{M}-162 \mathrm{Da}]^{+}\right)($Figura 47 e 48$)$.

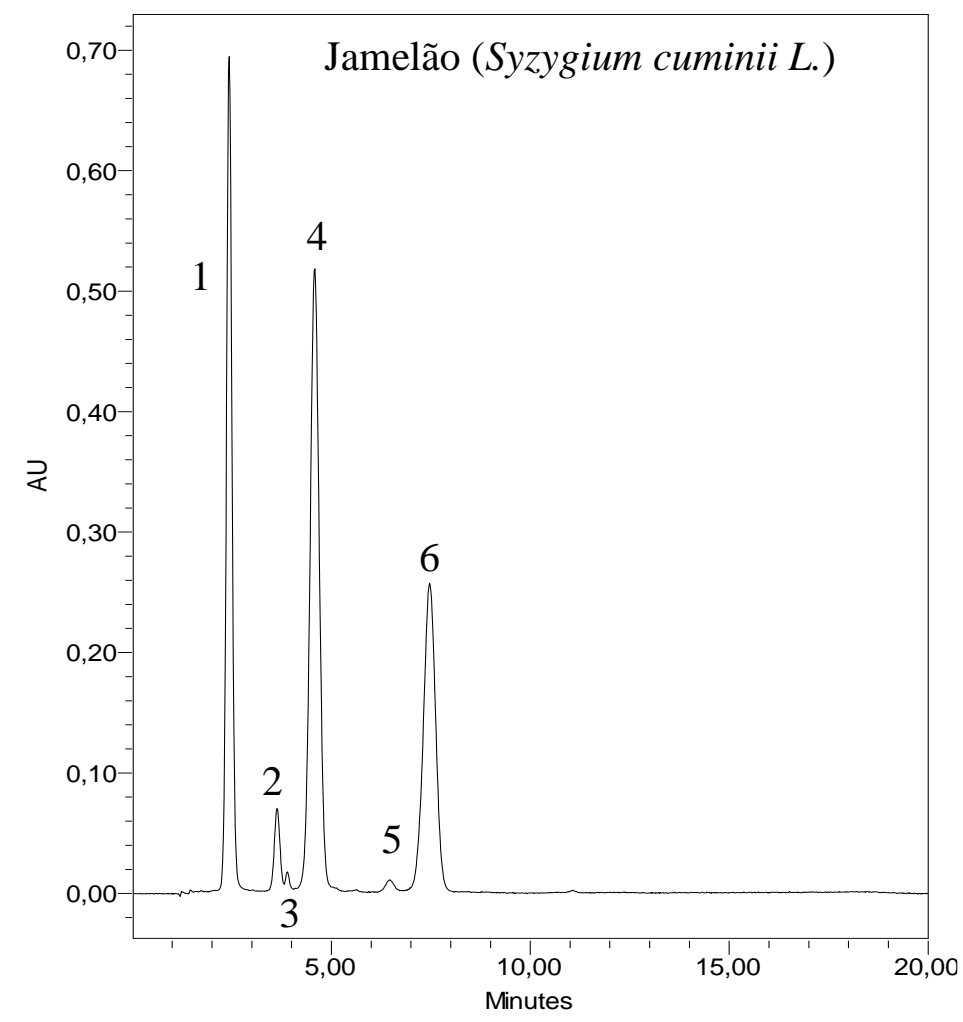

Figura 45: Cromatograma gerado da análise realizada por CLAE/DAD no extrato da casca dos frutos do jamelão (Syzygium cuminii), apresentou seis picos com duas bandas de absorção na região do UV-Vis máx a $520 \mathrm{~nm}$.

A substância 1 e 3 apresentaram as bandas de absorção ( $\lambda_{\text {máx }} 274,8$ e 520,1; 274,8 e $523,8 \mathrm{~nm}$ ) e presença do íon a $\mathrm{m} / z, 303,0927$ e 303,1943, indicando que a antocianidina era uma delfinidina em ambas antocianinas. A substância 2 apresentou as bandas de absorção características $\left(\lambda_{\operatorname{máx}} 277,1\right.$ e $\left.515,3 \mathrm{~nm}\right)$ e presença do íon a $\mathrm{m} / z$ 287,0698, indica que a antocianidina era uma cianidina. A substância 4 apresentou as bandas de absorção $\left(\lambda_{\text {máx }} 274,8\right.$ e 525,0) e presença do íon a $\mathrm{m} / \mathrm{z}, 317,1372$, indicando que a antocianidina era uma petunidina. A substância 5 apresentou bandas de absorção $\left(\lambda_{\text {máx }} 275,9\right.$ e $\left.514,1 \mathrm{~nm}\right)$ e presença do íon a $\mathrm{m} / \mathrm{z}$ 301,0728 indicando que a antocianidina era uma peonidina. E finalmente, a substância 6 apresentou bandas de absorção $\left(\lambda_{\text {máx }} 274,8\right.$ e $523,8 \mathrm{~nm}$ ) e presença do íon a $\mathrm{m} / \mathrm{z} 331,1596$, indicando que a antocianidina era uma delfinidina.

Sendo assim essas substâncias foram caracterizadas como: pico (1) delfinidina-3,5-di$O$-glicosídeo; pico (2) cianidina-3,5-di- $O$-glicosídeo; pico (4) petunidina-3,5-di- $O$-glicosídeo; pico (5) peonidina-3,5-di- $O$-glicosídeo; pico (6) malvidina-3,5-di- $O$-glicosídeo (Figura 45). Estes resultados estão coerentes com aqueles relatados em estudos anteriores com frutos do jamelão (Syzygium cuminii) (BRITO et al., 2007). Após revisão bibliográfica verificou-se que a antocianina delfinidina-3-O-glicosídeo, pico 3 , foi observada no perfil cromatográfico do 
jamelão pela primeira vez no presente trabalho. A título de exemplificação pode-se observar o APÊNDICE B.
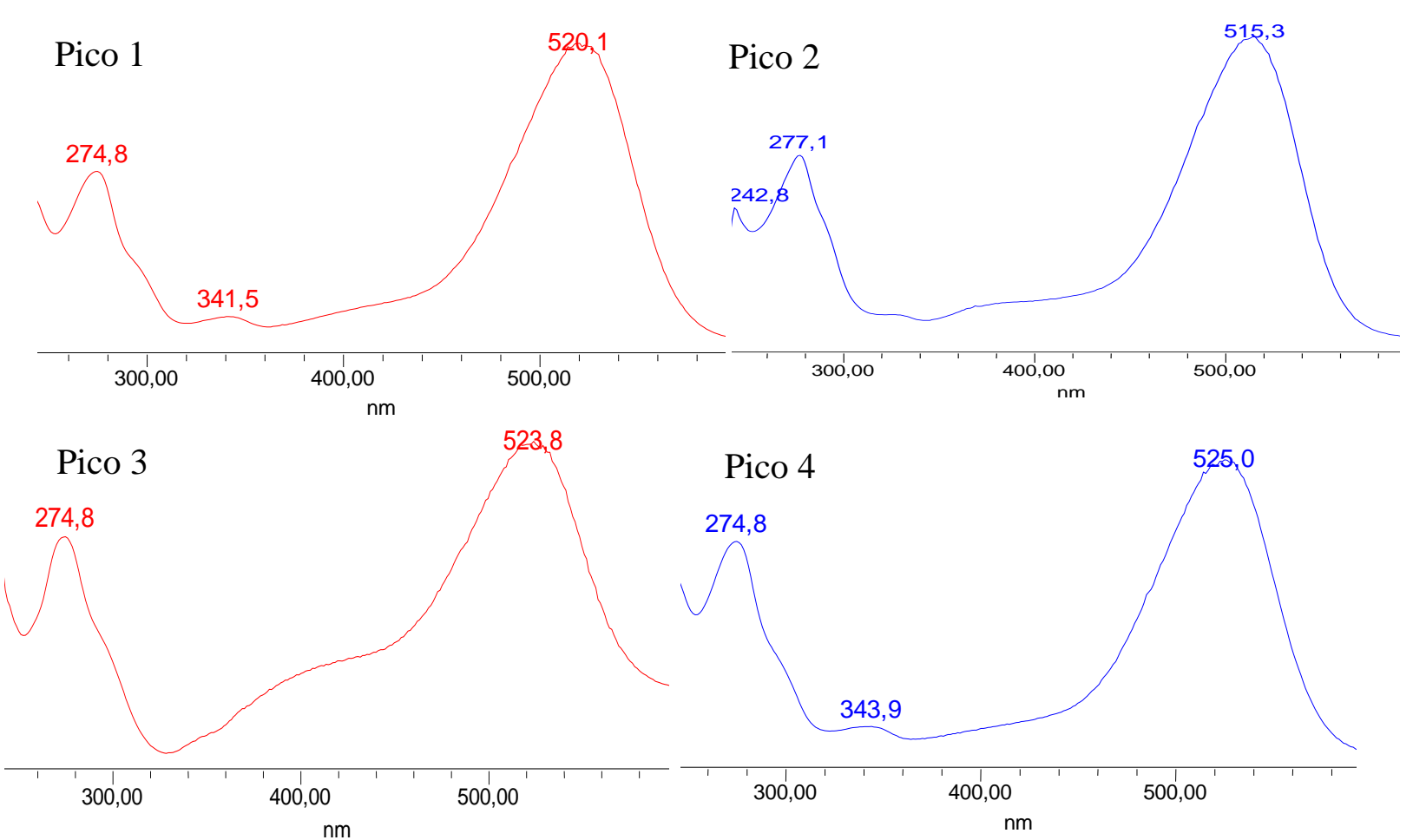

Pico 5

Pico 6

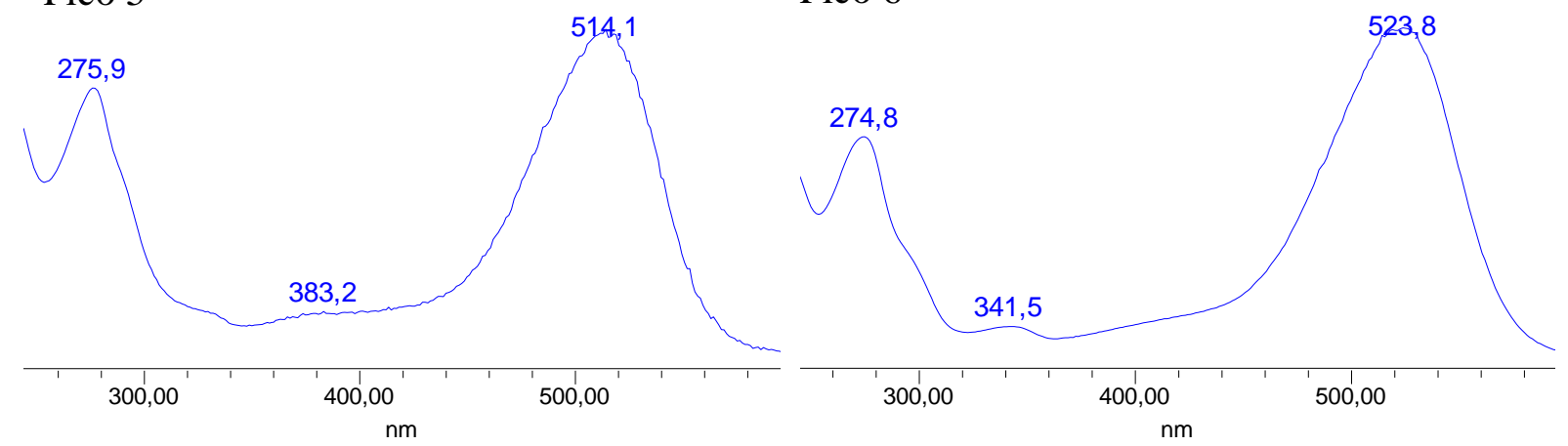

Figura 46: Espectros de absorção UV-Vis máx obtidos no DAD $(520 \mathrm{~nm})$, das seis substâncias da casca liofilizada do fruto do jamelão (Syzygium cuminii L.). 


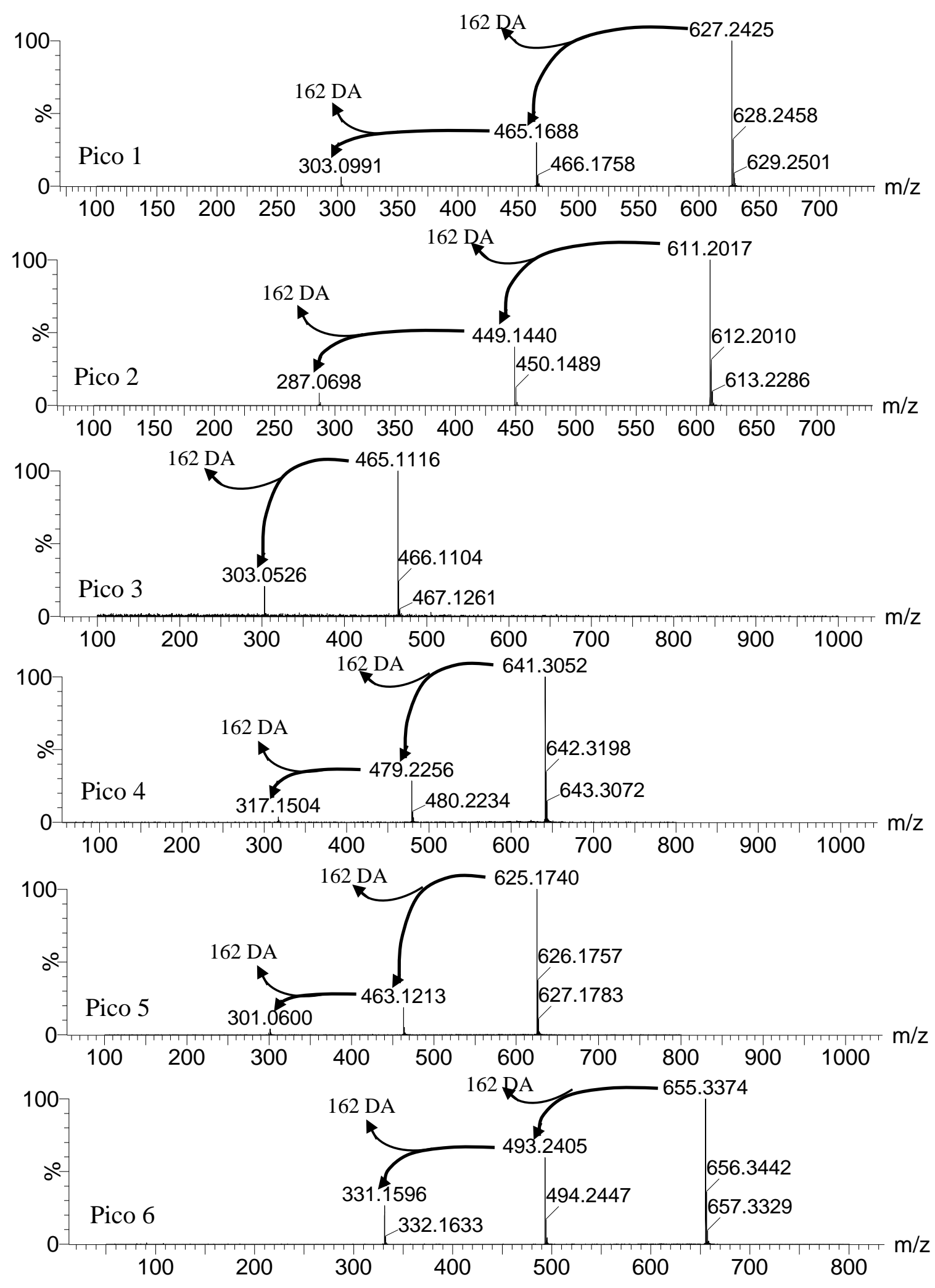

Figura 47: Espectros de massa exata, em modo EM/EM extraídos do CLUE-EM QTOF (ESI+), das substâncias equivalentes aos picos 1 ao 6 do extrato da casca liofilizada do fruto do jamelão (Syzygium cuminii L.). 


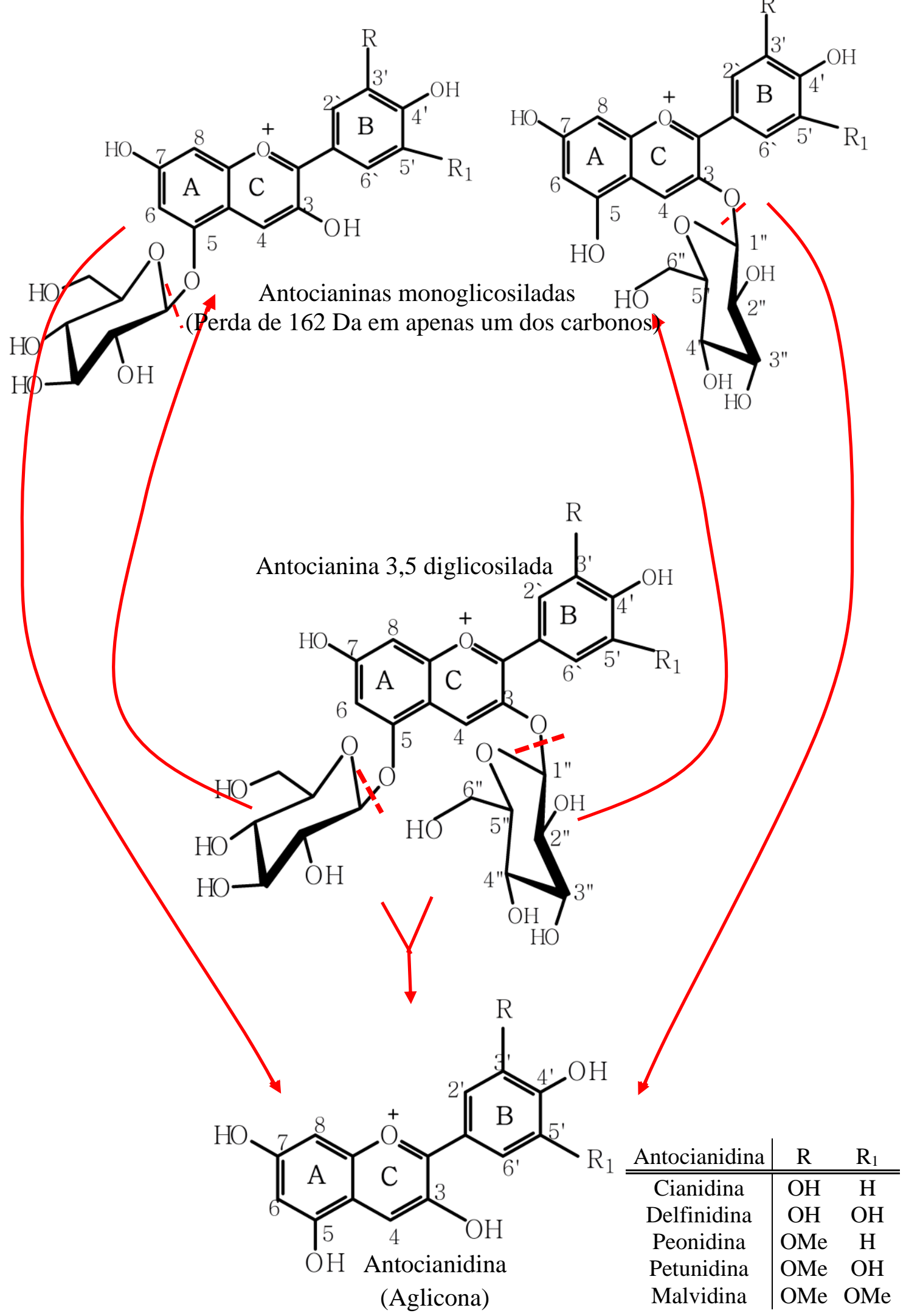

Figura 48: Esquema com as estruturas das antocianinas: diglicosiladas no $\mathrm{C}_{3}$ e $\mathrm{C}_{5}$; monoglicosilada no $\mathrm{C}_{3}$ ou $\mathrm{C}_{5}$ e, da antocianidina livre indicando as perdas dos glicosídeos. 


\section{Morango (Fragaria ssp)}

O cromatograma gerado da análise realizada por CLAE/DAD do extrato obtido a partir do pó liofilizado dos frutos de morangos, apresentou 4 picos que absorvem em 520nm (Figura 49). As 4 substâncias foram isoladas (segundo o item 3.7), e seus espectros de absorção UVVismáx e de massa acurada em modo EM/EM extraídos do CLUE-EM QTOF (ESI ${ }^{+}$) foram avaliados (Figura 50).
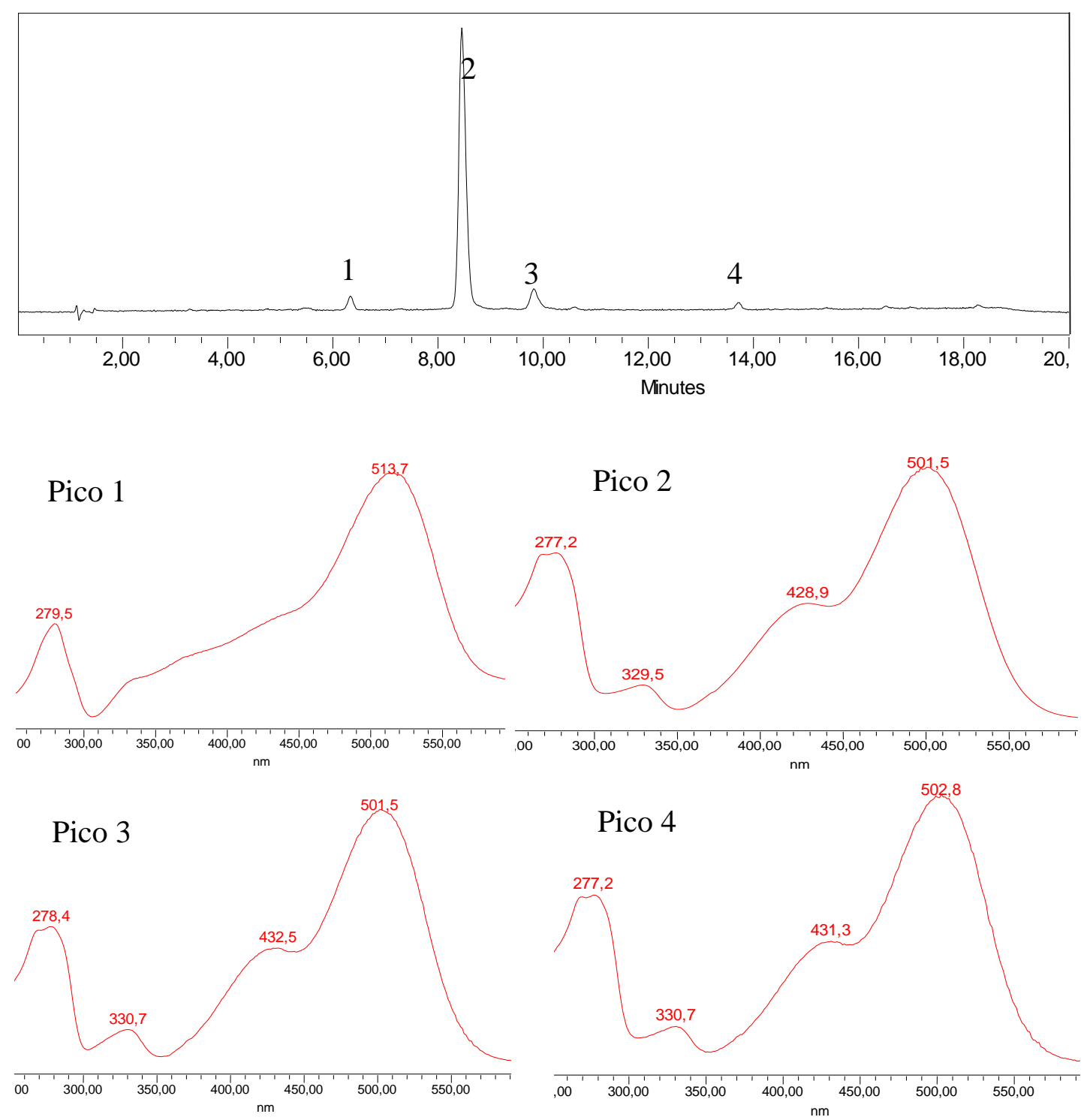

Figura 49: Cromatograma gerado da análise realizada por CLAE/DAD do extrato do morango liofilizado a 520 nm e espectros de absorção das 4 substâncias no UV-Vis máx. .

Para a substância 1 o espectro de UV-Vismáx mostrou duas bandas de absorção na região com $\lambda_{\text {máx }} 279,5$ e $513,7 \mathrm{~nm}$. Os dados obtidos em EM/EM mostrou a presença do íon molecular a $m / \mathrm{z}$ a 449,1684 e fragmento a $m / \mathrm{z} 287,0936$ após a perda de uma hexose ([M-162 Da $\left.]^{+}\right)$, 
indicando assim ser uma cianidina monoglicosilada (Figura 50). A coeluição da amostra com o padrão cianidina-3-O-glicosídeo, isolado do açaí (segundo o item 3.7, pág.39), confirmou a glicosilação da cianidina com a glicose.

Os espectros das substâncias 2, 3, e 4, gerados no DAD, apresentaram na região do visível, $\lambda_{\text {máx }}$ na faixa de 495-505nm e, uma banda na região de 420-440 $\mathrm{nm}$ característico de derivados de pelargonidina, conforme relatado em trabalhos na literatura (HONG e WROLSTAD, 1990).

O comprimento de onda na faixa visível está intimamente relacionado com o padrão de hidroxilação do anel B da antocianina. Em solução de metanol acidificado, a pelargonidina-3$O$-glicosideo apresenta $\lambda_{\text {máx }}$ em torno de $505 \mathrm{~nm}$ (GIUSTI, RODRIGUES-SAONA, WROSLTAD, 1999). A medida que o grau de hidroxilação aumenta no anel B, ocorre aumento no $\lambda_{\text {máx }}$ observado no visível.

As análises por espectrometria de massa acurada em modo EM/EM no CLUE-EMQTOF (ESI ${ }^{+}$) das substâncias 2, 3 e 4 apresentaram íon a $m / z$ 433,0995; 579,2447 e 475,1300. Dentre eles apenas a substância 3 apresentou dois fragmentos, um a $\mathrm{m} / \mathrm{z} 433,1647$ após a perda de uma desóxi-hexose $\left([\mathrm{M}-146 \mathrm{Da}]^{+}\right)$e o outro a $\mathrm{m} / z$ 271,0945 relativo à perda de hexose+desóxi-hexose $\left([\mathrm{M}-308 \mathrm{Da}]^{+}\right)$. Esse padrão de liberação já foi relatado no presente estudo para frutos como o açaí, juçara e berinjela e corresponde à perda da rutinose (308 Da) liberando a antocianidina (Figura 50 e 51).
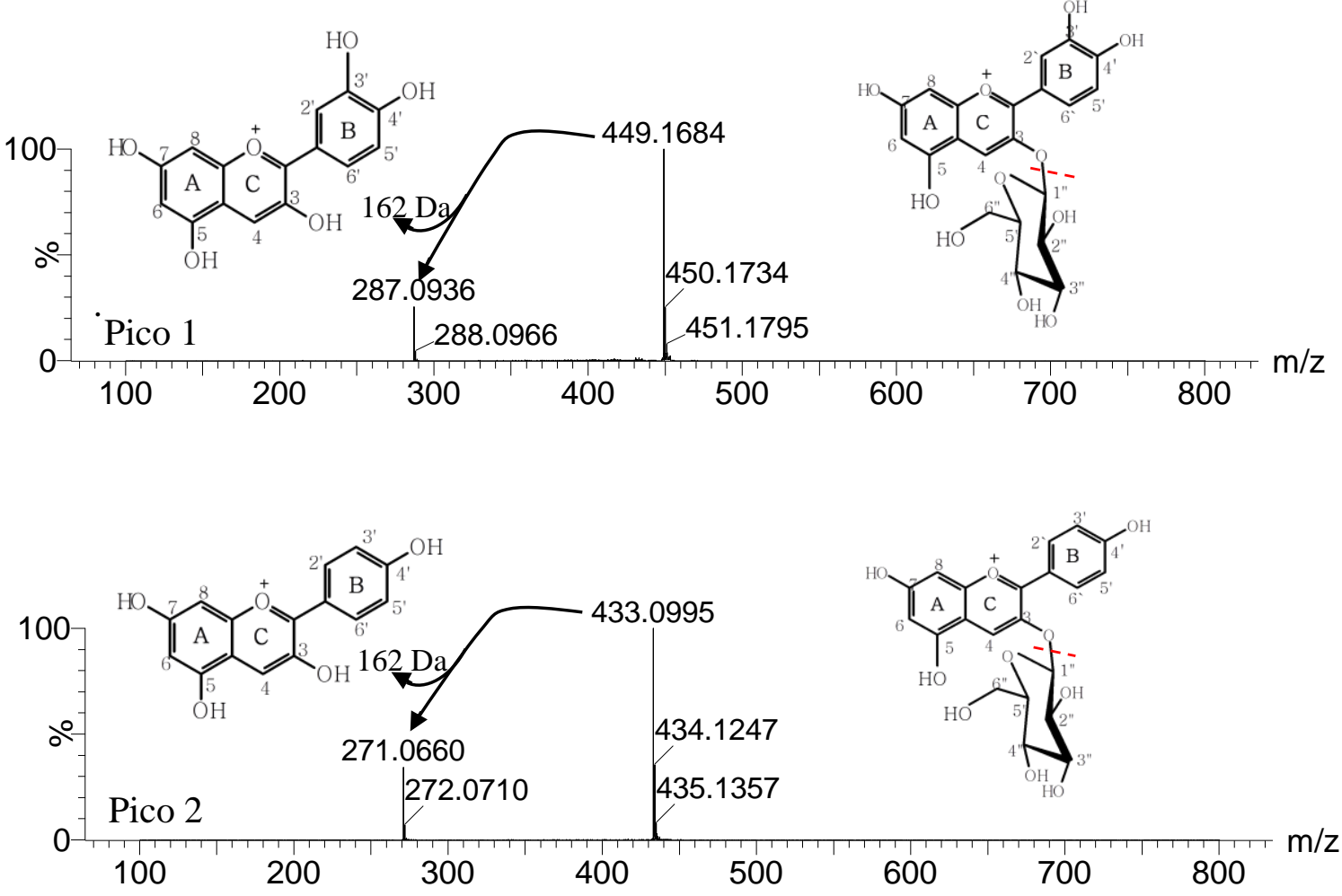

Figura 50: Espectro de massa acurada em modo EM/EM extraídos do CLUE-EM QTOF (ESI ${ }^{+}$) dos picos 1 e 2 do extrato do morango liofilizado.

As substâncias 2 e 4 apresentaram somente um fragmento a $\mathrm{m} / \mathrm{z} 271,0660$, onde foi observado a liberação da massa neutra correspondendo a perda de $162 \mathrm{Da}$ (hexose) para a substância 2 e, de 208 Da que corresponde a perda de uma hexose + acetila para a substância 
4. Sendo assim, as substâncias foram identificadas como: pico 1 cianidina-3- $O$-glicosídeo; pico 2 pelargonidina-3- $O$-glicosídeo; pico 3 pelargonidina-3- $O$-rutenosídeo e pico 4 pelargonidina3-O- (6" -acetila) -glicosídeo, sendo esses dados consistentes com os obtidos em trabalhos já reportados (SILVA et al., 2002; WU e PRIOR, 2005b; ZHANG et al., 2011).
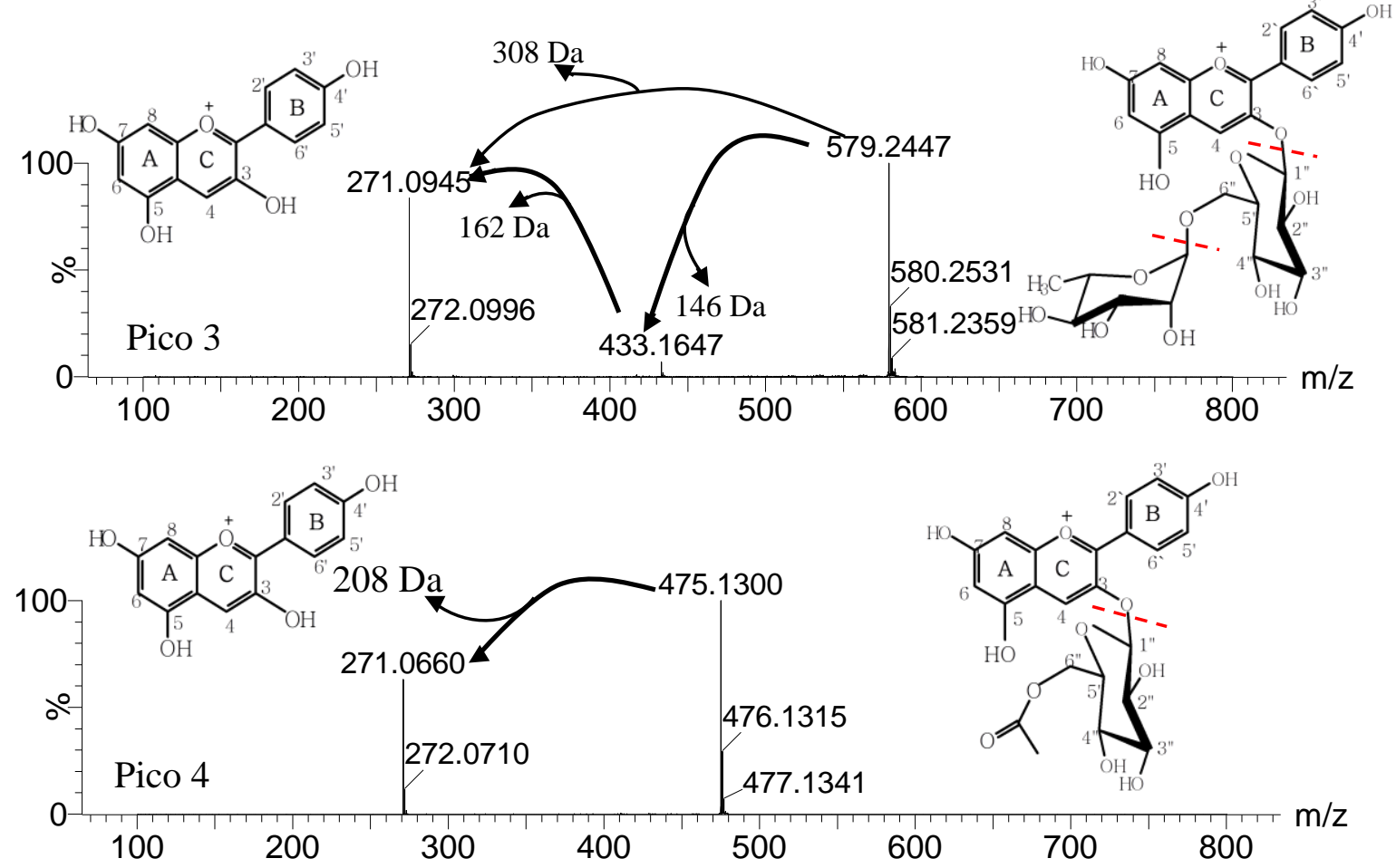

Figura 51: Espectro de massa acurada em modo EM/EM extraídos do CLUE-EM QTOF (ESI+) das substâncias 3 e 4 do extrato do morango liofilizado.

Mangostin (Garcinia mangostana L.)

O cromatograma gerado da análise realizada por CLAE/ DAD do extrato do pericarpo liofilizado do mangostin, apresentou sete picos que absorvem em 520nm. Para esse estudo apenas as duas substâncias majoritárias, picos 3 e 5, foram isoladas (segundo o item 3.7) e seus espectros de absorção UV-Vis máx avaliados (Figura 52). As substâncias isoladas também foram avaliadas no CLUE-EM QTOF (ESI ${ }^{+}$) seguindo condições de análise descritas no item 3.5.3.1 (Figura 53), gerando espectros de massa acurada em modo EM/EM

$\mathrm{Na}$ análise da substância do pico 3 o espectro de UV-Vis máx mostrou duas bandas de absorção com $\lambda_{\text {máx }} 279,5$ e 512,8 nm. Os dados obtidos no CLUE-EM QTOF (ESI ${ }^{+}$), em modo EM/EM, mostrou a presença do íon molecular a $\mathrm{m} / \mathrm{z}$ 611,1381 e fragmento a $\mathrm{m} / \mathrm{z}$ 287,0511 após a perda de uma hexose $\left([\mathrm{M}-162 \mathrm{Da}]^{+}\right)$. Para a substância do pico 5, no espectro de UV-Vismáx foram observadas as bandas $\lambda_{\text {máx }} 279,5$ e $516,5 \mathrm{~nm}$ e dados gerados no CLUE-EM QTOF $\left(\mathrm{ESI}^{+}\right)$ em modo EM/EM, mostrou o íon molecular a $\mathrm{m} / \mathrm{z}$ a 449,0661 e fragmento a $\mathrm{m} / \mathrm{z}$ 287,0321 após a perda de uma hexose $\left([\mathrm{M}-162 \mathrm{Da}]^{+}\right)$.

As bandas de absorção observadas ( $\lambda_{\operatorname{máx}} 279,5$ e $512,8 \mathrm{~nm}$ e $\lambda_{\operatorname{máx}} 279,5$ e $516,5 \mathrm{~nm}$ ) e a presença do íon a $\mathrm{m} / \mathrm{z} 287$ indicam que o pico 3 e 5 são antocianinas cuja aglicona é a cianidina. 
A substância 3 apresentou apenas um fragmento após a perda de $324 \mathrm{Da}$, indicando que essa antocianina possui um dissacarídeo como substituinte. Para confirmar o padrão de fragmentação apresentado pela substância, foram utilizadas outras energias de fragmentação acima de $4 \mathrm{eV}$. A utilização de um valor maior de energia, aumentando o poder de impacto sobre a molécula, serviu para certificar que a substância analisada gerou apenas um fragmento decorrente da perda de $324 \mathrm{Da}$.

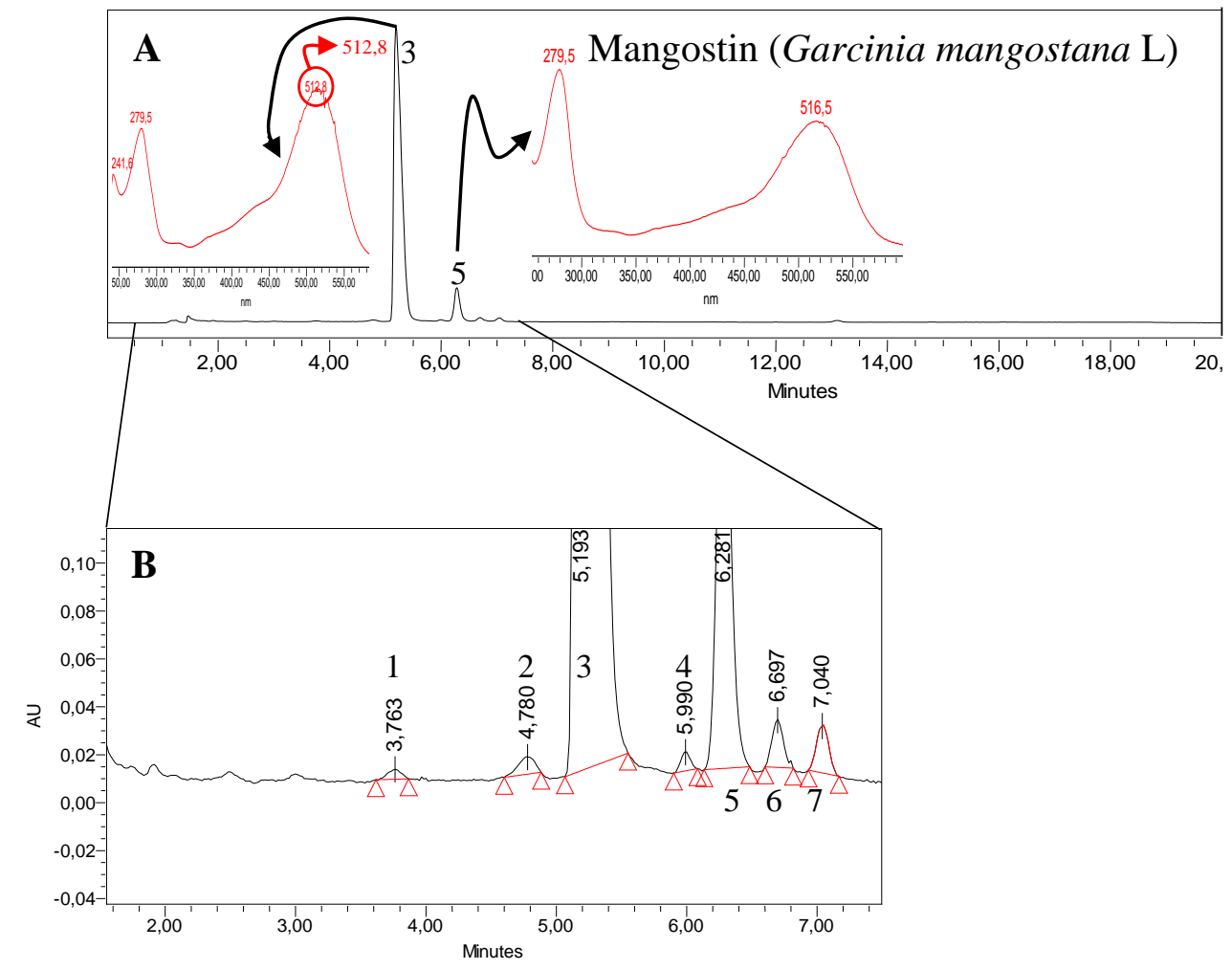

Figura 52: A) Cromatograma do extrato do pericarpo do mangostin liofilizado (Garcinia mangostana L.) extraído utilizando metodologia II a $520 \mathrm{~nm}$ e, espectros de absorção dos picos 3 e 5 no UV-Vis máx. B) Expansão do cromatograma A no intervalo de 1,0-7,5 minutos.

Os espectros obtidos indicaram que mesmo com o aumento em até quatro vezes do poder da energia impactante na molécula, o fragmento gerado a $\mathrm{m} / \mathrm{z} 287$ foi decorrente da perda de $324 \mathrm{Da}$. As escolhas das energias foram baseadas na obtenção de espectros que apresentassem, mesmo em baixa concentração, a presença do íon molecular a $\mathrm{m} / \mathrm{z} 611$ comprovando assim que o íon fragmento a $\mathrm{m} / \mathrm{z} 287$ é seu derivado (Figura 54).

$\mathrm{O}$ espectro gerado no EM/EM utilizando energia quatro vezes superior a utilizada inicialmente $(4,0 \mathrm{eV} \rightarrow 16,0 \mathrm{eV})$, apresenta o íon fragmento a $\mathrm{m} / \mathrm{z} 287,0449$, como íon majoritário e, o íon molecular a $\mathrm{m} / \mathrm{z}$ a 611,1290 a 15,31\% (Figura 54- Tabela 16). Portanto, a substância 4 foi identificada como cianidina ligada na posição do $\mathrm{C}_{3}$ ao dissacarídeo soforosídeo que é composto por duas hexoses $\left([\mathrm{M}-324 \mathrm{Da}]^{+}\right)$. A presença da substância cianidina-3-Osoforosídeo já foi relatada em trabalhos anteriores para frutos como: framboesa vermelha; morango proveniente "Oregon Strawberry Comission" e mangostin (WU e PRIOR, 2005a; TIAN et al., 2005; ZARENA e SANKAR, 2011).

Para a substância 5 os dados obtidos em modo EM/EM no CLUE-EM QTOF $\left(\mathrm{ESI}^{+}\right)$, mostrou a presença do íon molecular a $\mathrm{m} / \mathrm{z}$ a 449,0661 e fragmento a $\mathrm{m} / \mathrm{z} 287,0325$ após a perda 
de uma hexose $\left([\mathrm{M}-162 \mathrm{Da}]^{+}\right)$, indicando assim ser uma cianidina monoglicosilada (Figura 53 C).

A sobreposição do cromatograma (CLAE/DAD) da amostra com o do padrão de cianidina-3-O-glicosídeo (isolado do açaí segundo o item 3.7), mostrou que a substância 5 possui o mesmo tempo de retenção do padrão (Figura 55). Portanto, indica que a glicosilação da cianidina ocorre com o açúcar glicose. Esses dados são consistentes com trabalho publicado por Zarena e Sankar (2011), onde reportaram que encontraram as duas antocianinas, cianidina3- $O$-soforosídeo e cianidina-3- $O$-glicosídeo, quando analisaram por EM e RMN um extrato do pericarpo do mangostin (Garcinia mangostana L.).

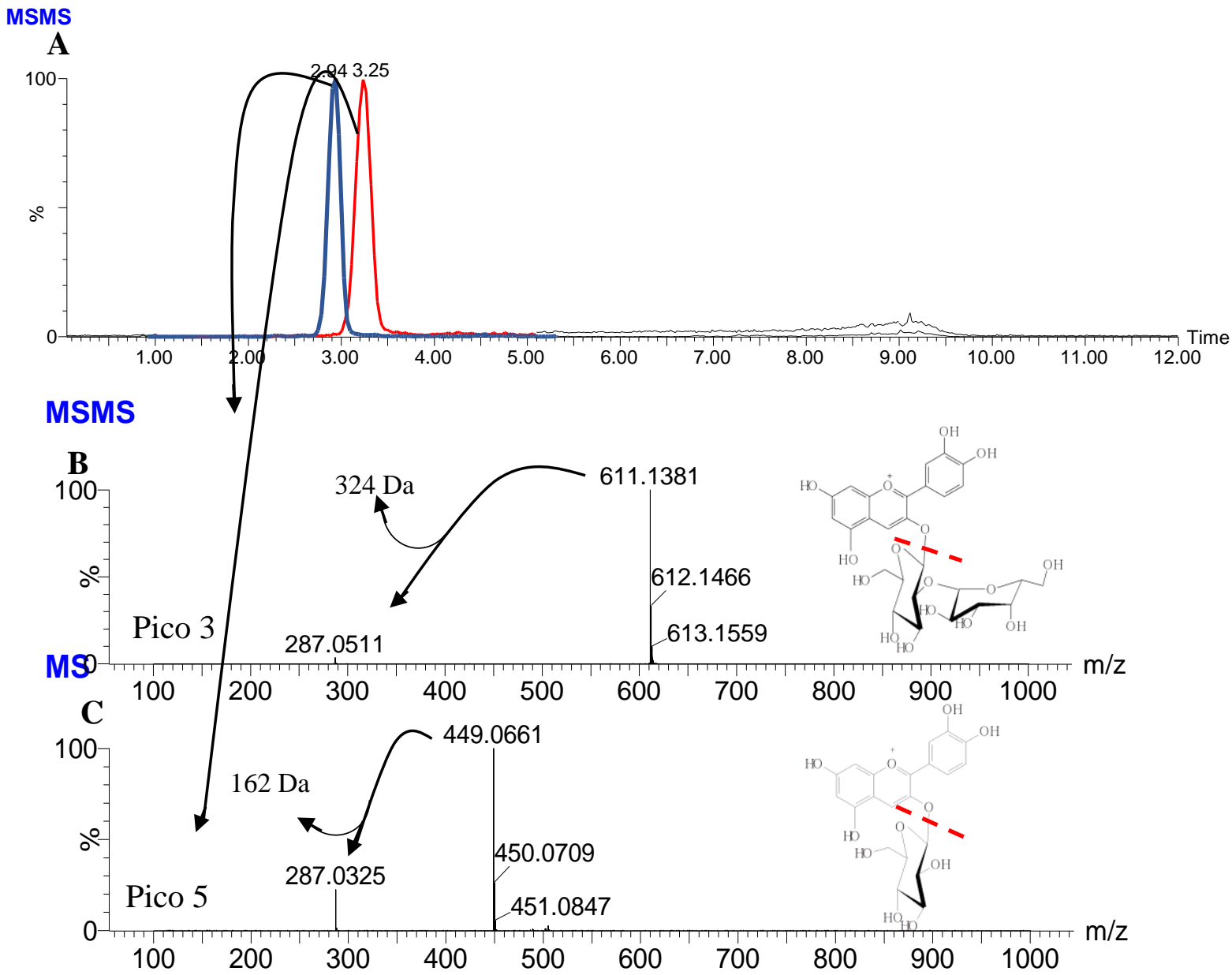

Figura 53: A) Cromatograma em modo EM/EM extraídos do CLUE-EM QTOF (ESI ${ }^{+}$) das substâncias 3 e 5, isoladas do extrato do pericarpo liofilizado do mangostin (Garcinia mangostana L.), filtrando os íons a $\mathrm{m} / \mathrm{z} 611$ (pico 3) e 449 (pico 5), B e C) Espectros em modo EM/EM extraídos no CLUE-EM QTOF (ESI ${ }^{+}$) onde (B) substância do pico 3 e (C) substância do pico 5. 


\section{MSMS}
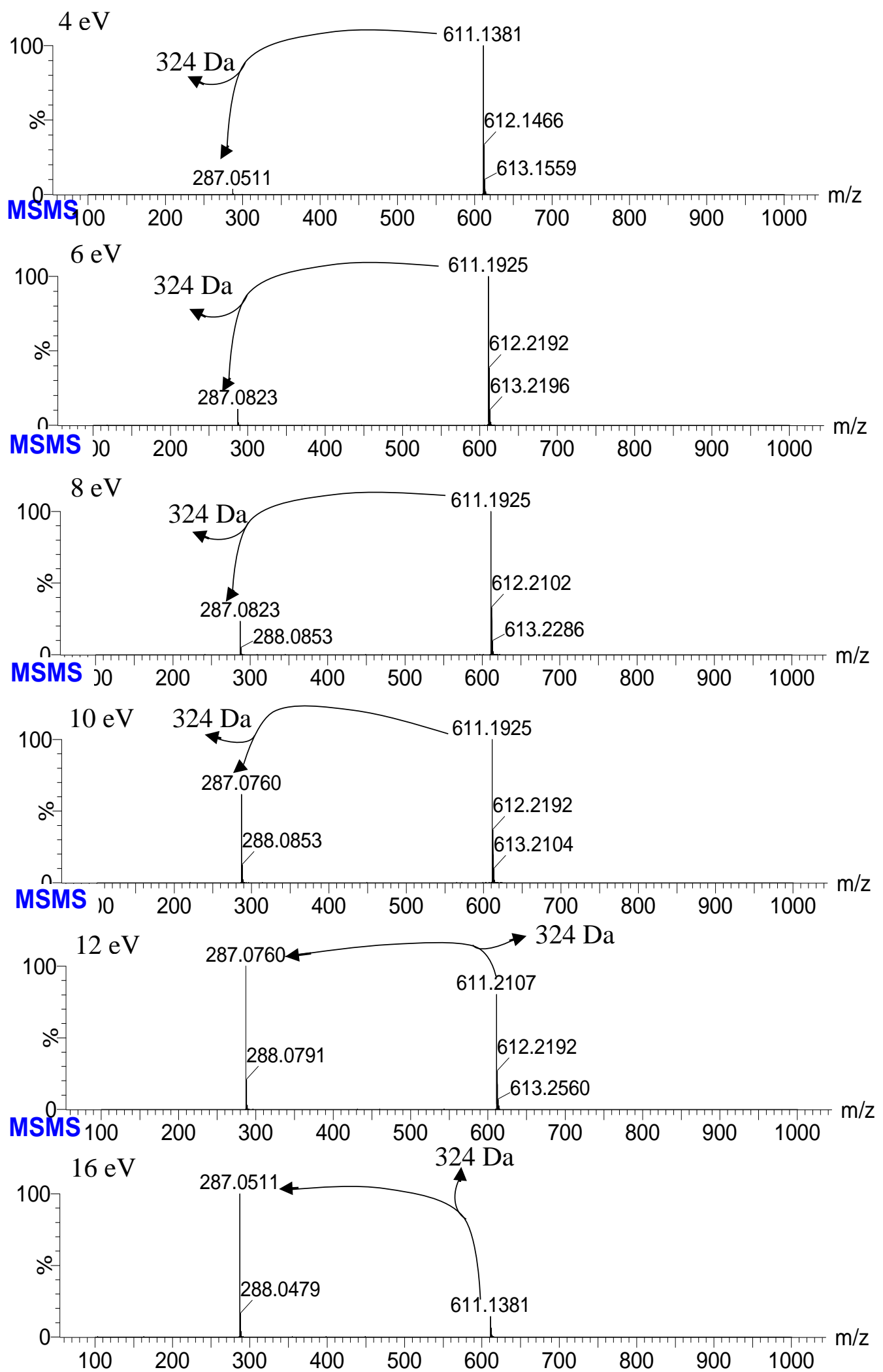

Figura 54: Espectro de massa da substância isolada 3 (mangostin) gerado no modo EM/EM, em condições de seis diferentes valores de energias de impacto $(4,6,8,10,12 \mathrm{e} 16 \mathrm{eV})$. 
Tabela 16: Massas encontradas nas condições de seis diferentes valores de energias de impacto para análise das antocianinas do mangostin.

\begin{tabular}{|c|c|c|c|c|}
\hline & Cianidina-3- $O$-soforosídeo & & & \\
\hline $\begin{array}{c}\text { Massa Encontrada } \pm \text { Desvio Padrão } \\
(\mathrm{m} / \mathrm{z})\end{array}$ & $\begin{array}{l}\text { Energia de colisão } \\
\qquad(\mathrm{eV})\end{array}$ & $\begin{array}{l}\text { Intensidade } \\
\text { do pico }\end{array}$ & $\%$ & Razão* \\
\hline $611,1381 \pm 0,0163$ & \multirow[t]{2}{*}{4} & $9,87 \times 10^{2}$ & 100,00 & \multirow{2}{*}{$10,0: 0,4$} \\
\hline $287,0511 \pm 0,0032$ & & $3,80 \times 10$ & 3,85 & \\
\hline $611,1925 \pm 0,0221$ & \multirow{2}{*}{6} & $3,57 \times 10^{3}$ & 100,00 & \multirow{2}{*}{$10,0: 1,0$} \\
\hline $287,0823 \pm 0,0189$ & & $3,62 \times 10^{2}$ & 10,14 & \\
\hline $611,1925 \pm 0,0221$ & \multirow{2}{*}{8} & $3,17 \times 10^{3}$ & 100,00 & \multirow{2}{*}{$10,0: 2,5$} \\
\hline $287,0823 \pm 0,0189$ & & $9,25 \times 10^{2}$ & 25,01 & \\
\hline $611,1925 \pm 0,0221$ & \multirow{2}{*}{10} & $2,98 \times 10^{3}$ & 100,00 & \multirow{2}{*}{$10,0: 5,8$} \\
\hline $287,076 \pm 0,0144$ & & $1,73 \times 10^{3}$ & 58,11 & \\
\hline $611,2107 \pm 0,0350$ & \multirow{2}{*}{12} & $5,31 \times 10^{2}$ & 78,67 & \multirow{2}{*}{$7,9: 10,0$} \\
\hline $287,076 \pm 0,0144$ & & $6,75 \times 10^{2}$ & 100,00 & \\
\hline $611,1381 \pm 0,0163$ & \multirow{2}{*}{16} & $5,77 \times 10^{2}$ & 15,31 & \multirow{2}{*}{$1,5: 10,0$} \\
\hline $287,0511 \pm 0,0032$ & & $3,77 \times 10^{3}$ & 100 & \\
\hline Substâncias & Fórmula Molecular & \multicolumn{3}{|c|}{ Massa Calculada } \\
\hline Cianidina-3-O-soforosídeo & $\mathrm{C}_{27} \mathrm{H}_{31} \mathrm{O}_{16}$ & \multicolumn{3}{|c|}{611,1612} \\
\hline Cianidina & $\mathrm{C}_{15} \mathrm{H}_{11} \mathrm{O}_{6}$ & \multicolumn{3}{|c|}{287,0556} \\
\hline \multicolumn{5}{|c|}{ *Razão entre o íon mais abundante e o de menor abundância } \\
\hline
\end{tabular}

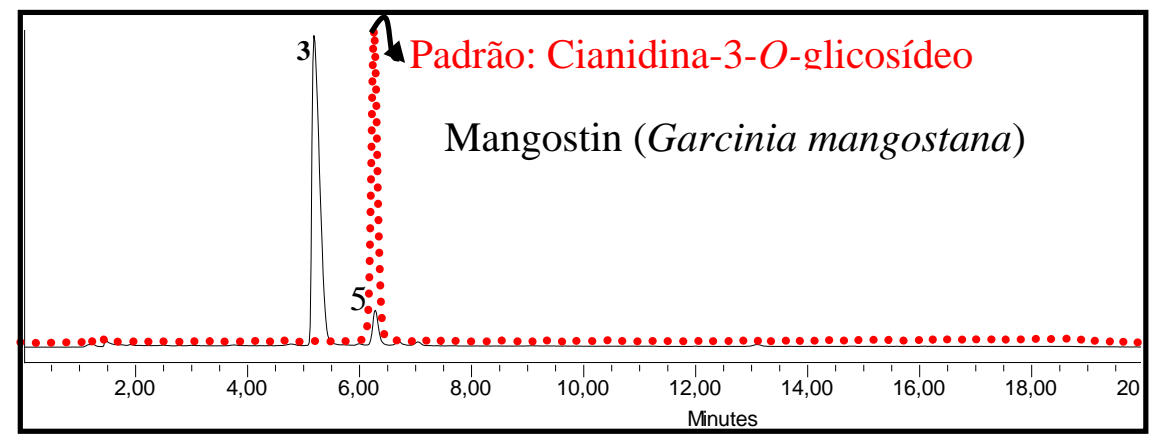

Figura 55: Apresenta sobreposição dos cromatogramas no CLAE/DAD $(520 \mathrm{~nm})$, do extrato do pericarpo liofilizado do mangostin (preto) e do padrão cianidina-3-O-glicosídeo (vermelho), isolado da matriz Euterpe oleracea Mart. (açaí). 


\section{Mirtilo (Vaccinium spp.)}

O mirtilo também conhecido em inglês como blueberry e arándano em espanhol, vem sendo largamente estudado no mundo científico pois, apresentam micronutrientes (vitaminas e sais minerais) e outros compostos conferindo assim valor nutritivo que contribuem com efeitos benéficos à saúde (BUSHWAY et al., 1983; SHAUGHNESSY, et al., 2009; KALEA, et al., 2010; BUNEA et al., 2013). Diversos autores relataram a presença de flavonoides e outros compostos fenólicos, no mirtilo, os quais possuem significativa contribuição na propriedade antioxidante conferida ao fruto (PRIOR et al., 1998; WOLFE et al., 2008; GAVRILOVA et al., 2011; YOUSEF et al., 2013; BUNEA et al., 2013). Dentre os flavonoides destacam-se as antocianinas que têm presença marcante nas cascas dos frutos, pigmento responsável pela sua intensa coloração violeta. $\mathrm{O}$ mirtilo está entre os alimentos vegetais que apresentam grande concentrações de antocianinas. Além disso, apresenta em seu perfil cinco das seis antocianidinas mais comuns em alimentos: delfinidina, cianidina, petunidina, peonidina e malvidina, conferindo a esse pequeno fruto grande diversidade desse pigmento.

Estas antocianinas têm sido identificadas, em geral, ligadas somente a três tipos de açúcares: galactose, glicose e arabinose. Mas, Wang e colaboradores (2014) relataram no estudo em mirtilo nativos Chinês (blueberry, Vaccinium uliginosum) a presença das antocianinas petunidina e malvidina ligadas à xilose. Em algumas variedades também foram identificadas antocianinas aciladas aos ácidos acéticos (PRIOR et al., 2001; WU e PRIOR, 2005b) e malônico (WU e PRIOR, 2005b). Sendo assim, pode-se observar que cultivares apresentam diferenças nos teores e na diversidade de antocianinas, mostrando que tanto o teor como a diversidade de antocianinas nos frutos são mais afetadas pelo seu genótipo do que influenciado por fatores ambientais e por práticas de cultivo.

A análise realizada por CLAE/DAD no extrato do fruto liofilizado do mirtilo, pelo presente estudo, revelou de início a presença de 20 picos (Figura 56). Todos os espectros de absorção correspondentes aos picos apresentaram as duas bandas no UV-Vis máx $_{\text {características }}$ dos pigmentos antociânicos (Figura 58-60). Foram realizadas varreduras nos 20 picos na região de 240 a 590nm no DAD (UV-Vis máx).

As análises dos picos 3 e 8 apresentaram mais de um valor para as bandas de maior comprimento de onda ( $\lambda_{\text {máx }}$ do visível). Suspeitou-se, portanto, que haveriam duas substâncias coeluindo nesses dois picos. As substâncias equivalentes aos picos foram isoladas utilizando a técnica de recolhimento dos picos na saída do detetor, após separação cromatográfica (Item 3.7). As análises no CLUE-EM-QTOF $\left(\mathrm{ESI}^{+}\right)$confirmaram a presença de duas substâncias distintas em cada um dos picos ( 3 e 8 ), totalizando assim a presença de quatro antocianinas. Com esses resultados a matriz foi caracterizada apresentando 22 substâncias em seu perfil antociânico a $520 \mathrm{~nm}$ (Figura 57), em substituição a caracterização das 20 realizada anteriormente (Figura 56).

Diferentes cultivares de mirtilos (gênero Vaccinium) foram relatados em trabalhos anteriores contendo de 14 a 27 antocianinas em seu perfil cromatográfico (PRIOR et al., 2001; KÄHKÖNEN et al., 2003; WU e PRIOR, 2005b; LOHACHOOMPOL et al., 2008; GAVRILOVA et al., 2011; MÜLLER, SCHANTZ e RICHLING, 2012; BUNEA et al., 2013; YOUSEF et al., 2013). A grande diversidade das antocianinas presentes na matriz, faz com que algumas delas possuam hidrofobicidade similares, dificultando sua separação cromatográfica. 


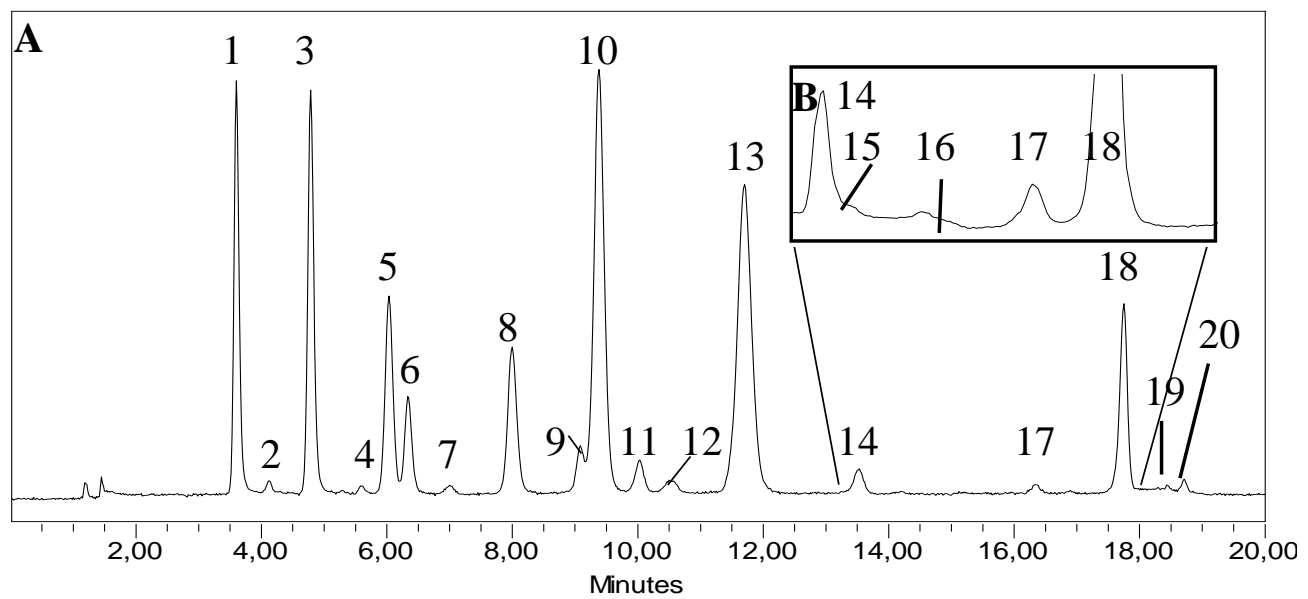

Figura 56: A) Cromatograma do extrato do mirtilo (Vaccinium spp) extraído utilizando metodologia II a 520 nm, B) Expansão do cromatograma A no intervalo de 13,7-18,0 minutos.

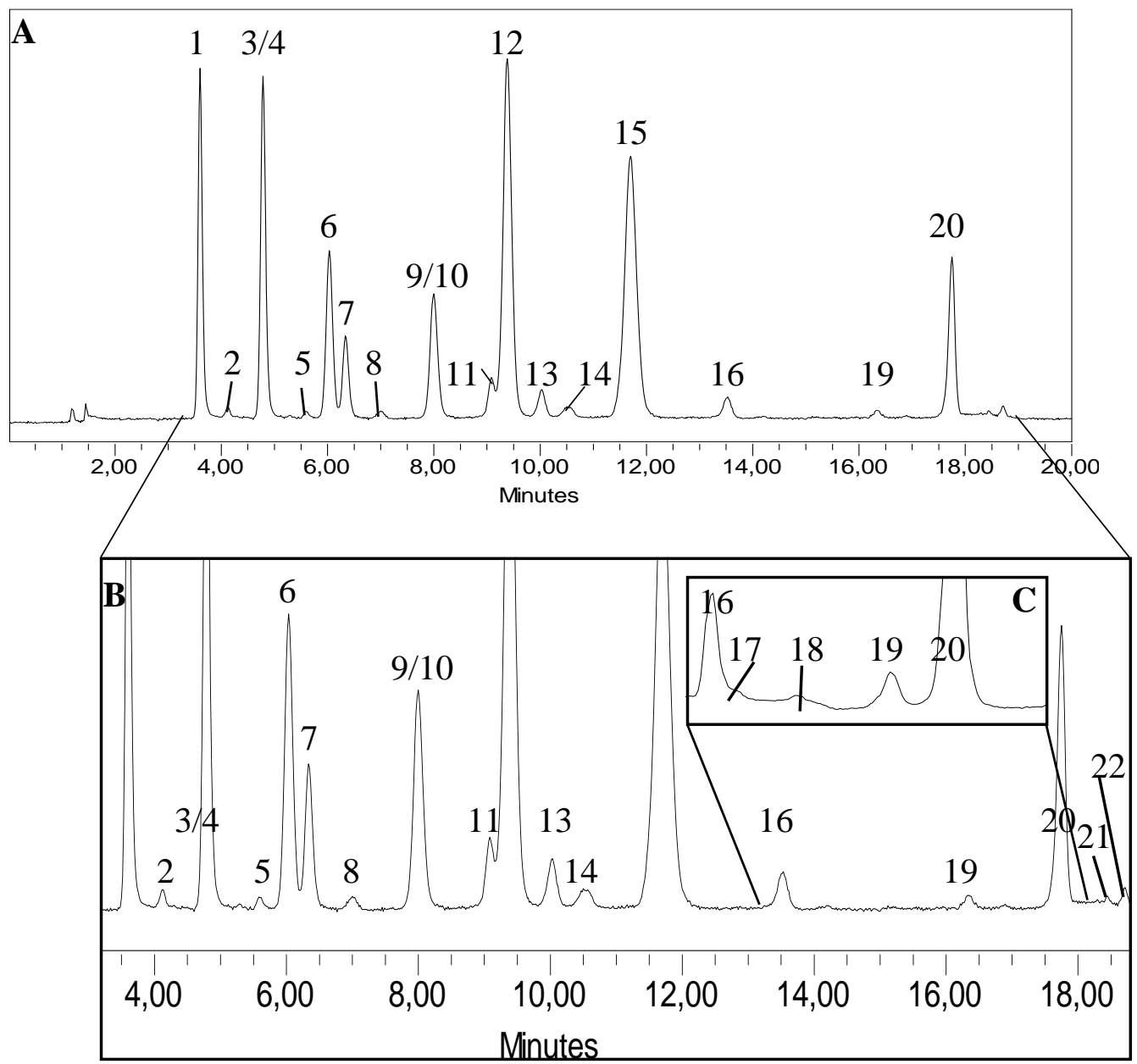

Figura 57: A) Cromatograma do extrato do mirtilo (Vaccinium spp) extraído utilizando metodologia II a 520 nm, B) Expansão do cromatograma A no intervalo de 3,5-19,0 minutos e C) Expansão do cromatograma B no intervalo de 13,7-18,5 minutos. 


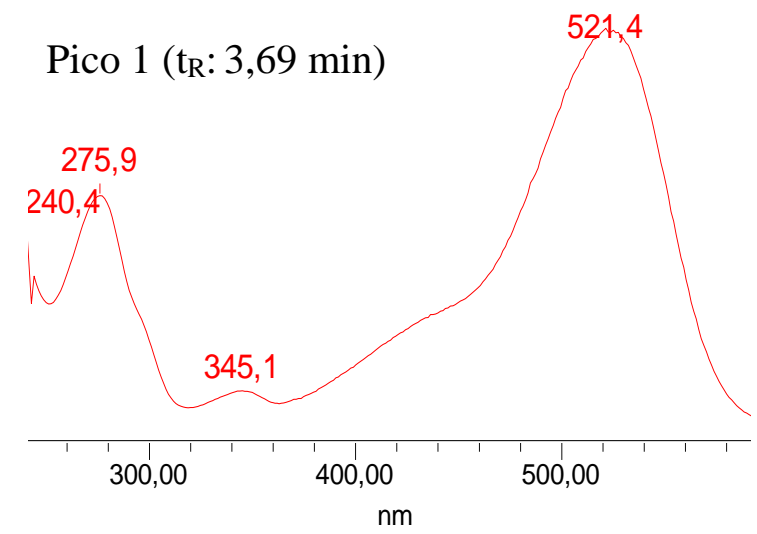

Pico $3\left(t_{R}: 4,89 \min \right)$

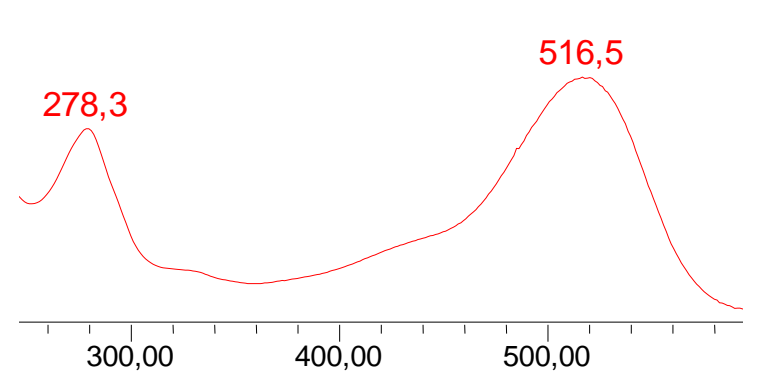

Pico $5\left(t_{R}: 5,65 \mathrm{~min}\right)$

279,5

252,2
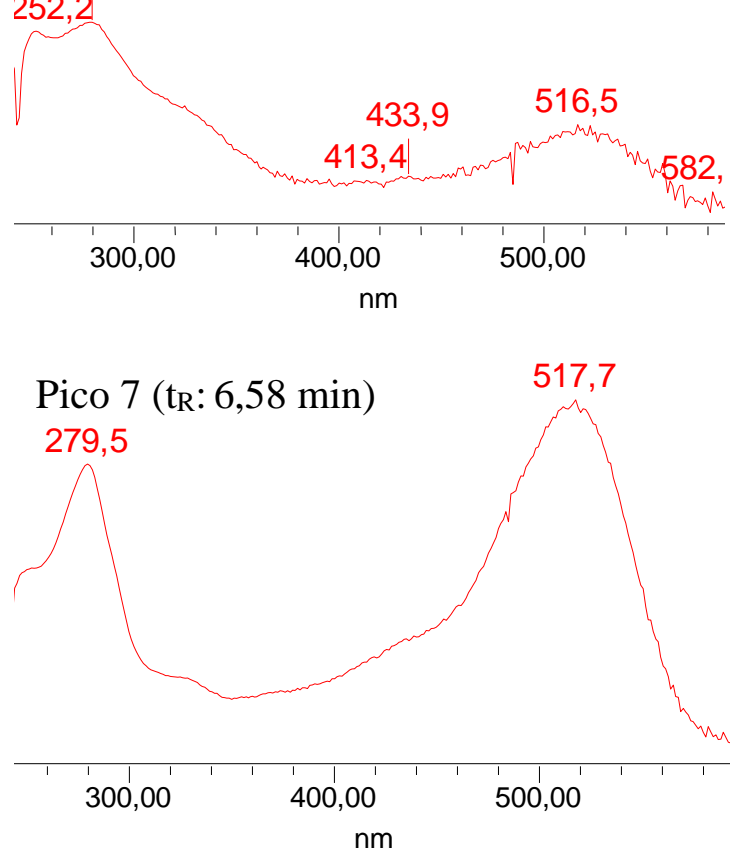

Pico $2\left(t_{R}: 4,22 \min \right)$

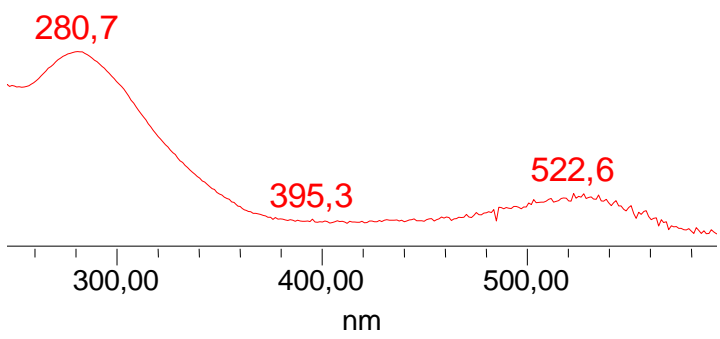

Pico $4\left(t_{R}: 4,89 \min \right)$

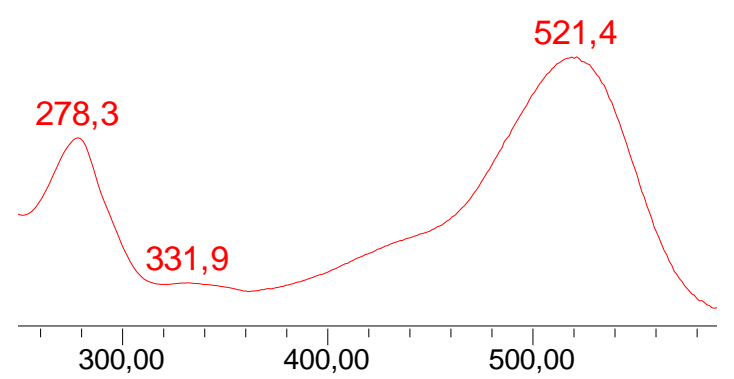

Pico 6 (tr: 6,04 min)

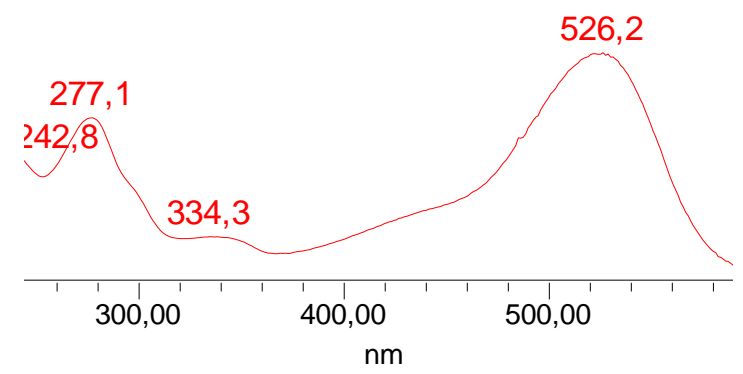

Pico $8\left(\mathrm{t}_{\mathrm{R}}: 6,86 \mathrm{~min}\right)$

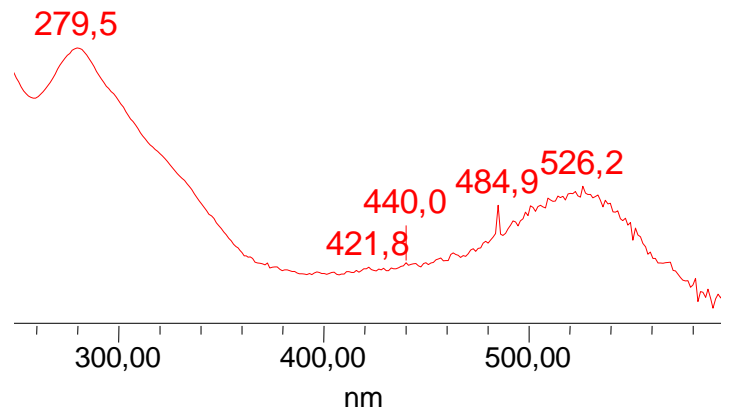

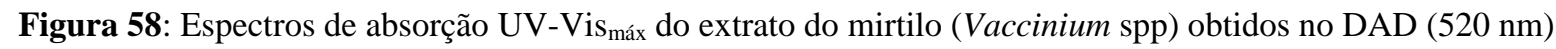
enumerados conforme cromatograma da Figura 57. 


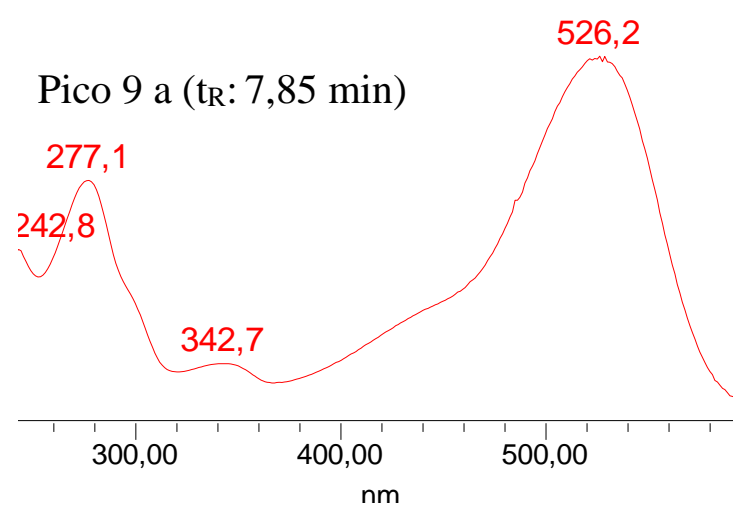

Pico $11\left(t_{R}: 9,19 \min \right)$

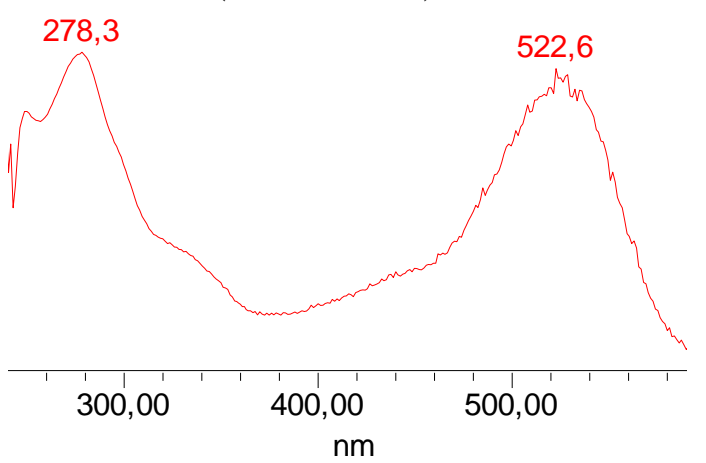

Pico 13 ( $\left.\mathrm{t}_{\mathrm{R}}: 9,98 \mathrm{~min}\right)$

279,5

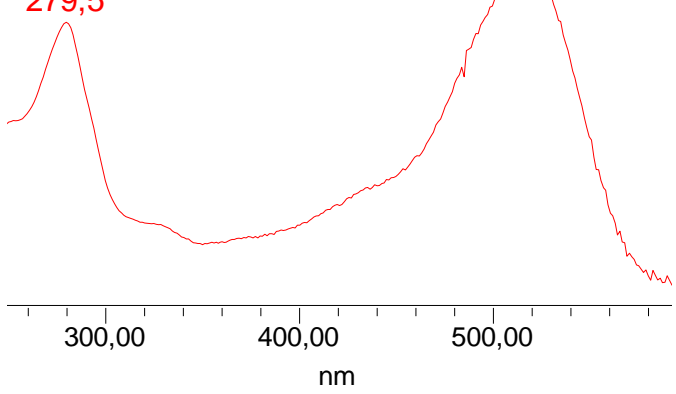

Pico $15\left(t_{R}: 11,71 \mathrm{~min}\right)$

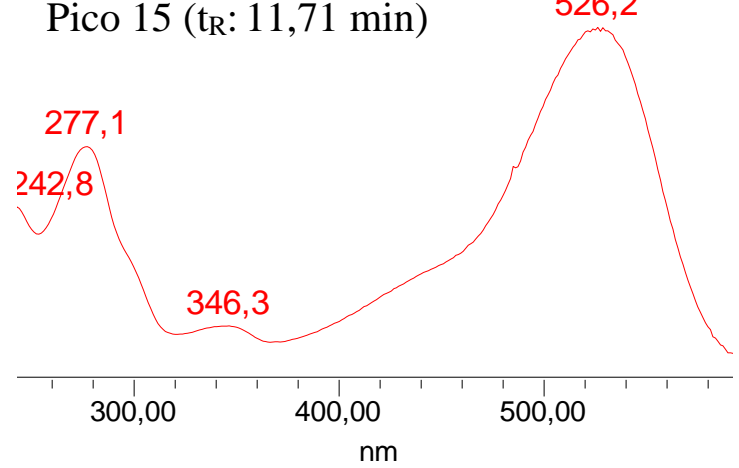

Pico $10-9 b\left(t_{R}: 7,85 \min \right)$

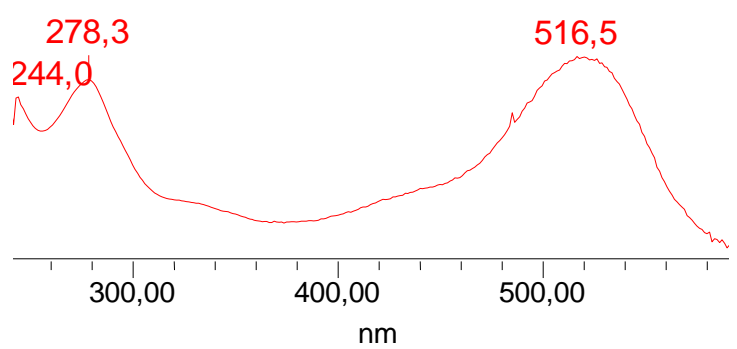

Pico $12\left(t_{R}: 9,48 \min \right)$ 526,2

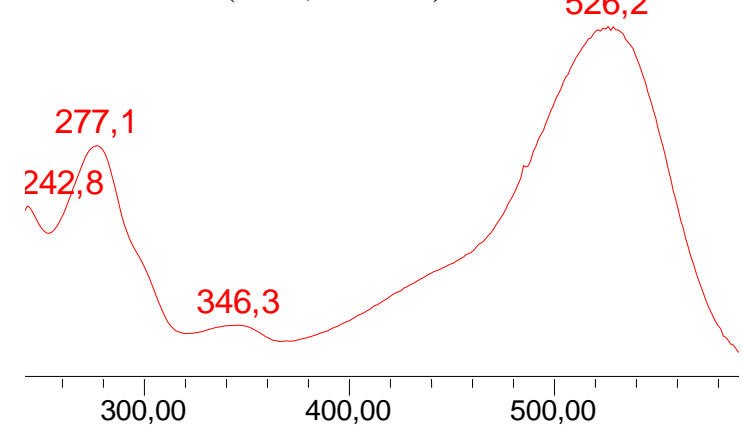

Pico 14 ( $\left.\mathrm{t}_{\mathrm{R}}: 10,67^{\mathrm{nm}} \mathrm{min}\right)$

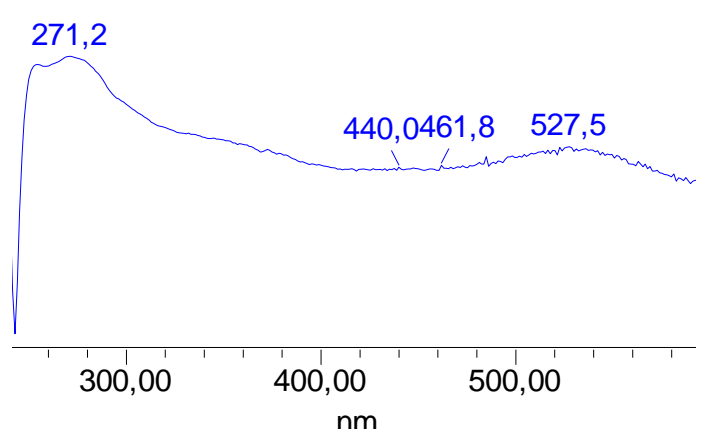

Pico $16\left(\mathrm{t}_{\mathrm{R}}: 13,67 \mathrm{~min}\right)$

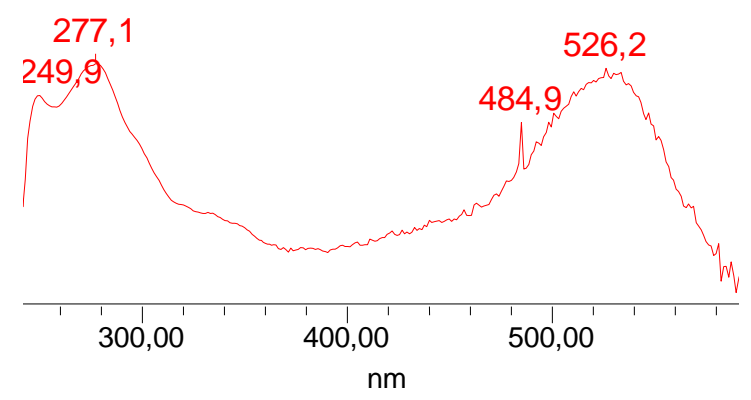

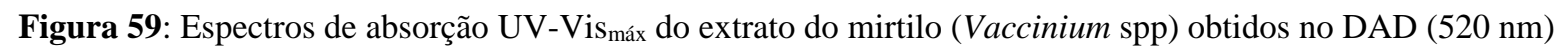
enumerados conforme cromatograma da Figura 57. 
Pico 17 ( $\left.\mathrm{t}_{\mathrm{R}}: 13,75 \mathrm{~min}\right)$ $293,8315,2$

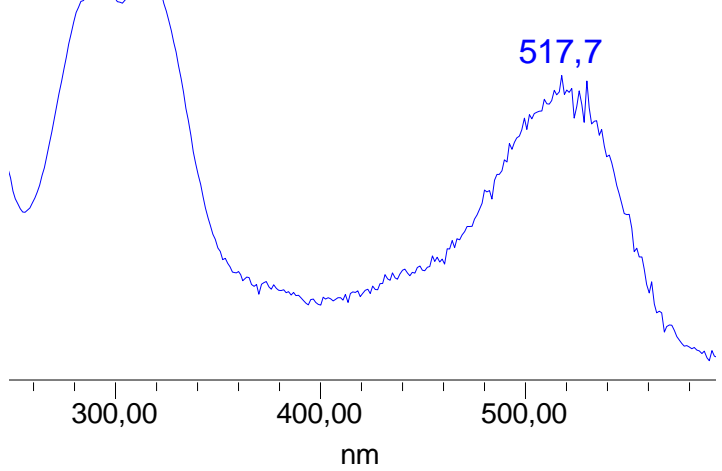

Pico 19 (t $t_{R}: 16,46$ min)

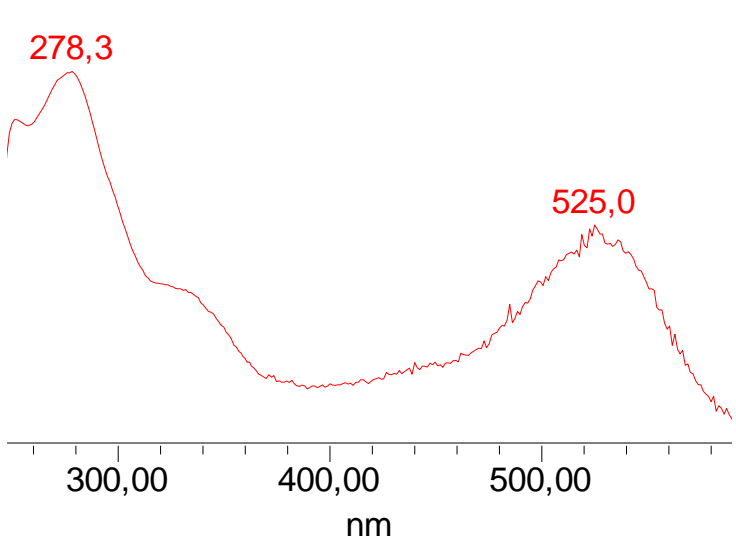

Pico $21\left(\mathrm{t}_{\mathrm{R}}: 18,61 \mathrm{~min}\right)$

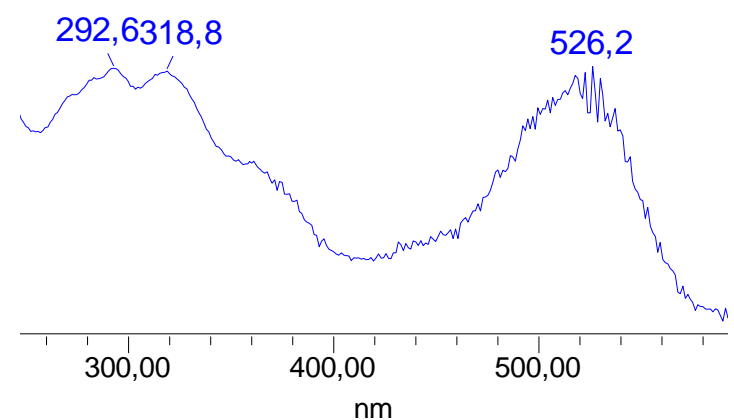

Pico 18 ( $\left.\mathrm{t}_{\mathrm{R}}: 14,25 \mathrm{~min}\right)$

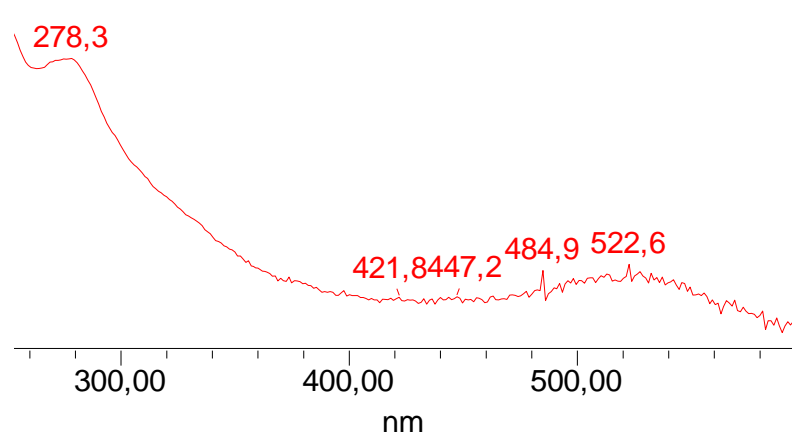

Pico 20 ( $\left.\mathrm{t}_{\mathrm{R}}: 17,72 \mathrm{~min}\right)$

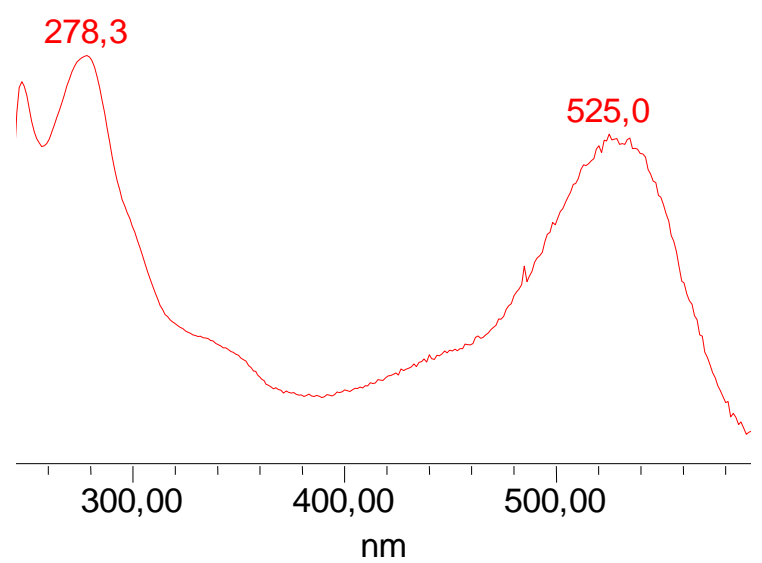

Pico $22\left(t_{R}: 18,79\right.$ min $)$

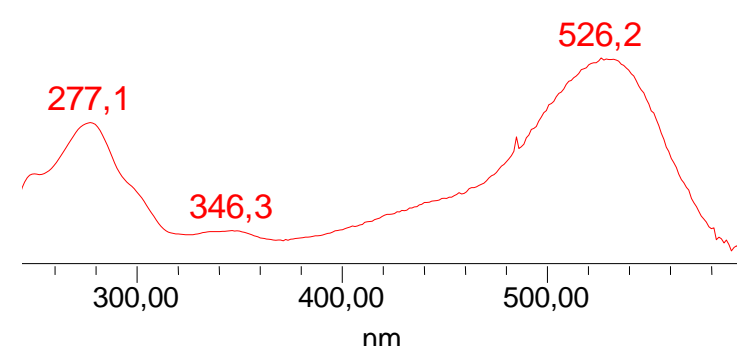

Figura 60: Espectros de absorção UV-Vis máx do extrato do mirtilo (Vaccinium spp) obtidos no DAD (520 nm) enumerados conforme cromatograma da Figura 57. 
Para as substâncias equivalentes aos picos 1 e 2 a análise realizada por CLAE/DAD revelou a presença de dois espectros de absorção com duas bandas cada um na região do UVVis $_{\text {máx }}$ (Figura 58). O isolamento dos picos 1 e 2, recolhido ao final do detetor do CLAE/DAD, possibilitou o estudo dessas duas substâncias, agora no CLUE-EM-QTOF (ESI ${ }^{+}$) (Figura 61)

Essas duas substâncias mostraram a presença de dois picos distintos com tempos de retenção muito próximos, em $t_{R}$ 2,51 e 2,60 minutos, respectivamente. As análises em modo EM/EM no CLUE-EM-QTOF $\left(\mathrm{ESI}^{+}\right)$apresentaram íons moleculares iguais, diferenciando somente nas casas decimais de suas massas acuradas, um a $m / z, 465,1036$ e fragmento 303,0590 (pico 1) após a perda de uma hexose $\left(\left[\mathrm{M}-162 \mathrm{Da}^{+}\right)\right.$e outro a $\mathrm{m} / z$ 465,1116 e fragmento 303,0590 (pico 2), após a perda também de uma hexose ([M-162 Da $]^{+}$(Figura 62).

MS

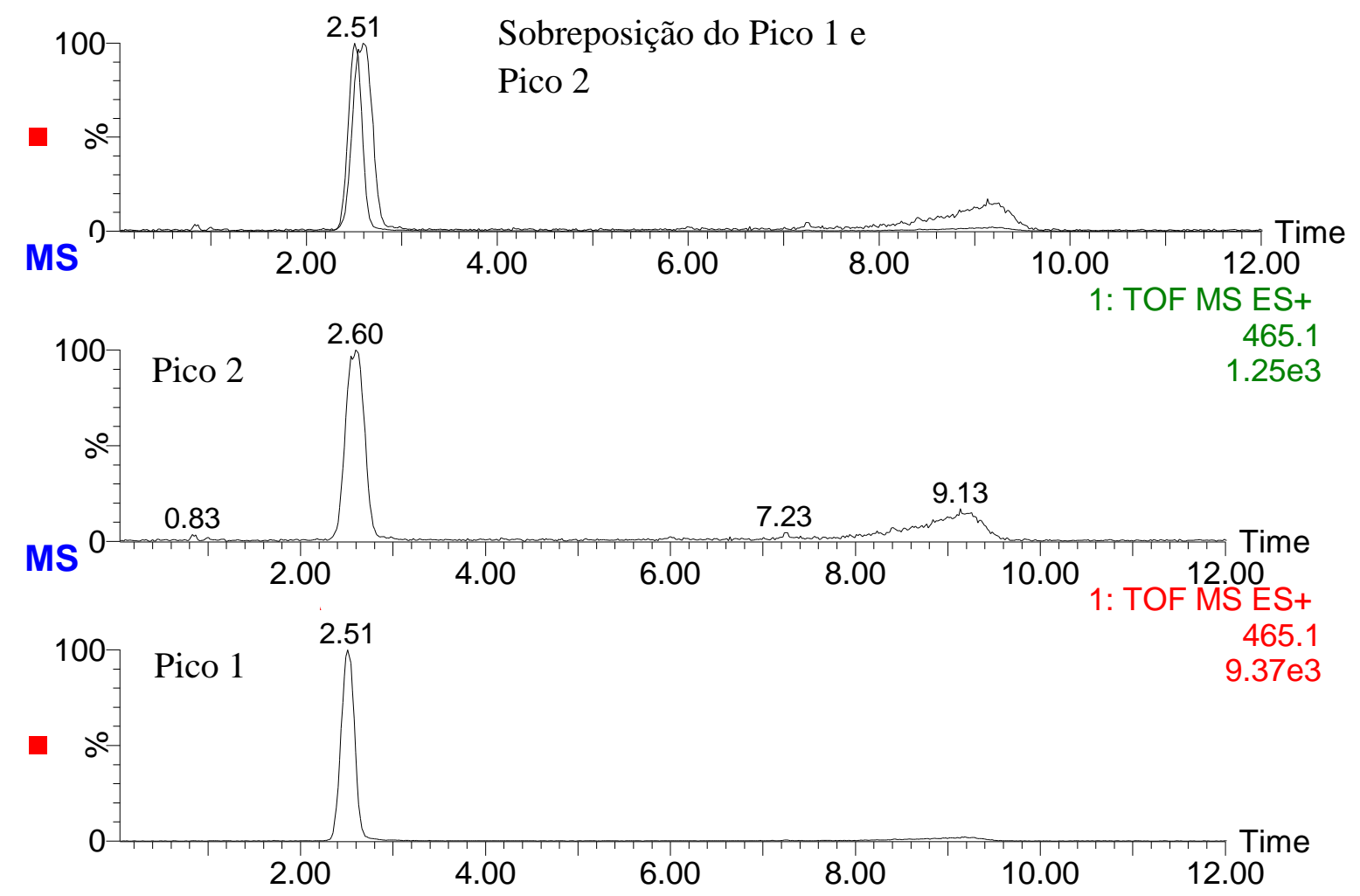

Figura 61: Cromatograma extraído no CLUE TOF-ESI ${ }^{+}$das substâncias 1 e 2, isoladas do extrato do mirtilo (Vaccinium spp), filtrando o íon a $\mathrm{m} / \mathrm{z} 465$. 

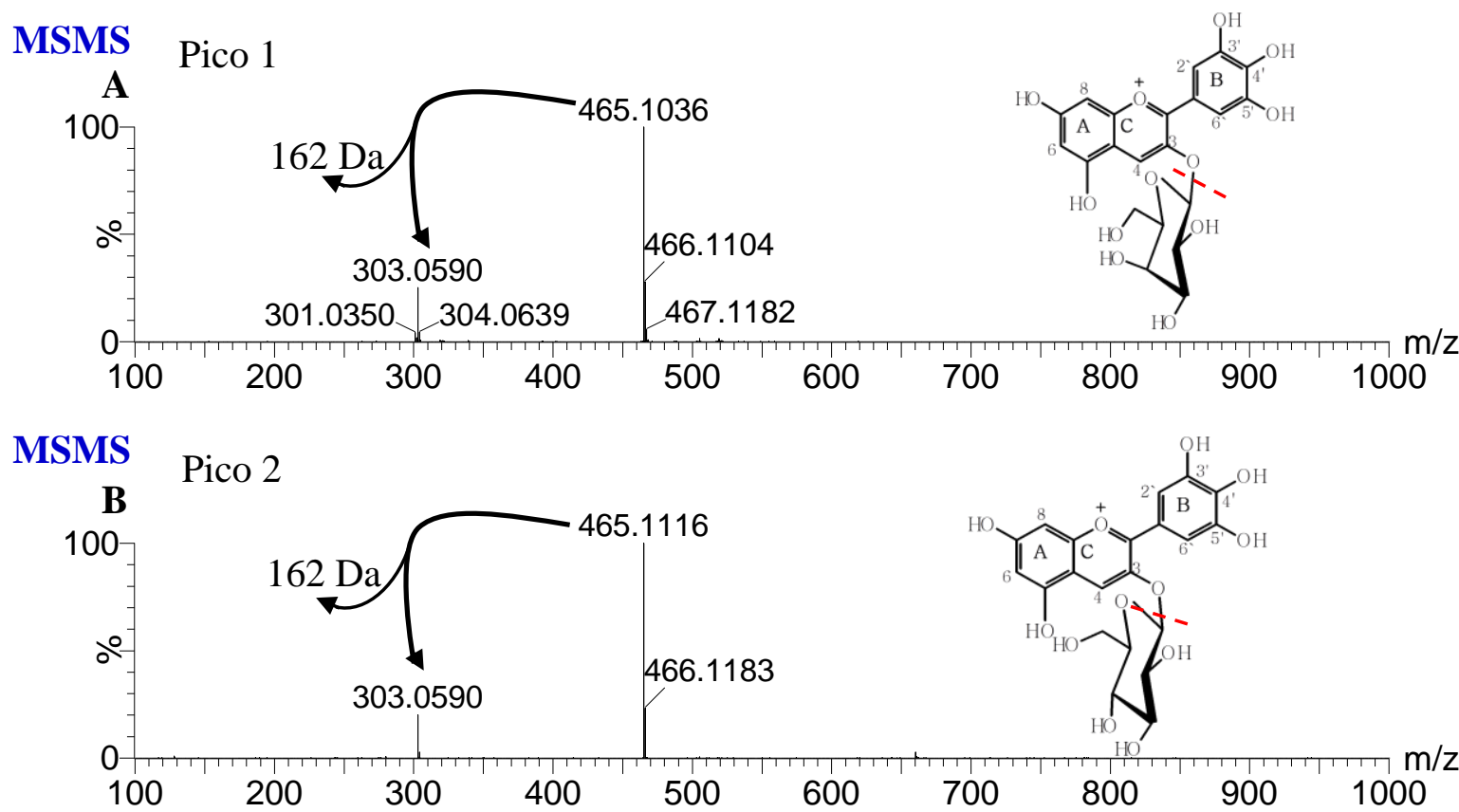

Figura 62: Espectros de massa acurada em modo EM/EM no CLUE-EM-QTOF (ESI $\left.{ }^{+}\right)$: (A) substância equivalente ao pico 1 e (B) substância equivalente ao pico 2 .

As bandas de absorção observadas no visível com $\lambda_{\text {máx }} 521,4$ e $522,6 \mathrm{~nm}$ e a presença do íon fragmento a $m / z$ 303,0590 indicam que os picos 1 e 2 apresentam antocianinas cuja aglicona é a delfinidina. A presença de apenas um fragmento após a perda de $162 \mathrm{Da}$ em ambas as substâncias analisadas (pico 1 e 2) indica que essas antocianinas apresentavam apenas uma hexose como substituinte. Como já observado anteriormente neste estudo, as substâncias glicosiladas ao açúcar galactose sempre eluem com o tempo de retenção inferior quando comparadas às glicosiladas ao açúcar glicose em sistema de fase reversa utilizado. Sendo assim, as substâncias foram identificadas como delfinidina -3-O- galactosídeo (pico 1) e delfinidina3-O-glicosídeo (pico 2).

Para a substância equivalente ao pico 3 a análise realizada por CLAE/DAD (Figura 56) revelou a presença de dois espectros de absorção UV-Vis máx distintos (Figura 58- Pico 3a e b). Cada espectro na região do UV-Vis máx apresentou duas bandas com os $\lambda_{\text {máx }} 278,3 / 516,5 \mathrm{~nm}$ e $278,3 / 521,4 \mathrm{~nm}$. Portanto, caracterizando a presença de duas antocianinas eluindo ao mesmo $t_{R}$ (4,89 minutos), essas substâncias passaram então a serem denominadas de pico 3 e 4 (Figura 57). Os dados obtidos em modo EM/EM no CLUE-EM-QTOF (ESI ${ }^{+}$(Figura 64) mostraram a presença de dois íons moleculares um a $\mathrm{m} / z$ 435,0936 e fragmento 303,0526 após a perda de uma pentose ([M-132 Da $]^{+}$) e outro a $\mathrm{m} / z$ 449,1050 e fragmento 287,0574 com perda de uma hexose $\left([\mathrm{M}-162 \mathrm{Da}]^{+}\right)$.

As bandas de absorção observadas $\lambda_{\text {máx }} 278,3$ e $521,4 \mathrm{~nm}$ e a presença do íon fragmento a $\mathrm{m} / \mathrm{z}, 303,0526$ indicam que a substância equivalente agora ao pico 3 possuía a antocianidina delfinidina. As bandas de absorção observadas $\lambda_{\text {máx }} 278,3$ e $516,4 \mathrm{~nm}$ e a presença do íon a fragmento $\mathrm{m} / \mathrm{z} 287$, indicam que a substância equivalente ao pico 3 possuía a antocianidina cianidina.

A identificação do tipo de açúcar ligado à antocianidina foi baseada no $t_{R}$ para ambas substâncias. A presença de cianidina ligada à hexose galactose confere a antocianindina um 
ganho na polaridade da molécula, diminuindo, portanto, $o t_{R}$ em relação a antocianidina ligada à hexose glicose. O mesmo foi observado em relação ao açúcar ligado à delfinidina, a presença da pentose $(132 \mathrm{Da})$ arabinose confere à molécula um aumento na polaridade do composto quando comparada ao outro isômero deste açúcar a xilose. Dados literários, anteriormente, publicados sobre mirtilo (WU e PRIOR, 2005a; LOHACHOOMPOL et al., 2008; MÜLLER, SCHANTZ e RICHLING, 2012) identificaram essas substâncias como cianidina-3-Ogalactosídeo e delfinidina-3-O - arabinosídeo, eluindo nessa ordem.

Ao extrair os cromatogramas dos íons moleculares das duas substâncias no CLUE-EMQTOF (ESI ${ }^{+}$) (Figura 63) e comparar com os dados da literatura, observou que ocorreu uma inversão na ordem de eluição dessas duas substâncias. Os espectros de massa acurada dessas substâncias adquiridos em modo EM/EM no CLUE-EM-QTOF (ESI ${ }^{+}$) (Figura 63) confirmam a presença dos íons moleculares e fragmentos referentes à delfinidina-3- $O$-arabinosídeo e cianidina-3-O-galactosídeo. Portanto, foi confirmada a presença dessas duas substâncias na matriz analisada.
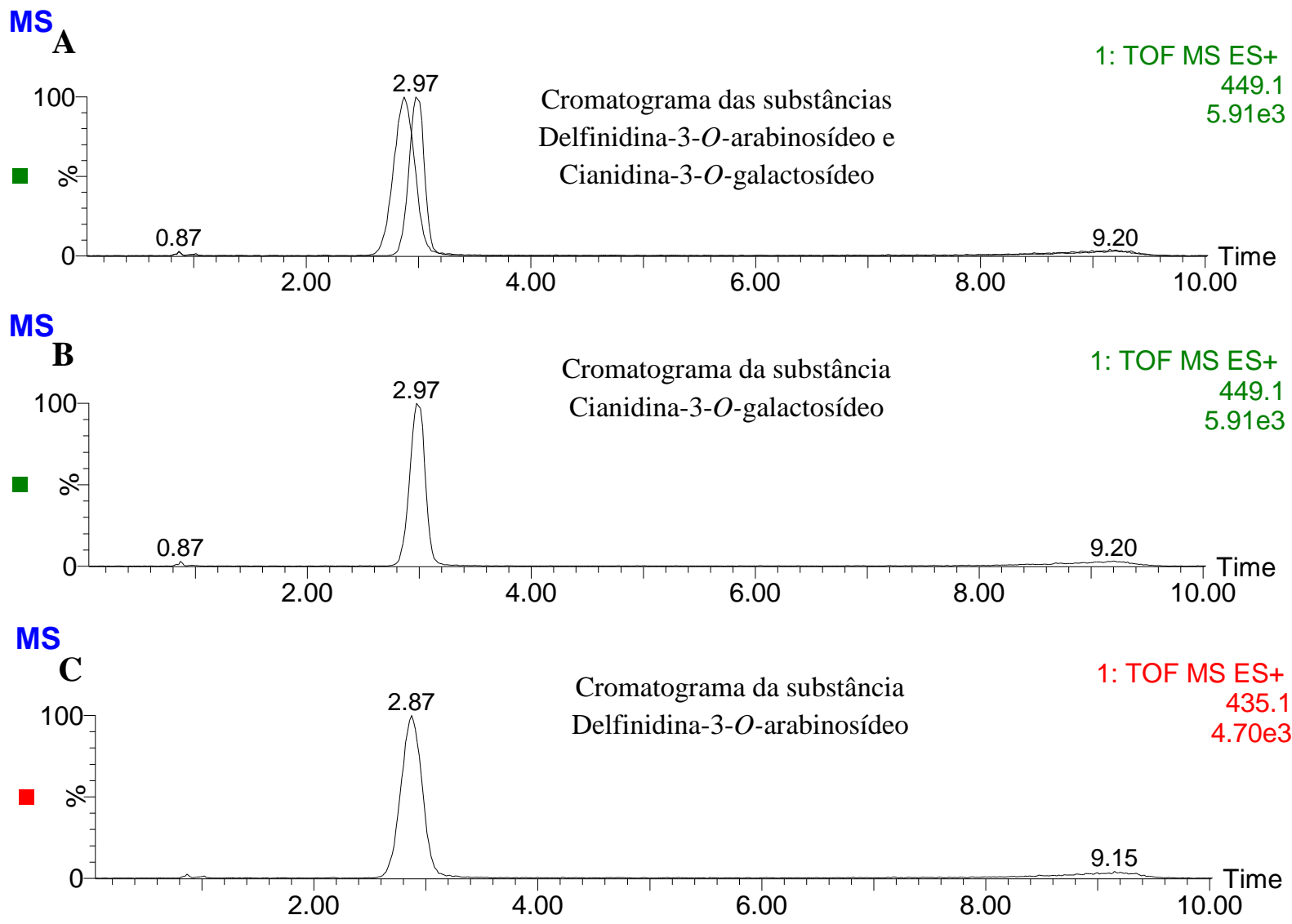

Figura 63: Cromatograma extraído do CLUE-EM-QTOF $\left(\mathrm{ESI}^{+}\right)$das substâncias equivalente ao pico 3a, isoladas do extrato do mirtilo (Vaccinium spp), filtrando os íons a $m / z, 449,1050$ (B) e 435,0936 (C) e (A) Sobreposição dos cromatogramas (B) e (C). 


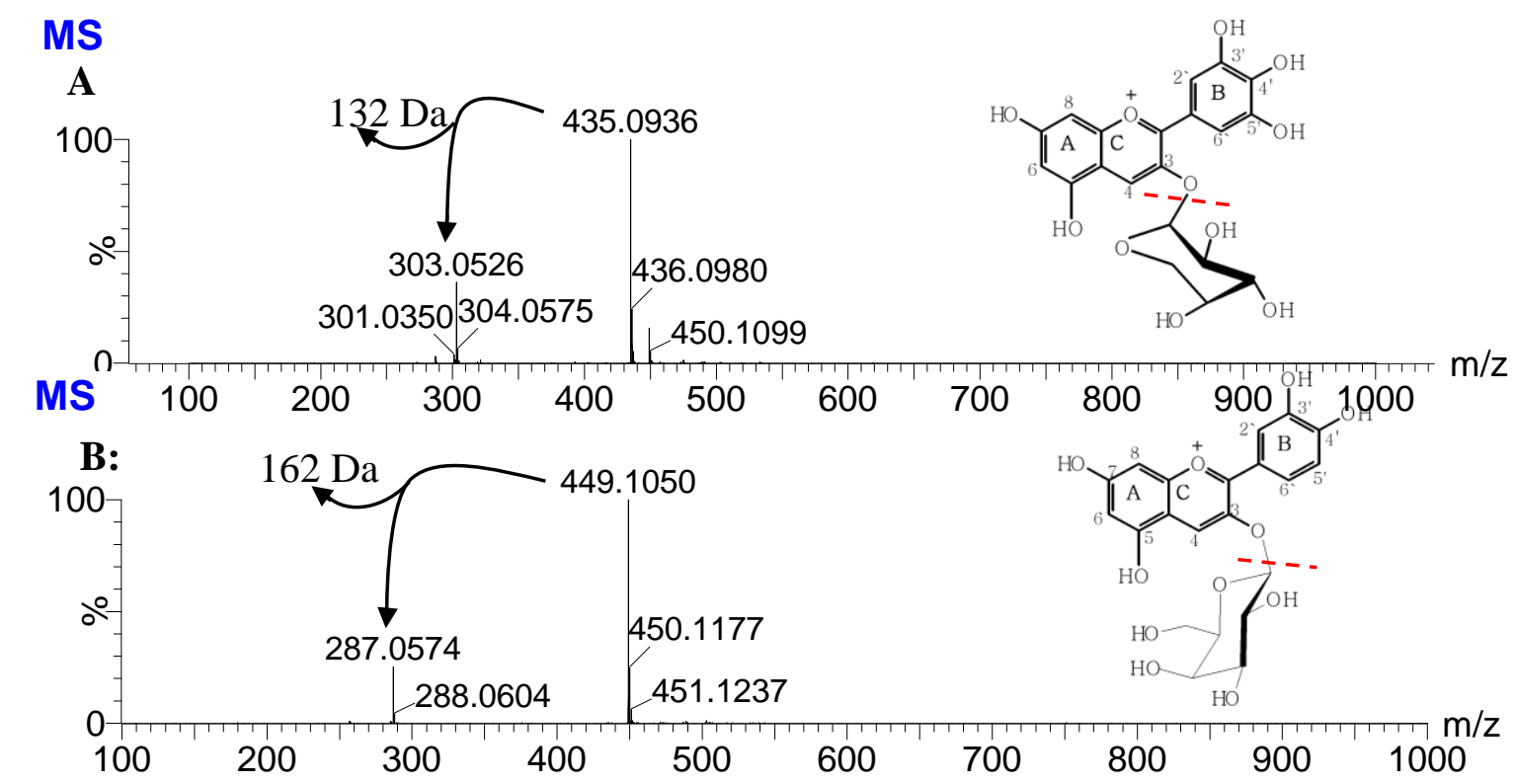

Figura 64: Espectros de massa acurada em modo EM/EM no CLUE-EM-QTOF (ESI+) da substância 3 (Figura 53): (A) delfinidina-3-O-arabinosídeo e (B) cianidina-3-O-galactosídeo.

As substâncias equivalentes dos picos 5 ao 8 da análise realizada por CLAE/DAD (Figura 57) revelaram a presença dos espectros de absorção na região do UV-Vis máx (Figura 58). Os espectros de absorção apresentaram duas bandas para cada um dos 4 picos com os $\lambda_{\text {máx: }}$ : $279,5 / 516,5 \mathrm{~nm} ; 277,5 / 526,2 \mathrm{~nm} ; 279,5 / 517,7 \mathrm{~nm}$ e 278,3/526,2 $\mathrm{nm}$, respectivamente onde todos são característicos de antocianinas. Os dados obtidos em modo EM/EM no CLUEEM/QTOF $\left(\mathrm{ESI}^{+}\right.$) (Figura 65) mostraram a presença de íons moleculares a $\mathrm{m} / \mathrm{z}: 449,1285 \mathrm{e}$ fragmento 287,0551 após a perda de uma hexose ([M-162 Da $\left.]^{+}\right) ; 479,1200$ e fragmento $317,0696$ após a perda de uma hexose ([M-162 Da $\left.]^{+}\right) ; 419,0977$ e fragmento 287,0574 após a perda de uma pentose ([M-132 Da $\left.]^{+}\right)$; e 479,1179 e fragmento 317,0667 após a perda de uma hexose $\left([\mathrm{M}-162 \mathrm{Da}]^{+}\right)$.

Sendo assim, as bandas características de absorção na região do UV-Vismáx das substâncias equivalentes aos picos 5 e 7 (Figura 58) e a presença dos íons fragmentos a $\mathrm{m} / z, 287$ em comum às duas antocianinas, indicaram que estas antocianidinas são cianidinas. No primeiro caso, pico 5, a antocianina correspondente apresenta-se ligada a uma hexose. O tempo de retenção observado tanto na análise por CLAE (Figura 57) quanto por CLUE (Figura 66) confirmam ser a presença de uma glicose, visto que, a cianidina-3- $O$-galactosídeo elui em tempo inferior.

A substância equivalente ao pico 7, outro derivado de cianidina, foi sugerida por este estudo estar ligada ao açúcar arabinose, uma vez que no sistema de fase reversa seu isômero xilose eluiria em tempo de retenção superior ao observado. Portanto, as duas antocianinas foram identificadas como cianidina-3- $O$-glicosídeo e cianidina-3- $O$-arabinosídeo, respectivamente.

Para as substâncias equivalentes aos picos 6 e 8 (Figura 56 ou 57), as bandas características no $\lambda_{\text {máx }} 526 \mathrm{~nm}$, da região do visível, e seus íons em comum, tanto os íons moleculares a $\mathrm{m} / z, 479$ assim como seus fragmentos a $\mathrm{m} / \mathrm{z}$ 317, indicam a presença de uma petunidina como antocianindina para as duas substâncias, ambas ligadas a uma hexose. Seguindo o raciocínio da 
polaridade, já discutido anteriormente, pode-se sugerir que a substância equivalente ao pico 6 é uma petunidina-3- $O$-galactosídeo e a substância equivalente ao pico 8 é uma petunidina-3$O$-glicosídeo. Todos os dados foram consistentes com trabalhos anteriormente publicados sobre algumas variedades de mirtilo (KÄHKÖNEN et al., 2003; WU e PRIOR, 2005b; LOHACHOOMPOL et al., 2008; GAVRILOVA et al., 2011; BUNEA et al., 2013; MÜLLER, SCHANTZ e RICHLING, 2012; YOUSEF et al., 2013).

\section{MSMS}
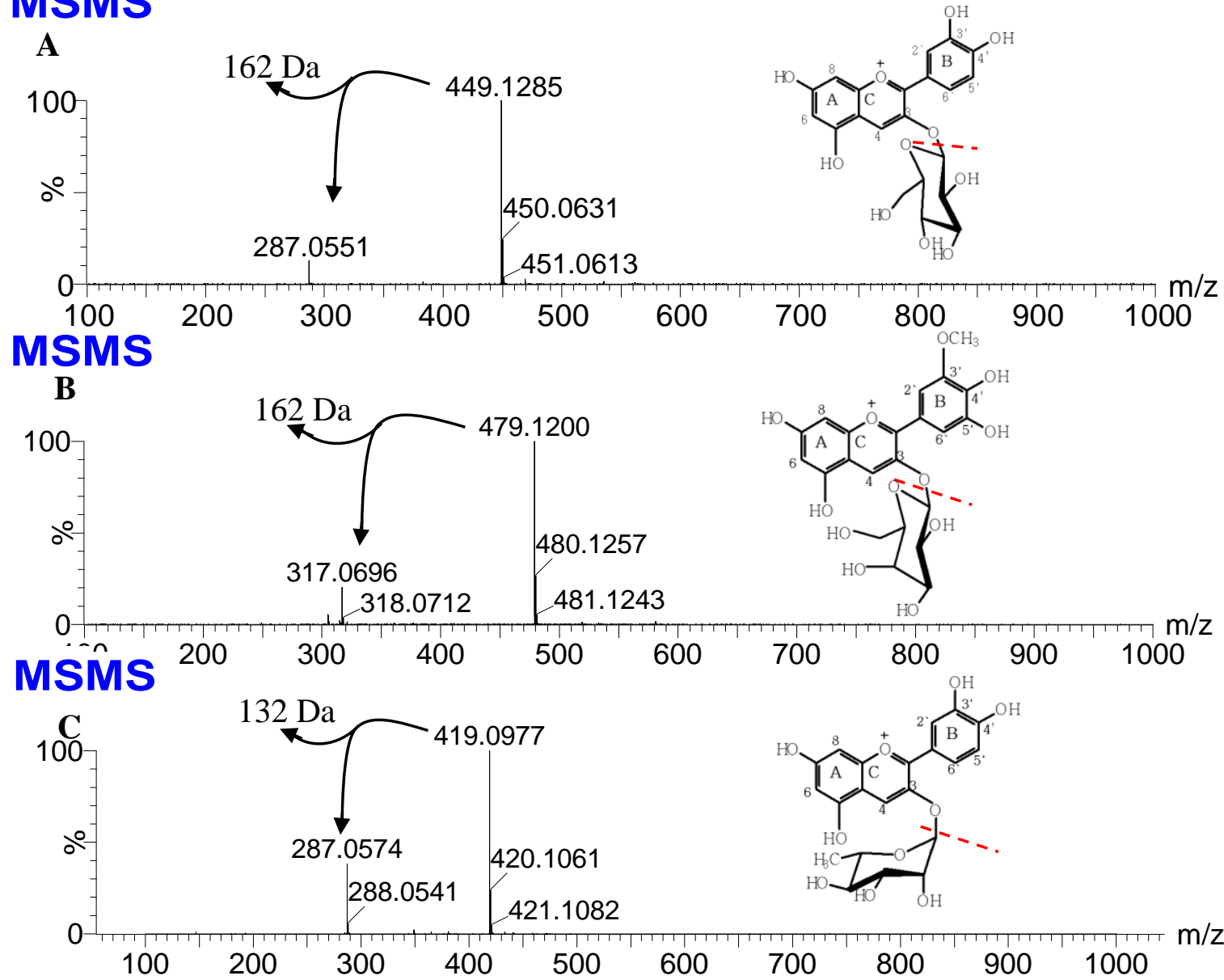

MSMS

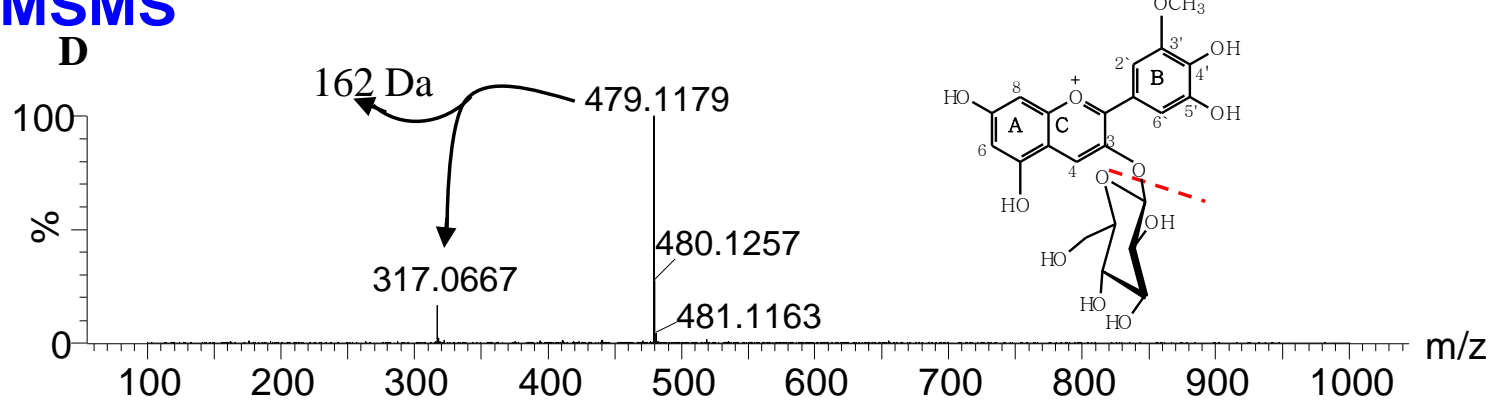

Figura 65: Espectros de massa acurada em modo EM/EM $\left(\mathrm{ESI}^{+}\right)$da substância 5: (A) cianidina-3-O-glicosídeo; (B) petunidina-3-O-galactosídeo; (C) cianidina-3-O-arabinosídeo e; (D) petunidina-3-O-glicosídeo 

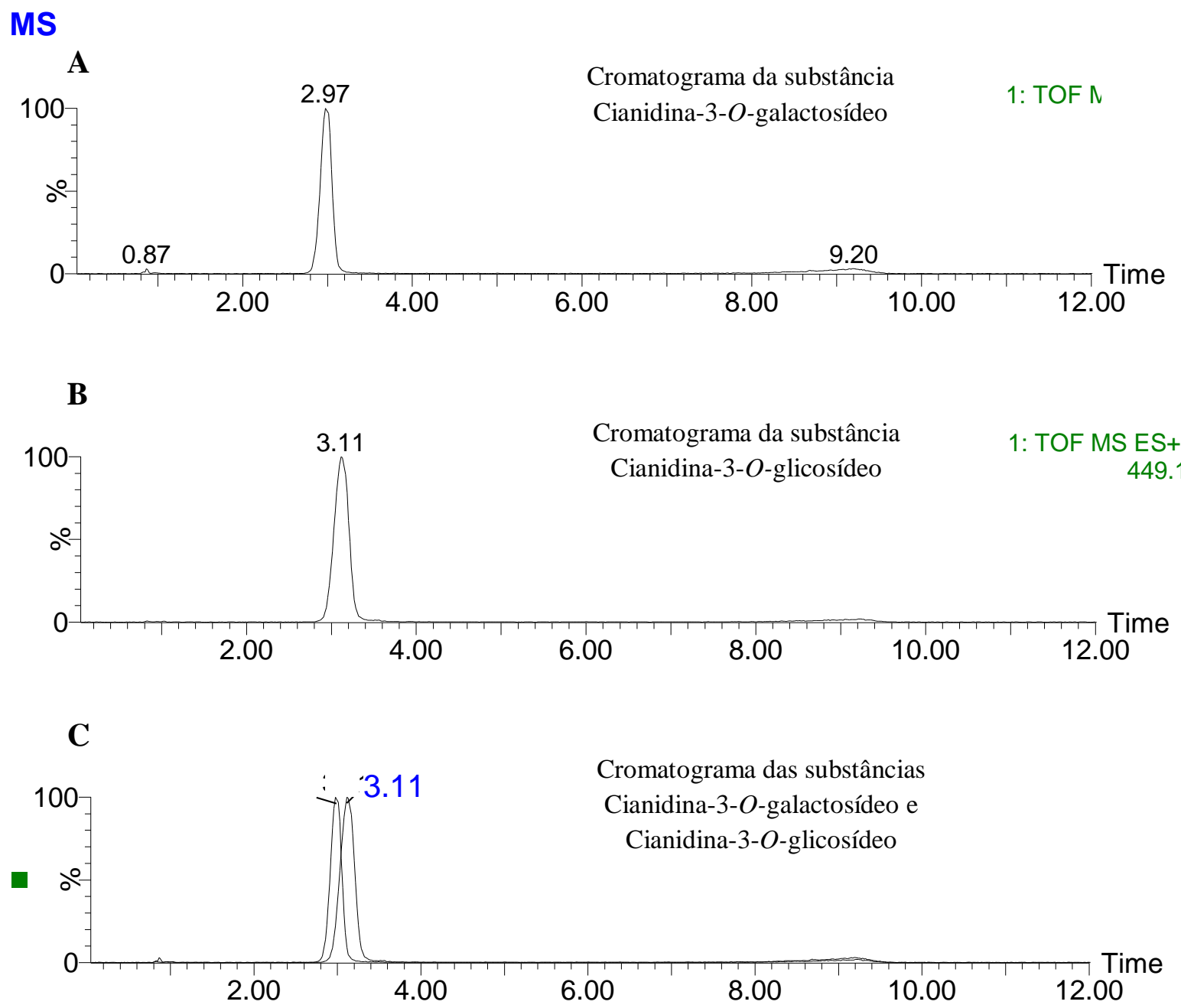

Figura 66: Cromatogramas extraídos no CLUE-EM-QTOF $\left(\mathrm{ESI}^{+}\right)$das substâncias equivalentes aos picos: 3a (A) e 5 (B), isoladas do extrato do mirtilo (Vaccinium spp), filtrando o íon a $\mathrm{m} / \mathrm{z} 449$. (C) Sobreposição dos cromatogramas (A) e (B).

A substância equivalente ao pico 9 da análise realizada por CLAE/DAD (Figura 57) revelou a presença de dois espectros de absorção UV-Vismáx distintos (Figura 59- Pico 9a e 9b). Cada espectro de absorção apresentou duas bandas com os $\lambda_{\text {máx }} 277,1 / 526,2 \mathrm{~nm}$ e 278,3/516,5 $\mathrm{nm}$. Esse fato caracterizou a presença de duas antocianinas eluindo com mesmo $t_{R}(7,85$ minutos). Essas substâncias foram então denominadas de pico 9 e 10 na Figura 57. Os dados obtidos em modo EM/EM no CLUE-EM-QTOF (ESI ${ }^{+}$) (Figura 67), mostraram a presença de dois íons moleculares, um a $\mathrm{m} / z$ 449,1129 e fragmento 317,0696 após a perda de uma pentose $\left([\mathrm{M}-132 \mathrm{Da}]^{+}\right)$e outro a $\mathrm{m} / \mathrm{z}, 463,1252$ e fragmento 301,0735 após a perda de uma hexose ([M$\left.162 \mathrm{Da}]^{+}\right)$.

As bandas de absorção observadas na região do visível com $\lambda_{\text {máx }} 526,2 \mathrm{~nm}$ e a presença do íon fragmento a $\mathrm{m} / \mathrm{z} 317,0735$ indicam que a substância equivalente ao pico 9 apresenta a antocianidina petunidina. As bandas de absorção observadas na região do visível com $\lambda_{\text {máx }} 516,5$ nm e a presença do íon a fragmento $\mathrm{m} / z$ 301,0735 indicam que a substância equivalente ao pico 10 possui a antocianidina peonidina. A ordem de eluição pôde ser conferida através do cromatograma extraído no CLUE-EM-QTOF $\left(\mathrm{ESI}^{+}\right)$(Figura 68). 


\section{MSMS}
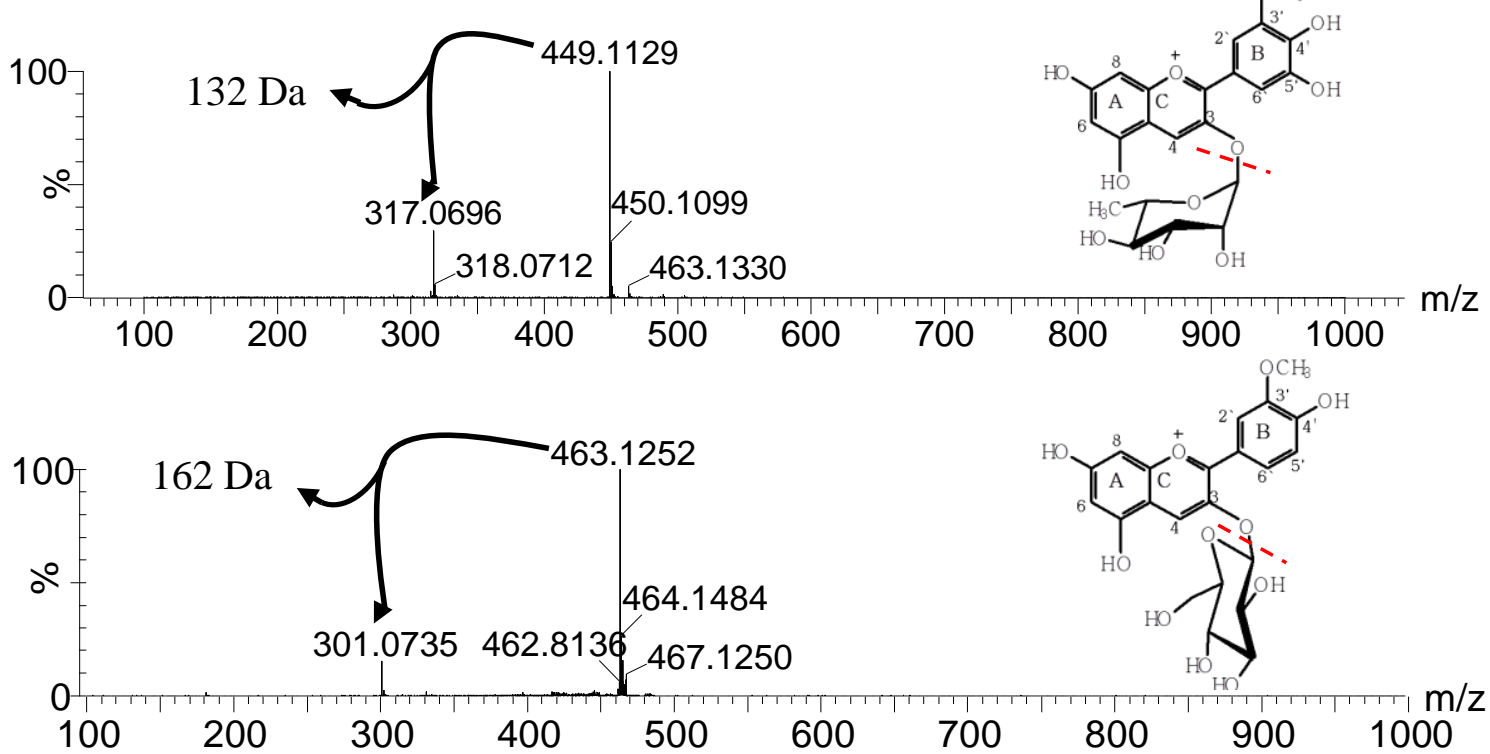

Figura 67: Espectros de massa acurada em modo EM/EM no CLUE-EM-QTOF (ESI $\left.{ }^{+}\right)$: (A) substância equivalente ao pico 9 e (B) substância equivalente ao pico 10 do cromatograma da Figura 57.

\section{MS}
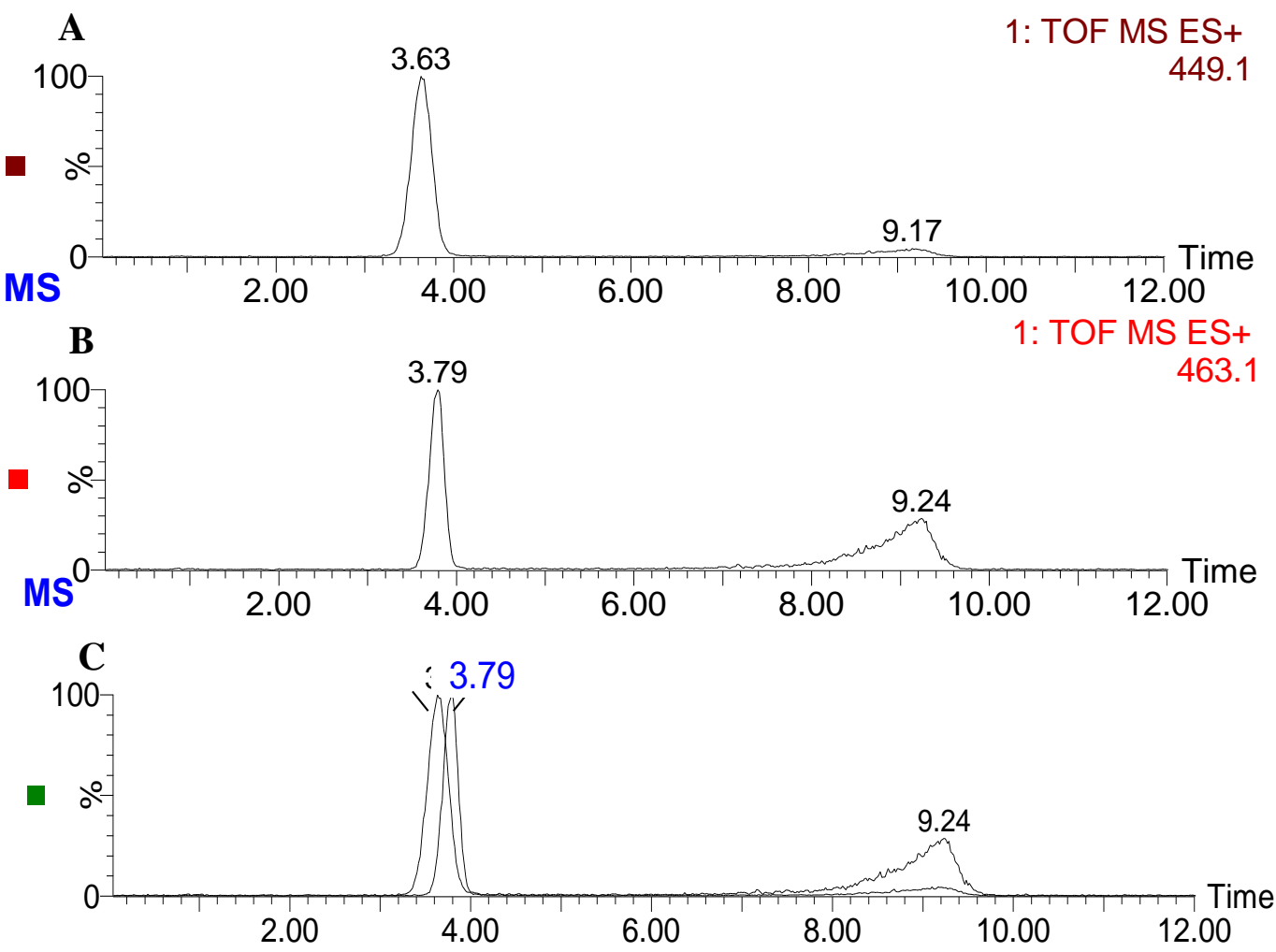

Figura 68: Cromatograma extraído do CLUE-EM-QTOF $\left(\mathrm{ESI}^{+}\right)$das substâncias equivalentes ao pico: 9 , isoladas do extrato do mirtilo (Vaccinium spp), filtrando os íons a $m / z$ 449,1050 (A) e 463,1252 (B) e (C) Sobreposição dos cromatogramas (B) e (C). 
A presença da antocianidina peonididina ligada aos açúcares galactose e glicose tem sido relatada por muitos pesquisadores em diferentes variedades e cultivares de mirtilo em trabalhos literários (KÄHKÖNEN et al., 2003; WU e PRIOR, 2005b; LOHACHOOMPOL et al., 2008; GAVRILOVA et al., 2011; MÜLLER, SCHANTZ e RICHLING, 2012; YOUSEF et al., 2013). Bunea e colaboradores (2013) estudando sete cultivares de mirtilo que cresceram na România, só identificaram a presença da peonidina ligada à galactose, não identificando a presença da peonidina-3-O-glicosídeo. A ordem de eluição, da peonidina ligada à galactose, utilizando o sistema de fase reversa, têm sido mostradas em todos os trabalhos consultados com tempo de retenção superior ao da petunidina-3-O-glicosídeo e, inferior ao da antocianina petunidina-3-O-arabnosídeo (KÄHKÖNEN et al., 2003; WU e PRIOR, 2005b; LOHACHOOMPOL et al., 2008; GAVRILOVA et al., 2011; MÜLLER, SCHANTZ e RICHLING, 2012; YOUSEF et al., 2013). Na matriz mirtilo do presente estudo não foi observada a presença da antocianina peonidina-3- $O$-galactosídeo, pois, sugere-se que a hexose ligada à aglicona peonidina seja uma glicose, já que possui tempo de retenção superior ao da antocianina petunidina-3- $O$-arabinosídeo. Portanto, este estudo caracterizou as antocianidinas equivalentes ao pico 9 como petunidina-3- $O$-arabinosídeo e, ao pico 10 como peonidina-3- $O$ glicosídeo.

As substâncias equivalentes aos picos de 11, 12, 15, 16, 19 e 20 observadas nas análises realizadas no CLAE/DAD (Figura 57) revelaram a presença de duas bandas para cada pico nos espectros de absorção UV-Vis máx (Figura 59 e 60), características de antocianinas.

Para esses picos, as bandas com os $\lambda_{\text {máx }}$ no visível apresentaram comprimento de onda superior a $520 \mathrm{~nm}$. O sistema de solventes utilizado em todas as análises realizadas tem

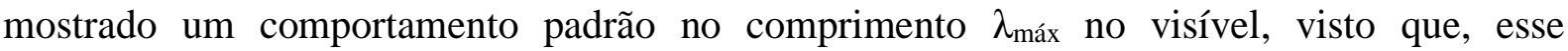
comprimento de onda está intimamente relacionado com o padrão de hidroxilação do anel B da antocianina.

Foram observados para as antocianinas derivadas de cianidina, pelargonidina e peonidina submetidas às leituras no visível, valores de $\lambda_{\text {máx }}$ inferiores a $520 \mathrm{~nm}$. Foi sugerido então a presença de antocianidinas como delfinidina, petunidina e malvidina.

A delfinidina logo em seguida foi descartada, pois, a molécula deveria estar ligada a um radical que conferisse grande apolaridade para justificar seu grande deslocamento no tempo de retenção, e sua antocianidina não foi detetada quando essas substâncias foram submetidas à analises no espectrômetro de massa acurada (CLUE-EM/EM-QTOF $\left(\mathrm{ESI}^{+}\right)$.

A substância equivalente ao pico 13 (Figura 57) apresentou na análise realizada por CLAE/DAD a presença de dois espectros de absorção UV-Vismáx (Figura 59- Pico 13), duas bandas na região do visível com os $\lambda_{\text {máx }} 279,5 / 517,7 \mathrm{~nm}$. Como seu $\lambda_{\text {máx }}$ no visível foi inferior a $520 \mathrm{~nm}$, foi sugerido ser uma antocianina derivada de cianidina ou peonidina, visto que as antocianinas derivadas de pelargonidinas neste sistema absorveram abaixo de $510 \mathrm{~nm}$.

Os dados obtidos para os picos 11, 12, 13, 15, 16, 19 e 20 no modo EM/EM no CLUEEM-QTOF $\left(\mathrm{ESI}^{+}\right.$) (Figura 69 e 70) foi observado para as substâncias equivalentes aos picos 11 e 12 valores idênticos de massa acurada para íons moleculares a $m / z$ 493,1404 e seus fragmentos a $m / z, 331,0893$, após a perda de uma hexose ([M-162 Da $\left.]^{+}\right)$; para a substância equivalente ao pico 13 o íon molecular a $\mathrm{m} / \mathrm{z} 433,1188$ e seu fragmento a $\mathrm{m} / \mathrm{z} 301,0797$, após a perda de uma pentose $\left([\mathrm{M}-132 \mathrm{Da}]^{+}\right)$; para a substância equivalente ao pico 15 o íon molecular a $\mathrm{m} / \mathrm{z} 463,1093$ e seu fragmento a $m / z$ 331,0825, após a perda de uma pentose ([M-132 Da $]^{+}$); para as substâncias equivalentes aos picos 16 e 20 os íons moleculares a $m / z, 535,1169$ e 535,1085 e 
seus fragmentos a $\mathrm{m} / \mathrm{z} 331,0690$ e 331,0690, respectivamente, após a perda de um fragmento de $204 \mathrm{Da}$; e para a substância equivalente ao pico 19 o íon molecular.

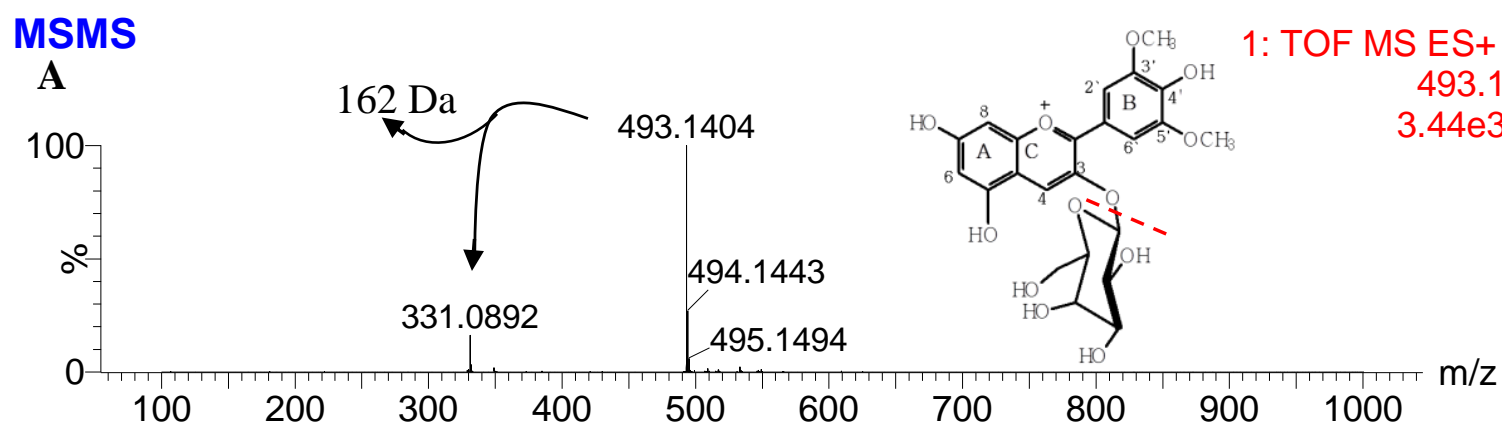

\section{MSMS}
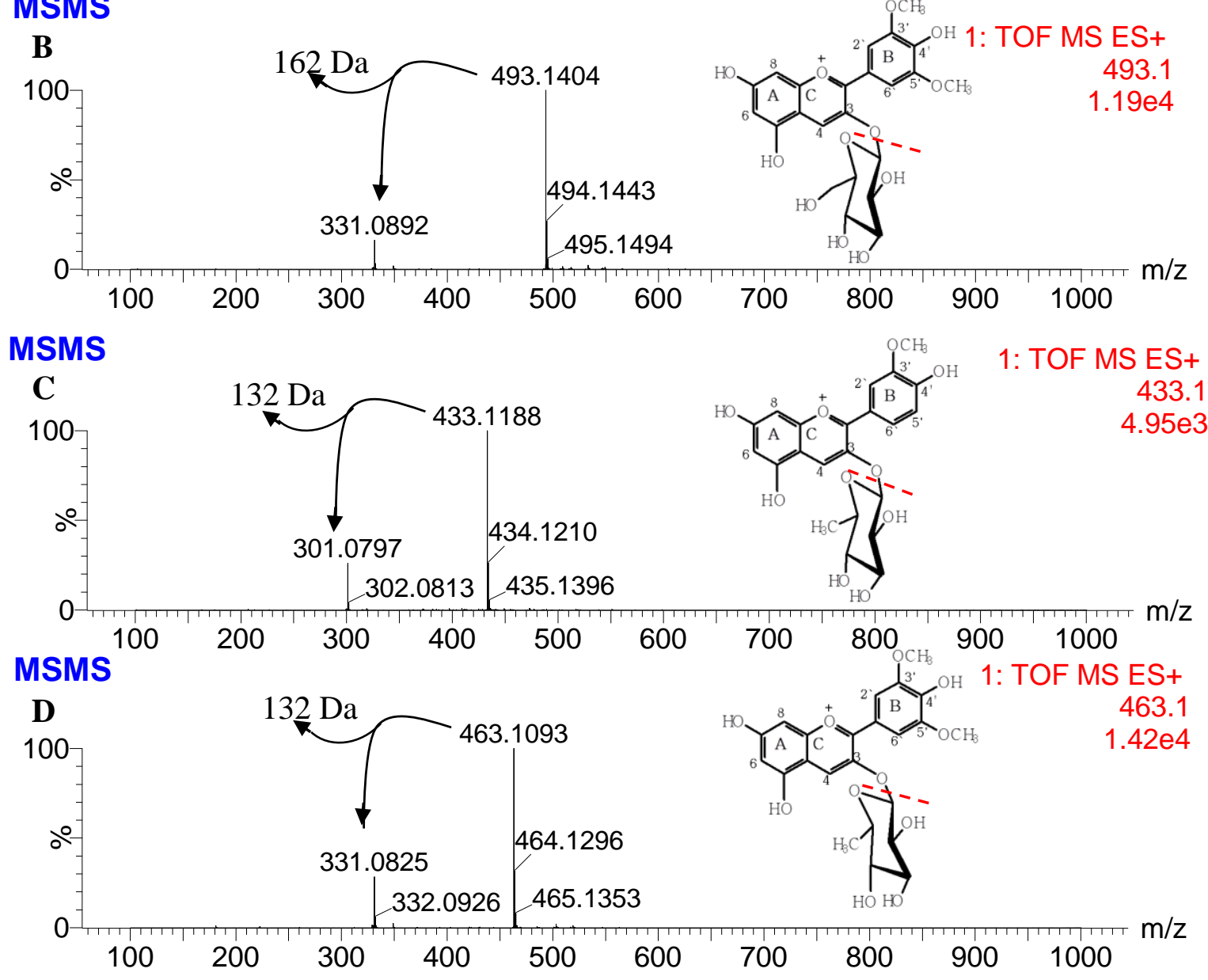

Figura 69: Espectros de massa acurada em modo EM/EM $\left(\mathrm{ESI}^{+}\right)$: $(\mathbf{A})$ substância equivalente ao pico 11; (B) substância equivalente ao pico 12; (C) substância equivalente ao pico 13; (D) substância equivalente ao pico 15. 


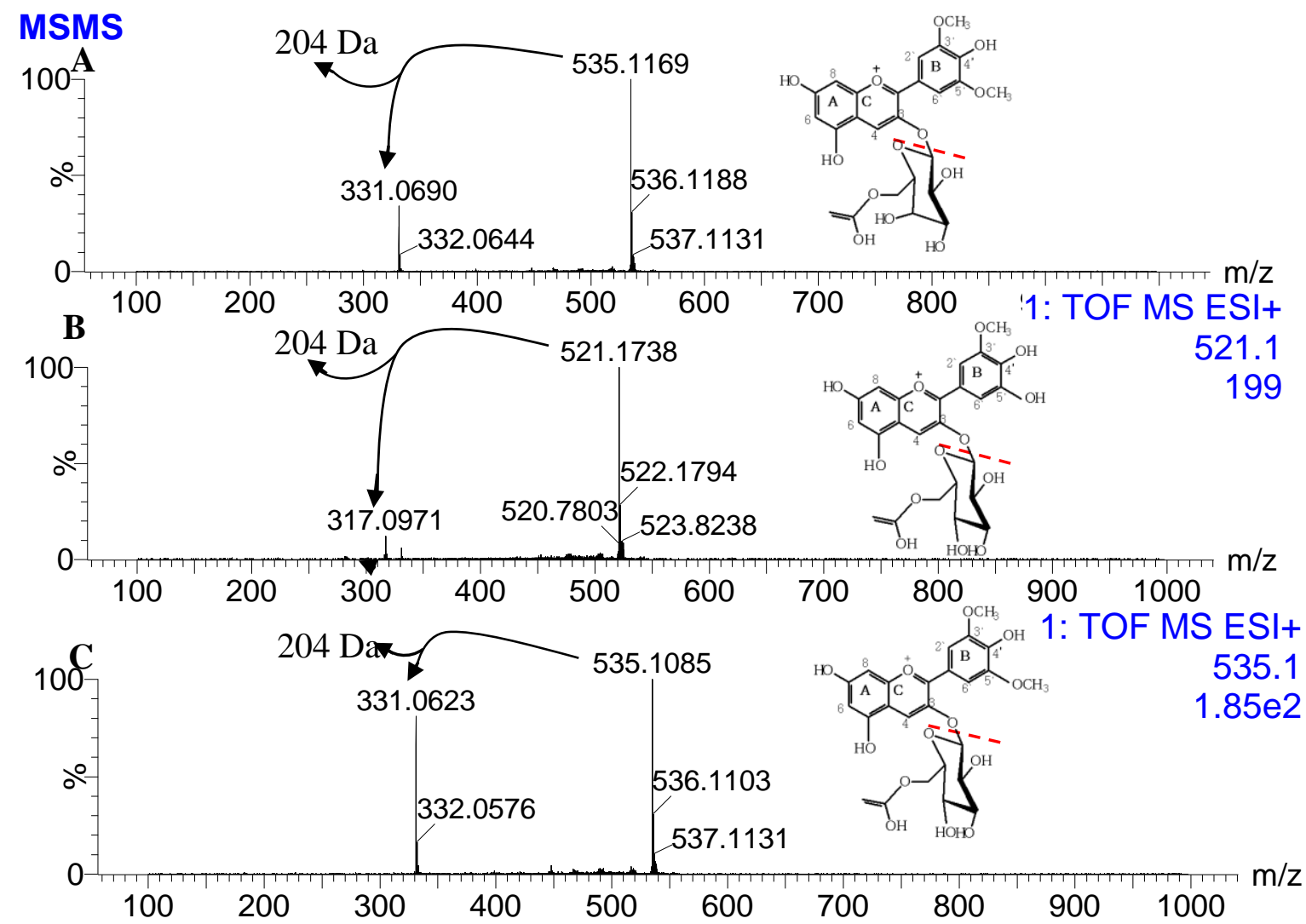

Figura 70: Espectros de massa acurada em modo EM/EM (ESI $\left.{ }^{+}\right)$: (A) substância equivalente ao pico 16; (B) substância equivalente ao pico $19 \mathrm{E}$; (C) substância equivalente ao pico 20 .

As bandas de absorção observadas no visível com $\lambda_{\text {máx }} 522,2$ e 526,2 nm associadas a presença do íon molecular a $\mathrm{m} / \mathrm{z} 493$ assim como seus fragmentos a $\mathrm{m} / \mathrm{z} 331$, indicaram a presença de uma malvidina ligada a uma hexose.

De acordo com a ordem de eluição sugere-se que a substância equivalente ao pico 11 é uma malvidina-3-O-galactosídeo e a substância equivalente ao pico 12 uma malvidina-3-Oglicosídeo. As substâncias equivalentes aos picos 13 e 15, apresentaram em comum a perda de $132 \mathrm{Da}$, de massa neutra, indicando o açúcar como arabinose, visto que de uma forma geral essa foi a pentose relatada por diversos trabalhos na literatura como presente nas variedades de mirtilo.

As respectivas antocianidinas ligadas a esse açúcar foram identificadas como peonidina para a substância equivalente ao pico 13 e malvidina para a substância equivalente ao pico 15 . Sendo assim, as antocianinas presentes nestas substâncias são peonidina-3- $O$-arabinosídeo e malvidina-3- $O$-arabinosídeo.

As substâncias equivalentes aos picos 16, 19 e 20 também apresentaram a perda de uma massa neutra em comum no valor de 204 Da. Além disso, as substâncias 16 e 20 apresentam também o mesmo valor de íon molecular $[\mathrm{M}]^{+}$a $\mathrm{m} / \mathrm{z} 535$ e fragmento a $\mathrm{m} / \mathrm{z}$ 331. Trabalhos literários consultados (PRIOR et al., 2001; KÄHKÖNEN et al., 2003; WU e PRIOR, 2005b; 
GAVRILOVA et al., 2011; YOUSEF et al., 2013) identificaram o radical (204 Da) ligado à antocianidina como sendo uma hexose ligada a acetila, pelo carbono de número 6 deste açúcar $(162+42 \mathrm{Da})$. Com essas ferramentas pode-se sugerir, através da ordem de eluição as antocianinas são: malvidina-3-O-(6"-acetila)-galactosídeo; petunidina-O-3-(6"-acetila)glicosídeo e malvidina-3-O-(6"-acetila)-glicosídeo.

A sugestão do açúcar ligado a petunidina ser uma glicose teve fundamento a partir da comparação com dados literários, onde essa antocianina sempre aparece entre as antocianinas malvidinas ligadas aos radicais hexosídeos (galactosídeo e glicosídeo) acilados à acetila (PRIOR et al., 2001; WU e PRIOR, 2005b; NICOUÉ; SAVARD e BELKACEMI, 2007; YOUSEF et al., 2013).

A antocianidina mais abundante no mirtilo foi a malvidina com cinco derivados (dois hexosídeos, um pentosídeo e dois hexosídeos acetilados), sendo malvidina-3-O-galactosideo com maior teor entre as antocianinas. Este dado apresentou conformidade com trabalhos publicados. Cinco das seis antocianidinas mais comuns em alimentos (delfinidina, cianidina, peonidina, petunidina e malvidina), que sempre são encontradas nas variedades de mirtilo, também foram observadas pelo presente estudo, estando ausente somente a antocianidina pelargonidina.

Confirmou-se também a ordem de eluição para os derivados de uma mesma antocianidina, utilizando o sistema em fase reversa. Após o incremento do solvente apolar durante a corrida cromatográfica, as antocianidinas ligadas aos galactosídeos eluem em tempo de retenção inferiores aos glicosídeos, que por sua vez saem antes dos pentosídeos (no caso arabinosídeo). Além disso, pode-se observar que a acilação nos açúcares das antocianinas provoca diminuição da polaridade, aumentando, portanto, o tempo de retenção. Isso faz com que essas antocianinas aciladas eluam depois de seus respectivos glicosídeos.

O presente estudo através das ferramentas utilizadas obteve a identificação de 17 das 22 antocianinas observadas. As cinco substâncias restantes não puderam ser isoladas e identificadas durante este procedimento, pois, necessitam de uma etapa de pré-concentração que não foi realizada para as antocianinas com baixíssimo teor na matriz.

A matriz utilizada, mirtilo (Vaccinium spp), será uma boa fonte de padrão das substâncias equivalentes aos picos $1,6,7,12,13,15,16$ e 20. Além disso, poderá ser utilizada como parâmetro para confirmação da presença dessas antocianinas em outras matrizes desconhecidas.

A matriz serviu também para avaliar o método de análise por CLAE desenvolvido neste estudo. Apesar da coeluição dos picos 3 e 9 o método mostrou estar apto para análise dessa matriz, visto que apresentou ótima resolução entre os picos das substâncias separando 17 das 22 substâncias presentes em apenas 20 minutos de corrida.

O tempo de corrida, portanto, seria uma excelente vantagem em relação às outras metodologias, pois, trabalhos publicados anteriormente usando diferentes metodologias com colunas de fase reversa, também mostraram dificuldade de separação das antocianinas nas diferentes matrizes de mirtilo analisadas. Em algumas das substâncias, mesmo com tempo de corrida superior a 40 minutos, houve coeluição. Isso pode ser justificado, pela grande similaridade na polaridade de algumas das substâncias presentes nas matrizes de mirtilo (Tabela 17). 
Tabela 17: Metodologias de separação cromatográfica de antocianinas em algumas variedades de mirtilo

\begin{tabular}{|c|c|c|c|c|c|c|c|}
\hline Método & Fase Móvel A & Fase Móvel B & $\begin{array}{c}\text { Coluna } \\
\mathrm{C}_{18}\end{array}$ & Gradiente & $\begin{array}{l}\text { Tempo de } \\
\text { corrida } \\
\text { (minutos) }\end{array}$ & $\begin{array}{l}\text { Número de } \\
\text { ACN } \\
\text { separadas }\end{array}$ & Referência \\
\hline LC/DAD & Metanol & 3\% Ácido Fórmico & $\begin{array}{l}\text { Xterra }^{\mathrm{TM}} \mathrm{MS} \\
(150 \mathrm{~mm} \mathrm{x} \\
2.1 \mathrm{~mm}, *)\end{array}$ & $\begin{array}{l}0-5 \min , 15-20 \% \text { A; } 5-10 \min , 20 \% \text { A; } 10-25 \\
\min , 20-25 \% \text { A; } 25-30 \mathrm{~min}, 25 \% \text { A; } 30-46 \text { min, } \\
25-70 \% \text { A; } 46-52 \text { min, } 70 \% \text { A; } 52-55 \text { min, } 70- \\
15 \% \text { A }\end{array}$ & 55 & $\begin{array}{l}13 \text { de } 14 \\
\text { presentes }\end{array}$ & $\begin{array}{l}\text { LOHACHOOMPOL } \\
\text { et al., } 2008\end{array}$ \\
\hline $\begin{array}{l}\text { HPLC/ } \\
\text { DAD }\end{array}$ & Metanol & 5\% Ácido Fórmico & $\begin{array}{l}\text { Zorbax, SB } \\
(250 \mathrm{~mm} \times \\
4.6 \mathrm{~mm}, 5 \mu \mathrm{m})\end{array}$ & $\begin{array}{l}0-2 \min , 5 \% \text { A; } 2-10 \min , 5-20 \% \text { A; } 10-15 \min \text {, } \\
20 \% \text { A; } 15-30 \mathrm{~min}, 20-25 \% \text { A; } 35-50 \text { min, } 25- \\
33 \% \text { A; } 50-55 \text { min, } 33 \% \text { A; } 55-65 \text { min, } 33-36 \% \\
\text { A; } 65-70 \text { min, } 36-45 \% \text { A; } 70-75 \text { min, } 45-53 \% \text { A }\end{array}$ & 90 & $\begin{array}{l}23 \text { de } 27 \\
\text { presentes }\end{array}$ & WU e PRIOR, 2005 \\
\hline $\begin{array}{l}\text { HPLC/ } \\
\text { UV-Vis }\end{array}$ & $\begin{array}{l}\text { ACN 50\%: Água } \\
40 \%: \text { Ácido Fór- } \\
\text { mico } 10 \%, \mathrm{v} / \mathrm{v} / \mathrm{v}\end{array}$ & $\begin{array}{l}\text { ACN 87\%: Água } \\
3 \%: \text { Ácido Fór- } \\
\text { mico }-10 \%, \mathrm{v} / \mathrm{v} / \mathrm{v}\end{array}$ & $\begin{array}{l}\text { Phenomenex, } \\
\quad(250 \mathrm{~mm} \times \\
4.6 \mathrm{~mm}, 3 \mu \mathrm{m})\end{array}$ & 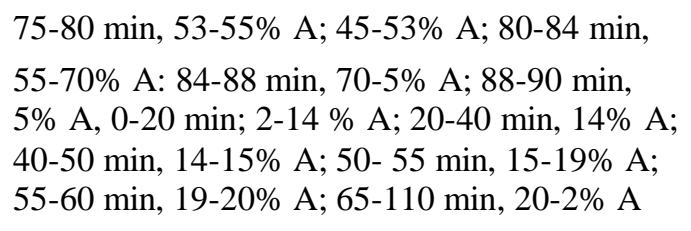 & 110 & $\begin{array}{c}15 \\
\text { presentes }\end{array}$ & $\begin{array}{l}\text { MÜLLER, } \\
\text { SCHANTZ e } \\
\text { RICHLING, } 2012\end{array}$ \\
\hline $\begin{array}{l}\text { HPLC/ } \\
\text { DAD }\end{array}$ & Metanol & 5\% Ácido Fórmico & $\begin{array}{l}\text { Zorbax, SB } \\
(150 \mathrm{~mm} \times \\
4.6 \mathrm{~mm}, 5 \mu \mathrm{m})\end{array}$ & $\begin{array}{l}0-5 \min ; 5 \% \text { A; } 5-45 \min , 5-50 \% \text { A; } 45-55 \min , \\
50-75 \% \text { A; } 55-65 \min , 75-100 \% \text { A }\end{array}$ & $65 * *$ & $\begin{array}{c}14 \text { de } 17 \\
\text { presentes }\end{array}$ & $\begin{array}{l}\text { GAVRILOVA et } \\
\text { al.,2011 }\end{array}$ \\
\hline $\begin{array}{l}\text { HPLC/ } \\
\text { DAD }\end{array}$ & Acetonitrila & $\begin{array}{l}\text { 4,5\% Ácido } \\
\text { Fórmico }\end{array}$ & - & $\begin{array}{l}0-9 \min ; 10 \% \text { A; } 9-26 \min , 10-12 \% \text { A; } 26-30 \\
\min , 12-25 \% \text { A;30- } 50 \mathrm{~min}, 25-90 \% \text { A }\end{array}$ & $50 * *$ & $\begin{array}{c}10 \\
\text { presentes }\end{array}$ & BUNEA et al., 2012 \\
\hline $\begin{array}{l}\mathrm{HPLC} / \\
\mathrm{UV}-\mathrm{V} \text { is }\end{array}$ & Metanol & 5\% Ácido Fórmico & $\begin{array}{l}\text { Zorbax, SB } \\
(150 \mathrm{~mm} \times \\
4.6 \mathrm{~mm}, 5 \mu \mathrm{m})\end{array}$ & $0-40 \min ; 5-35 \% \mathrm{~A}$ & $40 * *$ & $\begin{array}{l}19 \text { de } 22 \\
\text { presentes }\end{array}$ & PRIOR et al., 2001 \\
\hline $\begin{array}{l}\text { HPLC/ } \\
\text { DAD }\end{array}$ & Acetonitrila & $\begin{array}{l}10 \% \text { Ácido } \\
\text { Fórmico }\end{array}$ & $\begin{array}{l}\text { Zorbax, SB } \\
(150 \mathrm{~mm} \times \\
4.6 \mathrm{~mm}, 5 \mu \mathrm{m})\end{array}$ & $\begin{array}{l}0-5 \mathrm{~min} ; 2 \% \text { A; } 5-15 \mathrm{~min}, 2-9 \% \text { A; } 15-20 \mathrm{~min} \text {, } \\
9-11 \% \text { A; } 20-21 \mathrm{~min}, 11-30 \% \mathrm{~A} ; 21-26 \mathrm{~min} . \\
30-80 \% . ; 26-30 \mathrm{~min}, 80-5 \%, 30-45 \mathrm{~min}, 5 \%\end{array}$ & $45 * *$ & $\begin{array}{l}12 \text { de } 15 \\
\text { presentes }\end{array}$ & $\begin{array}{l}\text { KÄHKÖNEN et al., } \\
2003\end{array}$ \\
\hline $\begin{array}{l}\text { CLAE/ } \\
\text { DAD }\end{array}$ & Acetonitrila & 5\% Ácido Fórmico & $\begin{array}{c}\text { Thermo } \\
\text { Scientific } \\
\operatorname{BDS}^{\circledR}(100 \mathrm{~mm} \\
\times 4.6 \mathrm{~mm}, 2,4 \mu \mathrm{m}\end{array}$ & $\begin{array}{l}0-9 \min ; 10 \% \text { A; } 9-26 \min , 10-12 \% \text { A; } 26-30 \\
\min , 12-25 \% \text { A; } 30-50 \min , 25-90 \% \text { A }\end{array}$ & 20 & $\begin{array}{l}17 \text { de } 22 \\
\text { presentes }\end{array}$ & PRESENTE ESTUDO \\
\hline
\end{tabular}


Uva-preta do Chile (Vitis spp.)

A distribuição das antocianinas em uvas é complexa variando de acordo com a espécie. Algumas variedades de uvas podem apresentar, em uma única matriz, as seis antocianidinas mais comuns presentes em alimentos (delfinidina, cianidina, peonidina, pelargonidina, petunidina e malvidina) (WANG, RACE e SHRIKHANDE, 2003).

Dentre as antocianinas, anteriormente identificadas em perfis cromatográficos do epicarpo de uvas, as monoglicosiladas no carbono 3 (delfinidina-3-O-glicosídeos, cianidina-3$O$-glicosídeo, petunidina-3-O-glicosídeo, peonidina-3-O-glicosídeo e malvidina-3-Oglicosídeo e seus derivados acilados), e as diglicosiladas nos carbonos 3 e 5 (delfinidina-3,5- $O$ glicosídeos, cianidina-3,5-O-glicosídeo, petunidina-3,5-O-glicosídeo, peonidina-3,5-O glicosídeo e malvidina-3,5-O-glicosídeo) são os pigmentos mais comuns encontrados. A antocianina pelargonidina-3- $O$-glicosídeo foi identificada em algumas variedades de uva, mas em baixíssima concentração, como Concorde (cultivar da Vitis labrusca), Rubired e Salvador (híbridos de $V$. vinífera L. e $V$. ruspestris) (WANG, RACE e SHRIKHANDE, 2003; WU e PRIOR, 2005a).

As cultivares provenientes da espécie Vitis vinífera L. são exemplo onde podem ser encontradas somente as antocianidinas (delfinidina, cianidina, peonidina, petunidina e malvidina) monoglicosiladas no carbono 3, assim como seus derivados acilados com ácido pcoumárico, cafeico e acético (RUSTIONI et al., 2013).

A análise realizada por CLAE/DAD, a $520 \mathrm{~nm}$, no extrato obtido do epicarpo da uvapreta do Chile sem semente (cultivar de $V$. vinífera $\mathrm{spp}$ ), revelou a presença de 5 picos (Figura 71). Todos os espectros de absorção correspondentes a esses picos apresentaram duas bandas na região do UV-Vis máx a 520nm, características dos pigmentos antociânicos (Figura 72).

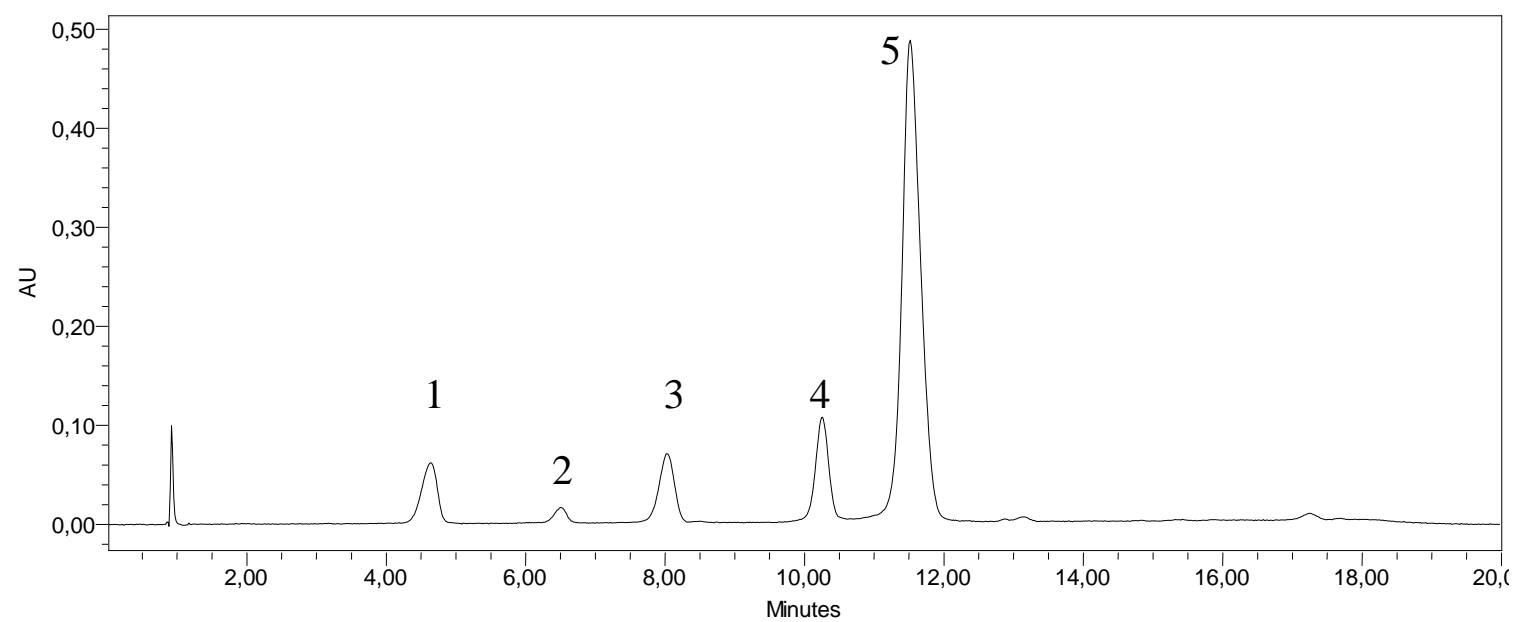

Figura 71: Cromatograma no CLAE/DAD a $520 \mathrm{~nm}$ do extrato do epicarpo da uva-preta do Chile utilizando metodologia II.

As identificações das substâncias foram baseadas nos seus espectros de absorção ( $\lambda_{\text {máx }}$ visível), seus tempos de retenção e nas suas respectivas massas moleculares acuradas. Os dados obtidos em modo EM/EM no CLUE-EM-QTOF $\left(\mathrm{ESI}^{+}\right)$mostraram a presença de íons moleculares para as substâncias do: pico 1 a $\mathrm{m} / \mathrm{z}$ 465,1036 e fragmento a $\mathrm{m} / \mathrm{z}$ 303,0590; pico 2 a $\mathrm{m} / \mathrm{z} 449,1050$ e fragmento a $\mathrm{m} / \mathrm{z}, 287,0511$; pico 3 a $\mathrm{m} / \mathrm{z}, 479,1200$ e fragmento a $\mathrm{m} / \mathrm{z}, 317,0696$; pico 4 a $\mathrm{m} / z$ 463,1330 e fragmento a $\mathrm{m} / z$ 301,0797 e; para o pico $5 \mathrm{a} \mathrm{m} / \mathrm{z}, 493,1404$ e fragmento 
a $m / z 331,0892$. Todos os fragmentos foram obtidos após a perda de uma hexose ([M-162 Da $\left.]^{+}\right)$, (Figura 73).

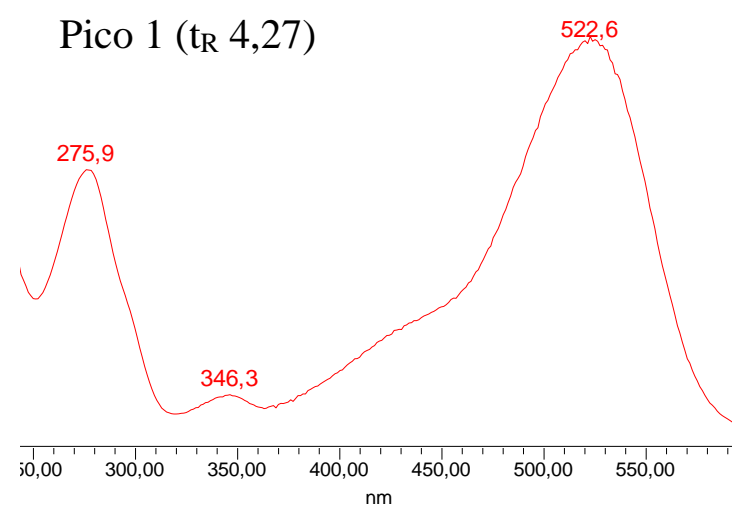

Pico $3\left(t_{R} 7,89\right)$

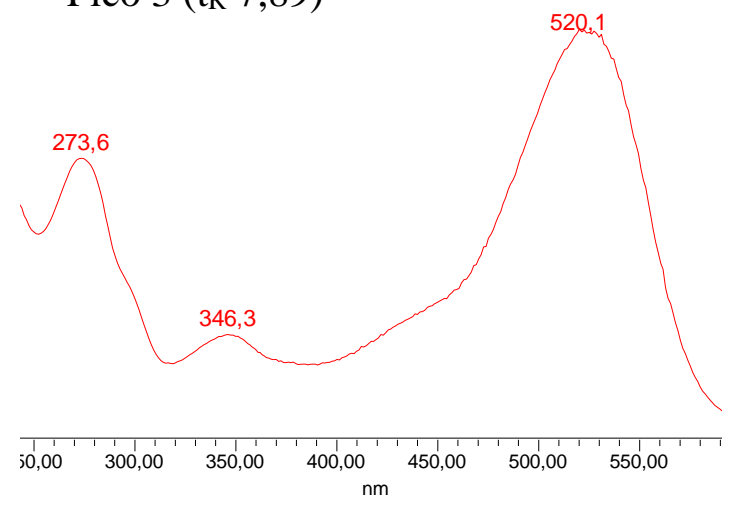

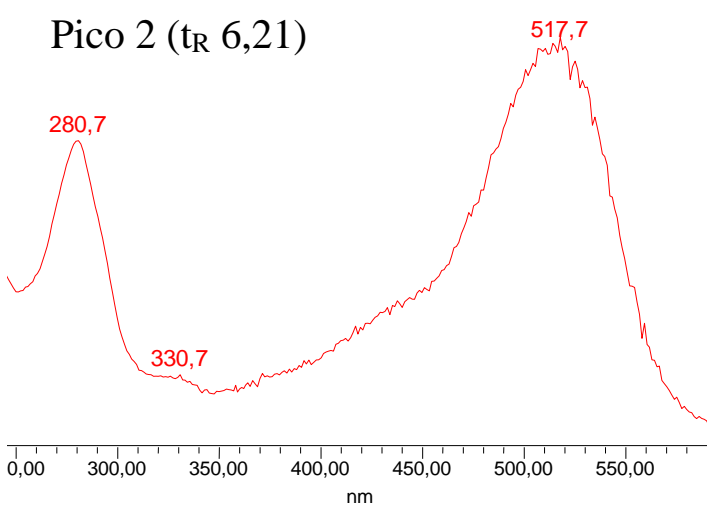

$\operatorname{Pico} 4\left(t_{R} 10,29\right)$

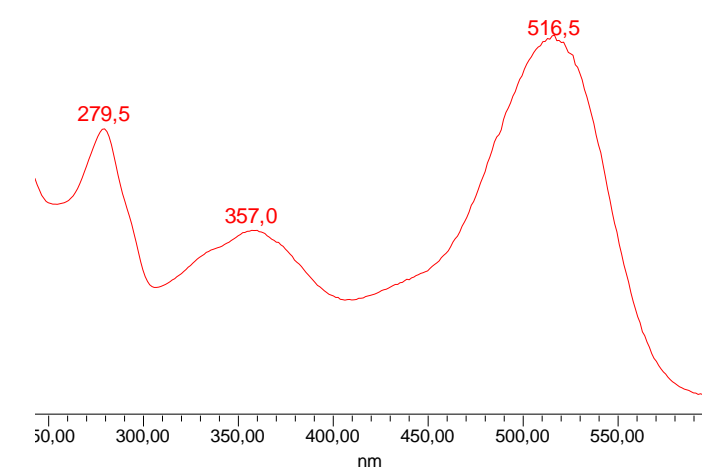

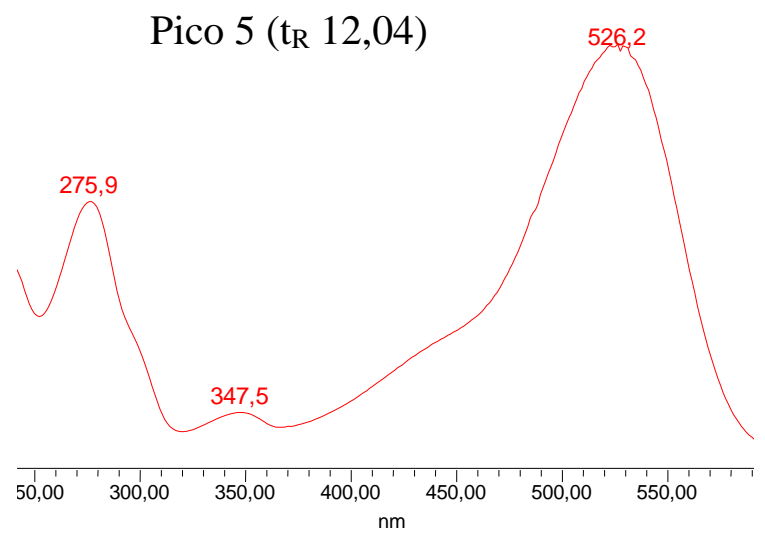

Figura 72: Espectros de absorção na região UV-Vis máx do extrato do epicarpo da uva-preta do Chile (Vitis vinifera spp) obtidos no DAD $(520 \mathrm{~nm})$ enumerados conforme cromatograma da Figura 71.

Com os dados obtidos das análises no CLAE/DAD e CLUE-EM-QTOF (ESI ${ }^{+}$) foi possível identificar as cinco substâncias presentes na matriz em questão (epicarpo da uva-preta do Chile). 


\section{MSMS}

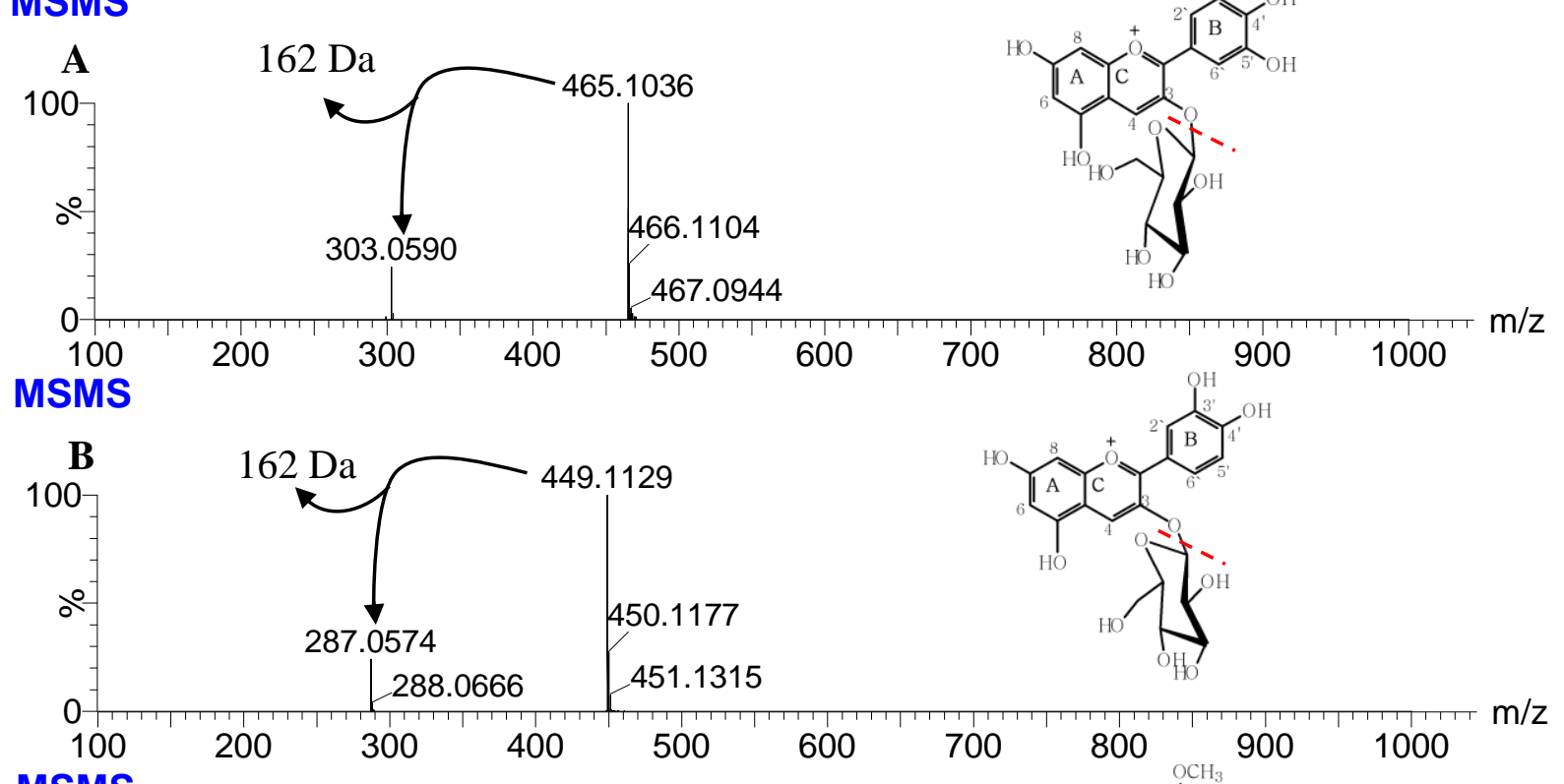

MSMS

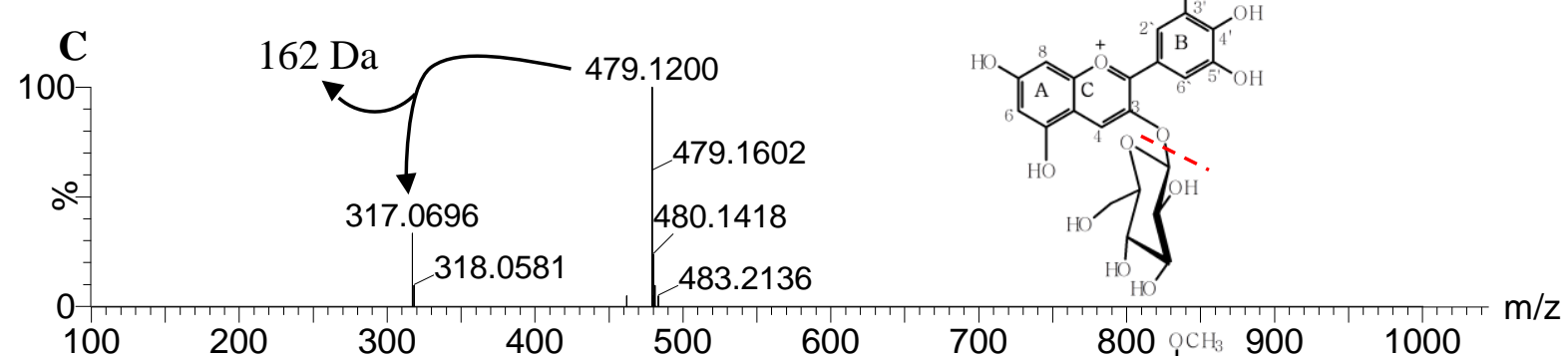

MSMS
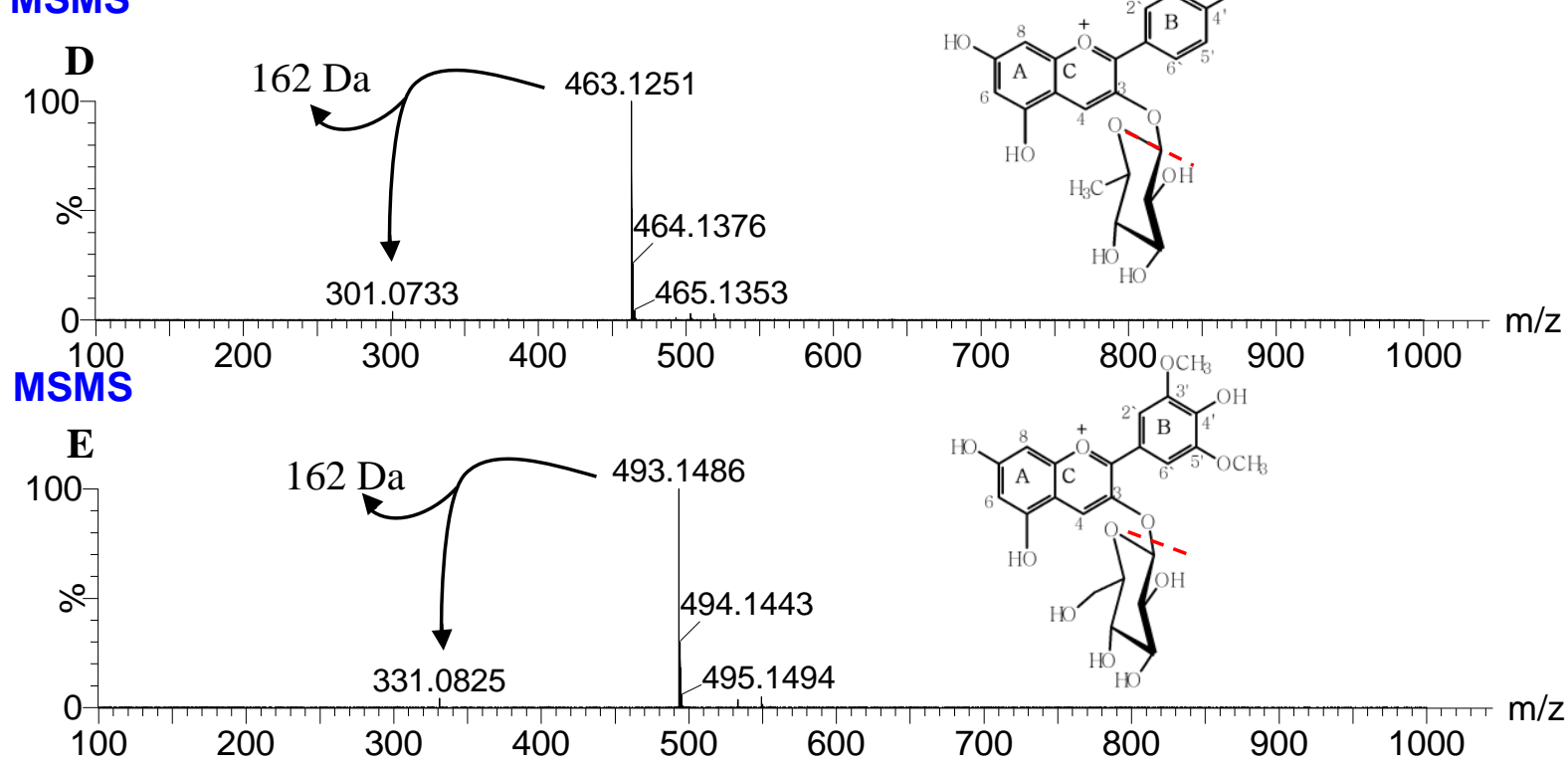

Figura 73: Espectros de massa acurada em modo EM/EM no CLUE-EM-QTOF (ESI ${ }^{+}$): (A) substância equivalente ao pico 1; (B) substância equivalente ao pico 2; (C) substância equivalente ao pico 3; (D) substância equivalente ao pico 4 e; (E) substância equivalente ao pico 5. 
A substância equivalente ao pico 1 foi identificada como delfinidina-3- $O$-glicosídeo,

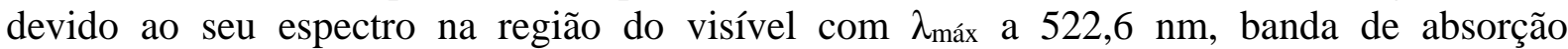
característica de derivados de delfinidina, e a presença do fragmento a $\mathrm{m} / \mathrm{z}$ 303,0590, após a perda de uma hexose (162 Da), dado obtido na análise em modo EM/EM no CLUE-EM-QTOF $\left(\mathrm{ESI}^{+}\right.$) (Figura 73), confirmando ser delfinidina a antocianidina. A hexose foi confirmada como glicose devido ao seu tempo de retenção.

A substância equivalente ao pico 2 foi identificada como cianidina-3- $O$-glicosídeo, pois, ao confrontar sob as mesmas condições cromatográficas, seu tempo de retenção no CLAE/DAD a $520 \mathrm{~nm}$ com o tempo de retenção do pico 2, cianidina-3-O-glicosídeo, do cromatograma da juçara (Euterpe edules) (Figura 74), matriz já caracterizada por este estudo (página 57) sob as mesmas condições de análise. A confirmação, de cianidina-3- $O$-glicosídeo, foi realizada ao observar seu íon molecular que apresentou massa exata a $\mathrm{m} / \mathrm{z} 449,1129$ e fragmento a $\mathrm{m} / \mathrm{z}$ 287,0574 no modo EM/EM no CLUE-EM-QTOF (ESI ${ }^{+}$(Figura 73).

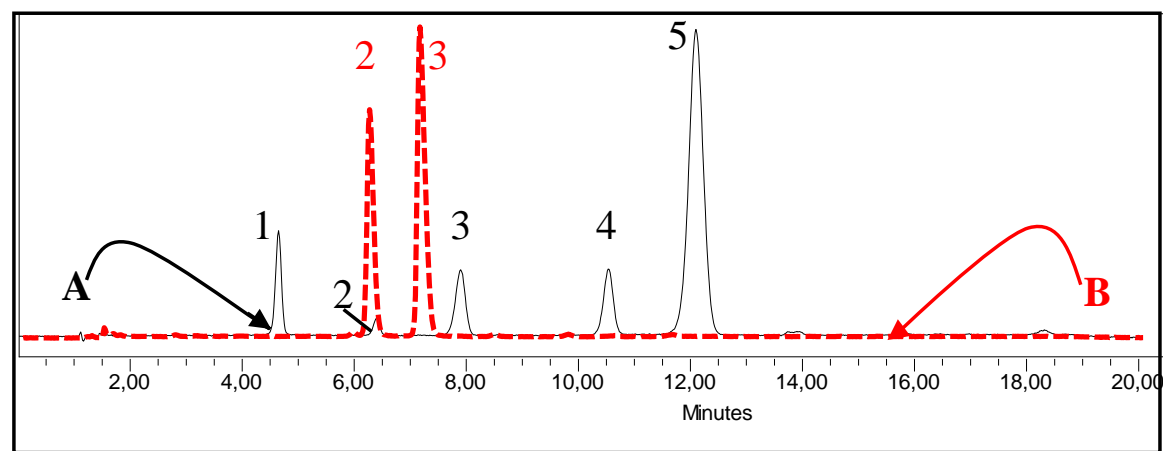

Figura 74: Sobreposição dos cromatogramas obtidos no CLAE/DAD a $520 \mathrm{~nm}$. (A) Cromatograma em preto obtido do extrato do epicarpo da uva-preta, (B) cromatograma em vermelho do extrato da Juçara, onde pico 2: cianidina-3-O-glicosídeo e 3 cianidina-3- $O$-rutenosídeo.

Para o Pico 3, o com comprimento de onda no visível com $\lambda_{\text {máx }}$ de $520 \mathrm{~nm}$ observado, sugeriu que a substância em questão seria derivada de antocianidinas como delfinidina, malvidina ou petunidina.

Através do seu íon molecular a $\mathrm{m} / \mathrm{z}$ 479,1200 e fragmento a $\mathrm{m} / \mathrm{z}$ 317,0696 observados no modo EM/EM no CLUE-EM-QTOF (ESI ${ }^{+}$(Figura 73) pode-se confirmar a presença da petunidina. A perda de 162 Da caracteriza uma hexose e o tempo de retenção no cromatograma indica uma glicose. Assim a substância foi caracterizada como sendo a petunidina-3-Oglicosídeo.

A substância referente ao pico 4, apesar de mostrar um comprimento de onda com valores próximos dos derivados de cianidina com $\lambda_{\text {máx }}$ de $516,5 \mathrm{~nm}$, dados gerados no modo EM/EM no CLUE-EM-QTOF (ESI ${ }^{+}$) quando aplicado uma energia de colisão de $4 \mathrm{eV}$ em seu íon molecular a $m / z$ 463,1251, mostrou fragmento a $m / z$ 301,0733 (Figura 73), característico da antocianidina peonidina, devido a perda de uma hexose (162 Da), no caso, sugere-se ser a glicose devido ao seu tempo de retenção.

A substância referente ao último pico (5), corresponde a antocianina majoritária dessa

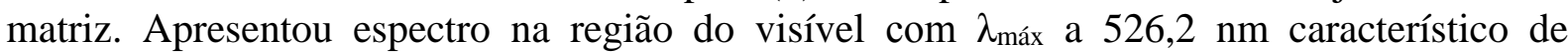
derivados de malvidina e petunidina. A delfinidina foi descartada pelo tempo de retenção apresentado. 
O íon molecular a $\mathrm{m} / \mathrm{z}$ a 493,1486 e fragmento a $\mathrm{m} / \mathrm{z}$ 331,0825 no modo EM/EM no CLUE-EM-QTOF (ESI ${ }^{+}$) (Figura 73), confirma a presença de um derivado da malvidina. A perda de 162 Da caracteriza uma hexose e o tempo de retenção uma glicose. Sendo, portanto, a antocianina identificada como malvidina-3-O-glicosídeo.

Os espectros de absorção na região do UV-Vismáx, também serviram como ferramenta indicando as cinco substâncias como derivados monossubstituido. Isto foi observado através dos valores encontrados na razão entre $E_{440} / E$ máx dos seus respectivos espectros de absorção, que apresentaram taxa acima de 30\% (Tabela 18), indicativo de antocianidinas glicosiladas em apenas um carbono da molécula (DYRBY, WESTERGAARD e STAPELFELDT, 2001; ARAPITSAS, SJÖBERG e TURNER, 2008; SUN, LIN e CHEN, 2013).

Tabela 18: Tempo de retenção das substâncias no cromatograma da Figura 71 e, valores da

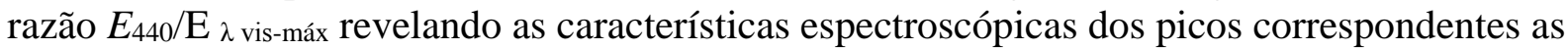
suas glicosilações.

\begin{tabular}{|c|c|c|c|c|c|c|}
\hline $\begin{array}{c}\mathrm{N}^{\circ} \\
\text { do pico }\end{array}$ & $\begin{array}{c}\mathbf{t}_{R} \\
\text { (Minutos) }\end{array}$ & $\begin{array}{c}\lambda_{\text {UVmáx }} \\
(\mathbf{n m})\end{array}$ & $\begin{array}{l}\lambda_{\text {vismáx }} \\
(\mathbf{n m})\end{array}$ & $\begin{array}{c}E_{440} / \mathbf{E}_{\lambda \text { vis-máx }} \\
(\%)\end{array}$ & $\begin{array}{c}E_{440} / \mathbf{E}_{\lambda \text { vis-máx }} \\
\text { Indicando }\end{array}$ & Antocianina \\
\hline 1 & 4,6 & 275,9 & 522,6 & 30 & monossubstituidas & $\begin{array}{l}\text { Delfinidina-3-O- } \\
\text { glicosídeo }\end{array}$ \\
\hline 2 & 6,5 & 280,7 & 517,7 & 33 & monossubstituidas & $\begin{array}{l}\text { Cianidina-3-O- } \\
\text { glicosídeo }\end{array}$ \\
\hline 3 & 8,0 & 273,6 & 520,1 & 30 & monossubstituidas & $\begin{array}{l}\text { Petunidina-3-O- } \\
\text { glicosídeo }\end{array}$ \\
\hline 4 & 10,3 & 279,5 & 516,5 & 33 & monossubstituidas & $\begin{array}{l}\text { Peonidina-3-O- } \\
\text { glicosídeo }\end{array}$ \\
\hline 5 & 11,5 & 275,9 & 526,2 & 31 & monossubstituidas & $\begin{array}{l}\text { Malvidina-3-O- } \\
\text { glicosídeo }\end{array}$ \\
\hline
\end{tabular}

Esses dados associados aos resultados obtidos no CLUE-EM-QTOF $\left(\mathrm{ESI}^{+}\right)$(Figura 73), confirmaram a ausência na matriz de antocianinas di-substituidas (no carbono 3 do anel C, piridínico, e no carbono 5 do anel A) na estrutura da antocianidina.

A presença de dois açúcares (glicosilando em carbonos distintos) são comuns em alguns cultivares de uvas provenientes de outras espécies como Vitis labrusca e V. ruspestris, mas não são observados em cultivares da Vitis vinífera L.

Esses dados observados foram muito importantes para caracterização da matriz analisada como cultivar da Vitis vinífera.

A caracterização das antocianinas presentes na uva se torna imprescindível e aumenta o conhecimento sobre os diferentes cultivares, sejam eles naturais ou melhorados. Este tipo de conhecimento fornece subsídios para diferencia-los entre si e, pode trazer informações que permitam uma melhoria na sua constituição genética, visto que a concentração e a variedade dos tipos de antocianinas é que irão determinar a intensidade da coloração dos vários cultivares de uvas (POMAR et al., 2005).

Todos os dados foram condizentes com os dados observados em trabalhos publicados anteriormente, além disso, observou-se que apenas o açúcar glicose é encontrado nas espécies 
de uvas, assim como nas caracterizações de vinhos provenientes dessa fruta (WANG, RACE e SHRIKHANDE, 2003; WU \& PRIOR, 2005a; POMAR et al., 2005; BRITO et al., 2007; DOWNEYA, ROCHFORT, 2008).

A análise por CLAE, utilizando uma coluna de fase reversa com diâmetro de partícula de $2,4 \mu \mathrm{m}$, possibilitou boa resolução entre os analitos (Figura 71). Esse fato tornou possível a coleta das substâncias de forma isolada, através da válvula seletora de canais (Rheodyne ${ }^{\circledR}$ ) com alto grau de pureza (acima de 98\%), evitando-se, desta forma, a contaminação das mesmas com os outros analitos da matriz. Portanto, essa matriz foi considerada uma excelente fonte das antocianinas: delfinidina, cianidina, peonidina, petunidina e malvidina, todas glicosiladas com o açúcar glicose ligado ao carbono 3 do anel piridínico (anel C) da estrutura da antocianidina.

$\mathrm{O}$ conhecimento adquirido no estudo das antocianinas da matriz descrita acima (epicarpo da Uva-preta do Chile), permitiu através da comparação dos seus tempo de retenção, espectros na região do visível e de seus dados de massa espectral obtidos no CLUE-EM-QTOF $\left(\mathrm{ESI}^{+}\right)$, a investigação de antocianinas presentes no perfil cromatográfico de outros cultivares de uvas como Red Globe ( Vitis vinífera L.) [Obtida de vários cruzamentos de cultivares: (Hunisa x Emperor) x (Hunisa x Emperor x Nocera)], Niagara Rosada (Vitis labrusca x Vitis vinifera L.) e; Kyoho [Vitis labruscana (Vitis vinífera x Vitis labrusca)](cultivar Tetraploide) (KOBAYASHI et al., 2002; Embrapa, 2005; CARVALHO, 2006; CARVALHO et al., 2008; IRICEVOLTO, 2009). Essas uvas, que são consideradas como tinta de mesa, são encontradas a venda no comércio varejista.

Os extratos dos cultivares Red Globe (RG), Niagara Rosada (NR) e Kyoho (K) (Figura 75) foram submetidos a mesma condição de análise por CLAE/DAD (520 nm) ao qual foi submetido o extrato do epicarpo da uva-preta do Chile.

Os perfis cromatográficos antociânico apresentados foram: 2 picos para Red Globe; 5 picos para Niagara Rosada e; 10 picos para Kyoho (Figura 76). As análises dos espectros de absorção indicaram a presença de duas bandas na região UV-Vismáx características de pigmentos antociânicos para todos os picos observados nas matrizes.

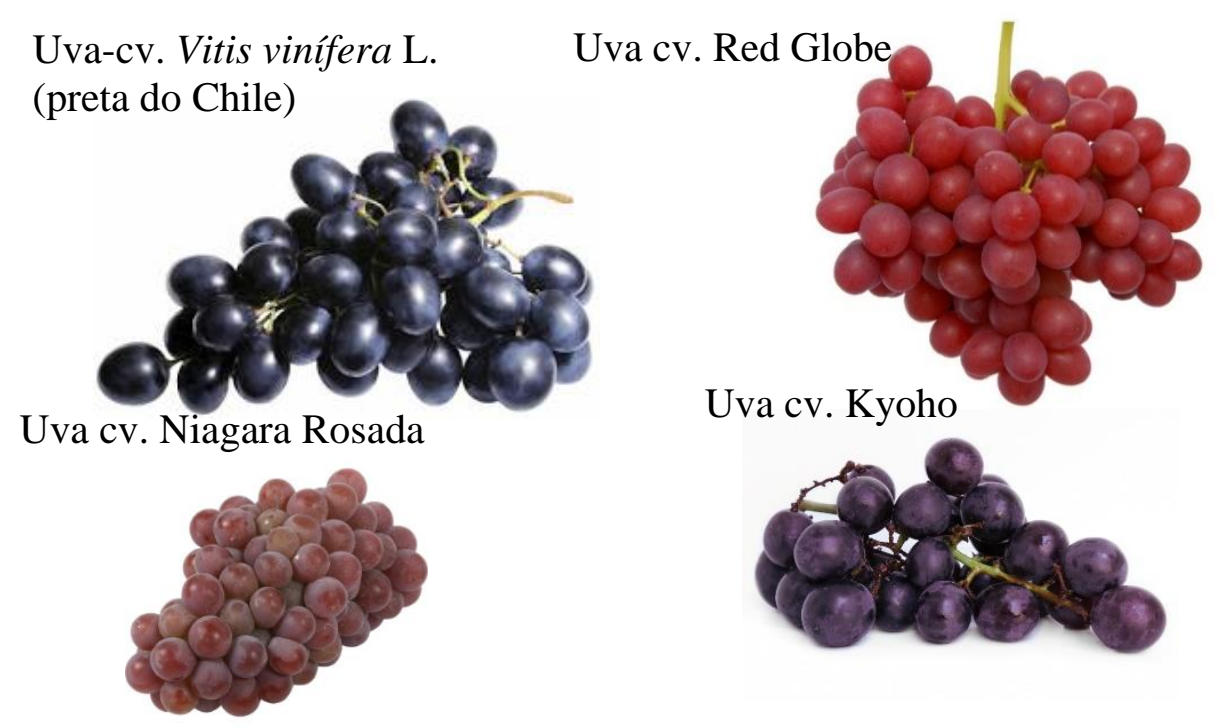

Figura 75: Cultivares (cv) de uvas finas tintas de mesa: Uva-preta do Chile; Red-Globe (RG); Niagara Rosada (NR); Kyoho (K). Fonte: Embrapa, 2005; DETONI et al., 2005. 

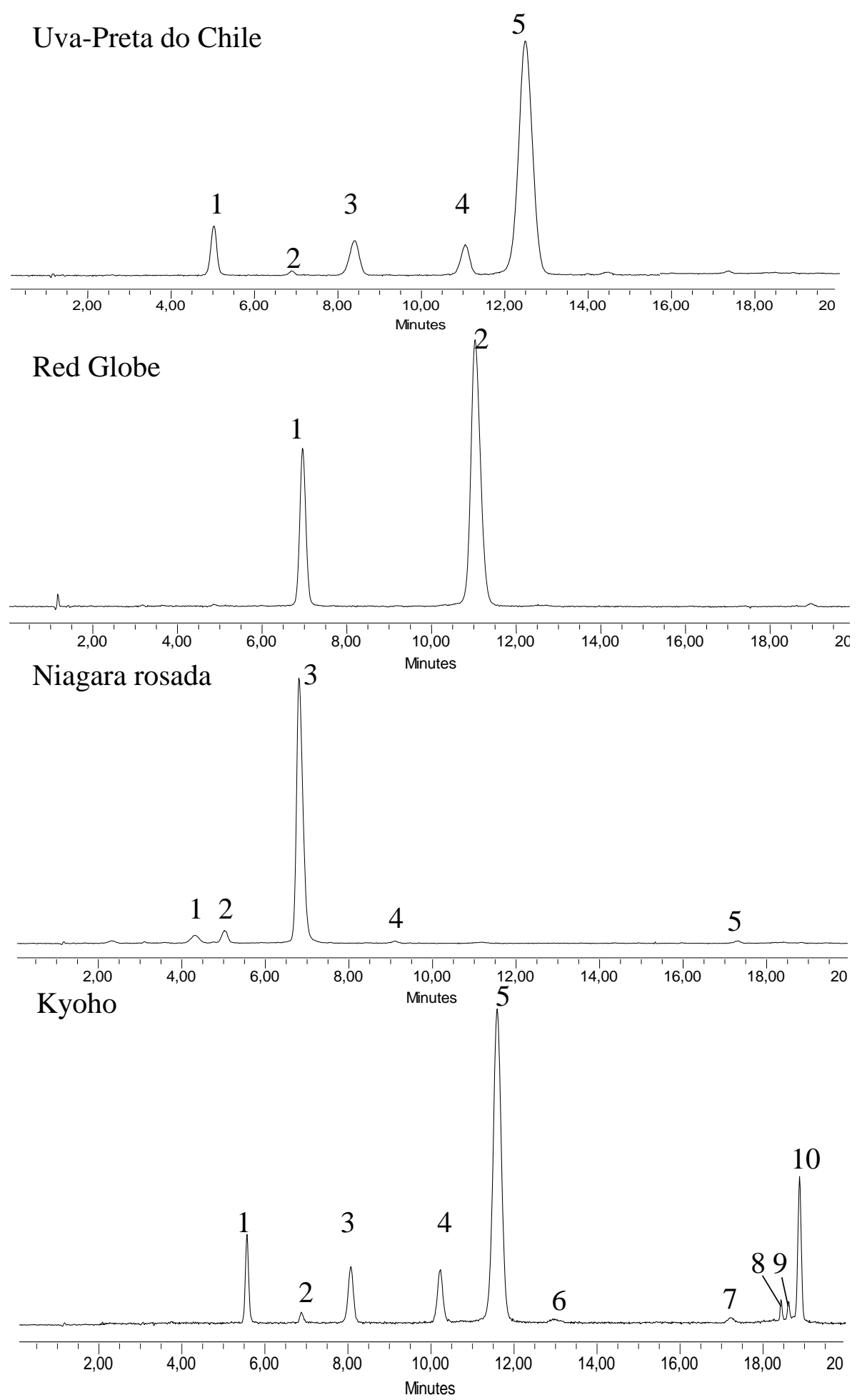

Figura 76: Cromatogramas das antocianinas, obtidos no CLAE/DAD a $520 \mathrm{~nm}$, dos extratos do epicarpo das uvas: Uva-Preta do Chile; Red Globe; Niagara Rosada; e Kyoho. Identificação dos picos Tabela 19. 
Apenas as antocianinas com concentrações significativas foram isoladas e analisadas por CLUE-EM-QTOF $\left(\mathrm{ESI}^{+}\right)$em modo EM/EM. Portanto, para interesse desse estudo foram identificadas as duas antocianinas em Red Globe como cianidina-3- $O$-glicosídeo e peonidina3-O-glicosídeo, uma antocianina na Niagara Rosada como cianidina-3-O-glicosídeo e cinco antocianinas na Kyoho como: delfinidina-3-O-glicosídeos; cianidina-3-O-glicosídeo; petunidina-3-O-glicosídeo; peonidina-3-O-glicosídeo e; malvidina-3-O-glicosídeo (Tabela 19).

Tabela 19: Tabela com identificações das antocianinas da Figura 76.

\begin{tabular}{|c|c|c|c|c|c|}
\hline Pico & $\begin{array}{c}t_{R} \\
(\min )\end{array}$ & $\begin{array}{l}\text { UV -Vis } \\
\lambda_{\text {máx. }} \\
(\mathrm{nm})\end{array}$ & $\begin{array}{l}{[\mathrm{M}]^{+}} \\
(\mathrm{m} / \mathrm{z})\end{array}$ & $\begin{array}{c}\text { EM/EM } \\
(m / z)\end{array}$ & Antocianina \\
\hline \multicolumn{6}{|c|}{ Uva-preta do Chile (Sem semente) } \\
\hline 1 & 5,0 & $275,9 / 522,6$ & 465,1136 & 303,0590 & delfinidina-3- $O$-glicosídeo \\
\hline 2 & 6,9 & $280,7 / 514,1$ & 449,1129 & 287,0574 & cianidina-3- $O$-glicosídeo \\
\hline 3 & 8,4 & $273,1 / 521,4$ & 479,1200 & 317,0696 & petunidina-3-O-glicosídeo \\
\hline 4 & 11,0 & $279,2 / 514,2$ & 463,1251 & 301,0733 & peonidina-3- $O$-glicosídeo \\
\hline 5 & 12,5 & $279,5 / 526,2$ & 493,1486 & 331,0825 & delfinidina-3-O-glicosídeo \\
\hline \multicolumn{6}{|c|}{ Red Globe } \\
\hline 1 & 6,9 & $279,5 / 514,1$ & 449,1050 & 287,0511 & cianidina-3-O-glicosídeo \\
\hline 2 & 10,9 & $278,3 / 514,1$ & 463,1251 & 301,0797 & peonidina-3-O-glicosídeo \\
\hline \multicolumn{6}{|c|}{ Niagara Rosada } \\
\hline 1 & 4,3 & $278,3 / 514,1$ & NI & NI & \\
\hline 2 & 5,0 & $277,1 / 521,6$ & NI & NI & \\
\hline 3 & 6,8 & $279,1 / 514,9$ & 449,1129 & 287,0574 & cianidina-3-O-glicosídeo \\
\hline 4 & 9,1 & $279,5 / 498,2$ & NI & $\mathrm{NI}$ & \\
\hline 5 & 17,7 & $279,5 / 520,1$ & $\mathrm{NI}$ & $\mathrm{NI}$ & \\
\hline \multicolumn{6}{|c|}{ Kyoho } \\
\hline 1 & 5,0 & $275,9 / 522,1$ & 465,1036 & 303,0526 & delfinidina-3-O-glicosídeo \\
\hline 2 & 6,9 & $279,5 / 514,1$ & 449,1050 & 287,0574 & cianidina-3-O-glicosídeo \\
\hline 3 & 8,4 & $277,1 / 521,4$ & 479,1280 & 317,0696 & petunidina-3-O-glicosídeo \\
\hline 4 & 11,0 & $279,2 / 514,2$ & 463,1330 & 301,0797 & peonidina-3-O-glicosídeo \\
\hline 5 & 12,5 & $279,5 / 526,2$ & 493,1323 & 331,0892 & delfinidina-3-O-glicosídeo \\
\hline $6-10$ & NI & NI & NI & NI & \\
\hline
\end{tabular}

Estes resultados mostram, como o observado na matriz da cultivar da Vitis vinífera $\mathrm{L}$ (Uva-Preta do Chile), que as matrizes das cultivares Nigara Rosada, Red Globe e Kyoho são também boas fontes de cinco das seis antocianinas mais comuns em alimentos (delfinidina-3$O$-glicosídeo, cianidina-3-O-glicosídeo, petunidina-3-O-glicosídeo, peonidina-3-O-glicosídeo e malvidina-3-O-glicosídeo).

A baixa concentração da antocianina cianidina-3-O-glicosídeo no perfil cromatográfico das uvas Kyoho e Uva-Preta sem semente do Chile, pode ser recompensada misturando os extratos das uvas Niagara Rosada ou Red Globe. Permitindo assim, a coleta das cinco substâncias com boa concentração utilizando apenas uma amostra. Utilizando de uma só vez os cinco canais da válvula coletora, diminuindo o tempo de coleta. 
Ao se comparar a cultivar Kyoho com a cultivar da espécie Vitis vinífera L., denominada pelo presente estudo como Uva-Preta do Chile, foi observado que as duas matrizes apresentaram relações semelhantes entre as cinco antocianinas monoglicosiladas identificadas. $\mathrm{O}$ extrato da uva Kyoho, apresenta ainda em seu perfil cromatográfico (520 nm) (Figura 76), outras substâncias que eluem acima de 12 minutos que não foram isoladas e analisadas pelo presente estudo, mas, que posteriormente podem ser investigadas. Como apresentam tempo de retenção superior aos das antocianinas monoglicosiladas identificadas pelo presente estudo, sugere-se a princípio serem antocianinas aciladas à ácidos orgânicos. Li e colaboradores (2013), identificaram na cultivar Kyoho obtida em Beijing (China), antocianinas monoglicosiladas e 3, 5-O-diglicosiladas e seus derivados acilados à ácidos orgânicos. Vale ressaltar, que não foi verificado semelhança entre o perfil caracterizado por Li e colaboradores, na cultivar chinesa e, o observado pelo presente estudo na cultivar de origem brasileira (proveniente do norte do Paraná).

Trabalhos publicados anteriormente identificaram a antocianidina malvidina-3,5-di- $O$ glicosídeo com maior hidrofobicidade entre as seis antocianidinas, mais comumente encontradas em alimentos, ligadas ao mesmo substituinte. Seu tempo de retenção é mostrado como inferior ao da cianidina-3- $O$ - glicosídeo em sistema de fase reversa (WU e PRIOR, 2005a; Li et al., 2013). Sendo assim, diferente do que foi observado por Li e colaboradores (2013), pode-se afirmar que mesmo após concentrar a amostra do extrato do epicarpo da uva Kyoho, não foram observados sinais significantes característicos de antocianinas diglicosiladas nos carbonos 3 e 5 nesta faixa de eluição.

\section{Acerola (M.emarginata)}

O perfil antociânico da polpa da acerola é relativamente simples quando comparada aos outros frutos analisados por este trabalho como mirtilo, ao qual apresentou 22 antocianinas e uva com 5 antocianinas.

A análise realizada por CLAE/DAD (a $520 \mathrm{~nm}$ ) no extrato de acerola, pelo presente estudo, revelou a presença de 2 picos (Figura 77). Os espectros de absorção correspondentes aos picos apresentaram as duas bandas no UV-Vismáx característicos dos pigmentos antociânicos (Figura 78).

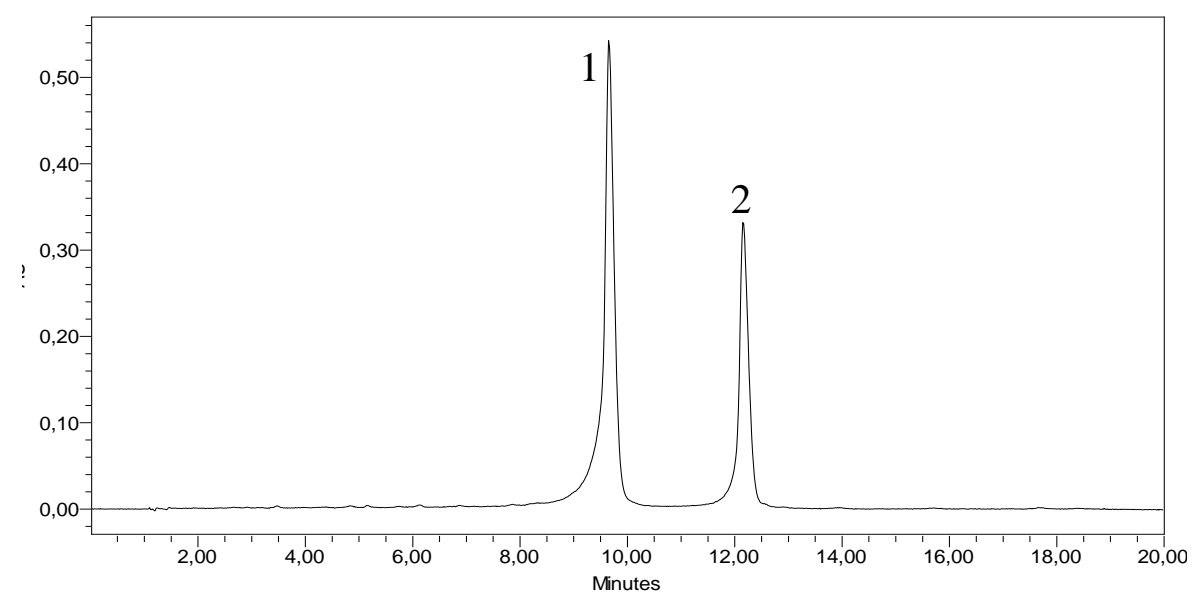

Figura 77: Cromatograma no CLAE/DAD a $520 \mathrm{~nm}$ do extrato da acerola utilizando metodologia II. 

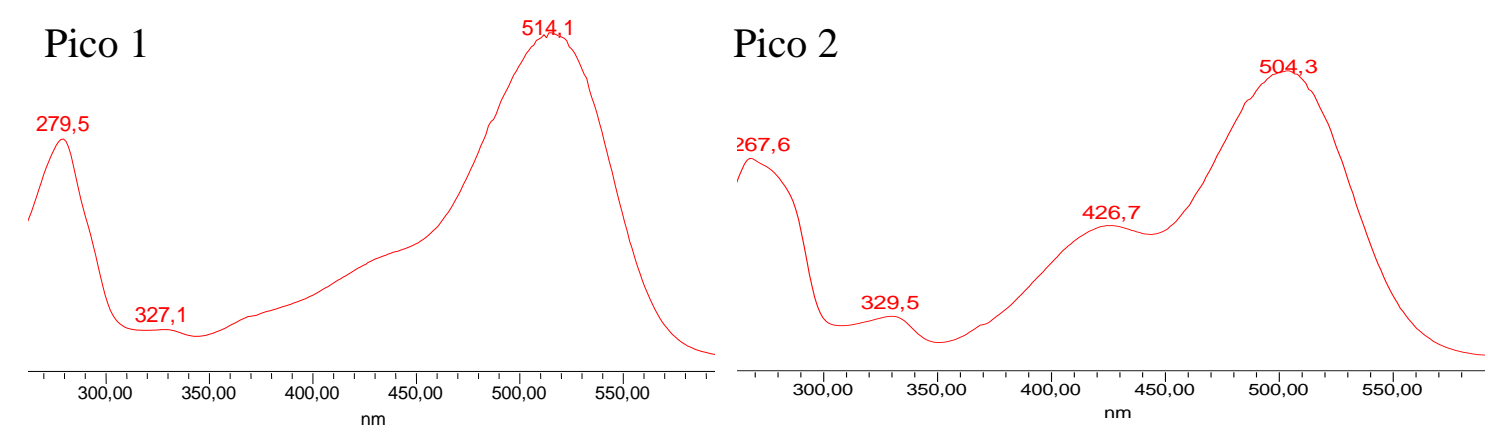

Figura 78: Espectros de absorção na região UV-Vis máx do extrato da acerola obtidos no DAD (520 nm) enumerados conforme cromatograma da Figura 77.

As substâncias foram coletadas isoladamente seguindo a metodologia do item 3.7, e cada substância isolada foi analisada por injeção direta no EM-QTOF $\left(\mathrm{ESI}^{+}\right) \mathrm{em}$ modo EM/EM (Figura 79).

A banda de absorção observada no visível com $\lambda_{\text {máx }} 514,1 \mathrm{~nm}$ para a substância equivalente ao pico 1, sugere a presença das antocianidinas cianidina ou peonidina. A análise em modo EM/EM no EM-QTOF $\left(\mathrm{ESI}^{+}\right)$revelou a presença do íon molecular a $\mathrm{m} / \mathrm{z}$ 433,1179 assim como seu fragmento a $\mathrm{m} / \mathrm{z} 287,0583$. A perda de massa neutra de $146 \mathrm{Da}$, indica uma desoxi-hexose, que ao comparar com a literatura foi identificada como ramnose (146 Da) (Figura 79).

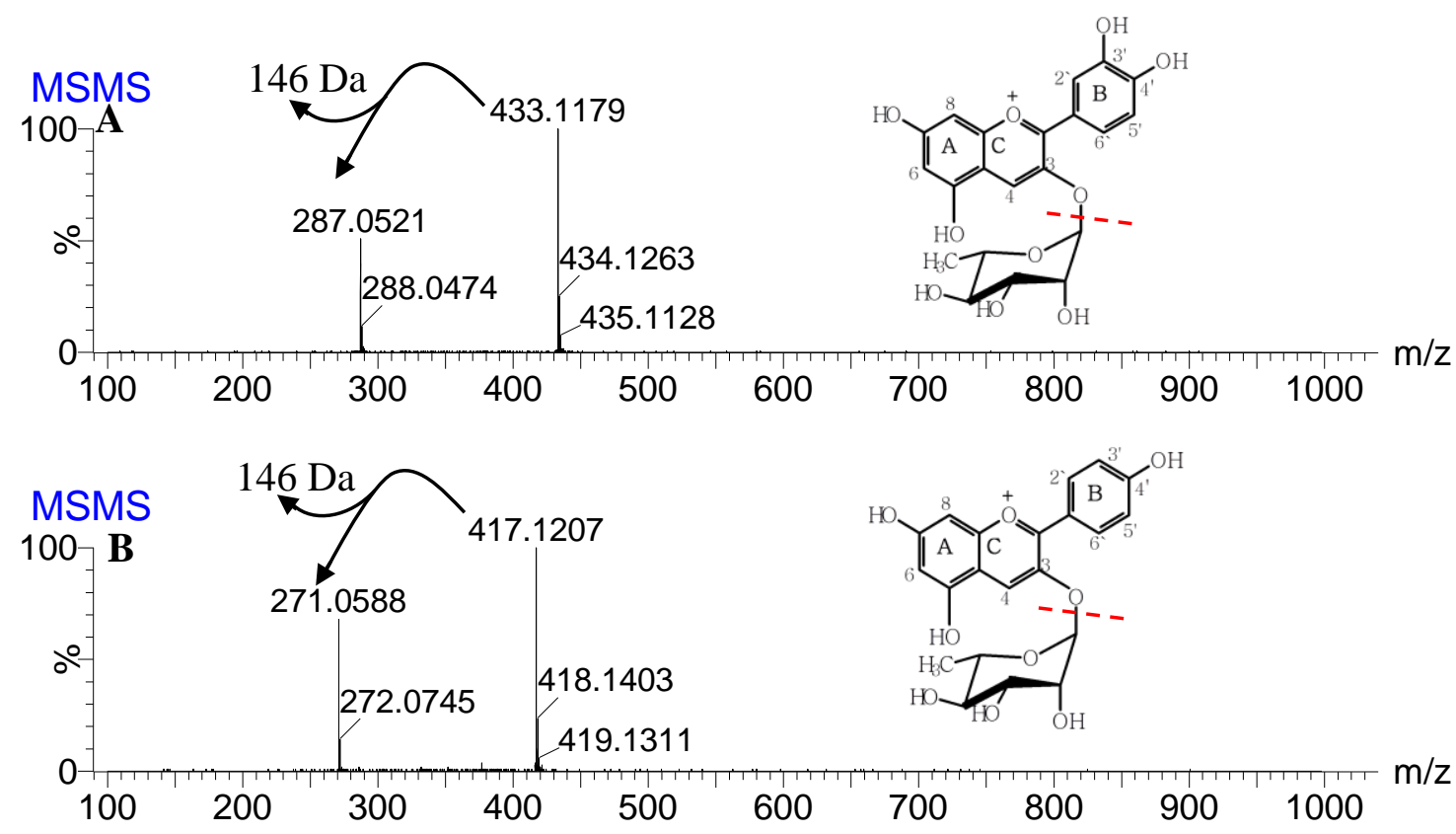

Figura 79: Espectros de massa acurada em modo EM/EM no EM-QTOF $\left(\mathrm{ESI}^{+}\right)$das substâncias equivalentes aos picos 1e 2 (Figura 77): (A) cianidina-3-O-ramnosídeo e (B) pelargonidina-3-O- ramnosídeo. 
A banda de absorção observada no visível para a substância 2, apresenta a característica de uma antocianidina pelargonidina, $\lambda_{\text {máx }} 504,3 \mathrm{~nm}$. Quando há absorção na região do visível com $\lambda_{\text {máx }}$ abaixo de $510 \mathrm{~nm}$, no sistema de solventes utilizado nesse estudo, caracteriza a presença da pelargonidina. Além disso, esta antocianidina apresenta uma absorção elevada na região de $430 \mathrm{~nm}$ quando comparada às outras cinco antocianidinas (delfinidina, cianidina, petunidina, peonidina e malvidina). A análise em modo EM/EM no EM-QTOF (ESI ${ }^{+}$revelou a presença do íon molecular a $\mathrm{m} / \mathrm{z}, 417,1207$ assim como seu fragmento a $\mathrm{m} / \mathrm{z} 271,0648$ confirmando a presença de uma pelargonidina ligada a uma desoxi-hexose, ramnose (146 Da (Figura 79).

De acordo com os resultados as antocianinas foram identificadas como: cianidina-3-Oramnosídeo e pelargonidina- 3- $O$ - ramnosídeo. Os dados obtidos são consistentes com os dados relatados por Brito (2007) e Rosso (2008) e seus colaboradores ao analisarem amostras de acerolas cultivadas no Brasil. Eles também observaram somente a presença das antocianidinas cianidina-3-O-ramnosídeo e pelargonidina- 3-O- ramnosídeo.

Em outras variedades de acerolas cultivadas no Brasil, também foi encontrada, além das cianidina e pelargonidina, a presença da antocianidina malvidina (VENDRAMINE e TRUGO, 2004).

Convém ressaltar que em nenhum dos trabalhos publicados houve relato da presença de acilações nas moléculas de antocianinas identificadas (LONGO e VASAPOLLO, VENDRAMINE e TRUGO, 2004; LIMA et al., 2005; BRITO et al., 2007; ROSSO et al., 2008).

A matriz utilizada, acerola, será uma boa fonte de padrão das substâncias cianidina-3$O$-ramnosídeo e pelargonidina-3-O- ramnosídeo. Visto que, as duas substâncias apresentam no perfil cromatográfico uma ótima resolução entre elas e uma boa concentração, que permitirão obter as substâncias sem necessidade de muitas injeções e coletas.

Além disso, a presença de antocianinas ligadas diretamente à ramnose é muito rara, principalmente a antocianidina pelargonidina. Tendo em vista a escassez de matrizes que contenham essa substância, o extrato de acerola foi considerada por este estudo, uma excelente fonte das antocianinas cianidina-3-O-ramnosídeo e pelargonidina- 3- $O$ - ramnosídeo.

Cebola roxa (Alliun cepa L.) e frambroesa (Rubus idaeus L.)

As matrizes cebola roxa e framboesa vermelha foram escolhidas com a intenção de obter um derivado de cianidinas diglicosiladas, massa molecular a $\mathrm{m} / \mathrm{z} 611$. O interesse nessas substâncias surgiu após a observação e obtenção de outras antocianinas derivadas de “cianidinas" que apresentaram seu íon molecular a m/z 611 (Figura 43, página 71 e Figura 53, página 77). Portanto, as duas matrizes foram submetidas as mesmas condições para análise no CLAE, e analisadas por dois detetores, DAD a $520 \mathrm{~nm}$ e EM-QTOF $\left(\mathrm{ESI}^{+}\right)$.

No perfil cromatográfico por CLAE/DAD a $520 \mathrm{~nm}$ para o extrato de cebola roxa, se observou a presença de 10 picos (Figura 80, A), mostrando assim muita semelhança ao perfil observado por Wu e Prior (2005b), apenas diferenciando nas relações entre os picos e suas concentrações.

No perfil cromatográfico por CLAE/DAD a $520 \mathrm{~nm}$ para o extrato de framboesa, se observou a presença de 8 picos (Figura 80, B), mostrando também muita semelhança ao perfil observado por Wu e Prior (2005a).

Usando como base a identificação realizada em trabalhos anteriormente publicados (Wu e PRIOR, 2005a, b), apenas as substâncias identificadas como picos 1 e 2 de cada perfil 
cromatográfico (Figura 80, A e B) eram de interesse para este estudo, visto que apresentam diferentes substituintes ligados a estrutura da antocianidina cianidina.

Para as substâncias equivalentes aos picos 1 e 2 (das duas matrizes) a análise realizada por CLAE/DAD revelou a presença de dois espectros de absorção com duas bandas cada um na região do UV-Vismáx (Figura 81). O isolamento dos picos 1 e 2 por meio da coleta ao final do detetor do CLAE/DAD, possibilitou o estudo dessas duas substâncias, agora no CLUE-EMQTOF $\left(\mathrm{ESI}^{+}\right)$(Figura 82).

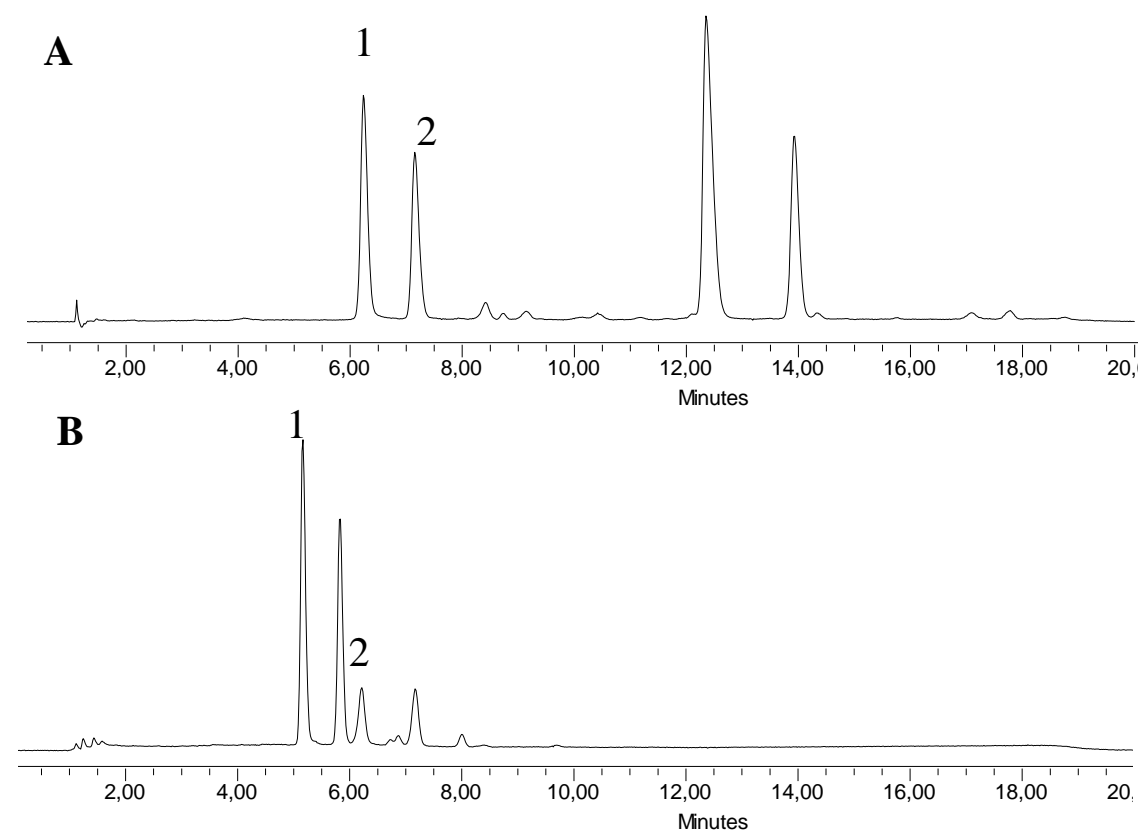

Figura 80: Cromatograma do extrato metanólico da cebola roxa (A) e framboesa vermelha (B), extraído utilizando a metodologia II de análise no CLAE/DAD a 520nm. Identificação dos picos 1 e 2, nos dois cromatogramas, na Tabela 21.
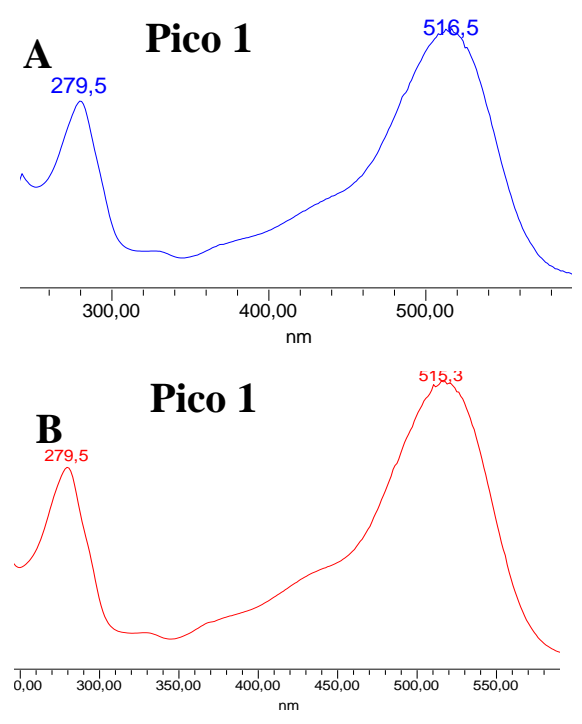
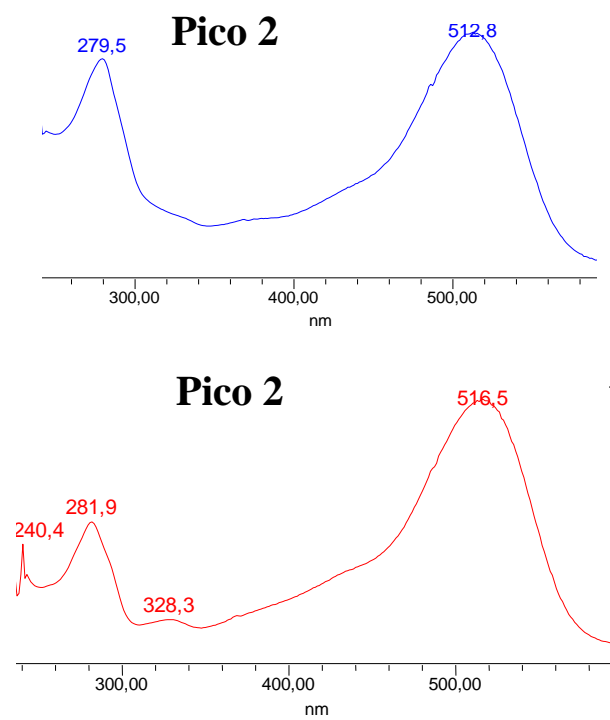

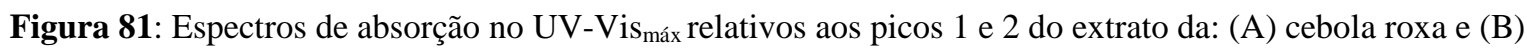
framboesa, obtidos no DAD $(520 \mathrm{~nm})$ enumerados conforme cromatograma da Figura 80. 
Para as substâncias equivalentes aos picos 1 (framboesa vermelha) e 2 (cebola roxa) dos cromatogramas da Figura 80, as análises em modo EM/EM no CLUE-EM-QTOF $\left(\mathrm{ESI}^{+}\right)$, apresentaram íons moleculares iguais, diferenciando apenas nas casas decimais, um a $\mathrm{m} / \mathrm{z}$ 611,1849 e fragmento 287,0586, e o outro $\mathrm{m} / \mathrm{z} 611,1539$ e fragmento 287,0546, respectivamente. Os dois íons moleculares indicaram a perda de duas hexoses de uma só vez $\left([\mathrm{M}-324 \mathrm{Da}]^{+}\right)$(Tabela 20).

Para as substâncias equivalentes aos picos 1 (cebola roxa) e 2 (framboesa) dos cromatogramas da Figura 80, as análises em modo EM/EM no CLUE-EM-QTOF $\left(\mathrm{ESI}^{+}\right)$ apresentaram íons moleculares iguais, diferenciando apenas nas casas decimais, um a $\mathrm{m} / \mathrm{z}$ 449,1397 e fragmento 287,0825, e o outro $\mathrm{m} / \mathrm{z}$ 449,1207 e fragmento 287,0525, respectivamente. Todos os dois íons moleculares indicaram a perda de uma hexose ([M-162 Da $\left.]^{+}\right)($Tabela 21).

Para todas as substâncias analisadas se pôde observar a presença de $\lambda_{\text {máx }}$ no visível com valores abaixo de $520 \mathrm{~nm}$. Somando-se a esse resultado os dados obtidos no modo EM/EM no CLUE-EM-QTOF $\left(\mathrm{ESI}^{+}\right.$), onde todos os fragmentos apresentam uma $\mathrm{m} / \mathrm{z} 287$, conclui-se que todas as antocianinas analisadas são derivadas de cianidinas.

Os espectros de absorção ainda serviram como ferramenta para acrescentar a informação sobre o número de substituição glicosídica, assim como sua posição na estrutura da antocianidina. Todos os valores calculados da razão $E_{440} / E \lambda$ vis-máx, apresentaram taxa acima de $28 \%$, indicam, portanto, que todas as antocianinas apresentam apenas glicosilação no carbono 3 do anel piridínico. Pois, uma razão $\left(E_{440} / E \lambda\right.$ vis-máx $)$ com valor de $15-24 \%$ indicaria a ocorrência de uma di-substituição na estrutura da antocianidina (DYRBY, WESTERGAARD e STAPELFELDT, 2001; ARAPITSAS, SJÖBERG e TURNER, 2008; SUN, LIN e CHEN, 2013).

De acordo com os dados, sugere-se para a substâncias equivalentes ao pico 1 da cebola roxa e pico 2 da framboesa a antocianina cianidina-3-O-glicosídeo. E, para as substâncias equivalentes ao pico 2 da cebola roxa e pico 1 da framboesa, a antocianina cianidina-3-Odiglicosídeo.

A escolha dessas duas matrizes também se fez devido à presença em comum da antocianina cianidina-3-O-glicosídeo. Essa antocianina serviu como marcador da ordem de eluição. Convém ressaltar que a ordem de eluição em sistema de fase reversa, parâmetro baseado pela hidrofobicidade da molécula, está diretamente relacionado ao grau de substituições e natureza dos açúcares presentes na estrutura deste pigmento (CHAOVANALIKIT, THOMPSON e WROLSTAD, 2004).

As duas cianidinas-3- $O$ - diglicosiladas (pico 2 do extrato da cebola roxa e o pico 1 do extrato da framboesa vermelha) apresentaram, portanto, o mesmo valor de $\mathrm{m} / \mathrm{z}$ tanto do íon molecular como do seu fragmento. Possuem também o mesmo comportamento de liberação da massa neutra (324 Da), após aplicação de variadas energias de colisão (4- 16 eV), mostrando somente a liberação do fragmento correspondente a sua antocianidina, no caso a cianidina.

Nesse caso, para as duas matrizes o tempo de retenção da antocianina cianidina-3-O glicosídeo foi um marco para diferenciar o tipo de açúcar (diglicosídeo) que compõe a antocianina que elui com valor inferior ou superior ao seu tempo de retenção, já que as duas antocianinas diglicosiladas eluem em tempo de retenção diferentes.

Todos os dados obtidos por este estudo foram consistentes com os dados observados em trabalhos publicados anteriormente (WU e PRIOR, 2005a b, STEIMER e SJÖBRG, 2011). Sendo assim, baseado na literatura, se pôde identificar a antocianina da substância equivalente ao pico 1 do extrato da framboesa vermelha como cianidina-3- $O$-soforosídeo e a antocianina equivalente ao pico 2 da cebola roxa como cianidina-3-O-laminaribiosídeo (Tabela 20). 
Tabela 20: Identificação das substâncias relativas aos picos 1 e 2 dos cromatogramas da cebola roxa e framboesa (Figura 80 ).

\begin{tabular}{|c|c|c|c|c|c|c|}
\hline Pico & $\begin{array}{c}t_{R} \\
(\min )\end{array}$ & $\begin{array}{l}\text { UV-vis } \\
(\mathrm{nm})\end{array}$ & $\begin{array}{c}E_{440} / \mathrm{E}_{\lambda \text { vis-máx }} \\
(\%)\end{array}$ & $\begin{array}{l}{[\mathrm{M}]^{+}} \\
(\mathrm{m} / \mathrm{z})\end{array}$ & $\begin{array}{c}\text { EM/EM } \\
(m / z)\end{array}$ & Antocianina \\
\hline \multicolumn{7}{|c|}{ Cebola roxa (Allium cepa $\mathbf{L}$.) } \\
\hline 1 & 6,3 & $275,9 / 516,5$ & 34 & 449,1397 & 287,0825 & cianidina-3-O-glicosídeo \\
\hline 2 & 7,2 & $279,5 / 512,8$ & 35 & 611,1539 & 287,0586 & cianidina-3-O-laminaribiosídeo \\
\hline \multicolumn{7}{|c|}{ Framboesa vermelha (Rubus idaeus L.) } \\
\hline 1 & 5,2 & $279,2 / 514,2$ & 33 & 611,1849 & 287,0586 & cianidina-3- $O$-soforosídeo \\
\hline 2 & 6,3 & $281,9 / 516,5$ & 31 & 449,1207 & 287,0525 & cianidina-3-O-glicosídeo \\
\hline
\end{tabular}

A diferença do tempo de retenção das duas antocianinas, cianidina-3- $O$-soforosídeo e cianidina-3-O-laminaribinosídeo, ocorre devido a diferentes ligações entre as duas glicoses. No caso do carboidrato soforosídeo, as duas moléculas de glicose estão ligadas entre si por ligações glicosídicas no carbono no 1 de uma das moléculas de glicose e o no 2 da outra molécula de glicose $(O-\beta$-D-glicopiranosil (2-1)-D-glicopiranose). No carboidrato lamirabiose, a ligação glicosídica é entre o carbono no 1 de uma das moléculas de glicose e o $\mathrm{n}-3$ da outra molécula de glicose ( $O$ - $\beta$-D-glicopiranosil (3-1)-D-glicopiranose) (Figura 82).

A presença da antocianina cianidina-3- $O$-soforosídeo já foi identificada e isolada pelo presente estudo no pericarpo do mangostin. Sendo assim, a matriz framboesa vermelha ficará como outra opção para obtenção desta substância.
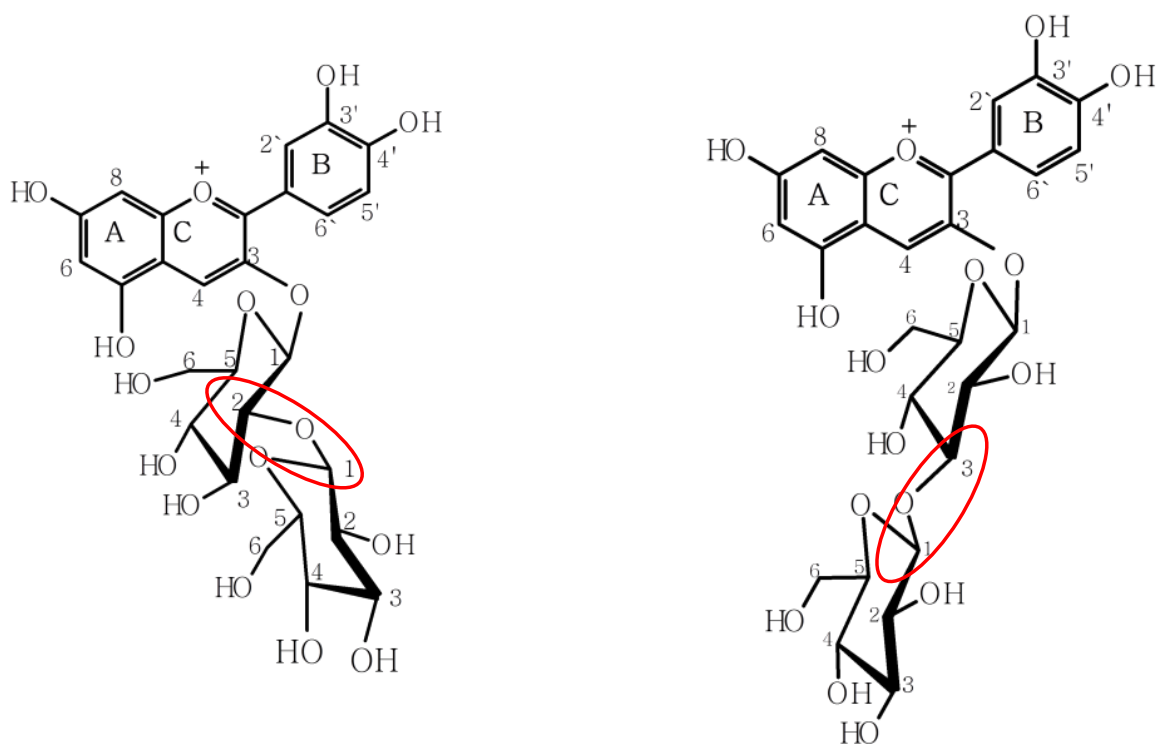

Figura 82: Estruturas das antocianinas: A) cianidina-3- $O$-soforosídeo e B) cianidina-3-O-laminaribiosídeo. 
Já a substância encontrada na cebola roxa, cianidina-3- $O$-lamirabinosídeo, ainda não havia sido isolada pelo presente estudo. Além disso, essa matriz apresenta-se como ótima opção para obtenção desta substância, devido a sua significante concentração na matriz. Esse fato associado à sua ótima resolução cromatográfica, torna possível concentrar mais o extrato permitindo a obtenção, da cianidina-3-O-laminaribiosídeo pura, com menor número de injeções.

Alface roxa (Lactuca sativa L.) e repolho roxo (Brassica oleracea L.)

As matrizes alface e repolho, ambos do grupo das variedades roxa, foram estudados com o objetivo de ampliar aquisição de novos derivados da antocianidina cianidina.

Trabalhos anteriormente publicados identificaram no perfil antociânico do repolho roxo, de 15 a 36 antocianinas (DYRBY, WESTERGAARD e STAPELFELDT, 2001; WU e PRIOR, 2005b; CHARRON et al.,2007; ARAPITSAS, SJÖBERG e TURNER, 2008; AHMADIANI et al., 2014). As caracterizações revelaram que a matriz traz a particularidade de apresentar, em geral, a antocianidina "cianidina" ligada à grande variedade de substituintes. Dentre essas antocianinas, a cianidina di-substituida e diglicosilada, apresentando um teor acima de $80 \%$, em relação aos outros pigmentos presentes, se mostrou interessante para o presente estudo.

A análise realizada por CLAE/DAD (a $520 \mathrm{~nm}$ ) no extrato de repolho roxo liofilizado, apresentou um cromatograma onde se observou 14 picos (Figura 83). Apenas a substância mais abundante, pico 1 , teve seu espectro na região UV-Vis máx analisado.

O isolamento do pico 1, o qual a substância equivalente foi recolhida ao final do detetor (CLAE/DAD), possibilitou o estudo dessa substância, agora no CLUE-EM-QTOF (ESI ${ }^{+}$em modo EM/EM (Figura 84).

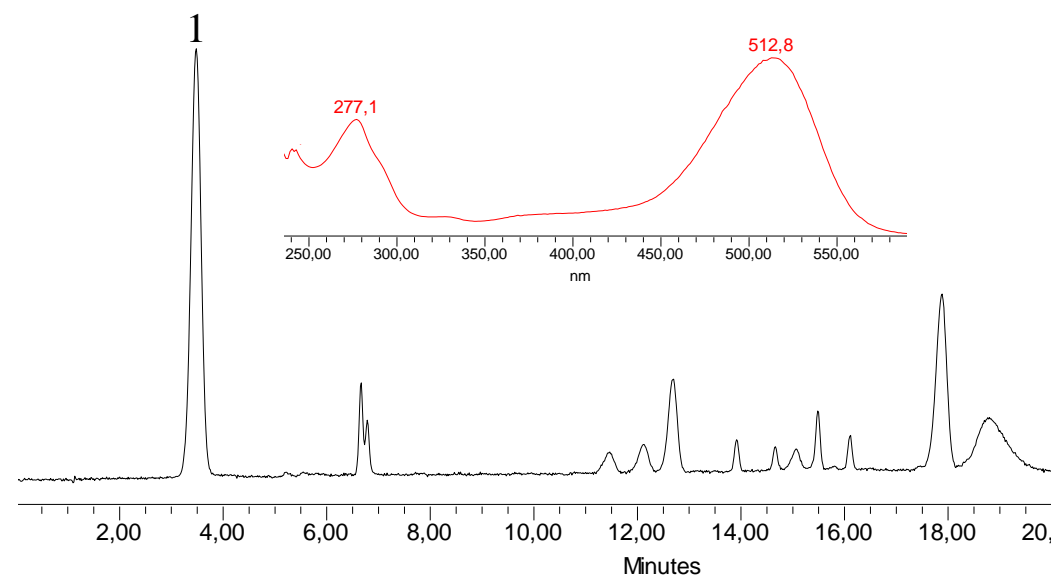

Figura 83: Cromatograma do extrato metanólico do repolho roxo extraído utilizando a metodologia II de análise no CLAE/DAD a 520nm. Espectro de absorção no UV-Vis máx da substância equivalente ao pico 1.

A análise realizada por inserção direta no espectrômetro de massa acurada (EMQTOF- ESI ${ }^{+}$), apresentou em modo EM/EM, quando aplicadas energias de colisão de 4, 8 e 
$16 \mathrm{eV}$, em geral a presença dos íons: molecular a $\mathrm{m} / \mathrm{z} 773,2136$ e seus fragmentos a $\mathrm{m} / \mathrm{z}$ : 611,$1563 ; 449,1050$ e; 287,0574. Todos os íons fragmentos indicam a perda de uma hexose (162 Da) (Figura 84).

O valor encontrado no visível para o $\lambda$ máx de $512,8 \mathrm{~nm}$ associado ao íon fragmento 287,0574 , caracterizou presença da antocianidina cianidina na molécula.

O espectro de absorção serviu como ferramenta para acrescentar a informação sobre o número de substituição glicosídica, assim como sua posição na estrutura da antocianidina. $\mathrm{O}$ valor calculado da razão $E_{440} / E \lambda$ vis-máx, apresentou taxa de $19 \%$, indicando, portanto, que a antocianina apresenta glicosilação no carbono 3 do anel piridínico e no carbono 5 do anel A, já que a razão $\left(E_{440} / E \lambda\right.$ vis-máx $)$ com valor de $15-24 \%$ indica a ocorrência de uma di-substituição na estrutura da antocianidina (DYRBY, WESTERGAARD e STAPELFELDT, 2001; ARAPITSAS, SJÖBERG e TURNER, 2008).

Em relação às massas acuradas extraídas no EM-QTOF (ESI+), as intensidades dos íons apresentados mostraram relação massa carga diferentes quando submetidos à diferentes energias de colisão (Tabela 21).

Tabela 21: Intensidade dos íons no EM-QTOF (ESI+), quando o íon molecular 773 filtrado é submetido à energia de colisão de 4, 8 e 16 eV.

\begin{tabular}{ccc}
\hline $\begin{array}{c}\text { Massa Exata } \\
(\boldsymbol{m} / \boldsymbol{z})\end{array}$ & $\begin{array}{c}\text { Energia de colisão } \\
(\mathbf{e V})\end{array}$ & Intensidade \\
\hline & & $\%$ \\
{$\left[\mathrm{M}^{+}\right]=773,2239$} & & 100 \\
$\mathrm{EM} / \mathrm{EM}=611,1744$ & 4 & 13,79 \\
$\mathrm{EM} / \mathrm{EM}=449,1440$ & & 24,14 \\
$\mathrm{EM} / \mathrm{EM}=287,0574$ & & 0 \\
& & \\
{$\left[\mathrm{M}^{+}\right]=773,2136$} & & 100 \\
$\mathrm{EM} / \mathrm{EM}=611,1563$ & 8 & 10 \\
$\mathrm{EM} / \mathrm{EM}=449,1050$ & & 33,3 \\
$\mathrm{EM} / \mathrm{EM}=287,0574$ & & 10 \\
& & \\
{$\left[\mathrm{M}^{+}\right]=773,2239$} & & 0 \\
$\mathrm{EM} / \mathrm{EM}=611,1653$ & 16 & 10,45 \\
$\mathrm{EM} / \mathrm{EM}=449,1206$ & & 100 \\
$\mathrm{EM} / \mathrm{EM}=287,0574$ & & \\
\hline
\end{tabular}

Através do padrão de fragmentação, pôde-se observar que a saída de massa neutra relativa a 342 Da seria rota preferencial em relação à saída de $162 \mathrm{Da}$. Isso pode ser explicado pela alta percentagem do íon fragmento a $\mathrm{m} / \mathrm{z}$ 449,1050, após perda de massa neutra de 324 Da (referente à duas hexoses), em relação ao íon fragmento a $\mathrm{m} / \mathrm{z} 611,1563$, após perda de 162 Da (referente à saída de uma hexose) (Figura 84).

De acordo com estudos anteriores, essa antocianina é diglicosilada no carbono 3 e monoglicosilada no carbono 5, sempre com o açúcar glicose, pois foi o único carboidrato 
encontrado nesta matriz (WU e PRIOR, 2005b; CHARRON et al.,2007; AHMADIANI et al., 2014).

O carboidrato soforosídeo foi proposto por alguns autores para a identificação do diglicosídeo (DYRBY, WESTERGAARD e STAPELFELDT, 2001; ARAPITSAS, SJÖBERG e TURNER, 2008).

Isto justificaria a preferência da retirada de massa neutra de $324 \mathrm{Da}$, pois, como já observado anteriormente nesse estudo, o dissacarídeo soforosídeo é retirado da estrutura da antocianidina sem que ocorra a quebra na ligação glicosídica entre os dois monossacarídeos, mesmo sendo submetido à altas energias de colisão no EM. Provavelmente, por causa da grande estabilidade da ligação glicosídica entre as duas glicoses.

A energia de colisão incidiria sobre a molécula de antocianina, liberando assim a massa neutra de 324 Da com preferência. Em seguida retiraria o monossacarídeo do carbono 5, liberando a antocianindina $(\mathrm{m} / \mathrm{z}, 287)$.

\section{MSMS}
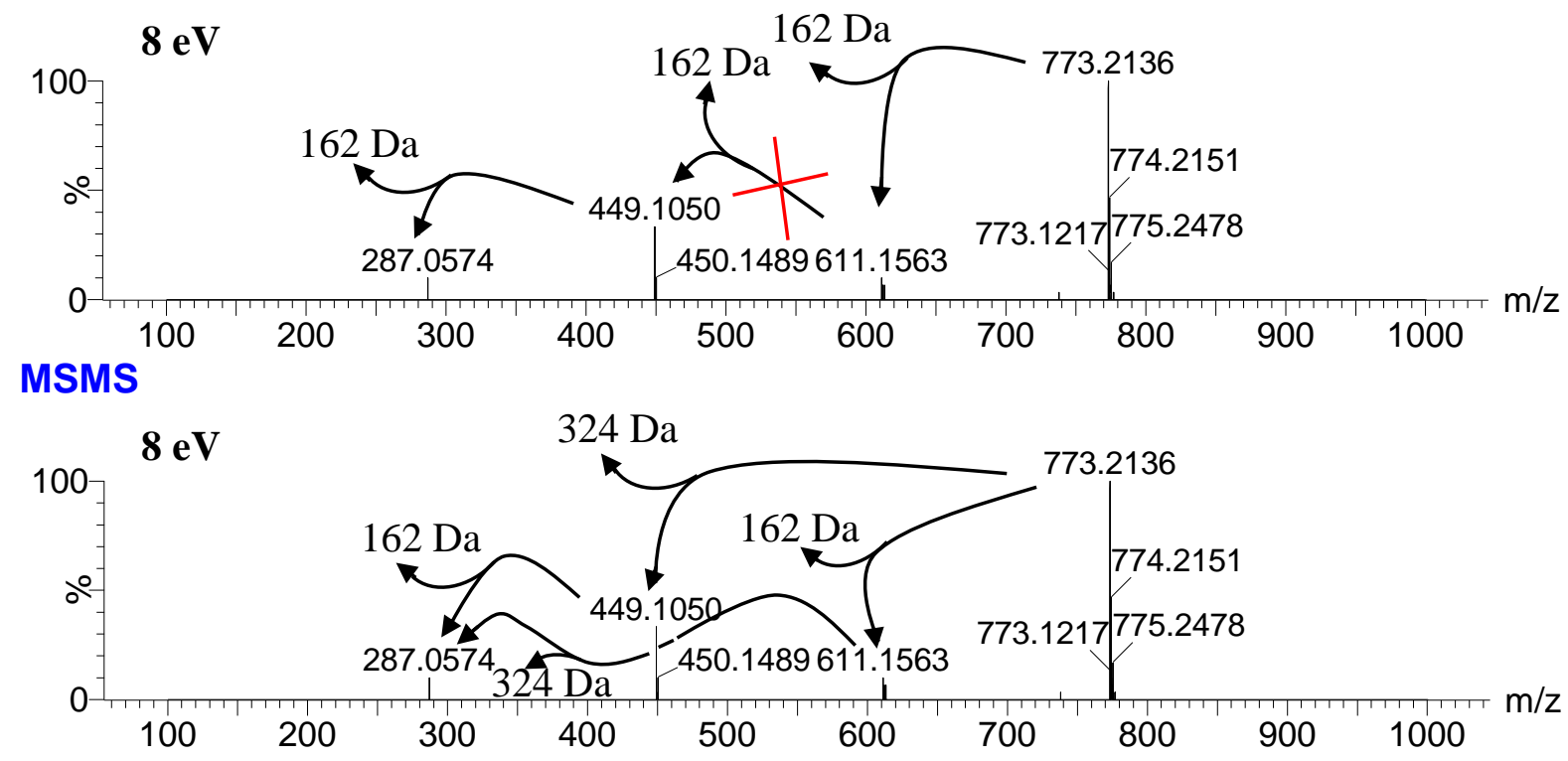

Figura 84: Espectro de massa acurada em modo EM/EM no EM-QTOF $\left(\mathrm{ESI}^{+}\right)$, após energia de colisão de 8 eV, da substância equivalente ao pico 1 da Figura 83 e, rota de fragmentação proposta.

A presença do soforosídeo pode ser sugerida também pelo tempo de retenção. Como já foi observado por este estudo, o dissacarídeo soforosídeo atribui à molécula da antocianina um ganho de polaridade em relação a antocianina monoglicosilada. Deslocando, portanto, seu tempo de retenção para um tempo inferior ao observado para a mesma antocianidina associada à apenas uma glicose (cianidina-3-O-glicosídeo). O contrário foi observado em relação ao dissacarídeo laminaribiosídeo, que apresenta tempo de retenção superior ao da cianidina-3-Oglicosídeo.

Em relação à substância isolada do extrato do repolho, a molécula ainda possui outra unidade de glicose ligada ao carbono 5 do anel A. Justificando o deslocamento ainda maior no tempo de retenção conferido à substância em questão, pois, o açúcar extra confere um 
incremento na polaridade da molécula em relação aos outros derivados, que possuem menor número de glicose na estrutura molecular.

A matriz alface roxa apresentou um perfil antociânico, no cromatograma extraído do CLAE/DAD, com quatro picos apresentando uma excelente resolução entre eles. Todos os espectros na região do UV-Vismáx mostraram duas bandas características de antocianinas (Figura 85). Apenas as substâncias referentes aos picos 1 e 3 foram isoladas após separação cromatográficas e analisadas no EM-QTOF $\left(\mathrm{ESI}^{+}\right)$.

A análise em modo EM/EM (EM-QTOF $\left(\mathrm{ESI}^{+}\right)$realizada por inserção direta, apresentou para a substância equivalente ao pico 1 o íon molecular a $m / z$ 449,1103 e fragmento a $\mathrm{m} / z$ 287,0517. A presença do íon fragmento associada ao comprimento de onda na região do visível 515,3 nm, confirmou a presença da antocianina cianidina. A hexose (162 Da) liberada confirma ser uma glicose pelo tempo de retenção $\left(t_{R}=6,3 \mathrm{~min}\right)$.

A substância equivalente ao pico 3, apresentou íon molecular a $\mathrm{m} / \mathrm{z} 535,1393 \mathrm{e}$ fragmentos a $m / z 449,1397$ e 287,0763 , indicando a perda de massa neutra no total $242 \mathrm{Da}$ (86 Da+162 Da).

Na literatura são poucos os trabalhos relatando a caracterização de antocianinas na alface roxa. Mas, os poucos trabalhos existentes apresentam a matriz da alface roxa com perfil cromatográfico simples, até quatro substâncias, onde, em geral, a substância equivalente ao pico 3 apresenta-se como majoritária (YAMAGUICHI et al., 1996; WU E PRIOR, 2005b; PARK et al., 2008).

Outra particularidade da matriz é a presença marcante de derivados da cianidina. Park e colaboradores (2008) ao estudarem a biossíntese de antocianinas em 20 variedades transgênicas de alface roxa, observaram a predominância de cianidinas e alguns traços de delfinidina.

O padrão de fragmentação apresentado no EM/EM por esse estudo, revela a perda de uma massa neutra de $86 \mathrm{Da}$ (ácido malônico, $\mathrm{C}_{3} \mathrm{H}_{2} \mathrm{O}_{3}$ ), liberando o fragmento a $m / z$ 449,1397. O fragmento a $\mathrm{m} / \mathrm{z}, 287,0763$ é liberado quando ocorre a perda da massa neutra de $162 \mathrm{Da}$ (hexose) (Figura 86), identificada como glicose, pois há prevalência deste açúcar na matriz.

As duas substâncias isoladas apresentam-se como majoritárias (pico 1 e 3) no cromatograma (Figura 85). Yamaguichi e colaboradores (1996) também observaram as duas antocianinas como majoritárias na matriz analisada e as identificaram como cianidina-3- $O$ glicosídeo e cianidina-3-O- (6"malonilglicosídeo).

Wu e Prior (2005b) também identificaram a majoritária na matriz da alface roxa como cianidina-3-O- (6"malonilglicosídeo). A identificação foi realizada através da comparação do $t_{R}$ e dados obtidos no EM e na literatura.

Dessa forma, após análise dos dados obtidos, principalmente no EM/EM este estudo indica as antocianinas equivalente ao pico 1 e 3 do extrato da alface roxa como cianidina-3$O$-glicosídeo e cianidina-3-O- (6"malonilglicosídeo), confirmando a presença dessas duas substâncias, na matriz de alface roxa analisada.

Esse fato, ratifica a presença dessas duas substâncias na matriz de alface roxa apesar dos estudos serem realizados em épocas, continentes e variedades diferentes. Pesquisadores sempre relataram a presença da majoritária cianidina-3-O- (6"malonilglicosídeo) e a presença da cianidina-3-O-glicosídeo nas matrizes, apresentando variação somente nas concentrações quando comparado os estudos (YAMAGUICHI et al., 1996; WU E PRIOR, 2005b; PARK et al., 2008).

No que diz respeito às antocianinas na matriz de repolho roxo, conclui-se que a matriz sempre apresenta um mesmo padrão de perfil antociânico, prevalecendo a substância cianidina-3-O- (6"malonilglicosídeo) com maior teor entre as substâncias encontradas, não 
importando a variedade ou lugar de procedência. Isso a torna uma excelente fonte de aquisição da substância cianidina-3-O- (6"malonilglicosídeo). Pois, apesar desta substância já ter sido encontrada em outras matrizes como cebola roxa e amora (WU e PRIOR, 2005a, b; FERREIRA, ROSSO e MERCADANTE, 2010), a concentração era muito baixa, sendo algumas vezes, dependendo da variedade dessas matrizes, até insignificante.

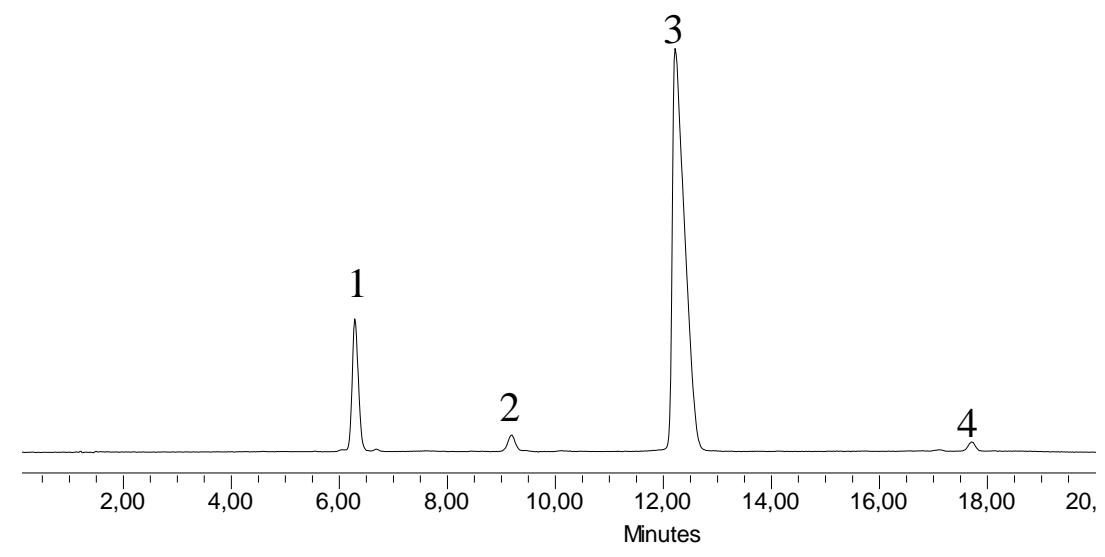

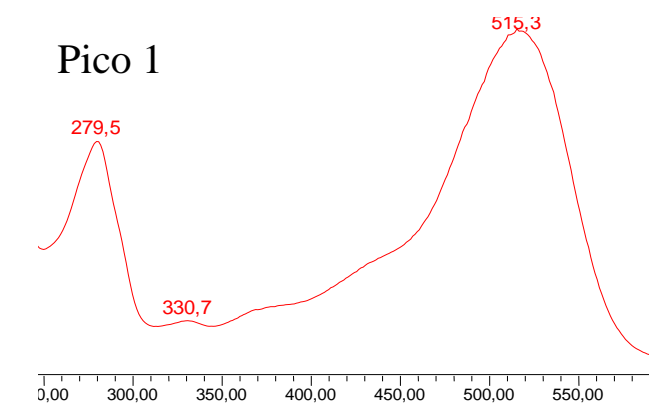

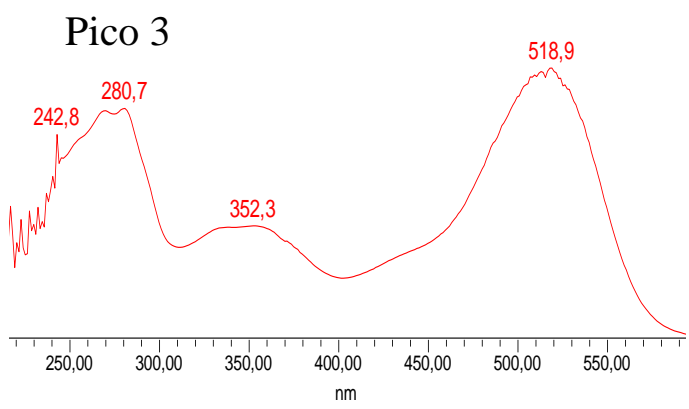

Pico 2

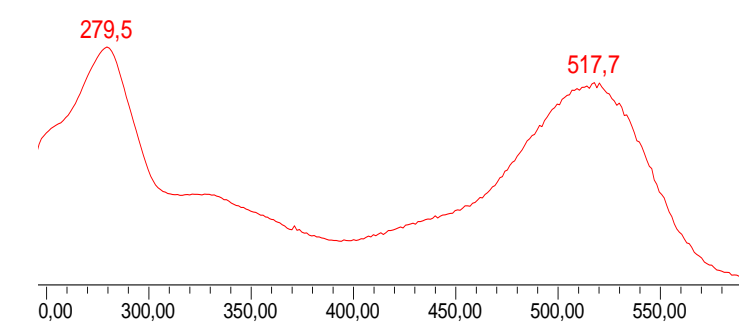

Pico 4

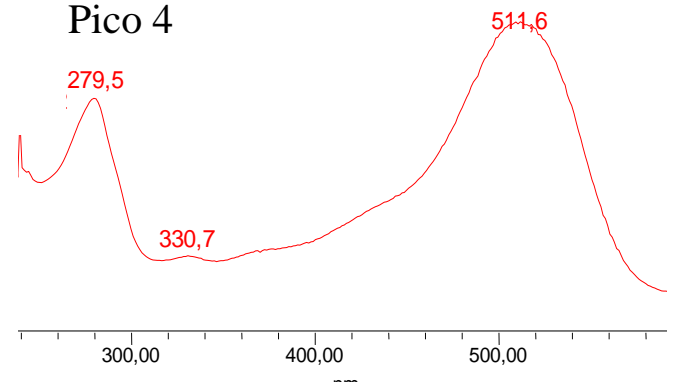

Figura 85: Cromatograma do extrato metanólico da alface roxa extraído no CLAE/DAD a 520nm, utilizando a metodologia II de análise. Espectros de absorção no UV-Vis máx relativo as substâncias equivalentes aos picos de 1 a 4 . 
Os tempos de retenção observados durante o presente estudo, relativo aos cromatogramas (CLAE/DAD) de cinco antocianinas com diferentes substituintes compostos pelo açúcar glicose, foram comparados e encontram-se na Tabela 22.

Tabela 22: Tempo de retenção no CLAE/DAD, no gradiente da metodologia II, de derivados de cianidinas do extrato do repolho roxo.

\begin{tabular}{lc}
\hline \multicolumn{1}{c}{ Antocianina } & $\mathbf{t}_{\mathbf{R}}$ \\
\hline Cianidina-3-O$O$-soforosídeo-5- $O$-glicosídeo & 3,5 \\
Cianidina-3,5-di- $O$-glicosídeo & 3,8 \\
Cianidina-3-O-soforosídeo & 5,2 \\
Cianidina-3- $O$-glicosídeo & 6,3 \\
Cianidina-3- $O$-laminaribiosídeo & 7,2 \\
Cianidina-3- $O$-rutenosídeo & 7,2 \\
Cianidina-3-O- $(6$ "malonilglicosídeo $)$ & 12,3 \\
\hline
\end{tabular}

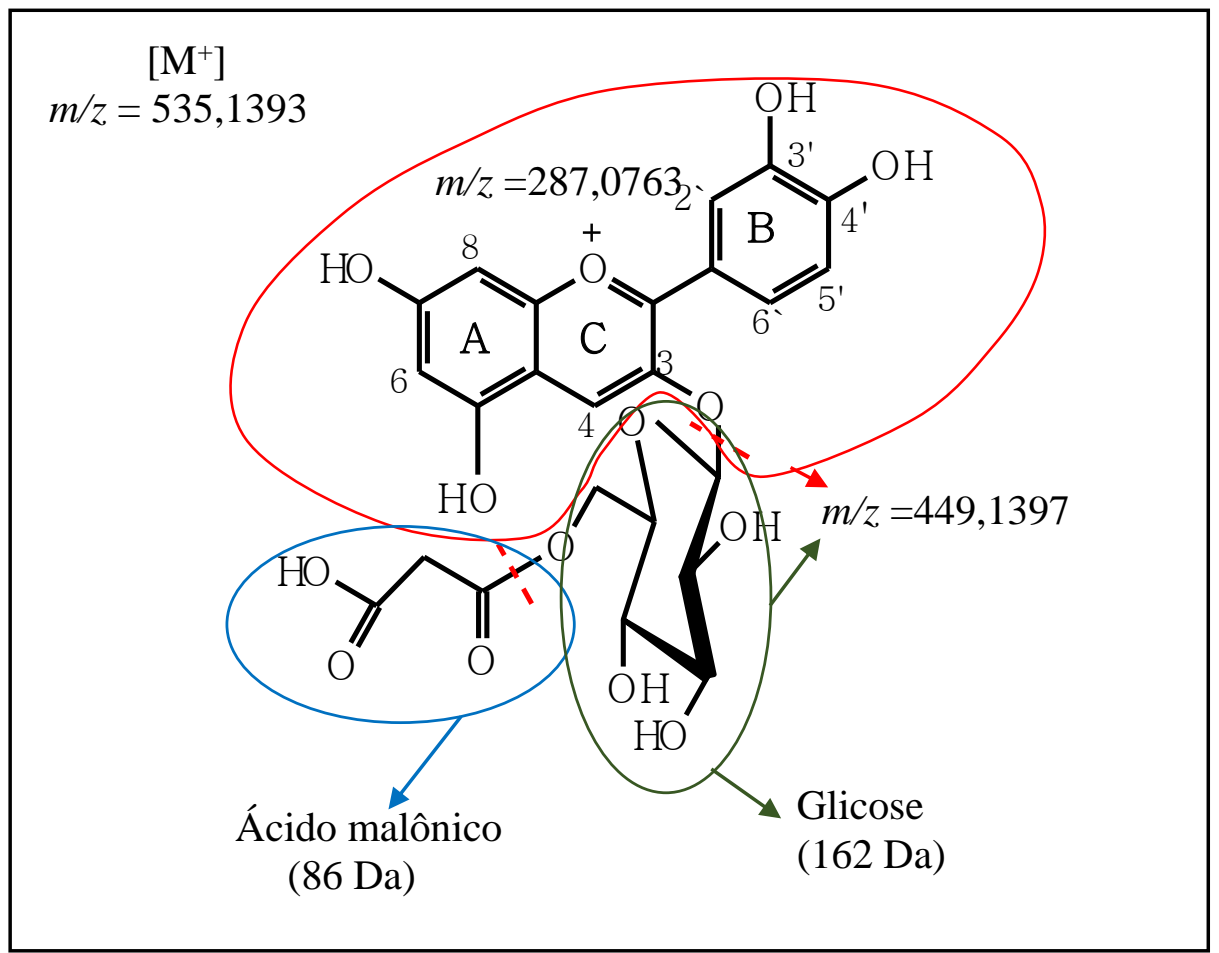

Figura 86: Estrutura da antocianidina cianidina-3-O- (6"malonilglicosídeo), indicando a massa acurada de seus fragmentos, após perda de massa neutra $86 \mathrm{Da}$ e $162 \mathrm{Da}$.

Os estudos das substâncias cianidina-3- $O$-soforosídeo-5-O-glicosídeo e cianidina-3$O$ - (6"malonilglicosídeo), foram de grande ajuda no entendimento em relação ao comportamento de hidrofobicidade durante o gradiente da metodologia, desenvolvida no presente trabalho (Tabela 22). Além disso, tornaram possíveis a aquisição dessas substâncias purificadas para uso como padrão de referência.

As matrizes também acrescentaram uma riqueza de informações sobre a rota de fragmentação quando submetida à determinadas energias de colisão. 
Fruto da amendoeira (Terminalia catappa L.)

O cromatograma obtido na análise por CLAE/DAD $(520 \mathrm{~nm})$ do extrato do fruto da amendoeira (Figura 87), revelou a presença de três picos que foram, a princípio, identificados como antocianinas devido a presença dos espectros de absorção na região do UV-Vismáx $\left(\lambda_{\text {máx }}\right.$ 280 e $520 \mathrm{~nm}$ ), característicos desse pigmento.

A análise por EM/EM apresentou para o pico (1) íon molecular a $m / z$ 465,1096 e fragmento a $m / z, 303,0590$ após a perda de uma hexose (162 Da), pico (2) íon molecular a $\mathrm{m} / \mathrm{z}$ 449,1083 e fragmento a $\mathrm{m} / \mathrm{z} 287,0556$ após a perda de uma hexose (162 Da) e pico (3) íon molecular a $\mathrm{m} / \mathrm{z} 433,1123$ e fragmento a $\mathrm{m} / \mathrm{z}$ 271,0596 após a perda de uma hexose (162 Da) (Figura 88).

Os dados no EM/EM dos íons fragmentos a $\mathrm{m} / \mathrm{z}: 303,0590 ; 287,0556$ e 271,0596, após à quebra da ligação glicosídica e liberação do açúcar substituinte (162 Da), somados aos resultados dos espectros de absorção (Figura 87), indicam os três picos como: delfinidina-3$O$-glucosídeo ( $\mathrm{t}_{\mathrm{R}} 4,2$ minutos) compreendendo a delfinidina $(303,0590)$ e a hexose $(162 \mathrm{Da})$; cianidina-3- $O$-glucosídeo ( $\mathrm{t}_{\mathrm{R}} 5,8$ minutos) compreendendo a cianidina $(287,0556)$ e a hexose $(162 \mathrm{Da})$; pelargonidina-3-O-glucosídeo ( $\mathrm{t}_{\mathrm{R}} 7,8$ minutos) compreendendo a pelargonidina $(271,0596)$ e a hexose (162 Da).
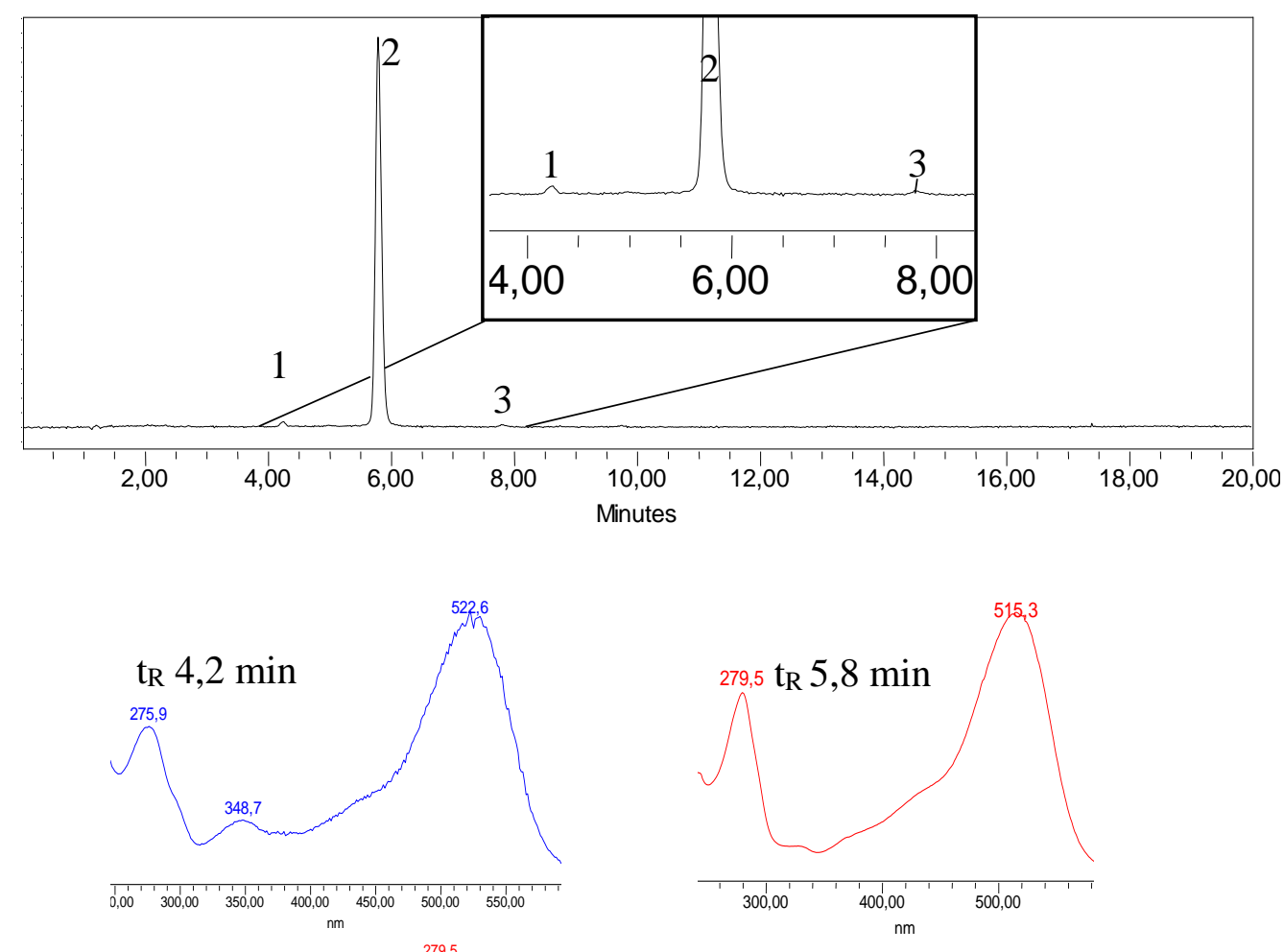

$\mathrm{t}_{\mathrm{R}} 7,8 \mathrm{~min}$

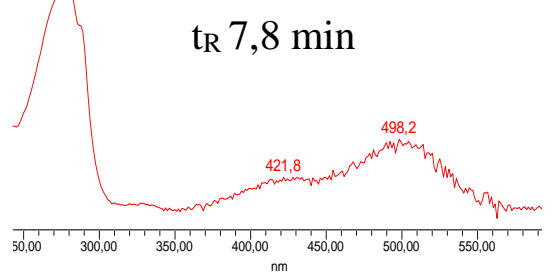

Figura 87: Cromatograma do extrato do fruto da amendoeira, CLAE/DAD $(520 \mathrm{~nm})$, e os espectros de absorção na região do UV-Vis máx. 


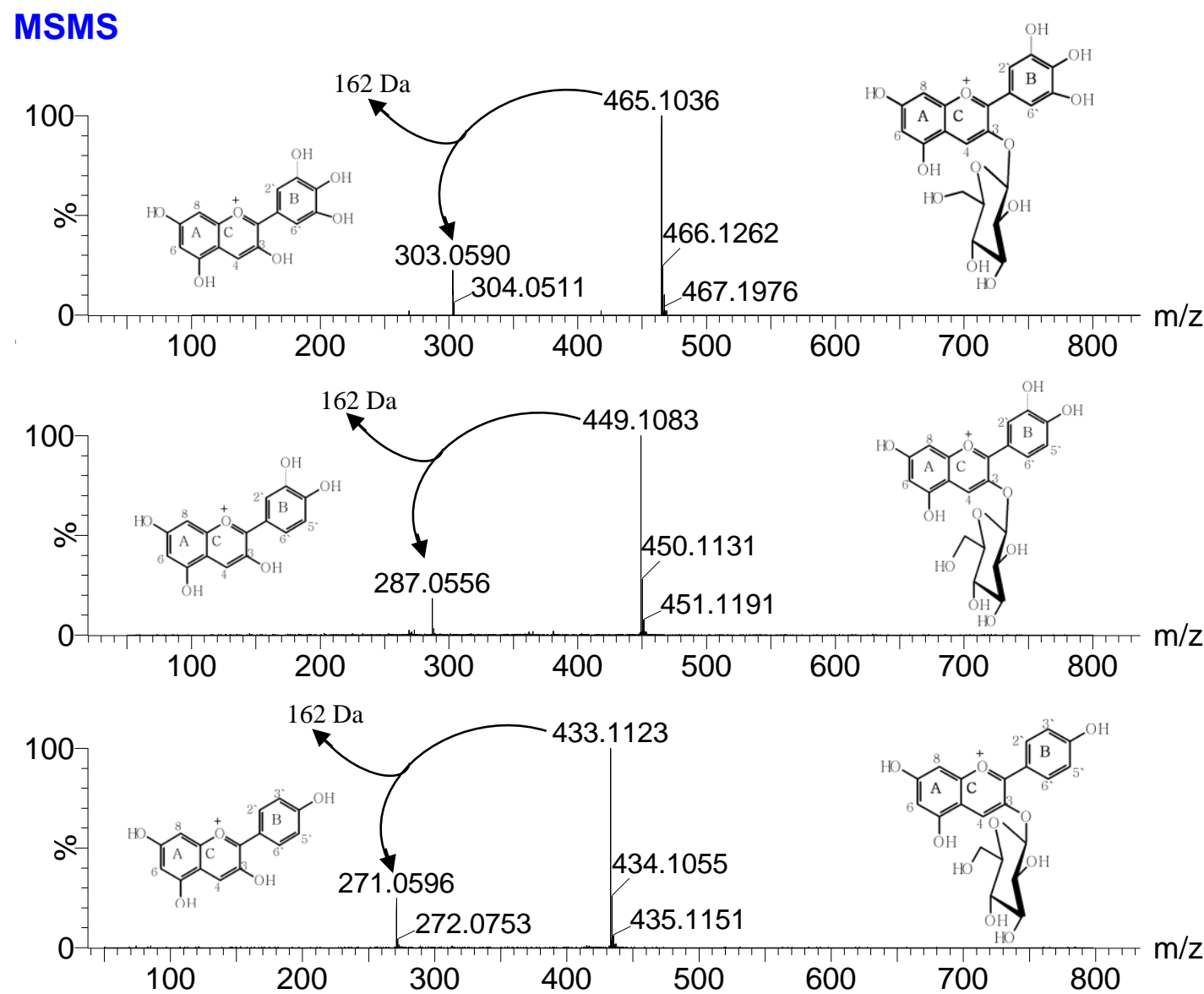

Figura 88: Espectros de massa em modo EM/EM, obtidos no EM QTOF $\left(\mathrm{ESI}^{+}\right)$, das substâncias obtidas a partir do extrato do fruto da amendoeira: picos (1); (2); (3), respectivamente.

A presença da glicose como o glicosídeo nas antocianinas foi baseada no $t_{R}$ de cada antocianina. O pico (1) e (3) tiveram seus $t_{\mathrm{R}}$ comparados ao $t_{\mathrm{R}}$ da delfinidina-3-O-glicosídeo presente no extrato da casca da berinjela (WU e PRIOR, 2005b) e, pelargonidina-3-Oglicosídeo presente no extrato de morango (SILVA et al., 2005), respectivamente, quando os extratos foram submetidos as mesmas condições de análise utilizada para o extrato do fruto da amêndoa.

A eluição no mesmo tempo de retenção indica que o pico (1) é uma delfinidina- $O$ glicosídeo e o pico (3) a pelargonidina-3-O-glicosídeo. Para o pico (2) o padrão isolado proveniente do fruto do açaí (cianidina-3-O-glicosídeo) foi utilizado na confirmação da identificação da substância equivalente a esse pico como cianidina-3-O-glicosídeo.

As análises realizadas por CLAE/DAD $(520 \mathrm{~nm})$ nas três partes do fruto, puderam comprovar que não há alteração no perfil cromatográfico das antocianinas (Figura 90), mas sim na sua concentração nessas partes do fruto.

A parte que apresenta visualmente pigmentação mais intensa, a parte mais fibrosa que envolve o caroço, apresentou uma concentração maior deste pigmento. Isso pode ser evidenciado pelas áreas dos picos (Tabela 23), o fruto possui 53\%, 73\% e 100\% desse pigmento na casca $(\mathrm{C})$, polpa $(\mathrm{P})$ e polpa fibrosa $(\mathrm{PF})$, respectivamente, a variação da concentração segue a ordem: $\mathrm{PF}>\mathrm{C}>\mathrm{P}$. 


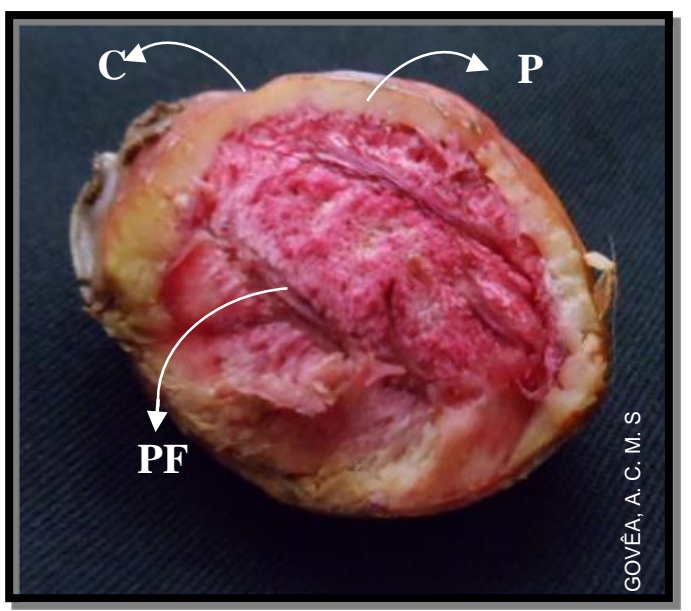

Figura 89: Fruto da amendoeira (Terminalia catappa L.) - C (casca); P (Polpa); PF (Parte Fibrosa).

Tabela 23: Massas e áreas observadas nos extratos do fruto amendoeira analisados por CLAE/DAD.

\begin{tabular}{lcc}
\hline & & Área* $^{*}$ \\
\hline Amostras & Massa* $^{*}$ & Pico 2 \\
\hline Amêndoa C & 0,2505 & 971506 \\
Amêndoa P & 0,2105 & 476643 \\
Amêndoa PF & 0,2353 & 1978326 \\
\hline *média & &
\end{tabular}

Ao início deste estudo haviam disponíveis na literatura poucos relatos sobre o perfil antociânico do fruto da Terminalia catappa L. Relatos sobre pigmentos, em geral, eram referentes as folhas (LÓPEZ-HERNÁNDEZ et al., 2001.), parte da T. catappa mais estudada na planta (CHYAUA et al.,2002; KO, WENG e CHIOU, 2002).

Nagappa e colaboradores (2003) estudaram in vitro a atividade antidiabética dos frutos da Terminalia catappa $\mathrm{L}$ de origem indiana em células pancreáticas e, relatam em seu trabalho a identificação somente da cianidina-3-O-glicosídeo.

Posteriormente a caracterização do perfil antociânico realizado pelo presente estudo, Pinto Junior e colaboradores (2011) apresentaram um trabalho caracterizando a presença de outras antocianinas no fruto ( $T$. catappa), confirmando a identificação realizada nesse estudo.

Esta matriz por ser considerada de fácil acesso, pois, pode ser encontrada em várias regiões de clima tropical, em particular o Brasil, como árvore escolhida para a ornamentações de praças públicas e regiões praianas.

A análise do extrato do fruto da Terminalia catappa, revelou um cromatograma (CLAE) com a presença de um pico majoritário, cianidina-3-O-glicosídeo, que apresenta uma pureza de $99 \%$ a $520 \mathrm{~nm}$ (Tabela 24).

Sendo assim, o presente estudo classifica a matriz do fruto da Terminalia catappa como potencial fonte da antocianina cianidina-3-O-glicosídeo. 


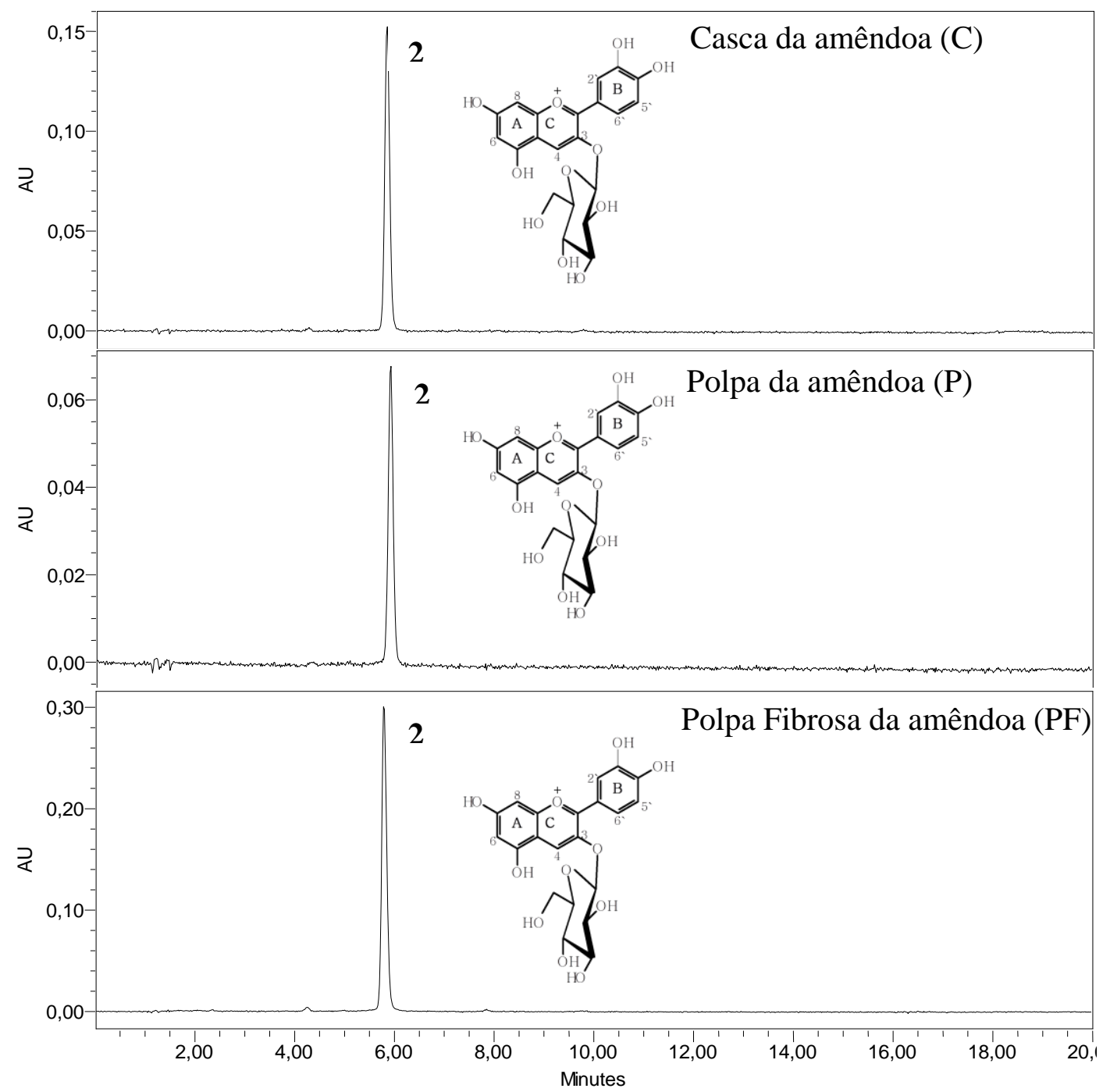

Figura 90: Cromatogramas representando o perfil dos extratos metanólicos obtidos da Casca, Polpa e Polpa Fibrosa do fruto da amendoeira (Terminalia catappa L.).

Tabela 24: Apresenta as antocianinas identificadas no perfil cromatográfico e suas concentrações na amostra.

\begin{tabular}{cclcccc}
\hline Pico & $\mathbf{t}_{\mathbf{R}}$ & \multicolumn{1}{c}{ Antocianina } & {$\left[\mathbf{M}^{+}\right]$} & $\mathbf{E M} / \mathbf{E M}$ & $\begin{array}{c}\text { Área do } \\
\text { Pico }\end{array}$ & $\begin{array}{c}\text { Área } \\
(\boldsymbol{\%})\end{array}$ \\
\hline 1 & 4,2 & Delfinidina-3- $O$-glicosídeo & 465,1036 & 303,0590 & 12251 & 0,65 \\
2 & 5,8 & Cianidina-3- $O$-glicosídeo & 449,1083 & 287,0556 & 1862297 & 99,01 \\
3 & 7,8 & Pelargonidina-3- $O$-glicosídeo & 433,1123 & 271,0596 & 6380 & 0,34 \\
\hline
\end{tabular}

As análises realizadas para identificações das antocianinas, nos extratos das matrizes (liofilizadas) amora-silvestre, flor do Ipê roxo e flor do Jambeiro vermelho. Nos extratos das cascas (liofilizadas) da manga (cv. Tommy), ameixa vermelha, jambo vermelho, jabuticaba (cv. P. grandifolia) e pera vermelha. Nos extratos da casca da soja-preta, da polpa da romã, das pétalas das flores, da romãzeira, da Erythrina e do Hibisco (salmão), no extrato das 
brácteas vermelha da planta Bico de Papagaio e na espata da flor de estrelícia ou ave-doparaíso (Strelitzia reginae), foram realizadas com objetivo de complementar o estudo com outras fontes para aquisição de antocianinas.

Os cromatogramas obtidos das análises realizadas no CLAE/DAD (520 nm) encontram-se na Figuras de 91 a 94, assim como, os resultados gerados para cada matriz sobre as antocianinas estão dispostos no Quadro 1.

As identificações dos pigmentos (Quadro 1) foram realizadas através de comparações: do tempo de retenção; espectro de absorção UV-Vismáx; dados espectrais, massa acurada, obtidos no EM-QTOF $\left(\mathrm{ESI}^{+}\right)$, com os resultados já obtidos no presente estudo.
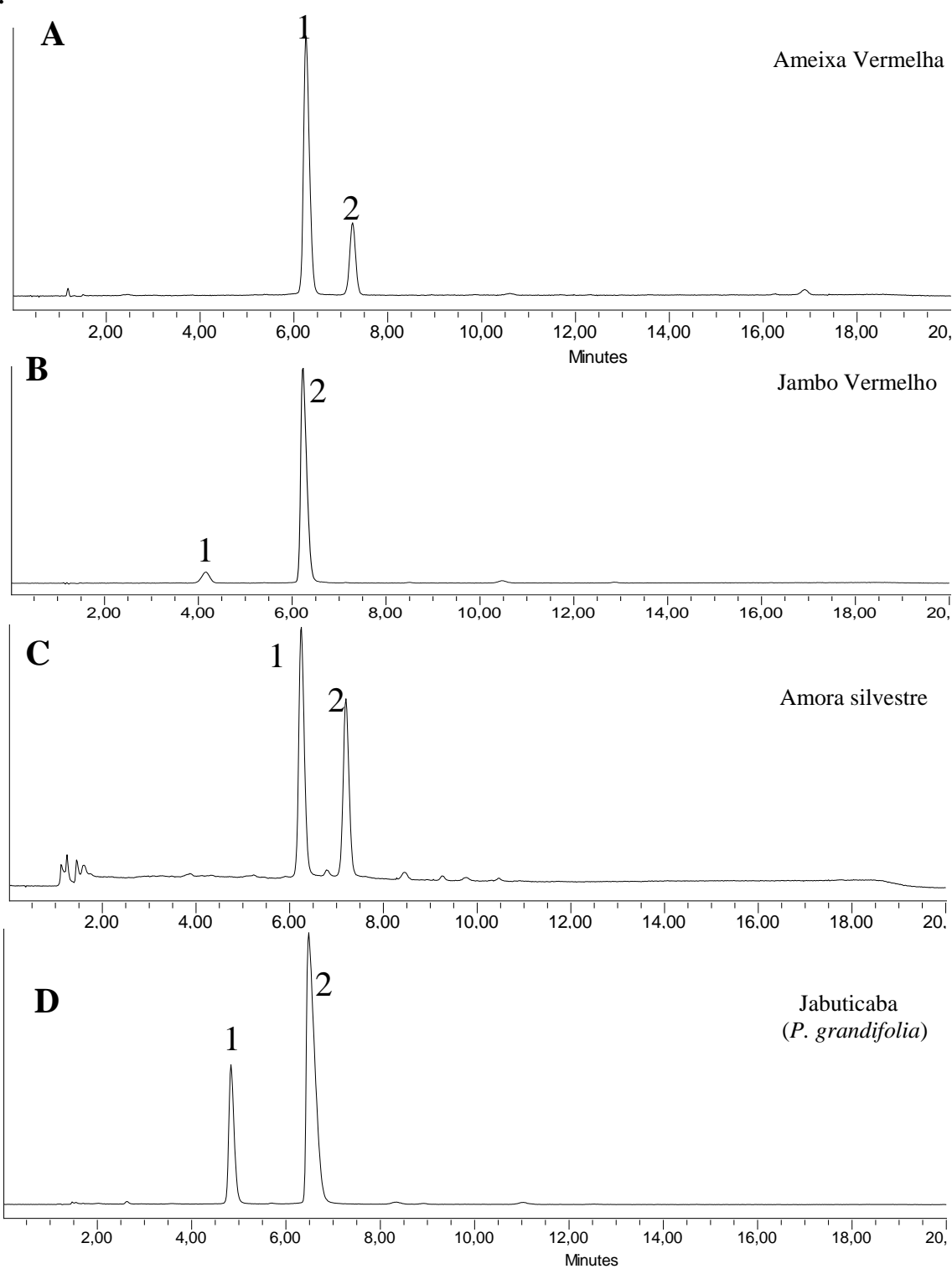

Figura 91: Cromatogramas extraído no CLAE/DAD a $520 \mathrm{~nm}$ das matrizes: A) ameixa vermelha; B) jambo vermelho; C) amora silvestre; D) Jabuticaba (cv. Plinia grandifolia). Identificação das substâncias numeradas, Quadro 1. 

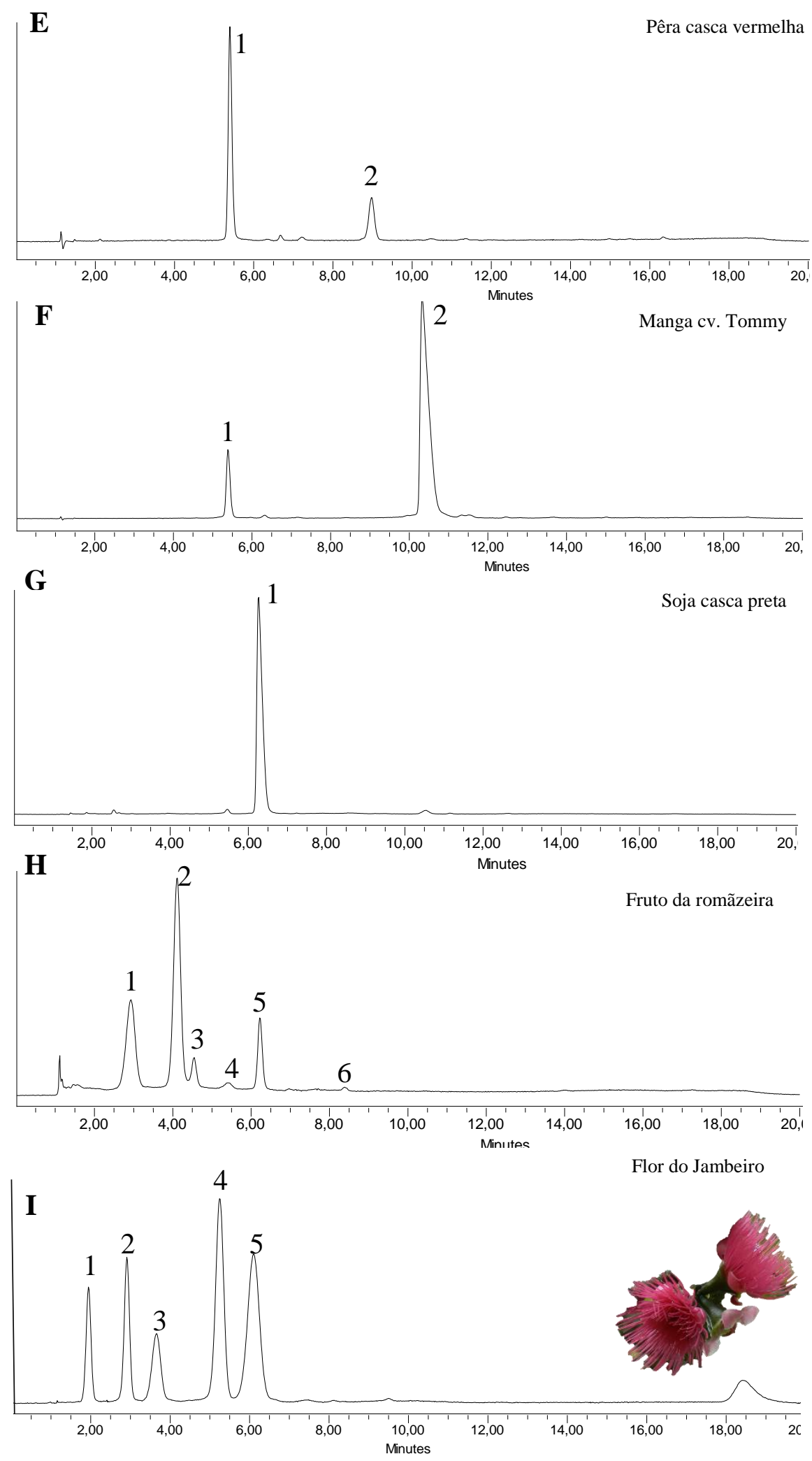

Figura 92: Cromatogramas extraído no CLAE/DAD A $520 \mathrm{~nm}$ das matrizes: E) Pera casca vermelha; F) Manga cv. Tommy G) Soja casca preta; H) Fruto da romãzeira; I) Flor do jambeiro. Identificação das substâncias numeradas, Quadro 1. 

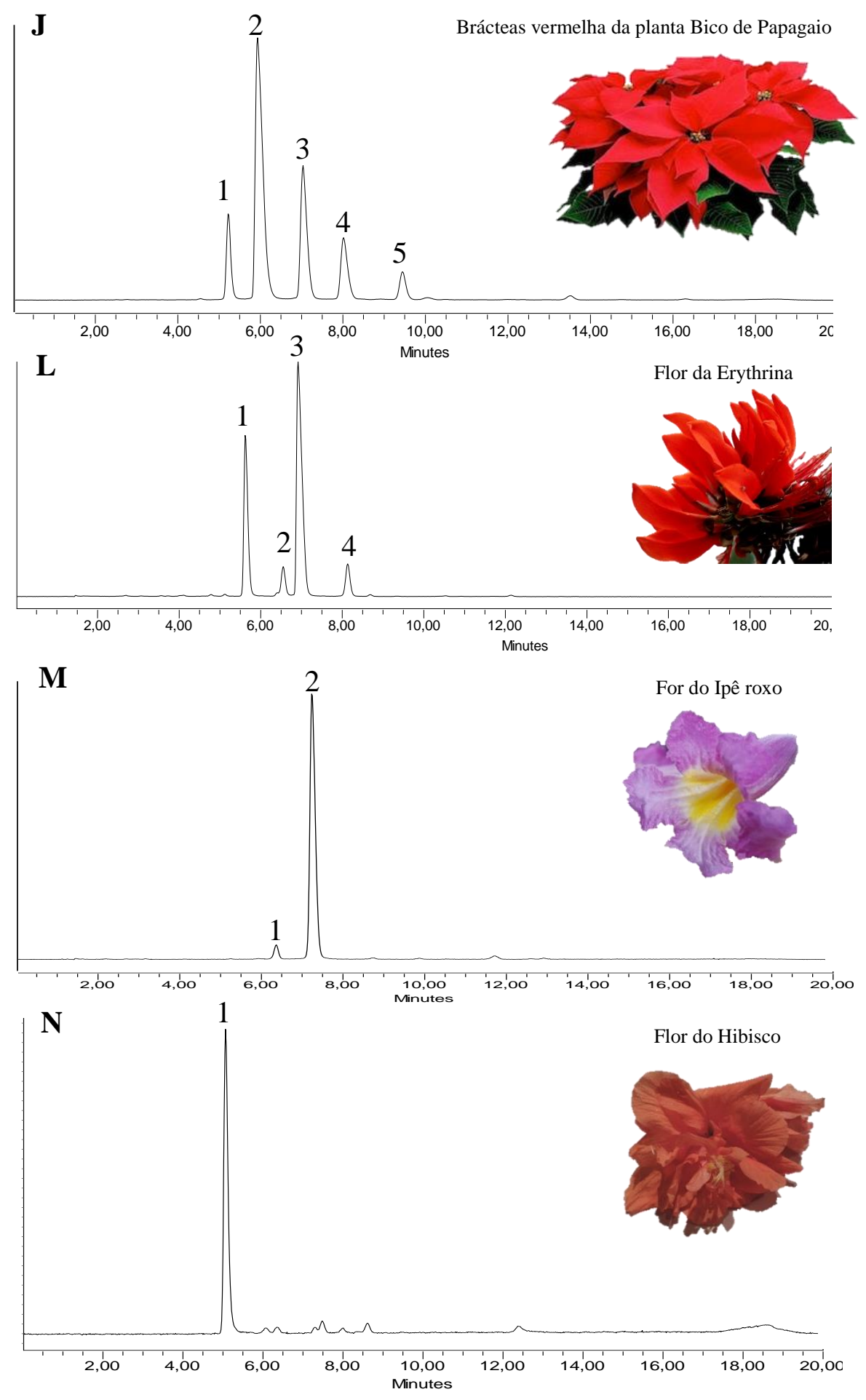

Figura 93: Cromatogramas extraído no CLAE/DAD A $520 \mathrm{~nm}$ das matrizes: J) Brácteas vermelha da planta Bico de Papagaio; L) Flor da Erythrina; M) Flor do Ipê roxo; N) Flor do Hibiscos. Identificação das substâncias numeradas na Quadro 1. 


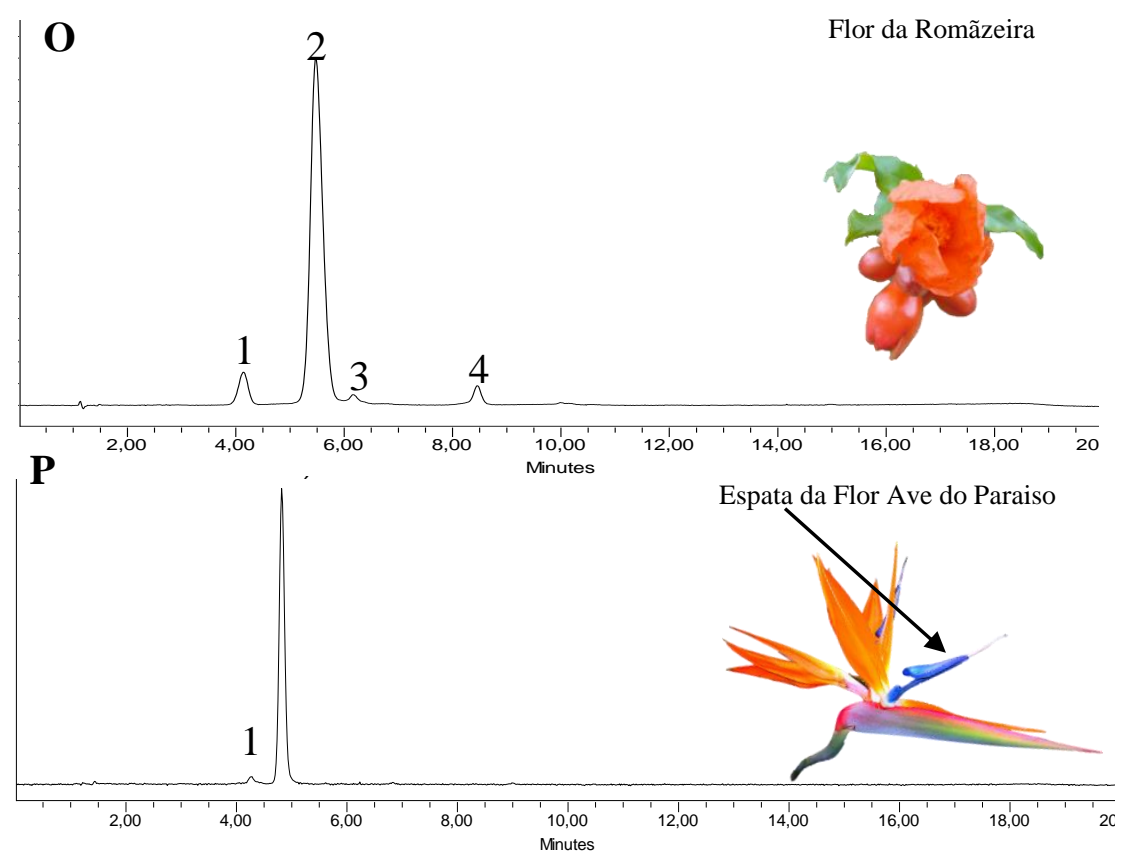

Figura 94: Cromatogramas extraído no CLAE/DAD A $520 \mathrm{~nm}$ das matrizes: O) Flor da romãzeira; P) Esparta da Flor Ave do Paraiso. Identificação das substâncias numeradas na Quadro 1.

Quadro 1: Dados obtidos nas análises: CLAE/DAD e EM-QTOF (ESI ${ }^{+}$, EM/EM. Picos numerados conforme cromatogramas das Figuras 91 até 94.

\begin{tabular}{|c|c|c|c|c|c|c|}
\hline Matriz & Pico & $\lambda(\mathbf{n m})^{\mathrm{a}}$ & $\begin{array}{c}\mathrm{t}_{\mathrm{R}} / \\
\mathrm{CLAE} \\
(\mathrm{min})\end{array}$ & $\begin{array}{l}{[\mathrm{M}]^{+}} \\
(m / z)\end{array}$ & $\begin{array}{c}\text { EM/EM } \\
(\mathbf{m} / \mathbf{z})\end{array}$ & Antocianina \\
\hline \multirow{2}{*}{ Ameixa Vermelha } & 1 & $279 / 516$ & 6,3 & 449,1057 & 287,0508 & Сy-3-O-glicosídeo \\
\hline & 2 & $279 / 517$ & 7,3 & 595,1279 & $449,1025 / 287,0507$ & Сy-3-O-ruteosídeo \\
\hline \multirow{2}{*}{ Jambo Vermelho* } & 1 & $277 / 512$ & 3,9 & 611,1761 & $449,1061 / 287,0676$ & Сy-3,5-di-O-glicosídeo \\
\hline & 2 & $279 / 515$ & 6,2 & 449,1089 & 287,0675 & Сy-3-O-glicosídeo \\
\hline \multirow{2}{*}{ Amora Silvestre } & 1 & $276 / 521$ & 6,2 & 449,1004 & 287,0407 & Сy-3-O-glicosídeo \\
\hline & 2 & $279 / 515$ & 7,3 & 595,1285 & $449,1025 / 287,0407$ & Сy-3-O-ruteosídeo \\
\hline \multirow{2}{*}{$\begin{array}{c}\text { Jabuticaba* } \\
\text { (P.grandifolia) }\end{array}$} & 1 & $276 / 521$ & 4,3 & 465,1081 & 303,0609 & Dp-3- $O$-glicosídeo \\
\hline & 2 & $279 / 515$ & 6,5 & 449,1004 & 287,0407 & Сy-3-O-glicosídeo \\
\hline \multirow{2}{*}{ Pêra casca Vermelha* } & 1 & $278 / 515$ & 5,9 & 449,1157 & 287,0586 & Cy-3-O-galactosídeo \\
\hline & 2 & $279 / 516$ & 8,9 & 463,1250 & 301,0708 & Pn-3-O-galactosídeo \\
\hline \multirow{2}{*}{ Manga Tommy* } & 1 & $278 / 516$ & 5,3 & 449,1057 & 287,0582 & Cy-3-O-galactosídeo \\
\hline & 2 & $279 / 516$ & 10,4 & 463,1250 & 301,0740 & Pn-3-O-glicosídeo \\
\hline \multirow{2}{*}{ Soja Preta } & 1 & $279 / 515$ & 5,4 & 449,1489 & 287,0570 & Cy-3-O-galactosídeo \\
\hline & 2 & $278 / 516$ & 6,3 & 449,1081 & 287,0555 & Сy-3-O-glicosídeo \\
\hline
\end{tabular}

a Solvente Fase móvel da análise cromatográfica (ácido fórmico $5 \%$ e acetonitrila)

*Perfil identificado pela primeira vez.

$\mathrm{Dp}=$ delfinidina, $\mathrm{Cy}=$ cianidina, $\mathrm{Pg}=$ pelargonidina, $\mathrm{Pt}=$ petunidina, $\mathrm{Pn}=$ peonidina e $\mathrm{Mv}=\mathrm{Malvidina}$ 
Quadro 1: Dados obtidos nas análises: CLAE/DAD e EM-QTOF (ESI $\left.{ }^{+}\right)$, EM/EM. Picos numerados conforme cromatogramas das Figuras 91 a 94 (Continuação).

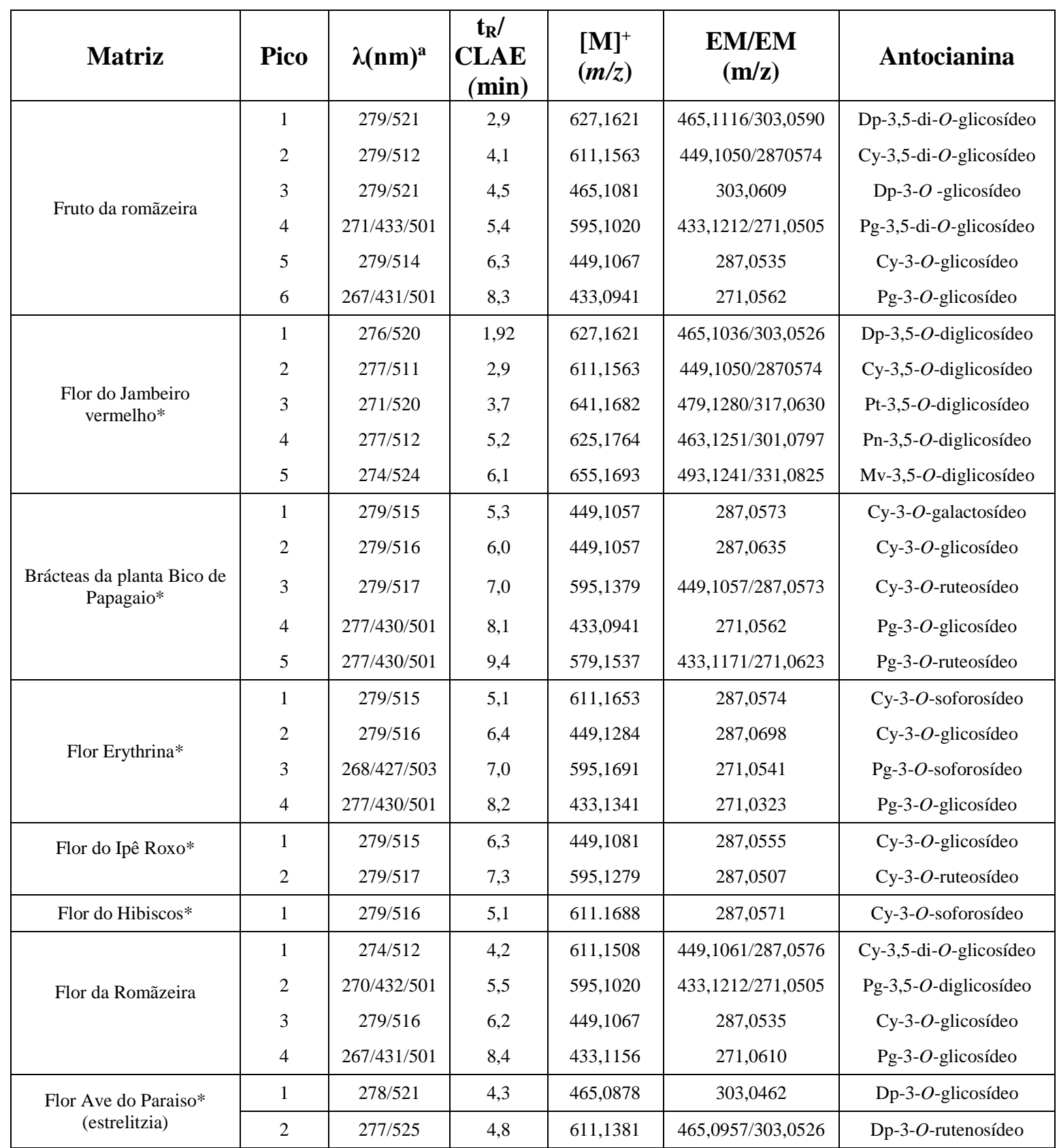

a Solvente Fase móvel da análise cromatográfica (ácido fórmico 5\%: 10\% e acetonitrila).

*Perfil identificado pela primeira vez.

$\mathrm{Dp}=$ delfinidina, $\mathrm{Cy}=$ cianidina, $\mathrm{Pg}=$ pelargonidina, $\mathrm{Pt}=$ petunidina, $\mathrm{Pn}=$ peonidina e $\mathrm{Mv}=$ Malvidina

Os extratos das cascas: ameixa vermelha, jambo vermelho; jabuticaba e soja de casca preta, assim como o extrato obtido da polpa da amora silvestre, revelaram ser excelentes fontes da antocianina cianidina-3-O-glicosídeo. Ao mesmo tempo, as matrizes da amora silvestre e 
ameixa de casca vermelha, podem fornecer a antocianina cianidina-3- $O$-rutenosídeo e, e da jabuticaba ( $P$. grandifolia) a antocianina delfinidina-3- $O$-glicosídeo.

Casca do jambo vermelho e da soja, apresentaram grande pureza no comprimento de onda a $520 \mathrm{~nm}, 96$ e 97\%, respectivamente. Tornando essas matrizes excelentes fontes para coleta dessas substâncias sem que ocorra a contaminação com outros analitos nesse comprimento. A título de exemplificação pode-se observar o APÊNDICE B para a identificação da majoritária do extrato da casca do jambo vermelho.

Os extratos das cascas da pêra vermelha e manga (Tommy), apresentaram duas substâncias majoritárias, tornando as duas matrizes boas fontes da antocianina cianidina-3-Oglactosídeo, já identificada anteriormente por este estudo na matriz da casca da maçã.

A segunda antocianina, nas duas matrizes, o tempo de retenção foi a ferramenta utilizada para diferenciar o tipo de açúcar substituinte. Pois, tanto os dados do $\lambda_{\text {máx }}$ do visível como o íon molecular e seu fragmento, para as substâncias das duas matrizes, apresentaram valores iguais.

Ao comparar o tempo de retenção das duas substâncias, nas duas matrizes em questão, se pode concluir que a substância da matriz da casca da pera elui em tempo de retenção inferior ao da casca da manga (Quadro 1).

Sendo assim, baseada na hidrofobicidade já elucidada para a metodologia utilizada, a antocianina da matriz da casca de pera vermelha foi indicada como sendo a peonidina-3-Ogalactosídeo e a da matriz da casca da manga sendo a peonidina-3-O-glicosídeo. Este fato foi confirmado quando se comparou o $t_{R}(10,4 \mathrm{~min})$ da substância do extrato da casca da manga com $t_{R}(10,3 \mathrm{~min})$ da antocianina peonidina 3-O-glicosídeo do extrato do epicarpo da uva preta do Chile, já anteriormente identificada por este estudo.

O extrato da romã apresentou em seu perfil três tipos de antocianidinas (delfinidina; cianidina e pelargonidina) todas ligadas à apenas um tipo de monossacarídeo, a glicose. A análise no EM/EM, revelou cada antocianidina estando mono e dissubstituídas (carbono 3 e 5 da estrutura) a esse açúcar (SANTIAGO et al., 2014).

Este estudo também comprovou que as flores podem ser uma excelente fonte de antocianinas, além das antocianinas obtidas de outras partes dos vegetais.

As matrizes de flores estudadas, revelaram que poderão fornecer desde antocianinas monoglicosiladas (mono e dissubistituídas) até antocianinas diglicosiladas (monossubstituída).

Além do jambeiro apresentar seus frutos como excelente provedor da antocianina cianidina-3-O-glicosídeo, apresentando alta concentração desta substância, as suas flores também foram consideradas boas fontes de antocianinas

Ao contrário do fruto, apresentam um perfil antociânico mais diversificado. Foram identificadas, pelo presente estudo, em seu perfil, cinco das seis antocianidinas mais comuns em alimentos (delfinidina, cianidina, petunidina, peonidina e malvidina). Todas dissubistituídas, com o monossacarídeo glicose, nos carbonos 3 e 5 da estrutura da antocianidina. $\mathrm{O}$ que faz dessa matriz uma excelente fonte dessas cinco substâncias em uma única amostra, pois, toda a coletas as cinco antocianidinas apresentam no perfil boa concentração.

O único problema seria concentrar a amostra com a finalidade de diminuir o número de injeções para a coleta, das substâncias isoladas, de forma satisfatória. As antocianinas dissubistituídas, apresentam a particularidade de alargamento na base do pico em relação às monoglicosiladas. Como elas eluem com tempo de retenção próximos, isso fará com que ocorra perda de resolução entre os picos, prejudicando a pureza final da substância isolada. 
Sendo assim recomenda-se um limite para essa concentração, que permita a coleta das substâncias sem interferir na sua pureza final (Figura 95).

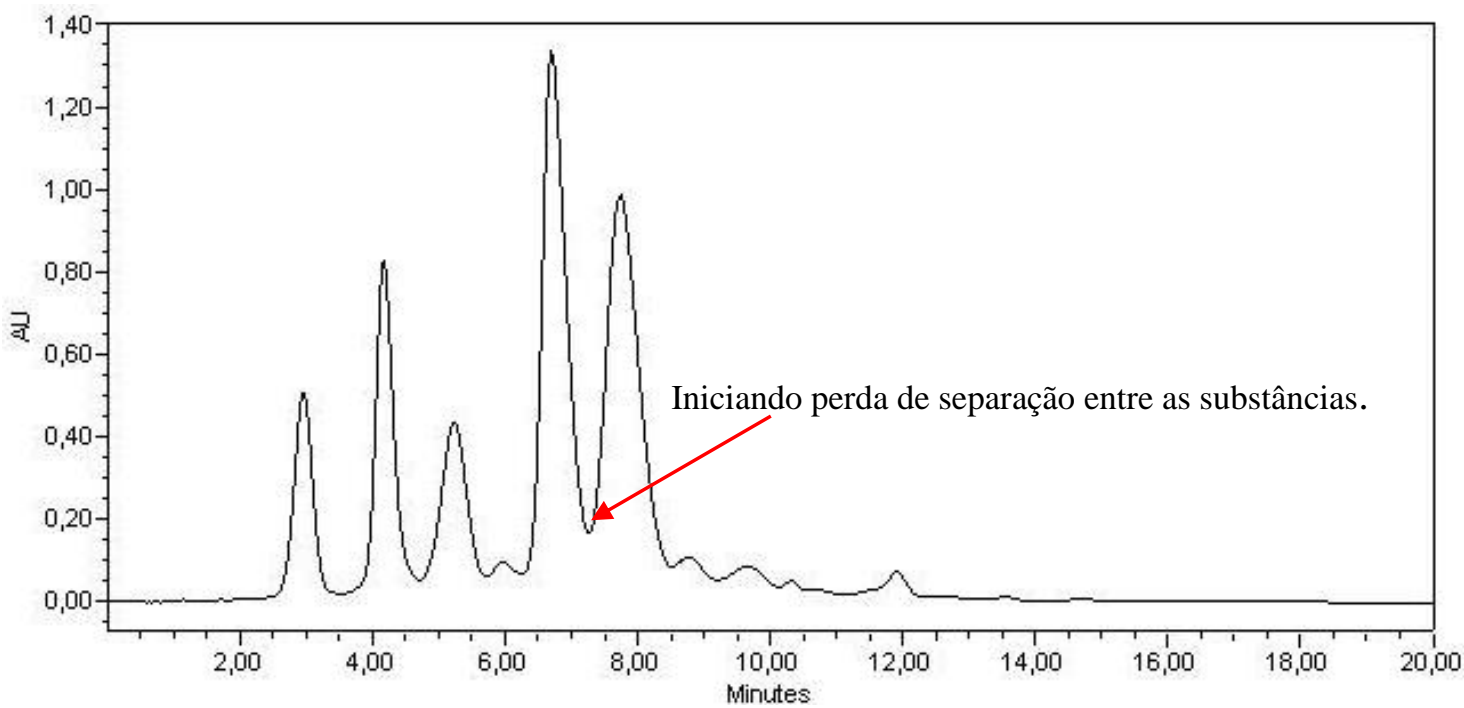

Figura 95: Cromatograma do perfil da matriz da flor do Jambeiro, mostrando um limite usado para recolhimento nas amostras que proporcione pureza adequada nas substâncias isoladas.

Neste estudo das antocianinas oriundas de flores, destacam-se as matrizes de flor do Ipê e do Hibisco. Cada uma apresentou alto teor de uma antocianina majoritária em seus perfis antociânicos, que foram identificadas pelo presente estudo como cianidina-3-O $O$-rutenosídeo (93\%) e cianidina-3-O-soforosídeo (84\%), respectivamente. Portanto, serão excelentes fontes provedoras destes pigmentos.

A flor da romãzeira apresenta uma antocianina majoritária, a pelargonidina-3,5-di $O$ - glicosídeo. Essa substância está presente em baixa concentração em matrizes de origem alimentícia como o próprio fruto da romãzeira (romã).

Além disso, são raros os padrões comercias de derivados de pelargonidina, existindo apenas para venda o cloreto de pelargonidina. Isso pode ser justificado através da baixa estabilidade dessa substância, mesmo em meio acidificado. Sendo assim, uma matriz de fácil acesso poderia ajudar a contornar essa dificuldade.

Seguindo o mesmo raciocínio da escassez no mercado de padrões comerciais de derivados de pelargonidina. As matrizes das brácteas da planta de Bico de Papagaio e pétalas das flores da Erythrina, mostraram em seus perfis antociânico, duas antocianinas derivadas da pelargonidina.

No perfil antociânico do extrato da pétala da flor do Bico de Papagaio foram identificadas a pelargonidina-3- $O$-glicosídeo e a pelargonidina-3-O-rutenosídeo e no perfil antociânico do extrato da pétala da flor da Erythrina, as antocianinas pelargonidina-3-Osoforosídeo e a pelargonidina-3-O-glicosídeo.

Em destaque a antocianina pelargonidina-3-O-diglicosídeo, sugerida como soforosídeo pelo presente estudo. Sendo, portanto, a identificação do dissacarídeo baseada no seu comportamento hidrofóbico e fragmentação ocorrida no EM/EM.

O estudo, realizado com outras matrizes neste presente estudo, as quais foram identificados os dissacarídeos soforosídeo e laminarabiosídeo ligados à cianidina. Assim como, o entendimento da rota de fragmentação do íon molecular no modo EM/EM, extraídos 
no EM-QTOF $\left(\mathrm{ESI}^{+}\right)$dessas substâncias. Proporcionaram ganho de conhecimento, que possibilita fundamentar a indicação do açúcar como soforosídeo na antocianina em questão.

Foi visto que a antocianidina monossubstituída diglicosiladas (3- $O$-soforosídeo), apresenta tempo de retenção inferior à sua correspondente monoglicosilada (3-O-glicosídeo). No caso da matriz da pétala da flor da Erythrina, as antocianinas pelargonidina-3-Odiglicosídeo possui tempo de retenção inferior ao da pelargonidina-3-O-glicosídeo. Esse fato associado aos dados obtidos no EM/EM, sugere que o dissacarídeo é o soforosídeo.

$\mathrm{O}$ extrato do morango foi escolhido por este estudo como a principal fonte fornecedora da antocianina pelargonidina-3-O-glicosídeo devido ao seu teor na matriz. Pois, além desta antocianina estar presente em concentração superior a $85 \%$ na matriz, apresenta excelente separação cromatográfica, permitindo assim a concentração da amostra a fim de que ocorra seu isolamento sem comprometimento da pureza das substâncias isoladas.

Vale salientar, que existem trabalhos, anteriormente publicados, indicando que sua presença é constante mesmo em outras variedades de morango. Apresentando sempre nos perfis estudados de matrizes de morango, a pelargonidina-3-O-glicosídeo como majoritária.

As diferenças têm sido observadas apenas em relação as outras substâncias que aparecem em menor concentração no perfil antociânico (SILVA et al.; 2002; WU e PRIOR, 2005b; ZHANG et al., 2011).

Pode ser fonte fornecedora das substâncias 1, 3 e 4 (Figura 49), também observadas neste trabalho na matriz de morango analisada. Mas, vale salientar que para a substância 1 , cianidina-3-O-glicosídeo, existem outras fontes que apresentam melhor rendimento na coleta como fruto da amendoeira e do jambeiro, o açaí, a juçara, entre outros aqui apresentados.

Para a substância 3 (pelargonidina-3-O-rutenosídeo), a matriz do morango poderia ser indicada como fonte alternativa, já que essa substância não é comumente encontrada em frutos. Mas, pode ser utilizado fontes alternativas que apresentam essa substância com melhor concentração na matriz como as brácteas da planta Bico de Papagaio (Figura 89).

A substância 4 (pelargonidina-3-O-(6"-acetila)-glicosídeo), apesar de muito baixa sua concentração na matriz morango, ela pode se tornar uma boa fonte se a matriz for concentrada, visto que, essa antocianina não foi observada em outras fontes estudadas e nem foram observados relatos na literatura, até o presente momento.

Será, portanto, necessário acrescentar uma etapa que permita aumentar a concentração dessas substâncias, após esse procedimento será possível prosseguir com o isolamento segundo o item 3.7 (pág. 39).

\section{Arroz Preto (Oryza sativa L)}

Ao contrário do arroz vermelho, o arroz preto (AP) ao ser submetido à extração já demonstrou visualmente possuir um pigmento hidrossolúvel, pois a solução de lavagem rapidamente apresentou uma forte coloração roxa.

Para confirmação da presença de pigmento antociânico foi realizada análise cromatográfica a 520nm, onde foi observado um perfil cromatográfico (Figura 96)) com 5 picos. A confirmação das substâncias como pigmentos antociânicos foi feita ao observar os espectros de absorção para os picos 3, 4 e 5.

Devido ao resultado insatisfatório, não permitindo observar os espectros de UV-Vis máx para as substâncias equivalentes aos picos 1 e 2 , pois, a concentração não foi suficiente para manifestar a presença das duas bandas características de absorção das antocianinas.

Optou-se por coletar as substâncias de modo que permitisse uma melhora na visualização dos espectros de absorção. 


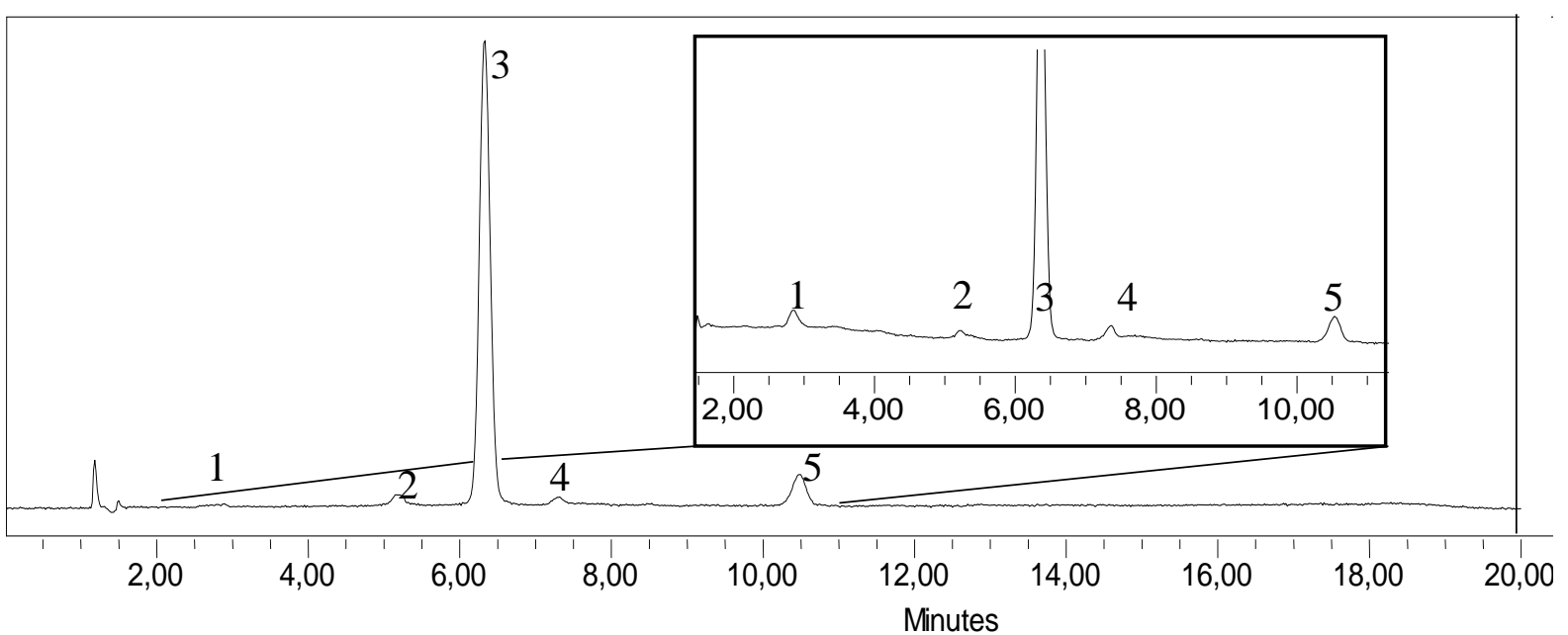

Figura 96: Cromatograma do perfil de antocianinas do extrato metanólico do arroz preto extraído no CLAE/DAD a $520 \mathrm{~nm}$.

Para o isolamento das substâncias, realizado após a separação cromatográfica no CLAE/DAD (Figura 97), conforme o item 3.7.5.1 através da válvula seletora de canais, Rheodyne, foram necessárias 20 coletas.

A concentração do material coletado, em coluna aberta (item 3.7.5.1), possibilitou a extração de cromatogramas (CLAE/DAD- $520 \mathrm{~nm}$ ), onde as substâncias, agora um pouco mais concentradas foram confirmadas tratando-se de cinco pigmentos antociânicos. Foi possível, portanto, observar as duas bandas na região do UV-Vis máx, característicos de antocianinas (Figura 98).

A princípio, foi utilizada como ferramenta de identificação das antocianinas a comparação dos tempos de retenção do cromatograma da amostra do arroz preto com o de outras matrizes que possuam antocianinas já identificadas, anteriormente, na literatura e/ou pelo presente estudo.

Como base para investigação de trabalhos da literatura foi utilizado um estudo realizado sobre arroz preto (Orysa sativa L.), de origem japônica, por Hou et al. (2011). Eles identificaram quatro antocianinas no perfil do arroz preto (Figura 99). Observou-se grande semelhança ao comparar o perfil por eles apresentado ao obtido no presente estudo. $\mathrm{O}$ tipo de arroz utilizado nesta pesquisa foi informado pelo comerciante no Brasil (fabricante do arroz preto marca Tio João) como proveniente da cultivar IC 600.

Essa cultivar foi desenvolvida para adaptação em solo brasileiro pelo Instituto Agronômico de Campinas (ICA), com objetivo comercial de uso doméstico (BASTOS; AZZINI e MCCLUNG, 2004). A semelhança observada entre os perfis cromatográficos das antocianinas dos dois tipos de arroz preto em questão (usado no estudo e da literatura), demonstram coerência, visto que, a cultivar IC 600 teve seu desenvolvimento a partir da cultivar asiática.

A identificação das substâncias na cultivar brasileira foi realizada pelo presente estudo, a princípio, através do pareamento do cromatograma obtido no CLAE/DAD com os cromatogramas de matrizes já identificadas, anteriormente pelo estudo, e que já possuíam suas massas acuradas confirmadas pela técnica CLUE acoplado ao EM/ QTOF $\left(\mathrm{ESI}^{+}\right)$. 

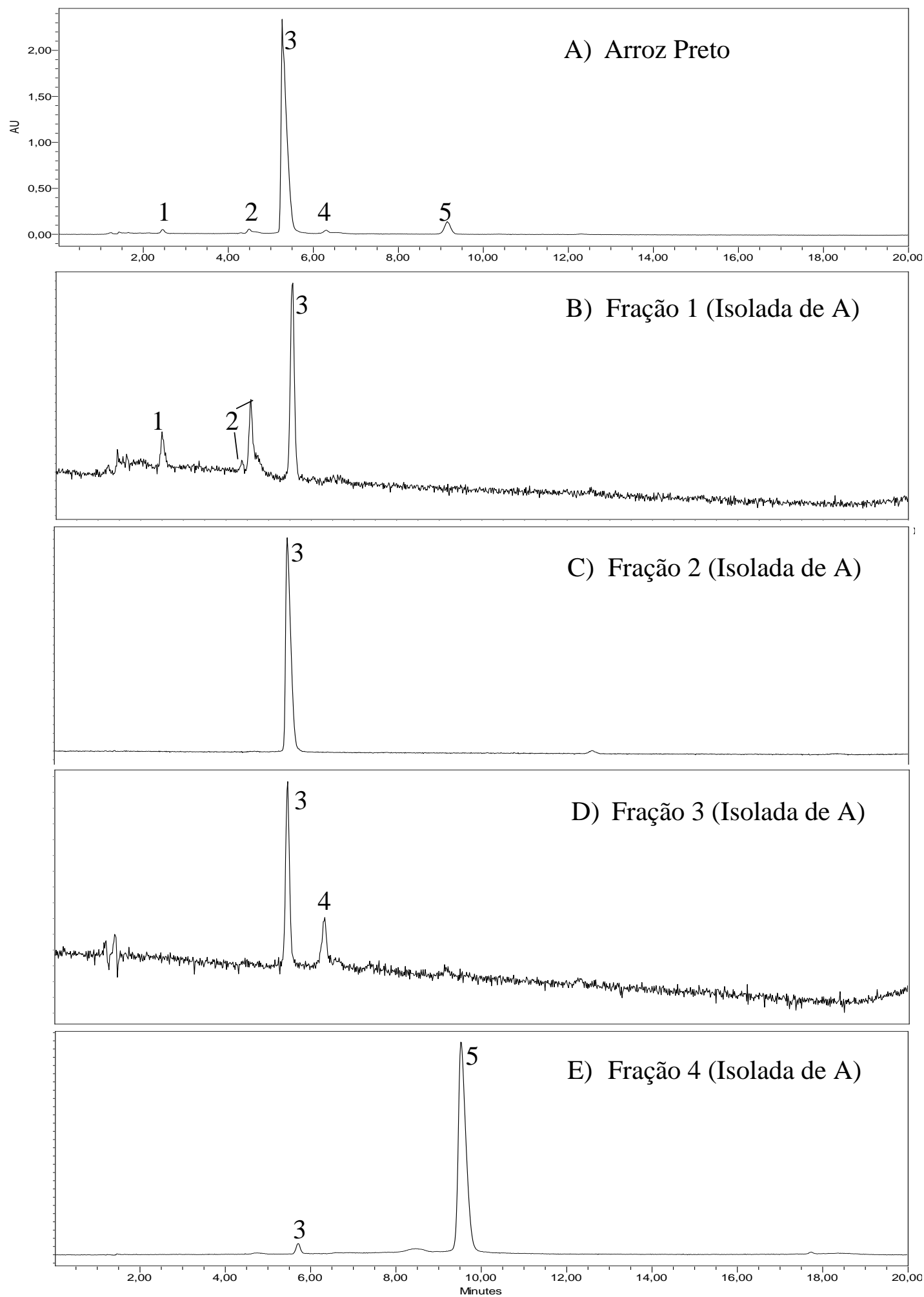

Figura 97: Cromatogramas extraídos no CLAE/DAD (520 nm). A) Extrato do arroz preto; B) Extrato da Fração 1 isolada C) Extrato da Fração 2 isolada; D) Extrato da Fração 3 isolada e; E) Extrato da Fração 4 isolada. 

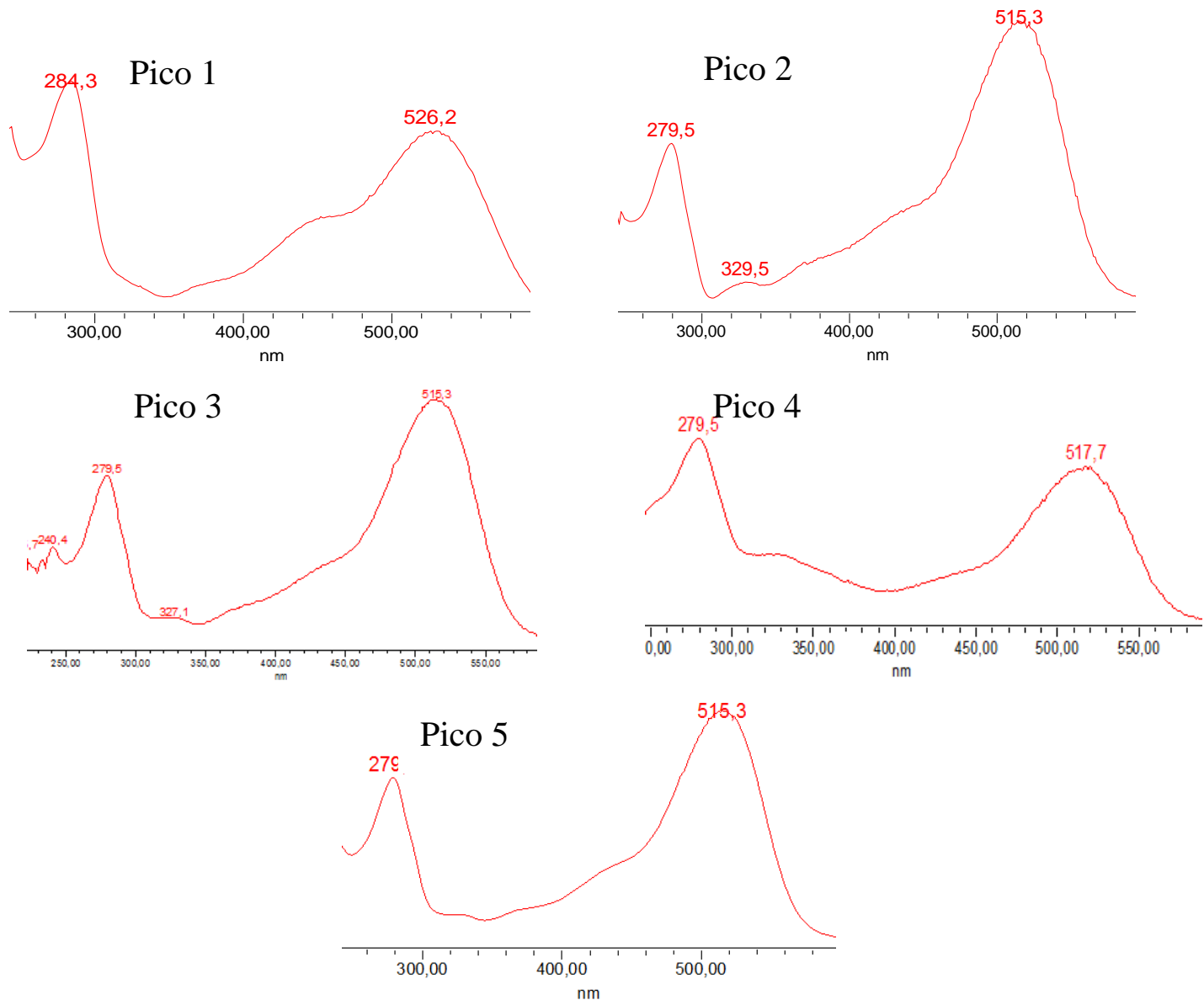

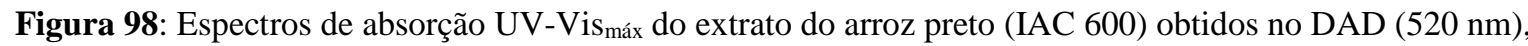
substancias relacionadas aos cromatogramas das Figuras 96 e 97.

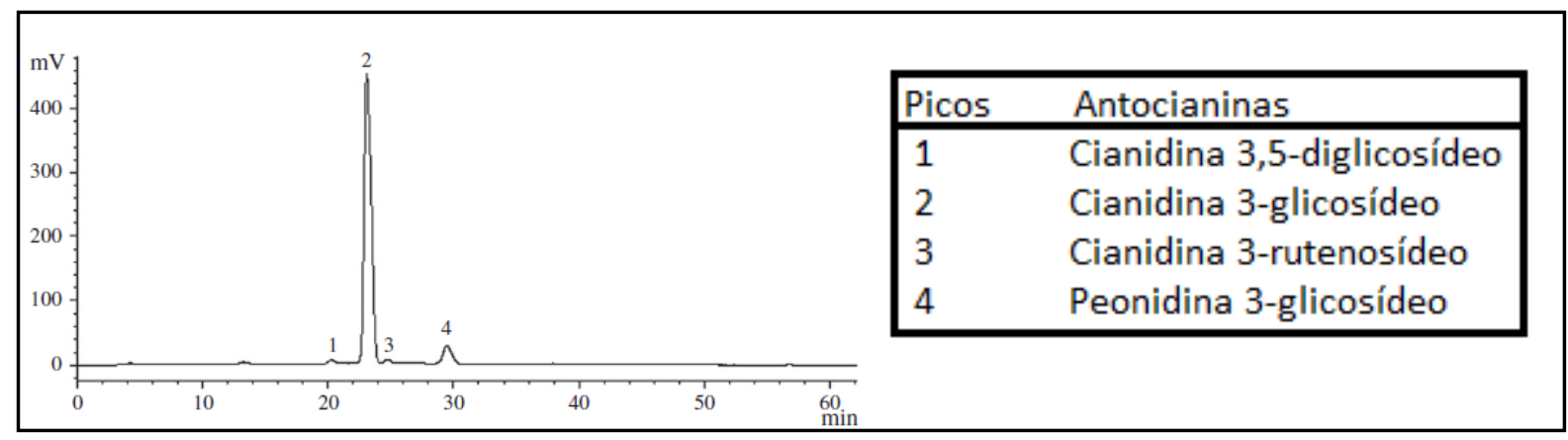

Figura 99: Cromatograma do perfil das antocianinas do arroz preto analisado e identificação das antocianinas por padrões e confirmação pela técnica de CL/EM (ES $\left.{ }^{+}\right)$. Fonte: Hou et al., 2011.

Através do confronto dos tempos de retenção e comparação dos espectros de absorção pode-se sugerir, a princípio, a identidade das quatro substâncias na matriz arroz preto. 
As análises por CLAE do extrato metanólico de quatros matrizes (casca de uva tinta chilena; jamelão; juçara e arroz preto) foram realizadas no mesmo dia sob as mesmas condições analíticas e fase móvel

Sendo assim, ficou caracterizado que as substâncias referentes aos picos 2 e 4 (cromatograma da casca de uva tinta chilena) possuem o mesmo tempo de retenção dos picos 3 e 5 (cromatograma do arroz preto). Os analitos 2 e 3 do cromatograma da juçara possuem o mesmo tempo de retenção dos analitos 3 e 4 do cromatograma do arroz preto (Figura 100 e Tabela 25).

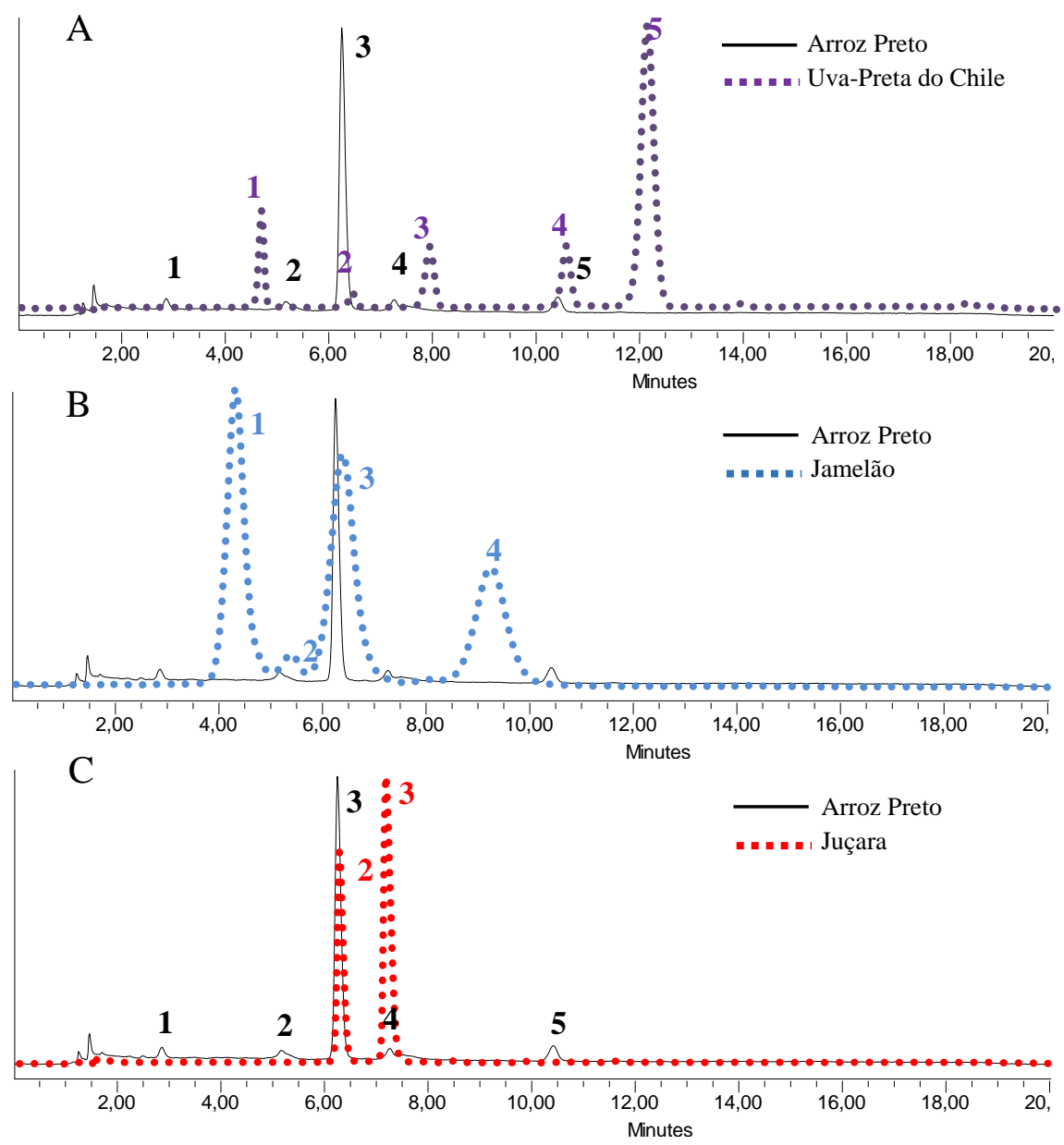

Figura 100: Sobreposição dos cromatogramas: Em preto o cromatograma com perfil de antocianinas do arroz preto, (A) em roxo o cromatograma com o perfil da casca de uva preta sem semente do Chile, (B) em azul o cromatograma com o perfil da casca do jamelão e (C) em vermelho o cromatograma com o perfil da juçara.

O analito 2 do cromatograma do jamelão coincidiu com o analito 2 do cromatograma do arroz preto. Portanto, foi sugerido que no arroz existe, respectivamente: cianidina-3,5-di$O$-glicosídeo; cianidina-3- $O$-glicosídeo; cianidina-3- $O$-rutenosídeo e a peonidina-3- $O$ glicosídeo (Figura 100), as mesmas antocianinas observadas e citadas por Hou et al. (2011). 
Tabela 25: Identificação das antocianinas referentes aos picos do cromatograma da Figura 100 por comparação dos $t_{R}$ das substâncias com o $t_{R}$ das substâncias já identificadas na uva, juçara e jamelão.

\begin{tabular}{cccccc}
\hline & Arroz Preto & Uva & Juçara & Jamelão & Antocianina \\
\hline$t_{R}$ (min) & 5,2 (Pico 2) & & & 5,2 (Pico 2) & Cy-3,5-di-O-glicosídeo \\
$t_{R}$ (min) & $6,3($ Pico 3) & $6,3($ Pico 2) & 6,3 (Pico 2) & & Cy-3-O-glicosídeo \\
$t_{R}$ (min) & $7,3($ Pico 4) & & 7,3 (Pico 3) & & Cy-3-O-rutenosídeo \\
$t_{R}(\min )$ & $10,5($ Pico 5) & $10,5($ Pico 4) & & & Pn-3-O-glicosídeo \\
\hline
\end{tabular}

Dessa forma, a identificação está de acordo com os dados observados na literatura (HOU et al.,2011). A concentração das substâncias também possibilitou observar a eluição com tempo de retenção muito próximos de outras substâncias na fração coletado número 2 (Figura 101).

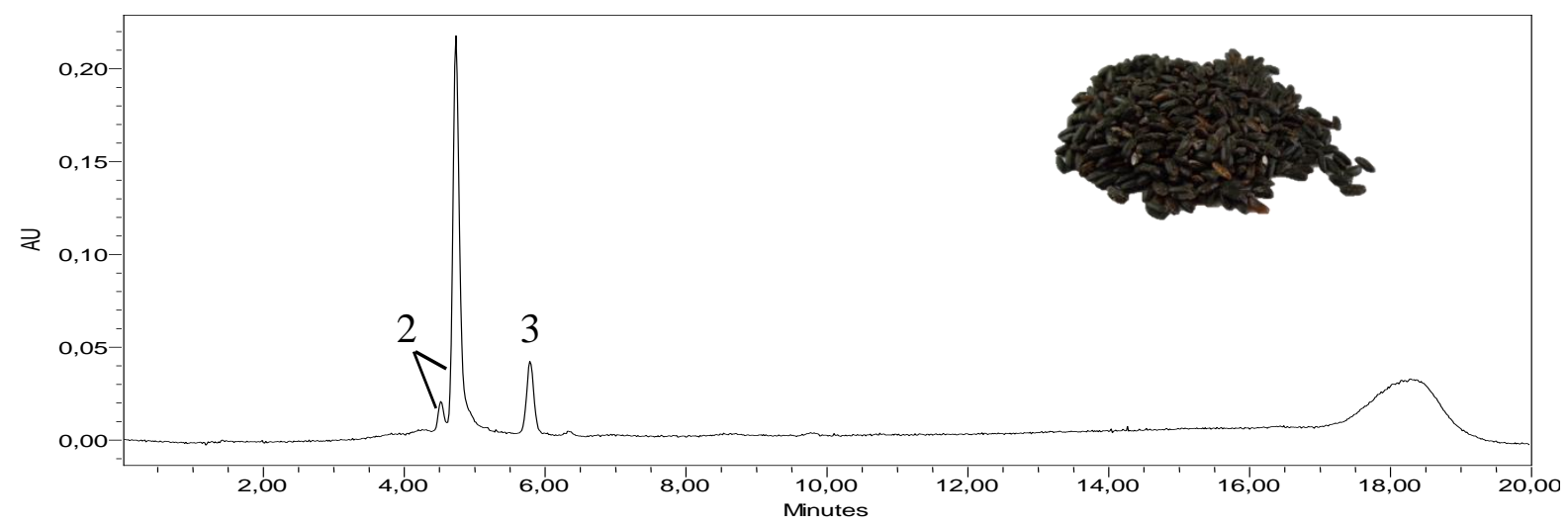

Figura 101: Cromatograma do perfil de antocianinas do extrato metanólico da Fração 2, extraído no CLAE/DAD a $520 \mathrm{~nm}$.

Para confirmação da presença de outras antocianinas, foram realizadas análises, por inserção direta, no extrato referente a Fração 2 no espectrômetro de massa acurada, EM-QTOF $\left(\mathrm{ESI}^{+}\right)$.

Os dados extraídos do EM-QTOF $\left(\mathrm{ESI}^{+}\right)$, mostraram a presença de íons moleculares a $m / z: 611,1925 ; 773,2035 ; 611,1653$ e; 449;1029.

Para a análise realizada no modo EM/EM do íon molecular a $m / z, 611,1925$ (100\%), foram observados os fragmentos a $\mathrm{m} / z$ 449,1095 (19,5\%) e 287,0574 (3,0\%). Onde a intensidade dos íons fragmentos a $\mathrm{m} / \mathrm{z} 449,1095$ e 287,0574, ao ser aplicada a energia de colisão de $10 \mathrm{eV}$, mostrou comportamento idêntico ao observado para as antocianinas -3,5di- $O$-glicosiladas (Figura 48), já identificadas em algumas matrizes por este estudo (jamelão, fruto da romãzeira e flor e fruto do jambeiro).

Nesta Fração 2, também foi observado outro íon molecular a $\mathrm{m} / z$ 611,1653, mas, apresentando padrão de fragmentação diferente ao observado acima. Os dados obtidos no EM/EM mostrou somente um fragmento a $m / z, 287,0698$ (27,6\%), após ser aplicada a energia de colisão de $8 \mathrm{eV}$. 
O padrão de fragmentação foi compatível ao observado para as antocianinas cianidina3-O-diglicosídeo, presentes nas matrizes do pericarpo do mangostin, framboesa e repolho roxo, matrizes já identificadas, anteriormente, por esse estudo.

Somando-se o tempo de retenção observado para a substância no CLAE/DAD aos dados espectrais obtidos, $\lambda_{\text {máx }}$ no visível e resultados obtidos no espectrômetro de massa acurada, pode-se identificar a substância presente no extrato do arroz preto (Figura 96), como cianidina-3- $O$-soforosídeo, a mesma antocianina presente no perfil cromatográfico nas matrizes do pericarpo do mangostin (Figura 52) e da de framboesa vermelha (Figura 80, B).

$\mathrm{Na}$ análise do íon molecular a $\mathrm{m} / \mathrm{z} 773,2035$, foram observados os fragmentos a $\mathrm{m} / \mathrm{z}$ : 611,1563 (10,0\%); 449,1150 (33,3\%) e; 287,0574 (10,0\%). Como anteriormente observado, este padrão de fragmentação caracteriza a presença de um substituinte diglicosilado e outro monoglicosilado em carbonos diferentes na estrutura da cianidina. Sugere-se, portanto, que a molécula seja uma cianidina-3-O-diglicosilada-5-O-glicosídeo.

A confirmação da identificação deste dissacarídeo só pôde ser sugerida baseada nos dados obtidos. Como a amostra já apresenta o açúcar soforosídeo, foi indicado sua presença como o diglicosídeo substituinte na antocianindina cianidina $(\mathrm{m} / \mathrm{z}, 287)$.

Mas, para elucidação desses substituintes na estrutura, assim como em quais carbonos se encontram, será necessário comparar seus dados ( $t_{R}$, espectros UV-Vismáx e de massa) com os do seu respectivo padrão de referência, ou obter as informações estruturais detalhadas através da técnica de espectroscopia de ressonância magnética nuclear, RMN.

A análise no EM, para o íon molecular a $\mathrm{m} / \mathrm{z} 449,1029$, mostrou o fragmento a $\mathrm{m} / \mathrm{z}$ 287,0589 , esse resultado associado ao tempo de retenção $\left(t_{R} 6,3 \mathrm{~min}\right.$ ), no sistema utilizado por esse estudo e, ao valor do $\lambda_{\text {máx }}$ na região do visível, confirmam a presença da cianidina-3$O$-glicosídeo, já sugerida anteriormente por comparação com outras matrizes que apresentam essa antocianina já identificada.

Foram realizadas análises através da inserção direta no EM-QTOF $\left(\mathrm{ESI}^{+}\right)$das Frações isoladas 3 e 4 (Figura 97), os resultados encontram-se no Quadro 2.

Quadro 2: Dados obtidos da análise no CLAE/DAD e no EM-QTOF (ESI ${ }^{+}$) do extrato do arroz preto (IAC 600). Picos numerados conforme cromatograma da Figura 96.

\begin{tabular}{|c|c|c|c|c|c|c|}
\hline Matriz & Pico & $\lambda(\mathbf{n m})^{\mathrm{a}}$ & $\begin{array}{c}\mathbf{t}_{\mathbf{R}} / \\
\mathrm{CLAE} \\
(\mathbf{m i n}) \\
\end{array}$ & $\begin{array}{l}{[\mathrm{M}]^{+}} \\
(\mathrm{m} / z)\end{array}$ & $\begin{array}{c}\text { EM/EM } \\
(m / z)\end{array}$ & Antocianina \\
\hline \multirow{7}{*}{ Arroz preto } & 1 & $284 / 526$ & 2,8 & NO & NO & NI \\
\hline & 2 & $279 / 515$ & NO & 611,1925 & $449,1095 / 287,0574$ & Cy-3,5-di-O-glicosídeo \\
\hline & 2 & $279 / 512$ & 5,0 & 773,2035 & $\begin{array}{c}611,1563 / 449,1150 \\
287,0574\end{array}$ & $\begin{array}{c}\text { Cy-3- } O \text {-diglicosídeo-5- } \\
O \text {-monoglicosídeo } \\
\text { (sugerida) }\end{array}$ \\
\hline & 2 & $279 / 515$ & 5,2 & 611,1653 & 287,0689 & Сy-3-O-soforosídeo \\
\hline & 3 & $279 / 515$ & 6,3 & 449,1029 & 287,0589 & Сy-3-O-glicosídeo \\
\hline & 4 & $279 / 517$ & 7,3 & 595,1659 & $449,1029 / 287,0598$ & Сy-3-O-rutenosídeo \\
\hline & 5 & $279 / 515$ & 10,5 & 463,1267 & 301,0724 & Pn--3-O-glicosídeo \\
\hline
\end{tabular}

${ }^{a}$ Solvente Fase móvel da análise cromatográfica (ácido fórmico 5\% e acetonitrila)

NO: não observado; NI: não identificado.

$\mathrm{Dp}=$ delfinidina, $\mathrm{Cy}=$ cianidina, $\mathrm{Pg}=$ pelargonidina, $\mathrm{Pt}=$ petunidina, $\mathrm{Pn}=$ peonidina $\mathrm{e} \mathrm{Mv}=\mathrm{Malvidina}$ 


\subsection{Isolamentos dos Pigmentos Antociânicos.}

Para obtenção de seis padrões de antocianinas monoglicosiladas: As antocianinas delfinidina-3-O-glicosídeo; cianidina-3- $O$-glicosídeo; petunidina-3- $O$-glicosídeo; peonidina3-O-glicosídeo; pelargonidina-3-O-glicosídeo e malvidina-3-O-glicosídeo. Foram utilizadas três fontes provedoras.
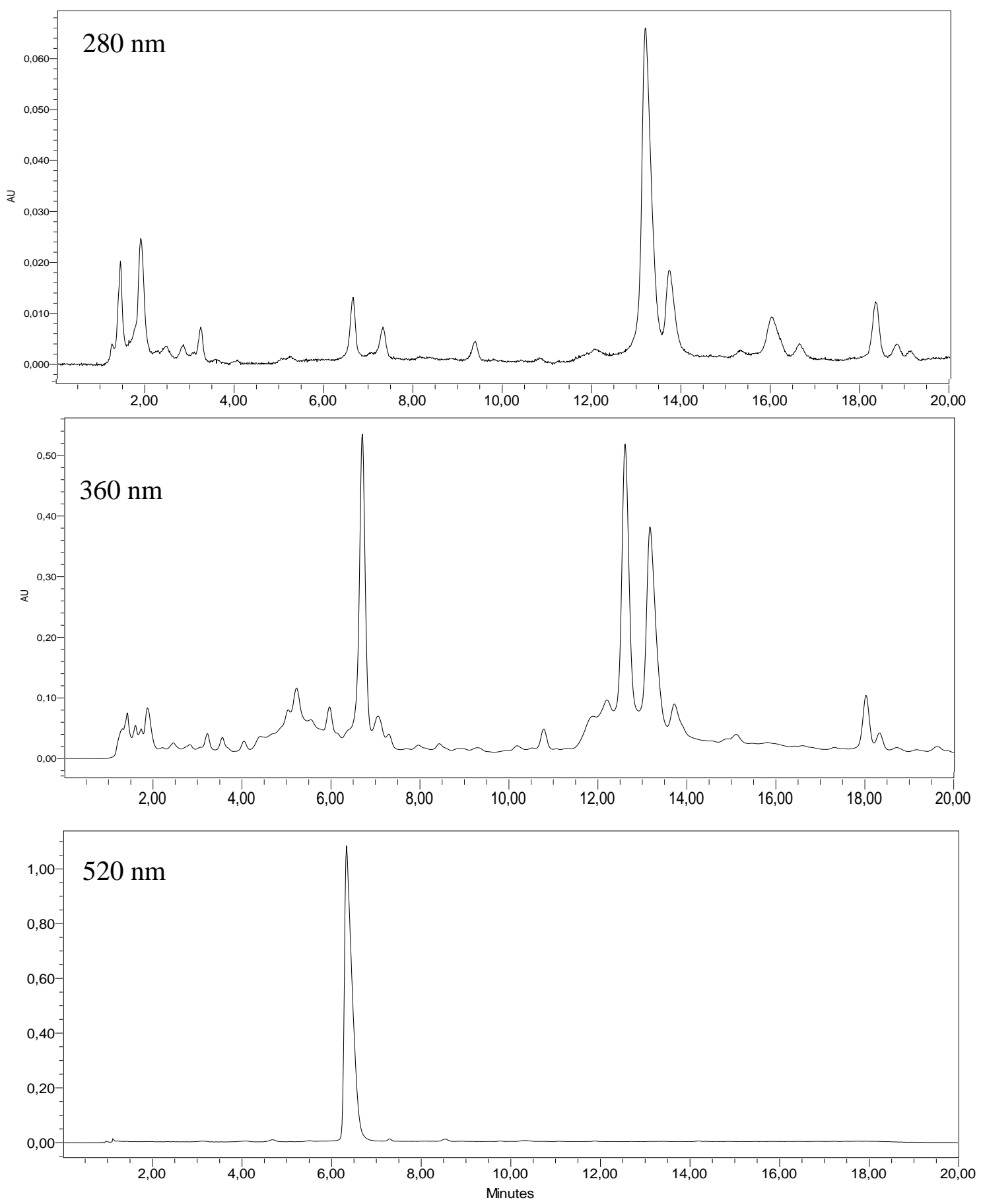

Figura 102: Cromatogramas do extrato do fruto da amendoeira extraídos no CLAE/DAD a 280, 360 e $520 \mathrm{~nm}$. 
A matriz escolhida para a coleta da antocianina cianidina-3- $O$-glicosídeo, fruto da amendoeira, apesar de apresentar alta pureza, 99\%, a $520 \mathrm{~nm}$, apresenta outros compostos nos comprimentos de 280 e $360 \mathrm{~nm}$ (Figura 102).

Essa matriz poderá servir como padrão para identificação da cianidina-3-O glicosideo, mas a presença de outros compostos em outros comprimentos de onda não a torna apta para utiliza-la na quantificação.

As antocianinas delfinidina-3-O-glicosídeo; petunidina-3-O-glicosídeo; peonidina-3$O$-glicosídeo e; malvidina-3- $O$-glicosídeo foram isoladas do extrato do epicarpo da UvaPreta sem semente do Chile. A antocianina pelargonidina-3-O-glicosídeo do extrato do morango.

Foi necessário partir de um extrato com alta concentração destas substâncias para que fosse possível diminuir o tempo e o número de injeções (Figura 103). Esse procedimento possibilitou amenizar gastos com solventes da fase móvel.

A liofilização das amostras tornou viável esse procedimento. A concentração, a partir do extrato liofilizado, obtida foi então satisfatória para realização das coletas.

Foram realizadas 80 injeções, que permitiram a obtenção dos extratos aquosos antociânicos referente às seis antocianinas isoladas. Foram gastos $80 \mathrm{~mL}$ de ácido fórmico e $160 \mathrm{~mL}$ de acetonitrila. Obteve-se quatro substâncias isoladas a partir do extrato do epicarpo da Uva-Preta do Chile.

Para a o isolamento das substâncias nas matrizes da amêndoa e morango, foram necessárias 50 injeções. Foram gastos $50 \mathrm{~mL}$ de ácido fórmico e $100 \mathrm{~mL}$ de acetonitrila.

Portanto, ao todo foram gastos $180 \mathrm{~mL}$ de ácido fórmico e $260 \mathrm{~mL}$ de acetonitrila para a coleta das seis antocianinas.

A não variação do tempo de retenção na corrida cromatográfica possibilitou a utilização de uma válvula seletora Rheodyne ${ }^{\circledR}$, automatizando e otimizando o tempo de isolamento dos analitos (Figura 104).

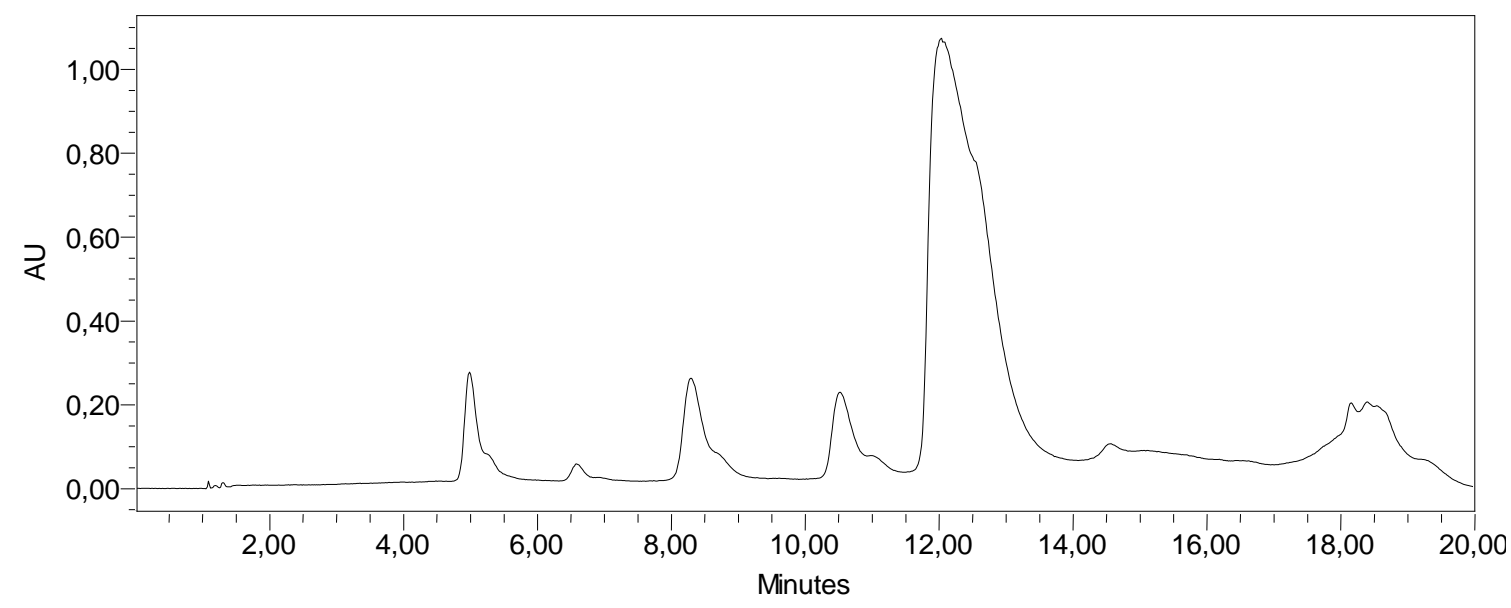

Figura 103: Cromatograma obtido do CLAE/DAD (520nm) do extrato concentrado da Uva-Preta do Chile.

Vale ressaltar que este tipo de procedimento foi uma adaptação realizada para que a mesma exercesse a função de coletor de amostras. Este procedimento viabilizou, portanto, a 
coleta de padrões isoladamente e sem a necessidade da presença constante de um operador para realização da coleta manual.

Somente os picos correspondentes às antocianinas de interesse foram coletados. Para o extrato da Uva-Preta do Chile a válvula foi programada, conforme descrito no item 3,7 para realização de quatro coletas distintas. A título de exemplificação pode-se observar os APÊNDICES C e F. Para os outros dois analitos provenientes das amostras dos extratos aquosos do fruto da amendoeira e do morango, a válvula somente foi programada para uma coleta em cada amostra.

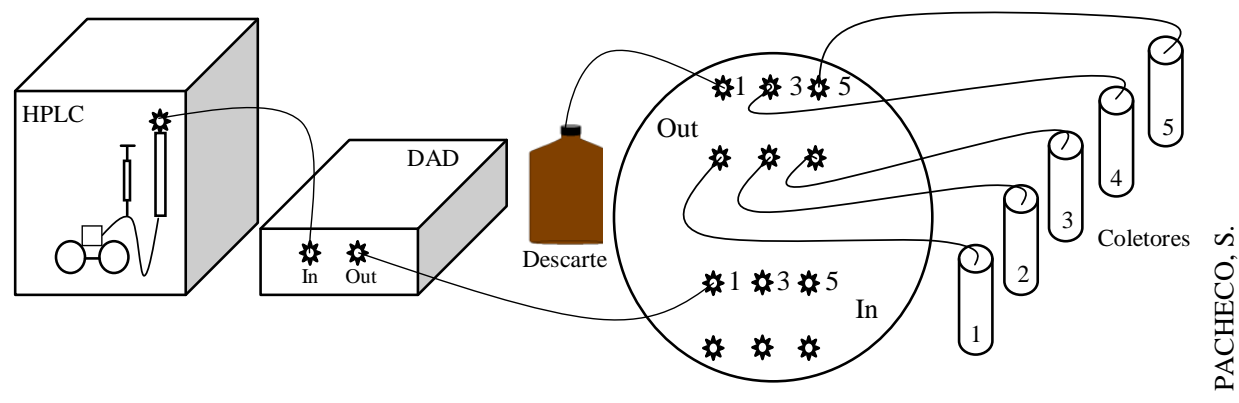

Figura 104: Esquema de funcionamento da válvula seletora com seis canais.

\subsubsection{Purificação e Concentração das Soluções com os Pigmentos Isolados}

Como a coleta das substâncias de interesse foi realizada durante sua eluição na corrida cromatográfica, as substâncias encontravam-se muito diluídas na fase móvel. A utilização do cartucho Sep Pak $C_{18}$ permitiu sua concentração e troca pelo solvente mais volátil, pois a alta concentração de água na fase móvel dificulta a secagem da solução por fluxo de nitrogênio.

\subsubsection{Análise cromatográfica das antocianinas isoladas (CLAE/DAD)}

Toda a corrida foi monitorada em três comprimentos de onda (520, 360 e $280 \mathrm{~nm})$ pelo software Empower ${ }^{\circledR}$ (Figura 105). Como relatado por Giust e colaboradores (1999), o percentual de área do pigmento antociânico isolado a 360 e $280 \mathrm{~nm}$ foram também utilizados como indicador de pureza, pois neste comprimento também ocorre a absorção de outros compostos fenólicos

A análise por CLAE/DAD da cianidina-3-O-glicosídeo petunidina-3-O-glicosídeo, peonidina-3-O-glicosídeo, pelargonidina-3- $O$-glicosídeo e malvidina-3-O-glicosídeo isoladas, nos três comprimentos de onda 520,360 e $280 \mathrm{~nm}$, mostraram nos comprimentos observados que o procedimento foi satisfatório para sua purificação.

Das outras cinco antocianinas isoladas, apenas a delfinidina-3-O-glicosídeo a pureza nos comprimentos de onda 360 e $280 \mathrm{~nm}$ não se mostrou satisfatória

O procedimento de isolamento para essa substância foi repetido, utilizando o extrato do primeiro procedimento. Desta vez, o isolamento foi realizado de forma independente e apenas 30 injeções foram suficientes. 
A metodologia utilizada para concentração foi a mesma realizada na primeira coleta. A amostra foi então submetida à nova análise por CLAE.

As purezas das seis antocianinas isoladas foram calculadas conforme a Equação I do item 3.7.2 (página 40) e estão descritas na Tabela 26.
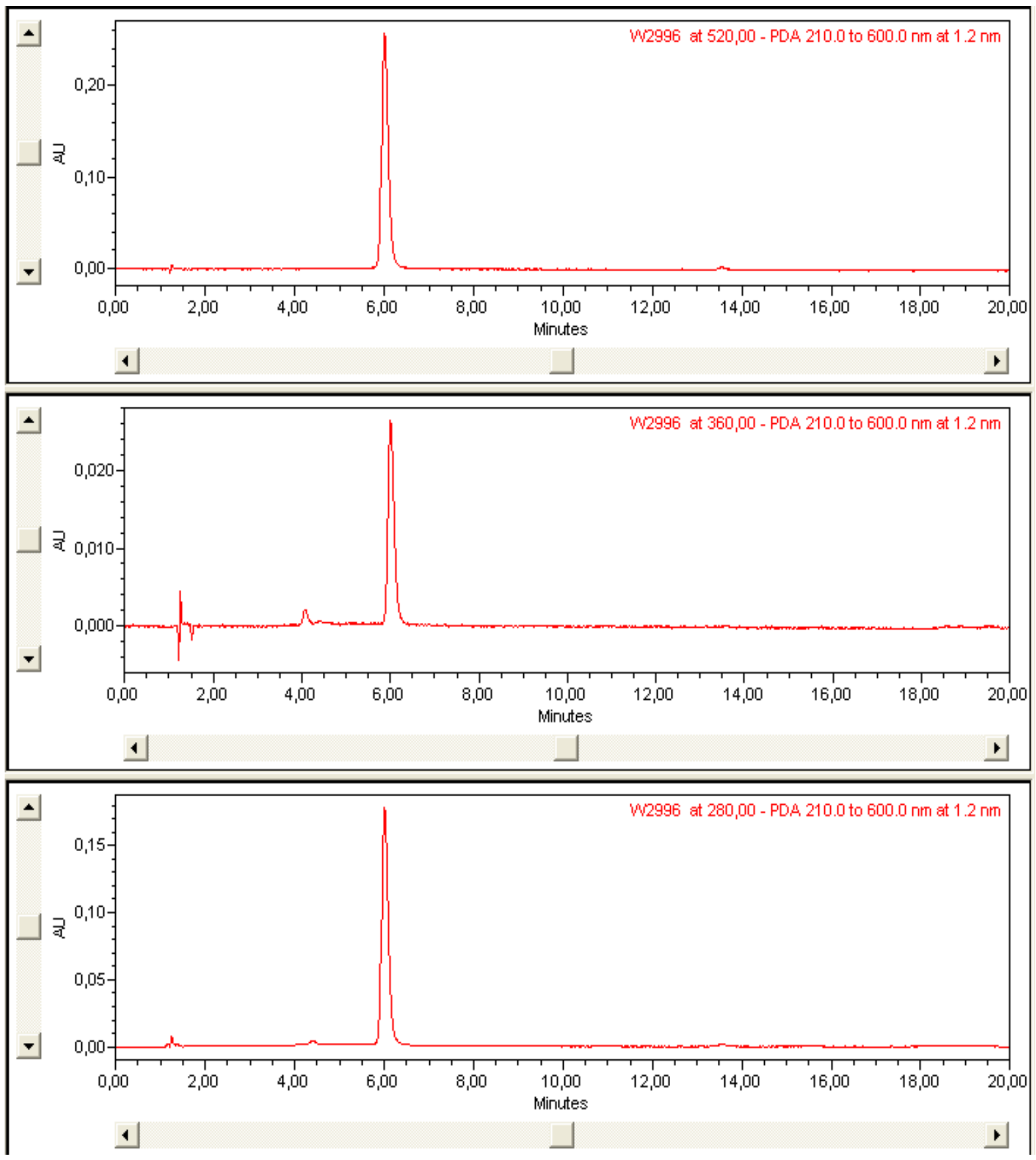

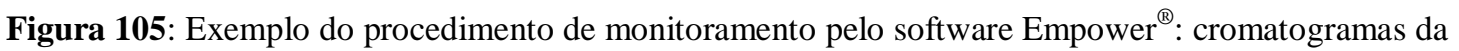
substância isolada e purificada, cianidina-3-O-glicosídeo em três comprimentos de onda 520, 360 e $280 \mathrm{~nm}$. 
Tabela 26: Percentagem de pureza dos analitos coletados em três comprimentos de onda.

\begin{tabular}{lcccc}
\hline Antocianina & Coleta & \% de Pureza 280nm & \% de Pureza 360nm & \% de Pureza 520nm \\
Dp-3-Glic & $1^{\text {a }}$ & 60,46 & 78,00 & 84,77 \\
Dp-3-Glic & $2^{\text {a }}$ & $\mathbf{9 5 , 0 6}$ & $\mathbf{9 5 , 0 5}$ & $\mathbf{9 9 , 8 2}$ \\
Cy-3-Glic & $\mathbf{1}^{\text {a }}$ & $\mathbf{9 6 , 2 5}$ & $\mathbf{9 6 , 0 3}$ & $\mathbf{9 9 , 3 3}$ \\
Pn-3Glic & $\mathbf{1}^{\text {a }}$ & $\mathbf{9 5 , 8 4}$ & $\mathbf{9 5 , 0 5}$ & $\mathbf{9 9 , 8 2}$ \\
Pg-3-Glic & $\mathbf{1}^{\text {a }}$ & $\mathbf{8 0 , 2 5}$ & $\mathbf{8 3 , 0 3}$ & $\mathbf{9 9 , 3 3}$ \\
Pt-3-Glic & $\mathbf{1}^{\text {a }}$ & $\mathbf{9 5 , 0 7}$ & $\mathbf{8 7 , 2}$ & $\mathbf{9 9 , 8 9}$ \\
Mv-3-Glic & $\mathbf{1}^{\text {a }}$ & $\mathbf{9 2 , 8 5}$ & $\mathbf{9 1 , 2}$ & $\mathbf{9 9 , 2 2}$ \\
\hline
\end{tabular}

Dp: delfinidina; Cy: cianidina; Pn: peonidina; Pg: pelargonidina; Pt: petunidina; Mv: malvidina; Glic: Glicosídeo
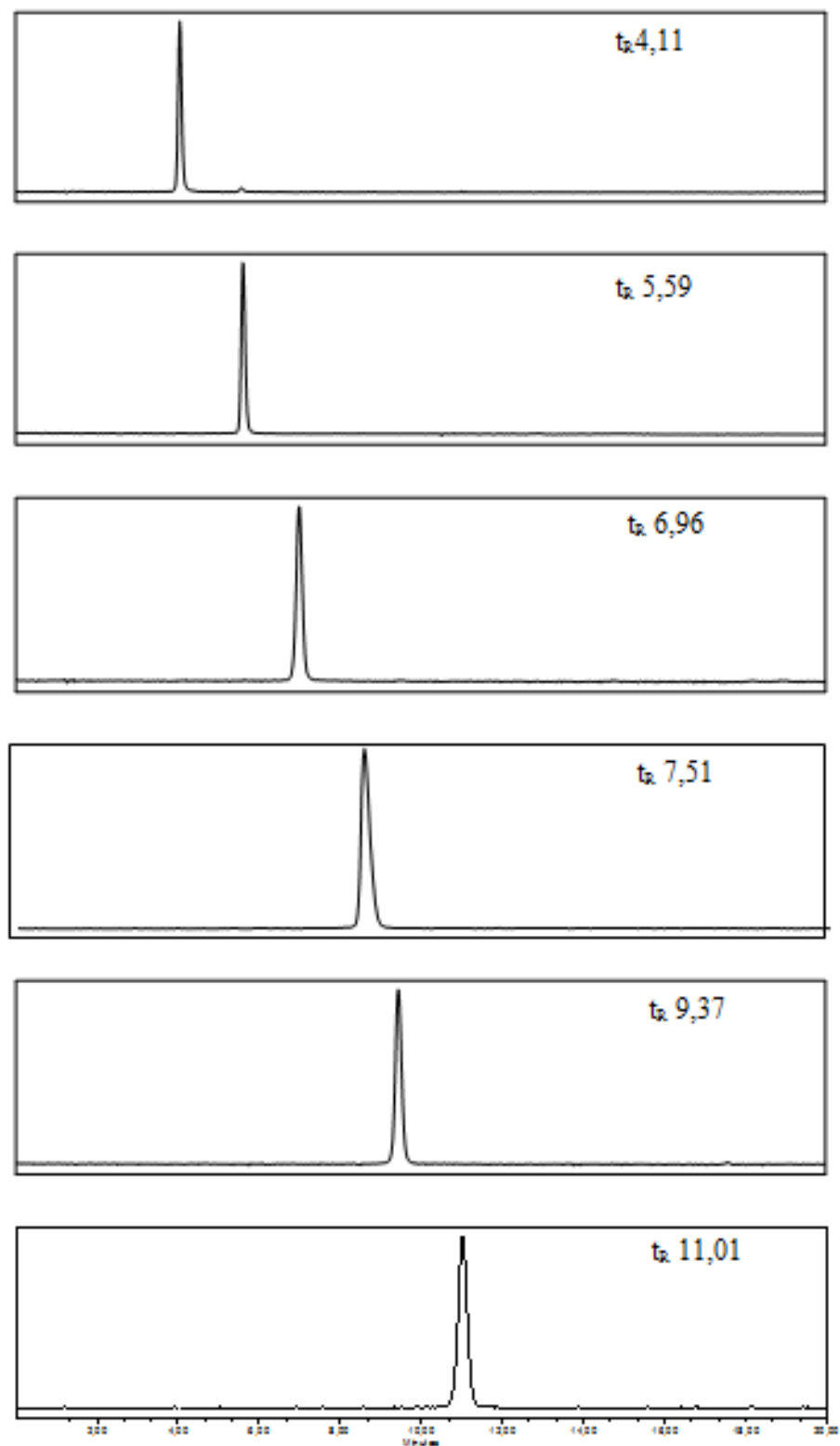

Figura 106: Cromatograma com a ordem de eluição das seis antocianinas (delfinidina, cianidina, petunidina, pelargonidina, peonidina e malvidina) monoglicosiladas isoladas, CLAE/DAD a 520nm. 
Uma solução das seis substâncias purificadas foi preparada, e submetida a análise por CLAE/DAD (Figura 107). Esta solução servirá para comparações de $t_{R}$ e dos espectro de

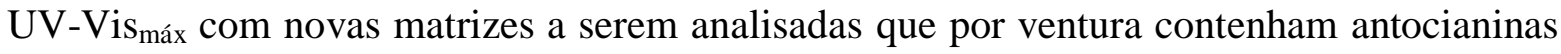
monoglicosiladas com o o açúcar glicose, fornecendo assim as primeiras informações sobre a(s) substância(s) na matriz.

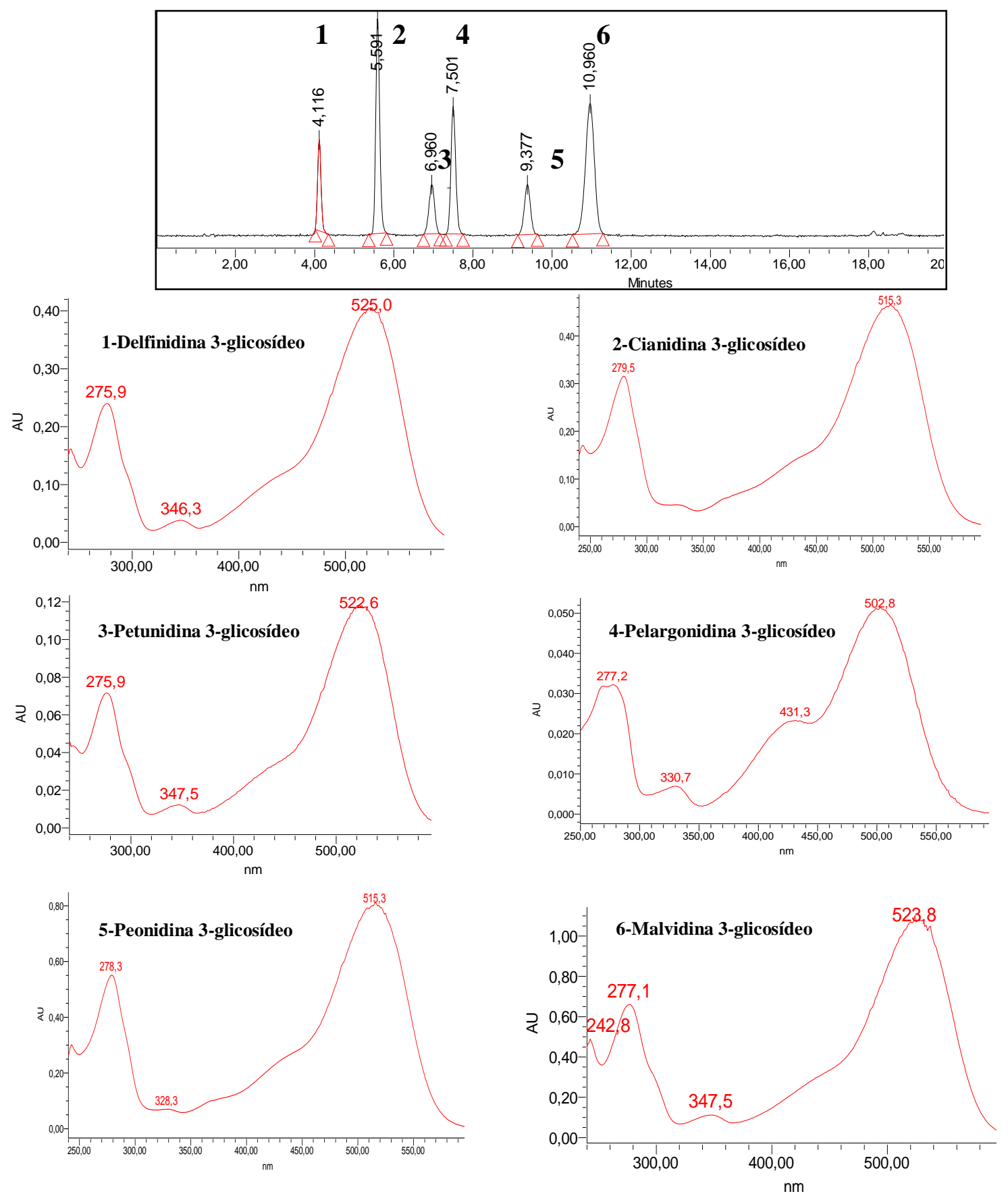

Figura 107: Cromatograma com seis antocianinas monoglicosiladas (1 delfinidina 3-glicosídeo; cianidina 3glicosídeo, 3- petunidina 3- glicosídeo, 4- pelargonidina 3-glicosídeo, 5-peonidina 3-glicosídeo, 6- malvidina 3-glicosídeo) e seus respectivos espectros UV-Vis máx a 520nm. 
$\mathrm{O}$ isolamento de antocianinas com pureza que permitem serem utilizadas como padrão analítico, possibilitou o estudo por espectrofotometria na região do visível, assim como da espectrometria de massas acuradas. A título de exemplificação pode-se observar os APÊNDICES D e E.

$\mathrm{O}$ isolamento das seis antocianinas monoglicosiladas pelo presente estudo, ainda possibilitou, através dos seus respectivos extratos, a observação visual da tendência da cor de cada antocianina pura em extratos metanólicos (Figura 108).

Uma substância pura apresenta um espectro sem nenhuma interferência, mostrando assim o real espectro da substância estudada naquele sistema, no caso fase-reversa. Com o conhecimento dos reais valores dos sinais $\left(\lambda_{\text {máx }}\right)$, fica mais confiável a comparação das substâncias de uma matriz ainda não estudada.

Dessa forma, a análise para a sua identificação se torna mais rápida e confiável. $\mathrm{O}$ mesmo pode ser observado para as antocianinas na espectrometria de massas onde, variando as condições do equipamento e utilizando substâncias puras, torna-se possível um estudo de fragmentações que permitirá diferenciar uma antocianina de outra, tanto quanto ao aspecto de substituições quanto ao seu núcleo principal.

Como exemplo, pode-se citar que foi possível observar através das rotas de fragmentações e diferenciar uma antocianina diglicosilada com o dissacarídeo (324 Da) ligado na posição do carbono três, no anel pirano da sua estrutura, de outra antocianina diglicosilada, mas que possuem dois monossacarídeos, cada um com valor de massa neutra de 162 Da, ligados nas posições 3 e 5 dos carbonos de sua estrutura (Figura 109).

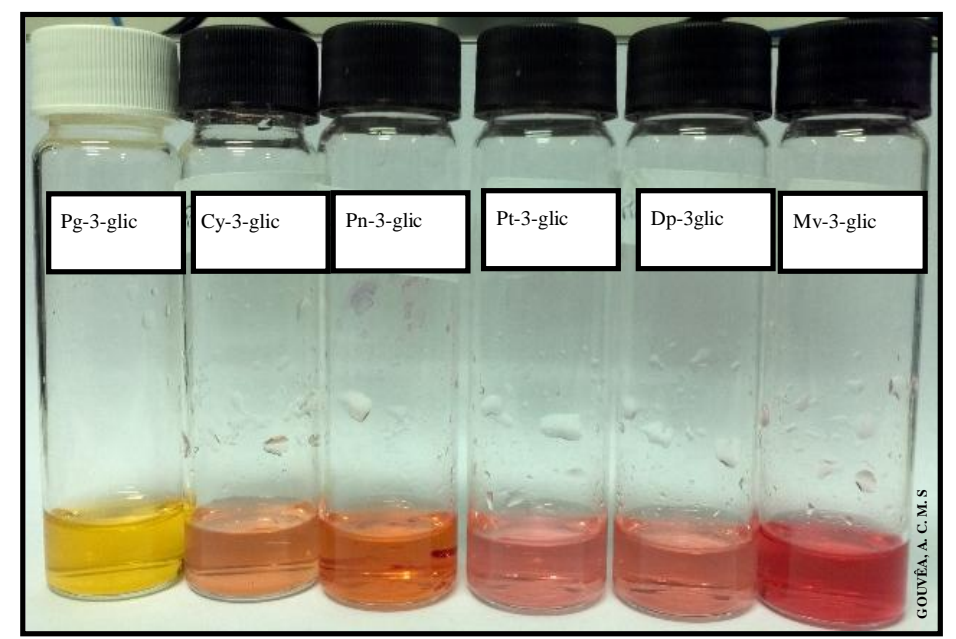

Figura 108: Extratos puros das seis antocianinas monoglicosiladas: Pelargonidina-3$O$-glicosídeo (Pg-3-glic); cianidina-3-O-glicosídeo (Cy-3-glic); peonidina-3-O-glicosídeo (Pn-3-glic); petunidina-3-O-glicosídeo (Pt-3-glic) e malvidina-3-O-glicosídeo (Mv-3-glic) diluídos na solução 1 (item 3.3). 


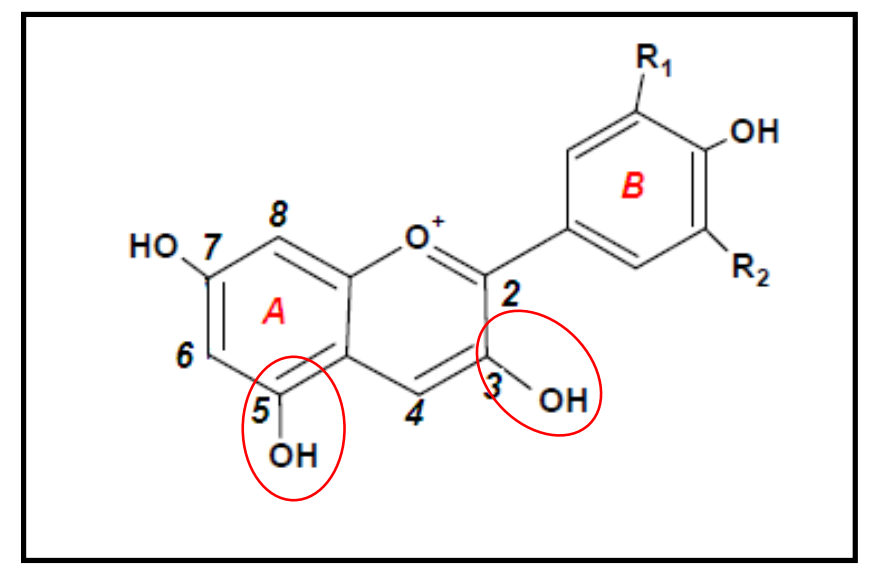

Figura 109: Estrutura da molécula da antocianina. Em destaque o $C_{3}$ do anel pirano e $C_{5}$ do anel $A$.

\subsubsection{Análise no CLUE/QTOF (ESI ${ }^{+}$, em modo EM/EM das substâncias isoladas}

As antocianinas isoladas também foram analisadas por espectrometria de massa acurada usando o detetor EM/QTOF (ESI ${ }^{+}$) acoplado ao CLUE.

As seis antocianinas monoglicosiladas foram analisadas no mesmo dia, delfinidina; cianidina; petunidina; pelargonidina peonidina e malvidina todas 3-O-glicosiladas (Figura 110). A presença da delfinidina-3- $O$-glicosídeo foi observada através de seu íon $[\mathrm{M}]^{+}$que apresentou $\mathrm{m} / \mathrm{z}$ 465,1078 e fragmento no modo EM/EM a $\mathrm{m} / \mathrm{z}$ 303,0590.

Para a antocianina cianidina-3-O-glicosídeo observado o íon molecular, $[\mathrm{M}]^{+}$, a $\mathrm{m} / z$ 449,1050 e fragmento no modo EM/EM a $\mathrm{m} / z$ 287,0511 que corresponde à massa molecular da aglicona cianidina devido à perda de um açúcar, no caso glicose.

A antocianina petunidina-3- $O$-glicosídeo apresentou íon molecular, $[\mathbf{M}]^{+}$, a $\mathrm{m} / \mathrm{z}$ 479,1168 e fragmento no modo EM/EM a $\mathrm{m} / z$ 317,0616, que corresponde à massa molecular da aglicona petunidina devido à perda da glicose.

A antocianina pelargonidina-3-O-glicosídeo apresentou íon molecular, $[\mathrm{M}]^{+}$, a $\mathrm{m} / \mathrm{z}$ 433,1265 e fragmento no EM/EM a $\mathrm{m} / \mathrm{z}$ 271,0662, que corresponde à sua aglicona pelargonidina devido à perda da glicose.

A antocianina peonidina-3- $O$-glicosídeo apresentou íon molecular, $[\mathrm{M}]^{+}$, a $\mathrm{m} / \mathrm{z}$ 463,1938 e fragmento no modo EM/EM a $\mathrm{m} / z$ 301,0797, que corresponde à massa molecular da peonidina devido à perda da glicose. A antocianina malvidina -3-O-glicosídeo apresentou íon molecular, [M] $]^{+}$, a $m / z$ 493,1404 e fragmento no EM/EM a $\mathrm{m} / z$ 331,0892, que corresponde à sua aglicona malvidina devido à perda da glicose.

Os resultados obtidos das análises no EM/QTOF $\left(\mathrm{ESI}^{+}\right)$, modo EM/EM, associados aos dados espectrais com $\lambda_{\text {máx }}$ na região do visível e características dos espectros de UV-

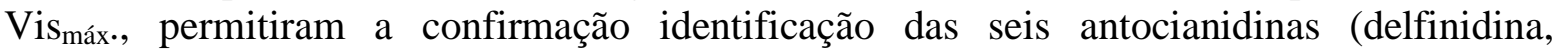
cianidina, petunidina, pelargonidina, peonidina e malvidina), assim como a informação de que todas as substâncias estão monossubstituída (Tabela 27).

$\mathrm{O}$ valor de $162 \mathrm{Da}$, correspondente a massa neutra perdida pelos íons moleculares das substâncias, indicaram ser uma hexose a molécula de açúcar. O tempo de retenção das substâncias, pode caracterizar o tipo de açúcar substituinte ligado à sua estrutura como 
glicose. Pois esse açúcar, como já relatado neste estudo, é mais hidrofóbico do que seu isômero a galactose.

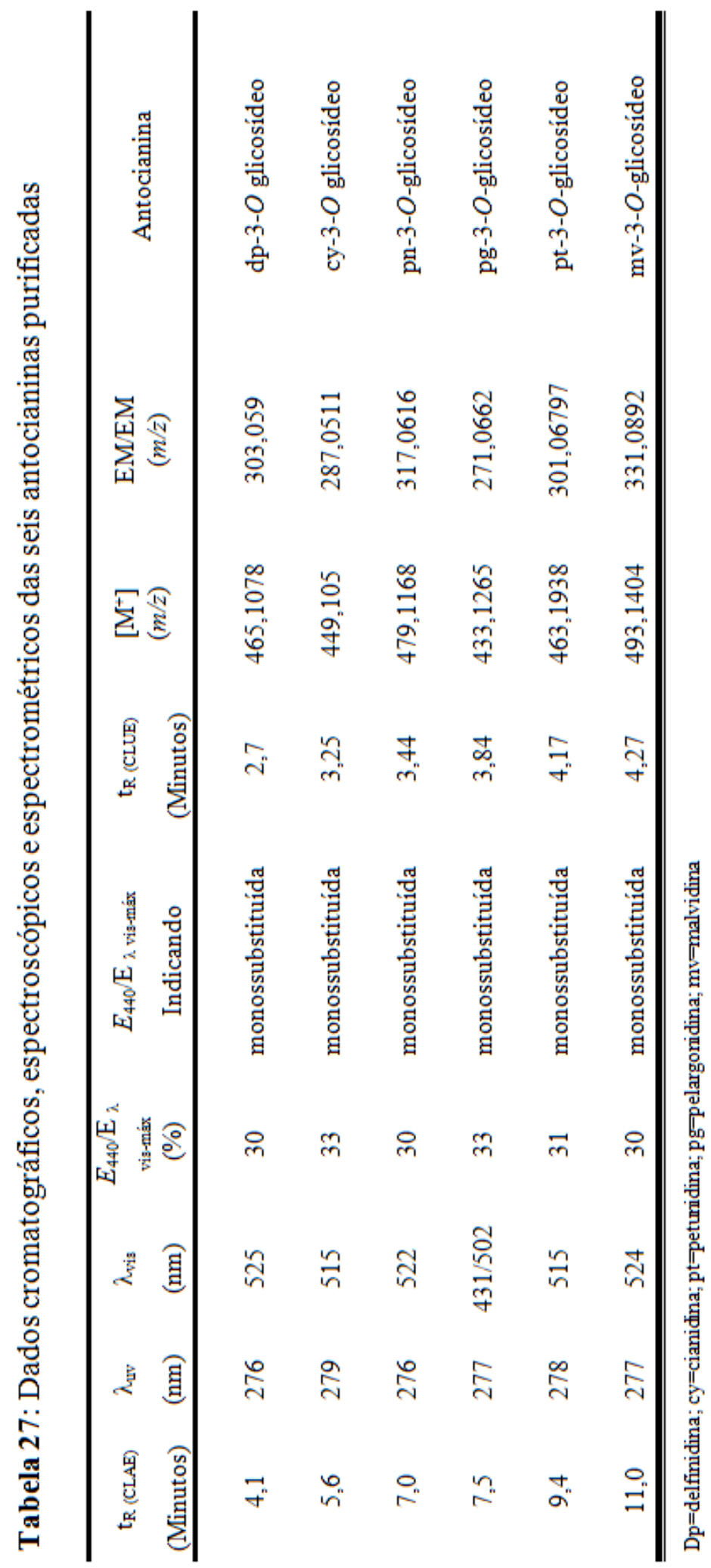


MS
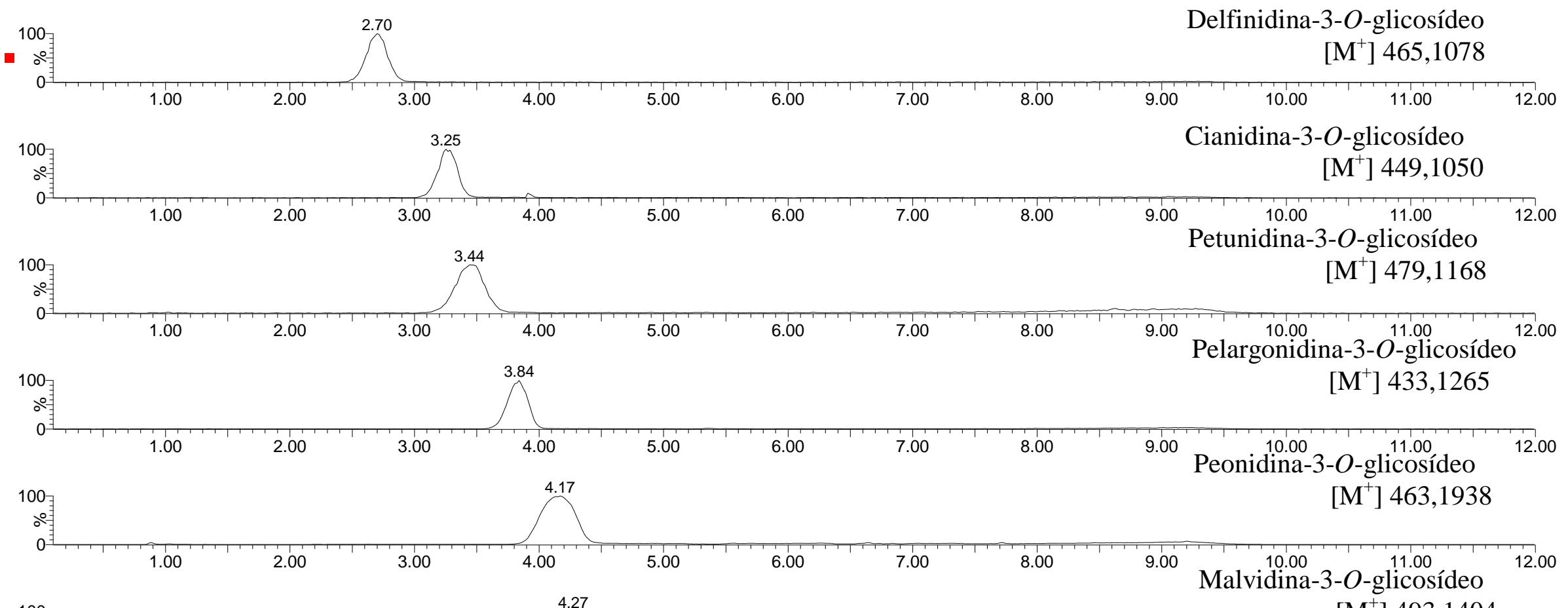

100
0

Figura 110: Cromatogramas das seis antocianinas isoladas no CLUE/EM QTOF $\left(\mathrm{ESI}^{+}\right)$. 


\subsubsection{Técnicas combinadas para purificação de antocianinas}

A presença da antocianina cianidina-3-O-glicosídeo na matriz do fruto da amendoeira com concentração de $99 \%$ a $520 \mathrm{~nm}$, faria dela um padrão nato se não fosse a presença de outras substâncias em outros comprimentos de onda (Figura 102) Para isolar a antocianina dessas substâncias foram necessária três etapas.

Para a primeira etapa de purificação do extrato foi utilizada uma coluna de vidro com recheio de fase $\mathrm{C}_{18}$, cujo objetivo foi a retirada de contaminantes que não possuissem afinidade com a fase reversa, como açúcares, lipídeos, proteinas, etc.

Para a retirada dos pigmentos adsorvidos à fase estacionária foi necessário a utilização de uma solução aquosa com percentagem mínima de solvente orgânico capaz de proporcionar o arraste do pigmento junto a fase móvel.

A solução 10 foi confeccionada baseada na proporção alcançada entre os solventes da fase móvel durante sua eluição na corrida cromatográfica. Esse fato propiciou o arraste de toda a cianidina-3-O-glicosídeo da fase estacionária, $\mathrm{C}_{18}$, da coluna de vidro.

Para a segunda etapa, o extrato aquoso obtido na etapa anterior, foi diluido 10 vezes com água ultrapura a fim de permitir sua utilização no cartucho OASIS ${ }^{\circledR}$ de troca catiônica. Esse cartucho MCX foi desenvolvido para simplificar e melhorar a preparação da amostra. Apresenta recheio combinando o mecanismo de troca catiônica forte (cátions) e interação de fase reversa para bases (HE e GIUST, 2011).

O adsorvente utilizado nesse cartucho é uma versão modificada do copolímero divinilbenzeno-vinilpirrolidona onde um átomo de hidrogênio do anel benzênco foi substituido por um grupo sulfônico. Sendo assim, o anel benzênico pode formar uma forte interação pi-pi com o anel da estrutura das antocianinas como também com as estruturas de outros compostos fenólicos (Figura 111).

O uso do metanol acidificado proporcionou a eluição dos compostos fenólicos com exeção das antocianinas. A forte interação iônica que ocorreu com a antocianina carregada positivamente e o grupo sulfônico fez com que a mesma permanecesse adsorvida à fase estaconária do cartucho.

O solvente básico utilizado $\left(\mathrm{NH}_{4} \mathrm{OH}\right)$, permitiu sua desorção, pois ao ser adicionado a fase móvel elevou o pH acima de 9,5 causando a desprotonação das antocianinas, portanto cessando a interação iônica entre a antocianina e o grupo sulfônico (Figura 111).

Com o pH elevado a estrutura das antocianinas passa de um cátion flavílio para uma base quinoidal que possui caráter aniônico, repelindo negativamente a carga do grupo sulfônico da estrutura hidrofóbica da fase estacionária do cartucho.

$\mathrm{O}$ excesso de $\mathrm{NH}_{4}$ também concorre com os locais de ligação dos catiões na resina, facilitando a dissociação da antocianina e grupo sulfônico.

Para evitar a degradação da antocianina é necessário que a solução seja acidificada imediatamente, pois estas substâncias são instáveis em $\mathrm{pH}$ mais elevado.

Para a terceira etapa foi utilizado o cartucho Sep Pak $\mathrm{C}_{18}$ que permitiu a retirada do sal formado, assim como proporcionou a conentração da amostra. A troca do solvente aquoso pelo solvente orgânico acidificado também permitu a secagem mais rápida da solução.

Esses procedimentos permitiram a retirada com êxito de outras substâncias que estavam presentes na amostra (Figura 112).

Em particular, o cartucho de troca iônica, permitiu o fracionamento das substâncias fenólicas, que apresentavam similar polaridade às antocianinas na mesma amostra. 
O extrato, da antocianina purificada, foi analisado por CLAE/DAD e evidenciou através da varredura nos $\lambda$ de 250-700nm (Max Plot), que a combinação das técnicas permitiram, com sucesso, o isolamento da cianidina-3-O-glicosídeo com alto grau de pureza, sem a necessidade do uso do sistema cromatográfico (Figura 112 e Tabela 29).

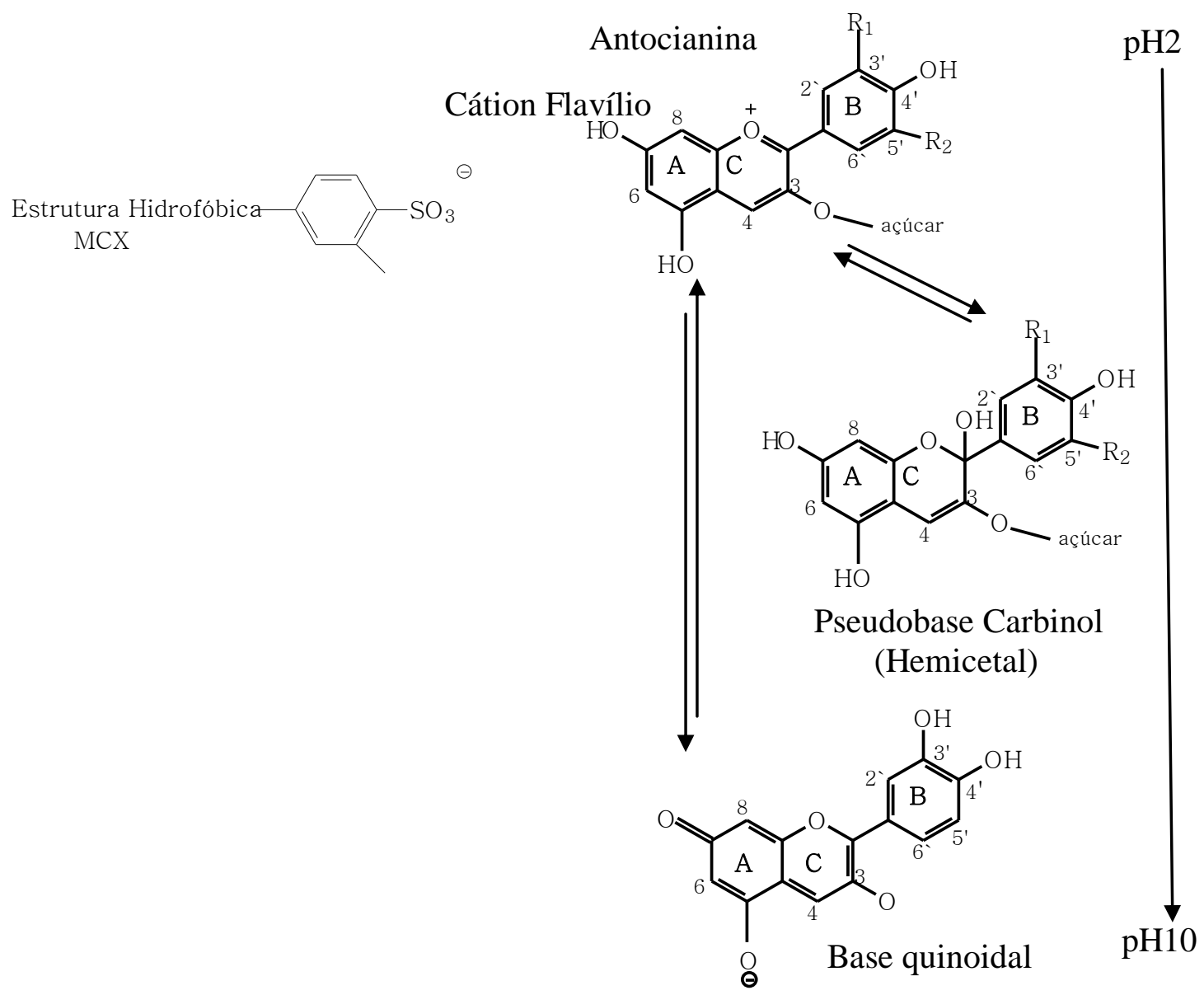

Figura 111: Estrutura química do sorbente MCX e molécula da antocianina em condições de $\mathrm{pH}$ diferentes, Fonte: He e Giust, 2011.

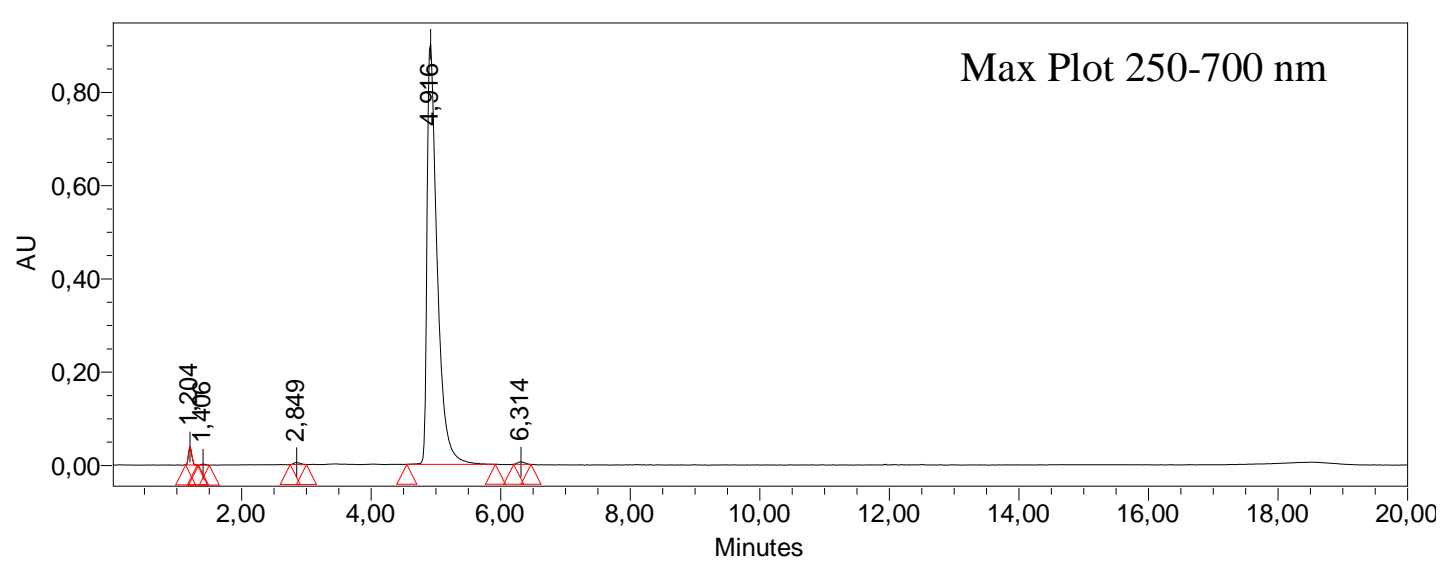

Figura 112: Cromatograma do extrato de cianidina-3- $O$-glicosídica purificada no $\lambda$ de 250-700nm (Max Plot), obtido do CLAE/DAD. Percentagens das substâncias na Tabela 28. 
Tabela 28: Percentagem da cianidina-3-O-glicosídeo purificada extraída no CLAE/DAD.

\begin{tabular}{ccccc}
\hline Pico & Antocianina & $\mathrm{t}_{\mathrm{R} \text { CLAE }}$ & Área & $\%$ Área \\
\hline 1 & - & 1,2 & 138801 & 1,39 \\
2 & - & 1,4 & 10831 & 0,11 \\
3 & - & 2,8 & 28960 & 0,29 \\
4 & Cianidina-3-O-glicosídeo & 5,0 & 9775591 & 97,78 \\
5 & - & 6,3 & 42894 & 0,43 \\
\hline
\end{tabular}

O mesmo procedimento poderá ser utilizado para purificar outras matrizes onde a concentração da substância majoritária exceda a $80 \%$ no $\lambda$ de $520 \mathrm{~nm}$ e, apresente outros compostos nos outros comprimentos.

Algumas matrizes estudadas neste trabalho apresentaram essa característica e servem como candidatas ao isolamento utilizando a combinação das três técnicas (Tabela 29).

Tabela 29: Antocianinas com percentagem de pureza acima de $80 \%$ a $520 \mathrm{~nm}$

\begin{tabular}{ll}
\hline \multicolumn{1}{c}{ Antocianina } & \multicolumn{1}{c}{ Matriz } \\
\hline Cy-3- $O$-galactosídeo & Maçã: $(86,0-90,0 \%) ;$ \\
Cy-3- $O$-glicosídeo & Jambo Vermelho (96,0\%) \\
Cy-3- $O$-rutenosídeo & Ipê roxo $(93,0 \%)$ \\
Cy-3- $O$-soforosídeo & Mangostin $(90,0 \%)$, Hibiscos cor salmão (84,0\%), arroz-preto (93\%) \\
Cy-3- $O$-soforosídeo & Alface roxa $(84,4 \%)$ \\
Dp-3- $O$-rutenosídeo & Berinjela $(93,0 \%)$, Espata da Flor Ave do Paraiso (96,0\%), \\
Pn3- $O$-glicosídeo & Manga Tommy (83,6\%), \\
Pg-3- $O$-glicosídeo & Morango $(85,0 \%)$ \\
Pg-3,5-di- $O$-glicosídeo & Flor da romãzeira $(90,0 \%)$ \\
\hline
\end{tabular}

$\mathrm{Dp}=$ delfinidina; $\mathrm{Cy}=$ cianidina; $\mathrm{Pn}=$ peonidina $\mathrm{Pg}=$ pelargonidina

A Tabela 30 apresenta as antocianinas isoladas das matrizes estudadas as quais foram purificadas de maneira que pudessem ser utilizadas como padrões analíticos (Tabela 30).

As antocianinas derivadas das antocianidinas: cianidina; delfinidina; peonidina; petunidina; malvidina e pelargonidina, encontradas nas 42 matrizes estudadas estão caracterizadas nas Tabelas de 31 a 36. 
Tabela 30: Antocianinas isoladas de fontes naturais para uso como padrões analíticos.

\begin{tabular}{|c|c|c|}
\hline & Antocianinas & Matrizes fontes \\
\hline 1 & Delfinidina-3-O-galactosídeo & Mirtilo \\
\hline 2 & Delfinidina-3,5-di- $O$-glicosídeo & Flor do Jambeiro \\
\hline 3 & Delfinidina-3-O-glicosídeo & Uva-preta sem caroço do Chile \\
\hline 4 & Cianidina-3,5-di-O-glicosídeo & Flor do Jambeiro \\
\hline 5 & Cianidina-3-O-soforosídeo & Mangostin \\
\hline 6 & Cianidina-3-O-glicosídeo & Fruto da amendoeira \\
\hline 7 & Cianidina-3-O-galactosídeo & Maçã \\
\hline 8 & Cianidina-3-O-grutenosídeo & Açaí \\
\hline 9 & Cianidina-3-O-arabinosídeo & Maçã \\
\hline 10 & Cianidina-3-O-xilosídeo & Maçã \\
\hline 11 & Cianidina-3-O-(6"malonilglicosídeo) & Maçã \\
\hline 12 & Cianidina-3-O- (dioxalilglicosídeo) & Alface roxa \\
\hline 13 & Petunidina-3,5-di- $O$-glicosídeo & Flor do Jambeiro \\
\hline 14 & Petunidina-3-O-glicosídeo & Uva-preta sem caroço do Chile \\
\hline 15 & Pelargonidina-3,5-di- $O$-glicosídeo & Flor da romãzeira \\
\hline 16 & Pelargonidina-3-O-glicosídeo & Morango \\
\hline 17 & Peonidina-3,5-di- $O$-glicosídeo & Flor do Jambeiro \\
\hline 18 & Peonidina-3- $O$-galactosídeo & Pêra de casca vermelha \\
\hline 19 & Peonidina-3-O-glicosídeo & Uva-preta sem caroço do Chile \\
\hline 20 & Malvidina-3,5-di- $O$-glicosídeo & Flor do Jambeiro \\
\hline 21 & Malvidina-3-O-galactosídeo & Mirtilo \\
\hline 22 & Malvidina-3-O-glicosídeo & Uva-preta sem caroço do Chile \\
\hline
\end{tabular}

Tabela 31: Antocianinas derivadas de Pelargonidina presentes em fontes naturais para uso como padrões.

\begin{tabular}{cc}
\hline Antocianinas & Fonte \\
\hline Pelargonidina-3- $O$-glicosídeo & $\begin{array}{r}\text { Morango; brácteas da planta Bico de Papagaio; } \\
\text { flor e fruto da romãzeira; fruto da Terminalia } \\
\text { catappa; Flor da Erythrina }\end{array}$ \\
Pelargonidina-3- $O$-rutenosídeo & Brácteas da planta Bico de Papagaio; Morango \\
Pelargonidina-3- $O$-soforosídeo & Flor da Erythrina \\
Pelargonidina-3,5-di- $O$-glicosídeo & Flor e fruto da romãzeira \\
Pelargonidina-3- $O$-ramnosídeo & Acerola \\
\hline
\end{tabular}


Tabela 32: Antocianinas derivadas de Cianidina presentes em fontes naturais para uso como padrões.

\begin{tabular}{|c|c|}
\hline Antocianinas & Fonte \\
\hline Cianidina-3-O-galactosídeo & $\begin{array}{c}\text { Maçã, Manga Tommy; Mirtilo; Soja casca preta; } \\
\text { brácteas da planta Bico de Papagaio; Pêra de casca } \\
\text { vermelha; N. obscura }\end{array}$ \\
\hline Cianidina-3- $O$-arabinosídeo & $\begin{array}{c}\text { Maçã cv (Fuji, Argentina, Red Delicius, Gala } \\
\text { Mirtilo; Eugenia sulcata (Pitanga-roxa); Amora (cv. } \\
\text { Tupy) }\end{array}$ \\
\hline \multirow[t]{2}{*}{ Cianidina-3- $O$-xilosídeo } & $\begin{array}{c}\text { Maçã cv (Fuji, Argentina, Red Delicius, Gala) } \\
\text { Maçã cv (Fuji, Argentina, Red Delicius, Gala); Eugênia } \\
\text { sulcata (Pitanga-roxa); N. obscura, }\end{array}$ \\
\hline & $\begin{array}{l}\text { Uvas (Red Globe; Niagara Rosada; Kyoho; Uva-Preta do } \\
\text { Chile); Juçara; brácteas da Planta Bico de Papagaio } \\
\text { Soja preta; Flor da Erythrina; Flor do Ipê Roxo; Amora } \\
\text { silvestre; Jabuticaba (P. grandifoliae P.trunciflora); } \\
\text { Açaí; }\end{array}$ \\
\hline Cianidina-3-O-glicosídeo & $\begin{array}{l}\text { flor do Ipê roxo N. obscura; flor da romãzeira; Morango; } \\
\text { Mirtilo; Alface-roxa; flor da Erythrina; Ameixa } \\
\text { vermelha; Eugenia sulcata (Pitanga-roxa); Amora (cv. } \\
\text { Tupy); arroz preto; Mangostin; framboesa; cebola roxa; } \\
\text { fruto da romãzeira }\end{array}$ \\
\hline Cianidina-3- $O$-rutenosídeo & $\begin{array}{c}\text { Açaí; Juçara; Ameixa casca vermelha, brácteas da planta } \\
\text { Bico de de papagaio; Amora silvestre; Flor do }\end{array}$ \\
\hline & Ipê Roxo; Amora (cv. Tupy e silvestre); arroz-preto \\
\hline Cianidina-3- $O$-soforosídeo & $\begin{array}{l}\text { Mangostin, Framboesa; Flor de Hibisco; Flor da } \\
\text { Erythrina; arroz-preto }\end{array}$ \\
\hline Cianidina-3- $O$-laminaribiosídeo & Cebola roxa \\
\hline Cianidina-3,5-di- $O$-glicosídeo & $\begin{array}{l}\text { Jamelão; Flor do Jambeiro; Jambo vermelho; flor da } \\
\text { romãzeira; arroz-preto; }\end{array}$ \\
\hline Cianidina-3-O-ramnosídeo & Acerola \\
\hline Cianidina-3-O-diglicosídeo-5-O-glicosídeo & Repolho roxo \\
\hline Cianidina-3-O- (6"malonilglicosídeo), & Alface roxa; Amora (cv. Tupy) \\
\hline Cianidina-3-O- (dioxalilglicosídeo), & Amora (cv. Tupy) \\
\hline
\end{tabular}


Tabela 33: Antocianinas derivadas de Delfinidina presentes em fontes naturais para uso como padrões analíticos.

\begin{tabular}{|c|c|}
\hline Antocianinas & Fonte \\
\hline Delfinidina-3- $O$-galactosídeo & Mirtilo; N. obscura \\
\hline Delfinidina-3- $O$-arabinosídeo & Mirtilo; \\
\hline Delfinidina-3- $O$-xilosídeo & N. obscura \\
\hline \multirow{3}{*}{ Delfinidina-3-O-glicosídeo } & Uvas (cv. Kyoho; Uva-Preta do Chile -s/semente); \\
\hline & Jabuticaba ( $P$. grandiflolia e $P$. trunciflora); Mirtilo; \\
\hline & $\begin{array}{l}\text { Berinjela; Jamelão; Eugenia sulcata (Pitanga-roxa) } \\
\text { Mirtilo; fruto da romãzeira; N. obscura; esparta da } \\
\text { flor Estrelizia (Ave do Paraiso) }\end{array}$ \\
\hline Delfinidina-3-O-rutenosídeo & Berinjela; esparta da flor Estrelizia (Ave do Paraiso) \\
\hline Delfinidina-3,5-di- $O$-glicosídeo & Jamelão; flor do Jambeiro; flor e fruto da romãzeira \\
\hline
\end{tabular}

Tabela 34: Antocianinas derivadas de Petunidina presentes em fontes naturais para uso como padrões, identificadas neste trabalho.

\begin{tabular}{cc}
\hline Antocianinas & Fonte \\
\hline Petunidina-3-O-galactosídeo & Mirtilo \\
Petunidina-3-O-arabinosídeo & Mirtilo; $N$. obscura \\
Petunidina-3-O-xilosídeo & N. obscura \\
Petunidina-3-O-glialactosídeo & Mirtilo; \\
Petunidina-3-O-glicosídeo & Uvas (cv. Kyoho; Uva-Preta do Chile -s/semente); \\
Netunidina-3,5-di- $O$-glicosídeo & obscura; Mirtilo \\
Petunidina-3-O- (6"-acetila) - & Mamelão; flor de Jambeiro \\
glicosídeo & Mirtilo
\end{tabular}


Tabela 35: Antocianinas derivadas de Peonidina presentes em fontes naturais para uso como padrões.

\begin{tabular}{cc}
\hline Antocianinas & Fonte \\
\hline Peonidina-3-O-galactosídeo & Mirtilo; Pêra de casca vermelha \\
Peonidina-3-O-arabinosídeo & Mirtilo; . obscura \\
Peoinidina-3-O-glicosídeo & $\begin{array}{l}\text { Uvas (Red Globe; Kyoho; Uva-Preta do Chile - } \\
\text { s/semente) } N \text { obscura; Manga cv. Tommy; } \\
\text { arroz-preto; Mirtilo; Eugenia sulcata (Pitanga-roxa) }\end{array}$ \\
Peonidina-3,5-di- $O$-glicosídeo & Jamelão; Flor do Jambeiro
\end{tabular}

Tabela 36: Antocianinas derivadas de Malvidina presentes em fontes naturais para uso como padrões, identificadas neste trabalho.

\begin{tabular}{cc}
\hline Antocianinas & Fonte \\
\hline Malvidina-3- $O$-galactosídeo & Mirtilo \\
Malvidina-3-O-arabinosídeo & Mirtilo \\
Malvidina-3-O-glicosídeo & Uvas (cv. Kyoho; Uva-Preta do Chile -s/semente); \\
Malvidina-3,5-di- $O$-glicosídeo & Mirtilo; N. obscura \\
Malvidina-3- $O$ - (6"-acetila) - \\
galactosídeo \\
Jalvidina-3- $O$ - (6"-acetila) - \\
glicosídeo
\end{tabular}

\subsection{Aplicação dos Padrões de Fontes Naturais}

O Brasil vem aumentando os estudos científicos, na área de alimentos, em grande parte por apresentar uma diversidade muito grande em árvores frutíferas nativas. Um dos destaques é a família Myrtaceae, cujas espécies vêm se destacando pela variedade de frutos encontrados e por apresentam grande potencial para pesquisa tecnológica. 
Seus frutos podem ser encontrados tanto no estado silvestre quanto cultivado em pomares domésticos. Alguns dos seus frutos já estudados têm mostrado serem ricos em flavonoides, composto da qual faz parte os pigmentos antociânicos.

Algumas espécies dessa Família têm ultimamente apresentado destaque no meio científico e já apresentam alguns trabalhos na literatura (GURAK et al., 2014). Entre esses frutos estão a jabuticaba ( $P$. grandifolia e $P$. trunciflora) e o jamelão (S.cumini) que também tiveram seus perfis antociânicos estudados no presente estudo.

Ainda existe um grande contingente de espécies pertencentes a esta família (Myrtaceae) na biodiversidade brasileira, que não possuem seus frutos quimicamente caracterizados.

Dessa forma, o presente trabalho, utilizando os métodos desenvolvidos para análise de antocianinas, identificou o perfil antociânico de duas espécies de frutos silvestres: Eugenia sulcata Spring ex Mart) e Neomitranthes obscura (DC.) N. Silveira (cv. de casca preta). Que podem ser encontradas por toda parte do país, mas são predominantes das áreas de Restingas da Costa Atlântica Brasileira.

A Eugenia sulcata Spring ex Mart, também conhecida por Pitanga-Negra Selvagem, apresenta um fruto comestível com coloração roxa, chegando quase ao preto na maturação (Figura 113).

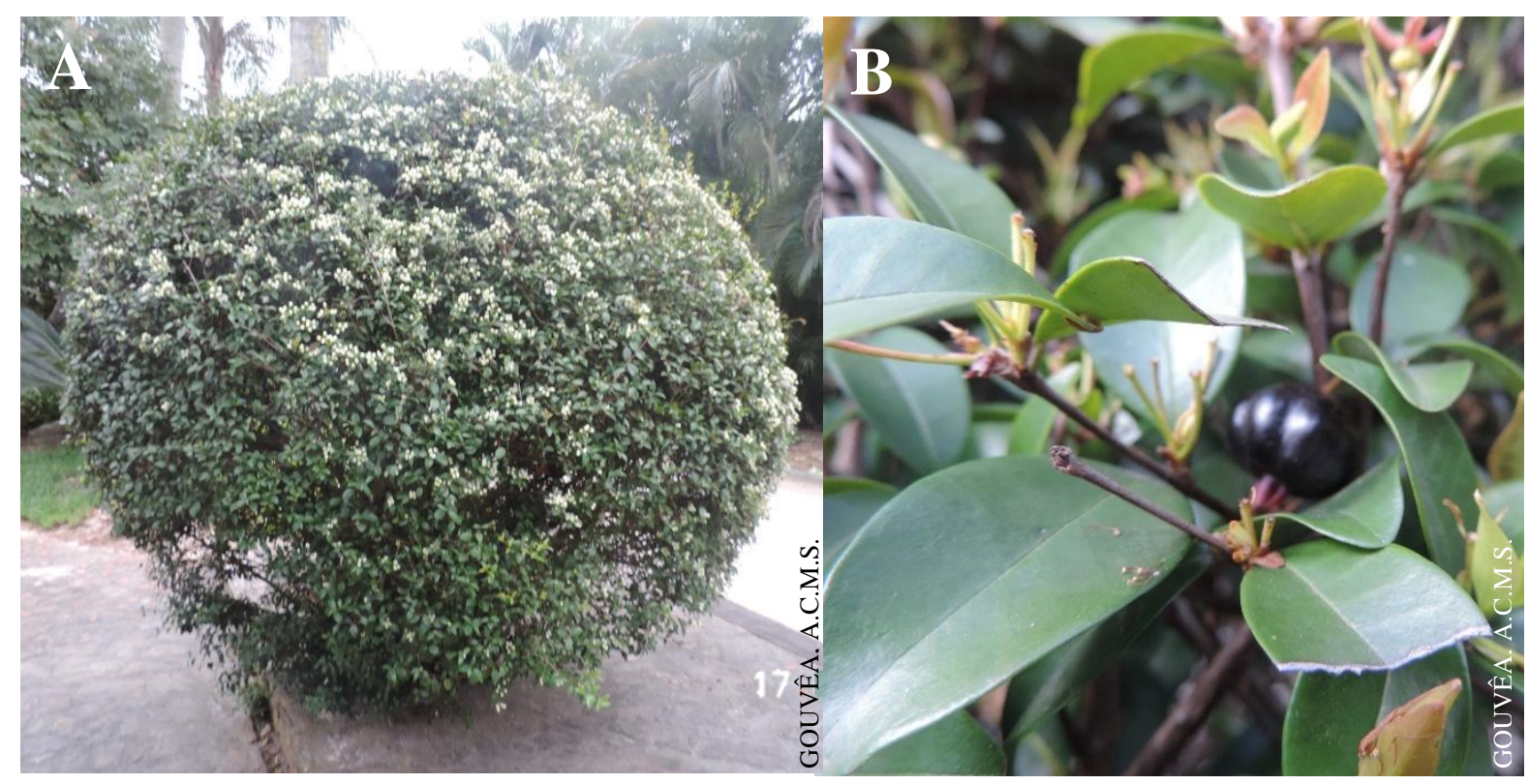

Figura 113: A) Árvore frutífera Eugenia sulcata Spring ex Mart. B), fruto da Eugenia sulcata (Pitanga-Negra Selvagem)

O pigmento deste pequeno fruto foi analisado por CLAE/DAD a $520 \mathrm{~nm}$ e apresentou um perfil cromatográfico onde foram observados a presença de 6 picos, dois majoritários (Figura114).

As substâncias equivalentes aos picos 2, 4, 5 e 6, mostraram resultados insatisfatórios para a observação dos espectros de absorção no UV-Vis máx, devido as suas baixas concentrações na amostra. 
Foi então repetido o procedimento de coleta das substâncias, utilizando a válvula seletiva de canais, conforme o procedimento realizado para a matriz do arroz preto (seguindo o item 3.7.5.1).

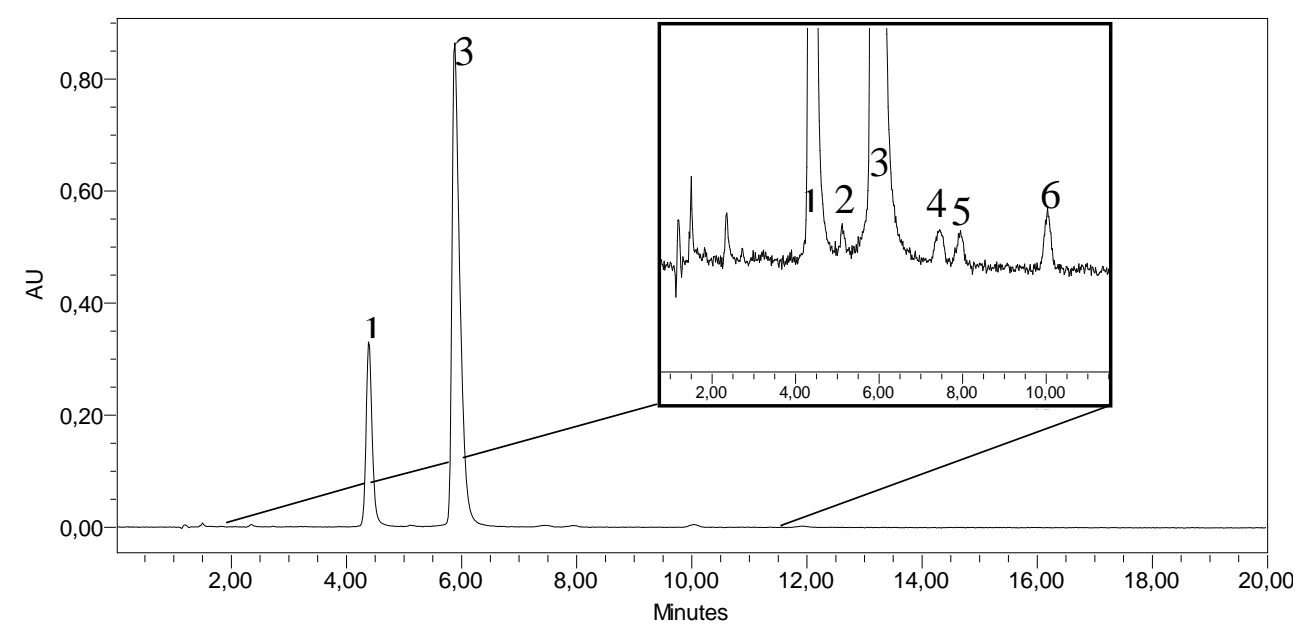

Figura 114: Perfil cromatográfico, no CLAE/DAD $(520 \mathrm{~nm})$, do extrato do fruto liofilizado da Pitanga-Negra Selvagem. Em destaque a expansão do cromatograma entre 1,5 e 11,0 minutos.

Deste modo foi possível evidenciar que os espectros UV-Vis ${ }_{\text {máx }}$ das substâncias equivalentes aos 6 picos, mostraram as duas bandas características das antocianinas (Quadro 3). Caracterizando, portanto a presença de seis antocianinas na matriz.

Para a identificação das substâncias foram utilizados os resultados obtidos dos espectros de absorção com o $\lambda_{\text {máx }}$ na região do visível, os dados extraídos no EM/QTOF $\left(\mathrm{ESI}^{+}\right)$, em modo EM/EM. E o tempo de retenção das substâncias (CLAE), que foram comparados aos de outras matrizes com as substâncias já identificadas, anteriormente, neste trabalho.

Nas análises realizadas no modo EM/EM, com apenas energia de colisão de 4 eV, já se observou a liberação dos fragmentos correspondentes as antocianidinas.

Para a substância equivalente ao pico 1 , foi observado o íon molecular a $\mathrm{m} / \mathrm{z}$ 465,1007 e o fragmento a $\mathrm{m} / \mathrm{z}$, 303,0505. A presença do íon fragmento a $\mathrm{m} / \mathrm{z}, 303,0505$

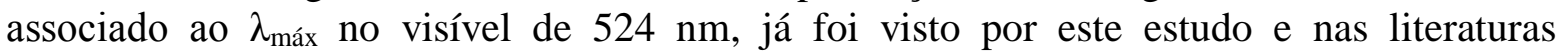
consultadas que é característico da presença de delfinidina ligada a uma hexose (162 Da). O tempo de retenção indica ser a glicose.

Para as substâncias equivalentes aos picos 2 e 3, foram observados o mesmo valor do íon molecular, $\mathrm{m} / \mathrm{z} 449$, como também apresentaram mesmo valor para seus fragmentos, $\mathrm{m} / \mathrm{z}$ 287. Apenas divergiram nas casas decimais tanto dos seus íons moleculares quanto dos seus fragmentos (Quadro 3).

A presença dos íons a $\mathrm{m} / \mathrm{z} 287$ associados aos $\lambda_{\text {máx }}$ no visível de $516 \mathrm{~nm}$, indicam que as duas substâncias apresentam a cianidina ligadas a uma hexose (162 Da).

O tempo de retenção caracterizou a primeira substância como cianidina-3-O galactosídeo e a segunda substância, seguindo a ordem de eluição, como a cianidina-3-Oglicosídeo. 
As substâncias 4 e 6, também apresentaram o mesmo íon molecular a $m / z$ 419, e fragmentos a $m / z$ 287, com diferença apenas nas casas decimais. Como já observado anteriormente, a presença do $\lambda_{\text {máx }}$ no visível de $516 \mathrm{~nm}$ associado ao valor a $m / z 287$ para os seus fragmentos, indicam ser a cianidina as antocianidinas das duas substâncias, cada uma ligada a uma pentose (132 Da).

Foi observado o tempo de retenção de 7,2 minutos para a substância 4 e de 10,0 minutos para a substância 6 . Como a arabinose confere a molécula um ganho de polaridade em relação a xilose, as antocianinas foram identificadas como cianidina-3- $O$-arabinosídeo e cianidina-3-O-xilosídeo, respectivamente.

A substância equivalente ao pico 6 , apresenta a particularidade do $\lambda_{\text {máx }}$ no visível de $501 \mathrm{~nm}$, característico de antocianidina pelargonidina, para o sistema do presente estudo. Sua massa acurada observada no EM/EM, confirmou ser esta a antocianidina, pois a substância apresentou fragmento a $m / z$ 271,0723, após perder massa neutra de $162 \mathrm{Da}$ (hexose).

Ao comparar seu tempo de retenção ao da substância majoritária da matriz do morango (pelargonidina-3-O-glicosídeo), ficou caracterizado que eram a mesma substância. Quadro 3.

Todos os dados obtidos no CLAE/DAD e no EM/QTOF (ESI+) estão descritos no

Quadro 3: Dados das análises do extrato do fruto da Eugenia sulcata no CLAE/DAD e EM/QTOF (ESI+) em modo EM/EM.

\begin{tabular}{|c|c|c|c|c|c|c|}
\hline Matriz & Pico & $\boldsymbol{\lambda}(\mathbf{n m})^{\mathbf{a}}$ & $\begin{array}{c}\mathbf{t}_{\mathbf{R}} / \\
\mathbf{C L A E} \\
(\mathbf{m i n})\end{array}$ & $\begin{array}{c}{[\mathbf{M}]^{+}} \\
(\boldsymbol{m} / \mathbf{z})\end{array}$ & $\begin{array}{c}\mathbf{E M} / \mathbf{E M} \\
(\mathbf{m} / \mathbf{z})\end{array}$ & Antocianina \\
\hline & 1 & $279 / 524$ & 4,4 & 465,1007 & 303,0505 & Dp-3-O-glicosídeo \\
& 2 & $279 / 516$ & 5,0 & 449,1081 & 287,0579 & Cy-3-O-galactosídeo \\
& 3 & $279 / 516$ & 6,0 & 449,1025 & 287,0587 & Cy-3- $O$-glicosídeo \\
& 4 & $279 / 516$ & 7,2 & 419,0878 & 287,0535 & Cy-3-O-arabinosídeo \\
& 5 & $277 / 426 / 501$ & 7,9 & 433,1188 & 271,0723 & Pg-3-O-glicosídeo \\
& 6 & $279 / 516$ & 10,0 & 419,0888 & 287,0698 & Cy-3-O-xilosídeo \\
\hline
\end{tabular}

${ }^{a}$ Solvente Fase móvel da análise cromatográfica (ácido fórmico 5\%: 10\% e acetonitrila).

*Perfil identificado pela primeira vez.

$\mathrm{Dp}=$ delfinidina, $\mathrm{Cy}=$ cianidina, $\mathrm{Pg}=$ pelargonidina, $\mathrm{Pt}=$ petunidina, $\mathrm{Pn}=$ peonidina

Os resultados mostram que o extrato do fruto da Eugenia sulcata, Pitanga-Negra Selvagem, apresenta no seu perfil cromatográfico antocianinas ligadas a apenas um substituinte.

Os resultados obtidos sobre o $t_{R}$ indicaram o ganho ou perda de polaridade conferida às substâncias através dos substituintes ligados a uma mesma antocianidina no sistema utilizado (Fase Reversa).

Somando-se a estes resultados os dados obtidos na região do visível, as informações sobre as massas acuradas de seus íons moleculares e fragmentos, assim como, o padrão de fragmentação sofrido pela molécula ao receber determinado valor de energia de colisão. Foi possível identificar nas seis antocianinas presentes na matriz, os três tipos de antocianidina (delfinidina, cianidina e pelargonidina) e os quatros tipos de monossacarídeos substituintes ligados à sua estrutura. 
Vale a pena salientar, que só serão possíveis as identificações com confiabilidade, se os resultados observados nos quatro parâmetros propostos, por este trabalho, atuarem como um conjunto de dados.

A matriz E. sulcata também mostrou ser uma excelente fonte alternativa das antocianinas delfinidina-3-O-glicosídeo e cianidina-3-O-glicosídeo que apresentam a percentagem de 35 e $75 \%$, respectivamente, na amostra.

A matriz Neomitranthes obscura de casca preta, conhecida popularmente por camboim de cachorro, pitanga de cachorro ou pitanga da restina apresenta um fruto de forma globulosa de casca dura, coloração negra quando atinge o estágio de maturação, e sabor adstringente (Figura 115).

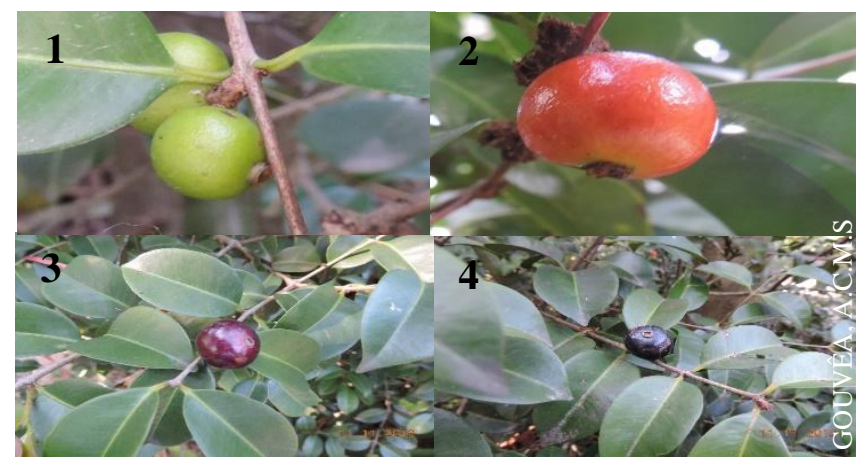

Figura 115: Neomitranthes obscura em quatro estágios de maturação.

Para identificação das antocianinas nessa matriz foram utilizadas as metodologias desenvolvidas neste trabalho, assim como, os padrões preparados.

Esse trabalho fez parte do Programa de Doutorado Sanduiche (PDSE-CAPES), no laboratório de Bromatologia e Hidrologia, da Faculdade de Farmácia de Universidade do Porto (Portugal) sob a orientação da professora Isabel M. P. L. V. O. Ferreira, PhD.

Foram identificadas 11 antocianinas, utilizando as técnicas, já bastante estudadas neste estudo. O ponto forte desse estudo, $N$. obscura, foi que proporcionou a validação da metodologia cromatográfica desenvolvida.

Material e métodos, assim como os resultados obtidos estão descritos no trabalho "Identification and quantification of anthocyanins in fruits from Neomitranthes obscura (DC) N.Silveira na endemic specie from Brazil by comparison of chromatographic methodologies", publicado na revista Food Chemistry, que se encontra no Apêndice G.

Os Apêndice $\mathrm{H}$ foi também exemplo de aplicação.

\subsection{Validação da Metodologia}

A metodologia desenvolvida para análise de antocianinas por cromatografia líquida foi validada através da comparação com um método de análise de antocianinas por cromatografia líquida já validado descrito por Oliveira e colaboradores (2013).

Material e métodos, assim como os resultados obtidos estão descritos no trabalho "Identification and quantification of anthocyanins in fruits from Neomitranthes obscura (DC) N.Silveira na endemic specie from Brazil by comparison of chromatographic methodologies", publicado na revista Food Chemistry, que se encontra no Apêndice G. 


\section{CONCLUSÃO}

Foi desenvolvida a metodologia de análise cromatrografica para antocianinas, utilizando coluna com fase estacionaria com partículas inferior a $3 \mu \mathrm{m}$.

Das quarenta e três matrizes estudadas e avaliadas, quarenta e duas apresentaram potencial para o isolamento de antocianinas. Apenas o arroz vermelho, não o apresentou pigmento antociânico.

O uso da ferramenta, massa acurada, acrescentou confiabilidade aos resultados

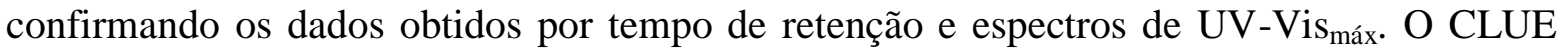
mostrou ser eficaz para análise de antocianinas, rápida com econômia de solvente, acoplado ao detetor de massas trouxe como vantagem a extração individual do íon molecular investigado mesmo quando coeluiam.

A válvula Rheodyne de seis canais, adaptada para coleta das substâncias detetadas, mostrou ser fundamental para o isolamento das antocianinas de forma automatizada, apresentando maior eficiência que um coletor de frações, em relação ao tempo e pureza da amostra recolhida.

A metodologia analítica proposta para identificação e quantificação de antocianinas por CLAE/DAD mostrou-se especifica, sensível, precisa e linear na faixa de concentração entre 0,021 a $0,070 \mathrm{mgL}^{-1}$, sendo adequada para avaliação das substâncias. Os ensaios de validação apresentados estão de acordo com as recomendações internacionais e vigentes no país.

Desse modo, torna-se possível a identificação e quantificação das principais antocianinas encontradas em alimentos, ainda que não haja padrão analítico disponíveis para a aquisição. 


\section{REFERÊNCIAS BIBLIOGRÁFICAS}

ABE, L. T., LAJOLO, F. M., GENOVESE, M. I. Potential dietary sources of ellagic acid and other antioxidants among fruits consumed in Brazil: jabuticaba (Myrciaria jaboticaba (Vell.) Berg). Journal of the Science of Food and Agriculture, v.92, 1679-1687., 2012.

AHMADIANI, N.; ROBBINS, R.J.; COLLINS, T. M.; GIUSTI, M. Anthocyanins Contents, Profiles, and Color Characteristics of Red Cabbage Extracts from Different Cultivars and Maturity Stages. Journal of Agricultural and Food Chemistry, v. 62, n. 4, p. 7524-7531, 2014.

ARAPITSAS, P.; SJÖBERG, P. J. R.; TURNER, C. Characterisation of anthocyanins in red cabbage using high resolution liquid chromatography coupled with photodiode array detection and electrospray ionization-linear ion trap mass spectrometry. Food Chemistry, v. 109, p. 219-226, 2008.

ARAUJO, M.C.P. de; GOUVÊA, A. C. M. S.; GODOY, R. L. de O.; OIANO NETO, J.; PACHECO, S.; ROSA, J. S. Adaptação de um método por cromatografia líquida de alta eficiência para análise de antocianinas em suco de açaí (Euterpe oleraceae Mart.). Embrapa Agroindústria de Alimentos, 2010.

AUGUSTA, I.M.; RESENDE, J.M.; BORGES, S.V.; MAIA, M.C.A.; COUTO, M.A.P.G. Caracterização física e química da casca e polpa de jambo vermelho (Syzygium malaccensis, L. Merryl e Perry). Ciência e Tecnologia de Alimentos, v. 30, n. 4, p. 928-932, 2010.

BASTOS, R. C.; AZZINI, L. E. ; MCCLUNG, A.M. IAC 600: cultivar tipo exótico preto. Instituto Agronômico de Campinas, 2004. Disponível em > http://www.iac.br/areasde pesquisa/graos/arroz.php> acessado em 22 de maio de 2012.

BELITZ, H.-D; GROSCH, W; and SCHIEBERLE, Peter. Food chemistry (4th rev. and extended ed). Berlin Springer, 2009Disponível<https://books.google.com.br/books?id=xtei ARU46SQC\&pg=PA690\&hl=ptBR\&source=gbs_selected_pages\&cad=2\#v=onepage\&q\&f $=$ false $>$ Acesso em 23/05/2013.

BICUDO, M. O. P.; RIBANI, R. H.; BETA, T. Anthocyanins, Phenolic Acids and Antioxidant Properties of Juçara Fruits (Euterpe edulis M.) Along the On-tree Ripening Process. Plant Foods for Human Nutrition, v.69, p.142-147. 2014.

BOBBIO, P. A.; BOBBIO, F. O. Química do Processamento de Alimentos. 2a edição. São Paulo: Varella, p.111, 1995. 
BRACKMANN, A.; STEFFENS, C. A.; GIEHL, R. F. H. Maturação da maçã ‘Fuji’ em função do atraso na colheita e da aplicação pré-colheita de Aminoetoxivinilglicina. Ciência Rural. v.34, n.3, 2004.

BRAVO, L. Polyphenols: Chemistry, Dietary Sources, Metabolism, and Nutritional Significance. Nutrition Reviews, v. 56, n. 11, p. 317-333, 1998.

BRIDLE, P.; TIMBERLAKE, C.F. Anthocyanins as natural food colours - selected aspects. Food Chemistry, v.58, n.1-2, p.103-109, 1997.

BRITO, E. S.; ARAÚJO, M. C. P.; ALVES, R. E.; CARKEET, C.; CLEVIDENCE, B. A.; NOVOTNY, J. A. Anthocyanins Present in Selected Tropical Fruits: Acerola, Jambolão, Jussara, and Guajiru. Journal of Agricultural and Food Chemistry. v. 55, p. 9389-9394, 2007.

BROUILLARD, J. R. In: Anthocyanins a food colors; Markakis, P., ed.; Academic Press: New York. 1982, Cap.1, p. 263.

BUNEA, A.; RUGINĂ, D.; SCONŢA, Z.; POP, R. M.; PINTEA, A.; SOCACIU, C.; TĂBĂRAN, F.; GROOTAERT, C.; STRUIJS, K.; VANCAMP, J. Anthocyanin determination in blueberry extracts from various cultivars and their antiproliferative and apoptotic properties in B16-F10 metastatic murine melanoma cells. Phytochemistry, v. 95, p. 436-444, 2013. http://dx.doi.org/10.1016/j.phytochem.2013.06.018.

BUSHWAY, R. J.; McGANN, D. F.; COOK, W. P.; BUSHWAY, A. A. Mineral and vitamin content of lowbush blueberries (Vaccinium angustifolium Aiot.). Journal of Food Science, v. 48, n.6, p. 1878-1880, 1983. Food Chemistry, v. 172, p. 183-189, 2015.

CAMPOS, D. D. P. Extração, Purificação e Isolamento de Antocianinas de Jambolão (Syzygium cuminii) e Avaliação dos seus Efeitos Biológicos. Campinas, S. P., 2006, 113 p., Dissertação ( Mestre em Química Analítica), Instituto de química, Universidade Estadual de Campinas ( UNICAMP).

CARVALHO, G. L. Conservação pós-colheita de uvas 'Red Globe' tratadas com cloreto de cálcio. Dissertação (Mestrado). Universidade Federal de Lavras, Lavras, 2006

CARVALHO, G. L.; LIMA, L. C. O.; SILVA, J. D.; SIQUEIRA, H. H.; MORAIS, E. C. Concentrações de cloreto de cálcio e tempos de armazenamento nos teores de açúcares redutores de uvas cv Red Globe (Vitis vinifera L.). Ciências e Agrotecnologia, Lavras, v. 32, n. 3, p. $894-899,2008$.

CBD (Secretariat of the Convention on Biological Diversity), citado por Rodriguez- Amaya, D. B.; Kimura, M.; Farfan- Amaya, J. em Fontes brasileiras de Composição de carotenoides em alimentos, n. 47. Disponível em: http://www.mma.gov.br/ estruturas/sbf_agrobio/ _publicacao/89_publicacao09032009113306.pdf> Acesso em 29/03/2013. 
CHAOVANALIKIT, A.; THOMPSON, M. M.; WROLSTAD, R. E. Characterization and quantification of anthocyanins and polyphenolics in blue honeysuckle (Lonicera caerulea L.). Journal of Agricultural and Food Chemistry, v. 52, n. 4, p. 848-852, 2004.

CHARRON, C. S; CLEVIDENCE, A. B.; BRITZ S. J.; NOVOTNY, J. A. Effect of Dose Size on Bioavailability of Acylated and Nonacylated Anthocyanins from Red Cabbage (Brassica oleracea L. Var. capitata). Journal of Agricultural and Food Chemistry, v. 55, p. 5354-5362, 2007.

CLERICI, M. T. P. S.; CARVALHO-SILVA, L. B. Nutritional bioactive compounds and technological aspects of minor fruits grown in Brazil. Food Research International, v.44, p.1658-1670, 2011.

COLLINS, C. H.; BRAGA, G.L.; BONATO, P.S. Fundamentos de Cromatografia. Campinas, SP: Editora da UNICAMP, 2006, 456 p.

COULTATE, T. P. Alimentos: a química de seus componentes. trad. FRAZZON, J. et al.,

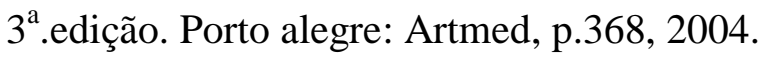

DEGÁSPARI C.H.; WASZCZYNSKYJ, N. Propriedades antioxidantes de compostos fenólicos. Visão Acadêmica, v.5, n.1, p.33-40, 2004.

DETONI, A. M.; CLEMENTE, E.; BRAGA, G. C.; HERZOG, N. F. M. Uva "Niágara Rosada" cultivada no sistema orgânico e armazenada em diferentes temperaturas. Ciências e Tecnologia de Alimentos, v. 25, n.3, p. 546-552, 2005.

DOWNHAM, A.; COLLINS, P. Colouring our foods in the last and next millennium. International Journal of Food Science Technology, v.35, n.1, p.5-22, 2000.

DYRBY, M.; WESTERGAARD, N.; STAPELFELDT, H. Light and heat sensitivity of red cabbage extract in soft drink model systems. Food Chemistry, v. 72, p. 431-437, 2001

EC - EUROPEAN UNION, Comission Regulation $n^{\circ}$ 401/2006, Laying down the methods of sampling and analysis for the official control of the levels of mycothoxins in foodstuffs. Jornal Oficial da União Européia, 2006.

EC - EUROPEAN UNION, Comission Regulation n $1881 / 2006$, Setting maximum levels for certain contaminants in foodstuffs. Jornal Oficial da União Européia, 2006.

EMBRAPA. Sistema de Produção de Uva de Mesa no Norte do Paraná. Embrapa Uva e Vinho: Sistema de Produção, versão Eletrônica (Dez/ 2005). Disponível em http://sistemasdeproducao.cnptia.embrapa.br/FontesHTML/Uva/MesaNorteParana/cultivare s.htm> Acesso em 23/03/2013. 
FALCÃO, L. D.; BARROS, D. M. GUACHE, C.; BORDIGNON, L. M. T. Copigmentação intra e intermolecular das antocianinas; uma revisão. Boletim Ceppa. v.21, n.2, p. 351-366, 2003.

FARIA, A. M., BOTTOLI, C. B. G., JARDIM, I. C. S. F.; COLLINS, C. H. Fases estacionárias monolíticas para separações cromatográficas. Química Nova. v. 29, n. 2 , p. 300-309, 2006.

FATEHI, M., SALEH, T. M., FATEHI-HASSANABAD, Z., FARROKHFAL, K., JAFARZADEH, M., DAVODI, S. A pharmacological study on Berberis vulgaris fruits extract. Journal of Ethnopharmacology. v.102, n.1, p. 46-52, 2005.

FAVARO, M. M. A. Extração, estabilidade e quantificaçãode antocianinas de frutas típicas brasileiras para aplicação industrial como corantes. Dissertação (Mestrado). Universidade Estadual de Campinas, 2008.

FRANCIS, F. J. Analysis of Anthocyanins. In: Anthocyanins as food colors. P. Markakis, P., ed; Academic Press: New York, 1982, p-182-205

FRANCK B., GEHRKEN H.P. Citreoviridins from Aspergillus terreus. Angew Chemistry Int Ed English., v. 19, n ${ }^{\text {0 }}$ 6, p.461-462, 1980.

FIGUEIREDO, P.; ELHABIRI, M.; SAITO, N.; BROUILLARD, R. Anthocyanin intramolecular interactions: a new mathematical approach to account for the remarkable colorant properties of the pigments extracted from Matthiola incana. Journal of Agricultural and Food Chemistry, v. 118, p. 4788-4793, 1996

FULEKI, T.; FRANCIS, F. J. Quantitative methods for anthocyanins. 1, Extraction and determination of total anthocyanin in Cranberries. Journal of Food Science. v.33, p. 72-77, 1968a.

FURLONG, E.B. et al. Aflatoxinas, ocratoxina A e zearalenona em alimentos da região sul do Rio Grande do Sul. Revista do Instituto Adolfo Lutz, São Paulo, v.58, n.2, p.105-111, 1999.

GALLORI, S.; BILIA, A.R.; BERGONZI, M.C.; BARBOSA, W.L.R., VINCIERI, F.F. Polyphenolic Constituents of Fruit Pulp of Euterpe oleraceae Mart. (Açai palm).

Cromatographia, v.59, n.11-12, p.739-743, 2004.

GALVANO, F. et al., Cyanidins: metabolismo and biological properties. J NutrBiochem, v. 15, n. 1, p. 2-11, 2004.

GASCHOVSKA, T., CASSADA, D., SUBBIAH, J., HANNA, M., THIPPAREDDI, H., SNOW, D. Enhanced anthocyanin extraction from red cabbage using pulsed electric field processing. Journal of Food Science. v. 75, n. 6, p. 323-329, 2010. 
GAVRILOVA, V.; KAJDŽANOSKA, M.; GJAMOVSKI, V.; STEFOVA, M. Separation, Characterization and Quantification of Phenolic Compounds in Blueberries and Red and Black Currants by HPLC-DAD-ESI-MS ${ }^{n}$. Journal of Agricultural and Food Chemistry, v. 59, p. 4009-4018, 2011.

GIUSTI, M. M.; WROLSTAD, R. E. Characterization of red radish anthocyanins. Journal of Food Science, v. 61, n. 2, p. 322-326, 1996.

GIUSTI, M. M.; RODRIGUES-SAONA, L.E; WROLSTAD, R. E. Molar Absortivity and Color Characteristics of Acylated and Nom-Acylated Pelargonidina-Based Anthocyanins. Journal Agriculture Food Chemistry. v. 47, p. 4631-4637, 1999.

GIUSTI, M. M.; WROSLTAD, E. R. Characterization and Measurement of Anthocyanins by UV-VISIBLE Spectroscopy. Current Protocols in Food Analytical Chemistry. New York: John Wiley \& Sons. Unit. F1.2.1-13, 2001.

GIUSTI, M. M.; WROLSTAD, R. E. Acylated anthocyanins from edible sources and their applications in food systems. Biochemical Engineering Journal. v. 14, n.3, p.217, 2003.

GOUVÊA, A. C. M. S.; ARAUJO, M. P. de; SHULZ, D. F.; PACHECO, S.; GODOY, R.L.O; CABRAL, L. M. C. Anthocyanins Standards ( cyanidin-3-O-glucoside and cyanidin3-O-rutenoside) isolation from freeze-dried açaí (Euterpe oleracea Mart.) by HPLC.

Ciências e Tecnologia de Alimentos,. v.32, n., p.1-4, 2012.

GUSEV, I.; HUANG, X.; HORVÁTH, C. Monolithic Chromatography and its Modern Applications. Disponível em: < Gusev, I.; Huang, X.; Horváth, C.; J. Chromatogr., A 1999, 855, 273> Acesso em 20/05/2013.

HARBONE, J. B. Comparative Biochemistry of the Flavonoids: Academic Press: London, 1967.

HARBONE, J. B. Phytochemical Methods- A guide to modern techniques plant analysis Chapman and Hallo New York $2^{\text {nd }}$ edition, 1984.

HRAZDINA, G., IREDALE, H., MATTICK, L.R. Anthocyanin composition of Brassica oleracea cv. Red Danish. Phytochemistry, v. 16, p. 297-299, 1977

HONG, X. V.; WROLSTAD, R.E. J. Use of HPLC Separation/Photodiode Array Detection for Characterization of Anthocyanins. Journal of Agricultural and Food Chemistry, v.38, n. 3, 1990.

HOU, Z.; QIN, P.; ZHANG, Z., CUI; Z. REN, G. Identification of anthocyanins isolated from black rice (Oryza sativa L.) and their degradation kinetics. Food Research International. 2011

HUSSEIN, H.S.; BRASEL, J.M. Toxicity, metabolism, and impact of mycotoxins on humans and animals. Toxicology, v.167, p.101-134, 2001. 
IACOBUCCI, G. A.; SWEENY, J. G. The chemistry of anthocyanins, anthocyanidins and related flavilium salts. Tetrahedron Letters, v. 39, n. 19, p. 3005-3038, 1983.

IRICEVOLTO, R. M. Aplicação de ácido naftalenoacético e cloreto de cálcio, na précolheita, para a conservação de uva 'Niagara Rosada'. Dissertação (Mestrado). Instituto Agronômico, Campinas, 2009.

JACKMAN, R. L.; YADA, R. Y.; TUNG, M. A.; SPEERS, R. A. anthocyanins as food colorants. Journal of Food Biochemistry. v. 11, p. 201-247, 1987.

JING, P.; ZHAO, S. J.; RUAN, S. Y.; SUI, Z. Q.; CHEN, L. H.; JIANG, L. L. Quantitative studies on structure-ORAC relationships of anthocyanins from eggplant and radish using 3D-QSAR. Food Chemistry, v. 145, p. 365-371, 2014.

JING, P.; QIAN, B.; ZHAO, S.; QI, X.; YE, L.; GIUSTI, M. M.; WAMG, X. Effect of glycosylation patterns of Chinese eggplant anthocyanins and other derivatives on antioxidant effectiveness in human colon cell lines. Food Chemistry, v. 172, p. 183-189, 2015.

JACKSON, R. Chemical constituents of grapes and winw. In: Wine Science. Principles and Applications. Food Science and Technology. $2^{a}$ edição. London: Academic Press, 2000, p.243.

JORDHEIM, M.; AABY, K.; FOSSEN, T.; SKREDE, G.; ANDERSEN, Ø. M. Molar Absorptivities and reducing capacity of pyranoanthocyanins and other anthocyanins. Journal Agriculture Food Chemistry. v. 55, p. 1091-10598, 2007.

KÄHKÖNEN, M. P.; HEINÄMÄKI, J.; OLLILAINEN, V.; HEINONEN, M. Berry anthocyanins: isolation, identification and antioxidant activitie. Journal of the Science of Food Agricultural, v. 83, p. 1403-1411, 2003.

KALEA, A. Z.; CLARK, K.; SCHUSCHKE, D. A.; KRISTO, A. S; KLIMIS-ZACAS, D. J. Dietary enrichment with wild blueberries (Vaccinium angustifolium) affects the vascular reactivity in the aorta of young spontaneously hypertensive rats. Journal of Nutritional Biochemistry, v. 21, p. 14-22, 2010.

KAY, C. D.; MAZZA, G.; HOLUB, J. B. Anthocyanins Exist in the circulation as metabolites in adult men. The Journal of Nutrition, p.2582-2588, 2005.

KUSKOSKI, E. M.; ASUERO, A. G.; GARCIA-PARILLA, M. C.; TRONCOSO, A. M.; FETT, R. Atividade antioxidante de pigmentos antociânicos. Ciência e Tecnologia de Alimentos, v. 24, n.4, p. 691-693, 2004.

KOBAYASHI, S.; ISHIMARU, M.; HIRAOKA, K.; HOND, C. Myb-related genes of the Kyoho grape (Vitis labruscana) regulate anthocyanin biosynthesis. Planta, v.215, p. 924933, 2002.Disponível em >http://download.bioon.com.cn/

upload/201101/16/132903paoox00 xaap lk181.attach.pdf> Acesso em 03/08/2014. 
KONG, J. M. Analysis and biological activities of anthocyanins. Phytochemistry, v. 64, p. 929-933, 2003.

KONG, J.-M., CHIA, L.-S., GOH, N.-K, CHIA, T.-F, BROUILLARD, R.Corrigendum to "Analysis and biological activities of anthocyanins".Phytochemistry, v. 69, p. 1039-1940, 2008.

LANÇAS, F. M. A Cromatografia Líquida Moderna e a Espectrometria de Massas: finalmente “compatíveis”? Scientia Chromatographica. v.1, n.2, p. 35- 61, 2009.

LANÇAS, F. M. O Renascimento das partículas superficialmente porosas ("core Shell particles") em HPLC. Scientia Chromatographica. v.2, n.2, p. 47- 54, 2010.

LANÇAS, F. M. Aumentando a eficiência das colunas de HPLC por meio da diminuição do diâmetro das partículas da fase estacionária: até onde? Scientia Chromatographica. v.3, n.1, p. 17- 23, 2011

LEITE-LEGATTI, A. V.; BATISTA, A. G.; DRAGANO, N. R. V.; MARQUES, A. C.; MALTA, L. G.; RICCIO, M. F.; EBERLIN, M. N.; MACHADO, A. R. T.; CARVALHOSILVA, L. B.; RUIZ, A. L. T. G.; CARVALHO, J. E.; PASTORE, G. M.; MARÓSTICA JÚNIOR, M. R. Jaboticaba peel: Antioxidant compounds, antiproliferative and antimutagenic activities. Food Research International, v. 49, p. 596-603, 2012.

LIMA, V. L. A. G.; PINHEIRO, I. O.; NASCIMENTO, M. S.; GOMES, P. B.; GUERRA, N. B. Identificação de antocianidinas em acerolas do banco ativo de germoplasma da Universidade Federal Rural de Pernambuco. Ciências e Tecnologia de Alimentos, v. 26, n.4, p. 927-935, 2006.

LOHACHOOMPOL, V.; MULHOLLAND, M.; SRZEDNICK, G.; CRASKE, J. Determination of anthocyanins in various cultivars of highbush and rabbiteye blueberries. Food Chemistry, v. 111, p. 249-254, 2008.

LONGO, L.; VASAPOLLO, G. Determination of anthocyanins in Ruscus aculeatus L. berries. Journal of Agricultural and Food Chemistry, v. 53, n. 2, p. 475-479, 2005.

MACZ-POP, G. A.; RIVAS-GONZALO, J. C.; PÉREZ-ALONSO, J. J.;

GONZALÉZPARAMÁS, A. M. Natural occurrence of free anthocyanin aglycones in beans (Phaseolus vulgaris L.). Food Chemistry. v.94, n.3, p. 448, 2006.

MALDENER, L.; JARDIM, I. C. S. F.; O estado da arte da cromatografia líquida de ultra eficiência. Quimica Nova, v. 32, n. 1, p. 214-222, 2009.

MARÇO, P. H.; POPPI, R. J. Procedimentos analíticos para identificação de antocianinas em extratos naturais. Química Nova. v.31, n. 5, p. 1218-1223, 2008. 
MARTÍNEZ-FLÓREZ, S.; GONZÁLEZ-GALLEGO, J.; CULEBRAS, J.M.; TUÑÓN, M.J. Los flavonoides: propriedades y acciones antioxidantes. Nutritional Hospital, v.17, n.6, p271-278, 2002.

MAZZA, G.; BROUILLARD, R.The mechanism of co-pigmentation of anthocyanins is aqueous. Phytochemistry. v. 29, p. 1097-1102, 1990.

MELETTI, L. M. M. Propagação de frutíferas tropicais. Guaíba: Agropecuária, p. 145-153, 2000.

MÜLLER, D.; SCHANTZ, M.; RICHLING, E. High Performance Liquid Chromatography Analysis of Anthocyanins in Bilberries (Vaccinium myrtillus L.), Blueberries (Vaccinium corymbosum L.), and Corresponding Juices. Journal of Food Science, v. 77, n. 4, p. 340$345,2012$.

NIJVELDT, R. J.; VAN-NOOD, E; VAN-HOORN, D. E.; BOELENS, P. G.; VANNORREN, K.; VAN-LEEUWEN, P. A. Flavonoids: a review of probable mechanisms of action and potencial applications. Americans Journal Clinical Nutritional. v.74, n.4, p. 418-425, 2001.

NICOUÉ, E. E.; SAVARD, S.; BELKACEMI, K. Anthocyanins in Wild Blueberries of Quebec: Extraction and Identification. Journal of Agriculture and Food Chemistry, v. 55, p. 5626-5635, 2007.

OLIVEIRA, J.; SILVA, M. A.; PAROLA, A. J.; MATEUS, N.; BRAS, N. F.; RAMOS; M. J. Structural characterization of a A-type linked trimeric anthocyanin derived pigment occurring in a young Port wine. Food Chemistry, v. 141, n. 3, p. 1987-1996, 2013.

POMAR, F.; NOVO, M.; MASA, A. Varietal differences among the anthocyanin profiles of 50 red table grape cultivars studied by high performance liquid chromatography. Journal of Chromatography A. v. 1094, p. 34-41, 2005.

PACHECO, S. Preparo de padrões analíticos, estudo de estabilidade e parâmetros de validação para ensaio de carotenoides por cromatografia líquida. Seroédica, 2009, RJ, 106p. Dissertação (Mestrado em Ciências dos Alimentos), Programa de Pós-Graduação em Ciências e Tecnologia de Alimentos, Universidade Federal Rural do Rio de Janeiro (UFRuralRJ).

PRIOR, R. L.; MARTIN, A.; CAO, G.; SOFIC, E.; McEWAN, J.; O’BRIEN, C.; LISCHNER, N.; EHLENFELDT, M.; KREWER, G.; MAINLAND, C. M. Antioxidant capacity as influenced by total phenolics and anthocyanin content, maturity and variety of Vaccinium species. Journal of Agriculture and Food Chemistry, v. 46, p. 2686-2693, 1998. 
PRIOR, R. L.; LAZARUS, S. A.; CAO, G.; MUCCITELL, H.; HAMMERSTONE, J. F. Identification of Procyanidins and Anthocyanins in Blueberries and Cranberries (Vaccinium Spp.) Using High-Performance Liquid Chromatography/Mass Spectrometry. Journal of Agricultural and Food Chemistry, v. 49, p. 1270-1276, 2001.

PUÉRTOLAS, E.; CREGENZÁN, O.; LUENGO, E., ÁLVAREZ, I., RASO, J. Pulsedelectric-field-assisted extraction of anthocyanins from purple-fleshed potato. Food Chemistry. v.136, p. 1330-1336, 2013.

REVILLA, E.; RYAN, J. M., ORTEGA, G. M. Comparison of several procedures used for the extraction of anthocyanins from red grape. Journal of Agriculture and Food Chemistry. v.46, p. 4592-4597, 1989.

REVILLA, E.; RYAN, J. M., ORTEGA, G. M. Microwave assisted extraction of anthocyanins from grape skins. Journal of Agriculture and Food Chemistry. v. 46, p.4592-4597. 1998.

ROSSO, V.V.; HILLEBRAND, S.; MONTILLA, E.C.; BOBBIO, F.O.; WINTERHALTER, P.; MERCADANTE, A.Z. Determination of anthocyanins from acerola (Malpighia emarginata DC.) and açai (Euterpe oleracea Mart.) by HPLC- PDA-MS/MS. Journal of Food Composition and Analysis, v.21, n.4, p.291-299. 2008.

RUFINO, M. S. M.; ALVES, R. E.; BRITO, E. S.; MORAIS, S. M.; SAMPAIO, C. G; PÉREZ-JIMÉNEZ, J; SAURACALIXTO, F. D. Determinação da atividade antioxidante total em frutas pela captura do radical livre ABTS+. Fortaleza: Embrapa Agroindústria Tropical, 2007 (Comunicado técnico, 128, ISSN 1679-6535).

RUFINO, M. S. M.; ALVES, R. E.; BRITO, E. S.; MORAIS, S. M.; PÉREZ-JIMÉNEZ, J; SAURA-CALIXTO, F. D.; MANCINI-FILHO, J. Bioactive compounds and antioxidant capacities of 18 non-traditional tropical fruits from Brazil. Food Chemistry, v. 121, p.996 $1002,2010$.

SAKAMURA, S.; WATANABE, S.; OBATA, Y. The structure of the major anthocyanin in eggplant. Agricultural and Biological Chemistry, v. 27, p. 663-665, 1963.

SANTIAGO, M. C. P. A.; GOUVÊA, A.C.M.S.; GODOY, R. L. O.; OIANO-NETO, J.; PACHECO, S.; ROSA, J. S. Adaptação de um método por cromatografia líquida de alta eficiência para análise de antocianinas em suco de açaí (Euterpe oleraceae Mart.). Rio de Janeiro: Embrapa Agroindústria de Alimentos, 2010 (Comunicado técnico, 162. Biblioteca: CTAA (FL CTE 0162 UMT).

SANTOS, D. T.; VEGGI, P. C.; MEIRELES, M. A. A. Extraction of antioxidant compounds from jabuticaba (Myrciaria cauliflora) skins: Yield, composition and economical evaluation. Journal of Food Engineering, v. 11, p. 23-31, 2010. 
SCHULZ, F. D. Avaliação da utilização da Cromatografia Líquida de Ultra Eficiência acoplada à espectrometria de massas de Alta Resolução como ferramenta para análise de alimentos. Rio de Janeiro, 2014, RJ, 179 p. Tese (Doutor em Ciências ), Instituto de Química, Programa de Pós-Graduação em Química, Universidade Federal do Rio de Janeiro (UFRJ).

SILVA, F. L.; PASCUAL-TERESA, S.; RIVAS-GONZALO, J.; SANTOS-BUELGA, C. Identification of anthocyanin pigments in strawberry (cv Camarosa) by LC using DAD and ESI-MS detection. Eur Food Res Technol, v. 214, p. 248-253, 2002.

SILVA, R. B.; COLLINS, K. E.; BOTTOLI, C. B. G. Cromatografia líquida capilar: estado da arte e aplicações. Quimica Nova, v. 34, n. 5, p. 841-849, 2011.

SILVA, M. G. C. P.; BARRETO, W. S.; SÊRODIO, M. H. Comparação nutricional da polpa dos frutos de juçara e de açaí. Artigo Técnico. Disponível em:<www.ceplac.gov. br/mapahtm. Acessoem: 17 de maio de 2013.

SILVERTEIN, R. M.; WEBSTER, F. X. Identificação Espectrométrica de Compostos Orgânicos. $6^{\text {a }}$ edição. Rio de Janeiro, RJ: LTC- Livros Técnicos e Científicos Editora S.A., 460 págs. 2000.

SHAUGHNESSY, K. S.; BOSWALL, I. A.; SCANLAN, A. P.; GOTTSCHALL-PASS, K. T.; SWEENEY, M. I. Diets containing blueberry extract lower blood pressure in spontaneously hypertensive stroke-prone rat. Nutrition Research, v. 29 p. 130-138, 2009.

SHENOY, V.R. Anthocyanins: Prospective food coulors. Current Science, v .64, n. 8, 1993.

SKREDE, G., WROLSTAD, R.E., DURST, R.W. Changes in Anthocyanins and Polyphenolics during juice processing of highbush blueberries (Vaccinium corymnbosum L.). Journal of Food Science, v. 65, n. 2, p. 357-364, 2000.

SKOOG, D. A.: HOLLER, F.J.; NIEMAN, T.A. Principles of instrumental analysis. 5 ed. Fort Worth: Saunders College Publishing, 849 p., 1997.

STEIMER, S.; SJÖBRG, J. R. Anthocyanin characterization utilizing Liquid Chromatography combined with advanced Mass Spectrometric Detection. Journal of Agricultural and Food Chemistry, v.59, p. 2988-2996, 2011

STRACK, D.; WRAY, V. Anthocyanins, In:" Methods in plant biochemistry". P.M Dey, J. B. Harborne (Eds.), Academic Press, New York, p. 325-356, 1989.

STRINGHETA, P.C.; BOBBIO, P.A. Copigmentação de Antocianinas. In: Uso de corantes naturais em alimentos processados. Disponível em: $<$ www.biotecnologia.com.br/revista/ bio14/copigment.pdf>. Acesso em: 12 jul.2012. 
TERCI, D. B. L. Aspectos analíticos e didáticos de antocianinas extraídas de frutas. Campinas, 2004, 223p. Tese (Doutora em Química Analítica), Instituto de Química, Universidade Estadual de Campinas (UNICAMP).

TÜRKER, N.; ERDOGDU, F. Effects of $\mathrm{pH}$ and temperature of extraction medium on effective diffusion coefficient of anthocyanin pigments of black carrot (Daucus carota var.L.). Journal of Food Engineering. v. 76, n. 4, p. 579, 2006.

VASCO, C., RUALES, J., KAMAL-ELDIN, A. Total phenolic compounds and antioxidant capacities of major fruits from Ecuador. Food Chemistry, v.111, n.4, p. 816-823, 2008.

VEER, P., JANSEN, M. C. J. F., KLERK, M., KOK, F. J. Fruits and vegetables in the prevention of cancer and cardiovascular disease. Public Health Nutrition, v.3, n.1, p.103$107,2000$.

VENDRAMINI, A. L. A.; TRUGO, L. C. Phenolic compounds in acerola fruit (Malpighia punicifolia, L.). Journal of the Brazilian Chemical Society, v. 15, n. 5, p. 664-668, 2004.

XAVIER, M. F. Estudo da extração de antocianinas em colunas recheadas. Florianópolis, SC, 2004, 120 p. Dissertação (Mestrado em Engenharia Química), Departamento de Engenharia Química, Universidade Federal de Santa Catarina (UFSC).

WANGE, E.; YINA, Y.; XU, C.; LIUB, J. Isolation of high-purity anthocyanin mixtures and monomers from blueberries using combined chromatographic techniques. Journal of Chromatography A, v. 1327, p. 39-48, 2014.

WATERS. Waters Synapt Mass Spectrometry System Operator's Guide. 2008.

WOLFE, K. L.; KANG, X.; HE, X.; DONG, M.; ZHANG, Q.; LIU, R. H. Cellular antioxidant activity of common fruits. Journal of Agricultural and Food Chemistry, v.56, n.18, p. 8418-8426, 2008.

WU, X.; PRIOR, R. L. Systematic Identification and Characterization of Anthocyanins by HPLC-ESI-MS/MS in Common Foods in the United States: Fruits and Berries. Journal of Agriculture and Food Chemistry. v., p. 2589-2599, 2005, a.

WU, X.; PRIOR, R. L. Identification and Characterization of Anthocyanins by HighPerformance Liquid Chromatography-Electrospray Ionization-Tandem Mass Spectrometry in Common Foods the United States: Vegetables, Nuts, and Grains. Journal Agricultural and Food Chemistry. v. 53, p. 3101-3113, 2005, b.

YOUSEF, G. G.; BROWN, A. F.; FUNAKOSHI, Y.; MBEUNKUI, F.; GRACE, M. H; BALLINGTON, J. R.; LORAINE, A.; LILA, M. A. Efficient Quantification of the HealthRelevant Anthocyanin and Phenolic Acid Profiles in Commercial Cultivars and Breeding Selections of Blueberries (Vaccinium spp.). Journal of Agricultural and Food Chemistry, v.61, p. 4806-4815, 2013. 


\title{
7 APÊNDICE
}

7.1 Apêndice A- (20th International Congress of Nutrition, Granada, Espanha)

\section{EVALUATION OF ANTHOCYANIN PROFILE IN APPLE PEEL OF THREE CULTIVARS PRODUCED IN BRAZIL}

\author{
Ana Cristina Miranda Senna Gouvêa ${ }^{1}$, Manuela Cristina Pessanha de Araujo \\ Santiago $^{2}$, Ronoel Luiz de Oliveira Godoy ${ }^{2}$, Renata Galhardo Borguini ${ }^{2}$, Sidney \\ Pacheco $^{2}$, Luzimar da Silva de Mattos do Nascimento ${ }^{2}$ \\ ${ }^{1}$ Program of Post Graduate Food Science and Technology, Rural Federal University of \\ Rio de Janeiro, Brazil \\ ${ }^{2}$ Embrapa Food Technology, Rio de Janeiro, Brazil
}

The annual apple production in Brazil has remained around one million tonnes/year. In the processing industry of fruit juices, apple juice is considered one of the main products. This juice production generates 25 to $30 \%$ of waste (bagasse: peel, pulp and seed) which has aroused the interest of the scientific community, aiming its use for the obtaining of new products from these residues. The peel is the part of the residue with the higher concentration of pectin and flavonoids, such as anthocyanin, being its antioxidant activity responsible for reducing the risk of cardiovascular diseases and chronic diseases such as cancer. The objective of this study was to compare the anthocyanin profile in apple peel of three cultivars produced in Brazil. The cultivars Gala, Fuji and Red Delicius were obtained in local market in the municipality of Rio de Janeiro, Brazil. The apple peels anthocyanins were extracted with acidified methanol solution. Chromatography analysis was performed on a Waters ${ }^{\circledR}$ Alliance 2695 system, with a Waters ${ }^{\circledR} 2996$ photodiode array detector, Thermo ${ }^{\circledR}$ Scientific C18 BDS $(100 \mathrm{~mm} \times 4.6 \mathrm{~mm} ; 2.4 \mu \mathrm{m})$ column and gradient elution method with acetonitrile and formic acid. It was observed the same anthocyanin profile among cultivars. The majoritary anthocyanin detect (Figure 1) was cyanidin-3-galactoside (corresponding to $88 \%$ of total anthocyanin content in the evaluated matrix). This anthocyanin, compared to others present in food, has one of the highest antioxidant activity. Therefore, the three apple cultivars can be considered a source of anthocyanin, being wasted each year by juice industry in large quantities, while could be used, for example, as a food ingredient with antioxidant properties. It could also allow the fruit sector to diversify its production and increase income.

Keywords: Antioxidant, flavonoids, residues. 
7.2 -Apêndice B- (VII Encontro Nacional de Cromatografia - SPQ/Porto, Portugal)

\title{
Identification of jambo (Syzygium malaccense L.) major anthocyanin by LC-MS-MS
}

\author{
$\underline{\text { Ana C. M. S. Gouvêa }}^{a}$, Daniel F. Schulz ${ }^{b}$, Manuela C. P. A. Santiago ${ }^{c}$, Ronoel L. O. \\ Godoy $^{c}$, Sidney Pacheco ${ }^{c}$, Jeane S. Rosa ${ }^{c}$ \\ ${ }^{a}$ Rural Federal University of Rio de Janeiro, Seropédica, Rio de Janeiro 23890-000 Brazil, \\ ${ }^{b}$ Chemistry Institute, Federal University of Rio de Janeiro, Rio de Janeiro 21949-900 Brazil, \\ ${ }^{c}$ Embrapa Food Technology, Av. das Américas, 29501 Rio de Janeiro 23020-470 Brazil. \\ acristinagouvea@hotmail.com
}

Anthocyanins are natural pigments from the flavonoid class that are responsible for the red, purple and blue colors of fruits and vegetables. Increased attention has been given to those compounds due their possible health benefits in preventing several diseases such as heart disease and cancer. For this reason, many studies have been done with specific fruits to evaluate if they are a good source of anthocyanins. The objective of this study was to identify the major anthocyanin of jambo (Syzygium malaccense L.) using an ultra performance liquid chromatographic (UPLC) system Waters Acquity® equipped with high resolution mass spectrometer Waters Synapt ${ }^{\circledR}$ ESI-qTOF. The chromatographic profile of anthocyanins present in jambo fruit was first obtained by the technique of high performance liquid chromatography (HPLC). HPLC was performed on a Waters ${ }^{\circledR}$ Alliance 2695 system, with a Waters ${ }^{\circledR} 2996$ photodiode array detector (PDA). The used column was a Symmetry ${ }^{\circledR}$ $\mathrm{C}_{18}(150 \mathrm{~mm} \times 4.6 ; 3.5 \mu \mathrm{m})$ and the mobile phase consisted of $10 \%$ aqueous formic acid and methanol. UPLC was performed on a Waters ${ }^{\circledR}$ Acquity system, with a Waters ${ }^{\circledR}$ Acquity UPLC BEH C18 column $(2.1 \times 150 \mathrm{~mm} ; 1.7 \mu \mathrm{m})$. The mobile phase consisted of acidified water and methanol. The MS high resolution system has an orthogonal quadrupole (t-wave ${ }^{\circledR}$ ) and a time of flight (TOF) analyser capable to $\mathrm{V}$ or $\mathrm{W}$ configuration. This equipment can produce accurate mass information, wich is a reliable tool to mass differentiation. The source was positive electrospray (ESI), and the following conditions were used: source temperature at $120^{\circ} \mathrm{C}$, desolvatation gas $\left(\mathrm{N}_{2}\right)$ at $12.5 \mathrm{~L} / \mathrm{min}$ and $500^{\circ} \mathrm{C}$, capillary exit set at $3.0 \mathrm{kV}$, sampling cone energy set at $25.0 \mathrm{~V}$ and extraction cone energy set at $4.0 \mathrm{~V}$. The major anthocyanin identification, cyanidin-3-O-glucoside, was based on data obtained by mass spectrometry for molecular ion and on its fragments. It was obtained a molecular ion at $\mathrm{m} / \mathrm{z}$ $=449.1092$, which is the molecular weight of the anthocyanin cyanidin-3-O-glucoside, and a $\mathrm{m} / \mathrm{z}=287.0498$ by MS-MS, which equals the molecular weight of the aglycone cyanidin. 
7.3 -Apêndice C- (III Conferência do Instituto Nacionais de Ciência e Tecnologia de Frutos Tropicais, Aracaju, Alagoas)

\section{Identificação das antocianinas majoritárias na casca de uva tinta sem semente utilizando CLUE-ESI-EM/EM}

Ana Cristina Miranda Senna Gouvêa ${ }^{1}$, Ronoel Luiz de Oliveira Godoy ${ }^{2}$, Manuela Cristina Pessanha de Araujo Santiago $^{2}, \underline{\text { Renata Galhardo Borguini }}^{2}$ e Sidney Pacheco ${ }^{2}$

1. Doutoranda em Ciência e Tecnologia de Alimentos/ DTA

Universidade Federal Rural do Rio de Janeiro

23890-000 - Seropédica - RJ; Brasil

acristinagouvea@hotmail.com

2. Laboratório de Cromatografia Líquida

Embrapa Agroindústria de Alimentos

23020-470 - Rio de Janeiro - RJ; Brasil

Palavras chave: cianidina, delfinidina, malvidina, peonidina, petunidina

\section{RESUMO}

As antocianinas, flavonoides com intensa atividade antioxidante, são os pigmentos responsáveis pela coloração na casca de vários tipos de uvas com tonalidade escura (uvas tintas). A concentração e a variedade dos tipos de antocianinas é que determinam a intensidade da coloração dos vários cultivares. Este trabalho teve como objetivo caracterizar e identificar as antocianinas majoritárias presentes na casca da uva tinta sem sementes, proveniente do Chile. A extração das antocianinas da casca do fruto foi realizada com solução de metanol acidificado, sendo a amostra submetida às etapas de sonificação e centrifugação. No desenvolvimento da análise cromatográfica, utilizou-se sistema Acquity da Waters ${ }^{\circledR}$ composto por um Cromatógrafo Líquido de Ultra Eficiência (CLUE), com coluna $\mathrm{C}_{18}(2,1 \times 150 \mathrm{~mm} ; 1,7 \mathrm{~mm})$ Acquity CLUE $\mathrm{BEH}$, modo de eluição gradiente com solvente A (ácido fórmico $0,1 \%$ ) e solvente B (acetonitrila), volume de injeção $1 \mu \mathrm{L}$, fluxo $0,35 \mathrm{~mL} / \mathrm{min}$ e temperatura da coluna de $45^{\circ} \mathrm{C}$. O sistema também é composto por analisador de massas de alta resolução Q-TOF com tempo de voo em modo V, fonte de ionização electrosspray modo positivo $\left(\mathrm{ESI}^{+}\right)$com as seguintes condições: temperatura da fonte igual a $120^{\circ} \mathrm{C}$, gás de secagem $\mathrm{N}_{2}$ a $500^{\circ} \mathrm{C}$, energia do capilar $3,0 \mathrm{kV}$, cone fixado em $25,0 \mathrm{~V}$ e energia de colisão de 8,0V. A identificação dos picos de maiores concentrações foi feita com base em dados existentes na literatura e pela comprovação através das suas respectivas massas moleculares exatas. Portanto, foi possível comprovar a presença das antocianinas delfinidina-3-glicosídeo, cianidina-3-glicosídeo, petunidina-3-glicosídeo, peonidina-3glicosídeo e malvidina-3-glicosídeo, cujos íons precursores e seus fragmentos que correspondem à perda de uma massa de 162Da (hexose) liberando suas agliconas são, respectivamente: $\mathrm{m} / \mathrm{z}$ 465,1036 e $\mathrm{m} / \mathrm{z}, 303,0526 ; \mathrm{m} / \mathrm{z}$ 449,1129 e $\mathrm{m} / \mathrm{z}, 287,0636 ; \mathrm{m} / \mathrm{z}, 479,1280$ e $\mathrm{m} / \mathrm{z}$ 317,0826; $\mathrm{m} / \mathrm{z}$ 463,1330 e m/z 301,0861; $\mathrm{m} / \mathrm{z}$ 493,1404 e $\mathrm{m} / \mathrm{z}$ 331,0959. Desse modo, pode-se identificar de maneira inequívoca o perfil das antocianinas presentes na matriz. 
7.4- Apêndice D (VII Fórum de Pós-Graduação da UFRRJ, Seropédica, Rio de Janeiro)

Caracterização de antocianinas por CLAE e identificação por espectrometria de massa de alta resolução (Q-TOF) em seis frutos de fácil acesso para uso como fonte de padrões analíticos

\section{Ana Cristina Miranda Senna Gouvêa ${ }^{1}$ \& Ronoel Luiz de Oliveira Godoy ${ }^{2}$}

1. Doutoranda do Programa de Pós-Graduação em Ciência e Tecnologia de Alimentos, e-mail: acristinagouvea@hotmail.com; 2. Embrapa Agroindústria de Alimentos - RJ, Brasil

\section{RESUMO}

Palavras Chaves: antocianinas; padrões; cromatografia; espectrômetro de massas.

A identificação de antocianinas por meio de CLAE é uma técnica muito eficiente, mas há necessidade de uso de padrões analíticos para sua identificação e quantificação. Devido à grande diversidade de substituintes em sua estrutura, o desafio está em encontrar disponíveis comercialmente padrões de referência desses diversos compostos. O referente trabalho teve como objetivo avaliar matrizes de fácil acesso, caracterizar seu perfil antociânico através da técnica de Cromatografia Líquida de Alta Eficiência e identificá-las utilizando a Espectrometria de Massa de Alta Resolução. Para tal, foram avaliadas seis matrizes: fruto da amendoeira; amora; casca de maçã; morango; jabuticaba e jamelão. A extração das antocianinas nos frutos foi realizada com solução de metanol acidificado, onde as amostras passaram por etapas de sonificação e centrifugação. A análise cromatográfica foi realizada em Cromatógrafo Líquido de Alta Eficiência acoplado ao detector de arranjo de fotodiodos, coluna $\mathrm{C}_{18}(100 \mathrm{~mm} \times 4,6 \mathrm{~mm} ; 2,4 \mu \mathrm{m})$, fluxo de $1,0 \mathrm{~mL} / \mathrm{min}$ e modo de eluição gradiente com acetonitrila e ácido fórmico. Para confirmação das antocianinas nas matrizes utilizou-se o espectrômetro de massa de alta resolução Waters Synapt ${ }^{\circledR}$ Q-ToF, com fonte de ionização no modo electrospray positivo (ESI+), tempo de voo $\mathrm{V}$, com as seguintes condições: temperatura da fonte igual a $120^{\circ} \mathrm{C}$, gás de dissolvatação $\mathrm{N}_{2}$ a $500^{\circ} \mathrm{C}$, energia do capilar $3,0 \mathrm{kV}$, cone fixado em $25,0 \mathrm{~V}$ e energia de colisão de $8,0 \mathrm{~V}$. Os perfis cromatográficos e os espectros de absorção (UV) das antocianinas foram comparados com dados na literatura, assim como, suas identificações foram realizadas através das suas respectivas massas moleculares exatas. Portanto, foi possível comprovar que as seis matrizes analisadas são promissoras fontes de padrões de referência, devido ao perfil cromatográfico apresentado.

Agência Financiadora: CNPq 
7.5-Apêndice E (Higiene Alimentar, v.27, n. 218-219, 2013)

\title{
AVALIAÇÃO DE FONTES NATURAIS DE ANTOCIANINAS PARA USO COMO PADRÕES PARA ANÁLISE EM FRUTOS VERMELHOS E SEUS PRODUTOS
}

\author{
Ana Cristina Miranda Senna GOUVÊA ${ }^{1^{\circ}}$; Manuela Cristina Pessanha de Araujo \\ SANTIAGO $^{2^{\circ}}$; Luciana Mouta de OLIVEIRA ${ }^{3^{\circ}}$; Ronoel Luiz de Oliveira GODOY ${ }^{2^{\circ}}$; \\ Fernanda Marques PEIXOTO ${ }^{3^{\circ}}$; Sidney PACHECO $^{2^{\circ}}$; Renata Galhardo BORGUINI ${ }^{2^{\circ}}$
}

\author{
1Universidade Federal Rural do Rio de Janeiro-e-mail: acristinagouvea@hotmail.com \\ ${ }^{2}$ Embrapa Agroindústria de Alimentos - RJ, Brasil \\ ${ }^{3}$ Centro Universitário Estadual da Zona Oeste (UEZO)
}

\section{INTRODUÇÃO}

As antocianinas, pigmentos hidrossolúveis, presentes em alimentos de origem vegetal, apresentam efeitos bioativos que estão relacionados ao poder antioxidante proporcionado. Sendo assim, vários trabalhos literários vêm relatando a importância do seu desempenho na redução ao risco de doenças: cardiovasculares; do sistema imunológico; do câncer e sua progressão (VOLP et al., 2008, WAN et al. 1999). Nos últimos anos, o grande interesse por alimentos naturais, saudáveis e que possam trazer consigo a proposta de atuar como coadjuvante na prevenção de doenças crônicas tem impulsionado o meio científico a identificar e quantificar os seus princípios ativos.

Para as análises de identificação e quantificação de antocianinas por Cromatografia Líquida de Alta Eficiência (CLAE), há necessidade de uso de padrões analíticos, mas, devido à grande diversidade de substituintes em sua estrutura, o desafio está em encontrar disponíveis comercialmente padrões de referência desses diversos compostos. Neste contexto, a obtenção destes padrões a partir de fontes naturais (PACHECO et al.,2013; GOUVÊA et al., 2012) poderá viabilizar a determinação, de forma mais precisa, as concentrações existentes dessas substâncias em alimentos que estejam na forma natural ou processados.

Este trabalho teve como objetivo analisar matrizes que possam servir de fontes para obtenção de padrões antociânicos, utilizando a técnica de cromatografia líquida de alta eficiência para seu isolamento. Assim sendo, esse fato, possibilitará a realização de análises cromatográficas que possam identificar e quantificar o teor de antocianinas, capacitando-a como ferramenta para avaliação da qualidade dos produtos.

\section{MATERIAL E MÉTODOS}

O presente trabalho foi realizado no laboratório de Cromatografia Líquida da Embrapa Agroindústria de Alimentos, Rio de Janeiro. Foram avaliadas as antocianinas em seis potenciais fontes para obtenção dos padrões: casca de maçã (Malus doméstica, cultivar "Fuji"), berinjela (Solanum melongena); mangostin (Garcinia mangostana L.) e uva preta chilena; fruto da amendoeira (Terminalia catappa) e morango (Fragaria spp.). Todos os solventes utilizados eram da Marca Tédia® grau CLAE, para extração e análise cromatográfica, e grau Massa para as análises no espectrômetro de massa. 
As extrações das antocianinas nas respectivas cascas dos frutos e nos frutos foram realizadas com solução de metanol acidificado, onde as amostras foram trituradas, logo em seguida, passaram por etapas de sonificação e centrifugação seguindo a metodologia proposta por Santiago et al. (2010). As análises cromatográficas foram realizadas em Cromatógrafo Líquido de Alta Eficiência (CLAE) acoplado ao detetor de arranjo de fotodiodos (DAD), coluna $\mathrm{C}_{\mathbf{1 8}}(100 \mathrm{~mm} \times 4,6 \mathrm{~mm} ; 2,4 \mu \mathrm{m})$, fluxo de $1,0 \mathrm{~mL} / \mathrm{min}$, temperatura da coluna de $40^{\circ} \mathrm{C}$ e modo de eluição gradiente com acetonitrila e ácido fórmico (GOUVÊA \& GODOY, 2011).

Alguns perfis cromatográficos e os espectros de absorção na região UV-Vis das antocianinas foram comparados com dados na literatura, somando-se a esses dados, suas identificações foram confirmadas através das suas respectivas massas moleculares exatas (EM/EM), utilizando como ferramenta o espectrômetro de massa de alta resolução Waters Synapt ${ }^{\circledR}$ Q-ToF, com fonte de ionização no modo electrospray positivo (ESI+), tempo de voo $\mathrm{V}$, com as seguintes condições: temperatura da fonte igual a $120^{\circ} \mathrm{C}$, gás de dissolvatação $\mathrm{N}_{2}$ a $500^{\circ} \mathrm{C}$, energia do capilar $3,0 \mathrm{kV}$, cone fixado em $25,0 \mathrm{~V}$ e energia de colisão de $8,0 \mathrm{~V}$.

\section{RESULTADOS E DISCUSSÃO}

Os perfis cromatográficos obtidos podem ser observados na Figura 1. A caracterização e a identificação das antocianinas nas matrizes estão relatadas no Quadro 1.
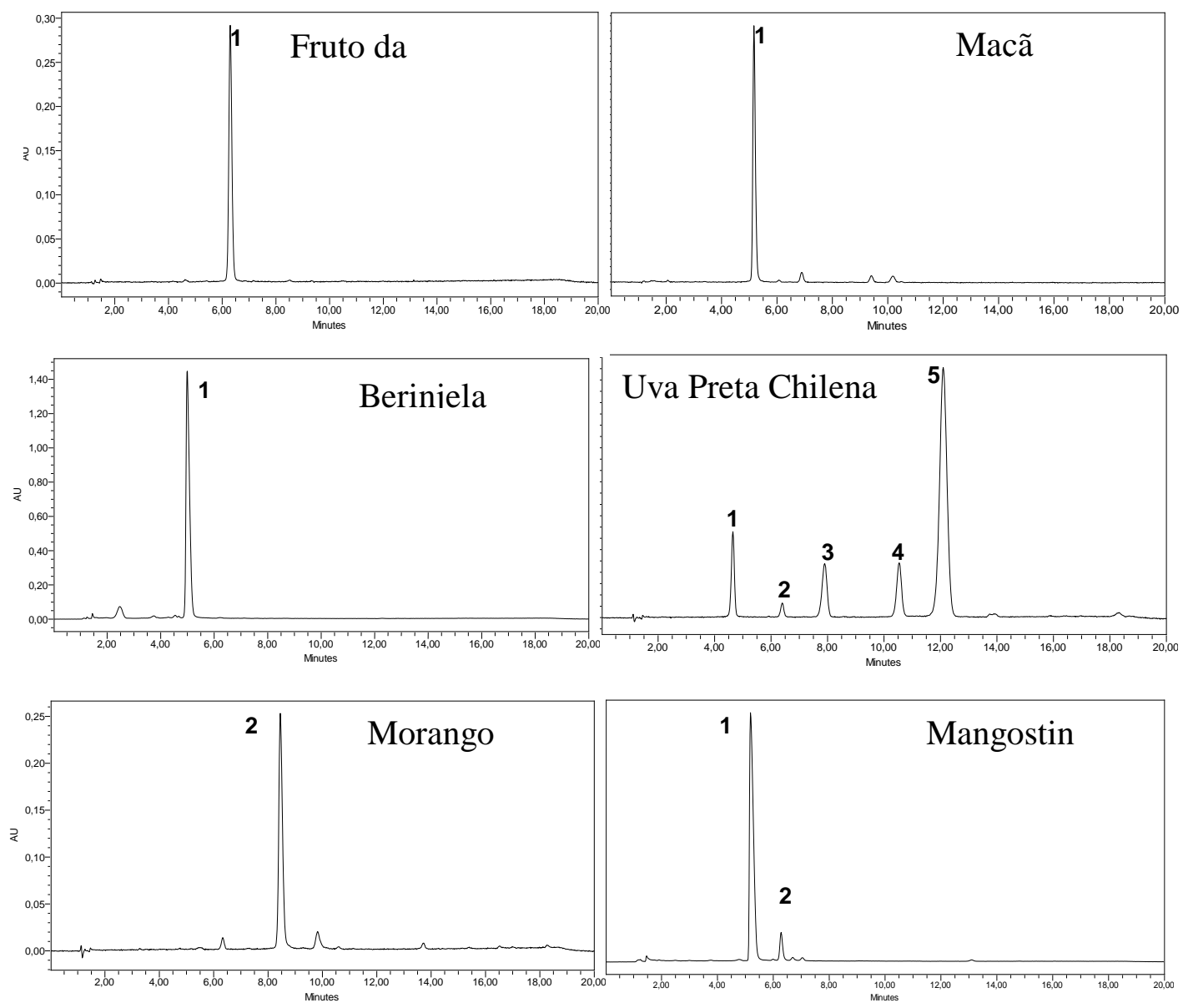
Figura 1: Perfil cromatográfico dos extratos metanólicos: fruto da amendoeira; casca da maçã; casca de berinjela; casca da uva preta Chilena; casca do mangostin e morango (picos numerados estão identificados no Quadro 1).

A numeração realizada foi referente aos analitos que puderam ser identificados pelo presente trabalho. Os que apresentaram concentração muito baixa, não entraram neste estudo, a não ser os que já apresentavam informações na literatura associado à análise espectrométrica (EM/EM).

Tabela 1: Apresenta as massas moleculares das seis antocianinas mais comumente encontradas em alimentos e dos açúcares encontrados nas amostras estudadas.

\begin{tabular}{ccc}
\hline Substâncias & MW & MW- H2O \\
\hline \multicolumn{3}{c}{ Antocianidinas } \\
pelargonidina & 271 & \\
cianidina & 287 & \\
peonidina & 301 & \\
petunidina & 317 & \\
delfinidina & 303 & \\
malvidina & 331 & \\
& Açúcares & \\
Galactose & 180 & 162 \\
Glicose & 180 & 162 \\
Rutinose & 326 & 308 \\
\hline
\end{tabular}

Quadro 1: Identificação das antocianinas numeradas nas amostras.

\begin{tabular}{|c|c|c|c|c|c|c|}
\hline Matriz & Pico & $\lambda(\mathbf{n m})^{\mathrm{a}}$ & $\begin{array}{c}t_{R} \\
\text { (min) }\end{array}$ & {$[\mathrm{M}]^{+}(\mathrm{m} / \mathrm{z})$} & $\begin{array}{c}\mathrm{EM} / \mathrm{EM} \\
(\mathrm{m} / \mathrm{z})\end{array}$ & Antocianina \\
\hline $\begin{array}{c}\text { Fruto da } \\
\text { amendoeira }\end{array}$ & 1 & $279 / 328 /, 515$ & 6,25 & 449,1083 & 287,0556 & Cy-3-Glicosídeo \\
\hline Maçã ${ }^{*}$ & 1 & $279 / 514$ & 5,38 & 449,1112 & 287,0508 & Cy -3-Galactosídeo \\
\hline Berinjela* & 1 & $277 / 343 / 525$ & 5,12 & 611,1616 & $465,1037 / 303,0500$ & Dp-3-Rutenosídeo \\
\hline \multirow{5}{*}{$\begin{array}{l}\text { Uva Preta } \\
\text { Chilena }\end{array}$} & 1 & $271 / 347 / 522$ & 4,27 & 465,1078 & 303,0616 & Dp-3-Glicosídeo \\
\hline & 2 & $279 / 362 / 515$ & 6,21 & 449,1083 & 287,0556 & Cy -3-Glicosídeo \\
\hline & 3 & $270 / 348 / 524$ & 7,89 & 479,1168 & 317,0746 & Pt-3-Glicosídeo \\
\hline & 4 & $279 / 330 / 517$ & 10,29 & 463,1248 & 301,0714 & Pn-3-Glicosídeo \\
\hline & 5 & $277 / 347 / 526$ & 12,04 & 493,1349 & 331,0864 & Mv-3-Glicosídeo \\
\hline Morango* & 2 & $267 / 328 / 431 / 501$ & 8,09 & 433,1156 & 271,061 & Pg-3-Glicosídeo \\
\hline \multirow[t]{2}{*}{ Mangostin* } & 1 & $279 / 330 / 512$ & 5,32 & 611,2424 & 287,0508 & Cy-3-Diglicosídeo \\
\hline & 2 & $279 / 328 / 515$ & 6,25 & 449,1001 & 287,0507 & Cy -3-Glicosídeo \\
\hline
\end{tabular}

${ }^{\text {a }}$ Solvente Fase móvel da análise cromatográfica (ácido fórmico 5\%: metanol 10\% / água Milli-Q®)

*Identificados somente os picos majoritários ou relatados na literatura.

$\mathrm{Dp}=$ delfinidina, $\mathrm{Cy}=$ cianidina, $\mathrm{Pg}=$ pelargonidina, $\mathrm{Pt}=$ petunidina, $\mathrm{Pn}=$ peonidina $\mathrm{e} \mathrm{Mv}=\mathrm{Malvidina}$

Dentre as amostras analisadas, a amostra do fruto da amendoeira sobressaiu em relação às outras, pois, apresentou uma pureza acima de 99\% para seu pico majoritário. O 
espectro de UV-visivel mostrou $\lambda_{\text {máx a }} 279,5$ e $515,3 \mathrm{~nm}$ característicos de derivados de cianidina ou peonidina. Seu íon molecular $[\mathrm{M}]^{+}$apresentou $\mathrm{m} / z$ 449,1083 e transição do $\mathrm{EM} / \mathrm{EM}$ a $\mathrm{m} / z$ 287,0556 que corresponde à massa molecular da aglicona cianidina devido à perda de uma hexose (162Da). A antocianidina cianidina também foi identificada no pico majoritário (pico 1) do cromatograma da amostra de casca de maçã, apresentando o mesmo valor de perda no EM/EM (162 Da). A diferença entre essas duas substâncias foi baseada nos seus $t_{R}, 6,25$ e 5,28 minutos, a configuração da estrutura molecular da galactose faz com que a molécula fique menor tempo retido na fase estacionária comparada à molécula que contém o açúcar glicose. Sendo assim, fica caracterizado, ser uma glicose, o açúcar ligado à aglicona para a substância que possui o maior tempo de retenção e galactose o de menor.

A amostra do extrato de berinjela apresentou uma absorção no comprimento de onda visível com $\lambda_{\text {máx }}$ de $525 \mathrm{~nm}$, característicos de derivados de delfinidina, petunidina e malvidina em solução de metanol acidificado (HONG\&WROLSTAD, 1990). Seu íon molecular $[\mathrm{M}]^{+}$apresentou $\mathrm{m} / \mathrm{z}$ 44611,1616 e transição do EM/EM a $\mathrm{m} / \mathrm{z}$ 465,1037e $\mathrm{m} / \mathrm{z}$ 303,0500 que corresponde à massa molecular com a perda de uma massa de 146Da (ramnose) e da sua aglicona delfinidina devido à perda de uma hexose (162Da). O dissacarídeo rutinose apresenta a particularidade de quando for submetido a uma energia de fragmentação liberar a ramnose (146Da) e em seguida a glicose (hexose-162Da) (FERREIRA, ROSSO \& MERCADANTE, 2010).

Foi possível comprovar, na amostra do extrato de casca de uva Chilena, a presença das antocianinas delfinidina-3-glicosídeo, cianidina-3-glicosídeo, petunidina-3-glicosídeo, peonidina-3-glicosídeo e malvidina-3-glicosídeo, através dos seus íons moleculares e suas transições, sua aglicona quando ocorre a liberação do açúcar (Quadro 1). A resolução entre as substâncias eluidas torna essa matriz uma excelente candidata para ser utilizado como fonte de padrão, o quinto pico que corresponde a malvidina-3-glicosídeo apresenta uma boa concentração indicando que não haverá necessidade de muitas coletas.

O pico majoritário observado no cromatograma do extrato do morango apresentou espectro de UV-visivel com $\lambda_{\text {máx a }}$ 267/328/431/501nm característicos de derivados de pelargonidina, a análise por espectrometria de massa confirmou através da obtenção dos valores de seu íon molecular [M] ${ }^{+}, m / z$ 433,1153 e transição do EM/EM a $m / z$ 271,061 que corresponde à massa molecular da aglicona pelargonidina devido à perda de uma hexose (162Da).

O extrato de casca do mangostin apresentou um pico majoritário (pico1) correspondente a uma antocianina diglicosilada, esse fato pôde ser identificado através da sua respectiva massa molecular exata, onde seu íon molecular $[\mathrm{M}]^{+}, \mathrm{m} / \mathrm{z}$ 611,2424 e sua transição do EM/EM a m/z 287,0508 que corresponde à massa molecular da aglicona cianidina devido à perda de duas hexoses (162Da). A presença de apenas uma transição caracteriza a perda de um dissacarídeo.

Todas as amostras analisadas apresentaram boa resolução, esse fato pode ser atribuído ao desempenho da coluna utilizada nas análises $\left(\mathrm{C}_{18}-100 \mathrm{~mm} \times 4,6 \mathrm{~mm} ; 2,4 \mu \mathrm{m}\right)$. Dessa forma, o isolamento do analito poderá ser efetuado com alto índice de pureza, evitando assim, sua contaminação com os outros analitos da amostra.

\section{CONCLUSÃO}

Desta forma, conclui-se que através da técnica de cromatografia líquida de alta eficiência puderam-se caracterizar os perfis das matrizes apresentadas neste estudo, assim como, a espectrometria de massas de alta resolução tornou possíveis as identificações das 
antocianinas que serão promissoras fontes de padrões de referência. Sendo assim, as matrizes apresentadas neste presente trabalho serão fontes das seis antocianinas glicosiladas mais encontradas em alimentos, e além de servirem para caracterizar a qualidade dos frutos vermelhos e seus produtos, também servirão para caracterizar a qualidade de suas próprias matrizes, visto que a perda da cor é um dos primeiros sinais de deterioração do produto. Ainda por cima, ressalta-se que as matrizes escolhidas são de fácil acesso, sendo o mangostin o que se apresenta mais oneroso dentre elas. De certo, este fato tornará possíveis as análises por CLAE com mais qualidade e menos oneroso, viabilizando-a como mais uma ferramenta que possa contribuir para avaliação da qualidade dos produtos.

\section{REFERÊNCIAS BIBLIOGRÁFICAS}

FERREIRA, D. S.; ROSSO, V. V. DE; MERCADANTE, A. Z. Compostos bioativos presentes em amora-preta (Rubus spp.). Revista Brasileira Fruticultura, vol.32 no.3, Jaboticabal Sept. 2010 Epub Oct 08, 2010

GIUSTI, M. M.; RODRÍGUEZ-SAONA, L. E.; GRIFFIN, D.; WROLSTAD, R. E. Electrospray and tandem mass spectroscopy as tools for anthocyanin characterization. $\boldsymbol{J}$. Agric. Food Chem., v. 47,n. 11, pg.4657-4664, 1999.

GOUVÊA, A. C. M. S.; GODOY, R.L.O. Redução do tempo de análise de antocianinas em amora-preta (Rubus spp.) por CLAE através de mudanças na fase móvel, $\mathrm{pH}$ e utilização de coluna com nova tecnologia. IV Forum de Pós -Graduação, UFRRJ, Seropédica, Rio de Janeiro, 2011.

GOUVÊA, A. C. M. S.; ARAUJO, M. P. de; SHUlZ, D. F.; PACHECO, S.; GODOY, R.L.O; CABRAL, L. M. C. Anthocyanins Standards ( cyanidin-3-O-glucoside and cyanidin3-O-rutenoside) isolation from freeze-dried açaí (Euterpe oleracea Mart.) by HPLC. Ciênc. Tecnol. Aliment. v.32, n., p.1-4, 2012.

HONG, X. V.; WROLSTAD, R.E. J. Use of HPLC Separation/Photodiode Array Detection for Characterization of Anthocyanins. Journal of Agricultural and Food Chemistry, v.38, n. 3, 1990.

SANTIAGO, M., C., P., A. ; GOUVÊA, A., C., M., S. ; GODOY, R., L., de O. ; OIANONETO, J. ; PACHECO, S. ; ROSA, J., S. . Adaptação de um método por cromatografia líquida de alta eficiência para análise de antocianinas em suco de açaí (Euterpe oleraceae Mart.). Rio de Janeiro: Embrapa Agroindústria de Alimentos, 2010 [(Comunicado técnico, 162. Biblioteca: CTAA (FL CTE 0162 UMT)].

PACHECO, S. ; GODOY, R. L. O. ; PEIXOTO F. ; GOUVEA, A. C. M. S. ; SANTIAGO, M. C. P. A. ; BORGUINI, R. G. ; FELBERG, I. . Preparation of High Purity Analytical Standards using High Performance Liquid Chromatography in Analytical Scale. Analytical Chemistry: An Indian Journal, v. 12, p. 194-197, 2013.

TIAN, Q.; GIUSTI, M. M.; STONER, G. D.; SCHWARTZ, S. J. Screening for anthocyanins using high-performance liquid chromatography coupled to electrospray 
ionization tandem mass spectrometry with precursor-ion analysis, product-ion analysis, common-neutral-loss analysis, and selected reaction monitoring. Journal of Chromatography A, v. 1091, pag. 72-82, 2005.

VOLP, A. C. P.; RENHE, I. R. T.; BARRA, K.; STRINGUETA, P. C. Flavonoides antocianinas: característica e propriedades na nutrição e saúde. Ver. Bras. Nutr. Clin. n.32, v.2, p. 141-149, 2008.

WANG, H.; NAIR, M.G.; STRASBURG, G.M.; CHANG, Y.C.; BOOREN, A.M.; GRAY, J.I.; et al. Antioxidant and antiinflammatory activities of anthocyanins and their aglycon, cyanidin, from tart cherries. Journal of Natural Products, v.62, n.2, p. 294-6, 1999. 
7.6- Apêndice F (Perspectiva da Ciência e Tecnologia, v. 6, n. 12, 2014)

Perspectivas da Ciência e Tecnologia, v.6, n. 1/2, (2014)

\title{
ISOLAMENTO DAS ANTOCIANINAS DO EPICARPO DE UVAS- PRETAS (Vitis spp.) POR CLAE/DAD E SUA IDENTIFICAÇÃO ATRAVÉS DO SISTEMA CLUE-QTOF-ESI /EM/EM
}

\author{
Isolation of black grapes (Vitis spp.) epicarp anthocyanins by HPLC/DAD and their \\ identification through CLUE-QTOF-ESI/MS/MS system
}

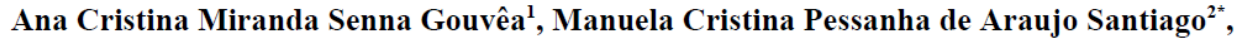
Luciana Mouta de Oliveira ${ }^{3}$, Ronoel Luiz de Oliveira Godoy ${ }^{2}$, Fernanda Marques Peixoto ${ }^{1,4}$, Sidney Pacheco ${ }^{2}$, Luzimar da Silva de Mattos do Nascimento ${ }^{2}$, Renata Galhardo Borguini ${ }^{2}$

${ }^{1}$ Universidade Federal Rural do Rio de Janeiro - BR 465, km 7, Seropédica, RJ, CEP: 238908-000, Brasil

${ }^{2}$ Embrapa Agroindústria de Alimentos - Avenida das Américas, 29501, Guaratiba, Rio de Janeiro, RJ, CEP: 23020-470, Brasil

${ }^{3}$ Universidade Federal do Estado do Rio de Janeiro - Avenida Pasteur, 296, Urca, Rio de Janeiro, RJ, CEP: 22290-240, Brasil

${ }^{4}$ Centro Universitário Estadual da Zona Oeste (UEZO) - Av. Manuel Caldeira de Alvarenga, 1203 Campo Grande - Rio de Janeiro - RJ, 23070-200, Brasil
}

*Autor correspondente: manuela.santiago@embrapa.br

\section{RESUMO}

As antocianinas, flavonoides com intensa atividade antioxidante, são os pigmentos responsáveis pela coloração no epicarpo de vários tipos de uvas com tonalidade escura. A concentração e a variedade dos tipos de antocianinas é que determinam a intensidade da coloração dos vários cultivares e dos produtos obtidos a partir dos mesmos. Este trabalho teve como objetivo o isolamento e a identificação das antocianinas majoritárias presentes no epicarpo de uvas-pretas sem sementes (Vitis spp.) adquiridas em mercado local do Rio de Janeiro, provenientes do Chile (indicação do rótulo). A extração das antocianinas do fruto foi realizada com solução de metanol acidificado, sendo a amostra submetida às etapas de sonificação e centrifugação. Para a separação e isolamento das antocianinas foi utilizado um Cromatógrafo Líquido de Alta Efíciência (CLAE) Alliance modelo $2690 / 5$ da Waters ${ }^{\circledR}$, acoplado ao detetor de arranjo de fotodiodos Waters ${ }^{\circledR}$. Na etapa de identificação, utilizou-se sistema CL-EM/EM Waters ${ }^{\circledR}$ composto por um Cromatógrafo Líquido de Ultra Efíciência (CLUE) e analisador de massas de alta resolução Q-TOF. A identificação das antocianinas majoritárias foi feita com base em dados existentes na literatura e pela comprovação através das suas respectivas massas moleculares exatas. Portanto, foi possível comprovar a presença das antocianinas delfinidina-3-glicosídeo, cianidina-3-glicosídeo, petunidina-3-glicosídeo, peonidina-3-glicosídeo e malvidina-3-glicosídeo, cujos íons precursores e seus fragmentos que correspondem à perda de uma massa de 162Da (hexose), liberando suas agliconas são, respectivamente: m/z 465,1078 e m/z 303,$0616 ; \mathrm{m} / \mathrm{z} 449,1083$ e m/z 287,0556; m/z 479,1168 e m/z 317,0746; m/z 463,1248 e m/z 301,$0714 ; \mathrm{m} / \mathrm{z} 493,1349 \mathrm{e} \mathrm{m} / \mathrm{z} 331,0864$.

Palavras-chave: antocianinas monoglicosiladas, cromatografia líquida, espectrometria de massas. 


\section{ABSTRACT}

Anthocyanins, flavonoids with strong antioxidant activity, are the pigments responsible for the epicarp color of various types of dark grapes. The concentration and the variety of anthocyanins types determine the color intensity of various cultivars and of products obtained from the same. This study aimed to characterize and identify the majority anthocyanins present in black grapes epicarp ink seeded, from Chile (Vitis spp.). The fruit anthocyanins extraction was performed with acidified methanol solution, and the sample was subjected to sonication and centrifugation steps. For the separation and isolation of anthocyanins it was used a High Performance Liquid Chromatography Alliance $2690 / 5$ model from Waters ${ }^{\mathrm{TM}}$, coupled to a photodiode array detector Waters ${ }^{\mathrm{TM}}$. In the identification step, it was used a LC-MS/MS system with an Ultra Efficiency Liquid Chromatograph and a high resolution mass analyzer Q-TOF. The identification of the majority anthocyanins was performed according to data previously reported in the literature and to their respective exact molecular masses. Therefore, it was possible to confirm the presence of the anthocyanins delphinidin3-glucoside, cyanidin-3-glucoside, petunidin-3-glucoside, peonidin-3-glucoside and malvidin-3glucoside, whose precursor ions and their fragments corresponding to the loss of a mass of $162 \mathrm{Da}$ (hexose) releasing their aglycones are respectively: $\mathrm{m} / \mathrm{z} 465.1078$ and $\mathrm{m} / \mathrm{z} 303.0616 ; \mathrm{m} / \mathrm{z} 449.1083$ and $\mathrm{m} / \mathrm{z} 287.0556 ; \mathrm{m} / \mathrm{z} 479.1168$ and $\mathrm{m} / \mathrm{z} 317.0746 ; \mathrm{m} / \mathrm{z} 463.1248$ and $\mathrm{m} / \mathrm{z} 301.0714 ; \mathrm{m} / \mathrm{z} 493.1349$ and $\mathrm{m} / \mathrm{z} 331,0864$.

Keywords: mono-glycosylated anthocyanins, liquid chromatography, mass spectrometry

\section{INTRODUÇÃO}

A produção mundial de uvas comerciais, assim como de mesa, vem crescendo ano após ano. Apesar das videiras terem capacidade de adaptação em diferentes condições climáticas, o melhor desenvolvimento das mesmas ocorre em regiões de clima mediterrâneo (CHAVARRIA et al., 2007). Relatório da Food and Agriculture Organization (FAO, 2011), das Nações Unidas, indica o Brasil ocupando a $12^{\mathrm{a}}$ posição na produção mundial de uva, e China e a Itália como os maiores produtores

As antocianinas, flavonoides com intensa atividade antioxidante, são os pigmentos responsáveis pela coloração no epicarpo de vários tipos de uvas com tonalidade que varia do vermelho ao preto. Suas agliconas (antocianidinas) são altamente reativas e dificilmente são encontradas naturalmente, portanto, são menos estáveis quando comparadas aos seus respectivos glicosídeos (antocianinas). Consideradas metabólitos secundários, têm sido frequentemente usadas como marcadores químicos (em quimiotaxonomia). A presença de antocianinas em uvas tintas, além de conferir atributos de qualidade ao alimento eleva o potencial antioxidante desse fruto e seus produtos. Diversos trabalhos científicos atribuem ao consumo de alimentos que possuem essas substâncias, à redução do risco de desenvolvimento de doenças crônicas não transmissíveis, tais como: cardiovasculares, cânceres, doenças neurodegenerativas e enfermidades inflamatórias (KUSKOSKI et al., 2004; MARTÍNEZ-FLÓREZ et al., 2005; ABE et al., 2007). 
A distribuição das antocianinas em uvas é complexa variando de acordo com o cultivar. Dentre as antocianinas monoglicosiladas encontradas em uvas, as principais são: delfinidina-3-glicosídeo; cianidina-3-glicosídeo; petunidina-3-glicosídeo; peonidina-3-glicosídeo e malvidina-3-glicosídeo. Vitis vinifera L., cultivar de colaração vermelha, é um dos exemplos aonde são encontradas somente as antocianinas monoglicosiladas acima citadas, assim como seus derivados acilados com ácido pcoumárico, cafeico e acético (RUSTIONI et al., 2013).

A caracterização das antocianinas presentes na uva se torna imprescindível e aumenta o conhecimento sobre os diferentes cultivares, sejam eles naturais ou melhorados. Este tipo de conhecimento fornece subsídios para diferenciá-los entre si e pode trazer informações que permitam uma melhoria na sua constituição genética, visto que a concentração e a variedade dos tipos de antocianinas é que irão determinar a intensidade da coloração dos vários cultivares de uvas (POMAR et al., 2005)

Na literatura há relatos sobre a identificação das antocianinas presentes em vinhos, mas há pouca informação sobre as uvas propriamente ditas, como no estudo realizado por ANDRADE et al. (2013). Sabe-se que a composição de antocianinas na bebida está relacionada à presença destes pigmentos no fruto (CÁCERES et al., 2012), mas não é possível atribuir que tal perfil seja idêntico ao da matéria-prima, uma vez que os processos para obtenção e armazenamento do vinho podem acarretar alterações no perfil destes compostos.

Desta forma, este trabalho teve como objetivo isolar e identificar, através de uma técnica precisa, segura e de alta resolução, as antocianinas presentes no epicarpo de uvas-pretas (Vitis spp.) sem sementes provenientes do Chile, comercializadas em um mercado local na cidade do Rio de Janeiro, RJ.

\section{MATERIAL E MÉTODOS}

\section{Matéria-prima}

Os frutos de uva-preta (Vitis spp.) sem sementes provenientes do Chile foram comprados em mercado local no bairro do Recreio dos Bandeirantes, zona oeste do município do Rio de Janeiro, RJ. As bagas foram abertas e despolpadas manualmente e, cada 100 gramas de fruto deu origem a 11,32 gramas de "cascas" (epicarpos), tendo sido esta quantidade congelada e liofilizada durante 24 horas em liofilizador Líotop modelo L101 à temperatura de $-40^{\circ} \mathrm{C}$. Do material liofilizado, obteve-se um pó utilizando o moinho IKA, modelo A1. O pó foi acondicionado em embalagens herméticas laminadas à temperatura ambiente, ficando, desta forma, a amostra protegida da luz e umidade do ar até o momento das análises. 


\section{Extração das antocianinas}

Os pigmentos antociânicos do pó foram extraídos utilizando-se a metodologia de extração para antocianinas descrita por SANTIAGO et al. (2010), onde pesou-se $1 \mathrm{~g}$ do liofilizado para obtenção de um extrato concentrado que possibilitou a coleta para identificar as antocianinas. A amostra foi acondicionada em um tubo de centrífuga de $50 \mathrm{~mL}$, onde foram adicionados $2 \mathrm{~mL}$ de solução de extração (ácido fórmico/ metanol-10:90, v/v), com subsequentes etapas de agitação em vortex durante 1 minuto, sonificação por 10 minutos no ultrasson Cleanears, e centrifugação a 6000rpm por um período de 10 minutos. O sobrenadante foi transferido para um frasco, onde foi submetido à secagem sob fluxo de ar comprimido filtrado. Posteriormente, o sobrenadante seco foi diluído com $4 \mathrm{~mL}$ de solução para injeção, $5 \%$ de ácido fórmico em água de Milli-Q ${ }^{\circledR}$ : metanol (90:10, v/v), e acondicionado em vial específico para o injetor do cromatógrafo.

\section{Isolamento das antocianinas por CLAE}

Para a separação e isolamento das antocianinas foi utilizado um Cromatógrafo Líquido de Alta Eficiência Waters ${ }^{\circledR}$, Alliance modelo 2690/5, acoplado ao detetor de arranjo de fotodiodos Waters ${ }^{\circledR}$ (DAD), modelo 2996, software Empower ${ }^{\circledR}$, coluna $\mathrm{C}_{18}$ Thermo (100mm x 4,6mm; 2,4mm), $20 \mu \mathrm{L}$ de injeção, fluxo de $1,0 \mathrm{~mL} \cdot \mathrm{min}^{-1}$ e modo de eluição gradiente com acetonitrila (solvente A) e solução aquosa de ácido fórmico 5\% (Solvente B). O gradiente inicia com 5\% do sovente A e 95\% do solvente $\mathrm{B}$ até $5 \mathrm{~min}$, depois vai aumentando o solvente A até $13 \%$ durante $10 \mathrm{~min}$, em seguida mantém o solvente A a $14 \%$ por $1 \mathrm{~min}$, e após decresce o solvente A até chegar a $5 \%$ durante $2 \mathrm{mim}$ e $30 \mathrm{seg}$, e finalmente matém o solvente A a $5 \%$ por $3 \mathrm{~min} 30 \mathrm{seg}$ para reequilibrar a coluna. A análise foi realizada no comprimento de onda de $520 \mathrm{~nm}$, e foram necessárias seis injeções do extrato concentrado para recolhimento em concentração adequada de cada pico referente a cada uma das antocianinas para a obtenção das substâncias isoladas. As coletas das antocianinas foram realizadas manualmente diretamente da saída do detetor.

\section{Purificação das antocianinas isoladas}

Após a coleta foi realizado o clean up do extrato de cada antocianina isolada. A purificação foi realizada através da técnica de extração em fase sólida adaptada da metodologia descrita por RODRIGUEZ-SAONA \& WROLSTAD (2001). Foram utilizados cartuchos Sep Pack $C_{18}$ Waters ${ }^{\circledR}$, previamente acondicionados com solução de metanol acidificado (ácido fórmico $0,1 \%$ ). Esta técnica além de propiciar a remoção da antocianina da fase móvel em que se encontrava diluída, concentrando-a, também proporcionou a remoção de eventuais açúcares livres, e outros compostos polares que por ventura ali se encontravam diluídos. O extrato antociânico eluido foi então seco em temperatura ambiente sob fluxo de ar comprimido filtrado. 


\section{Análise das antocianinas por espectrometria de massas (EM)}

As cinco amostras coletadas foram secas e, cada uma, isoladamente, foi diluída em $1 \mathrm{~mL}$ de solução aquosa de ácido fórmico $0,1 \%$. Para análise, $10 \mu \mathrm{L}$ do extrato antociânico foi diluído em $990 \mu \mathrm{L}$ de solução aquosa de ácido fórmico $0,1 \%$ / metanol $(60: 40, \mathrm{v} / \mathrm{v})$. A análise de identificação de antocianinas foi realizada utilizando o sistema Acquity da Waters ${ }^{\circledR}$ composto por um Cromatógrafo Líquido de Ultra Eficiência (CLUE), com coluna $\mathrm{C}_{18}(2,1 \times 150 \mathrm{~mm} ; 1,7 \mathrm{~mm})$ Acquity CLUE BEH, modo de eluição gradiente com solvente A (solução aquosa de ácido fórmico $0,1 \%$ ) e solvente $\mathrm{B}$ (acetonitrila), volume de injeção $1 \mu \mathrm{L}$, fluxo $0,35 \mathrm{~mL} / \mathrm{min}$ e temperatura da coluna de $45^{\circ} \mathrm{C} . \mathrm{O}$ cromatógrafo está acoplado ao Espectrômetro de Massas de alta resolução Waters Synapt ${ }^{\circledR}$ Q-TOF, com fonte de ionização no modo electrospray positivo (ESI+), tempo de voo V, com as seguintes condições: temperatura da fonte igual a $120^{\circ} \mathrm{C}$, gás de dissolvatação $\mathrm{N}_{2}$ a $500^{\circ} \mathrm{C}$, energia do capilar $3,0 \mathrm{kV}$, cone fixado em $25,0 \mathrm{~V}$ e energia de colisão de $8,0 \mathrm{~V}$.

Todos os solventes utilizados foram da marca Tedia ${ }^{\circledR}$ grau CLAE, para extração e análise cromatográfica, e grau Massa para as análises no espectrômetro de massa.

\section{RESULTADOS E DISCUSSÃO}

A análise por CLAE, utilizando uma coluna de fase reversa com diâmetro de partícula de $2,4 \mu \mathrm{m}$, possibilitou boa resolução entre os analitos (Figura 1). Esse fato tornou possível a coleta das substâncias de forma isolada com alto grau de pureza (acima de 98\%), evitando-se desta forma a contaminação das mesmas com os outros analitos da amostra.

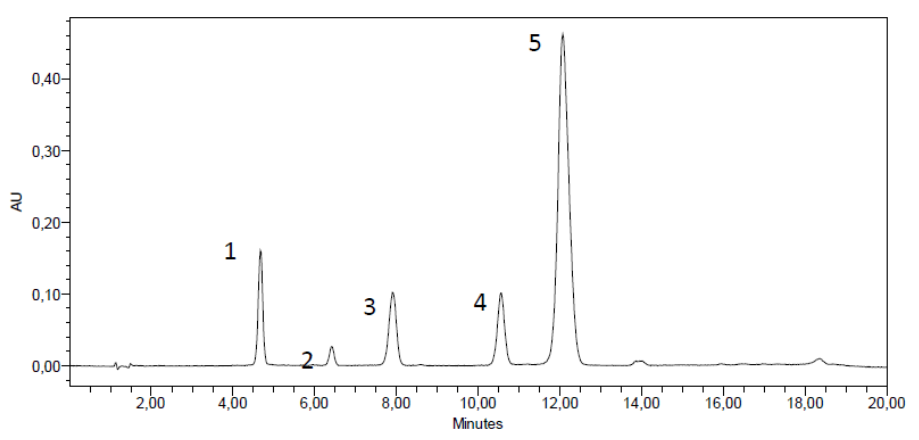

Figura 1: Perfil cromatográfico antociânico do extrato metanólico do epicarpo de uva preta chilena no comprimento de onda a $520 \mathrm{~nm}$. Pico $1=$ delfinidina-3-glicosídeo, pico $2=$ cianidina-3glicosídeo, pico 3= petunidina-3-glicosídeo, pico4= peonidina-3-glicosídeo e pico 4= malvidina-3glicosídeo. 
A identificação dos analitos foi baseada nos seus $t_{R}$ 's e suas respectivas massas moleculares exatas, as quais foram confrontadas com dados existentes em trabalhos científicos (WU \& PRIOR, 2005, BRITO et al., 2007). Foi possível comprovar na amostra do extrato de casca de uva-preta Chilena, a presença das antocianinas: delfinidina-3-glicosídeo (pico 1) que foi sugerida devido ao seu espectro UV-visível que mostrou $\lambda$ máx a 271 e $522 \mathrm{~nm}$ característicos de derivados de delfinidina. Seu íon molecular [M]+ apresentou $\mathrm{m} / \mathrm{z}$ 465,1078 e fragmento $\mathrm{m} / \mathrm{z}$ 303,0616 no EM/EM que corresponde à massa molecular da aglicona delfinidina devido à perda de um açúcar $(162 \mathrm{Da})$, no caso glicose devido ao seu tempo de retenção (Tabela 1 e Figura 3A). O pico 2 foi identificado como cianidina-3glicosídeo, pois, ao confrontar sob as mesmas condições cromatográficas, seu tempo de retenção com o tempo de retenção do pico 2 da juçara ou palmito-juçara (Euterpe edulis) (Figura 2), matriz já identificada na literatura por BRITO et al. (2007). foi possível sugerir tratar-se de cianidina-3glicosídeo. A confirmação foi realizada ao se observar que seu íon [M]+ apresentou $\mathrm{m} / z$ 449,1083 e fragmento $\mathrm{m} / z 287,0556$ no EM/EM que corresponde à massa molecular da aglicona cianidina devido à perda de um açúcar $(162 \mathrm{Da})$, no caso sugere-se ser a glicose devido ao seu $t_{\mathrm{R}}$ (Tabela 1 e Figura 3B). Pico 3 foi identificado como petunidina-3-glicosídeo através do seu íon molecular [M]+ que apresentou $\mathrm{m} / \mathrm{z} 479,1168$ e fragmento $\mathrm{m} / z$ 317,0746 no EM/EM que corresponde à massa molecular da aglicona petunidina devido à perda de um açúcar $(162 \mathrm{Da})$, no caso sugere-se ser a glicose devido ao seu $t_{R}$ (Tabela 1 e Figura 3C). O pico 4, apesar de mostrar um comprimento de onda com valores próximos dos derivados de cianidina com $\lambda$ máx de $517 \mathrm{~nm}$, quando aplicado uma energia de colisão de $8 \mathrm{v}$ em seu íon molecular [M] $+m / z 463,1248$ foi observado o fragmento $\mathrm{m} / z$ 301,0714 característico da aglicona peonidina devido à perda de um açúcar (162 Da), no caso sugere-se ser a glicose devido ao seu $t_{R}$ (Tabela 1 e Figura 3D). O último pico, corresponde a antocianina majoritária dessa matriz. Apresentou espectro UV-visível com $\lambda$ máx a 277 e $526 \mathrm{~nm}$ característicos de derivados de malvidina. Seu íon molecular [M]+ apresentou $\mathrm{m} / z$ 493,1349 e fragmento $\mathrm{m} / \mathrm{z} 331,0864$ d no EM/EM, devido à perda de um açúcar (162 Da), no caso sugere-se ser a glicose devido ao seu $t_{R}$ (Tabela 1 e Figura $3 E$ ).

\section{CONCLUSÕES}

Com o presente trabalho pôde-se identificar de maneira inequívoca o perfil das antocianinas presentes no epicarpo das uvas-pretas sem semente (Vitis spp.) provenientes do Chile. O conhecimento da composição das antocianinas do fruto permite o monitoramento do comportamento destes pigmentos nas bebidas obtidas a partir desta matéria-prima, possibilitando maior controle de qualidade do produto final. Cabe ressaltar que o conhecimento do perfil antociânico das uvas, permite a diferenciação entre os diversos cultivares, já que a diferente coloração entre os mesmos está associado à variação da composição das antocianinas nas cascas.

\section{AGRADECIMENTOS}

Ao CNPq, pela bolsa concebida à Ana Cristina Miranda Senna Gouvêa. 


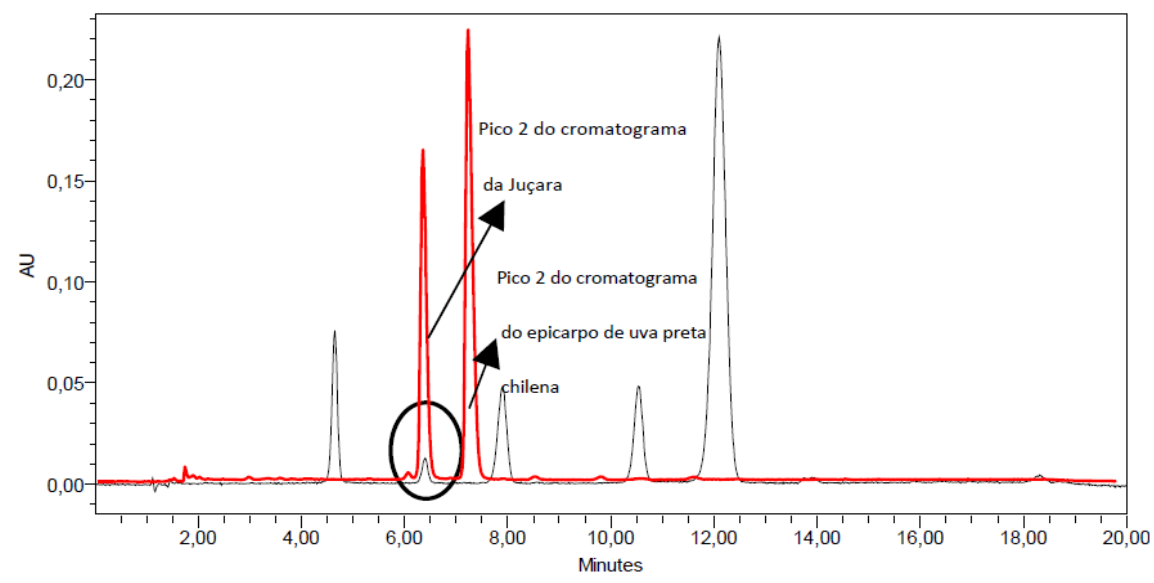

Figura 2: Sobreposição dos cromatogramas do epicarpo de uva preta chilena (em preto) e da juçara, Euterpe edulis (em vermelho), sob as mesmas condições cromatográficas. Pico $2=$ cianidina-3-glicosídeo $\left(t_{R}=6,21\right)$

Tabela 1. Identificação das antocianinas numeradas na amostra

\begin{tabular}{ccccccc}
\hline Matriz & Pico & $\boldsymbol{\lambda ( \mathbf { n m } ) ^ { \mathbf { a } }}$ & $\begin{array}{c}\mathbf{t}_{\mathbf{R}}{ }^{\mathbf{a}} \\
(\mathbf{m i n})\end{array}$ & {$[\mathbf{M}]^{+}(\mathbf{m} / \mathbf{z})$} & $\begin{array}{c}\mathbf{E M} / \mathbf{E M} \\
(\mathbf{m} / \boldsymbol{z})\end{array}$ & Antocianina \\
\hline & 1 & $271 / 522$ & 4,27 & 465,1078 & 303,0616 & Dp-3-Glicosídeo \\
& 2 & $279 / 515$ & 6,21 & 449,1083 & 287,0556 & Cy-3-Glicosídeo \\
Uva Preta & 3 & $270 / 524$ & 7,89 & 479,1168 & 317,0746 & Pt-3-Glicosídeo \\
Chilena & 4 & $279 / 517$ & 10,29 & 463,1248 & 301,0714 & Pn-3-Glicosídeo \\
& 5 & $277 / 526$ & 12,04 & 493,1349 & 331,0864 & Mv-3-Glicosídeo
\end{tabular}

${ }^{a}$ Solvente Fase móvel da análise cromatográfica (solução aquosa de ácido fórmico 5\%: metanol 10\% / água Milli-Q ${ }^{\circledR}$ ) $\mathrm{Dp}=$ delfinidina, $\mathrm{Cy}=$ cianidina, $\mathrm{Pt}=$ petunidina, $\mathrm{Pn}=$ peonidina $\mathrm{e} \mathrm{Mv}=$ malvidina 
Perspectivas da Ciência e Tecnologia, v.6, n. 1/2, (2014)
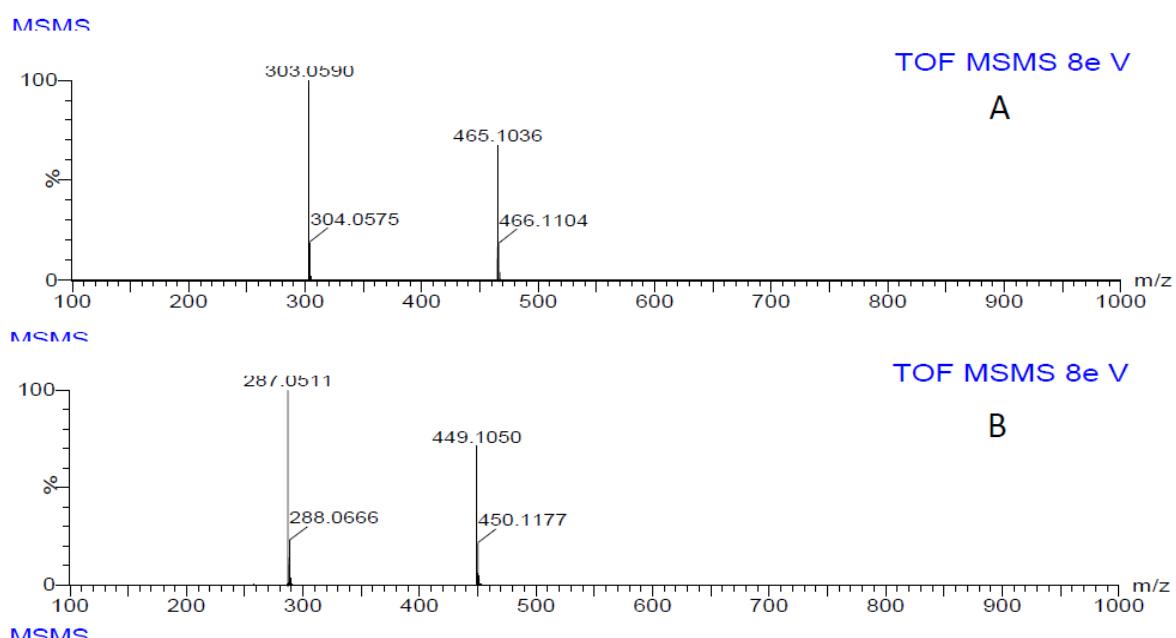

TOF MSMS 8 e V
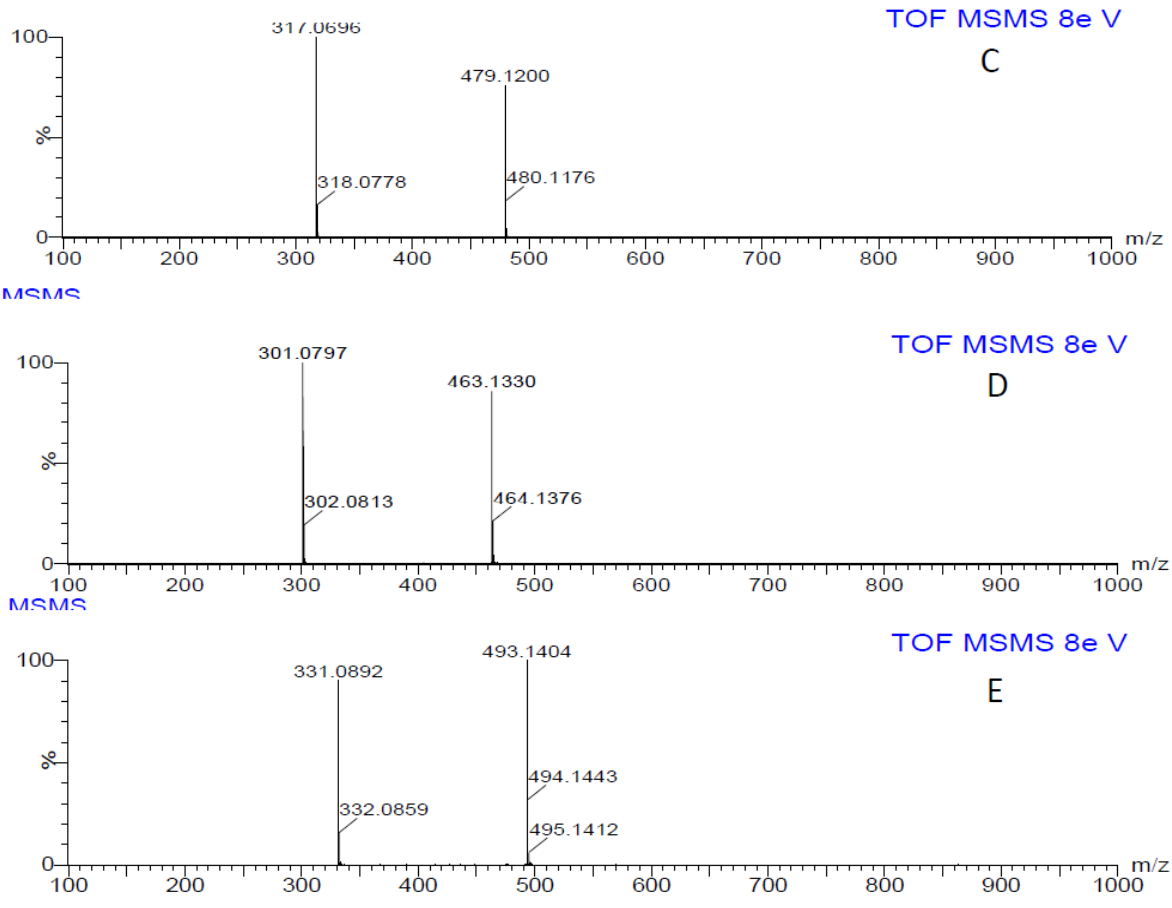

Figura 3: Espectros de massas das antocianinas isoladas da casca da uva-preta chilena (Espectro A: delfinidina-3-glicosídeo; espectro $\mathrm{B}$ : cianidina-3-glicosídeo; espectro C: petunidina-3glicosídeo: espectro D: peonidina-3-glicosídeo: espectro E: malvidina-3-glicosídeo) 


\section{REFERÊNCIAS BIBLIOGRÁFICAS}

ABE L.T.; DA MOTA, R.V.; LAJOLO, F.M.; GENOVESE, M.I. Compostos fenólicos e capacidade antioxidante de cultivares de uvas Vitis labrusca L. e Vitis vinifera L. Ciência e Tecnologia de Alimentos, 27, 394-400, 2007.

ANDRADE, R.H.S.; NASCIMENTO, L.S.; PEREIRA, G.E.; HALlWASS, F.; PAIM, A.P.S. Anthocyanic composition of Brazilian red wines and use of HPLC-UV-Vis associated to chemometrics to distinguish wines from different regions. Microchemical Journal, 110, 256-262, 2013.

BRITO, E.S.; ARAUJO, M.C.P.; ALVES, R.E.; CARKEET, C.; CLEVIDENCE, B.A.; NOVOTY, J. A. Anthocyanins Present in Selecred Tropical Fruits: acerola, jambolão, jussara and guajiru. Journal of Agriculture and Food Chemistry, 55, 9389-9394, 2007.

CÁCERES, A.; PEÑA-NEIRA, A.; GALVEZ, A.; OBREQUE-SLIER, E.; LÓPEZ-SOLÍS, R.; CANALS, J.M. Phenolic compositions of grapes and wines from cultivar Cabernet Sauvignon produced in Chile and theirs relationship to commercial value. Journal of Agriculture and Food Chemistry, 60, 8694-8702, 2012.

CHAVARRIA, G.; SANTOS, H.P.; SÔNEGO, O.R.; MARODIN, G.A.B.; BERGAMASCHI, H.; CARDOSO, L.S. Incidência de doenças e necessidade de controle em cultivo protegido de videira. Revista Brasileira de Fruticultura, 29, 477-482, 2007.

FAO. Statistical Databases. Disponível em: $<$ http://faostat.fao.org/ $>$. Acesso em: 20 novembro de 2014.

KUSKOSKI, E.M.; ASUERO, A.G.; GARCIA-PARILlA, M.C.; TRONCOSO, A.M.; FETT, R. Actividad antioxidante de pigmentos antociánicos. Ciência e Tecnologia de Alimentos, 24, 691-693, 2004.

MARTÍNEZ-FLÓREZ, S.; GONZÁlEZ-GALlEGO, J.; CULEBRAS, J.M.; TUÑóN, M.J. Los flavonóides: propriedades y acciones antioxidantes. Nutritional Hospital, 17, 271- 278, 2002.

POMAR, F., NOVO, M., \& MASA, A. Varietal differences among the anthocyanins profiles of 50 red table grape cultivars studied by high performance liquid chromatography. Journal of Chromatography A, 1094, 34-41, 2005.

RODRIGUEZ-SAONA, L.E; WROLSTAD, R.E. Extraction, isolation, and purification of anthocyanins. In: WROLSTAD, R. E. (Ed.) Current Protocols in Food Analytical Chemistry, New York: John Wiley \& Sons, 2001. p.F1 1.1-1.11.

RUSTIONI, L.; DI MEO, F.; GUILlAUME, M.; FAILlA, O.; TROUILlAS, P. Tuning color variation in grape anthocyanins at the molecular scale. Food Chemistry, 141, 4349-4357, 2013.

SANTIAGO, M.C.P.A.; GOUVÊA, A.C.M.S.; GODOY, R.L.O.; OIANO-NETO, J.; PACHECO, S.; ROSA, J.S. Adaptação de um método por cromatografia líquida de alta eficiência para análise de antocianinas em suco de açaí (Euterpe oleraceae Mart.). Rio de Janeiro: Embrapa Agroindústria de Alimentos, 2010 (Comunicado técnico, 162. Biblioteca: CTAA (FL CTE 0162 UMT)).

WU, X.; PRIOR, R. L. Systematic Identification and Characterization of Anthocyanins by HPLC-ESIMS/MS in Common Foods in United States: Fruits and Berries. Journal of Agriculture and Food Chemistry, 53, 2589- 2599, 2005. 
7.7-Apêndice G (Food Chemistry, v. 185, 2015)

Food Chemistry 185 (2015) 277-283

Analytical Methods

\title{
Identification and quantification of anthocyanins in fruits from Neomitranthes obscura (DC.) N. Silveira an endemic specie from Brazil by comparison of chromatographic methodologies
}

Ana Cristina M.S. Gouvêa ${ }^{a}$, Armindo Melo ${ }^{b}$, Manuela C.P.A. Santiago ${ }^{c}$, Fernanda M. Peixoto ${ }^{a}$, Vitor Freitas ${ }^{\mathrm{d}}$, Ronoel L.O. Godoy ${ }^{\mathrm{c}}$, Isabel M.P.L.V.O. Ferreira ${ }^{\mathrm{b}, *}$

${ }^{a}$ Universidade Federal Rural do Rio de Janeiro (UFRRJ) - Programa em Pós-Graduação em Ciência e Tecnologia de Alimentos, Rodovia BR 465 - km 7, Campus Universitário Seropédica, 23851-970 Rio de Janeiro, RJ, Brazil

${ }^{\mathrm{b}}$ LAQV/REQUIMTE/Laboratório de Bromatologia e Hidrologia, Faculdade de Farmácia, Universidade do Porto, Rua Jorge Viterbo Ferreira 228, 4050-313 Porto, Portugal 'Embrapa Agroindústria de Alimentos, Laboratório de Cromatografia Líquida, Avenida das Américas 29501, 23020-470 Guaratiba, Rio de Janeiro, RJ, Brazil ${ }^{\mathrm{d}}$ LAQV/REQUIMTE/Chemistry Investigation Centre (CIQ), Department of Chemistry and Biochemistry, Faculty of Sciences, University of Porto, R. Campo Alegre 687, 4169-007 Porto, Portugal

\section{A R T I C L E I N F O}

Article history:

Received 19 October 2014

Received in revised form 17 January 2015

Accepted 17 February 2015

Available online 24 February 2015

\section{Keywords:}

Neomitranthes obscura

Anthocyanins

HPLC/DAD/MS

Myrtaceae

\begin{abstract}
A B S T R A C T
Neomitranthes obscura (DC.) N. Silveira is a Brazilian fruit belonging to the Myrtaceae family that contains anthocyanins in the peel and was studied for the first time in this work. Delphinidin-3-0-galactoside, delphinidin-3-0-glucoside, cyanidin-3-0-galactoside, cyanidin-3-0-glucoside, cyanidin-3-0-arabinoside, petunidin-3-O-glucoside, pelargonidin-3-O-glucoside, peonidin-3-O-galactoside, peonidin-3-O-glucoside, cyanidin-3-0-xyloside were separated and identified by LC/DAD/MS and by co-elution with standards. Reliable quantification of anthocyanins in the mature fruits was performed by HPLC/DAD using weighted linear regression model from 0.05 to $50 \mathrm{mg}$ of cyaniding-3-0-glucoside $\mathrm{L}^{-1}$ because it gave better fit quality than least squares linear regression. Good precision and accuracy were obtained. The total anthocyanin content of mature fruits was $263.6 \pm 8.2 \mathrm{mg}$ of cyanidin-3-0-glucoside equivalents $100 \mathrm{~g}^{-1}$ fresh weight, which was in the same range found in literature for anthocyanin rich fruits.
\end{abstract}

\section{Introduction}

Neomitranthes obscura (DC.) N. Silveira is an endemic plant of the Brazilian Atlantic Forest and widely spread in the sandbanks of "Restinga". This term comprises ecosystems defined by sandy plain land adjacent to the sea, and includes not only botanic but also ecological, and geological aspects. Vegetation of this kind of system is characterized by different contrasting types of formation, from herbaceous to forest, growing on open or inaccessible locations (Ramos, Monteiro, da Silva, Nakamura, \& Siani, 2010) This vegetation grows in sandy soils that are very poor in nutrients, associated to the other contrasting seasonal effects, such as the unequal precipitation annual ratio and water distribution in the near subsoil.

Fruits from flora of "Restinga" have not been valued adequately since studies about its composition are scarce. With regard to $N$. obscura belonging to the Myrtaceae family only the chemical

\footnotetext{
* Corresponding author. Tel.: +351 220428642; fax: +351 226093390 .

E-mail address: isabel.ferreir@ff.up.pt (LM.P.LV.O. Ferreira).

composition of essential oils were analysed (Amaral et al., 2013; Ramos et al., 2010). However, its fruits contain anthocyanins that contribute to the peel colour, although its composition and quantitation has not yet been described.

Anthocyanins are important components of fruits, especially berries. It is well known that anthocyanins can promote many positive health benefits, such as reduction in the risk of coronary heart diseases and diabetes, anti-cancer, ageing resistance and obesity control (Jayaprakasam, Olson, Schutzki, Tai, \& Nair, 2006 Sumner et al., 2005). The most common aglycone forms of anthocyanin in food are cyanidin, delphinidin, peonidin, petunidin, pelargonidin and malvidin, however they are naturally found as glucosides having glucose, galactose, rhamnose, xylose or arabinose sugars usually linked to the $\mathrm{C}_{3}$ in pyrylium ring of the anthocyanidin skeleton (Castaneda-Ovando, Pacheco-Hernandez, PaezHernandez, Rodriguez, \& Galan-Vidal, 2009; Wang \& Stoner, 2008).

Separation of anthocyanins is usually performed by reversed phase-high performance liquid chromatography (RP-HPLC). For maximum chromatographic efficiency highly acidic mobile phase $(\mathrm{pH}<2)$ is required to ensure that anthocyanins are predominantly 
intense $m / z$ in the first scan, and the third was $\mathrm{ms}^{2}$ and $\mathrm{ms}^{3}$ of the most intense $m / z$ using relative collision energy of $45 \mathrm{eV}$.

\subsection{HPLC-DAD quantification}

The HPLC system was from Gilson (France), consisting of two pumps (305 and 306), an 805 manometric module, a 811C dynamic mixer, an injection port with a $20 \mu \mathrm{L}$ loop (Rheodyne, USA) and a photodiode array detector (Prostar 335 DAD from Varian, USA) controlled by a data processor software (Varian Star Workstation, USA).

The chromatographic separation was performed using an ACE (Advanced Chromatography Tecnologies, Aberdeen, Scotland) 5 $\mathrm{C}_{18}$ column $(250 \times 4.6 \mathrm{~mm} ; 5 \mu \mathrm{m} ; 100 \AA)$ at room temperature and a Hypersil BDS (Thermo Fisher Scientific, Waltham, MA, USA) $\mathrm{C}_{18}$ column $(100 \times 4.6 \mathrm{~mm} ; 2.4 \mu \mathrm{m})$ at $40^{\circ} \mathrm{C}$. The two columns were coded as ACE 5 and TS, respectively. Two different mobile phases were assayed. Mobile phase 1 consisted of $10 \%$ aqueous formic acid (90:10; v/v) as solvent $A$ and formic acid/water/methanol $(10: 40: 50 ; v / v / v)$ as solvent $B$, separation was performed at ambient temperature (Oliveira, Amaro, Pinho, \& Ferreira, 2010; Queiroz, Oliveira, Pinho, \& Ferreira, 2009) The gradient was $20 \%$ solvent B over $3 \mathrm{~min}$, followed by a linear gradient up to $30 \%$ solvent B within $15 \mathrm{~min}$ and held there for $2 \mathrm{~min}$, then was linear gradient up to $60 \%$ solvent B in $13 \mathrm{~min}$ and held there for $2 \mathrm{~min}$. Returning back to initial conditions, $20 \%$ solvent B in $5 \mathrm{~min}$ and held there for $8 \mathrm{~min}$ for column rinse and re-equilibration. Mobile phase 2 consisted of $5 \%$ formic acid/water $(5: 95 ; \mathrm{v} / \mathrm{v})$ as solvent $\mathrm{A}$ and acetonitrile as solvent B. The gradient was linear from $5 \%$ to $10.5 \%$ solvent B over $7 \mathrm{~min} 30 \mathrm{~s}$ and held there for $4 \mathrm{~min} 30 \mathrm{~s}$, then linear gradient up to $12 \%$ solvent B over $1 \mathrm{~min}$, then another linear gradient up to $14 \%$ solvent B over $1 \mathrm{~min}$ and then reduced back to $5 \%$ solvent B at $2 \mathrm{~min} 30 \mathrm{~s}$ and held there for $3 \mathrm{~min} 30 \mathrm{~s}$ for column rinse and re-equilibration. The flow rate was always $1 \mathrm{~mL} \mathrm{~min}^{-1}$ and DAD was set to collect the signal at $520 \mathrm{~nm}$.

\subsection{Method validation}

Method validation was performed by evaluation of linearity and linear range, limit of detection, limit of quantification, precision, accuracy, as well as measurement of uncertainties followed International Conference on Harmonisation Guidelines (ICH) (International Conference on, Harmonisation (ICH), 2005). The study of the linearity included calculation of random errors in the $y$-direction $\left(S_{\mathrm{y} / \mathrm{x}}\right)$ as well as standard deviations for the slope $\left(S_{\mathrm{b}}\right)$ and intercept $\left(S_{\mathrm{a}}\right)$ associated with the line. Least squares linear regression in some cases includes a significant proportion of errors at the lower end of the calibration line that are underestimated. Weighted linear regression model is more complex than least squares linear regression but is preferred when the variance is not equal in all of the points of the calibration line (Mansilha et al., 2010). The uncertainty for the calibration curve $(U)$ gave information about the variability of the method. $U$ was measured as the ratio between the estimated standard deviation of $X_{0}$ standards and $X_{0}$ value, two standards with concentrations $0.05 \mathrm{mg} \mathrm{L}^{-1}$ and $5 \mathrm{mg} \mathrm{L}^{-1}$ were used for this purpose. The reliability of weighted regression was confirmed by calculating the percentage relative error (\%RE) expressed as the concentration found from weighted and unweighted regression equations with the theoretical standard concentration (Mansilha et al., 2010). The sum of absolute $\%$ RE give an indication of fit quality.

The limit of detection (LOD), defined as the lowest amount that can be differentiated from the background noise and limit of quantification (LOQ) defined as the lowest concentration that can be quantified with acceptable precision and accuracy were based on the calibration curve parameters (Miller \& Miller, 2005). The precision of the method was evaluated by repeatability or intraday precision when applying the same operating conditions over the same day and by intermediate precision that evaluate the variations on different days. Nine determinations were performed for assessment of precision (3 concentration levels/3 replicates). Accuracy was evaluated by recovery experiments as recommended by $\mathrm{ICH}$ by adding known amounts of cyanidin-3-O-glucoside to the fruit matrix in three different levels of concentration $(0.05,1.00$ and $50.0 \mathrm{mg} \mathrm{L}^{-1}$ ).

\section{Results and discussion}

\subsection{Identification by $L C / D A D / M S$}

The anthocyanins identification and peak assignment was based on comparison of their mass spectral data, including retention times, molecular ion peaks, $\mathrm{ms}^{2}$ and $\mathrm{ms}^{3}$ fragments with those of standards and published data. Table 1 summarizes data obtained from $\mathrm{LC} / \mathrm{DAD} / \mathrm{MS}$ analyses. The two major peaks were numbered as peak 2 and peak 4 and presented $m / z$ from ESI-MS of 465 and 449 respectively, which were in accordance with the mass weight for $\mathrm{C}_{21} \mathrm{H}_{21} \mathrm{O}_{12}$ (465) and $\mathrm{C}_{21} \mathrm{H}_{21} \mathrm{O}_{11}$ (449). The $\mathrm{ms}^{2}$ mass fragments were $m / z 303$ and 287 , respectively that were related to the loss of one hexose $-\mathrm{H}_{2} \mathrm{O},[\mathrm{M}]^{+}-162 \mathrm{Da}$. The UV-Vis spectrum of the two peaks indicated that the visible $\lambda_{\max }$ was $523 \mathrm{~nm}$ and $514 \mathrm{~nm}$, respectively. Thus, peak 2 was identified as delphinidin and peak 4 was identified as cyanidin, both linked to a hexose. The sugars are commonly found in foods attached to a single posi tion of the anthocyanins and usually the connection occurs at posi tion 3 of the pyrylium ring (Wu \& Prior, 2005a). It should be highlighted that anthocyanins that present galactoside or glu coside linked to similar anthocyanin structure present identical mass spectral properties and cannot be distinguished exclusively by mass spectrometry. Delphinidin-3-O-glucoside and cyanidin3-O-glucoside were confirmed as the peak 2 and 4, respectively, by co-injection with the respective standards. The elution order using reversed phase HPLC shows that galactoside linked to the anthocyanin increases its polarity when compared with the glucoside. The same occurs with the retention time of arabinoside linked to anthocyanin when compared with xyloside, facts that have been confirmed from published data (Wu \& Prior, 2005b). This information helped to elucidate about anthocyanins composition of $N$. obscura that shared the same mass profile in terms of having an anthocyanidin plus a hexose or pentose, but with different retention times.

Eight minor peaks have also been identified by HPLC-MS (peaks $1,3,5,6,7,8,9$ and 10 ). The identity of peaks $1,3,6,7,8$ and 9 were confirmed by comparison of peak retention times, mass data and UV-Vis spectrum with those of standards. Simultaneously with the peak 6 was observed other mass data, $[\mathrm{M}]^{+} \mathrm{m} / \mathrm{z} 435$ $\mathrm{ms}^{2} \mathrm{~m} / z$ 303, $\mathrm{ms}^{3} \mathrm{~m} / z 257,229$, identified as delphinidin plus pentose. According to the literature the elution order of anthocyanins by reversed phase HPLC is cyanidin-3-O-galactoside followed by delphinidin-3-0-arabinoside and afterwards cyanidin-3-0-glucoside (Wu \& Prior, 2005b). Thus, the delphinidin-3-O-arabinoside does not correspond to peak 6 because its elution is between petunidin-3-O-glucoside and pelargonidin-3-O-glucoside, since only two pentoses were identified in this fruit (arabinoside and xyloside) this peak was identified as delphinidin-3-O-xyloside. Peak 5 and peak 10 shared a similar mass spectral $[\mathrm{M}]^{+} \mathrm{m} / \mathrm{z} 419$; $\mathrm{ms}^{2} \mathrm{~m} / \mathrm{z} 287, \mathrm{~ms}^{3} \mathrm{~m} / \mathrm{z} 213,137$ the retention times were such as common pentoses, arabinoside and xyloside, respectively compared with data of $\mathrm{Wu}$ and Prior (2005b). Pelargonidin-3-Oglucoside (peak 7) was also confirmed by addition of standard from strawberry (Amaro et al., 2013). Structural identification of the las 
Table 1

Molecular ion and respective fragments $\mathrm{ms}^{2}$ and $\mathrm{ms}^{3}$ obtained by LC-DAD/MS of anthocyanins detected in fruits of N. obscura.

\begin{tabular}{|c|c|c|c|c|c|c|c|}
\hline Peak & Rt (min) LicroCart ${ }^{\star}$ column & $\lambda \max (\mathrm{nm})$ & MW & {$[\mathrm{M}]^{+}(\mathrm{m} / \mathrm{z})$} & $\mathrm{ms}^{2}(m / z)$ & $\mathrm{ms}^{3}(m / z)$ & Peak assignment \\
\hline 1 & 25.96 & 523 & 465 & 465 & 303 & $257: 229$ & Delphinidin-3-0-galactoside \\
\hline 2 & 27.65 & 523 & 465 & 465 & 303 & $257: 229$ & Delphinidin-3-0-glucoside \\
\hline 3 & 30.29 & 514 & 449 & 449 & 287 & 213:137 & Cyanidin-3-0-galactoside \\
\hline 6 & 36.80 & 520 & 479 & 479 & 317 & $302: 274$ & Petunidin-3-0-glucoside \\
\hline 6 & 36.93 & 523 & 435 & 435 & 303 & $257: 229$ & Delphinidin-3-0-xyloside \\
\hline 7 & 37.01 & 505 & 433 & 433 & 271 & $141: 121$ & Pelargonidin-3-0-glucoside \\
\hline 11 & 46.20 & - & - & 477 & 287 & 213:137 & Cyanidin + MW (190 Da) \\
\hline
\end{tabular}

trace peak, mass spectral $[\mathrm{M}]^{+} \mathrm{m} / \mathrm{z} 477 ; \mathrm{ms}^{2} \mathrm{~m} / \mathrm{z} 287, \mathrm{~ms}^{3} \mathrm{~m} / \mathrm{z} 213$ 137 which was numbered as 11 was not possible with the information given by MS data, thus this peak remained as unknown. This peak is from a cyanidin but the group linked to the anthocyanidin (MW $=190 \mathrm{Da})$ was not identified.

$N$. obscura presents five of the six common anthocyanidins found in foods: delphinidin; cyanidin; pelargonidin; petunidin and peonidin and its anthocyanins contain four common sugars linked to the pyrylium ring (galactose, glucose, arabinose and xylose). One linked radical-group could not be identified.

\subsection{Separation by different HPLC/DAD methodologies}

Fig. 1 presents the typical separation chromatogram of the anthocyanins of $N$. obscura using ACE 5 column and mobile phase 1 containing $10 \%$ aqueous formic acid $(90: 10 ; \mathrm{v} / \mathrm{v})$ as solvent A and formic acid/water/methanol (10:40:50; v/v/v) as solvent B. All the anthocyanins identified previously by LC/DAD/MS were observed in the chromatogram: (1) delphinidin-3-O-galactoside, (2) delphinidin-3-O-glucoside, (3) cyanidin-3-O-galactoside, (4) cyanidin-3-O-glucoside, (5) cyanidin-3-O-arabinoside, (6) petunidin-3-0-glucoside + delphinidin-3-0-xyloside, (7) pelargonidin-3-O-glucoside, (8) peonidin-3-O-galactoside, (9) peonidin3-O-glucoside, (10) cyanidin-3-O-xyloside. Compound identification was based on RP-HPLC elution order, UV-Vis spectra and by standards addition.
Mobile phase 2 containing 5\% formic acid/water (5:95; v/v) as solvent A and acetonitrile as solvent B was also tested in the ACE 5 column; however, this gradient was not appropriate because only peaks 1-4 were separated (chromatogram not shown).

Chromatographic separation of the anthocyanins from N. obscura was also performed using TS column and using the two mobile phases that were tested previously with the ACE 5 column, typical chromatograms are presented in Fig. 2A and B. The TS column enabled an efficient chromatographic separation; this column provides shorter retention times because the used temperature is higher $\left(40{ }^{\circ} \mathrm{C}\right)$ and the particle size is smaller $(2.4 \mu \mathrm{m})$, all the anthocyanins identified previously were observed in the chromatograms with lower retention times. The peaks 1-4 eluted within the first $5 \mathrm{~min}$ using the mobile phase 1 whereas these peaks eluted between 7 and 10 min using the mobile phase 2, thus the last was preferred to avoid the elution of interfering polar compounds in the same retention time of anthocyanins. Comparison between the two chromatographic methodologies was performed using the ACE 5 column with the mobile phase 1, coded as method 1 and the TS column using the mobile phase 2, codded as method 2.

\subsection{Methods validation according to international regulations}

A calibration curve covering a large concentration range (from 0.05 to $50 \mathrm{mg}$ of cyaniding-3-glucoside $\mathrm{L}^{-1}$ ) was needed due to the differences in the amount of individual anthocyanins observed

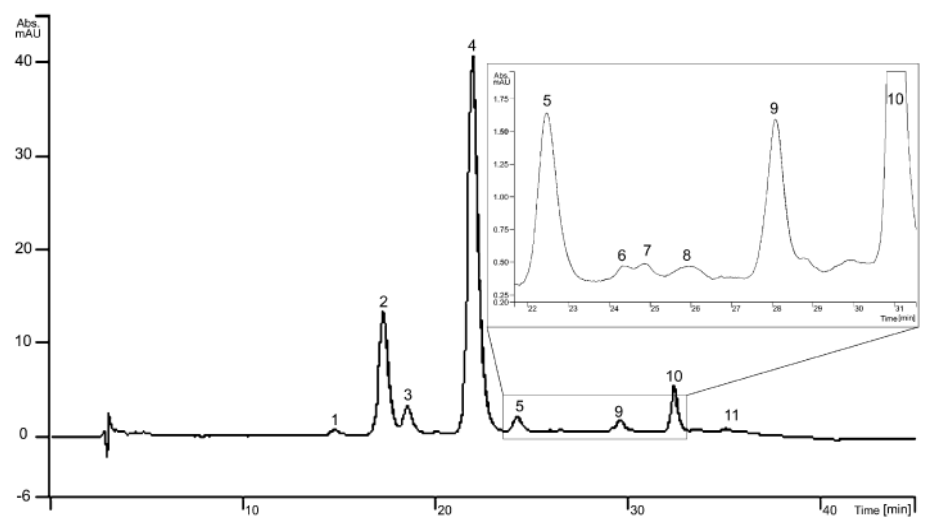

Fig. 1. Typical chromatogram for separation of anthocyanins of $N$. obscura using ACE 5 column and mobile phase 1 containing $10 \%$ aqueous formic acid (90:10; $\mathrm{v} / \mathrm{v}$ ) as solvent A and formic acid/water/methanol (10:40:50; v/v/v) as solvent B, coded as method 1. Peak 1 - delphinidin-3-O-galactoside; peak 2 - delphinidin-3-0-glucoside; peak 3 cyanidin-3-0-galactoside: peak 4 - cyanidin-3-0-glucoside; peak 5 - cyanidin-3-0-arabinoside; peak 6 - petunidin-3-0-glucoside and delphinidin-3-0-xyloside: peak 7 pelargonidin-3-O-glucoside; peak 8 - peonidin-3-O-galactoside; peak 9 - peonidin-3-O-glucoside; peak 10 - cyanidin-3-0-xyloside; peak 11 - cyanidin + MW (190 Da). 

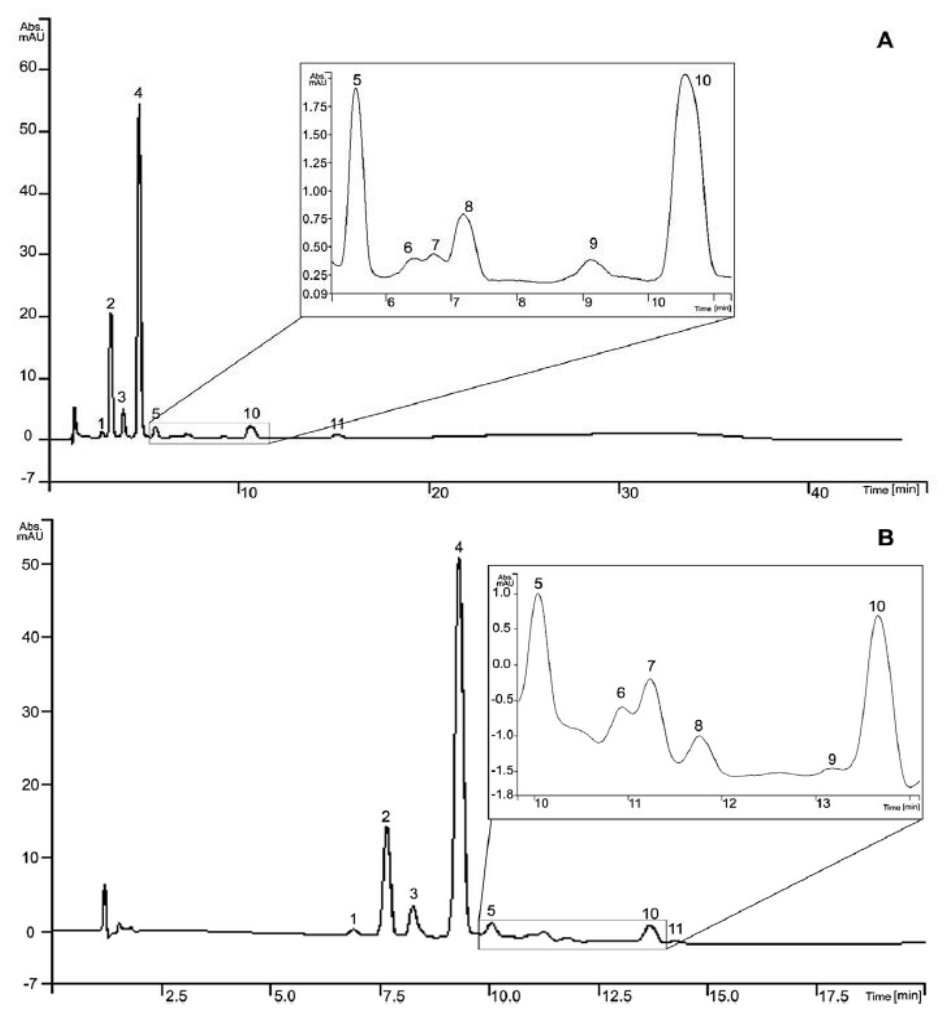

Fig. 2. Typical chromatogram for separation of anthocyanins of $\mathrm{N}$. obscura using TS column and (A) mobile phase 1 containing 10\% aqueous formic acid (90:10; $\mathrm{v} / \mathrm{v}$ ) as solvent A and formic acid/water/methanol $(10: 40: 50 ; \mathrm{v} / \mathrm{v} / \mathrm{v})$ as solvent $\mathrm{B}$; and (B) mobile phase 2 containing $5 \%$ formic acid/water $(5: 95 ; \mathrm{v} / \mathrm{v})$ as solvent $A$ and acetonitrile as solvent $B$ the last conditions were coded as method 2 . Peak 1 - del phinidin-3-O-galactoside; peak 2 - delphinidin-3-O-glucoside; peak 3 - cyanidin-3-0-galactoside; peak 4 - cyanidin3-O-glucoside; peak 5 - cyanidin-3-0-arabinoside; peak 6 - petunidin-3-0-glucoside and delphinidin-3-0-xyloside; peak 7 - pelargonidin-3-0-glucoside; peak 8 - peonidi3-O-galactoside; peak 9 - peonidin-3-O-glucoside; peak 10 - cyanidin-3-O-xyloside; peak 11 - cyanidin + MW (190 Da).

in $N$. Obscura fruits. Two models were used to obtain cyaniding3-glucoside calibration curve, least squares linear regression and weighted linear regression models, the calibration curves were obtained by using method 1 and method 2 . The weighted regressions presented lower variability of \%RE (less than $8 \%$ ) for all concentrations using both columns, whereas least squares linear regression presented high \%RE for low concentrations (up to $38 \%$ and $75 \%$, respectively for ACE 5 and TS columns). For ACE 5 column the sum of absolute \%RE was 69.88 for least squares linear regression and 36.02 for weighted regressions, whereas for TS column the sum of absolute \%RE was 130.52 for least squares linear regression and 18.54 for weighted regressions these parameters gave an indication of fit quality of weighted regression model, thus it was preferred. Regression parameters obtained after application of the weighting factors for both methods are summarized in Table 2 . Low LOD values, $0.031 \mathrm{mg} \mathrm{L}^{-1}$ and $0.021 \mathrm{mg} \mathrm{L}^{-1}$ were obtained respectively for method 1 and method 2 . LOQ values were $0.103 \mathrm{mg} \mathrm{L}^{-1}$ and $0.070 \mathrm{mg} \mathrm{L}^{-1}$ for method 1 and method 2. The uncertainties associated with calibration curve $(U)$ were lower than $1 \%$ for a concentration of $5 \mathrm{mg} \mathrm{L}^{-1}$ but increased near the detection limit.

Comparison between the slope and intercept of the calibration curves of method 1 and method 2 was performed. For comparison of slopes it was applied Student's t-test, and the $t$-value calculated was 0.0089 , lower than the tabulated value 1.943 with $95 \%$ confidence. The same statistical treatment was performed for comparison between the intercept of the calibration curves obtained using both methods and the $t$-value calculated was 0.107 , lower than the tabulated value 1.943 with $95 \%$ confidence. The null hypothesis is accepted in both cases, no significant differences were observed in the slope and the intercept of the calibration curves obtained by both methods (Zar, 2010). However, the

Table 2

Quality calibration parameters, detection and quantification limits, related standard deviations and uncertainties.

\begin{tabular}{|c|c|c|c|c|c|c|c|c|}
\hline & $b_{\mathrm{w}} \pm S_{(\mathrm{b}) \mathrm{w}}$ & $a_{\mathrm{w}} \pm S_{(\mathrm{a}) \mathrm{w}}$ & $r_{w}^{2}$ & $\operatorname{LOD}\left(\mathrm{mg} \mathrm{L}^{-1}\right)$ & $\operatorname{LOQ}\left(\mathrm{mg} \mathrm{L}^{-1}\right)$ & $S_{(y / x) w}$ & $\% U_{0.05}\left(\mathrm{mg} \mathrm{L}^{-1}\right)$ & $\% U_{5\left(\mathrm{mg} \mathrm{L}^{-1}\right)}$ \\
\hline Method 1 & $371328.1 \pm 79.2$ & $-922.6 \pm 1476.3$ & 0.9995 & 0.031 & 0.103 & 3824.88 & 21.65 & 0.79 \\
\hline Method 2 & $370798.2 \pm 54.0$ & $1445.7 \pm 1007.6$ & 0.9998 & 0.021 & 0.070 & 2610.46 & 14.77 & 0.51 \\
\hline
\end{tabular}

Method 1 - ACE 5 column and mobile phase 1 ; method 2 - TS column and mobile phase 2 ; $b_{\mathrm{w}}$ - weighted slope; $a_{\mathrm{w}}$ - weighted intercept; $r_{\mathrm{w}}^{2}$ - weighted correlation coefficient; $S_{(b) w}$ and $S_{(a) w}$ - standard deviations of the weighted slope and weighted intercept; $S_{(y / x) w}-$ standard deviation of y-residuals of weighted regression line; LOD - limit of detection: LOQ - limit of quantification; $U$ - uncertainties associated with calibration. 
Table 3

Results on repeatability and accuracy of method 2 for cyanidin-3-0-glucoside in $N$. obscura.

\begin{tabular}{|c|c|c|c|c|c|c|c|c|}
\hline & \multicolumn{6}{|c|}{ Precision RSD (\%) } & \multicolumn{2}{|l|}{ Recovery } \\
\hline & Intrad & & & Interc & & & \multirow{2}{*}{$\begin{array}{l}\begin{array}{l}\text { Exp. Conc. } \\
\left(\mathrm{mg} \mathrm{L}^{-1}\right)\end{array} \\
2.5\end{array}$} & \multirow{2}{*}{$\begin{array}{l}\begin{array}{l}\text { Mean } \\
\text { recovery } \\
(\%)\end{array} \\
2.5\end{array}$} \\
\hline $\begin{array}{l}\text { Spiked level } \\
\left(\mathrm{mg} \mathrm{L}^{-1}\right)\end{array}$ & 0.05 & 1 & 50 & 0.05 & 1 & 50 & & \\
\hline Method 2 & 5.4 & 1.2 & 1.0 & 5.7 & 3.5 & 8.4 & $2.37 \pm 0.03$ & 94.7 \\
\hline
\end{tabular}

Table 4

Anthocyanins content in N. obscura assayed by method 2, results are expressed as ms of cyanidin-3-0-glucoside equivalents $100 \mathrm{~g}^{-1}$ fresh weight

\begin{tabular}{clr}
\hline Peak & Anthocyanin & $\mathrm{mg} \mathrm{100}^{-1}$ \\
\hline 1 & Delphinidin-3-O-galactoside & $1.9 \pm 0.2$ \\
2 & Delphinidin-3-O-glucoside & $48.1 \pm 1.6$ \\
3 & Cyanidin-3-0-galactoside & $12.7 \pm 0.7$ \\
4 & Cyanidin-3-O-glucoside & $175.8 \pm 5.3$ \\
5 & Cyanidin-3-0-arabinoside & $7.2 \pm 0.3$ \\
6 & Petunidin-3-O-glucoside/Delphinidin-3-0-xyloside & $3.1 \pm 0.0$ \\
7 & Pelargonidin-3-glucoside & $0.3 \pm 0.0$ \\
8 & Peonidin-3-O-galactoside & $1.2 \pm 0.0$ \\
9 & Peonidin-3-O-glucoside & $0.3 \pm 0.0$ \\
10 & Cyanidin-3-0-xyloside & $11.4 \pm 0.4$ \\
11 & Cyanidin + MW (190 Da) & $1.6 \pm 0.4$ \\
& Total anthocyanin content & $263.6 \pm 8.2$ \\
\end{tabular}

method 2 enabled reduced analyses time and mobile phase consumption added with the use of lower amounts of formic acid that is advantageous to the maintenance of chromatographic equipment, thus it was preferred for further studies.

Results from precision and accuracy of method 2 are summarized in Table 3. The coefficients of variation ranged between $1.0 \%$ and $5.4 \%$ for the inter-day assays and between $3.5 \%$ and $8.4 \%$ for the intra-day tests. These results are excellent since the precision should be lower than $15 \%$, except at the LOQ which can be up to $20 \%$. Concerning the accuracy the mean recovery of the method was $94.7 \%$. The control limits for this parameter are set between $70 \%$ and $120 \%$.

\subsection{Analyses of mature fruits}

Method 2 was applied on the separation and quantification of anthocyanins in $N$. obscura. The total anthocyanin content of mature fruits is $263.6 \pm 8.2 \mathrm{mg}$ of cyanidin-3-glucoside equivalents/100 $\mathrm{g}$ fresh weight, the amount of each anthocyanin is presented in Table 4. The content of anthocyanins in fresh material was evaluated on the basis of moisture of fresh and freeze-dried fruits. The cyanidin was the predominant contributor with $78.9 \%$, followed by delphinidin with $18.9 \%$ and adding up the other anthocyanins that contributed only with $2 \%$ of total. Thus although the quantification was performed using an external standard curve of cyanidin-3-0-glucoside the possible error in quantification is not relevant. The total anthocyanin content was similar to that described in literature for anthocyanin rich berries, such as jussara that contains $290 \mathrm{mg} / 100 \mathrm{~g}$ fresh weight (De Brito et al., 2007), açaí that contains $224 \mathrm{mg} / 100 \mathrm{~g}$ fresh weight (Pacheco-Palencia, Duncan, \& Talcott, 2009) and blackberry, which contains $245 \mathrm{mg}$ / $100 \mathrm{~g}$ fresh weight (Wu et al., 2006).

\section{Conclusions}

This study describes for the first time the identification and quantification of anthocyanins in fruits of N. obscura (DC.) N. Silveira, an endemic plant of the Brazilian Atlantic Forest that belongs to the Myrtaceae family. These fruits from flora of Brazilian "Restinga" have not been valued adequately because studies about its composition are scarce. However, this work highlights that $N$. obscura is a potential source of bioactive compounds, because it contains delphinidin-3-0-galactoside, delphinidin-3-0-glicoside, cyanidin-3-0-galactoside, cyanidin-3-0-glicoside, cyanidin-3-0arabinoside, petunidin-3-O-glicoside, pelargonidin-3-O-glicoside, peonidin-3-O-galactoside, peonidin-3-O-glicoside, cyanidin-3-0xyloside. Two different chromatographic methods that differed in the column length and its particle size, the mobile phase, gradient and elution temperature were compared. The method that enables reduced analyses time and less mobile phase consumption with lower amounts of formic acid was validated for reliable quantification of anthocyanins in $N$. obscura fruits. The total anthocyanin content of mature fruits was in the same range found in literature for anthocyanin rich fruits.

\section{Acknowledgements}

This work received financial support from the European Union (FEDER funds through COMPETE) and National Funds (FCT, Fundação para a Ciência e Tecnologia) through project Pest-C/EQB/ LA0006/2013. The work also received financial support from the European Union (FEDER funds) under the framework of QREN through Project NORTE-07-0124-FEDER-000069. The author, Ana Cristina M.S. Gouvêa, also would like to thank to the Brazilian Research Agency (Coordenação de Aperfeiçoamento de Nível Superior - CAPES) for its financial support, and gratefully acknowledge Dr Marcelo da Costa Souza for assistance in the certification of the identified Myrtaceae species.

\section{References}

Abad-Garcia, B., Berrueta, L. A., Garmon-Lobato, S., Gallo, B., \& Vicente, F. (2009). A general analytical strategy for the characterization of phenolic compounds in fruit juices by high-performance liquid chromatography with diode array detection coupled to electrospray ionization and triple quadrupole mass spectrometry. Journal of Chromatography A, 1216(28), 5398-5415.

Alberts, P., Stander, M. A., \& de Villiers, A. (2012). Advanced ultra high pressure liquid chromatography-tandem mass spectrometric methods for the screening of red wine anthocyanins and derived pigments. Joumal of Chromatography $A$, $1235,92-102$

Amaral, R. R., Fernandes, C. P., Caramel, O. P., Tietbohl, L. A. C., Santos, M. G. Carvalho, J. C. T., et al. (2013). Essential oils from fruits with different colors and leaves of Neomitranthes obscura (DC.) N. Silveira: An endemic species from Brazilian Atlantic Forest. Biomed Research International [ID 723181].

Amaro, L. F., Soares, M. T., Pinho, C., Almeida, I. F., Pinho, O., \& Ferreira, I. M. P. L. V. O. (2013). Processing and storage effects on anthocyanin composition and antioxidant activity of jams produced with Camarosa strawberry. Internationa Journal of Food Science and Technology, 48(10), 2071-2077.

Berente, B., Garcia, D. D. L., Reichenbacher, M., \& Danzer, K. (2000). Method development for the determination of anthocyanins in red wines by highperformance liquid chromatography and classification of German red wines by means of multivariate statistical methods. Journal of Chromatography A, 871(12), 95-103.

Castaneda-Ovando, A., Pacheco-Hernandez, M. D., Paez-Hernandez, M. E., Rodriguez, J. A., \& Galan-Vidal, C. A. (2009). Chemical studies of anthocyanins: A review. Food Chemistry. 113(4). 859-871.

De Brito, E. S., De Araujo, M. C. P., Alves, R. E., Carkeet, C., Clevidence, B. A., \& Novotny, J. A. (2007). Anthocyanins present in selected tropical fruits: Acerola. jambolao, jussara, and guajiru. Journal of Agricultural and Food Chemistry, 55(23), 9389-9394.

de Villiers, A., Cabooter, D., Lynen, F., Desmet, G., \& Sandra, P. (2009). High performance liquid chromatography analysis of wine anthocyanins revisited: Effect of particle size and temperature. Joumal of Chromatography A, 1216(15), 3270-3279.

International Conference on, Harmonisation (ICH). (2005). Harmonised tripartite guideline, validation of analytical procedures: Text and methodology Q2 (R1). Jayaprakasam, B., Olson, L. K., Schutzki, R. E., Tai, M. H., \& Nair, M. G. (2006). Amelioration of obesity and glucose intolerance in high-fat-fed C57BL/6 mice by anthocyanins and ursolic acid in Comelian cherry (Cornus mas). Journal of Agricultural and Food Chemistry, 54(1), 243-248.

Mansilha, C., Melo, A., Rebelo, H., Ferreira, I. M. P. L. V. O., Pinho, O., Domingues, V., et al. (2010). Quantification of endocrine disruptors and pesticides in water by gas chromatography-tandem mass spectrometry. Method validation using 
weighted linear regression schemes. Journal of Chromatography A, 1217(43), 6681-6691.

Miller, J. N., \& Miller, J. C. (2005). Statistics and chemometrics for analytical chemistry. England: Pearson/Prentice Hall.

Oliveira, C., Amaro, L. F., Pinho, O., \& Ferreira, I. M. P. L. V. O. (2010). Cooked blueberries: Anthocyanin and anthocyanidin degradation and their radicalscavenging activity. Journal of Agricultural and Food Chemistry, 58(16), 9006-9012.

Oliveira, J., da Silva, M. A., Parola, A. J., Mateus, N., Bras, N. F., Ramos, M. J., et al. (2013). Structural characterization of a A-type linked trimeric anthocyanin derived pigment occurring in a young Port wine. Food Chemistry, 141(3), 1987-1996.

Pacheco-Palencia, L. A., Duncan, C. E., \& Talcott, S. T. (2009). Phytochemical composition and thermal stability of two commercial acai species, Euterpe oleracea and Euterpe precatoria. Food Chemistry, 115(4), 1199-1205.

Queiroz, F., Oliveira, C., Pinho, O., \& Ferreira, I. M. P. L. V. O. (2009), Degradation of anthocyanins and anthocyanidins in blueberry jams/stuffed fish. Journal of Agricultural and Food Chemistry, 57(22), 10712-10717.

Ramos, M. F. D., Monteiro, S. D., da Silva, V. P., Nakamura, M. J., \& Siani, A. C. (2010). Essential oils from Myrtaceae species of the Brazilian Southeastern Maritime Forest (Restinga). Joumal of Essential Oil Research, 22(2), 109-113.
Sumner, M. D., Elliott-Eller, M., Weidner, G., Daubenmier, J. J., Chew, M. H., Marlin, R., et al. (2005). Effects of pomegranate juice consumption on myocardia perfusion in patients with coronary heart disease. American Journal of Cardiology, 96(6), 810-814.

Wang, L. S., \& Stoner, G. D. (2008). Anthocyanins and their role in cancer prevention Cancer Letters, 269(2), 281-290.

Wu, X., Beecher, G. R., Holden, J. M., Haytowitz, D. B., Gebhardt, S. E., \& Prior, R. (2006). Concentrations of anthocyanins in common foods in the United States and estimation of normal consumption. Journal of Agriculture and Food Chemistry, 54(11), 4069-4075.

Wu, X. L., \& Prior, R. L. (2005a). Identification and characterization of anthocyanins by high-performance liquid chromatography-electrospray ionization-tandem mass spectrometry in common foods in the United States: Vegetables, nuts, and grains. Journal of Agricultural and Food Chemistry, 53(8), 3101-3113.

Wu, X. L., \& Prior, R. L. (2005b). Systematic identification and characterization of anthocyanins by HPLC-ESI-MS/MS in common foods in the United States: Fruits and berries. Journal of Agricultural and Food Chemistry, 53(7), 2589-2599. Zar, J. H. (2010), Comparing simple linear regression equations. In J. H. Zar (Ed.). Biostatistical analysis. New Jersey: Prentice-Hall/Pearson. 
7.8- Apêndice H (Food Technology, v.17, 2014)

Food Technology

Campinas, v. 17 , n. 1, p. $51-57$, jan./mar. 2014 DOI: http://dx.doi.org/10.1590/bjft.2014.008

\section{Analytical standards production for the analysis of pomegranate anthocyanins by HPLC}

Produção de padrões analíticos para análise de antocianinas da romã por CLAE

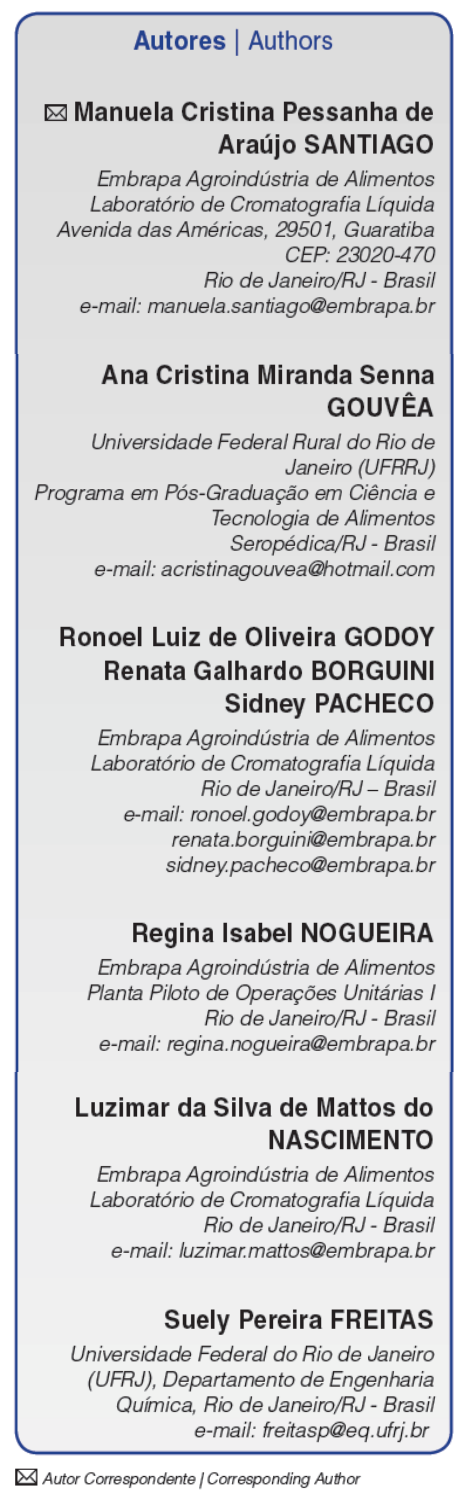

Recebido / Received: 22/08/2013 Aprovado / Approved: 11/03/2014 Publicado / Published: mar./2014

\section{Summary}

Pomegranate (Punica granatum L.) is a fruit with a long medicinal history, especially due to its phenolic compounds content, such as the anthocyanins, which are reported as one of the most important natural antioxidants. The analysis of the anthocyanins by high performance liquid chromatography (HPLC) can be considered as an important tool to evaluate the quality of pomegranate juice. For research laboratories the major challenge in using HPLC for quantitative analyses is the acquisition of high purity analytical standards, since these are expensive and in some cases not even commercially available. The aim of this study was to obtain analytical standards for the qualitative and quantitative analysis of the anthocyanins from pomegranate. Five vegetable matrices (pomegranate flower, jambolan, jabuticaba, blackberry and strawberry fruits) were used to isolate each of the six anthocyanins present in pomegranate fruit, using an analytical HPLC scale with non-destructive detection, it being possible to subsequently use them as analytical standards. Furthermore, their identities were confirmed by high resolution mass spectrometry. The proposed procedure showed that it is possible to obtain analytical standards of anthocyanins with a high purity grade ( 98.0 to $99.9 \%$ ) from natural sources, which was proved to be an economic strategy for the production of standards by laboratories according to their research requirements.

Key words: Liquid chromatography; Cyanidin; Delphinidin; Pelargonidin;

Punica granatum L.

\section{Resumo}

Romã (Punica granatum L.) é um fruto com um longo histórico medicinal, especialmente devido aos compostos fenólicos presentes em sua composição, como as antocianinas, as quais são relatadas como um dos mais importantes antioxidantes naturais. A análise de antocianinas por Cromatografia Líquida de Alta Eficiência (CLAE) pode ser considerada uma ferramenta importante para avaliar a qualidade do suco de romã. Para os laboratórios de pesquisa, o maior desafio para a análise quantitativa pela técnica de CLAE é a aquisição de padrões analíticos de alta pureza, uma vez que eles são caros e, em alguns casos, não se encontram disponíveis comercialmente. O objetivo deste estudo foi obter padrões analíticos para a análise qualitativa e quantitativa de antocianinas da romã Cinco matrizes vegetais (flor de romã e frutos de jambolão, jabuticaba, amora e morango) foram usadas para isolar cada uma das seis antocianinas presentes no fruto da romã, usando a escala analítica com detecção não destrutiva, sendo possível usá-las posteriormente como padrões analíticos. Além disso, as suas identidades foram confirmadas pela técnica de espectrometria de massa de alta resolução. O procedimento proposto mostrou que é possível obter padrões analíticos de antocianinas com elevado grau de pureza (98,0\%-99,9\%) a partir de fontes naturais e provou ser uma estratégia econômica para os laboratórios que necessitam adquirir padrões, de acordo com as necessidades de suas pesquisas. Palavras-chave: Cromatografia líquida; Cianidina; Delfinidina; Pelargonidina; Punica granatum $L$. 
Analytical standards for the analysis of pomegranate anthocyanins by HPLC

SANTIAGO, M. C. P. A. et al.

\section{Introduction}

The pomegranate (Punica granatum L.) fruit, native from Iran and endemic in the Middle East, grows in semiarid climates. In recent years there has been renewed interest in the global nutraceutical and functional benefits of this fruit, both fresh and processed (SUMNER et al., 2005).

The pomegranate fruit has some phenolic compounds such as anthocyanins (delphinidin, cyanidin and pelargonidin) in its composition, and also quercetin, phenolic acids and tannins (punicalagin). The fruit is consumed fresh or processed as juice and can be used in the food industry for the manufacture of juice beverages, soft drinks, confectionary products and also colorants (QU et al., 2011).

Due to the increased demand for healthy products, anthocyanin-rich fruits have great potential as raw materials in food formulations, acting as one of the most important natural antioxidants and being responsible for the intense red colour of pomegranate juice based products. The colour is one of the quality parameters that most promotes sensory acceptability by consumers (GIL et al., 2000; ALIGHOURCHI and BARZEGAR, 2009; BOROCHOV-NEORI et al., 2009; PATRAS et al., 2010). Thus, the analysis of anthocyanins by a reliable technique, such as HPLC, can be considered as an important tool to evaluate pomegranate juice quality. Besides the sensory-organoleptic characteristics, knowledge of the anthocyanin profile of pomegranate materials becomes important, since it allows for the identification of adulteration in these products (ZHANG et al., 2009). Thus the analysis of the anthocyanins by a reliable technique can also be considered as an important tool to evaluate pomegranate juice authenticity.

Studies on the characterization and quantification of the phytochemical and antioxidant properties of fruits have become essential and increase awareness about the different cultivars, whether natural or enhanced. Knowledge of the quality and chemical characteristics of some species provides subsidies to distinguish them from each other, and can also provide information to enable an improvement in their genetics, since the concentration and variety of types of the anthocyanins is what will determine the intensity of colouring of the various fruit cultivars (POMAR et al., 2005; ÖZGEN et al., 2009).

The major challenge in the quantitative analysis of compounds by HPLC, especially of anthocyanins, is the obtaining of analytical standards. Standardization is certainly the largest source of analytical errors, because it directly impacts the final result (KIMURA and RODRIGUEZ-AMAYA, 2002). In some countries the acquisition of high purity analytical standards usually depends on highly expensive importations, and in addition there are no commercial standards available for many of the anthocyanins found in nature.

The production of analytical standards of anthocyanins by isolation is considered to be a challenge, mainly due to the difficulties of obtaining crystalline anthocyanins, free from impurities, in sufficient amounts to allow for reliable weighing (GIUSTI et al., 1999). Thus the aim of this study was to isolate analytical anthocyanin standards from different matrices, using a practical and reliable method known as the analytical HPLC scale with non-destructive detection, for the qualitative and quantitative analysis of pomegranate fruit anthocyanins.

\section{Materials and methods}

\subsection{Chemicals}

HPLC grade acetonitrile, 96\% formic acid and methanol were purchased from Tedia (USA). Ultrapure water was obtained from the Milli- $Q^{\text {TM }}$ Gradient $10 A$ System (Merck Millipore, USA). Delphinidin-3,5-diglucoside chloride was purchased from Chromadex (USA).

\subsection{Samples}

Samples with the potential for use as sources of the anthocyanins of interest, based on their high content of these compounds, were selected for this study as follows: pomegranate flower, jambolan (peel), jabuticaba (peel), blackberry (whole fruit) and strawberry (whole fruit) (Table 1). Pomegranate flowers were collected in the western region of Rio de Janeiro city. Pomegranate fruits (from the Brazilian semiarid region), strawberry (Fragaria spp.), jabuticaba (Plinia spp.) and jambolan (Syzygium cumini) fruits were purchased in the Rio de Janeiro market. Pomegranate juice was obtained by extraction from the arils. For the blackberry and strawberry juices, the whole fruits were processed in a blender. The jambolan and jabuticaba peels, blackberry and strawberry juices and the pomegranate flowers were freeze-dried in a Liotop ${ }^{\mathrm{TM}}$ L101 (Liobras, Brazil) at $-40^{\circ} \mathrm{C}$ for 24 hours, and stored at $-18^{\circ} \mathrm{C}$ until extraction.

Table 1. Vegetable matrices selected for the isolation of the anthocyanins.

\begin{tabular}{|cc}
\hline Anthocyanin & Matrix selected \\
\hline Delphinidin-3,5-diglucoside & Jambolan fruit \\
Cyanidin-3,5-diglucoside & Jambolan fruit \\
Delphinidin-3-glucoside & Jabuticaba fruit \\
Pelargonidin-3,5-diglucoside & Pomegranate flower \\
Cyanidin-3-glucoside & Blackberry fruit \\
Pelargonidin-3-glucoside & Strawberry fruit \\
\hline
\end{tabular}


Analytical standards for the analysis of pomegranate anthocyanins by HPLC

SANTIAGO, M. C. P. A. et al.

\subsection{Sample extraction}

Two grams of each freeze-dried sample were weighed into four centrifuge tubes with lids for extraction with methanol: formic acid (10:90, v/v) under sonication, following by centrifugation (BRITO et al., 2007). All the materials obtained in the supernatants after extraction were concentrated using a Büchi RE rotatory evaporator (Switzerland) at $38^{\circ} \mathrm{C}$ for 4 hours. The dried extract was diluted with $4 \mathrm{~mL}$ of a $5 \%$ formic acid solution in water: methanol $(90: 10, v / v)$ and filtered through a hydrophilic type Millex ${ }^{\mathrm{TM}}$ membrane $(0.45 \mu \mathrm{m}$; Merck Millipore; USA) directly into an automatic chromatograph injector vial.

\subsection{HPLC-PDA evaluation of the anthocyanins}

Chromatographic analysis was carried out following the methodology described by Brito et al. (2007), using a Waters (USA) Alliance ${ }^{\mathrm{TM}} 2695$ system equipped with a Waters 2996 photodiode array detector (at $520 \mathrm{~nm}$ ). A Thermo Scientific $C_{18}$ BDS $(100 \mathrm{~mm} \times 4.6 \mathrm{~mm}$; $2.4 \mu \mathrm{m}$; USA) column was used with an injection volume of $20 \mu \mathrm{L}$, mobile phase consisting of $5 \%$ aqueous formic acid (solvent A) and acetonitrile (solvent $\mathrm{B}$ ) in the gradient elution mode (Table 2) with a flow rate of $1.0 \mathrm{~mL} \mathrm{~min}{ }^{1}$. The column temperature was $40^{\circ} \mathrm{C}$

\subsection{Conditions for the isolation of the anthocyanins by HPLC-PDA}

The anthocyanins were isolated following the methodology described by Brito et al. (2007) using a Waters (USA) Alliance ${ }^{\mathrm{TM}} 2695$ system equipped with a Waters 2996 photodiode array detector (at $520 \mathrm{~nm}$ ). A

Table 2. Gradient elution mode for the evaluation of the anthocyanins.

\begin{tabular}{ccc} 
Time (minutes) & Solvent A (\%) & Solvent B (\%) \\
\hline 0 & 95 & 5 \\
2 & 93 & 7 \\
10 & 90 & 10 \\
12 & 95 & 5 \\
14 & 90 & 10 \\
\hline
\end{tabular}

Solvent A: $5 \%$ aqueous formic acid. Solvent B: acetonitrile

Table 3. Gradient elution mode for isolation of the anthocyanins.

\begin{tabular}{ccc} 
Time (minutes) & Solvent A (\%) & Solvent B (\%) \\
\hline 0 & 95 & 5 \\
2 & 95 & 5 \\
10 & 90 & 10 \\
15 & 87 & 13 \\
16.5 & 80 & 20 \\
18 & 95 & 5 \\
20 & 95 & 5 \\
\hline
\end{tabular}

Solvent A: $5 \%$ aqueous formic acid. Solvent B: acetonitrile
Symmetry ${ }^{\mathrm{TM}} \mathrm{C}_{18}$ column (150 $\mathrm{mm} \times 4.6$; $3.5 \mu \mathrm{m}$; Waters; USA) was used with an injection volume of $50 \mu \mathrm{L}$, mobile phase consisting of $5 \%$ aqueous formic acid (solvent $A$ ) and acetonitrile (solvent $\mathrm{B}$ ), in the gradient elution mode

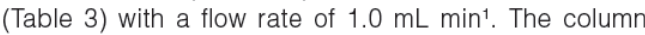
temperature was $40^{\circ} \mathrm{C}$.

\subsection{Anthocyanin isolation method}

The anthocyanins were isolated by liquid chromatography coupled to a Rheodyne six-channe selection valve (GOUVÊA et al., 2012). The valve was adapted to select output channels rather than possible columns, replacing the traditional fraction collector Substances of interest were collected on elution, according to the retention time of each anthocyanin, using a selector valve commanded by Empower ${ }^{\mathrm{TM}}$ software (Waters, USA)

\subsection{Concentration of the standards}

For the concentration step, a Waters (USA) Sep-Pak ${ }^{\mathrm{TM}} \mathrm{C}_{18}$ cartridge previously packed with methanol was saturated with the aqueous extract of the isolated anthocyanins. The cartridge was then washed with an aqueous solution of $0.01 \% \mathrm{HCl}$ to remove the more polar compounds present, such as sugars and phenolic acids, and the anthocyanin pigments retained were eluted with methanol. The eluted anthocyanin pigments were dried under a filtered compressed air flow, and diluted with a $5 \%$ formic acid solution in water: methanol (90:10, $\mathrm{v} / \mathrm{v}$ ) in a $5 \mathrm{~mL}$ amber volumetric flask. Aliquots of each isolated anthocyanin were injected under the same chromatographic conditions described above, and the peak areas used to check the purity.

\subsection{MS/MS condition}

A high resolution Waters mass spectrometer (USA) Synapt ${ }^{\mathrm{TM}}$ ESI-QTOF, with direct injection, was used to confirm the identity of the anthocyanins isolated. The MS source used was positive electrospray ionization $\left(E S I^{+}\right)$ with the following conditions: source temperature at 120 ${ }^{\circ} \mathrm{C}$, desolvation gas $\left(\mathrm{N}_{2}\right)$ delivered at $12.5 \mathrm{~L} \mathrm{~min}^{-1}$ at 500 ${ }^{\circ} \mathrm{C}$, capillary exit set at $3.0 \mathrm{kV}$, sampling cone energy set at $25.0 \mathrm{~V}$ and extraction cone energy set at $4.0 \mathrm{~V}$.

\subsection{Calculation of the concentrations of the standards}

$200 \mu \mathrm{L}$ aliquots of the solutions obtained after concentration were collected, dried under a filtered compressed air flow and diluted with $2.0 \mathrm{~mL}$ of the appropriate solution for each anthocyanin, according to the molar absorptivity used (Table 4). The corresponding anthocyanin concentration of these solutions was calculated using the Beer-Lambert law from the 
Analytical standards for the analysis of pomegranate anthocyanins by HPLC

SANTIAGO, M. C. P. A. et al.

absorbance reading obtained using a Shimadzu UV-1800 spectrophotometer (Japan).

\subsection{Product evaluation}

The anthocyanin profile of the different pomegranate products such as the juice and microcapsules, obtained in the laboratory using a spray drying process, were evaluated to verify the application of the method.

\section{Results and discussion}

The chromatogram obtained from the pomegranate juice presented six anthocyanins (delphinidin-3,5-diglucoside; cyanidin-3,5-diglucoside; delphinidin-3-glucoside; pelargonidin-3,5-diglucoside; cyanidin-3-glucoside; pelargonidin-3-glucoside) (Figure 1). The same anthocyanins profile was reported by Gil et al. (2000) for pomegranate juice.

The six fruits chosen as anthocyanin sources made it possible to isolate these compounds by the HPLC technique with a great grade of purity at $520 \mathrm{~nm}$ (Figure 2), which is the same wavelength that the anthocyanins are detected and quantified using the proposed analytical method.

The purity of the isolated anthocyanins was calculated by evaluating the peak area of each one in relation to the total area of the chromatogram. Verification of the purity of the compounds at different wavelengths ensured an accurate calculation of their concentration. The purity of the isolated anthocyanins was also checked at 280 and $360 \mathrm{~nm}$, since at those wavelengths occurs the absorption by other compounds that could cause interference, such as other phenolic compounds (GIUSTI et al., 1999). Values above $90 \%$ of purity were obtained for all the six compounds evaluated at these two wavelengths.

The high values for purity obtained ensured there were no interfering substances that could cause bathochromic or hypsochromic effects of the ultraviolet/visible absorption spectra The compounds isolated in the $5 \%$ formic acid: methanol (90:10, v/v) solution showed values for concentration that were in an appropriate range to permit the construction

Table 4. Maximum absorption ( $\lambda$ ), specific solution used and molar absorptivity of each pomegranate anthocyanin.

\begin{tabular}{cccc}
\hline Anthocyanins & $\lambda(\mathbf{n m})$ & Specific solution & Molar Absorptivity \\
\hline Delphinidin-3,5-diglucoside & 520 & $1 \% \mathrm{HCl}$ in MeOH & $40368^{*}$ \\
Cyanidin-3,5-diglucoside & 508.5 & $1 \% \mathrm{HCl}$ in MeOH & $35000^{\star *}$ \\
Delphinidin-3-glucoside & 543 & $1 \% \mathrm{HCl}$ in MeOH & $29000^{\star *}$ \\
Pelargonidin-3,5-Diglucoside diglucoside & 510 & $1 \% \mathrm{HCl}$ in MeOH & $32360^{\star *}$ \\
Cyanidin-3-glucoside & 530 & $1 \% \mathrm{HCl}$ in MeOH & $34300^{\star *}$ \\
Pelargonidin-3-glucoside & 496 & $1 \% \mathrm{HCl}$ in $\mathrm{H}_{2} \mathrm{O}$ & $31620^{\star *}$ \\
\hline
\end{tabular}

"Molar absorptivity calculated by spectrophotometry using a commercial analytical standard of the anthocyanin, purchased from Chromadex(USA). ** Source: Giusti et al. (1999).

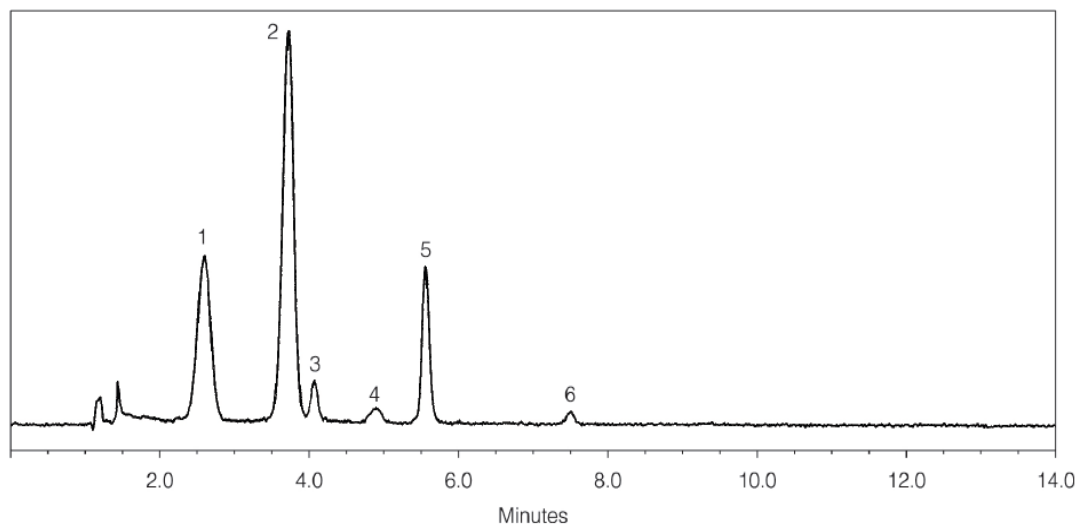

Figure 1. Chromatogram of the pomegranate juice anthocyanins (peak 1: delphinidin-3,5-diglucoside; peak 2: cyanidin-3,5diglucoside; peak 3: delphinidin-3-glucoside; peak 4: pelargonidin-3,5-diglucoside; peak 5: cyanidin-3-glucoside; peak 6: pelargonidin-3-glucoside). 
Analytical standards for the analysis of pomegranate anthocyanins by HPLC

SANTIAGO, M. C. P. A. et al
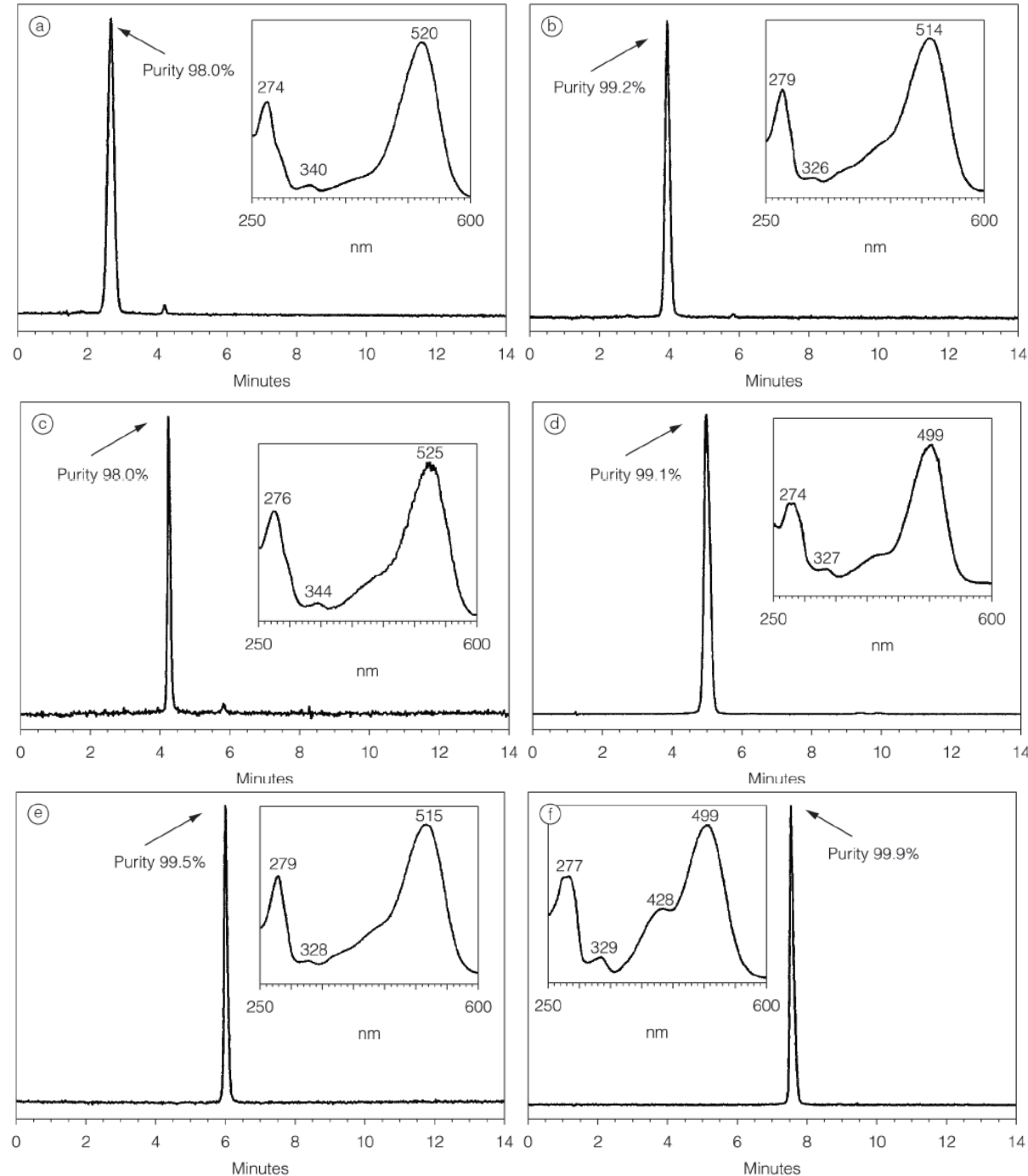

Figure 2. Chromatogram and UV/Nis spectra at $520 \mathrm{~nm}$ of the isolated anthocyanins: a) delphinidin-3,5-diglucoside; b) cyanidin3,5-diglucoside; c) delphinidin-3-glucoside; d) pelargonidin-3,5-diglucoside; e) cyanidin-3-glucoside; f) pelargonidin-3-glucoside.

of highly linear calibration curves (Table 5), allowing for the quantification of the matrix evaluated.

All the six anthocyanins isolated could be used as analytical standards, since besides the high grade of purity, the identity of each was confirmed by a reliable technique, such as high resolution mass spectrometry (Table 6).
As described by Müller et al. (2012) the use of single isolated anthocyanin standards better reflects the absolute content of these compounds in a solution than the use of just one anthocyanin to calculate all their concentrations. The same authors found higher anthocyanin contents in blueberries (Vaccinium corymbosum L.) and bilberries (Vaccinium myrtillus L.), using single isolated standards 
Analytical standards for the analysis of pomegranate anthocyanins by HPLC

SANTIAGO, M. C. P. A. et al.

Table 5. Data for the external standard calibration curves.

\begin{tabular}{|c|c|c|c|}
\hline \multirow[t]{2}{*}{ Anthocyanin } & \multicolumn{2}{|c|}{ Calibration curve data } & \multirow{2}{*}{$\begin{array}{c}\text { Concentration range } \\
\left(\mu \mathrm{g} \mathrm{mL} \mathrm{L}^{-1}\right)\end{array}$} \\
\hline & Equation & $\left(\mathrm{R}^{2}\right)$ & \\
\hline Delphinidin-3,5-diglucoside & $Y=9.89^{*} 10^{6} X+3.45^{*} 10^{4}$ & 0.999 & $3.20-102.34$ \\
\hline Cyanidin-3,5-diglucoside & $Y=8.23^{*} 10^{6} X+3^{*} 10^{5}$ & 0.989 & $25.75-103.00$ \\
\hline Delphinidin-3-glucoside & $Y=1.09^{*} 10^{7} X+3.35^{\star} 10^{4}$ & 0.995 & $3.25-13.00$ \\
\hline Pelargonidin-3,5-diglucoside & $Y=4.59^{*} 10^{7} X+4.61^{*} 10^{3}$ & 0.992 & $0.27-3.58$ \\
\hline Cyanidin-3-glucoside & $Y=9.55^{\star} 10^{6} X+2.65^{\star} 10^{4}$ & 0.998 & $1.21-21.21$ \\
\hline Pelargonidin-3-glucoside & $Y=4.59^{*} 10^{7} X+4.61^{*} 10^{3}$ & 0.998 & $0.27-2.16$ \\
\hline
\end{tabular}

Table 6. Identification of the anthocyanins isolated by high resolution mass spectrometry.

\begin{tabular}{ccccc} 
Peak & $\mathbf{t}_{\mathbf{R}}(\mathbf{m i n})$ & {$\left[^{\mathbf{M}}\right]^{+}(\mathbf{m} / \mathbf{z})$} & MS/MS $(\mathbf{m} / \mathbf{z})$ & Anthocyanin \\
\hline 1 & 1.8 & 627.1781 & $465.1274 / 303.0672$ & Delphinidin-3,5-diglucoside \\
2 & 2.6 & 611.1812 & $449.1287 / 287.0653$ & Cyanidin-3,5-diglucoside \\
3 & 2.9 & 465.1115 & 303.0608 & Delphinidin-3-glucoside \\
4 & 3.6 & 595.2229 & $433.1647 / 271.1086$ & Pelargonidin-3,5-diglucoside \\
5 & 4.0 & 449.1287 & 287.0716 & Cyanidin-3-glucoside \\
6 & 5.4 & 433.1424 & 271.0739 & Pelargonidin-3-glucoside \\
\hline
\end{tabular}

Table 7. Anthocyanin concentrations in raw pomegranate juice and microcapsules obtained by spray drying.

\begin{tabular}{|c|c|c|}
\hline \multirow{2}{*}{ Anthocyanin } & \multicolumn{2}{|c|}{ Concentration $\left(\mathrm{mg}^{\left.100 \mathrm{~g}^{-1}\right)^{*}}\right.$} \\
\hline & Raw juice & Microcapsules \\
\hline Delphinidin-3,5-diglucoside & $8.32 \pm 0.45$ & $27.00 \pm 0.74$ \\
\hline Cyanidin-3,5-diglucoside & $10.78 \pm 0.40$ & $57.42 \pm 1.17$ \\
\hline Delphinidin-3-glucoside & $0.53 \pm 0.01$ & $3.23 \pm 0.03$ \\
\hline Pelargonidin-3,5-diglucoside & $0.49 \pm 0.02$ & $1.93 \pm 0.18$ \\
\hline Cyanidin-3-glucoside & $5.50 \pm 0.18$ & $20.43 \pm 0.56$ \\
\hline Pelargonidin-3-glucoside & $0.46 \pm 0.01$ & $1.49 \pm 0.12$ \\
\hline
\end{tabular}

${ }^{*}$ Values expressed as means of two determinations \pm standard deviation.

in the quantification step than by using cyanindin-3glucoside equivalents.

The proposed method is an important tool for the quality control of pomegranate drinks and other pomegranate products. The possibility of this evaluation is important not only for consumers but also for industry, since it can be used to understand and optimize some of the operational parameters that could influence the stability of the bioactive compounds, in this case, more specifically, of the anthocyanins.

Using the isolated anthocyanins and the calibration curves prepared, it was possible to evaluate the contents of these compounds in different pomegranate products such as juice and the microcapsules obtained by spray drying, as shown in Table 7.

\section{Conclusion}

The proposed procedure showed that it was possible to obtain analytical anthocyanin standards with a high grade of purity from natural sources, and proved to be a feasible alternative for laboratories to produce standards according to their research requirements.

Furthermore, these standards could be used in the analysis of other matrices where the same anthocyanins are present.

\section{Acknowledgments}

To CNPQ and FAPERJ for their financial support.

\section{References}

ALIGHOURCHI, H.; BARZEGAR, M. Some physicochemical characteristics and degradation kinetic of anthocyanin of reconstituted pomegranate juice during storage. Journal of Food Engineering, Oxford, v. 90, n. 2, p. 179-185, 2009. http:// dx.doi.org/10.1016/j.jfoodeng.2008.06.019

BOROCHOV-NEORI, H.; JUDEINSTEIN, S.; TRIPLER, E.; HARARI, M.; GREENBERG, A.; SHOMER, I.; HOLLAND, D. Seasonal and cultivar variations in antioxidant and sensory quality of pomegranate (Punica granatum L.) fruit. Journal 
Analytical standards for the analysis of pomegranate anthocyanins by HPLC

SANTIAGO, M. C. P. A. et al.

of Food Composition and Analysis, San Diego, v. 22, n. 3 p. 189-195, 2009. http://dx.doi.org/10.1016/j.jfca.2008.10.011

BRITO, E. S.; ARAUJO, M. C. P.; ALVES, R. E.; CARKEET, C. CLEVIDENCE, B. A.; NOVOTY, J. A. Anthocyanins present in selecred tropical fruits: acerola, jambolão, jussara and guajiru. Journal of Agriculture and Food Chemistry, Washington v. 55, n. 23, p. 9389-9394, 2007. PMid:17929888. http://dx.doi. org/10.1021/jf0715020

GIL, M.; TOMAS-BARBERAN, F. A.; HESS-PIERCE, B HOLCROFT, D. M.; KADER, A. A. Antioxidant activity of pomegranate juice and its relationship with phenolic composition and processing. Journal of Agricultural and Food Chemistry Washington, v. 48, n. 10, p. $4581-4589,2000$. http://dx.doi. org/10.1021/jfo00404a

GIUSTI, M. M.; RODRÍGUEZ-SAONA, L. E.; WROLSTAD, R. E. Molar absorptivity and color characteristics of acylated and non-acylated pelargonidin-based anthocyanins. Journal of Agricultural and Food Chemistry, Washington, v. 47, n. 11 p. 4631-4637, 1999. http://dx.doi.org/10.1021/jf981271k

GOUVEA, A. C. M. S. SANTIAGO, M. C. P. A.; PACHECO, S; GODOY, R. L. O.; CABRAL, L. M. C. Anthocyanins standards (cyanidin-3-O-glucoside and cyanidin-3-O-rutenosideo) isolation from freeze-dried açal (Euterpe oleraceae Mart.) by HPLC. Ciência e Tecnologia de Alimentos, Campinas, v. 32, n. 1, p. 43-46, 2012. http://dx.doi.org/10.1590/S010120612012005000001

KIMURA, M.; RODRIGUEZ-AMAYA, D. B. A Scheme for obtaining standards and hplc quantification of leafy vegetable carotenoids. Food Chemistry, New York, v. 78, n. 3, p. 389-398, 2002. http:// dx.doi.org/10.1016/S0308-8146(02)00203-0

MÜLLER, D.; SCHANTZ, M.; RICHLING, E. High performance liquid chromatography analysis of anthocyanins in bilberries (Vaccinium myrtillus L.), blueberries (Vaccinium corymbosum L.), and corresponding juices. Journal of Food Science, Chicago, v. 77 , n. 4, p. 340-345, 2012. PMid:22394068. http://dx.doi. org/10.1111/j.1750-3841.2011.02605.x

OZGEN, M.; SERÇE, S.; KAYA, C. Phytochemical and antioxidant properties of anthocyanin-rich morus nigra and morus rubra fruits. Scientia Horticulturae, Kent, v. 119, n. 3, p. 275-279, 2009. http://dx.doi.org/10.1016/j.scienta.2008.08.007

PATRAS, A.; BRUNTON, N. P.; O'DONNELL, C.; TIWARI, B. K. Effect of thermal processing on anthocyanin stability in foods: mechanisms and kinetics of degradation. Trends in Food Science and Technology, Cambridge, v. 21, n. 1, p. 3-11, 2010. http://dx.doi.org/10.1016/j.tifs.2009.07.004

POMAR, F.; NOVO, M.; MASA, A. Varietal differences among the anthocyanin profile of 50 red table grape cultivars studied by high performance liquid chromatography. Journal of Chromatography A, Amsterdam, v. 1094, n. 1-2, p.34-41, 2005

QU, W.; BREKSA III, A. P.; PAN, Z.; MA, H. Quantitative determination of major polyphenol constituents in pomegranate products. Food Chemistry, New York, v. 132, n. 3, p. 1585-1591, 2011. http://dx.doi.org/10.1016/j.foodchem.2011.11.106

SUMNER, M. D.; ELLIOTT-ELLER, M.; WEIDNER, G. DAUBENMIER, J. J.; CHEW, M. H.; MARLIN, R. Effects of pomegranate juice consumption on myocardial perfusion in patients with coronary heart disease. Journal of Cardiology, Japan, v. 96, n. 6, p. 810-814, 2005. PMid:16169367. http:// dx.doi.org/10.1016/j.amjcard.2005.05.026

ZHANG, Y.; WANG, D.; LEE, R. P.; HENNING, S. M.; HEBER, D. California hass avocado: profiling of carotenoids, tocopherol, fatty acid, and fat content during maturation and from differen growing areas. Journal of Agricultural and Food Chemistry, Washington, v. 57, n. 21, p. 7395-7400, 2009. PMid:20349921. http://dx.doi.org/10.1021/jf9010017 